Portland State University

PDXScholar

$1-1-1985$

\title{
Job satisfaction of teachers in the Portland Metropolitan Area: an examination of differing factors and their relationship to Herzberg and Lortie theories
}

Laura Lee Perko

Portland State University

Follow this and additional works at: https://pdxscholar.library.pdx.edu/open_access_etds Let us know how access to this document benefits you.

\section{Recommended Citation}

Perko, Laura Lee, "Job satisfaction of teachers in the Portland Metropolitan Area: an examination of differing factors and their relationship to Herzberg and Lortie theories" (1985). Dissertations and Theses. Paper 833.

https://doi.org/10.15760/etd.833

This Dissertation is brought to you for free and open access. It has been accepted for inclusion in Dissertations and Theses by an authorized administrator of PDXScholar. Please contact us if we can make this document more accessible: pdxscholar@pdx.edu. 
JOB SATISFACTION OF TEACHERS

IN THE PORTLAND METROPOLITAN AREA:

AN EXAMINATION OF DIFFERING FACTORS

AND

THEIR RELATIONSHIP TO

HERZBERG AND LORTIE THEORIES

by

LAURA LEE PERKO

A dissertation submitted in partial fulfillment of the requirements for the degree of

DOCTOR OF EDUCATION

in

PUBLIC SCHOOL ADMINISTRATION \& SUPERVISION

Portland State University

University of Oregon

C 1985 Jaura Lee Perko 
TO THE OFFICE OF GRADUATE STUDIES AND RESEARCH:

The members of the Committee approve the dissertation of Laura Lee Perko, presented May 15, 1985.

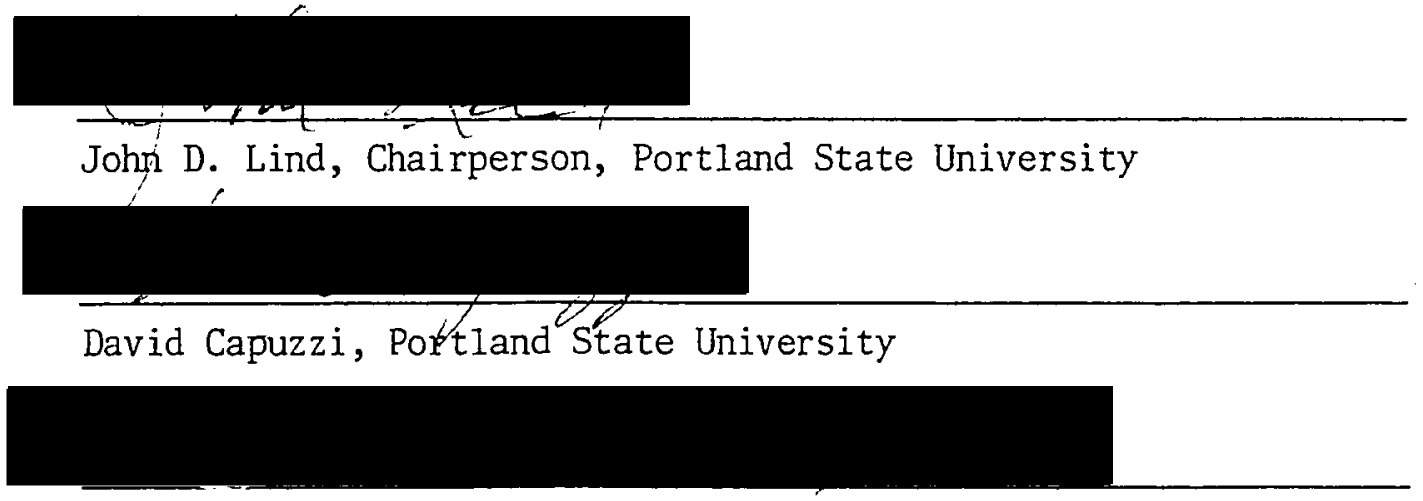

Colin Dunkeld, Portland State University

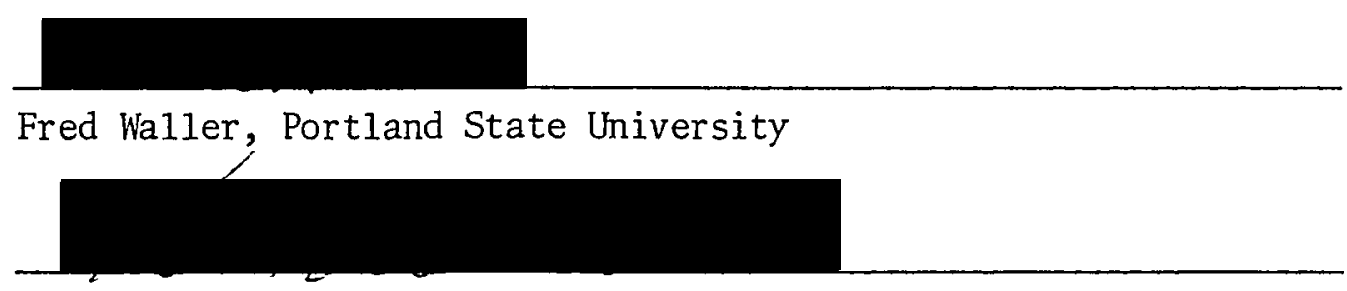

Keith A. Acheson, University of Oregon
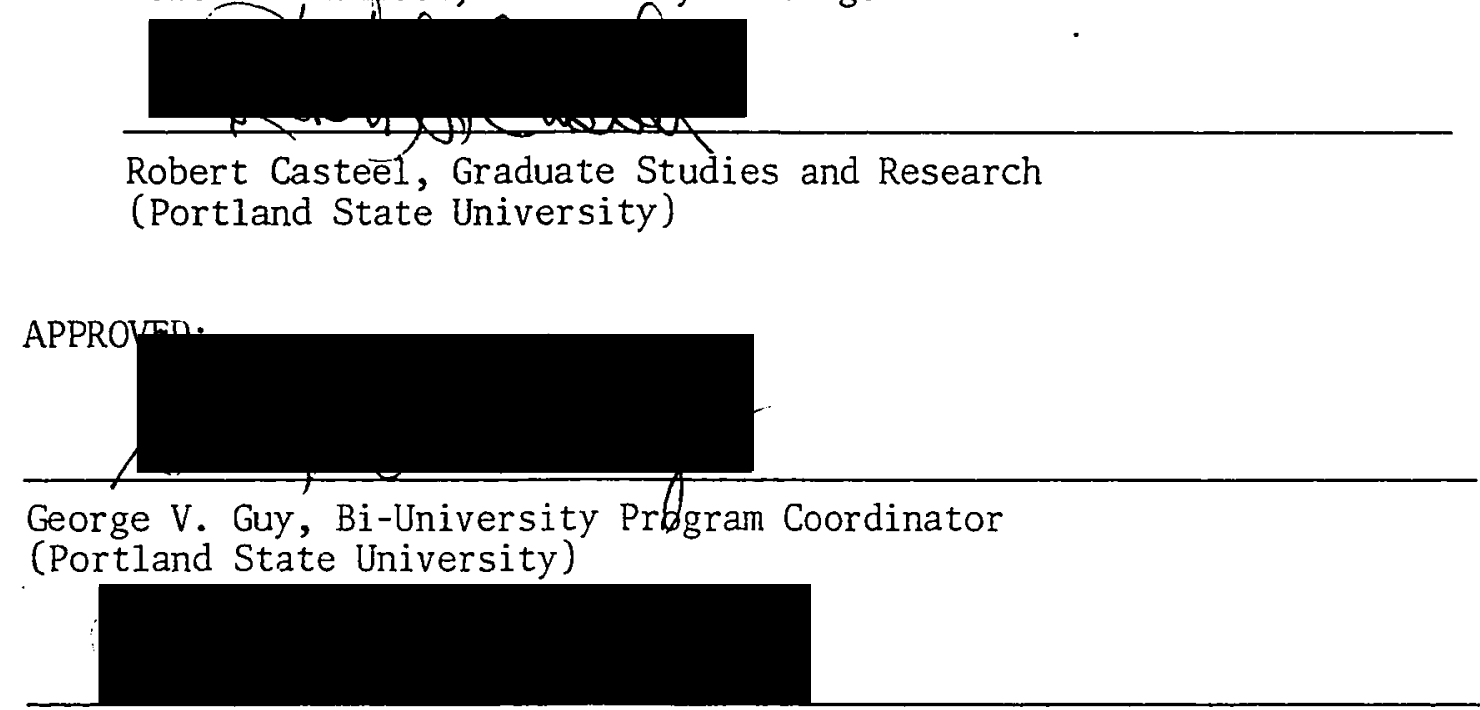

Richard A. Schmuck, Bi-University Program Coordinator

(University of Oregon)

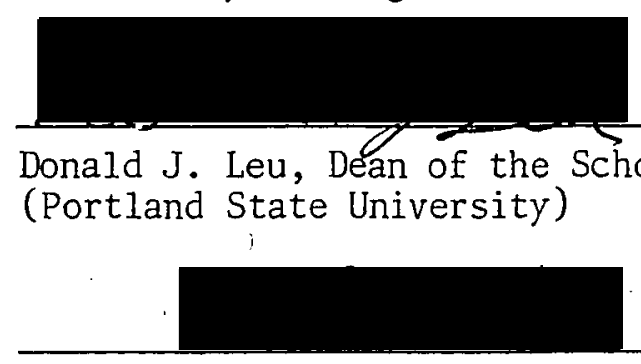

Jim F. Heath, Dean, Graduate Studies and Research

(Portland State University). 
Dedicated to

Joseph M. Perko 


\section{ACKNOWLEDGEMENTS}

The foundations for my formal education and my profession as an educator rest with Portland Public Schools and Portland State University. This siualy permits me to acknowledge both institutions as resources of personal and professional growth.

I gratefully acknowledge the study materials shared with me from research conducted in 1981 by Dr. Lynda C. Falkenstein, then Associate Professor at Portland State University, and by Dr. Walter Hathaway, Director of Research and Evaluation, Portland Public Schools. Dr. Hathaway has been a primary resource during the development of the current study, and I value his support.

I am particularly appreciative of the guidance from $\mathrm{Dr}$. John Lind, School of Education, Portland State University, who has served as my teacher and the chairperson of my doctoral committee. To each member of my doctoral cormittee, as each has also been iny teacher, i am grateful for patierce and guidance.

I wish to express fullest gratitude to the Superintendent and Executive Deputy Superintendent of Portland Public Schools for permitting me to access resources to develop this study in accord with my role as a personnel administrator for a public school district.

I am deeply indebted to the staff and support from the following departments: Research and Evaluation, Educational Media, Data Processing, Word Processing, Publication Services, and my colleagues in Personnel Services. I an grateful for the assistance of Connie Stanton, Professional Library; Gary Williams, Kan Yagi, 
Dean Forbes, and George Ingebo, Research and Evaluation; and Michelle Batten, Word Processing. And I want to give special acknowledgement to my secretary, Alaina Romaniello, for her important assistance during the developing process of the study.

I truly appreciate the support and interest from the administrators and teaching staff from the seven public school districts that participated in this study and gave the time to permit the data collection.

Finally, I extend very special gratitude to my parents, Max and Matilda Burgholzer, and to my husband, Joseph M. Perko, for their patience and encouragement, and most of all, for their continuing belief in me and what I try to do. 
TAB LE OF CONTENTS

PAGE

DEDICATION . . . . . . . . . . . . . . . . . .

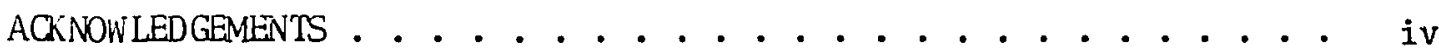

LIST OF TABLES . . . . . . . . . . . . . . . . ix

LIST OF FIGURES . . . . . . . . . . . . . . . . xiii

CHAPTER

I. INTROLUCTION . . . . . . . . . . . . . 1

Examination of the Problem .......... . 2

Rationale for the Study . . . . . . . . . 4

"Job Satisfaction" as a Term of Reference . . . . 8

Definition of Terms ............. 15

II. THEORETICAL BACKGROUND . . . . . . . . . . 25

Needs and Gratification as Related to Motivation . . . 26

Psychological or "Social Factors" in the Work

Setting: Integrating the Goals of the Individual

with the Goals of the Organization . . . . . . . 34

Differing Assumptions Leading to Studies

of Job Satisfaction . . . . . . . . . 39

Herzberg's 'Motivator-Hygiene" Theory -

"Dual-Factor" Theory ............. . 42

Teachers and Teaching as a Basis for Sociological

Study and Theory . . . . . . . . . . . 49

Lortie's Theory on Teachers and Teaching . . . . 50

Integration of Herzberg's Theory and Lortie's

Theory .............. . 53

III. REVIBN OF LITERATURE . . . . . . . . . . . 57

The Worker and the Organization ........ 57

Job Satisfaction of Teachers in America and

E1sewhere: Dissatisfaction and Its Impact . . . . . 60 
Herzberg's "Motivator-Hygiene Theory -

"Dual-Factor" Theory: Supporters, Challengers, Mediators or Compromisers .......... 78

Lortie's Theory on Schoolteachers . . . . . . 103

IV. METHDLOLOGY . . . . . . . . . . . . . 110

Design and Development of the Instrument . . . . . 110

Design for the Study . . . . . . . . . . . 114

Questions To Be Answered by this Study:

How Information Will Be Used . . . . . . . . . 121

Research Questions, Predictions, Hypotheses,

and Analyses To Be Used . . . . . . . . . 123

V. ANALYSES OF RESULTS . . . . . . . . . . . . . 134

Response and Respondent Information . . . . . . 134

The First Research Question and Findings . . . . . . 134

The Second Research Question and Findings . . . . 140

The Third Research Question and Findings . . . . . 157

VI. SLMMARY, DISCUSSION, CONCLUSIONS, AND RECOMMENDATIONS • . 170

Sumnary ................. 170

Discussion ............... . 173

Research Question \#1 and Findings . . . . . . 173

Research Question \#2 and Findings . . . . . . 179

Research Question \#3 and Findings . . . . . . 194

Other Findings . . . . . . . . . . 251

Conclusions . . . . . . . . . . . 286

Research Question \#1 and Findings . . . . . 286

Research Question \#2 and Findings . . . . . 288

Research Question \#3 and Findings . . . . . . 308

Other Conclusions . . . . . . . . . 322 
viii

CHAPTER

PAGE

Recommendations .............. 357

Recommendations for Further Research . . . . 357

Other Reconmendations ........... 364

BI BLIOGRAPHY . . . . . . . . . . . . . . . . 377

SUPPLEMENTAL REFERENCE LIST . . . . . . . . . . . . . . 389

APPENDICES . . . . . . . . . . . . . . . 392

A Sumnary of Investigations Attempting to Replicate or

Investigate Herzberg Theory (Burke, 1966; House \&

Wigdor, 1967) . . . . . . . . . . . . . 393

B Studies of Teachers and Factors Associated with Job

Satisfaction (Perko, 1984) . . . . . . . . 400

C List of Factors Defined as Motivators or Hygienes

(Herzberg, Lortie) . . . . . . . . . . . . 414

D Questionnaire $\left(\mathrm{Q}_{2}\right), 1984$........... 415

E Questionnaire $\left(Q_{1}\right), 1981$ (Falkenstein, 1982;

Hathaway, 1982) . . . . . . . . . . . 426

F Tables of Items - Questionnaire $\left(Q_{2}\right), 1984$

(Sections II, III, IV) . . . . . . . . . . . . 437

G Comparative Data $-Q_{1}-1981$ and $Q_{2}-1984$..... 470 


\section{LIST OF TABLES}

TABLE

PAGE

I. Statistical Table Sample (Krecje \& Margan, 1970) . . . . 119

II. Data on II.24 - Chi-square test for Research Question \#l - 135

III. Data on II.25 - Chi-square test for Research Question \#1 - 136

IV. Data on IV.1 - Chi-square test for Research Question \#1 - 137

V. Data on IV.2 - Chi-square test for Research Question \#1 - 138

VI. Data on IV.3 - Chi-square test for Research Question \#1 - 139

VII. Data on IV. 8 - Chi-square test for Research Question \#1 - 139

VII. Data on IV.46 - Chi-square test for Research Question \#1 - 140

IX. Tested Motivators/Intrinsic Factors as Related to

Satisfaction (Herzberg List) . . . . . . . . 141

X. Tested Hygienes/Extrinsic Factors as Related to

Dissatisfaction (Herzberg List) . . . . . . . 142

XI. Satisfaction Indicators - Motivators/Intrinsic

Factors (Kendall's tau) ............. 144

XII. Satisfaction Indicators - Hygienes/Extrinsic

Factors (Kenda11's tau) ............ 147

XIII. Factors Contributing Most Frequently to Job Satisfaction

of Teachers in the PMA (1984, $\mathrm{Q}_{2}$ ) - Conformity with

Herzberg's Theory ................ 149

XIV. Factors Contributing Most Frequently to Job

Dissatisfaction of Teachers in the PMA (1984, Q2) -

Conformity with Herzberg's Theory . . . . . . . . 151 
TABLE

PAGE

XV. The Factor Contributing Most Frequently to Job

Satisfaction of Teachers in the PMA (1984, Q2) -

Conformity with Lortie's Theory . . . . . . . . 152

XVI. Sources of Satisfaction for Teachers in the PMA

(1984, Q2) - Conformity with Lortie's Theory . . . . 153

XVII. A Very Important Source of Satisfaction for Teachers in the PMA (1984, Q2) - Conformity with Lortie's Theory . 154

XVIII. A Very Important Source of Satisfaction for Teachers

in the PMA - Compared Data (1981 and 1984) -

Conformity with Lortie's Theory . . . . . . . . . 154

XIX. Sources of Satisfaction for Teachers in the PMA -

Compared Data (1981 and 1984) - Conformity with Lortie's

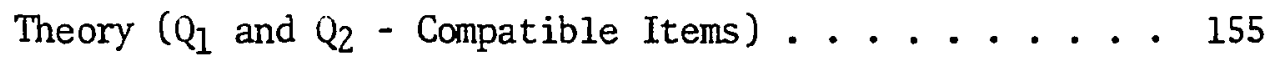

XX. Variable Pair - Satisfaction/Age (Kendall's tau) . . . 158

XXI. Variable Pair - Satisfaction/Sex (Kendall's tau) . . . 160

XXII. Variable Pair - Satisfaction/Grade Level

(Kendall's tau)............... 162

XXIII. Variable Pair - Satisfaction/Years in Service

(Kendall's tau)............... 164

XXIV. Variable Pair - Satisfaction/Highest Degree Earned

(Kendall's tau)................ 166

XXV. Ages of the Teachers in the PMA in 1981 (Item I.2) . . 195

XXVI. Compared Ages of the Teachers in the PMA in 1981

and 1984 . . . . . . . . . . . . . . . 197 
TABLE

PAGE

XXVII. National Demographic Data (Age) . . . . . . . 198

XXVIII. Cross Tabulations - Satisfaction Indicator (IV.46) by Age, 1984 . . . . . . . . . . . . 200

XXIX. Cross Tabulations - Satisfaction Indicator (II.25) by Age, 1984 . . . . . . . . . . . . . 203

XXX. Sex of Teachers in the PMA in 1984 (Item I.1) . . . 207

XXXI. Comparative Data - Sex of Teachers in the PMA, $1981\left(\mathrm{Q}_{1}\right)$ and $1984\left(\mathrm{Q}_{2}\right) \ldots . . . . . . . . . .208$

XXXII. National Demographic Data (Sex) . . . . . . 209

XXXIII. Cross Tabulations - Satisfaction Indicator (IV.46) by $\operatorname{Sex}, 1984$..................... 210

XXXIV. Cross Tabulations - Satisfaction Indicator (II.25) by Sex, 1984 . . . . . . . . . . . . 212

XXXV. Grade Levels of Teachers in the PMA in 1984 (Item I.13) . . . . . . . . . . . . 214

XXXVI. Grade Levels of Teachers in the PMA in $1981\left(Q_{1}\right)$ and

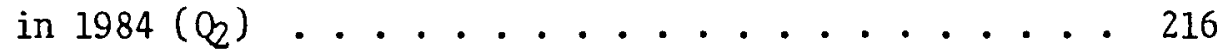

XXXVII. National Demographic Data (Grade Levels/Assignment) . . 217

XXXVIII. Cross Tabulations - Satisfaction Indicator (IV.46) by Grade Level, 1984 . . . . . . . . . . 218

XXXIX. Cross Tabulations - Satisfaction Indicator (II.25) by Grade Level, 1984 . . . . . . . . . . . 221

XL. Total Years in Teaching in the PMA (Item I.6) . . . 225 
XLI. Compared Years in Service of Teachers in the PMA in 1981 (Item 3) and 1984 (Item I.6) . . . . . . 227

XLII. National Demographic Data (Years in Service) . . . . 227

XLIII. Cross Tabulations - Satisfaction Indicator (IV.46) by Total Years in Service . . . . . . . . . 230

XLIV. Cross Tabulations - Satisfaction Indicator (II.25) by Total Years in Service . . . . . . . . . 233

XLV. Highest Degree Earned - Teachers in the PMA, 1984 (Item I.4) .............. 237

XLVI. Compared Education (Highest Legree Earned) of Teachers in the PMA, 1981 and 1984 . . . . . . . . 238

XLVII. National Demographic Data (Highest Academic Degree Earnedj . . . . . . . . . . . 239

XLVIII. Cross Tabulations - Satisfaction Indicator (IV.46) by Highest Degree Earned, 1984 . . . . . . . . . . 241

XLIX. Cross Tabulations - Satisfaction Indicator (IV.46) by Highest Degree Earned, 1984 . . . . . . . . 244

L. Percentages - Sources of Satisfaction, 1984, Forced Choices (Item IV.47) . . . . . . . . 283

LI. Percentages - Sources of Satisfaction, 1984 Forced Choices (Item IV.48) . . . . . . . . 284

LII. Percentages - Sources of Satisfaction, 1984, Forced Choices (Item IV.49) . . . . . . . . 284

LIII. Percentages - The Factor to Influence Change in Teaching, 1984, Forced Choice (IV.45) . . . . . 285 


\section{LIST OF FIGURES}

F IGURE

PAGE

1 A cyclical concept of job satisfaction (Chase, 1976-77, p. 1)

2 Adaptation of Maslow's theory of hierarchical needs (1954)

3 Adaptation of Maslow's theory of hierarchical needs (1954) and Herzberg's dual-factor or bidimensional theory of growth needs as motivators and pain-avoidance needs as hygienes (1959 \& 1974). (Drawn from Kaiser, 1981 , p. 36; adapted for this study.)

4 The relationship of Maslow and Herzberg theories to a motivating situation. (Drawn from Hersey \& Blanchard, 1977, p. 67.)

5 The relationships between the motivation-hygiene theory and Maslcw's hierarchy of needs. (Drawn from Hersey \& Blanchard, 1977, p. 67.)

6 Maslow's nierarchy of needs related to motivation seekers and hygiene seekers. (Drawn from Sergiovanni \& Carver, 1980, p. 118.)

7 Differentiating motivation seekers from hygiene seekers. (Drawn from Sergiovanni \& Carver, 1980, p. 119.)

8 Ages of Teachers in the PMA, 1981 and 1984

9 Satisfaction Indicator (IV. 46) by Age, PMA, 1984

10 Dissatisfaction Indicator (IV.46) by Age, PMA, 1.984 
$\operatorname{xiv}$

FIGURE

PAGE

11 Sex of Teachers in the PMA, 1981 and 1984208

12 Satisfaction Indicator (IV.46) by Sex, PMA, 1984211

13 Dissatisfaction Indicator (IV.46) by Sex, PMA, 1984

14 Grade Levels of Teachers in the PMA, $1984 \quad 214$

15 Satisfaction Indicator (IV.46) by Grade Level, 1984219

16 Dissatisfaction Indicator (IV.46) by Grade Level, $1984 \quad 219$

17 Total Years in Teaching Service in the PMA, 1984

18 Years in Service in the PMA, 1981 and 1984226

19 Satisfaction Indicator (IV.46) by Years in Service, $1984 \quad 231$

20 Dissatisfaction Indicator (IV.46) by Years

in Service, 1984

21 Highest Degree Earned - Teachers in the PMA, 1984237

22 Highest Degree Earned - Teachers in the PMA, 1981 and 1984238

23 Satisfaction Indicator (IV.46) by Highest Degree Earned, 1984

24 Dissatisfaction Indicator (IV.46) by Highest Degree Earned, 1984

25 Job Satisfaction for Teachers in the PMA - Factors 288

26 Factors Contributing Most Frequently to Job Satisfaction of Teachers in the PMA, $1984 \quad 297$

27 The Factor Contributing Most Frequently to Job Satisfaction of Teachers in the PMA, 1984

28 Factors Contributing Most Frequently to Job Dissatisfaction of Teachers in the PMA, 1984 
$\begin{array}{ll}\text { FIGURE PAGE } & \text { PRE }\end{array}$

29 The Factor Contributing Most Frequently to Job Dissatisfaction of Teachers in the PMA, 1984

30 Needs and Gratification as Related to Motivators and Hygienes 
AN ABSTRACT OF THE DISSERTATION OF Laura Lee Perko for the Doctor of Education in Public School Administration and Supervision presented May 15, 1985.

Title: Job Satisfaction of Teachers in the Portland Metropolitan Area: An Examination of Differing Factors and Their Relationship to Herzberg and Lortie Theories.

APPROVED BY MEMBERS OF THE DISSERTATION COMMITTEE:
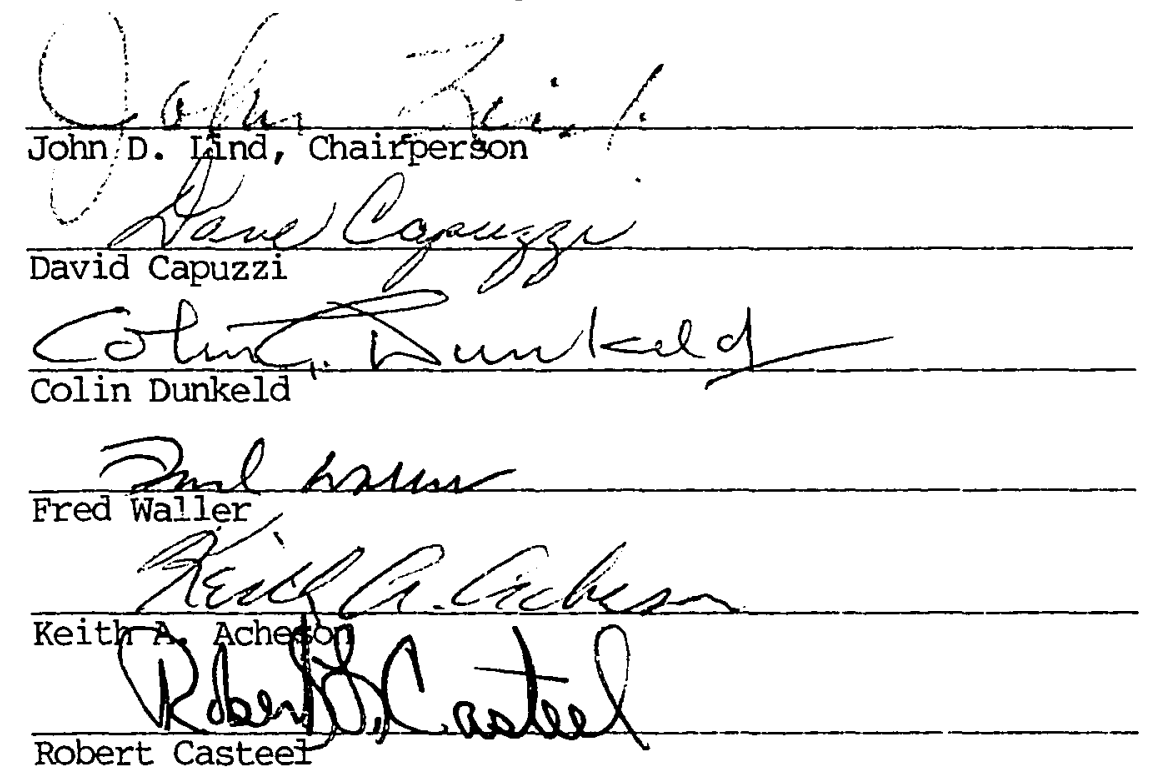
This study addresses job satisfaction of public school teachers in seven districts of the Portland Metropolitan Area $(\mathrm{N}=2,133$; validated response $=1,444$; ratio of 67.698 percent). The three research questions are: (1) How satisfied are teachers in the PMA with their jobs? (2) What are the primary differing factors affecting teacher satisfaction and dissatisfaction, and do these factors and their relationship to satisfaction conform with Herzberg and Lortie theories? (3) How does satisfaction and dissatisfaction vary as a. function of the following "demographic" factors: age, sex, grade level, years of service, highest degree earned? Findings from the three research questions are: (1) Teachers in the PMA are very satisfied with their jobs. (2) Motivators (or intrinsic factors) contribute to satisfaction more than they contribute to dissatisfaction, and this finding tends to conform with part of Herzberg's dual-factor theory; hygienes (or extrinsic factors) are seen to contribute to satisfaction more than to dissatisfaction (opposite to the prediction), and this finding does not conform with part of the dual-factor theory. Factors that contribute most frequently to satisfaction of teachers in the PMA are: interpersonal relations with students and fellow teachers, sense of achievement, teaching as a kind of work, and opportunities to help others. Factors contributing most frequently to dissatisfaction are: salary, time spent preparing for teaching or on school-related activities outside of teaching or preparation for teaching, status, and policies and practices of the school district. The finding that interpersonal relations with students is the factor that contributes most frequently 
to teacher satisfaction "..es tend to conform with Lortie's theory. (3) Age, sex, and grade levels of assignment are seen to be significantly related to job satisfaction. Older teachers tend to be more satisfied than younger teachers; women tend to be more satisfied. than men are with teaching; teachers of primary grades (through 4-6) tend to be more satisfied than teachers of higher grades (6-8, 7-9, 9-12). Years of service and highest degree earned are not seen to be significantly related to job satisfaction. Comparative data from 1981 and 1984 indicate that: the age of teachers, the percentage of women, and the average number of years of service are increasing for teachers in the PMA. 
". . And he would gladly learn, and gladly teach"

(Chaucer, Prologue, The Canterbury Tales) 
CHAPTER I

INTRODUCTION

How satisfied or dissatisfied are public school teachers with their jobs as educators? What leads to teacher job satisfaction and dissatisfaction? What factors of the job setting could be changed to improve teacher job satisfaction and to reduce teacher job dissatisfaction? These three questions persist in the studies of teacher job attitudes. Research has not yet answered these questions fully, and answers seem to be essential if public education is to include response to the needs and expectations of present and future staff in its efforts to change and improve. In addition, individual and group :titudes are subject to change for a variety of reasons; therefore, continuing study is needed to measure attitudes and attitudinal change and to assess the significance of expressed attitudes or indicated change.

Consequently, this study is directed toward gaining more insight into personal attitudes and feelings of teachers about teaching, to learn more about primary areas of job satisfaction and dissatisfaction and about what teachers identify as important in their roles as public educators. In a broad sense of intention, the study is undertaken in the hope that findings will be useful to the public and to public educators addressing common goals and concerns. In a narrower sense of intention, the study is undertaken in the hope that the findings will help guide and support personnel services in public schools and public school districts. 
As an introduction to the study, it is appropriate to include:

- examination of the problem

- rationale for the study

- "job satisfaction" as a term of reference

- definition of terms

\section{Examination of the Problem}

Public education is addressing claims of inadequacy and mandates for improved effectiveness and reform. Since Silberman's presentation of Crisis in the Classroom: The Remaking of American Education (1970), negative opinions of crisis in schools are mounting. Recent reports by Boyer (1983) on the need for reform in secondary education and the publication of the National Commission on Excellence in Education (1983) confirming the United States as "a nation at iisk" unless the educational system undergoes immediate and drastic reform have added to negative publicity. Malaise in public education is predominantly established, and concerns are sweeping to include the entire system of public education and teachers as members of a profession. Prescriptions for treatment of illness or symptoms of illness generally target the teacher (Adams, 1975). Teaching has been labeled "The Imperiled Profession" (Duke, 1984) and "A Troubled Profession" (Durbin, 1983). Teacher competency and accountability are being questioned as part of the assessment of problem ("Help! Teacher Can't Teach," 1980). Bridges (1983) cites thirteen years of Gallup Polls to attest to public concerns about the quality of the teaching force, and surveys conducted by the American Association of School 
Administrators in 1974, 1976, and 1977, to attest to administrative opinion on the management of teacher incompetency, teacher failure in the classroom, and the organizational and individual consequences of unsatisfactory and inept teachers (pp. 1-3). Noting that much of the negative literature is based on impression, Bridges recommends empirical research, theory, and practice to reinforce or dispel views of "declines in the intellectual talent pool" and assumptions that "the fittest are not surviving" in teaching (p. 3). Chapman (1983) notes that teachers are frequently criticized in the media; the social status of teachers and the respect assigned to them are diminishing; and teacher morale is suffering. Chapman warns that teacher morale may be related to achievement, and he stresses the need to understand "the ingredients of career satisfaction" for teachers ( $p, 40$ ). Pellicer (1984) links job satisfaction of teachers with their work attendance and notes that "the absence of job satisfaction has been correlated with serious withdrawal problems... including high turnover and excessive employee absenteeism," confirming accordingly that job satisfaction "should be a concern of management" (p. 44). A study by the American Federation of Teachers, in 1984, is but one example of the growing body of literature on teacher stress and burnout. Conclusions from this report include comment that teachers in the study "appear apathetic about and alienated from their jobs, based on their feeling that 'they can't effect change'" (p. 5). As another example, Farrell (1984) reports on schools as a "tale of mediocrity," including as representative a teacher's lament: "My God, I'm wasting my time," along with references to "good teachers, young 
and old, who are giving up" (p. C4). And as a final example, Steinberg (1984) numbers American school teachers on strike at the beginning of the 1984-85 school year as "nearly 7,300 . . disrupting school for more than 108,000 students in eight states," along with editorial commentary that other teacher strikes have been narrowly averted or are possible or pending and subject to settlements of critical issues (p. A18 3M).

Certainly, much negative opinion about teachers and teaching prevails, stemming from the public and from public educators. However, many teachers remain in teaching, and the likelihood that they may be able to provide invaluable information to benefit the profession seems important to consider (Falkenstein, 1982; Hathaway, 1982). If the factors that serve to satisfy or reward teachers can be better established, surely the data could be used positively as recommendations for change and improvements to guide or direct human resources (and resources in general) to better advantage. The focus for reform in public education might then become one of organizational renewal as a "goal-seeking change effort rather than as a problem.solving change effort" (Brooks, 1982, p. 39).

\section{Rationale for the Study}

The history of public education in America reflects change and constancy. Ideologies have changed about the purpose and processes of teaching and the role of the teacher. As national, state, and local efforts of governance, various requirements and standards have been set and adjusted to direct education and educators. In response to 
chariging directives and identified needs, schools and instructional programs have been built or dismantled. Yet, within the dynamics of changing ideas about education, the issue of how the teacher views the job of teaching remains a constant factor (Herzberg, Mausner, Snyderman, 1959, p. $x$ ). The attitude of the individual teacher in the classroom--or teachers in some configuration, addressing the role of teaching--may well be the determining factor in the success or failure of public education in our nation (Brembeck in Waller, 1932, 1965, Introduction).

Krowing more about teacher attitudes is significant at any time, but knowing more about this determining factor seems particularly critical at this time, seen by some as "hard times": when public school systems are dealing with increasing or changing needs and decreasing resources, and when the efforts of all public educators are being challenged and directed toward reaffirming commitments to excellence and promoting the advancement of education in our public schools (Boyer, 1983; Leggett, 1981; The National Commission on Excellence in Education, 1983).

Statistical analyses of data from public school teachers should produce some guiding information that could be useful to those involved in recommending or implementing the designs for positive change in public education. The data have potential for bringing better understanding of the goals of teachers into focus with the goals of public school systems. As Bidwell (1973) points out, teaching is indivisible from the organizational characteristics of schools and classrooms. At the same time, teaching is social. 
Teachers are intricately involved in social and psychological processes of interpersonal exchanges and relationships (Bidwell, 1973, pp. 413-414). The interactions generate responses or developing attitudes that may be examined as expressions of satisfaction and dissatisfaction about teaching or being a teacher. Modern organizational theory recognizes job satisfaction of staff as a key to effectiveness and change or renewal within an organization. Therefore, it is significant to see how the attitudes of teachers may be related to aspects of organizational theory that address psychological and sociological influences. It is also significant to see whether the attitudes of teachers may be related to demographic factors or identified categories of teachers in public school classrooms.

As targets for potential use and benefit, a current study of teacher job attitudes could lead to:

For the public:

- increased understandings of teachers and teaching

- irgproved communications and more positive relationships between the community and its public schools

For public educators:

- improved assessments of the role of the teacher

- improved job satisfaction of teachers

- increased understanding of how job satisfaction could be related to motivation or performance of teachers

- increased understanding of how public school administrators could assist the success of the teacher in the classroom

- more effective schools and schooling for students in public schools 
For personnel services:

- more effective cooperation with colleges and universities in developing preservice and teacher training programs

- improved procedures for staffing and assignment

- improved procedures for designing and providing inservice and staff development programs or plans of assistance

- improved information for projecting job opportunity or upward mobility and job turnover or attrition

- increased understandings of factors which tend to satisfy or reward teachers, to assist districts to direct resources--including those which may be entailed in collective bargaining or professional negotiations

\section{Purpose of the Study}

Thus, with recognition of immediate and far-reaching problems and a rationale for study that includes potential for use and benefit, the purpose of this study is to collect and analyze information on job satisfaction of teachers in the Portland Metropolitan Area (PMA). In an effort to acknowledge the significance of aspects of organizational theory and sociological theory, this study is based, in part, on Herzberg's Dual-Factor Theory (1959) and Lortie's Theory (1973, 1975). Elements of Herzberg's Dual-Factor Theory (1959) rest on earlier research by Moxley (1977) considering job satisfaction of faculty in higher education. Elements of Lortie's Theory (1975) rest on earlier research by Falkenstein (1982) and Hathaway (1982) considering job satisfaction of public school teachers. The current study includes sampled responses of public school teachers in seven school districts as data to be applied to three basic research questions:

1. How satisfied are teachers in the PMA with their jobs? 
2. What are the primary differing factors affecting teacher satisfaction and dissatisfacton, and do these factors and their relationship to satisfaction and dissatisfaction conform with Herzberg and Lortie theories?

3. How does satisfaction and dissatisfaction vary as a function of the following teacher "demographic" factors:

Age

Sex

Grade level

Years of service

Education -- highest degree earned

"Job Satisfaction" as a Term of Reference

What is job satisfaction? Although "job satisfaction" is a term without an absolute definition (Ashbaugh, 1982, p. 195; Herzberg, Mausner, Peterson \& Capwe11, 1957, p. 1), it is a term widely used to embrace various constructs in studies of workers and their attitudes and feelings about their work. Before listing the operational definitions for the various and related terms to be used in this study, it is appropriate to provide some background discussion of the assumptions and viewpoints that have led to the formulation of the definitions for the current research.

Research and theory have developed to address relationships between psychological states (based on human needs and their attainment and relative importance) and the factors or variables of the job setting to refer to transitory or enduring stages or degrees of positive or negative feelings or characterizations of feelings that may lead to the formulation of attitudes or dispositions or opinions about the content and context of the job. Within that concept, the worker has needs which may or may not be met within the work setting. 
The needs may or may not be of equal importance to the worker. As the prioritized needs are met or not met, the worker reacts subjectively to the complex interrelationship of needs and factors. A comprehensive term of reference for the overall concept, subject to definition, is "job satisfaction."

\section{Assumptions}

For the purposes of this study, the definition of "job satisfaction" as a comprehensive term of reference related to positive and negative attitudes and feelings of teachers about teaching will be based on the following assumptions:

- that factors or variables can be identifed which may serve as motivators or satisfiers, which may bring or contribute to feelings of pleasure, gratification, or well-being; and that factors or variables can be identified which may serve to bring or contribute to feelings of dissatisfaction;

- that attitudes or opinions may stem from feelings or subjective reactions -- pleasurable or unpleasurable -- that one may have to a situation;

- that individual teachers can and will express feelings and attitudes or opinions about particular factors or variables and form characterizations of those feelings or attitudes;

- that satisfaction can also be studied as related to the characteristics of the individual teacher in the job role, the congruence among the many roles of the teacher, and the teacher's affective and cognitive orientation to the role of the teacher as well as to the individual and institutional expectations of that role;

- that changes in cause-effect relationships may result from changes in the environment or in the individual or in the complex interrelationships of factors;

- that individual responses of teachers may be sampled and studied to form statistical assessments of a group or population of teachers.

(Ashbaugh, 1982; Herzberg et al, 1959; Lortie, 1975; Seashore \& Taber, 1975; Sergiovanni, 1976, 1977) 
Related Terms of Reference

Terms such as "job satisfaction" and "job attitudes" or "satisfaction" and "morale," along with terms such as "work role" and "motivation," have been subject to various definitions by researchers and theorists who have used them discretely, or synonymously, or with some degree of overlap. Some of the following definitions and discussions may serve as examples:

"Job Satisfaction" and "Job Attitudes." Vroom (1964) maintains that the terms "job satisfaction" and "job attitudes" may be used interchangeably:

Both refer to affective orientations on the part of individuals toward work roles which they are presently occupying. Positive attitudes toward the job are conceptually equivalent to job satisfaction and negative attitudes toward the job are equivalent to job dissatisfaction (p. 99).

"Satisfaction" and "Morale." References to "satisfaction" and "morale" may be used synonymously, or as related but distinguishable, or as overlapping. As noted by Gorton (1982, p. 1904), "employee satisfaction and morale are attitudinal variables that reflect positive or negative feelings about particular persons or situations" in the development of concepts or theories. Ashbaugh (1982) states that:

The concepts of job satisfaction and morale are related but distinguishable. Both refer to positive emotional states which may be experienced by employees. Morale is more future oriented, while satisfaction is more present and past oriented. Morale has a group referent, while satisfaction refers to the appraisal made by a single individual of his job situation (p. 200).

When applied to teaching, "satisfaction" seems to refer to "the extent to which a person can meet personal professional needs as an 
employee" (Strauss, 1974, in Gorton; 1982, p. 1904); "morale" tends to apply to a group, as in the common reference to "staff morale" (Gross $\&$ Herriott, 1965, in Gorton, 1982, p. 1904); however, "morale" may also be used as a reference to an individual:

To the individual, an understanding of the forces that lead to improved morale would bring greater happiness and greater self-realization (Herzberg et al, 1959, ix).

Morale is not an abstraction; rather it is concrete in the sense that it directly affects the quality and quantity of an individual's output (Brayfield \& Crockett, 1955, in Lawler \& Porter, 1967, p. 20).

Coverdale (1974) addresses the concept of morale as "elusive to define." He says that it concerns the "mental or emotional attitudes of teachers toward the components of their job"--taking into context the "atmosphere" or "climate" in which they work, and "their individual orientation towards their task." Thus, morale may be an individual "matter of subjective perception." Or, as a group concept, morale may be expressed by elements such as "group cohesion and cooperative fumctioning of the teachers who comprise the staff of a school." Coverdale summarizes morale as "some human quality which prompts a person to produce at maximum output," and he states that "it can usually be increased by favourably modifying any condition that will increase job satisfaction" (p. 35).

Vroom (1964) addresses the concept of job satisfaction by noting that the term "morale" has a variety of meanings, "some of which correspond closely to the concepts of attitude and satisfaction" (p. 99). "Job morale" may be defined as "an individual's 'mental attitude toward all features of his work and toward all of the people 
with whom he works"" or as "'the extent to which the individual's needs are satisfied and the extent to which the individual perceives that satisfaction as stemming from his total job situation"' (p. 99). "Work Role" and "Motivation." Vroom (1964) provides two additional definitions which may be useful to the contextual references for this study. He defines the "work role" as a "set of functions to be performed by the role occupant" (p. 6). And although the present study will not attempt to explore employee "motivation" per se, a definition may be helpful as reference. Vroom defines "motivation" as "a process governing choices made by persons . . . among alternative forms of voluntary activity," excluding reflexes or "autonomic nervous" responses such as "salivation or heart rate" (p. 6). Thus, "motivation" may be seen as individual "willingness to exert effort to attain organizational goals" (p. 5).

A Comprehensive Definition of "Job Satisfaction." Chase (1976-77) relates job satisfaction, morale, motivation, work, and achievement to summarize and simplify a complex cycle including the worker, the work, and the organization:

The dynamics of work, that is, of purpose-achieving behavior, in any organization may be summed up as follows: (1) motivation releases energy for work directed toward organization objectives; (2) work under appropriate conditions leads to achievement; (3) a sense of achievement, when accompanied by recognition and other awards, tends to produce satisfaction; (4) the experience of satisfaction predisposes toward further achievements in the belief that they will also prove rewarding; and thus (5) satisfaction is transformed into morale, or the disposition to productive work; (6) this disposition is actualized and the stored energy released by motivation; (7) work follows, leading to satisfaction; and so the cycle continues ( $p .2)$. 


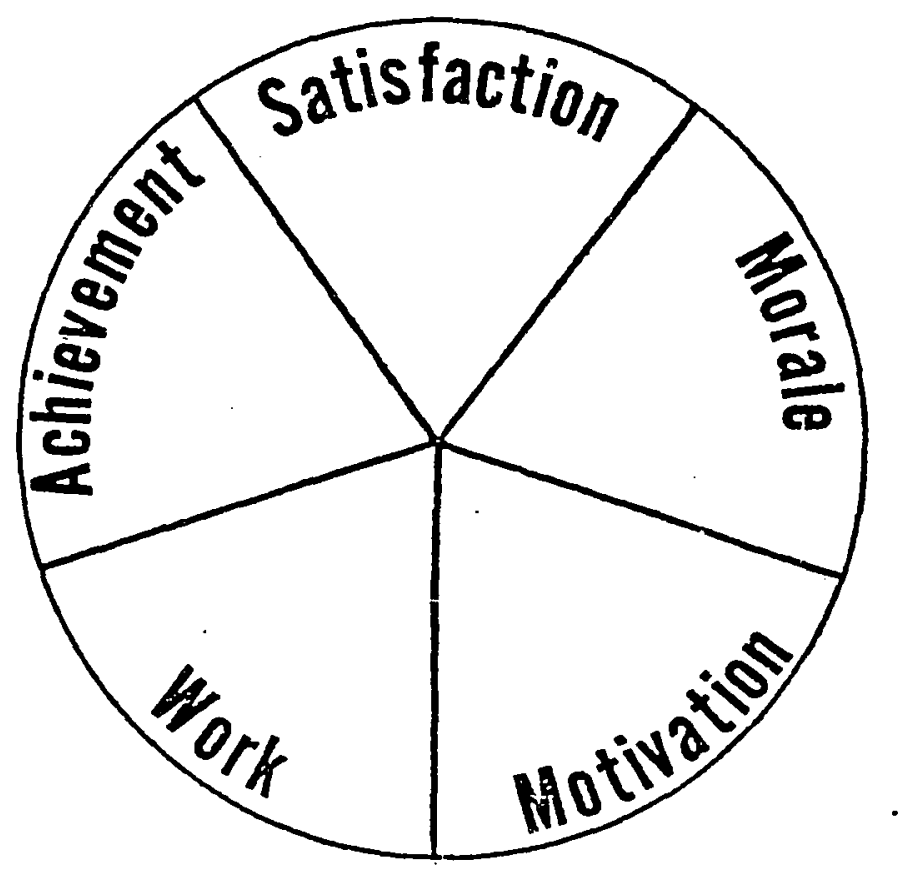

Figure 1: A cyclical concept of job satisfaction (Chase, 1976-77, p. 1)

In expanding on the interrelated or cyclical concept of job satisfaction, Chase (1976-77) explains further:

Satisfaction grows out of a sense of achievement and of being valued in an organization. It is a result of past experiences and typically is uppermost in a state of rest between activities. Morale is compounded from a commitment to common purposes and a sense of unfulfillment or challenge and is powerfully influenced by the expectation (grounded in past experience) of satisfying future achievement. Motivation springs from interaction between the ready organism (individual or group) and the external situation, and is the trigger which releases energy for work. Work is behavior directed toward organization goals, which, when performed under favorable conditions, results in achievement. Achievement in organization terms is the attainment of, or progress toward, goals; but for the individual in the organization it is the feeling of a task well done or of a substantial contribution to goal attainment (p.2). 
Most simply, as a comprehensive definition of job satisfaction with focus on the individual, Locke (1969) confirms interrelationships as:

- . the pleasurable emotional state resulting from the appraisal of one's job as achieving or facilitating one's job values (p. 316).

Summary. Although researchers and theorists have not necessarily reached common agreements on an absolute definition for "job satisfaction" and other related terms of reference, the differences in meaning and usage are more often based on construance or subtle interpretations than they are based on controversy or opposition. Thus, in order to establish the operational definitions for terms to be used in the current study, it is appropriate to consider the purposes of the current study, what the study will attermpt to do and what the study will not attempt to do. This study will attempt to explore expressions of positive or negative attitudes or feelings within compatible and commonly intermingled concepts of "job satisfaction" and "job attitudes," and "satisfaction" and "morale," as reflected by teachers expressing their views on their "work roles." This study will not attempt to assess "motivation" beyond analyses of expressed factors of satisfaction or dissatisfaction, the importance of such factors to teachers in general or to subgroups of teachers. This study will not presume to explain complex causal linkages withir cyclical concepts, although significant relationships may be identified in the process of data analyses. This study will not attempt to determine how satisfaction and performance may be related, but the research may assist further study to explore and explain these 
relationships. And, finally, to shape the study and discussion, basic definitions are necessary. As T.S. Eliot has Sweeney explain: "I gotta use words when I talk to you" (Eliot, 1963, p. 123; in Herzberg, 1966, ix).

\section{Definition of Terms}

For the purpose of the current study, the operational definition of terms to be used, as discussed in this chapter or to be discussed in subsequent chapters, will be as follows:

Administrators:

Supervisors or principals in leadership positions in public school systems and assigned to schools or district administrative offices.

\section{Ancillary:}

Auxiliary or supplementary, used by Lortie (1975) to refer to factors that may be expected to be part of the job or the work role and that may be viewed positively by some and negatively by others (pp. 101, 103-105).

\section{Attitudes:}

Dispositions or opinions that may stem from feelings and may be accompanied by feelings, with particular reference to work or workers (e.g., job attitudes).

Bidimensional

Used by Herzberg and fellow researchers (1974) to refer to needs as established in a dichotomy: growth needs and pain-avoidance needs that may function independently. That which gratifies 
growth needs operates along a dimension of emptiness-fulfillment and serves as motivators; that which gratifies the pain-avoidance needs operates along a dimension of pain-relief and serves as hygienes or maintainers, but not as motivators (pp. 411-418).

Bi-polar Theory:

(Traditional Theory) Theory that finds satisfaction and dissatisfaction on extreme ends of a continuum, as feelings or characterizations of feelings related to factors. The opposite of satisfaction is dissatisfaction.

Concomitant Satisfaction:

Satisfaction derived from working in a particular physical environment or with a particular group (Friedlander, 1963, p. 250).

Dichotomy:

Division into two parts or opposed subclasses.

\section{Dissatisfiers:}

(Hygienes) Factors operating individually or collectively to alter individual job attitudes of dissatisfaction. If the findings of the present study conform with Herzberg's theory (1959), a given factor serving as a dissatisfier will operate only in a negative disection to increase job dissatisfaction; absence of the negative factor would not result in satisfaction (Sergiovanni, 1966, pp. 8-9).

Dual-factor Theory:

Theory developed by Herzberg and fellow researchers as a system of factors that will serve as satisfiers or motivators and 
another system of factors that will serve as dissatisfiers or hygienes (Herzberg et al, 1959).

\section{Ethos:}

The characteristic and distinguishing attitudes or habits of a group, with particular reference to school teachers (Lortie, $1975)$.

Extrinsic:

Not inherent; being, becoming, or acting from the outside (e.g., extrinsic rewards or extrinsic job factors) (Herzberg, 1959, p. 81 ; Lortie, 1975, pp. $101-105)$.

Factor or Facet Satisfaction:

Positive or negative evaluations of particular aspects or variables, with particular reference to the job and the work role (e.g., teaching and the role of the teacher).

\section{Feelings:}

Subjective reactions--pleasurable or unpleasurable--that relate to or stem from a situation or experience; what is attributed to something as a result of individual impression, with particular reference to work or workers.

\section{First-level Factors:}

Situations that are antecedent to a job attitude, resulting from concrete events, "an objective element of the situation in which the respondent finds a source for . . good or bad feelings about the job" (Herzberg, 1959, p. 44).

Hierarchy:

A system of graded or prioritized ranks; factors or variables 
arranged or expressed in order of rank or importance, with particular reference to Maslow (1954).

Hygienes:

(Dissatisfiers) Factors operating individually or collectively to alter individual job attitudes of dissatisfaction. If the findings of the present study conform with Herzberg's theory (1959), a given factor serving as a dissatisfier will operate only in a negative direction to increase job dissatisfaction; absence of the negative factor will only serve as a maintainer and will not result in satisfaction (Herzberg, 1959).

Intrinsic:

Essential, inherent, not dependent on external circumstances; used in this study to refer to rewards or factors that may be defined as motivators (Herzberg, 1959) or used interchangeably with "psychic" (Lortie, 1975).

Job Attitudes:

Individual and representative expressions of positive or negative opinions that may stem from feelings and may be accompanied by feelings about the job or the work role (e.g., teaching and the role of the teacher).

Job Content:

Related to work itself, doing the job, intrinsic factors or variables identified by Herzberg (1959) as related to motivators or by Lortie (1975) as related to "psychic" rewards.

Job Context:

Related to conditions of work, external or intrinsic factors or 
variables identified by Herzberg (1959) as hygienes.

Job Satisfaction:

A comprehensive term related to positive and negative attitudes and feelings about the job and the work role (e.g., teaching and the role of the teacher).

Morale:

Used interchangeably with satisfaction to refer to degrees of positive or negative expressions from an individual or group assessing elements of work and the work role.

Motivation:

Related to purpose or intention, related to incentives and goals or the accomplishment of tasks and gratification of needs, with particular reference to Maslow (1954) and Herzberg (1959). "A process governing choices" (Vroom, 1964, p. 6); "willingness to exert effort to attain organizational goals" (Vroom, 1964, p. 5). Motivation Inversion:

The degree to which an individual seeks to satisfy pain-avoidance needs, relating feelings of satisfaction to the absence of pain or to hygiene factors rather than to fulfillment of growth needs or to motivator factors, to support "dual-factor" theory (Herzberg, Wiener, Mathapo, \& Wiesen, 1974, pp. 411-418).

Motivator-Hygiene Theory:

(Dual-Factor Theory) Theory developed by Herzberg and fellow researchers as a system of factors that will serve as satisfiers or motivators and another system of factors that will serve as dissatisfiers or hygienes (Herzberg et a1., 1959). 


\section{Motivators:}

(Satisfiers) Factors operating individually or collectively to alter individual job attitudes or feelings of satisfaction. If the findings of the present study conform with Herzberg's theory (1959), a given factor serving as a satisfier will operate only in a positive direction to increase job satisfaction; absence of the positive factor would not result in dissatisfaction (Sergiovanni, 1966, pp. 8-9).

\section{Organization:}

A body or structure of individuals brought together as a systematized unit or entity for a common purpose or enterprise, with identified roles and goals (e.g., a public school system).

Overall Job Satisfaction:

"The sum of evaluations of the discriminable elements of which the job is composed" (Locke, 1969, p. 330). Comprehensive evaluation of the total work role of the teacher (drawn from Lawler, 1973, p. 64, in Holdaway, 1978, p. 11).

\section{Personne1:}

Persons employed in work, enterprise, or service, with particular reference to employees in a public school system.

Portland Metropolitan Area:

(PMA) The eight public school districts that participated in a study in 1981, reported by Falkenstein (1982) and Hathaway (1982), invited to participate in a follow-up study in 1984. Seven public school districts in the same area participated in the 1984 study. 
Prepotent:

Superior in power, force, or influence, with particular reference to factors or variables operating in hierarchical order as established by Maslow (1954).

Primary or Lower Grades

Used in this study to refer to grade levels from pre-kindergarten through grades four-six.

Principals:

The certificated administrative leaders assigned to supervise the staff and programs in public schools; often identified as the instructional leaders in the school buildings (Goodlad et al., $1979-80)$.

Psychic:

of the psyche, or mind; used interchangeably with "intrinsic" by Lortie (1975) to refer to "subjective valuations made in the course of work engagement" (p. 101), as related to "psychic" rewards.

Respondents:

Classroom teachers (PreK-K-12) from the random sample in the seven participating school districts who responded to the survey instrument.

Sample:

Classroom teachers (PreK-K-12) selected at random in the seven participating public school districts to represent one-third of the total teacher population and to receive the survey instrument. 
Satisfaction:

Used interchangeably with "morale" to refer to degrees of positive or negative expressions from an individual or group assessing elements of work and the work role.

\section{Satisfiers:}

(Motivators) Factors operating individually or collectively to alter individual job attitudes or feelings of satisfaction. If the findings of the present study conform with Herzberg's theory (1959), a given factor serving as a satisfier will operate only in a positive direction to increase job satisfaction; absence of the positive factor would not result in dissatisfaction (Sergiovanni, 1966, pp. 8-9).

Second-Level Factors:

Needs or drives activated by concrete events or situations. Used by Herzberg et al (1959) to categorize answers subjects would give to probing questions about the reasons for identified feelings (pp. 26-28, 49-50).

\section{Social Factors:}

Factors or variables of social influence in the work setting, pertaining to the individual worker's reaction or groups of workers in interaction.

\section{Staff:}

A group of workers or employees, with particular reference to employees in a public school building or systen. 
Students:

(Pupils) The children (PreK-K-12) interrelating with, and being instructed and supervised by, certificated personnel in public school buildings.

Traditional Theory:

(Bi-Polar Theory) Theory that finds satisfaction and dissatisfaction on extreme ends of a continuum, as feelings or characterizations of feelings related to factors. The opposite of satisfaction is dissatisfaction.

Teachers:

The certificated instructors actively engaged in classroom teaching (grades PreK-K-12) in public schools.

Unidimensional:

Operating on one dimension; used in this study to refer to expressions ranging from satisfaction to dissatisfaction for any given factor as operating on a continuum (bi-polar).

Upper or Higher Grades

Used in this study to refer to grade levels from six through eight, seven through nine, or nine through twelve.

Work Role:

A set of functions to be performed by the role occupant (Vroom, 1964, p. 6), with particular reference to the role of the teacher.

Sumnary

Thus, in recognition of a problem and rationale for a study that includes purpose and potential benefit or practical application, and 
with terms of reference that have been subjected to operational definition, the current study on job satisfaction is based on an identified need for direct and continuing information from teachers in public school systems in the Portland Metropolitan Area. Public school educators are addressing claims of inadequacy and mandates for reform at national, state, and local levels. Teachers are being affixed with labels such as "The Imperiled Profession" (Duke, 1984) and "The Troubled Profession" (Durbin, 1983) as major contributors to "A Nation at Risk" (1983). The current research is being conducted in the hope that the data may provide helpful information for the public, public school educators, and the many issues related to roles and perceptions that could assist efforts of change or reform in public education; but it is particularly directed toward potential benefits for the gamut of personnel services associated with public school teachers.

The current study rests on theoretical background which will be discussed in the following chapter. 
CHAPTER II

THEORETICAL BACKGROUND

The theoretical background for study of job satisfaction of teachers has developed from psychological study, study of organizations and social factors operating within organizations and systems of enterprise, various assumptions, and sociological study of the "ethos" of schoolteachers. For the purposes of this study, the discussion on theoretical background will include the following addresses:

- theory on needs and gratification as related to motivation;

- theory on psychological or "social factors" in the work setting: integrating the goals of the individual with the goals of the organization;

- differing assumptions leading to studies of job satisfaction;

- Herzberg's "motivator-hygiene" theory--"dual-factor" theory;

- teachers and teaching as a basis for sociological study and theory;

- Lortie's Theory on teachers and teaching;

- integration of Herzberg's theory and Lortie's theory.

As reference and support for the current study, it is appropriate to examine some of the research and theory that has developed and merged to assist those who seek better understanding of human beings involved in common enterprise, bringing together needs, expectations or goals, and myriad social influences as factors that may serve to satisfy or dissatisfy individuals or groups that will have profound impact on the success or failure of the common enterprise. 


\section{Needs and Gratification as Related to Motivation}

A theory of human motivation establishing an order of higher and lower needs and gratification of needs in psychological theory, validating a psychological approach to science, is developed by Abraham Maslow (1943, 1954). In Motivation and Personality (1954), he establishes the concept of a need hierarchy of prepotency as linked to motivation theory, which may be related to the motivation to work (Aldeferer, 1969; Ashbaugh, 1982; Herzberg et al., 1959, p. 110). In accord with this theory, when a basic need is fulfilled or satisfied the next higher need emerges, with an accompanying premise that fulfilled needs do not serve as "active motivators" (Herzberg et al., 1959, p. 110). Within Maslow's construct, the hierarchy begins with basic physiological needs, such as food and shelter, and progresses in prepotent order through need for safety and security, through need for social belonging and affiliation, through need for recognition and achievement or esteem, through need for the opportunity to accept responsibility and gain advancement as a stage of highest order or "self-actualization" (Maslow, 1954). Maslow's model leads to the assumption that differing needs, emerging prepotently at progressive stages of the hierarchy, will require differing types of gratification, with emphasis always on the highest psychological order of need, "self-actualization" (Lawler \& Porter, 1967, p. 26).

Thus, in establishing a framework for feelings related to work, Maslow's theory is a useful reference for identifying and patterning needs or motives (Hersey \& Blanchard, 1972, p. 66; Kaiser, 1981, 1982). 


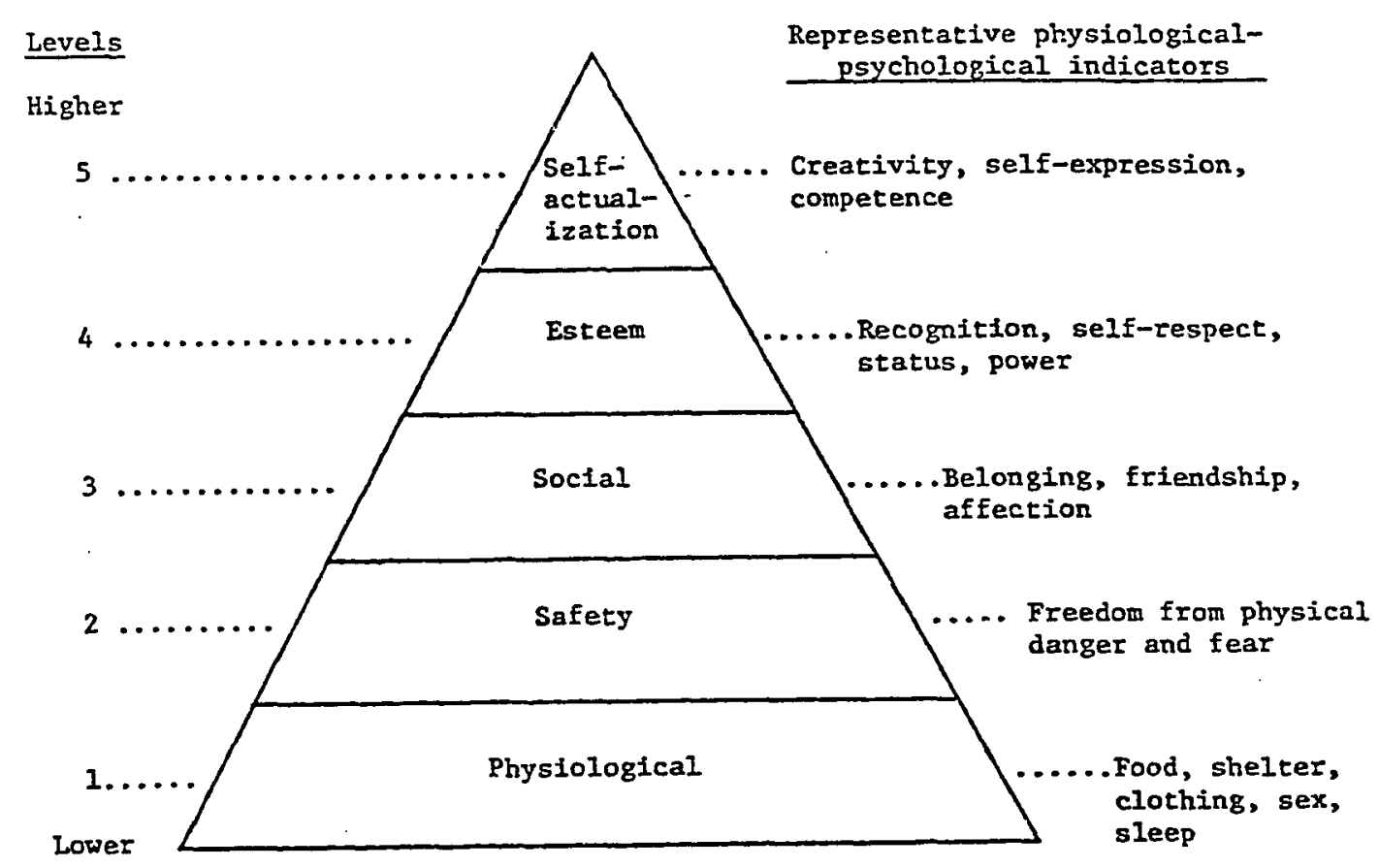

Figure 2: Adaptation of Maslow's theory of hierarchical needs (1954)

As a departure from Maslow's theory of hierarchy and prepotency of needs extending from deficiency to actualization (1954), Herzberg, Wiener, Mathapo, and Wiesen (1974) outline a "bidimensional" approach to needs and expressions of feelings related to meeting the needs. This theory may also be related to motivation. In the Herzberg system, the needs are established in a dichotomy: growth needs and pain-avoidance needs. They may function independently. That which gratifies the growth needs operates along a dimension of emptinessfulfillment and serves as motivators. That which gratifies the pain-avoidance needs operates along a dimension of pain-relief and serves as hygienes or maintainers, but not as motivators (pp. 411-418). 
Within either Maslow's theory of higher and lower needs and concepts of hierarchy and prepotency (1954) or Herzberg's "bidimensional" theory of needs (1974), individual needs and sets of needs and their gratifications may be related to job satisfaction and motivation to perform.

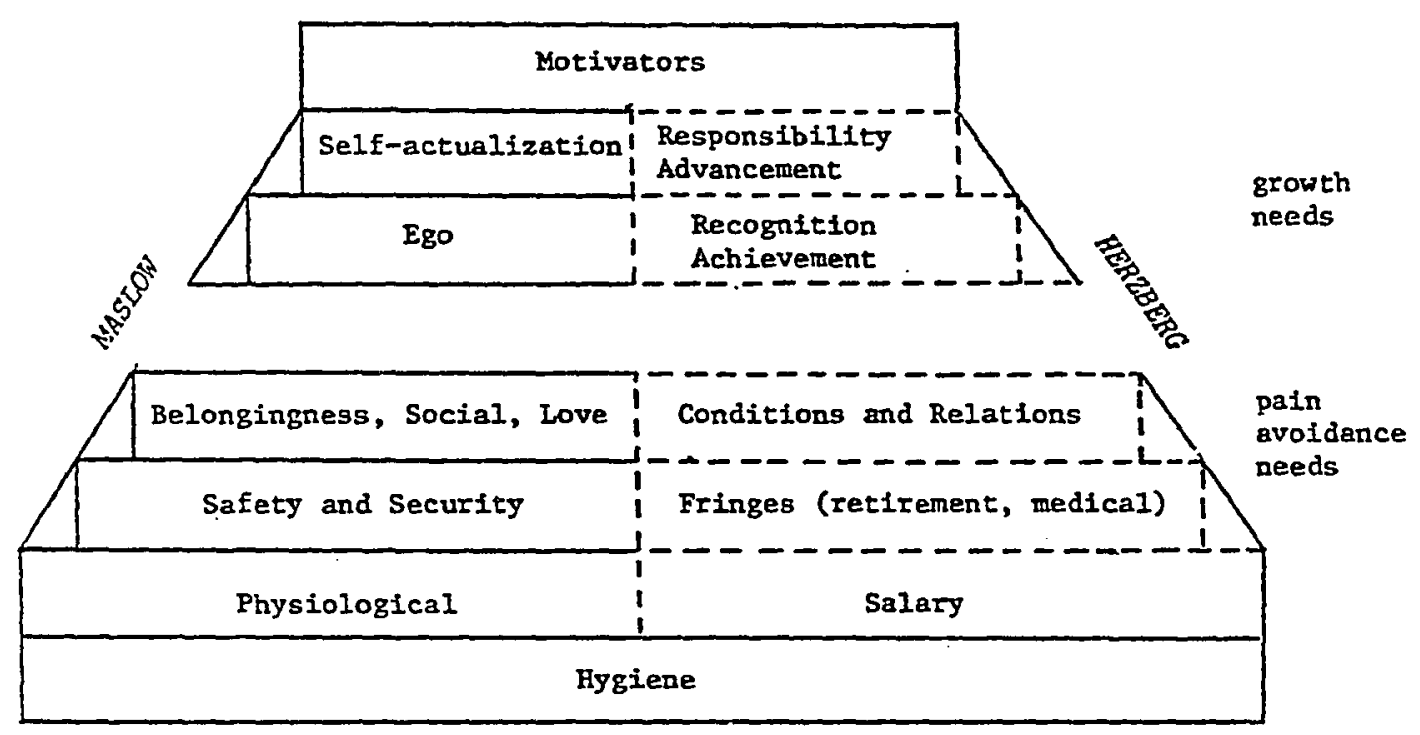

NEEDS AND GRATIFICATION AS RETATED TO MOTIVATION

KASLOW

hierarchical

prepoterit

Irom lower order to higher order Erom deficiency to actualization related to motivation
HERZBERG

bidimensional operating Independently pain-avoidance needs - pain-relief growth needs - emptiness-fulfillment growth needs as intrinsic/motivators pain avoidance needs as extrinsicl hygienes, not motivators

Figure 3: Adaptation of Maslow's theory of hierarchical needs (1954) and Herzberg's dual-factor or bidimensional theory of growth needs as motivators and pain avoidance needs as hygienes (1959 \& 1974). (Drawn from Kaiser, 1981, p. 36; adapted for this study) 
Rewards as "Intrinsic," "Extrinsic," or "Ancillary"

That rewards influence or are related to satisfaction and motivation to perform is a common assumption of research in job satisfaction, often referenced to Maslow's theory on hierarchical needs and gratifications (1954) and also referenced to Herzberg's "bidimensional" system (1974). Job-related rewards are most often classified in two types: "intrinsic" and "extrinsic," but they may also be classified into three types: "intrinsic," "extrinsic," or "ancillary." Each of the types of rewards is subject to definition by researchers or theorists, and each type of reward may also be subject to the perceptions and preferences of individuals or subgroups and their job values in relationship to the qualities of the job, its content or context (Centers \& Bugenta1, 1966, pp. 193-197; Daniel \& Esser, 1980, pp. 556-573; Deci, 1975; Friedlander, 1966, p. 151; 0'Reilly \& Caldwell, 1980, pp. 559-565).

"Intrinsic" Rewards. "Intrinsic" rewards may be defined as "motivators," related to job content and influencing job satisfaction (Herzberg et al, 1959), associated with "basic needs to feel competent and self-determining" (Deci, 1976, in ACSA, 1979, p. 11). They may be further defined as "psychic" rewards and related to primary factors leading to job satisfaction (Lortie, 1975, p. 101). Lawler and Porter (1967) note that intrinsic rewards are given by the self to the self or "internally mediated" and are directly related to successful performance (p. 24). A good example of such a reward might be the feeling of having accomplished something worthwhile. Lortie (1975) defines such rewards interchangeably as "intrinsic" or "psychic," and 
he notes that they consist of "subjective valuations made in the course of work engagement." They may vary from worker to worker, but they center around work achievement or the sense of achievement gained from doing the job (Lortie, 1975, p. 101). Any rewards that relate to "self-actualization" or higher order growth categories, as identified by Maslow (1954) or Herzberg et al. (1974), become primary examples of intrinsic rewards (Lawler \& Porter, 1967, p. 24).

"Extrinsic" Rewards. "Extrinsic" rewards may be defined as "hygienes," related to job context and influencing job dissatisfaction (Herzberg et a1, 1959); or they may be related to primary factors leading to "a shift of motivation" (Deci, 1976, in ACSA, 1979, p. 11), or job tension, ambivalence of role and discontent (Lortie, 1975). Lawler and Porter (1967) define extrinsic rewards as those which are "organizationally controlled," with examples such as "pay, promotion, status, and security"l--those which satisfy Maslow's lower level needs (pp. 23-24). Bredeson, Fruth, and Kasten (1983) support the view of extrinsic rewards as within the control of the organization and extend differentiated categories of extrinsic rewards to include: system rewards (lockstep salary schedules), individual rewards (acknowledgement of excellent performance), and peer rewards (informal support) (p. 56). Lortie (1975) relates extrinsic rewards to "money, income, a level of prestige, and power over others"--in the sense that they "exist independently of the individual who occupies the role" and have an "objective quality" (pp. 101, 103-105).

"Ancillary" Rewards. "Ancillary" rewards are defined by Lortie (1975) as "simultaneously objective and subjective." They are seen to 
refer to job characteristics which are relatively stable and may be taken for granted as job expectations, but they may be perceived as benefits to some workers and not to others. Thus, they are linked to individual preferences and perceptions. An example of a factor which could fall within this category might be the work-year calendar for teachers (pp. 101, 103-105).

Perception of Reward - Preference for Reward. Perception of reward, or preference for reward, as important to the individual or the group, is generally regarded as a significant aspect of data collection on job satisfaction (Vroom, 1964). As Lawler and Porter (1967) note:

An individual's satisfaction is a function both of the number and amount of rewards he receives as well as what he considers to be a fair level of reward. An individual can be satisfied with a small amount of reward if he feels that it is a fair amount of reward for his job (p. 24).

In extending this idea by relating rewards to performance, Lawler and Porter (1967) propose that intrinsic rewards that satisfy the nigher needs, such as self-actualization, are "more likely to be related to performance than are extrinsic rewards which have been given by someone else and therefore have a weaker relationship between their reception and performance" (p. 26).

Friedlander (1963, 1966), in study of motivations to work and organizational performance, and underlying sources of satisfaction, examines intrinsic needs as "self-actualizing" or "ego involving" and based on "internalized motivations." He examines extrinsic needs as "externalized motivation or as striving to fulfill deficiency or maintenance needs." The "motivation-individual benefit relationship" 
(1966, p. 143), as a concept for job satisfaction, leads him to identify "three distinct, though related, types of satisfactions to be derived from work:

. . the return in the form of monetary rewards and prestige; intrinsic satisfactions or the pleasure in a specific activity and in the accomplishments of specific ends; and concomitant satisfactions, such as those derived from working in a particular physical environment or with a particular group (1963, p. 250).

Locke, Smith, Kendall, Hulin, and Miller (1964), and Locke (1969) have developed a model to explain the relationships between what an employee wants and how much of that something the employee wants. In short, the importance of a factor to individuals may differ in degree, related to the interaction of perception and preference. In accord with this "interactionist" concept, Locke notes that job satisfaction and dissatisfaction may be viewed as "a function of the perceived relationship between what one wants from one's job and what one perceives it as offering" (1969, p. 316). In considering individual workers and their values, Locke maintains that values are relational; they are judged as estimates of perceptions weighed against value standards:

The causes of job satisfaction are not in the job nor solely in the man, but lie in the relationship between them. The prediction of job satisfaction necessarily requires an interactive approach--not because . . . correlational studies have "proved" it, but because of the nature of man and the evaluation process (1969, p. 319).

Sunmary

The three defined types of career rewards--intrinsic, extrinsic, and ancillary--are seen to be related to sources of job satisfaction and dissatisfaction. The attitudes may be derived from various components 
of work, such as: receiving salary or being recognized, doing the job or reaching a set goal, or working in a particular environment or social setting (Friedlander, 1963, p. 250). The rewards may be intangible or tangible. They may be given by the self to the self, or they may be given directly or indirectly by the organization or place of work. They may result from the content of work or the context of work (Herzberg et al., 1959, 1966, 1968, 1974). They may be expected or unexpected (O'Reilly \& Caldwell, 1980, pp. 559-565). They are based on some real or perceived element of need (deficiency, lack of actualization or growth, lack of relief or fulfillment or preference). They are generally seen to be related to motivations to work and organizational performance (Daniel \& Esser, 1980, pp. 566-573; Deci, 1975; Friedlander, 1963, 1966; Herzberg et al., 1959, 1966, 1968, 1974; Lawler \& Porter, 1967; Vroom, 1964), but the cause-effect relationships are not yet clearly defined.

The goal is to uncover rewards which cut across the preferences of individuals (Lortie, 1975, p. 101).

This study will include address to factors as influences to attitudes or feelings that may be seen to contribute to satisfaction (or reward) or dissatisfaction of public school teachers in the PMA. The factors will be considered as a dichotomy of motivators (intrinsic) and hygienes (extrinsic), in acknowledgement of Herzberg's theory (1959) and compatible with Lortie's theory (1975). This study will include visual inspection of factors contributing most frequently to satisfaction of teachers in the PMA, to seek some data that may be related to Lortie's findings on intrinsic or "psychic" factors that 
contribute to primary rewards for schoolteachers (1975, pp. 101, 103-104, 106, 109, 119-125, 141, 187-200). This study will not include direct address to factors or rewards defined by Lortie as ancillary (pp. 101, 103-105).

Psychological or "Social Factors" in the Work Setting:

Integrating the Goals of the Individual

with the Goals of the Organization

Levels of psychological satisfaction of workers in the work setting or "social factors" which may influence performance have been of continuing and increasing interest to organizations and systems of enterprise since the unexpected findings of Elton Mayo and his research associates, reported by Roethlisberger and Dickson in Management and the Worker (1939, in Etzioni, 1964, p. 33). These studies, conducted at the Western Electric Company Works in Chicago, from 1927 to 1932, to test the effect of illumination on worker production, have become known as the "Hawthorne Studies." Findings from these studies first led to the conclusion that "increased production was the result of the changed social situation of the workers, modifications in their level of psychological satisfaction, and new patterns of social action" (Etzioni, 1964, p. 33). From study of workers in the Bank Wiring Room, it was then concluded that the social norms of a group may operate just as effectively to restrict production. Thus, the satisfaction of the worker and the influence of "social factors" are seen to be important influences on the performance of the organization; and thus, it has become accepted that 
organizations should consider the goals of their workers in relationship to the goals of the organization.

Extensions of theory on psychological or social factors in the work setting are bringing greater recognition to the importance of the individual worker as significant to the success of the organizational system. The worker comes to the organization with goals or expectations and needs that may or may not mesh with the goals of the organization. The worker influences the system as an individual and as a member of a group and group culture. In turn, the worker is influenced by the system and its culture (Lieberman $q$ Miller, 1978). The interrelationships of influences result in formulated job attitudes that are variables to be considered as the organization frames goals, strives to meet them, and addresses plans for change or renewal. The individual worker represents a vital resource to the potential of the group enterprise. Thus, a central concern for the organizational system is to consider how the goals of the individual may be integrated with the goals of the organization in mutual benefit.

The integration of the individual and the organizational goals is the fundamental challenge.. . as conflicting goals are a source of job stress (Davis, 1981, p. 37).

A worker's satisfaction and productivity . . . is [sic] largely determined by the degree to which the worker's expectations match the organization's (Childers \& Podemski, 1982-83, p. 3 ).

Concepts for integrating the individual and individual expectations and goals with the organization and organizational expectations or goals--as organizational "fit" for mutual benefit to the individual and the organization--include the following addresses: 
(1) seeking congruence in staff recruitment and assignment, (2) recognizing incongruence as a benefit to staff development and organizational change and growth, and (3) seeking information from staff and providing staff with decision-making and problem-solving opportunities and active roles in goal-based change or reform processes for organizational renewal.

In Modern Organizations (1964), Etzioni emphasizes the social environment of organizational systems and the fact that it is important to organizational enterprise to recruit persons who have the "requisite psychological characteristics" (p. 110). Logically, by knowing the factors that increase satisfaction and decrease dissatisfaction and by being sensitive to change or need for change, an organization--such as a school system--could better select and place personnel to meet its needs and increase its effectiveness. At the same time it could increase the probability for job satisfaction of individual staff members, by encouraging positive social environments in preference to "any deliberate efforts by the organization to shape personalities according to its needs" (p. 110).

In Integrating the Individual and the Organization (1964), Argyris extends his earlier research on personality and organization (1957) into organizational theory and practice including factors which may lead to "unintended consequences with negative effects on the organization and the individual" (p. vii). He develops a theme that both the individual and the organization have to "give a little" in order to "profit from each other" (p. 3). His major thrust is toward increasing individual and organizational effectiveness concomitant 
with the hypothesis that "the incongruence between the individual and the organization can provide the basis for a continued challenge, which as it is fulfilled, will tend to help man to enhance his own growth and to develop organizations that will tend to be viable and effective" (p. 7). In shori, understandings of "incongruence" between the individual and the organization could form a basis for increased effectiveness of both the worker and the system of enterprise.

In Theory Z (1981), Ouchi articulates an even more recent theory on the significance of "social factors" within the organizational work setting, including concern for the satisfaction of the worker as a benefit to the system. The concepts of Theory $Z$ emphasize communicating directly with the workers, bringing shared insights toward problem identification and solution, and promoting the vested interests of individual contributors toward group enterprise. Implicit in Ouchi's theory are elements of Maslow's developed theory and model of human needs (1954), as efforts to recognize and promote what is important to the worker, what will motivate the worker, and what will provide the highest possible levels of psychological satisfaction to the worker within the context of "social factors" of the work setting. Pascale and Athos (1981) extend these concepts into guides and applications for management, as a '5-S' framework of strategy, structure, systems, style, and superordinate goals directed toward "organizational capability."

And, finally, as an address to organization and renewal within public school systems, Brooks (1982) cites the importance of integrating the goals and potential contributions of individual 
teachers with the processes of organizational renewal. His outline for organizational renewal in education is integrative and responsive:

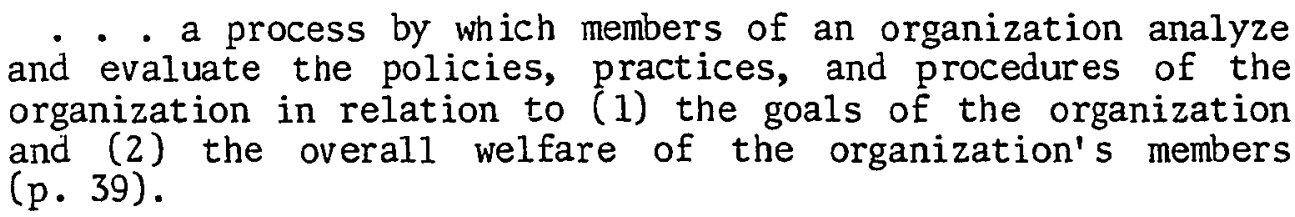

Brooks supports methodologies for change in school organization which seek direct input from individual staff members and which allow for "meaningful, though not necessarily direct, participation" in change or renewal efforts, and he addresses the importance of shared responsibilities of individuals as contributors and of the organization to the contributors $(p, 44)$.

Ultimately, Brooks directs all recommendations for renewal or productive change in organizations to the significance of psychological or social factors and the significance of needs and rewards. "Most change efforts do not address the perceived needs of organizational members . . responsibility ... is more relevant to meaningful change than material inducements and rewards . . the opportunity to take responsibility often constitutes a more powerful reward than material gains" (p. 44). He concludes with reference to the important values in an organization as an address to the opportunity it may permit and provide for individual contribution and growth:

The opportumity to make a meaningful contribution to the organization, the opportunity to have satisfying interpersonal relationships, the opportunity to accept responsibility, the opportunity for recognition and advancement, and the opportunity to stretch oneself to grow (French \& Bell, in Brooks, 1982, p. 44). 
Differing Assumptions Leading to Studies of Job Satisfaction

Since the recognition of the importance of human relations and social factors as psychological influences on groups and indiviauals in the work setting (Hoppock, 1935; Roethlisberger \& Dickson, 1939), job satisfaction has been generally regarded as important to research ${ }^{1}$, and myriad studies have been conducted worldwide to collect data on job satisfaction from groups and individuals in various occupations. Data collection techniques include observations or direct inquiry of subjects by personal interview or survey instrument. However, purposes for study are often based on differing assumptions. Some assumptions are:

- that job satisfaction is "the conceptual equivalent of the valence of the job or the person performing it" . . . with "assumed correspondence between satisfaction and valence -. . If we consider job satisfaction as the valence of a work role to its occupant, it becomes clear that there could be different valences associated wth different properties of work roles." Therefore, "job satisfaction is best treated as a set of dimensions rather than a single dimension" (Vroom, 1964, p. 101).

- that measures of job satisfaction with "different aspects of work roles are associated because they are functionally interdependent"; thus they are subject to change--"Changes in satisfaction with one aspect . . may result in changed satisfaction with another aspect" (Vroom, 1964, p. 104).

- that "social outcomes" provided in the work setting may be an important factor (Etzioni, 1964; Lawler \& Porter, 1967; Ouchi, 1981 ; Vroom, 1964).

- that job satisfaction may be environmentally caused . . . "therefore, attempts to solve job frustrations typically involve changing the work situation rather than attempting

1 Herzberg, Mausner, Snyderman affirm that although Peter Drucker has stated than ar. investigation of workers' job attitudes was "immoral" and "unjustified" and "no business of anyone but the worker himself," the study is indeed justifiable and ethical (1959, p. x). 
personality changes in the dissatisfied individual" (Vroom, 1964, p. 159).

- that worker satisfaction affects performance. "Morale is not an abstraction; rather it is concrete in the sense that it directly affects the quality and quantity of an individual's output," and "Employee morale--reduces turnover--cuts down absenteeism and tardiness; lifts production" (Brayfield \& Crockett, 1955, pp. 396-424, in Lawler \& Porter, 1967, pp. 20, 22).

- that satisfaction and performance are clearly related to some degree (Vroom, 1964), but it is not clear how the relationship operates (Lawler \& Porter, 1967, p. 22).

- that rewards influence or are related to satisfaction. "Job satisfaction is closely affected by the amount of rewards that people derive from their jobs" (Vroom, 1964, p. 246; in Lawier \& Porter, 1967, p. 23).

- that rewards may vary in type and importance and may be related to satisfaction or dissatisfaction, depending on the variable or the relative importance of that variable (Herzberg et al., 1959; Lawler \& Porter, 1967; Lortie, 1975; Vroom, 1964).

- that different rewards may be significant to individuals at different stages of their development or in fulfillment of different needs emerging and operating at different times (Lawler \& Porter, 1967; Maslow, 1964; Vroom, 1964). ". . . it seems clear that for a large proportion of individuals the decision to seek or to continue to work is based partly on anticipated rewards obtained from work that have nothing to do with money or the uses to which money may be put" (Vroom, 1964, p. 32).

- that perfornance may lead to rewards which may lead to satisfaction--that satisfaction does not cause performance, but is caused by it (Lawler \& Porter, 1967, p. 23).

- that job satisfaction "varies directly and proportionately with the extent to which those needs of an individual satisfiable in a job situation are actually satisfied" (Schaffer, 1953, in Ashbaugh, 1982, p. 197; Vroom, 1964, p. 162).

- that job satisfaction is related to the "differences between the actual outcomes a person receives and some other desired outcome level," based on expectancy and discrepancy (Ashbaugh, 1982, p. 197; Childers \& Podemski, 1982-83, pp. 2-10). 
- that job satisfaction is related to "a person's perceived input-outcome balance . . . the perceived equity of a person's rewards is determined by his input-outcome balance which, in turn, determines satisfaction . . . either under-reward or over-reward can lead to dissatisfaction" (Adams, 1963, in Ashbaugh, 1982, p. 197).

- that data on job satisfaction and the motivation to work has potential "social usefulness," with accompanying emphasis on benefit and practicality to a larger population (Herzberg et al., 1959, p. x).

- that data on job satisfaction may serve as social indicators: (1) to signal societal change, (2) to monitor and warn of "societal dislocation" or organizational policy or program failure, and (3) to serve to guide formulation of policy and program (Seashore \& Taber, 1975, p. 333). This assumption carries implicit recommendation to seek direct and continuing information from staff in order to better guide or change an organizational system.

Summary -- Prevailing Assumption, Common Assumptions

A better understanding of the causes of job satisfaction is desirable, not because it will enable us to become completely satisfied, but because it may help to relieve that intense and painful dissatisfaction which injures both the individual and the society in which he lives (Hoppock, 1935, p. 52).

As summary, a prevailing assumption is that it is important to determine the causes or sources of job satisfaction as potential for benefit to the worker and to the enterprise of an organizaton, to promote positive influences and to ameliorate negative influences. At present, no conclusive research demonstrates that the most satisfed worker is the most motivated worker (Lawler \& Porter, 1967, p. 21). Indeed, Maslow's hierarchical theory as related to motivation may suggest to the contrary. Deci (1975, in ASCA School Management Digest, 1979, p. 11) and Gorton (1976, in Gorton, 1982, p. 1904) have affirmed that satisfaction may reduce performance or motivation. Nevertheless, it is generally assumed that the most dissatisfied 
worker will not be the best motivated or best performing worker; and it is generally assumed that high job satisfaction is a desirable goal and "desired state" for an organization and its staff (Gorton, 1982, p. 1904; Seashore \& Taber, 1975, p. 366), as well as a "source of societal adaptivity" (Seashore \& Taber, 1975, p. 366). As Ashbaugh states in relating job satisfaction to educators:

If administrators expect to increase job satisfaction, they must work on those factors which make a difference to teachers. When teachers find their work intrinsically and extrinsically rewarding, job satisfaction may increase... . Satisfaction seems to follow performance when the performance results in outcomes valued by the person (1982, p. 201).

As Lawler and Porter note, "positive job attitudes are favorable to increased productivity" (1967, p. 21).

This study will accept common assumptions that satisfaction and performance are related but will not seek to assess the relationship between satisfaction and performance; it will focus on satisfaction and dissatisfaction and related variables as identified by responding teachers; and it will consider what kinds of rewards are identified as significant or satisfying to teachers.

Finally, this study will accept common assumptions that information on job satisfaction of teachers has "potential social usefulness" and could be of benefit to the public and to public educators--with particular emphasis on benefit to personnel services (Herzberg et al., 1957, p. 222).

\section{Herzberg's "Motivator-Hygiene" Theory -- "Dual-Factor" Theory}

Extending from the "Hawthorne studies" of the 1930's, various theories have developed from studies of workers and organizations of 
workers. A major theory that has guided much research on motivation to work and worker job satisfaction is Herzberg's "motivator-hygiene" theory (Herzberg et a1., 1959). This theory stems from a premise that a sequence of events, bound in time, may be studied on the basis of how the individual characterizes or rates personal attitudes as positive, negative, or some scaling of positive or negative. A basic hypothesis is that the factors leading to positive attitudes and those leading to negative attitudes would differ.

Dual-Factor Theory

Herzberg divides factors related to job attitudes into two categories: (1) as motivators or satisfiers, and (2) as hygienes or dissatisfiers:

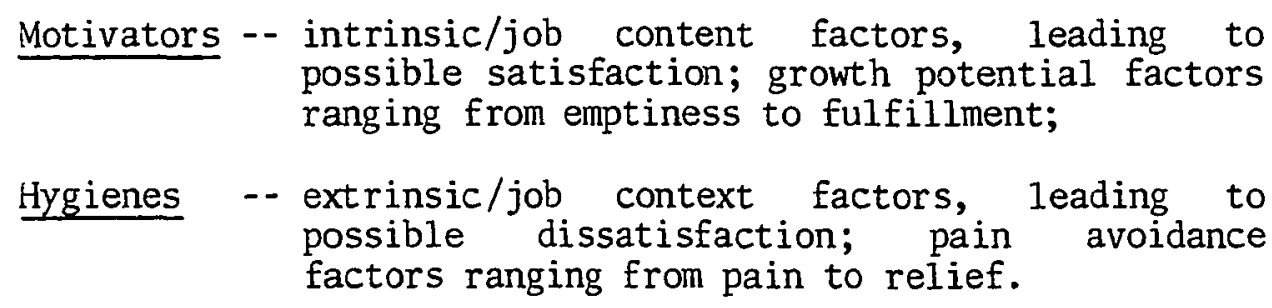

Witnin Herzberg's theory, job satisfiers or motivators are factors involved in doing the work (job content); the job dissatisfiers or hygienes are factors that define the work (job context). Herzberg does not view the factors and attitudes toward them as operating on a continuum. Thus, this theory is termed "dual-factor" or "two-factor" in opposition to what may be termed "bi-polar theory" or "traditional theory" which would find satisfaction and dissatisfaction on extreme ends of a continuum, as feelings or characterizations of feelings related to factors: 
The dual-factor theory -- the absence of satisfaction leads to an extreme of being neither satisfied nor dissatisfied;

the absence of dissatisfaction leads to an extreme of being neither dissatisfied nor satisfied.

The bi-polar theory -- the opposite of satisfaction is dissatisfaction (as a continuum of feeling or attitude on any given factor) (Moxley, 1977, p. 7).

It would follow under bi-polar theory that the removal of an element bringing satisfaction would result in dissatisfaction, and the reverse. It would follow under dual-factor theory that satisfaction and dissatisfaction result from separate factors. Motivators may lead to satisfaction but not to dissatisfaction. Hygienes may lead to dissatisfaction but not to satisfaction. This aspect of Herzberg theory has been subject to some criticism or dispute and much exanination. It will be discussed further in the next chapter and included in the context of this current study.

Considering "First-level Factors"

Drawing from Flanagan's "critical incident" method (1954, in Herzberg et a1., 1959, pp. 12, 21, 23), the Herzberg team used semistructured interviews to form the data base. They asked subject accountants and engineers to recall a time when they felt exceptionally good or bad about their present jobs or others they had held. The analyses of the interview statements set up division into "thought units" about an event or condition leading to attitudes that Herzberg termed "first-level factors" (pp. 26-28, 44, 49) and "secont-1evel factors" (pp. 26-28, 49-50): 
First-level factors describe situations that are antecedent to a person's attitude toward a job. Thus, first-level factors relate to concrete events or situations reported by the respondent.

Second-level factors describe needs or drives activated by these events. Individual second-level responses would categorize the answers the subject would give to probing questions about the reasons for the identified feelings.

This study will accept a priori identification by Herzberg and others of first-level factors, identified in The Motivation to Work $(1959$, p. 28) as a description of the objective occurrences during the sequence of events, with emphasis on those identified by the respondent as being related to personal attitudes. In Work and the Nature of Man (1966), Herzberg affirms that the first-level analysis of events is more objective and takes precedence over the second level of analysis, which is more subjective. This study will not attempt to address the Herzberg hypothesis that factors and effects in 1ong-range sequences of events would differ from those in short-range sequences (1959, p. 29).

Herzberg has identified a first-level factor as "an objective element of the situation in which the respondent finds a source for . . good or bad feelings about the job" (1959, p. 44), establishing fourteen categories of first-level factors. This study will include the categories of factors for Level One as identified by Herzberg as a priori:

First-level factors:

1. Recognition - based on some act of recognition directed toward the individual, which could come from almost any source: supervisor, peer, or public, etc. This category includes what Herzberg terms "negative recognition" such as criticism or blame. 
2. Achievement - based on some specific success, including: completing a job, solving a problem, and/or seeing the results of individual effort.

3. Possibility of growth - based on some reported evidence that the respondent's possibilities for growth are increased or decreased.

4. Advancement - based on actual changes in the status or position of the respondent.

5. Salary - based on all sequences of events in which compensation is received or expected.

6. Interpersonal relations - based on characteristics of interaction. Herzberg has set up three subdivisions:

- interpersonal relations - superior

- interpersonal relations - peer

- interpersonal relations - subordinate

7. Supervision - technical - based on the technical aspects of the supervisor's role: competence/incompetence, willingness/unwillingness to delegate responsibility, willingness/unwillingness to teach, etc., leading to "exceptional feelings about the job."

8. Responsibility - based on the respondent's reported satisfaction from being given responsibility for personal work or the work of others or for being given new responsibilities. This category also includes loss of satisfacton from lack of responsibility.

9. Company policy and administration - based on sequences in which some overall aspect of the company is a factor: good/poor communications, agreement/disagreement with company goals, adequacy/inadequacy of company management or organization, beneficial/harmful effects from personnel policies.

10. Working conditions - based on physical conditions of work, the amount of work, the facilities available for doing the job.

11. Work itself - based on the actual doing of the job or the duties of the job and how the respondent feels about doing all or part of the job.

12. Effect on personal life - based on situations in which the job affects some aspect of the respondent's personal life, to affect individual feelings about the job. 
13. Status - based on some sign of status as being a factor in the respondent's feelings about the job.

14. Job security - based on some objective sign of the presence or absence of job security: tenure/lack of tenure, stability/lack of stability in the company or organization.

Established Factor Types as "Motivator" or "Hygiene"

The present study will accept a priori categories for factors classified by Herzberg and his team (1959, 1966, 1968, 1974), and established by subsequent researchers--including Moxley (1977) and Sergiovanni (1966, 1967, 1980) into factor types as "motivator" (or potential satisfier, found in the work itself) or "hygiene" (or potential dissatisfier, found in the environment of the work). The identified "first-level factors" are classified as follows:

$\begin{array}{ll}\text { Factor Type } & \text { Factor } \\ \text { Motivator } & \text { Achievement } \\ \text { Motivator } & \text { Recognition } \\ \text { Motivator } & \text { Work itself } \\ \text { Motivator } & \text { Responsibility } \\ \text { Motivator } & \text { Advancement } \\ \text { Motivator } & \text { Possibility of growth }\end{array}$

2In Motivation to Work (1959), Herzberg and his research team identified "possibility of growth" more often as a second-level factor and rarely as a first-level factor (p. 68). Sergiovanni (1966) lists "possibility of growth" as a dissatisfier or hygiene. However, Herzberg, in Work and the Nature of Man (1966), defines "possibility of growth" as a "task-centered motivator" ( .77$)$; Hersey \& Blanchard (1972) include "growth and development" as a motivator; Moxley (1977) lists "possibility of growth" as a motivator; and the current study will accept the definition of "possibility of growth" as a motivator as a priori, subject to analys is in the current study. 


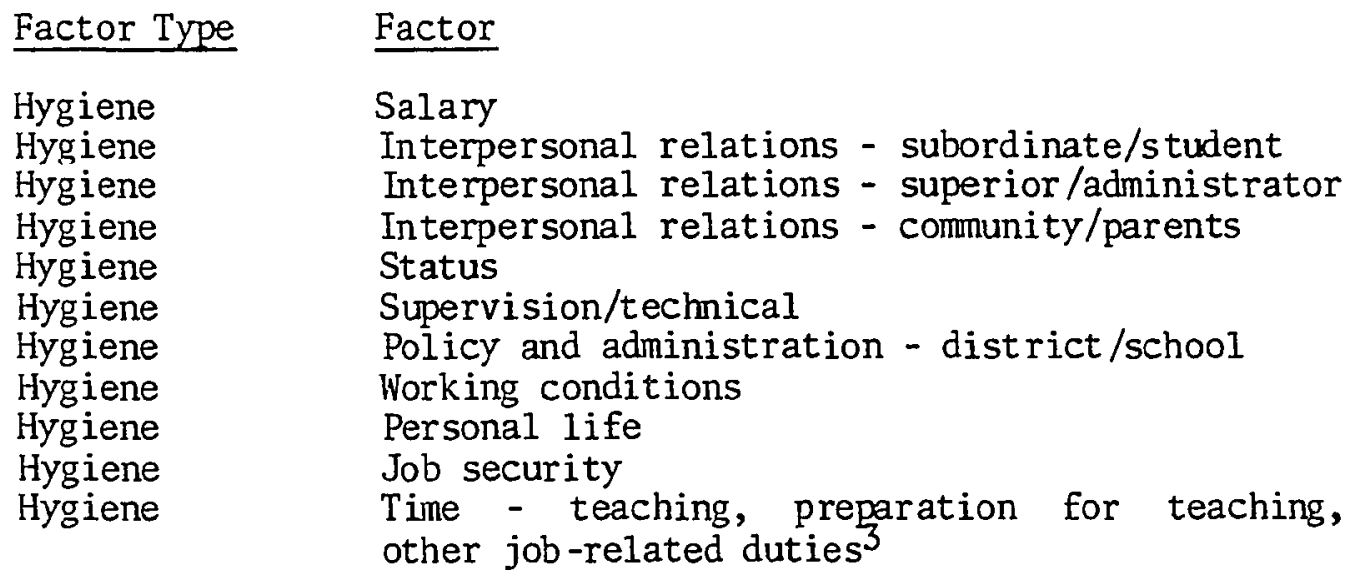

Five Major Factors Identified as "Motivator s"

The five major factors previously identified by Herzberg and others (1959, p. 81) as "motivators"--"intrinsic" and related to doing the job itself (job content) are:

Recognition

Achievement

Work itself

Advancement

Responsibility

These factors will be tested in the current study.

Five Major Factors Identified as "Hygienes"

The five major factors previously identified by Herzberg and others (1959, p. 81) as "hygienes"--"extrinsic" and related to the job environment ( job context) are:

$$
\begin{gathered}
\text { Company policies } \\
\text { Technical competence of supervisor(s) } \\
\text { Interpersonal relations in supervision } \\
\text { Working conditions }
\end{gathered}
$$

These factors will be tested in the current study.

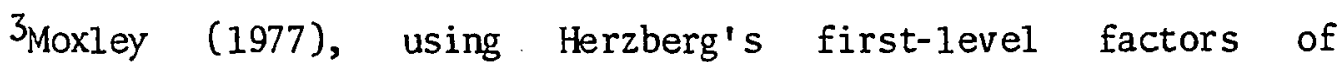
established motivators and hygienes in her study of job satisfaction of faculty members in higher education, notes the strong significance of the "time element" as a hygiene factor reflecting teacher dissatisfaction; thus, this factor is included as a priori (Abstract). 
Teachers and Teaching as a Basis for Sociological Study and Theory

Descriptive, explanative, and predictive theoretical models, and also comparable empirical investigations which specifically relate to the work attitude of educators, are limited in number and scope (Miskel, 1975, p. 38, in Holdaway, 1978, p. 6).

Waller (1932) brings initial insights to the sociology of teaching and the school as a social institution. He views the individuals who operate within a school as networked and interlocked; and he suggests that it is this network, and the roles and relationships of the individuals within it, that "determine the outcomes of education" (Brembeck in Waller, 1932, 1965, Introduction). Waller asserts what he says every teacher already knows: "that the world of the school is a social world," and he believes:

That all teachers, great and small, have need of insight into the social realities of school life, that they perish, as teachers, for lack of it (Waller, 1932, 1965, Preface).

Therefore, Waller directs his study toward gaining usable insight of the school "as it really is," and his stated purpose is "to give insight into concrete situations of a typical school" (Waller, 1932, 1965, Preface).

Hoppock (1935) brings comparative study to the job attitudes of teachers by researching the extremes of satisfaction and dissatisfaction as expressed by 500 teachers from 51 urban and rural communities in the northeastern area of the United States. The 100 "best satisfied" and the 100 "least satisfied" were sampled to respond to 200 questions on aspects of job satisfaction. This study finds 
"relationships, direct or indirect, between job satisfaction and emotional adjustment, religion, superiors and associates, size of community in which employed, feelings of success, praise, family influence, social status, vocational choice, interest in work, monotony, fatigue, and age" (p. 44).

Lortie's Theory on Teachers and Teaching

Following Waller (1932) and Hoppock (1935), Lortie (1975) has contributed a major sociological study of school teachers and teaching as work (1973). Lortie's theory centers on a sociological examination of school teachers in which the research "attempts to define the nature and content of the ethos of the teaching profession--the pattern of orientation and sentiments which is peculiar to teachers" (1975, Introduction). His methods of investigation include historical review, surveys, observations, and interviews. Initially, the study focused on ninety-four personal interviews of representative teachers in the Boston Metropolitan Area, identified as the Five Towns sample. Additionally, he conducted a study of all professional staff in Dade County, Florida. The data were collected by questionnaire and permitted him to support and extend the findings of the preliminary investigation in Five Towns. Although Lortie addresses many aspects of becoming and being a teacher, he places particular focus on the career and work rewards of teachers in conjumction with the importance of various types of rewards as teacher perceptions and preferences. These findings may be summarized and generalized as theory related to teacher job satisfaction. 
Primary Rewards in Teaching

In addressing what kinds of gratification are available to teachers and what tends to please or displease teachers in their work roles, Lortie proposes that teaching fosters emphasis on reward for the present rather than reward for the future (p. 101). He classifies job rewards related to teaching into three types: "psychic" or "intrinsic" (used interchangeably), "extrinsic," and "ancillary." Psychic rewards, stemning entirely from subjective valuations, come Erom the "course of work engagement," may vary from person to person, but are also more or less defined or bound by "the nature of the occupation and its tasks" (101). Extrinsic rewards are seen as "attached to a role," including examples such as income, prestige, or power; Lortie views such rewards as existing independently of the individual teacher in the particular job role, and thus he defines them as objective. Ancillary rewards may stem from subjective or objective valuations made by the teacher about characteristics of teaching. A particular characteristic may be generally known as a given or stable condition of the job, but it may be seen as a benefit to one teacher and a drawback to another. Lortie uses the work schedule of a teacher as an example of a factor that might bring a sense of reward to some teachers but not to others (p. 101).

In data analysis, Lortie emphasizes the importance of the intrinsic or psychic rewards for teachers. Primary rewards for teachers come from achievement with students and reiationships with students (pp. 106, 119-125, 187-200). He notes that teachers tend to make little distinction between the idea of "work gratification" and 
the idea of "work goals"--or satisfaction gained from the work of teaching and satisfaction gained from reaching classroom objectives. For teachers, Lortie finds that satisfaction is directly related to desired outcomes for students and feelings of influencing students (1975, pp. 101, 104). The basic sense of psychic reward is connected to classroom achievement, the sense of having accomplished a goal (p. 109). Factors which teachers identify as coming between their goals and gratifications may become primary sources for dissatisfaction.

"Roots of Ambivalence"

Lortie's theory addresses the teacher's attempt to balance the dilemma or tension created by associating factors or characteristics of teaching. The tensions between the primary sources of satisfaction and the primary sources of dissatisfaction establish the "roots of ambivalence" for teachers (pp. 181, 184-186). The wants of teachers revolve around their preoccupations and their beliefs about the role of the teacher. They want to direct their efforts toward their students; they want to focus on instruction. They believe in these comnitments as central to their purpose. Lortie believes that teachers often feel that obstacles are placed in their way, and they do not have the power or authority to remove them. They want to do their jobs as they see them or define them, and they want to receive rewards (or praise or recognition) for doing their jobs with dedication. Lortie finds that tension is created between the major sources of satisfaction and the major sources of dissatisfaction (pp. $163-165)$. 
Major sources of difficulty or discontent to teachers are associated by Lortie with such factors as:

Tasks and use of time - potentially productive/inert time (p. 176)

Interpersonal relations with other than students (p. 177)

Income (pp. 96, 183)

Availability of resources (pp. 184-186)

Need for support (pp. 73, $177-179,206)$.

Therefore, says Lortie, teachers are dealing with internal contradictions and dilemna in their roles. Thus, they attempt to balance the tensions between independence and autonomy with participation, control, and subordination--and the result is identified by Lortie as the "roots of ambivalence" (pp. 181, 184-186).

Integration of Herzberg's Theory and Lortie's Theory

Sources of teacher job satisfaction and dissatisfaction may be explored in relationship to Herzberg's theory and the identification of motivator and hygiene factors, and they may also be explored in relationship to Lortie's theory on rewards and primary sources of rewards for teachers. Both Herzberg and Lortie consider job-related needs in conjunction with job-related rewards as intrinsic and extrinsic; both explore primary sources of rewards as contributing to attitudes and expressions of satisfaction or dissatisfaction. Herzberg establishes "dual-factor" theory, contending that degrees of satisfaction and dissatisfaction do not operate on a polar continuum; thus, distinct factors or classifications may lead to satisfaction or dissatisfaction. And, although Lortie does not atțempt to set up or explore the dual-factor concept, both researchers and theorists 
support job satisfaction as a desired state for the worker and the organization of enterprise. Both attach similar importance to intrinsic factors as being the contributors to job satisfaction and to extrinsic factors as being the contributors to job dissatisfaction.

It is on this basis, and with these recognitions of similarity and difference, that the present study is designed to bring further consideration to elements of Herzberg's theory and elements of Lortie's theory as significant to a study of the job satisfaction of public school teachers. Moxley Study (1977)

In 1977, Moxley completed research of faculty members in the field of higher education by using a questionnaire as a survey instrument instead of the personal interview method used by Herzberg researchers. She included previously identified "motivator" and "hygiene" factors as accepted first-level factors from Herzberg's theory. In addition, she included Flanagan's critical incident theory (1954, in Herzberg et a1., 1959, pp. 12, 21, 23), along with an examination of Porter's need satisfaction research related to Maslow's theory on hierarchical and prepotent needs (1954).

The Moxley study is significant to the present study for two reasons: (1) she represents researchers of Herzberg's theory who have validated the use of a questionnaire as a survey instrument instead of personal interview for data collection, and (2) she represents one of the researchers who have deemed it important to address the topic of job satisfaction of educators. 
Falkenstein and Hathaway Study (1981)

In 1981, Falkenstein (1982) and Hathaway $(1982)^{4}$ conducted research of public school teachers in the Portland Metropolitan Area (PMA). The research instrument was a questionnaire drawing from Lortie study and theory (1975). The initial study by Lortie was based on 94 personal interviews of teachers randomly selected from five towns in the Boston Metropolitan Area, with extended research based on a questionnaire distributed to all professional staff in Dade County, Florida $(\mathrm{N}=5837) .^{5}$ The Falkenstein and Hathaway research instrument was distributed to one-third of the teachers in the participating public school districts, a random selection of 2,377 subjects for sample. 6

The Falkenstein and Hathaway study is significant to the present study for three reasons: (1) the 1981 data base is a questionnaire addressing job attitudes of public school teachers, and (2) it serves to represent population similarity ${ }^{7}$ for the current follow-up study

${ }^{4}$ Dr. Lynda Falkenstein served as an associate professor at Portland State University during the period of the 1981 study. She collaborated in the research with Dr. Walter Hathaway, Director of Research and Evaluation, Portland Public Schools.

5 cited in Holdaway (1978, p. 25).

${ }^{6}$ The districts participating in the 1981 study are as follows: (1) in Oregon - Beaverton S.D., Estacada S.D., Hillsboro Secondary S.D., Portland S.D., Rural Dell S.D., and Tigard S.D.; (2) in Washington - Evergreen S.D. and Vancouver S.D.

7The districts participating in the 1984 study are as follows: (1) in Oregon - Beaverton S.D., Hillsboro Elementary and Secondary S.D.'S, Portland S.D., Rural Dell S.D. and Tigard S.D.; (2) in Washington - Vancouver S.D. Note: Estacada S.D. and Evergreen S.D. declined participation in the current study; Hillsboro Elementary S.D. requested participation in the current study. 
of classroom teachers from the cooperating public school districts in the Portland Metropolitan Area. Thus, (3) the 1981 study provides some opportunity for analysis of responses to the same items in the 1981 instrument $\left(Q_{1}\right)$ and the 1984 instrument $\left(Q_{2}\right)$.

Summary

Although no single theory has emerged to serve all the research seeking to know more about the many factors associated with workers and their work in some system of organization, or with teachers in their work as public school personnel, the combined efforts of researchers and theorists are serving to pilot and propel an expanding field of study and literature that gives testimony to the recognized importance of the study and of the importance to seek and share practical and validated information. A review of literature related to research and theory will follow in the next chapter. 
CHAPTER III

\section{REVIEW OF LITERATURE}

Inasmuch as this study is directed toward the general issue of job satisfaction of teachers as well as to the consideration of Herzberg's theory (1959) and Lortie's theory (1975) in relationship to factors contributing to satisfaction and dissatisfaction--with reference to previous study by Moxley (1977) and by Falkenstein (1982) and Hathaway (1982), as a follow-up study of research on teachers in the Portland Metropolitan Area - the review of literature will include studies and discussion on:

- the worker and the organization;

- job satisfaction of teachers in America and elsewhere: dissatisfaction and its impact;

- Herzberg's "Dual-Factor" or "Motivator-Hygiene" Theory: Supporters, Challengers, Mediators or Compromisers;

- Lortie's theory on schoolteachers.

The review will serve as background for the present research and its findings.

The Worker and the Organization

Modern organizational theory supports the study of job satisfaction of workers as a significant area of inquiry and a key to planning and implementing positive change. Studies have extended from an initial address to business and industry to include many kinds of organizations and systems of enterprise in America and elsewhere. The studies generate from purposes that anticipate benefits for society or 
social systems dealing with management and betterment for individuals. The benefit of such study as data for personnel services is seen as immediate and practical. The following references may serve as examples of rationale for broad-based studies focusing on workers and organizations. Seashore and Taber (1975) emphasize the need for study in support of societal values, as social indicators which can lead to "a desired state for the individual . . and a source of societal adaptivity" (p. 366). Lawler and Porter (1967) see such study as practical to management dealing with absenteeism and turnover and in considering types of people and needs that may be satisfied in an organization (p. 28). Hersey and Blanchard (1972) accept that such study is important to management of organizational behavior and using human resources--as a way to "work with and through people to accomplish organizational goals" (frontispiece). They further promote study as helpful in identifying needs or motives and in bringing "insights to the goals and incentives that tend to satisfy these needs" (p. 66). The benefit for the worker is the potential for job enrichment (p. 69). Etzioni (1964) commends study as resource information for organizations considering how to "construct human groupings that are as rational as possible, and at the same time produce a minimum of undesirable side effects and a maximum of satisfaction" (p. 2). Argyris (1964) relates individual personality and integration within the organization to concepts that pre-employment and personnel services based on factors which contribute to satisfaction and decrease dissatisfaction could assist individuals to select careers that will fit their needs or offer 
opportunity to realize their expectations or goals and also fit with the organizational efforts to achieve goals. Vroom (1964) undertakes study to help understand work and motivation, with focus on individual behavior in the work setting. Herzberg and fellow researchers (1957, 1959, 1966) are generating continuing study into the broad area of motivation to work. They are trying to understand more of "the nature of man" in the work setting by analyzing direct information from workers. And, finally, recent writing by Ouchi (1981), echoed by Pascale and Athos (1981), urges recognition of human needs as guides to promote individual growth and "organizational capability" as part of an effort to blueprint a philosophy to structure and promote a "Z organization" and a "Z culture."

Thus, in the literature dealing with attitudes of workers in organizations, the support for study stems from potential benefit for the worker and the organization as each interrelates with the other. The goals of the worker are seen to be related to the goals of the organization, and the satisfaction of the worker is seen to be related to potential for successful change or operation of the organization. This potential seems particularly important to public education (Dreeben, 1973). The purpose of public education is directed toward the successful education of the students in its classrooms. Factors which serve to satisfy the teacher may weil be related to the attitudes the teacher reflects in the classroom (Brophy, 1979). That possibility serves as a primary rationale for more understanding of job satisfaction of teachers (Berliner, 1980). 
Job Satisfaction of Teacher's in America and Elsewhere: Dissatisfaction and Its Impact

Those supporting the study of job satisfaction as important to education include growing numbers of researchers from several countries. Studies have developed in various regions in the United States, Canada, Great Britain, Australia, and elsewhere, anticipating cultural and cross-cultural data potential. Once again, the rationale for broad-based studies considering the attitudes of teachers includes the potential for benefit to the educational system and to educators and carries implications for personnel services. Various studies and findings address elements of satisfaction and dissatisfaction and contributing factors for teachers. Sergiovanni (1966) launched a major study of teacher job satisfaction under the guiding premise that much practice in personnel administration may be misdirected efforts to control factors which have limited effects of motivating teachers (p. 5). Boynan (1982) supports study of teacher job satisfaction in order to extend understandings of associations between satisfaction and performance (p. 32). Pajak and Blumberg (1979) examine teachers' attachment to work as a "central life interest." They find that teachers differ from workers in other occupational groups, and they conclude that the majority of teachers are not job oriented in their "central life interests" (pp. 3-16). Gorton (1982) maintains that studies of teacher job satisfaction and morale "merit increased attention" because of the increasing number of reviews that highlight teacher dissatisfaction, stress, and burnout; and he makes recommendations to decrease such factors (p. 1903). As an element of 
the dissatisfaction of teachers, Retsinas (1982) points to the continuing lack of power of teachers within the complicated systems of school districts, school boards, and professional associations that obstruct the teachers' long-standing search for professional autonomy. Childers and Podemski (1982-83) suggest that the unrealistic expectations of teachers may be major contributors to job dissatisfaction, loss of teacher confidence, and burnout; they find that satisfaction and production in the first year of teaching are largely determined by the degree to which the expectations of the individual teacher match those of the organization (pp. 2-10). Citing "the teacher's predicament," Grant (1983) emphasizes the withdrawal of teachers from teaching as "one of the most disturbing signs that we face a crisis in education," and he cites a variety of contributing factors (p. 593). Bloland (1980) explores factors associated with teachers leaving teaching as a concern for "the qualitative and humanistic aspects of occupational turnover . . . an examination of the contributing factors may lead to better understanding of issues involved" (pp. 13-14). Fitzgerald (1978) addresses elements of change in teacher career attitudes, and he notes that research of personal attitudes should serve as an avenue to identify trends (p. 29). This reasoning is supported by Nationwide Teacher Opinion Polls, 1979-81, conducted annually, to survey teacher attitudes on a national scale. Teacher responses from 1979 through 1981 indicate increasing teacher dissatisfaction with their jobs (NEA Polls, 1979-81). In 1981, 37\% of the nation's teachers expressed dissatisfaction with teaching, and $45 \%$ responded that they would probably not elect to enter teaching again 
if they had the opportunity to choose all over again (NEA Poll, 1981, p. 15). However, the NEA Poll of 1983 marks an increase across the nation in the numbers of teachers who express satisfaction with their jobs, and $58 \%$ confin that they would definitely or probably choose to enter teaching again (NEA Po11, 1983, p. 9).

Thus, attitudes of teachers are subject to change over periods of time and for a variety of reasons. But, if the factor of teacher job attitudes remains a constant factor in public education--and it does--then it is important to explore the comprehensive field of literature on the subject and bring added detail to representative research and findings on job satisfaction of teachers in America and elsewhere, including focus on research and findings that target factors of dissatisfaction and its impact.

\section{American Studies}

The following studies serve as examples of research conducted in America since 1970 that consider aspects of job satisfaction of teachers. In 1975, Deever and Shockley highlighted the study conducted by Clauson in 1971-72 to exanine job satisfaction of teachers in extended school programs. Findings Erom this study of Arizona teachers indicate a relationship betw on many factors and characteristics of teachers involved in extended year programs. The study supports the Fourth Quarter Plan (or year-round school) with the particular recomnendations that teaching staff should be involved in the planning and have appropriate orientation. Fitzgerald (1978) reports on studies of 1972 and 1977 addressing career needs and 
satisfactions of Michigan teachers. Findings from this study indicate that service is the most satisfying aspect of teaching; work accomplishment is $: t \in$ least satisfying. Cooperation of staff and liking the job $:$ : identified as the most important factors contributing to teacher satisfaction or dissatisfaction, and teacher needs were not being met as well in 1977 as they were in 1972 . Evenson (1979) reports on a study of work related attitudes of professionals in special education in California, Utah, and Nevada, compared with other portions of the country. Findings indicate that the work concept scale is higher for special educators than for social studies teachers and lower for special educators than for career/vocational teachers. In addition, in the group studies, the administrators express more positive attitudes than do teachers, counselors, and resource specialists. Murnane and Phillips (1977) explore what matters to teachers in a midwest urban school district by surveying teachers in seven schools. This study concludes that teachers in different schools indicate different levels of satisfaction that cannot be fully attributed to teacher demographic characteristics or school characteristics. This report suggests a need to recognize the multifaceted concepts of job satisfaction and supports the view that school policies should be designed to accommodate "differential effects of various aspects of satisfaction" (p. 1). Peterson (1978) addresses work concepts of educators in Colorado, including teachers, counselors, and other unclassified, and Finds that satisfaction relates to developing values and attitudes as educators--preparing students with realistic expectations and 
developing student competencies; whereas dissatisfaction relates to pay inequities, poor job design, lack of worker control, and prevailing beliefs that hard work builds character and that job success depends on "knowing the right people" (p. 1). From Florida, Villeme and Hall (1980) consider the relation of teacher attitude to variables including satisfaction with teaching as indicated by first-year teachers. They find that attitudes of new teachers are more affected by levels being taught rather than by any particular type of training the teachers have received, and they find no significant relationships between teacher attitudes and variables of employment or demographics. The study concludes with the suggestion that teacher attitudes change during the first year after graduation from the teacher training institution, and if the attitudes of teachers are to be molded or influenced by their employing schools it will be important to immerse new teachers in school-based inservice during the early years of teaching (pp. 88-89). As part of the comprehensive address to "Effective Schools" by Goodlad and Associates (1979-80) extending research from California, the team of Bentzen, Williams, and Heckman (1980) looks at teachers in relationship to their job satisfaction. This study finds that elementary teachers are more satisfied with their jobs than are secondary teachers; that elementary teachers tend to focus elements of satisfaction on staff relations and secondary. teachers tend to shift this focus to leadership; that the more satisfied teachers are with their work the more likely they are to be satisfied with the organizational climate; that reasons for leaving teaching include lack of satisfaction with 
performance and the salary received (pp. 394-397). From New York and Michigan, Chapman and Lowther (1982) report on study of graduates from University of Michigan teacher training programs from 1946 through 1976, incluaing focus on teacher satisfaction with teaching. This study finds that women indicate greater job satisfaction than do men; job satisfaction is negatively related to supervision; writing ability is negatively related to satisfaction; and job satisfaction is related to being able to give little importance to that which is difficult to achieve (pp. 241-247). Chapman (1983) shifts the research to center on graduates from three public institutions in Indiana, sampling those who noted that teaching was their first employment after graduation as well as their current employment. From this study, he finds that personal characteristics do not significantly predict career satisfaction for teachers; that high school teachers place more emphasis on their skills and abilities as related to their job satisfaction than do elementary teachers; that different levels of salary do not relate to different levels of career satisfaction; and that satisfied teachers tend to place importance on receiving recognition from their school administrators (pp. 40-50).

Focus on Teacher-Administrator Rapport. Literature on "Effective Schools" by Brookover and Lezotte (1979), Edmonds (1978, 1979), Edmonds and Fredericksen (1977), Goodlad et al. (1979-80), Madden (1976), and others--targeting the principal as instructional leader for effective schooling--is directing research attention to teacher-administrator rapport and perceptions of leadership styles. Chapman's finding that the school administrator operates as a factor 
in teacher job satisfaction (1983, pp. 40-50) is one example of this attention. Jago and Vroom (1975) note that perceptions of leaders and subordinates do not tend to agree on the style and behavior of the leader (pp. 103-120). Ingle and Munsterman (1977) 1ook at the relationship of values to group satisfaction in rural and small town schools in Illinois and Indiana and find that a difference exists between value congruence in high and low group satisfaction schools. Surprising to the researchers, high morale schools have greater value incongruence between principal and teachers; schools with a high degree of group morale have a high degree of group dispersion; and principals as a group tend to hold similar values and teachers as a group tend to differ in values from principals. Concluding that the school principal seems to be the key to school morale, Ingle and Munsterman comment that leaders who practice democratic processes tend to have high group satisfaction schools and that greater emphasis should be placed on group goals and task orientation and professional development in schools (pp. 12-14). In 1980, Fraser sampled Montana teachers on supervisory behavior in relationship to teacher job satisfaction. He finds that satisfaction with supervision is but one element of job satisfaction for teachers; it is distinct, and it relates to a perceived difference between what the teacher experiences and what the teacher expects. This study finds very few differences in teacher attitudes are related to demographic factors and concludes with the recommendation that administrators should know what the attitudes of their teachers are in order to improve supervisory behavior and increase teacher job satisfaction (pp. 224-231). And, as 
a final example of address to teacher-administrator rapport as a factor in effective schooling, Greenfield and Blase (1981), from university departments of educational administration in Ohio and New Mexico, in seeking to understand what motivates teachers and influences their performance, conclude that principals who understand interrelations between teacher efforts, valued outcomes, and levels of satisfaction, can be more effective in helping improve instruction by helping teachers do their jobs more effectively (pp. 1-9).

\section{International Studies Cross-Cultural Study}

Growing interest in topics related to teacher job attitudes has led to international and cross-cultural study.

Canada. Within the last decade, researchers in Canada have been studying data on teacher characteristics and expressed job attitudes. In 1972-73 and 1979-80, the Canadian Teachers' Federation conducted a comprehensive study of characteristics of public school teachers, to chart changes and trends and to establish a basis for continuing study. Although this research does not address job attitudes of teachers, it does address elements of teaching that influence teacher attitudes, and it does form a background for extended study. Some of the changes and trends indicated in this study are: increase in the proportion of part-time teachers, reduction in the number of promotional opportunities (particularly for women), decrease in the proportion of teachers under age 30, increase in the proportion of teachers with at least one academic degree-with particular note of the increasing qualifications of female teachers and especially those 
in elementary schools. Holdaway (1978) includes attention to characteristics of teachers in Alberta in a study of variables such as age, sex, and years of teaching experience and levels of satisfaction with work and work experience. Findings from this study indicate that overall teacher satisfaction is seen to be related to "working with students"; and that overall teacher dissatisfaction is seen to be related to "attitudes of society and parents," "administration and policies," and "physical conditions." The finding that a large proportion of teachers are satisfied with their classroom work and personal relationships is related to aspects of teaching in which teachers have "considerable control." Areas of dissatisfaction are seen to be related to areas in which teachers view themselves as having little or no control, such as "the nature of the instructional and evaluation processes" (p. 152). Knoop (1981) reports on the results of a study in Nova Scotia on the effects of perceived leadership styles of school principals in relationship to teacher satisfaction with supervision, participation in decision-making, and the overall job of teaching. Responses strongly support the hypothesis that considerate leadership by principals contributes to teacher satisfaction with supervision, recognizing that supervision is only one aspect of job satisfaction (p. 10). Participation in decision making is found to be significantly and positively related to both job satisfaction and satisfaction with supervision (p. 11). In general, the study finds that "considerate leadership behavior is desirable in education" and is closely related to teacher satisfaction (pp. 11-15). Nederveen (1982) explores teacher job satisfaction in 
Alberta in conjunction with modern language curricular variables. Findings from this study confirm correlations between satisfaction and personal factors. Female teachers express greater job satisfaction than do male teachers. Nonforeign language teachers express greater job satisfaction than do foreign language teachers. Positive relationships are found between job satisfaction and age and years of teaching experience. As a general assessment, the modern language teachers indicate a high level of satisfaction with their jobs and a concern for curricular matters' 'ract, Summary, pp. 103-104). Haughey and Murphy (1983) address their study to rural teachers in British Columbia, seeking data on teacher satisfaction with the quality of worklife. This research finds that only 22 percent of the respondents are moderately or highly satisfied with their jobs. Teachers express dissatisfaction with administrative practices and the community perceptions of teachers. They express satisfaction in their interactions with students, the relationships with colleagues, and the autonomy they acquire as teachers (pp. 56-66).

Great Britain. British researchers Helawell and Smithers (1983) assess data from students enrolled in education programs and graduates from teacher-training programs to explore commitments to teaching. Findings from this study indicate that many students in programs of teacher training would have preferred other careers; that students in post-graduate programs tend more often than undergraduates to view teaching as an ideal career; and that the teaching profession is seen as more attractive to women than it is to men. The study concludes that commitment to teaching has little to do with teacher training. 
"It is those who see themselves as being at an advantage who tend to be the most comnitted in the sense of actually intending to take up teaching" (p. 50).

Scotland. Scottish researchers Brown and McIntire (1982) follow assumptions that "what teachers do is affected by what they think" and that 'teachers' attitudes toward an innovation are an important factor in its implementation" ( $p .35$ ) to extend research on what influences teachers to implement changes in their teaching, with particular focus on teacher attitudes about integrated science. Findings indicate that if teachers are to make fundamental changes in pedagogy they must have convincing reasons for doing so. Attitudinal changes leading to behavioral changes depend on making changes rewarding or nonthreatening to teachers in their daily practices:

These benefits might be of a material sort or might be such as to make the teacher's job easier or more satisfying . . . (p. 40).

Australia. Two studies will serve to represent interests in job satisfaction and job retention of teachers in Australia. In 1971, Coverdale (1974, 1975) conducted research of State school teachers in New South Wales, as an exploration or a "pipe opener" of primary determinants of teacher morale. Findings suggest three factors as primary influences in undermining morale and job satisfaction: (1) work demands--being further "messed about"; (2) ambiguous social status and social ambivalence-not being taken seriously as professionals; and (3) the image of teachers--being of average intelligence, being without the drive to enter a more rewarding or demanding career (1975, p. 30). Citing "wastage of teachers" (1974, 
p. 34), Coverdale summarizes findings by stating that "all is not well in the world of the teacher and that there is currently a 'teacher crisis' in Australia"--with expressed dissatisfaction for the system as "formal, unbending, and often humiliating"; and additional dissatisfaction for rigidity of curriculum and lack of teacher representation in policy making--leading many a teacher to become a "disillusioned missionary" (1975, p. 33).

Deschamp and Beck (1979) study factors influencing low staff retention in rural schools in Western Australia. They find that teachers feel disadvantaged by rural or "country service." Factors leading to low job retention and dissatisfaction include: cost of living and travel, low salary, poor housing, limited professional contact and support of opportunity for further study, limited opportunity for promotion, restricted social life, and apathetic reception from local residents. Factors which influence increased job retention and satisfaction include: school facilities, job challenge, staff relationships, climate, and recreational facilities. The researchers acknowledge that some factors are difficult or impossible to change, but that increased allowances and long service leaves would be powerful incentives for teachers to stay in rural schools in Australia (p. 24).

Cross-Cultural Study - Sweden and the State of Washington. A study of job attitudes of secondary teachers in Sweden and the State of Washington, by Peterson (1976), signals the potential of cross-cultural research. The study explores how teachers view job satisfaction, professionalism, and collective negotiations. Findings 
indicate that teachers in both settings are generally satisfied with their jobs and opportunities to meet professional expectations. High job satisfaction and professional values are found to be compatible with support for collective negotiations; however, the respondents do not indicate that they are particularly impressed with the results of collective negotiations as having impact on their salaries, decision-making roles, and overall job satisfaction. The study notes that teachers satisfied in one area of factors are likely to be satisfied in other areas of factors, although the interrelationshp of factors remains unexplained. Finally, the study notes that national differences and expectations result in differences of responses for approximately 70 percent of the comparisons, and this leads to rationale for expanded cross-cultural study of job attitudes of teachers (p. 123). (See also Thurman, 1977.)

Dissatisfaction and Its Impact

A growing body of literature deals with dissatisfaction of teachers and the impact of dissatisfaction on teachers and public education. The reviews and studies targeting factors of dissatisfaction include discussion of issues related to teacher stress, frustrations, and burnout, and other physical and psychological influences or factors of a changing social climate that are leading teachers to make career changes or walk out of their classrooms. A substantial body of reviews notes that increasing expressions of dissatisfaction by teachers should serve as a warning to public education and those concerned with the teaching profession. 
In an overview of demographic factors and the effects of factors associated with dissatisfaction and career change of secondary school teachers, Bloland (1980) lists the following as personal and professional influences: salary (with particular influence on male teachers), lack of opportunity for advancement (with particular influence on female teachers), professional frustration (with particular address to lack of time for teaching), influences and preferences of friends and spouse; and various other school-related factors such as student attitudes and discipline, and relationships with colleagues and school administrators (pp. 13-23). 0ther researchers and reviewers have reinforced and supplemented the list with regional and focal studies of factors related to teacher dissatisfactions, stress, burnout, career change or walk-out behavior. The following may serve as examples. From a study of teachers attending a workshop in Michigan, Sparks (1979) notes that teachers are "beset by demands for accountability, increasing violence in the school, decreasing job security and mobility, and the expectation that public education can be responsible for the amelioration of social problems" (p. 447). From this study, he finds that 46 percent of the responding teachers indicate dissatisfaction with their jobs and would not choose teaching again as a career. Seventy percent of these teachers indicate that they "feel trapped" in their present jobs and take their frustrations home with them at the end of the day, and 36 percent acknowledge that their work frequently interferes with their home life. Ninety-one percent say they have little or no influence in curriculum or policy-making decisions, and 
75 percent claim that their jobs are physically or emotionally stressful (p. 448). From a study of the quality of worklife for Michigan teachers, Cook, Cornbluh, and Abramis (1982) find that "teachers are significantly less satisfied with the quality of their worklives, more apt to fear losing their jobs, and more likely to experience problems with their jobs" than are other workers in our nation (p. 636). Additional factors related to dissatisfaction include: feelings of being trapped in jobs or assignments, concerns for health or safety or umpleasant work environments leading to illness or injury (pp. 636-637). From Illinois, Kaiser (1982) cites "motivation deprivation" as among factors which influence longevity or burnout of teachers. Considering teacher needs and job inducements in terms of Maslow's "never-ending chain of desires" and Herzberg's "motivation-hygiene" theory, Kaiser concludes that absence of reward influences motivation and performance. The deprivation of rewards such as "a change for advancement, responsibility, a sense of achievement, and recognition for excellence in performance" will lead more and more experienced teachers to burn out or leave the teaching profession to look for other jobs--with no reason to stay--"leaving the unmotivated hygiene seekers to fill the ranks of our schools" (p. 19). From a study of secondary teachers in Iowa, Sweeney (1981-82) finds that their higher needs--such as self-actualization, a feeling of self-fulfillment, worthwhile accomplishment, and personal growth--are not being met, with deficiencies increasing during the last decade and most pronounced for teachers now in the 35-44 age category and related to the ability level of the students they teach 
(1981, pp. 203-208). From a two-year study of teachers in Texas Public Schools, Maddux, Henderson, and Darby (1980) and Henderson, Darby, and Maddux (1982) conclude that one in three teachers is considering leaving teaching, and of this group nearly half cite low salaries as the major factor of discontent. Other reasons include adninistrative problems, excessive paperwork, lack of decision-making opportunities or input for school policy making, and student-related problems such as discipline and willingness to study and learn (1980, pp. 1-9). From the two studies, the researchers predict a severe teacher shortage in Texas in the near future $(1980,1982)$. From a study of perceived occupational stress of teachers in a large school system in the Middle Atlantic states, Morracco, D'Arienzi, and Danford (1983) find that dissatisfaction with career choice is a "serious issue from this sample." Nearly 52 percent of the respondents note that they would not again elect to enter teaching; $35 \%$ express dissatisfaction, and $9 \%$ say they are very dissatisfied. The researchers conclude that stress in teaching may contribute to dissatisfaction with teaching, would have a negative effect on performance, and is a factor in teacher absence (pp. 44-50). In reporting on a study of teacher personalities and beliefs for "clues to job problems," Education USA (1984) refers to data from teachers in six Southeastern schools who believe that their "efficacy" and "professional self-worth" are reduced by "low salaries, isolation, lack of recognition, uncertainty about competence, and alienation"; study from two additional urban schools finds that major stresses for teachers result from "lack of respect and barriers to teaching" 
(p. 281). These findings are echoed by Ashton and Webb (1984) in reporting the data from the study and in linking teacher efficacy to school climate and effective schools (Ed-Line, 1984). From Florida, Purrington and Jones (1970) examine work environment, risk taking, and walk-out behavior of teachers and find that high dissatisfaction with intrinsic and extrinsic job factors and high risk-taking propensity are related to a teacher's decision to strike (Abstract, pp. 46-47). From Louisiana, Levitov and Wangberg (1983) identify nine factors contributing to teacher job stress and dissatisfaction, with descriptors including: negative feelings about work (societal, institutional, personal), unpleasant work environment, lack of public and parent support and respect, feeling selfish about taking time for self, lack of control over subject matter and teaching methods and lack of role in decision making, too much to do, feeling guilty about lack of perfection, physical problems, and poor health habits (pp. 20-21; AFT Report, 1984, p. 5). In a study limited to female teachers in the South, West, and Midwest, Metzger and Wangberg (1981) and Wangberg, Metzger, and Levitov (1982) find that 40 percent of their respondents would not again elect to become teachers. Factors of dissatisfaction include: unfavorable working conditions (low salary, lack of professional contacts and adult contacts, and inflexible hours) and the changing social climate or changing perceptions of female career options (broadening career opportunities for women in fields outside education) (1981, p. 213). Davis (1981) and Earls (1981) limit their study to address causes of stress and avoidance of burnout for physical education teachers. Davis cites 
factors affecting physical education programs and staff in the last decade to be potential causes for stress related to: declining enrollments, decreased professional mobility, staff reductions, shrinking budgets, increased demand for accountability, along with declining confidence in public education (p. 37). Additional causes for stress may be related to poor quality relationships, a sense of isolation, problems with time management, life changes and stages, institutional practices and policies, and public criticism of teachers and schools (p. 37). Earls adds to the list of contributors such factors as: summer employment, responsibilities, associated with coaching, moonlighting to supplement salary, and continuing education or professional commitment; all consume time, divert energies, and may result in stresses or relate to dissatisfaction with teaching (pp. 41-42).

Summary

Thus, the list of factors that may contribute to teacher dissatisfaction is comprehensive, and the impact of teacher dissatisfaction is identified in research and literary reviews as critical to public education--extending from the qualified candidates who do not select teaching to the dissatisfied teachers in the profession to the dissatisfied teachers who leave the profession. Factors contributing to dissatisfaction may be personal, professional, and social. They may be related to employment expectancies, comnitments to employnent, conditions of employment, and perceived alternatives outside of teaching (Michaels \& Spector, 1982, 
pp. 953-959). They may be related to needs and lack of rewards or job inducements; they may impact on motivation and performance; and they made lead to stress, burnout, or walk-out behavior and career change for teachers. Concerns for the withdrawal of talent from teaching and the impact of stress-related factors on the talented who remain in teaching are identified by Grant (1983) as "a crisis in education," and he draws attention to the present shortage of qualified teachers in many cities (pp. 593-594). Darling-Hammond (1984) warns of a "coming crisis in teaching":

Unless policies that restructure the teaching profession are pursued. Until teaching becomes a more attractive career alternative, the problems of attracting and retaining talented teachers will undermine the success of other reforms intended to upgrade educational programs and curricula (v.).

The focus and findings in a growing body of literature center on this problem and carry sweeping implications and critical predictions. If these warnings are valid and unless validated conditions that contribute significantly to widespread teacher dissatisfaction are ameliorated, it does not bode well for public education and the students in public school classrooms. Better understandings of the factors that influence job satisfaction should be useful to benefit the organization of public schools and the teaching staff in efforts to reform and extend commitments to improve the quality of education.

Herzberg's "Motivator -hygiene" or "Dual-factor" Theory: Supporters, Challengers, Mediators or Compromisers

Among the most discussed theories addressing job satisfaction or job attitudes, including considerations of factors as "intrinsic" or 
"extrinsic" and how they may influence or be related to motivation, is Herzberg's "motivator-hygiene" or "dual-factor" theory (1959, 1966, 1968, 1975). A basic hypothesis of Herzberg's theory is that satisfaction and dissatisfaction do not initiate from the sane factor or group of factors but initiate from different or distinct factors or groups of factors. Certain factors operate as motivators and may lead to satisfaction but not to dissatisfaction, and certain factors operate as hygienes and may lead to dissatisfaction but not to satisfaction. Satisfaction is seen to be related to intrinsic factors linked to job content, and dissatisfaction is seen to be related to extrinsic factors linked to job context. In opposition to bi-polar theory, in which satisfaction and dissatisfaction may be seen to operate on a continuum for a factor, Herzberg's theory is termed "dual-factor" or "two-factor." Although the theory emerged in reference to workers in business and industry, in studies related to notivation (Herzberg et al., 1959), it has been used and tested often in assessments of job attitudes of workers in various career fields, including education. And although the initial and recommended method of data collection by Herzberg and his researchers was based on semi-structured interview questions and probes, including use of Flanagan's "critical incident" method to explore when respondents felt exceptionally good or bad about aspects of the job, those who seek data from large samples or from samples not easily available for personal interviews have tended to adjust the data collection fornat to include Herzberg's factors in survey instruments or questionnaires. However, elements of Herzberg's "dual-factor" theory, 
as well as to some lesser degree the method of data collection, are subject to much discussion and some dispute. Commentaries on various topics related to job attitudes, in research and critical overview, include frequent references to Herzberg's theory, but researchers and reviewers do not all accept the theory equally. Consequently, references to the theory tend to cluster into three categories: (1) those who acknowledge the theory or use it and accept it, (2) those who address limitations of the theory or dispute and reject it, and (3) those who accept part of the theory or seek a middle ground of compromise to include part of the theory.

Supporters of the "Motivator-hygiene" or "Dual-factor" Theory

Included among the supporters of Herzberg's "motivator-hygiene" or "dual-factor" theory are those who address elements of job satisfaction or job attitudes in business and industry or of workers other than educators; other supporters consider the theory in specific reference to educators. The initial address is to workers in general outside the realm of educators in schools.

In a study of attitude change in the preretirement period, Saleh (1964) supports Herzberg's motivation theory as compatible with findings that the job attitudes of older workers approaching retirement will differ from those of workers in mid-career. In general, Saleh finds that job-related factors (motivators) provide satisfaction, whereas context-related factors (hygienes) may provide dissatisfaction. However, says Saleh, in the preretirement period attitudes change, and the dominant concern for the older worker shifts 
to context-related factors that are easier to attain as sources of on-the-job satisfaction than are the job-related or job-content factors that might be seen as primary to mid-career workers. Saleh bases his explanation on a "system of need hierarchy" which varies from Maslow's theory of prepotency and which he finds implicit in Herzberg's dual-factor theory (pp. 310-312):

The channels for self-actualization and satisfaction are not on the same dimension with other needs which mainly have the power to reduce dissatisfaction. Thus, a person may be able to actualize while his needs for safety and love are not fully gratified. It appears then that the second explanation is to be preferred for understanding the shift in sources of satisfaction from the motivators in middle age to the hygienes in the preretirement paiiod (p. 312).

In a study of job satisfaction variables among female clerical workers and college females, Williamson and Karras (1970) use ten job characteristics drawn from Herzberg's list of motivators and hygienes to form the basis for their research. Findings from this study indicate a basic difference in the needs and expectations of the two female categories. The college females rank motivators significantly higher for "self" than do the clerical workers. The researchers explain the difference in terms of the "greater need" of the college females for self-actualization and the greater expectation of opportunity to advance and accept higher responsibilities "and other motivators" than indicated by the female clerical workers (pp. 343-346).

In Management of Organizational Behavior: Utilizing Human

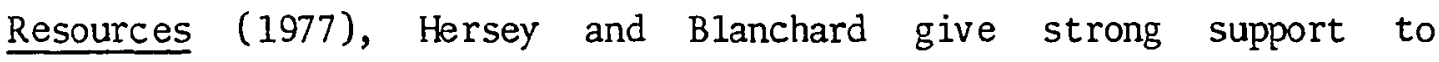
Herzberg's motivator-hygiene theory as one that "has broad implications for management and its efforts toward effective 
utilization of human resources," with potential to benefit industry and the individual worker (p. 65). Hersey and Blanchard agree with Meyers (1968, p. 64, in Hersey \& Blanchard, 1977, p. 66) that Herzberg's theory is easily translatable to supervisory action at all levels of responsibility (p. 66). They tie Herzberg's ideas to Maslow's need hierarchy and express belief that "the physiological, safety, social, and part of the esteem needs are all hygiene factors"; the esteem needs are divided into subgroups for status and for recognition. Recognition, as part of esteem, and self-actualization are seen as motivators and tend to become more important as people "mature" (p. 64). These writers link needs and incentives to behavior or a "motivating situation." The primary intention, credited to Herzberg, is for management to design work environments to promote job enrichment by providing the worker with opportumity for "deliberate upgrading of responsibility, scope, and challenge in work"--as specific ways to build esteem and self-actualization and "to satisfy the motivators" (p. 69).

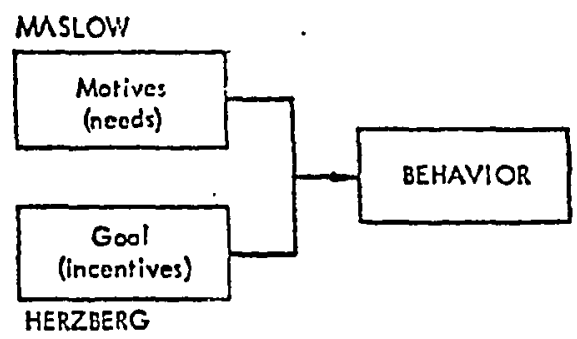

Figure 4. The relationship of Maslow's and Herzberg's theories to a motivating situation. (Drawn from Hersey \& Blanchard, 1977, p. 67.) 


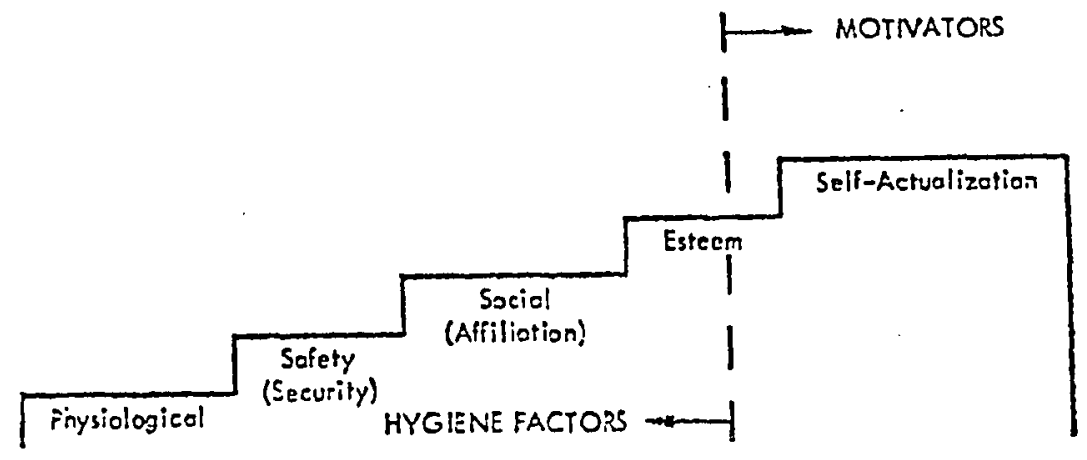

Figure 5. The relationships between the motivation-hygiene theory and Maslow's hierarchy of needs. (Drawn from Hersey $\&$ Blanchard, 1977, p. 67.)

In 1974, Herzberg, Wiener, Mathapo, and Wiesen extend explanations of the motivator-hygiene theory (1959) in a study of "motivational inversion" of males being treated for mental health disorders in a veterans' hospital. In motivator-hygiene theory, the sense of "fulfillment requires satisfaction of the growth needs." "Motivational inversion" is determined to be the degree to which an individual is actively seeking to satisfy pain avoidance needs. In support of the motivator-hygiene theory, this research finds that the less-disturbed person is more likely to relate feelings of satisfaction to fulfillment of growth needs or motivators; the nore-disturbed person is more likely to relate feelings of satisfaction to the absence of pain or hygienes. In short, the less disturbed the person is the lower the "motivational inversion"; the more disturbed the person is the higher the "motivational inversion" (pp. 411-418). Thus, this study supports the previously established "dual-factor" theory as operating bidimensionally (Herzberg et al., 1959, 1966, 1974). 
In a study of the organizational factors contributing to the motivation of 4-H volumteer personnel, Freeman (1978) uses Herzberg's motivator-hygiene theory (1959) for the research design, in considered relationship with Maslow's hierarchy of needs (1954). This study finds that factors contributing to job satisfaction are recognition, work itself, responsibility, personal growth, achievement, and relations with members and parents. Factors contributing to job dissatisfacton are guidance and training, policy and administration, and relationship with leaders. These findings largely support the dichotomy set by Herzberg and lead to conclusions that administrators of volunteer programs "should minimize opportunity for hygiene factors to become significant . . Effective management will provide a work environment conducive to meeting the needs of volunteers in order to create a sense of job satisfaction" (Abstract, pp. 24-35).

In a study of sources of job satisfaction and dissatisfaction of community education coordinators in six mid-Atlantic states, Sheppard (1979) builds on Herzberg's motivator-hygiene theory to design the research. Results support the view that Herzberg's "dual-factor" theory can be applied to community education coordinators. Achievement, interpersonal relations with subordinates, and recognition are among the factors found to motivate coordinators to "strive for a high level of performance." Lack of achievement, however, is also associated with dissatisfaction. Policy and administration, interpersonal relations with superordinates, supervision, and working conditions are the identified factors leading to job dissatisfaction. This research leads to the conclusion that: 
More careful attention to the nurturing of the sources of job satisfaction and the reduction of sources of job dissatisfaction should bring about increased program and job performance, lower turnover and absenteeism, and greater opportunities for selfactualization on the part of the coordinators (Abstract, pp. 52-63).

Sergiovanni (1966) offers strong support to Herzberg's "dual-factor" theory in a study of satisfaction and dissatisfaction of teachers. Findings from this research conform with Herzberg's hypothesis that some factors contributing to the job satisfaction and dissatisfaction of teachers are polar in a positive direction and that other factors are polar in a negative direction. Factors operating to provide satisfaction tend to focus on the work itself (job content), and factors operating to provide dissatisfaction tend to focus on the conditions of work (job context). Teacher job satisfaction stems predominantly from achievement, recognition, and responsibility. Teacher dissatisfaction stems predominantly from interpersonal relations with subordinates and peers, supervision, school policy and administration, personal life, status, and "unfairness." Subgroups of teachers tend not to differ in their responses to factors related to job satisfaction and dissatisfaction (1966, Abstract, pp. iii-vi, pp. 109-116). In The New School Executive (1980, Ch. 6), Sergiovanni and Carver continue to support Herzberg's theory in their own address to "job satisfaction" as "motivation in practice" (p. 120) within current theory on administration and organization of schools as an "applied science." In this frame of reference, job satisfaction is linked with human needs to establish two categories of teachers: motivation seekers and hygiene seekers (p. 118). Each type of teacher 
requires different motivational strategies and opportunities.

Therefore, it is important for school administrators to understand rewards systems for teachers as individuals and as motivation seekers or as hygiene seekers in order to promote need fulfillment:

Through providing proper motivation opportunities one provides for satisfaction at work and therefore enables oneself and others to fulfill basic and growth needs (Sergiovanni \& Carver, 1980, p. 132).

Motivation saskers focus here

1. Thes? are hisher ordir neets-mosi basic in a hum:zolistic sense-visich are best inet on the job by ad:suncing the watisfiers. Exemples of thase are: achie:tement, recogilltion, responsi bility. asvancemant, and work itself.

2. Extraordinarv perfurmance is stimu. lated by provitling for these nesds, but perfurmanee does no: decrease if they are absert.

3. Clojure seeksers seek sutisiaction of these nexts through motivs:ional channz!s charjeterized by work sticcess and individual achievement.

4. Hrijunsibility saekers sek' soitis faction of th $=5$ se ned's through noti vational channels which give thern supervisrory responsibility over athers.
- Hygiens sephers fousu hi:re

1. These are lawer-order neesls-most basic in an arim:alistic sense - which are best riet on the jub by c.imiriating the dissatisliers. Examplos of these are: supervision, sjlary. policy and administration, bensfits, interpersonat re!ationship, working conditions, and personal life.

2. Extraordinary performance is not stimulated by fulfilling these naeds. but performance dccreases as clissatisfuction increases.

3. Instrumentalists with motivationa! potentiat focts here by choice and seth higher levels of satisfiction olf the job.

4. Instrumentalists without mo:ivational potential are failure-avoiders and are fixaied at lower need levels. This is a symptom of poor mental health.

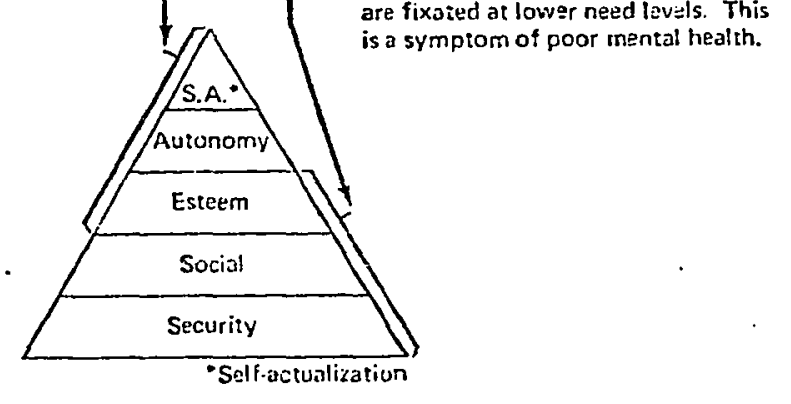

Figure 6. Maslow's hierarchy of needs related to motivation seekers and hygiene seekers. (Drawn from Sergiovanni \& Carver, The New School Executive, 1980, p. 118.) 


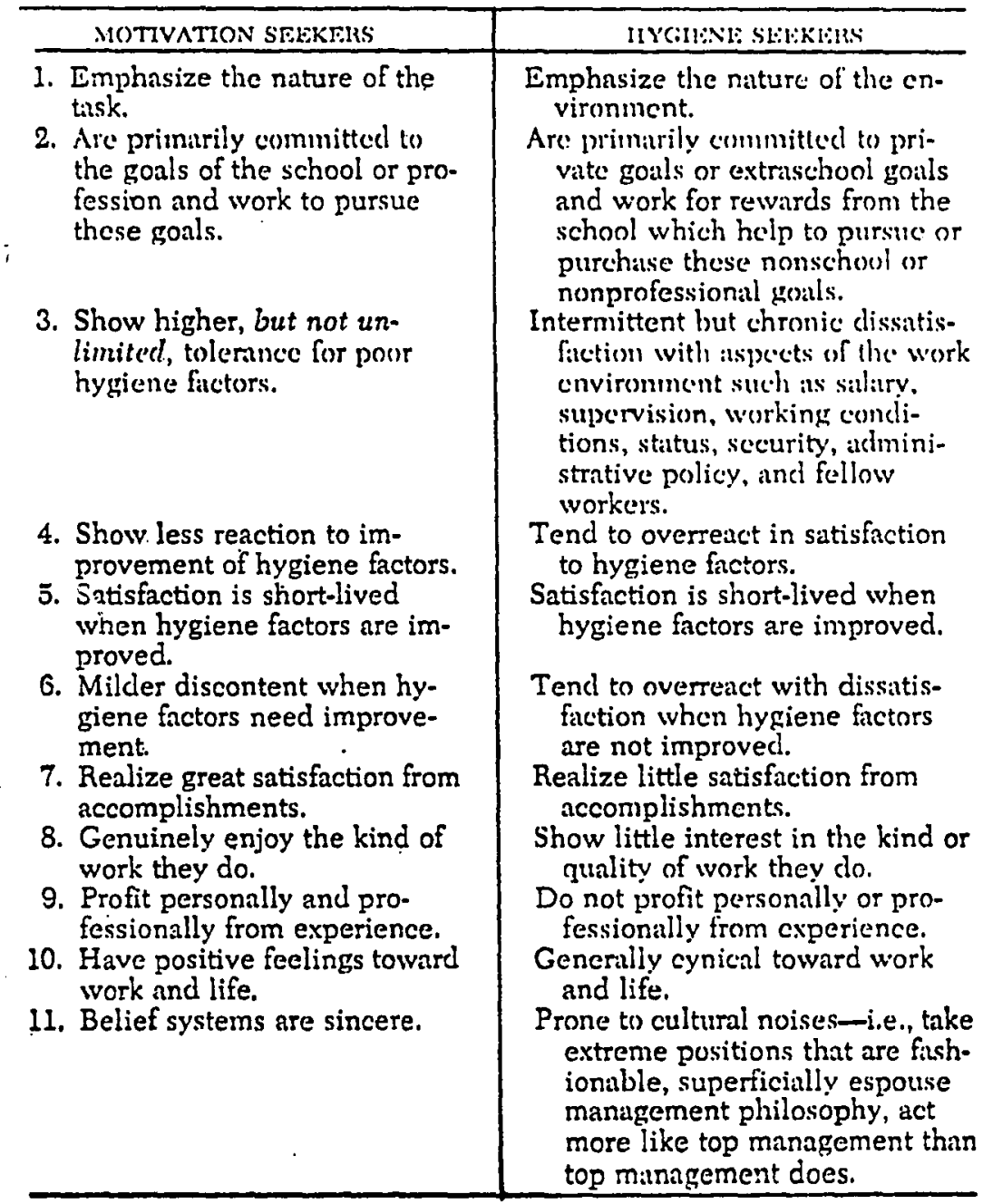

SOURCE: Adapted from Table II, p. 90 from Work and the Nature of Man by Frederick Herzberg (World Publishing Company). Copyright (c) 1960 by Frederick Herzberg. Reprinted by permission of Harper \& Row, Publishers, Inc.

\footnotetext{
Figure 7. Differentiating Motivation Seekers from Hygiene Seekers. (Drawn from Sergiovanni \& Carver, The New School Executive, 1980, p. 119.)
} 
In 1972, Miskel, Glasnapp, and Hatley report on a study of 3,400 school teachers in Kansas, focusing on work motivation, organizational incentives, job satisfaction, and primary life interests. The research instrument for this study rests on Herzberg's two-factor theory of work motivation, initially developed by Borgatta (1967, in Miskel et al, 1972, p. 4) into a survey instrument identified as the Work Components Study (WCS), and modified by Miske1 (1972) as the Educational Work Components Study (EWCS) (Miskel \& Heller, 1973). Findings from the 1972 study indicate:

- The female elementary and secondary teachers who score higher on satisfaction are more job oriented, have a job in which there is higher potential for personal challenge and development, less work pressure, and more incentives relating to physical surroundings, and where the tolerance for work pressure is higher.

- Male elementary teachers who score higher on job satisfacton are more job oriented.

- Work role, voluntarism, ideal incentives are added variables to build a quasi-theory of satisfaction for educational organization.

(Miskel et al., 1972, Abstract)

Miskel and his fellow researchers conclude that their proposed model requires that the "conceptualization of work motivation developed by Herzberg must be modified to conform with the findings of the current study" (1972, p. 53). This study finds that motivators and hygienes do not operate exclusively; the two types are seen to interact "to assist in the determination of the ideal incentives," and the "relative ranking given to a particular incentive in a set of incentives will vary from person to person" (1972, p. 53). This leads to a summary conclusion that "the higher the primary life interests 
are in the job, the higher the satisfaction" (1972, p. 54). The 1973 study by Miskel and Heller serves to validate the EWCS an its theoretical foundation--including Herzberg's theory--to suggest its potential for "probing many provocative relationships based on work motivation" (1973, p. 46).

In developing an organizational model for employee job satisfaction applicable "to all levels of personnel in the school system," Schmidt (1980) rests his model on four assumptions that initiate from Herzberg's "motivator-hygiene" theory. Noting that educational systems offer iimited opportunities for educators to achieve job satisfaction and that "concentrated power and increasing centralization can lead to apathy and inflexibility," Schmidt says:

- the organizational structure of education does not require the work of educators to be limited or frustrating;

- educational work should be congenial, absorbing, motivating, and exciting;

- educators want to understand their environment and to be proactive;

- the power of educators to "regulate their working methods, to set their goals and standards and even to have a role in determining their rewards is a key to sustained productivity (p. 80).

In support of Herzberg's views, Schmidt sets a purpose for developing an organizational model for job satisfaction to try to "develop avenues and opportunities for the needs of each individual to be met in order that all staff have maximum opportunities for growt h" (p. 87).

In an article on "motivation deprivation," identifying factors specific to the motivation needs of teachers and the job of teaching, 
Kaiser (1981) maintains that "an excellent explanation of teacher motivation and burnout can be extracted from the work of Frederick Herzberg" (p. 36). He supports this position by proposing that "motivation is situational" (p. 35), and "Herzberg places much of the responsibility for employee motivation on the employing organization and the factors built into the job itself' (p. 36). He finds that school boards typically offer teachers "hygiene" factors that will not serve to fulfill, satisfy, or motivate; teachers are thus deprived of factors that will serve to meet growth needs:

If motivating factors are nonexistent, and if hygiene factors are eroding with the national economy, there will be no reason to stay (1981, p. 38).

Moreover, people looking for "responsibility, a chance for advancement, a sense of achievement, and recognition for excellence in performance will continue to look toward job markets other than that of education" ( $p .38)$.

Frase, Hetzel, and Grant (1980) use and accept Herzberg's motivation-hygiene theory as "an appropriate foundation for developing and operating a system to reward excellent teaching" (p. 269). Thus, they present a Program for Excellence with a reward system alternative to merit pay supporting Herzberg's theory: "(1) participating teachers valued the rewards very highly, (2) they perceived the rewards as special recognition for teaching excellence, and (3) they perceived the rewards as motivation to continue their excellent teaching practices" (p. 269). The school district and the teachers are seen to benefit mutually. 
In an overview of research on teacher motivation, Silver (1982) includes Herzberg's theoretical framework, along with Vroom's theory (1964), as "especially relevant to the issue of job factors approach," noting that it has "generated a substantial body of research and bears important implications for practice" (p. 551). From her own review of literature on Herzberg's theory, Silver draws a "conservative conclusion" pertinent to the theory that "the aspects of work that are intrinsic to the tasks themselves are significantly related to individuals' attitudes and their levels of motivation" (p. 551). Accordingly, she suggests:

Educational leaders can influence the sense of achievement, recognition, challenge, responsibility, advancement, and growth possibilities that teachers and other staff members experience at work. Therefore, there is a strong probability that they can have considerable impact on teachers' degrees of satisfaction and levels of motivation (p. 551).

Challengers of the "Motivator-Hygiene" or "Dual-Factor" Theory

Although many researchers and reviewers have tended to support Herzberg's theory, the literature also includes those who challenge or dispute the theory or aspects of it, including address to validity, methodology, or limitations.

In a study of convergent and discriminant validity for areas and methods of rating job satisfaction, Locke, Smith, Kendall, Hulin, and Miller (1964) include Herzberg in bringing question to prevailing research on job satisfaction. They maintain "the relationships of satisfactions to other variables are far from clear . . . In other areas of job satisfaction, findings have been so conflicting and equivocal that there is no semblance of a general law" (p. 313). 
These researchers posit that job satisfaction is an "affective response which is a result of experience on the job and will function as an independent variable . . only under very special circumstances related to the individual and his situation" (p. 314). Accordingly, they test and recommend the Campbell-Fiske model "for a rigorous kind of 'construct' validity, which if not a substitute for predictive validity, is for certain measures, a superior replacement for it" (p. 319$)$.

Ewen (1964) extends the criticism of Herzberg's theory by considering some determinants of job satisfaction by examining the generality of Herzberg's research. Ewen notes that Herzberg's findings are in "direct opposition to the traditional idea that a given variable in a work situation can cause both job satisfaction and job dissatisfaction" (p. 161). In addition, Ewen cites deficiencies in Herzberg's methodology, including: "the narrow range of jobs investigated, the use of only one measure of job attitudes, the absence of any validity and reliability data, and the absence of any measure of overall job satisfaction" (p. 161). Thus, in summary, Ewen concludes that Herzberg's results cannot be generalized beyond the situation in which they were collected (pp. 161-163).

Ewen, Hulin, Smith, and Locke (1966) conduct an empirical test of the Herzberg two-factor theory and contradict findings from Herzberg's research. In their study, neither the Herzberg theory nor the traditional (bi-polar) theory is accepted. They find that "intrinsic factors are more strongly related to both overall satisfaction and overall dissatisfaction than the extrinsic factor" (p. 544). They 
suggest that "the functioning of the extrinsic variables may depend on the level of satisfaction with the intrinsic variables" (p. 544). And they conclude "that the concepts of 'satisfiers' and 'dissatisfiers' do not accurately represent the manner in which job-satisfaction variables operate" (p. 544).

In an effort to detemine "what is job satisfaction," Locke (1969) includes criticism of Herzberg's two-factor theory and does not accept Herzberg's position that "factors related to work itself... can cause only job satisfaction but cannot cause job dissatisfaction" and the reverse (p. 332). Locke maintains that "overall job satisfaction is a function of satisfaction with the separate elements," and he suggests that Herzberg's position is:

- certain elements or outcomes cannot cause satisfaction or dissatisfaction at all;

- the importance of work content factors drops to zero whenever content values are frustrated;

- although workers value success they are indifferent to failure;

- whenever intrinsic work values are fulfilled their importance drops to zero so that no actual satisfaction results (p. 332).

And for this assertion, Locke says, Herzberg has offered no proof. In addition, Locke finds biases in Herzberg's classification system, and notes that it is "not surprising therefore that nearly all the studies designed to test Herzberg's theory which have not used his method or his classification system have failed to support the theory" (p. 332).

Centers and Bugental (1966) question classification of job values as "intrinsic" or "extrinsic" and the assumption that "some motives 
are related to the work activity itself and others to external or contextual factors" (p. 193), and consequently they bring question to Herzberg's theory of dichotomy and its conclusion "that job satisfaction results primarily from intrinsic job factors while job dissatisfaction results primarily from extrinsic factors" (p. 193). They address their study to the motivational strength of job factors, and they find that job motivations vary for men and women and for workers at different occupational levels. Thus, the "reward-value of different types of job incentives can be expected to differ for different parts of the working population; different types of supervision should be effective for men and women, or for white-collar as opposed to blue-collar workers" (p. 196). They conclude by acknowledging that the identified differences may be circumstantial:

It could be said that individuals in lower-level occupations are more likely to be motivated by lower-order needs . . . because these are not sufficiently gratified to allow higher-order needs (the self-fulfillment possible in the job itself) to become prepotent (p. 197).

In considering intrinsic and extrinsic factors in job satisfaction, Wernimont (1966) notes that a number of studies have not given support to Herzberg's theory. Generally, says Wernimont, the "satisfiers" seem to be accepted or supported more. often than the "dissatisfiers." In addition, Herzberg's methods and conclusions are cited to have been discounted or questioned. Accordingly, Wernimont affirms that "in view of the many possible deficiencies of the Herzberg et al study, the validity of their conclusions is certainly questionable" (p. 41). Supporting this position, Wernimont's own study finds much "differently from what Herzberg et al. theory would 
have predicted." In the Wernimont study, the major dissatisfiers are all intrinsic factors (p. 48). Wernimont extends his position to include worker expectations, and this leads to his conclusion that "two different sets of expectations were seen to be the major determinants of how job-attitude factors affect overall job satisfaction" (p. 50).

In a paper delivered at the American Psychological Association meeting in Cnicago, September, 1966, Vroom expresses some of his observations on Herzberg's two-factor theory and states his own concerns in an effort to "resolve some differences" (p. 1). He questions the "critical incident" or "story-telling" method of data collection and maintains that other studies using other than story-telling do not support the two-factor theory. He points out that descriptions of events do not mirror events (p. 6). People tend to take credit when things go well, but protect their own "self-concept when things go poorly by blaming their failure on the environment" (p. 7). However, Vroom does find himself in at least "partial agreement" with Herzberg's strategy:

I do believe that the nature of the task has an important bearing on the strength of the worker's desire to perform it ... I also believe that if extensive and systematic attention were given to the motivational effects of job or task variables, that significant differences would be observed in effects on individuals with different personality characteristics (p. 10).

In conclusion, Vroom draws a summary to the differences between his own views and those of Herzberg, as follows:

I do not believe that it has been conclusively demonstrated that satisfaction and dissatisfaction are in fact different dimensions or that the former is produced only by job content and the latter only by job context. Nor, do I believe that one 
can only improve the performance of individual workers by changing the content and not the context of their jobs. My own review of the evidence leads me to the conclusion that workers' verbal reports of their satisfaction with their job and the objective measures of their turnover rates are affected by the amount of rewards which they derive from their jobs regardless of whether the source of these rewards is the content or the context of the work. Their level of performance, on the other hand, is affected by the basis for the attainment of the rewards--specifically, to the extent to which effective performance is intrinsically rewarding or leads to the attainment of rewards controlled by other persons in the work environment (p. 11).

House and Wigdor (1967) review the evidence and add to the criticism of Herzberg's dual-factor theory. They note criticisms that the theory is methodologically bound, based on faulty research, and inconsistent with previously accepted evidence ( $p .371$ ); and they include tables and exhibits of various investigations related to the theory and the results (pp. 374-383). From this review, they find that Herzberg (1966) "yields conclusions contradictory to the proposition of the Two-Factor theory that satisfiers and dissatisfiers are unidimensional and independent . . . Since the data do not support the satisfier-dissatisfier dichotomy, the second proposition of the Two-Factor theory, that satisfiers have more motivational force than dissatisfiers, appears highly suspect" (p. 385). They, therefore, agree with the position credited to Dunnette, Campbell, and Hakel (1967, in House \& Wigdor, 1967) that "the Two-Factor theory is an oversimplification of the relationships between motivation and satisfaction, and the sources of job satisfaction and dissatisfaction" (p. 387).

In a study of job satisfaction of industrial arts teachers at the college level, Kaufman and Buffer (1978) do not accept Herzberg's 
Two-Factor theory. Their study reveals "that both intrinsic and extrinsic job dimensions served as sources of job satisfaction and dissatisfaction" (p. 55). Accordingly, they support the "traditional model of job satisfaction," with the accompanying premise that any variable of the job can serve as either a satisfier or dissatisfier. They do conclude that industrial arts educators place importance on "intrinsically rewarding activities" related to the role of "communicator of information" and tend to derive satisfaction from the opportunity to teach students (p. 55).

Young and Davis (1983) consider the applicability of Herzberg's dual factor theory(ies) for public school superintendents. Findings from their study "cast serious doubt on Herzberg's notion of a dual factor continuum for job satisfaction and job dissatisfaction" (p. 65). Their data support the traditional theory that satisfaction and dissatisfaction represent bipolar degrees on the same continuum, and they recommend that educational researchers consider other theories or develop "an overall theory appropriate for all educational employees" (p. 65).

Mediators or Compromisers with Partial Support and Questions or Partial Disagreements

Among the researchers and reviewers of Herzberg's dual-factor theory are those who accept a middle ground, accepting part of the theory, questioning part of the theory, and disputing part of the theory.

In a study of the underlying sources of job satisfaction (1963) 
and a following study on the "motivations to work and organizational performance" of white and blue collar workers (1966), Friedlander both contradicts and accepts parts of Herzberg theory as it may be related to the satisfaction of the worker in the work environment and as it may be related to rewards and worker performance. In the study on sources of job satisfaction (1963), Friedlander examines theory of two types of job elements that may be related to worker satisfaction: the factors in the work process which may influence or pernit growth to self-actualization, and the factors in the environment which lead to physical or monetary rewards. Friedlander's findings do not support the Herzberg position in full. Friedlander finds that underlying sources of job satisfaction operate more intricately than outlined in the dual-factor theory. In this study, both extrinsic and intrinsic factors are found to operate as sources of job satisfaction as "job elements occur together more frequently" (pp. 249-250). However, this researcher concedes that the factors tend to fall within Herzberg's concepts of hygienes and motivators (p. 250). Friedlander rests this study on findings of three "distinct though related types of satisfaction" that may link to the job: extrinsic hygienes, such as money and prestige; intrinsic motivators, such as pleasure received from a particular activity or from reaching a goal; and the added category of concomitant satisfactions, such as "those derived from working in a particular physical environment or with a particular group" (p. 250). From this study, Friedlander finds "no significant differences in overall job satisfaction" among three groups of employees examined on the bases of differing age, salary, and 
occupational patterns (p. 246). In the following study (1966), Friedlander considers Herzberg's team research (1959) in relationship to "motivation-individual benefit," to consider whether the worker who is motivated by self-actualization is a better worker than a fellow worker who may be motivated by "deficiency needs" (p. 143). From this study, Friedlander shifts his own position slightly and once again accepts some of Herzberg's theory, but noted limitations are increasing. In this research of white and blue collar workers, Friedlander maintains that "no data are presented to indicate a direct relationship between incidents involving intrinsic job characteristics and incidents containing self-reports of increased job performance" (p. 143). Suggesting that self-reports of increased performance may be "nothing more than moral justification for increased job enjoyment" (p. 143), Friedlander turns to the "relevance of situational variables" influenced by organizational reward systems.-."by positively or negatively influencing certain worker response behaviors" (p. 144). Among the white-collar workers, "few significant relationships are found between intrinsic self-actualizing motivations and job performance" (p. 143). Among the blue-collar workers, "no significant relationships are found between any of the motivational measures and job performance" (p. 143). However, in this study, Friedlander proposes that as both categories of workers advance in age and tenure, "work becomes nore meaningful for the high performers but less meaningful for the lower performers," and the social environment becomes increasingly important for both high and low performers (p. 143 ). 
It is possible that the cultural norms of blue-collar workers are sufficiently different from those of white-collar workers that each group behaves in accordance with its individual principles, and generalizations concerning the motivationperformance relationship cannot be made from one cultural group to the other (1966, p. 151).

Burke (1966) seeks to answer the question: "Are Herzberg's motivators and hygienes unidimensional?" and tests Herzberg's two classes of factors to see how they affect job satisfaction and dissatisfaction. His findings both accept and reject the dual-factor theory. He maintains that results do not support the unidimensional attribute for the motivators and the hygienes, and he suggests that Herzberg's two-factor theory may be an "oversimplified representation of job satisfaction" (p. 317). However, he concedes, "the basic distinction between intrinsic job characteristics and environmental job characteristics seems to be a useful one for purposes of research" (p. 317).

Soliman (1970) tests the methodological issues of the motivationhygiene theory of job attitudes in an attempt to reconcile the theory with traditional theories of job attitudes. His research partially supports the hypothesis "that one- and two-factor theories of job attitudes can be reconciled" (p. 452). He rests on the position that:

When the environment (organization) provides adequately for the satisfaction of all kinds of needs, the motivators become more powerful sources of satisfaction than hygiene factors. If the environment deprives people of all kinds of needs, hygiene factors become more powerful sources of dissatisfaction than motivators" (p. 452).

Moxley (1977) brings both support and question to Herzberg's dual-factor theory from her test of the theory in a study of job satisfaction of faculty teaching in higher education. In support, her 
101

data indicate that different factors contribute to satisfaction and dissatisfaction. Herzberg's identified motivators--such as "achievement," "recognition," and "growth opportunities"--are strong contributors to satisfactions or satisfying experiences. Herzberg's identified hygiene factors--such as those related to "policy," "salary," "supervision," and the added component of "time"--are strong contributors to dissatisfaction. However, this researcher also brings question to the theory by noting that the motivator factors of "responsibility" and "advancement" and the hygiene factor of "interpersonal relations with students" operate unidimensionally, but opposite to the direction that Herzberg theory would predict (Abstract, pp. 32-42).

Medved (1982) addresses the applicability of Herzberg's motivation-hygiene theory in a study of teachers from a small suburban school district in the Midwest, by using a questionnaire designed to mirror Herzberg's research theory and by including consideration of criticism of Herzberg's procedures. Medved brings both disagreement and support to the theory, and he also suggests some variations of the theory. In partial disagreement with the dual-factor theory, he finds that "those factors that most often contribute to the satisfaction of teachers are also, if absent, most often the cause for teacher dissatisfaction" (p. 555). But, he concurs that these factors are most often the motivators and associated with the higher order of needs of "recognition and self-actualization" established by Maslow (1954). He also finds that the intrinsic nature of education as a profession along with the sense of accomplishment that may be derived 
from it can provide much satisfaction for educators. In general, he finds that teachers seem to be motivated by the factors that have long served to attract candidates to the profession: the sense of accomplishment and responsibility that accompany the work itself, but he notes increasing dissatisfaction or concern being expressed by teachers for the lack of recognition or sense of worth they are being afforded by society, and he concludes by suggesting that this could be remedied by reinforcement "through better pay and other forms of tangible recognition" (p. 555).

\section{Summary}

Much research has been conducted to examine Herzberg's dual-factor theory in business and industry and in areas of education, including public education. Appendix A summarizes some of the studies initially compiled by Burke (1966) and House and Wigdor (1967). Appendix B summarizes various studies compiled for the present study, including research and review that use or consider Herzberg's theory. Examination of the various studies and commentaries addressing Herzberg's theory, or some aspects of the comprehensive theory, reveals conflicting findings. However, it is not the purpose of the present study to attempt to validate Herzberg's theory or to attempt to eliminate methodological problems that may be associated with that research. Rather, it is the intention of this study to see how data on teacher job satisfaction and dissatisfaction will conform with the major hypothesis of the "dual-factor" theory: 
- that job satisfaction and dissatisfaction do not initiate from the same factors

- that some factors may lead to satisfaction but will not lead to dissatisfaction on a single continuum

- that some factors may lead to dissatisfaction but will not lead to satisfaction on a single continuum

- that factors which influence satisfaction may operate as motivators and will be related to intrinsic aspects of work content

- that factors which influence dissatisfaction may operate as hygienes and will be related to extrinsic aspects of work context or work environment.

\section{Lortie's Theory on Schoolteachers}

Although the views and research of Lortie (1973, 1975) are frequently included in discussions of the social psychology of schoolteachers and teaching, the references to Lortie in the topical literature do not seem to be regarded as controversial or subject to dispute. In general, he is credited for his work in considering the sociology of teaching and the role of the teacher in the social system of the school along with his considerations of what matters to teachers, what serves as their rewards and satisfactions, and what serves as their disappointments or dissatisfactions.

Bidwell (1973) makes an early reference to Lortie's views of 1969 in discussing "relations between social organizations and teaching activity as they occur in formally organized schools" (p. 414). Dreeben (1973) refers to Lortie's perception that principals have a right to supervise and evaluate the work of their teachers, and, therefore, principals occupy $\mathrm{a}$ position of bureaucratic 
superordination relative to teachers" (p. 458). Dreeban continues his examination of "the school as a workplace" by citing Lortie's reports that teachers find their sources of satisfaction, accomplishments, and competence in the classroom (p. 469), and the additional observation from Lortie that teaching activities are "indivisible" and cannot easily be broken into "component tasks" (p. 470). In "Observations on Teaching as Work," Lortie (1973) refers to his own earlier arguments (1970) that "the actuality of options" in schools "deeply influences decision-making processes" (p. 476) as he finds that schools are being:

subject matter, as unjust to members of minority groups, as
tools of international communism, as pathologically
bureaucratic and unresponsive to the public will, as
destructive of the human spirit, as perpetuators of class
privilege and as conducted in mindless fashion (1973, p. 476).

He also notes, from his earlier (1969) work, that "schools, in comparison with other types of institutions, have received little social scientific description useful to investigators" (p. 478). Thus, his text from major study, published in 1975, will rest on his earlier positions and findings from 1966, 1968, and 1969, as he explores the "riddle" of "teacher socialization" and the "ethos" of school teaching from the vantage point of the schoolteacher.

Murnane and Phillips (1977), in their study of "The school as a workplace: What matters to teachers," make reference to differences in the work attitudes of male and female teachers by citing Lortie's (1975) argument that "most men treat teaching as a stepping stone to a higher position and most women do not" (1977, p. 15); and they make a 
second acknowledgement to Lortie (1975) in his finding that "teachers acknowledge the legitimacy of a prescribed curriculum, but value some personal freedom in implementing it" (p. 16).

Holdaway (1978), in a study of satisfaction of teachers in Alberta, Canada, includes Lortie (1975) in his examination of literature and notes that NEA studies reviewed by Lortie (1975) do not establish a relationship for teachers between job involvement or commitment and job satisfaction (p. 31).

In designing their own study on "central life interests of teachers," Pajak and Blumberg (1979) refer to Lortie's views (1975) that "career rewards in the teaching profession are structured in such a way that instrumental participation rather than full comitment among teachers seems to develop" (p. 4). Thus, in Lortie's arguments, there are no "staged improvements in income, power, and status among teachers who persist"; and the absence of these staged improvements "results in a weak relationship between effort and reward" (p. 4). The realization for teachers that their efforts bring little reward "negatively affects" their "self-investment" in teaching. Thus, Pajak and Blumberg agree with Lortie that the result for the classroom is a "subtle depreciation" of teaching. with little to compensate for being "only a teacher." U1timately, the lack of a "hierarchy in teaching" means that those who would advance, through administrative ranks, must "abandon the classroom"--which means that "teaching requires less than lifetime commitment" for those who would seek to include other work or personal life roles (1979, pp. 4-5). 
In their discussion of the opportunities of principals to motivate teachers by understanding factors that shape performance, Greenfield and Blase (1981) support findings of earlier research, including Lortie's (1973, 1975), with conclusions that:

- New teachers are particularly involved in achieving "the fundamentals of professional mastery" and should not be first assigned "to a difficult classroom situation; their adjustment to teaching is difficult enough under the best of circumstances" (p. 8).

- Experienced teachers are attempting to extend their influences beyond instruction to guide students and help them solve personal problems; therefore, principals should understand that the teacher is trying to develop "whole" students (p. 8).

- Principals can help teachers by removing barriers that interfere with the time and effort teachers need for teaching (p. 8).

- Principals can use "performance-motivation theory as a framework for intervening in and guiding the work of teachers." Such understanding helps principals to provide inservice, counseling, and "other strategies" to "monitor and improve teacher performance" (p. 9).

Ashbaugh (1982) includes reference to Lortie's research with elenientary teachers (1975) to support a summary or his discussion on "what is job satisfaction," maintaining that teachers "are willing to trade technical control of the school by the principal for interpersonal control of the classroom by the teacher"; the trade-off becomes an intrinsic and symbolic reward for teachers "in a normative compliance relationship with their superiors" (p. 201).

Wangberg, Metzger, and Levitov (1982) include reference to Lortie's study of elementary teachers (1975) in their research of working conditions and career options that lead to female elementary teacher job dissatisfaction. They cite Lortie's findings that 
teachers are "highly intrinsically job motivated, gaining their greatest satisfaction from positive contact with students" as evidence that career attitudes for female teachers may be changing. They suggest that both experienced and less experienced female teachers are realizing additional career options, and this appears to be influencing their dissatisfaction with their roles. Furthermore, "when teaching allows less positive interaction with students the job may become less satisfying, and the quality of teaching may suffer" (p. 39).

In the Encylopedia of Educational Research (5th ed., 1982), both Boyan (p. 25) and Gorton (p. 1907) credit Lortie as having contributed to research on teacher job satisfaction and having provided data on the "life of the teacher and teacher socialization" in terms of the "social system and role perspectives" in schools (p. 25). Gorton summarizes Lortie's views by stating that:

If teacher satisfaction is to be increased, efforts will need to be made to improve the teaching situation itself ... however,.. . this improvement will not be easy because of the problematic nature of teaching in that goals are intangible and unclear, assessment is difficult, and expectations and behavior of the clientele are diverse (p. 1907).

Chapman and Lowther (1982) and Chapman (1983) cite Lortie's findings in their studies of teachers' career satisfaction. Chapman and Lowther (1982) accept Lortie's findings that "teaching is unstaged and frontloaded"--teachers know that long service and special performance will bring little financial reward (p. 242). Chapman (1983) includes observations by Lortie (1975) that teachers "are often isolated and cut off from each other. Teachers who rely on recognition from colleagues are apt to be disappointed and .. dissatisfied" (p. 47). 
In their study of organizational incentives and secondary school teaching, Bredeson, Fruth, and Kasten (1983) credit Lortie with "one of the most thorough sociological studies of teaching as an occupation" (p. 53). These researchers rest their own study on Lortie's classification of rewards as "extrinsic, ancillary, and psychic" and his suggestion that "internalized motivations" (from psychic rewards serving as internal satisfactions) are of primary significance to teachers (p. 53). And they accept Lortie's theory by forming their own conclusions that:

The most powerful motivational forces which attract, maintain, and keep successful teachers in the classroom are a complex of intrinsic rewards which come together in the ideal occupational combination of working with students, seeing students learn and succeed, believing one's job in service to others is valuable, and being able to continue growing personally and professionally (p. 57).

External rewards are not enough to sustain in the professional teachers who are comnitted to children and curriculum (p. 58).

Falkenstein (1982) and Hathaway (1982) draw part of their study of teacher motivation and reward from Lortie's questions used to survey teachers in Five Towns in the Boston Metropolitan Area. From their own study of teachers in the Portland Metropolitan Area, Falkenstein and thathay tend to support Lortie's theory that:

The primary source of satisfaction for most teachers studied comes from personal relationships established with their students (Falkenstein, 1982, p. 2).

Our teachers reported that they value and gain considerable satisfaction from their students, their colleagues, the feeling of "reaching and influencing young people," the feeling of being creative, and the intellectual growth and activity offered by their work (Hathaway, 1982, p. 14). 
Sumnary

An overview of the literature in the field of job satisfaction of workers in general and of teachers in particular confirms many purposes for study and many possibilities for additional study to bring benefit to public education and to educators. Among many addresses to the topic of job satisfaction, no one theory has emerged to be accepted by all researchers. Herzberg's dual-factor theory is subject to commendation, controversy, and continuing questions or efforts of compromise as a theory on which to structure study of satisfactions and rewards of workers; however, the theory is frequently acknowledged as a way to gather basic data on factors influencing job satisfaction and dissatisfaction. Lortie's theory is generally recommended as significant to sociological study of teachers. Both Herzberg and Lortie consider elements of reward as significant to job satisfaction. Therefore, the current research will include analysis of how the job satisfaction of teachers conforms to Herzberg's dual-factor theory and Lortie's theory in the hope that the findings will be useful to the continuing searches for ways to bring improvement and positive or goal-based change to public education, by suggesting ways to increase job satisfaction of teachers and to assist personnel services for public educators. (See Appendices A and B for summaries of studies on job satisfaction, including focus on Herzberg's theories and Lortie's theories. See Appendix C for a listing of factors as used in this study and defined as motivators/intrinsic factors or hygienes/extrinsic factors.) 


\section{CHAPTER IV}

METHODOLOGY

Design and Development of the Instrument

The survey instrument for this study has been designed and developed as a questionnaire, to include closed rating choices (largely fivescale) and open responses. The instrument is a modification of the questionriaire used in 1981 by Falkenstein and Hathaway $\left(Q_{1}\right)$, now developed as a four-part questionnaire $\left(Q_{2}\right)$, with 125 items, to include:

\section{Part I:}

Seventeen items of background and demographic information.

Part II:

Twenty-five items based on identified first-level factors included by Herzberg and fellow researchers to establish sixteen factors as motivators or hygienes, as the basis of the dual-factor or two-factor theory to study job satisfaction and dissatisfaction (1959, 1966). This section of the instrument (Q) is similar in format to a section of the questionnaire used by Moxley (1977) to study job satisfaction in higher education faculty. The present instrument includes the following additions and adjustments of Herzberg's factors for research of teachers:

Time--added and based on Lortie study (1975), Moxley study (1977), and acceptance of this factor for a study of teacher job satisfaction: time spent in teaching, time spent in 
preparation for teaching, time spent on school-related activities outside of classroom preparation and teaching students.

Interpersonal relations - subordinates--adjusted and construed to mean students, based on the role of the teacher as a supervisor relating with students. 8

Interpersonal relations - parents and the community--added and based on the role of the teacher relating with parents and the school community.

In general, this study of teachers preserves the definitions in the context already established by Herzberg. However, the category of interpersonal relations - students addresses attitudes toward students; the category of interpersonal relations - parents and the community addresses attitudes toward parents and representatives of the school community; the category of interpersonal relations - fellow teachers addresses attitudes toward colleagues and in identified social involvement--time spent together in school as well as in time spent socially outside school hours; and the category of interpersonal relations - administrators addresses attitudes about the competence of the administrator/supervisor and perceptions about whether the administrator/supervisor gives professional support to the individual teacher as a staff member. The category of policy and administration addresses attitudes on the policies and practices of the school and the school district.

${ }^{8}$ The adjustment of Interpersonal Relations - Subordinates to Interpersonal Relations - Students is based on similar adjustment in the research of Moxley (1977, pp. 15, 21, 22) and Sergiovanni (1966, p. 42). 
The present instrument does not include address to Flanagan's "critical-incident" method (1954, in Herzberg et al., 1959). In Herzberg's early study (1959), respondents were asked in semi-structured interviews to recount when they felt exceptionally good or bad about their jobs. Vroom (1966) questions the validity of the "story-telling" method of data collection (p. 6). Moxley (1977) notes that the written format for response on "critical incidents" has been used successfully by Herzberg (1963), Leon (1973), and Schwartz, Jenusiatis, and Stark (1973) (in Moxley, 1977, p. 14). Moxley (1977) did include two questions in her instrument, seeking recount of three aspects of teaching that evoked exceptionally good feelings and three aspects of teaching that evoked exceptionally bad feelings. In her findings, she comments that "the faculty may have struggled to record dissatisfying situations . . . in some cases the respondents did not supply the three requested bad experiences but always offered three good experiences" (p. 34). Therefore, the present study does not include the "critical-incident" method of rating recalled experiences.

Rating Scales (Part II): The rating scale is as follows:

Very satisfied

Somewhat satisfied

Neither satisfied nor dissatisfied

Somewhat dissatisfied

Very dissatisfied 
Part III:

Twenty-five items of importance rating, modified from the earlier (1981) questionnaire used by Falkenstein and Hathaway in their study of teachers in the PMA, based on primary work by Lortie (1975).

Rating Scale (Part III): The rating scale is as follows:

Very important

Sonewhat important

Neither important nor unimportant

Somewhat unimportant

Very unimportant

Part IV:

Fifty-eight items based on expressions of attitudes and feelings about teaching, including modified and replicated items from the earlier (1981) questionnaire used by Falkenstein and Hathaway and by Lortie (1975). (See Appendix E - $Q_{1}$ Questionnaire.)

Forty-nine items are forced choice; nine items are open for brief response. (See Appendix $D-Q_{2}$ Questionnaire.)

\section{Validity of the Instrument}

The following steps have been taken to determine and protect the validity of the instrument $\left(Q_{2}\right)$ used in the current study:

1. The instrument is based on theory and previously-conducted studies.

2. The earlier studies are regarded as valid (findings have not been disputed and have been reported as printed information and as presentations to professional meetings). 
3. The instrument used previously by Falkenstein $\left(Q_{1}\right)$ was designed cooperatively with Dr. Walter Hathaway, Research and Evaluation Department, Portland Public Schools. The instrument used in 1981, based on theory and study by Lortie (1975), was examined prior to distribution, and has been examined since distribution--most recently, it was sent for further review by Dr. Joseph Hanson, Director, Technical Assistance Center, Northwest Regional Educational Laboratory; his recommendations have been considered in the editing of the current instrument.

4. The current instrument $\left(Q_{2}\right)$ has been developed in collaboration with the staff of the Research and Evaluation Department, Portland Public Schools, under the direct supervision of Dr. Walter Hathaway, Director of Research and Evaluation. It has been reviewed by Dr. Joseph Hanson, N.W.R.E.L., and other specialists in Research and Evaluation. It has also been examined and approved by representatives of Portland Association of Teachers (P.A.T.).

Design for the Study

Elements of design for the study include the following:

1. It is based on theory and study of job satisfaction including research by Frederick Herzberg and others (1959) and a sociological study of school teachers conducted by Dan C. Lortie (1975). 
2. It is based on a review of literature on job satisfaction, motivation, and work, with focus on teachers and teaching in educational institutions.

3. It is based, in part, on a study conducted three years ago (1981) by Dr. Lynda C. Falkenstein, then Associate Professor at Portland State University, in collaboration with Dr. Walter Hathaway, Director of Research and Evaluation, Portland Public Schools.

a. The 1981 study was conducted in eight school districts in an area identified as the Portland Metropolitan Area (PMA).

b. The eight school districts that cooperated in the 1981 study are:

\section{Oregon:}

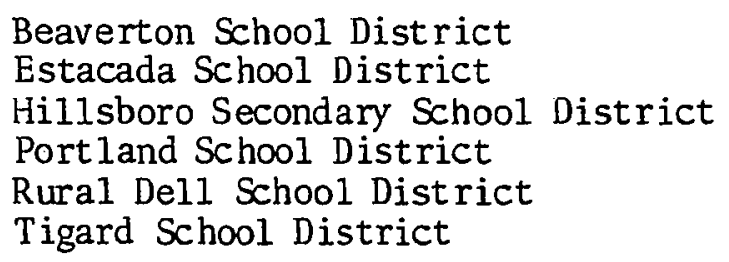

Washington:

Evergreen School District Vancouver School District

c. The 1981 study included a sample of one-third of the school teachers in the participating districts, a random selection of 2,377 subjects served as sample.

d. The 1981 study was based on an instrument $\left(Q_{1}\right)$ including 108 items on a questionnaire of closed and open-ended items, drawing directly and indirectly from 
the published study by Lortie (1975). The study is based on 1,538 responses $(64.7 \%)$.

4. It is based, in part, on a study conducted in 1975 by Linda S. Moxley--"Job Satisfaction of Faculty Teaching Higher Education. An Examination of Herzberg's Dual Factor Theory and Porter's Need Satisfaction Research" (published June, 1977).

a. The Moxley study used a questionnaire of identified first level factors, drawn from Herzberg, with a seven-scale rating, ranging each item from satisfaction to dissatisfaction--including an option for the respondent to select "neither satisfied nor dissatisfied" as part of the study of dual-factor theory.

b. The Moxley study included: (1) two open-ended items seeking three examples each of when the respondents felt "exceptionally good" and "exceptionally bad" about the job of teaching in higher education, (2) twenty-six response items on job satisfaction, and (3) fourteen response items on demographic and institutional information.

c. The survey instrument was issued to two humdred randomly selected faculty members in higher education. The study is based on seventy-three responses $(46.2 \%)$.

5. The current study has attempted to follow the 1981 study by Falkenstein and Hathaway to the extent of inviting the same eight school districts to participate in the 1984 research. 
Two school districts that cooperated in the 1981 study elected not to participate in the follow-up study; they are Estacada and Evergreen School Districts. One school district that was not included in the 1981 study requested participation in the 1984 research; it is Hillsboro Elementary Public Schools. Thus, the districts that cooperated in the 1984 study are:

Oregon:

Beaverton School District

Hillsboro Elementary School District

Hillsboro Secondary School District

Portland School District

Rural Dell School District

Tigard School District

Washington:

Vancouver School District

In addition, data from the 1981 research are available for review and analyses of the data from 1984 .

The instrument for the 1984 study $\left(Q_{2}\right)$ includes items drawn directly from the 1981 instrument $\left(Q_{1}\right)$ to permit follow-up analyses of identical and similar items as responses from a similar population of public school teachers after a three-year period.

\section{Sampling Procedures}

Sampling procedures for the study include the following:

1. The cooperating districts have been assured that results will be kept confidential as data on any individual district and subject only to statistical analyses for the sample of the PMA population of public school teachers. If a district 
requests isolated data, that district will receive selective data for its own district staff and schools, but not for individual respondents.

2. The sample size is one-third of the teaching staff actually involved in classroom instruction in the schools and programs for the participating districts, with the single exception of Hillsboro Elementary School District that requested survey instruments for the total teaching staff. Based on information received from each participating district, a total of 2,133 instruments were distributed to the administrative offices for each school district.

3. All participating school districts received the instruments on April 18, 1984. Following distribution of the instruments in the school buildings, teachers were given five days to complete and return the questionnaire, in a sealed envelope, to central collection sites. All instruments were returned from the participating districts by May 18, 1984 .

4. Teachers forming the sample were identified by random selection. Two pattems of distribution were selected at random, marked A and $B$. The A pattern requested one-third distribution beginning with the first teacher's name on the first mailbox in the school office and continuing with every third teacher. The $B$ pattern requested one-third distribution beginning with the last teacher's name on the last mailbox in the school office in a reverse pattern. No teachers were identified by name. 


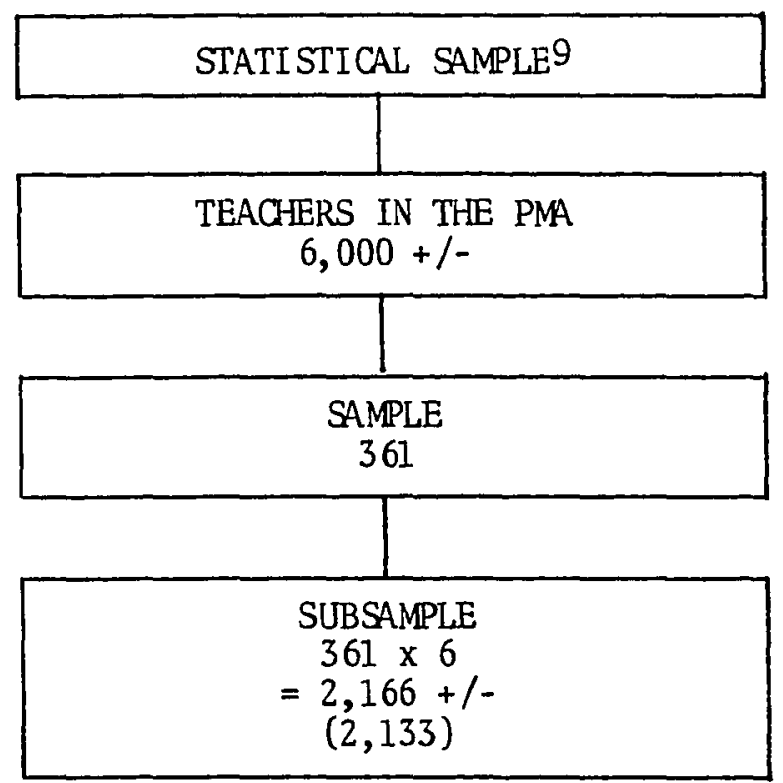

Table I. Statistical Sample Table (Krecje \& Margan, 1970)

5. The survey instruments were coded by school district, school, and the number set to complete the one-third distribution pattern.

6. Teachers receiving the survey instrument were advised that all individual responses will be confidential, to be used for statistical data analyses. The compiled results will be made available, upon request and completion of the study, to all who participate.

9 Table for deternining sample for a given population drawn from R.V. Krecje and D.W. Margan, Determining sample size for research activities, Educational and Psychological Measurement, vol. 30, 1970, pp. 607-610; D.E. Hinkle and J.D. Oliver, How large should a sample be? A question with no simple answer? Or . . ., Educational and Psychological Measurement, 1983, 1051-1059; consultation with L. Hales, Portland State University, and $W$. Hathaway, Research and Evaluation, Portland Public Schools. Distribution numbers for classroom teachers in schools were provided by the administrative offices of each of the participating districts. The distribution ratio is one-third of the total population $(\mathrm{N}=2,133)$. 
7. Additional steps taken to protect the integrity of the data for the current study include the following:

a. The research was conducted through Portland State University, as a "neutral" institution and as the institution authorizing the 1981 and 1984 studies.

b. The survey instrument was accompanied by a return envelope, to be sealed by the respondent, to reduce concerns of individual identity in any given school and to protect confidentiality.

c. The survey instruments, in the sealed envelopes, were returned to a central site in each building for delivery to the Blanchard Education Service Center, Portland Public Schools, for data analyses by the researcher.

\section{Approvals}

Approvals for the study include the following:

1. Dr. Lynda Falkenstein and Dr. Walter Hathaway, collaborators for the research conducted in 1981, have given full approval and release of all data in support of the follow-up study in 1984. Falkenstein had previously secured full release for the 1981 study to include direct and indirect reference to Lortie's study in a letter from Dan C. Lortie, acknowledging that his published work Schoolteacher: A Sociological Study (1975) is in the "public domain."

2. All cooperating school districts gave full permission for the conducted research. 
3. All participation of respondents was voluntary.

4. The Portland Association of Teachers (P.A.T.) gave full support to the data collection from teachers in the Portland School District.

5. Portland State University gave full permission for the research to be conducted under the name of the institution.

6. The survey instrument was reviewed and approved by research and evaluation specialists and administrators from Northwest Regional Educational Laboratory and Portland Public Schools.

7. Particular support for the study rests on full approval from the Superintendent and Executive Deputy Superintendent of Portland Public Schools, authorizing technical assistance.

8. Dr. Walter Hathaway, Director of Research and Evaluation, Portland Public Schools, has provided direct information from the 1981 study as well as encouragement and guidance for the design and analyses of the current study.

\section{Questions To Be Answered by this Study:}

How Information Will be Used

With methods of statistical analyses, this study will attempt. to answer the questions directly posed in the hypotheses, as follows:

1. How satisfied are teachers in the PMA with their jobs?

2. What are the primary differing factors affecting teacher satisfaction and dissatisfaction, and do these factors and their relationships conform with Herzberg and Lortie theories?

3. How does satisfaction and dissatisfaction vary as a function of the following teacher "demographic" factors: 
(a.) Age

(b.) Sex

(c.) Grade level

(d.) Years in service

(e.) Education (highest degree earned)

In addition, the study may provide some information in relationship to the following questions:

1. How stable are the levels and sources of satisfaction and dissatisfaction for teachers in the PMA? (Will a follow-up study after a three-year period find significant change in the levels and sources of job satisfaction and dissatisfaction for teachers?)

2. How can we reduce job dissatisfaction and improve job satisfaction among $\mathrm{K}-12$ public school teachers?

The information could be useful in a variety of ways: as information for the public, for public school districts, and for public school teachers.

1. As information for the public, it could serve to improve communications and cooperative relationships between community representatives (particularly parents) and community schools and school teachers.

2. As information for public school districts, it could serve to support personnel services--from selection and staffing, to assignment, to designing and providing inservice and staff development programs or plans of assistance, to cooperating in preservice and teacher training programs with colleges and 
universities, to collective bargaining and allocation of district resources--linked to a better understanding of the teacher and teaching and the opportunity to guide or direct human resources (and resources in general) to better advantage.

3. As information for public school teachers, it could serve to establisin individual attitudes within a group concept, identification of the self within a job concept (including job content and job context). Such information could lead to: (a.) improved morale or satisfaction, (b.) improved performance or motivation, (c.) more effective schools and schooling.

The information will be used in a general analysis of a sampling of school teachers within a defined area of public school districts. It will not be used to identify particular districts, or schools, or teachers. However, districts may request their own statistical data, and participants may request statistical data related to the analyses or findings in general.

Research Questions, Predictions, Hypotheses, and Analyses To Be Used

The research questions, predictions, hypotheses, and analyses to be used for this study are as follows: 
Question\# 1 HOW SATISFIED ARE TEACHERS IN THE PMA ${ }^{10}$ WITH THEIR JOBS?

Prediction Teachers in the PMA are generally satisfied with

$\# 1$

Research

Hypothes is

$\# 1$

$\underline{\mathrm{Nul1}}$

Hypothesis

$\# 1$

\#I their jobs.

The proportion of respondents expressing satisfaction with teaching will be significantly greater than the proportion of respondents expressing dissatisfaction.

$$
\mathrm{H}_{1}: \mathrm{P}_{1} \neq \mathrm{P}_{2}
$$

The proportion of respondents expressing satisfaction with teaching will not be significantly greater than the proportion expressing dissatisfaction.

$$
\mathrm{H}_{0}: \mathrm{P}_{1}=\mathrm{P}_{\mathrm{S}} \text { DIS }
$$

Analyses 1. A Chi-square $\left(x^{2}\right)^{11}$ test of significance on frequencies of responses to each item directly

10PMA - The Portland Metropolitan Area, including a sampling of one-third of the public school teacher population in the school districts that initially cooperated in a 1981 study and agreed to a follow-up data collection of a similar population. The eight districts represented in the 1981 study are: Oregon - Beaverton S.D., Estacada S.D., Hillsboro Secondary S.D., Portland S.D., Rural Dell S.D., Tigard S.D.; Washington - Evergreen S.D., Vancouver S.D. The seven districts represented in the 1984 study are: Oregon - Beaverton S.D., Hillsboro Elementary S.D., Hillsboro Secondary S.D., Portland S.D., Rural Dell S.D.; Washington - Vancouver S.D.

${ }^{11} \mathrm{~A}$ measure of discrepancy existing between observed and expected frequencies is supplied by the statistic $X^{2}$, called Chi-square. The Chi-square test for goodness of fit can be used to determine how well theoretical distributions fit empirical distributions (e.g., those obtained from sample data). M.R. Spiegel, Theory and Problems of Statistics, New York: Schaum Publishing Company, 1961, p. 202 . 
assessing satisfaction. ${ }^{12}$ Level of significance

- .05 two-tailed, nondirectional.

2. Visual inspection of cell frequencies to each item directly assessing satisfaction to determine direction of relationship.

Question \#2 WHAT ARE THE PRIMARY DIFFERING FACTORS AFFECTING TEACHER SATISFACTION AND DISSATISFACTION, AND DO THESE FACTORS AND THEIR RELATIONSHIP TO SATISFACTION AND DISSATISFACTION CONFORM WITH HERZBERG AND LORTIE THEORIES? ${ }^{13}$

Predictions Motivators, as defined by Herzberg, or intrinsic or psychic factors, as defined by Lortie, will \#2a contribute to job satisfaction more than they will contribute to dissatisfaction.

Hygienes, as defined by Herzberg, or extrinsic \#2b factors, as defined by Lortie, will contribute to job dissatisfaction more than they will contribute to satisfaction.

$12_{\text {See }} \mathrm{Q}_{2}$ - Questionnaire Instrument. Items tested are II. 24,25 ; IV. $1,2,3,8,46$.

13Herzberg's theory will be drawn from studies by Frederick Herzberg and others $(1959,1966)$ addressing his views on motivation and work, motivators and hygienes, dual-factors of satisfaction and dissatisfaction. Lortie's theory will be drawn from research by Dan C. Lortie (1975). Adjustments and additions of factors identified by Herzberg (1959, 1966) are based on research of educators by Moxley (1977) and Sergiovanni (1966). Lortie research served as the basis for a study conducted in 1981 by Lynda C. Falkenstein, Portland State University, and Walter Hathaway, Portland Public Schools, as research of teachers in the PMA. See Appendix C. 
Research There is a direct, significant relationship Hypothesis between measures of motivators (Herzberg), or \#2a intrinsic or psychic factors (Lortie), and measures of satisfaction.

$$
\mathrm{H}_{1}: \mathrm{P}_{1}>\mathrm{P}_{\mathrm{M}}
$$

Null There is not a direct, significant relationship Hypothesis between measures of motivators (Herzberg), or $\# 2 \mathrm{a}$ intrinsic or psychic factors (Lortie), and measures of satisfaction.

$$
\mathrm{H}_{0}: \mathrm{P}_{1}=\mathrm{P}_{\mathrm{M}}
$$

Analyses

Bivariate correlational analyses (Kendall's $\# 2 \mathrm{a}$ $\mathrm{tau}^{14}$ ) of each measure of a motivator, or each measure of an intrinsic factor, and each measure of satisfaction. These tests to be used both for significance and for direction of relationship. Level of confidence - .05, one-tailed.

14 Kendall's tau is a technique for producing standardized coefficients based on the amount of agreement between two sets of ordinal rankings, taking into account the tied ranks. The general formula for tau is $t=\frac{1}{1 / 2 N(N-1)}$ Statistical Package for the Social Sciences, 2nd ed., New York: McGraw-Hill, 1975, p. 290. Kendall's tau is a ranking method correlation coefficient which rests on no special assumptions and has numerous applications, including the testing of hypotheses. M.G. Kendall, Rank Correlation Methods, London: Griffin, 1948, in Fundamental Statistics in Psychology and Education, 4th ed., H.F. Harlow, ed., New York: McGraw-Hill, 1956, p. 308. The Kendall rank correlation coefficient, tau, is suitable as a measure of correlation with the same sort of data for which Spearman rank correlation is useful-- if at least ordinal measure of both the $X$ and $Y$ variables has been achieved, then tau will give a measure of the degree of association or correlation between the two sets of ranks. The sampling distribution of tau under the null hypothesis is known, and therefore, tau, like Spearman rank, is subject to tests of significance. One advantage of tau over Spearman rank is that tau can be generalized to a partial correlation coefficient. S. Siegel, Nonparametric Statistics for the Behavioral Sciences, New York: McGraw-Hi11, 1956, pp. 213-214. 
Research There is an inverse, significant relationship Hypothesis between measures of hygienes (Herzberg), or $\# 2 \mathrm{~b}$ extrinsic factors (Lortie), and measures of satisfaction.

$$
\mathrm{H}_{1}: \mathrm{P}_{1}<\mathrm{P}_{2}
$$

$\underline{\mathrm{Null}}$

There is not an inverse significant relationship Hypothes is between measures of hygienes (Herzberg), or $\# 2 \mathrm{~b}$ extrinsic factors (Lortie), and measures of satisfaction.

$$
\mathrm{H}_{0}: \mathrm{P}_{1}=\mathrm{P}_{2}
$$

Analyses Bivariate correlational analyses (Kendall's tau) \#2b of each measure of a hygiene and each measure of an extrinsic factor and each measure of satisfaction. These tests to be used for significance and for direction of relationship. Level of confidence - .05, one-tailed.

Predictions Data from the present study of teachers will not \#2c conform with Herzberg's list of primary factors operating as motivators or satisfiers and as hygienes or dissatisfiers (1959, p. 81).

$\# 2 \mathrm{~d}$ Data from the present study of teachers will conform with Lortie's theory of factors operating as intrinsic rewards or sources of satisfaction for teachers (1975). 
Research The factors identified in the present study of Hypothesis teachers as contributing most frequently to $\# 2 \mathrm{c}$ satisfaction and dissatisfaction will not conform with Herzberg's (1959) identified list of primary factors operating as motivators or satisfiers and as hygienes and dissatisfiers.

Nul1 The factors identified in the present study as Hypothesis contributing most frequently to satisfaction and $\# 2 \mathrm{C}$ dissatisfaction will conform with Herzberg's list of primary factors operating as motivators or satisfiers and as hygienes or dissatisfaction.

Analyses Visual inspection of frequency counts of factors \#2c in the present study that are identified in percentages as contributing most frequently to satisfaction and dissatisfaction to determine whether the teacher respondents indicate factors that conform with Herzberg's (1959) list of primary factors operating as motivators or satisfiers and as hygienes or dissatisfiers.

NOTE: These data and findings may not be regarded as statistically significant; however, they should provide useful evidence in support of the purposes and benefit potential for the present study. 
Research

Hypothesis

\#2d

$\underline{\text { Null }}$

Hypothesis

$\# 2 d$

Analyses

\# $2 \mathrm{~d}$

The factors identified in the present study of teachers as contributing most frequently to satisfaction will conform with Lortie's theory (1975) that teachers receive satisfactions (or intrinsic rewards) from their interrelationships with students.

The factors identified in the present study as contributing most frequently to satisfaction will not conform with Lortie's theory (1975) that teachers receive satisfactions. (or intrinsic rewards) from their interrelations with students (pp. 101, 104, 106, 109).

Visual inspection of frequency counts of factors in the present study that are identified in percentages as contributing most frequently to satisfaction, to determine whether the teacher respondents will indicate factors that conform with Lortie's theory (1975).

NOTE: These data and findings may not be regarded as statistically significant; however, they should provide useful evidence in support of the purposes and benefit potential for the present study.

Question \#3 HOW DOES JOB SATISFACTION AND DISSATISFACTION VARY AS A FUNCIION OF THE FOLLOWING TEACHER "DEMOGRAPHIC" FACTORS: 
(3a.) Age

(3b.) Sex

(3c.) Grade leve1

(3d.) Years in service

(3e.) Education (highest degree earned)

Prediction Job satisfaction and dissatisfaction will vary \#3 significantly as a function of each of the factors of age, sex, grade level, years in service, and education.

$\underline{\text { Research }}$

There is a significant relationship between age Hypothesis and measures of satisfaction.

\#3a

$$
\mathrm{H}_{1}: \mathrm{P}_{\mathrm{A}} \neq \mathrm{P}_{\mathrm{S}}
$$

Nul1

There is not a significant relationship between Hypothesis

$\# 3 a$ age and measures of satisfaction.

$$
\mathrm{H}_{0}: \mathrm{P}_{1}=\mathrm{P}_{2}
$$

Analyses

$\# 3 a$

Bivariate correlational analyses (Kendall's tau) of each measure of age and measures of satisfaction. These tests will be used both for significance and for direction of relationship. Level of confidence - .05, two-tailed.

Research There is a direct, significant relationship kypothesis between sex and measures of satisfaction. The $\# 3 \mathrm{~b}$ proportion of women respondents expressing satisfaction with teaching will be significantly greater than the proportion of men respondents expressing satisfaction.

$$
\mathrm{H}_{1}: \mathrm{P}_{1} \underset{\text { SW }}{>\mathrm{P}_{2}}
$$


Null

Hypothesis

\# $3 \mathrm{~b}$

Analyses

\#3:

Research

Hypothesis

$\# 3 c$

$\underline{\mathrm{Nul1}}$

Hypothesis

$\# 3 \mathrm{c}$
There is not a direct, significant relationship between sex and measures of satisfaction. The proportion of women respondents expressing satisfaction with teaching will not be significantly greater than the proportion of men respondents expressing satisfaction.

$$
\mathrm{H}_{0}: \mathrm{P}_{\mathrm{SW}_{\mathrm{SW}}}=\mathrm{P}_{2}
$$

Bivariate correlational analyses (Kendall's tau) of sex and measures of satisfaction. These tests will be used both for significance and for direction of relationship. Level of confidence .05 one-tailed (directional).

There is a direct, significant relationship between grade level and measures of satisfaction. The proportion of respondents teaching at the primary and lower grades (Pre-K-K - 4-6) and expressing satisfaction with teaching will be significantly greater than the proportion of respondents teaching at the higher or upper grades (6-8/7-9/9-12) and expressing satisfaction.

$$
\mathrm{H}_{1}: \mathrm{P}_{1} \underset{\text { GLSPG }}{>} \mathrm{P}_{2}
$$

There is not a direct, significant relationship between grade level and measures of satisfaction. The proportion of respondents teaching at the primary and lower grades and expressing satisfac- 
tion with teaching will not be significantly greater than the proportion of respondents teaching at the higher or upper grades and expressing satisfaction.

$$
\mathrm{H}_{0}: \mathrm{P}_{1} \stackrel{=}{=} \mathrm{P}_{2}
$$

Analyses

Bivariate correlational analyses (Kendall's tau)

$\# 3 c$

of each measure of grade level and measures of satisfaction. These tests will be used both for significance and for direction of relationship. Level of confidence - .05 one-tailed.

Research There is a significant relationship between years Hypothesis in service and measures of satisfaction.

$\# 3 d$

$$
\mathrm{H}_{1}: \mathrm{P}_{1} \neq \mathrm{P}_{2}
$$

$\underline{\text { Null }}$

There is not a significant relationship between Hypothesis years in service and measures of satisfaction.

$\# 3 d$

$$
\mathrm{H}_{0}: \mathrm{P}_{1}=\mathrm{P}_{2}
$$

Analyses

Bivariate correlational analyses (Kendall's tau)

\#3d of each measure of years in service and measures of satisfaction. These tests will be used for significance and for direction of relationship. Level of confidence - .05 two-tailed.

Research There is a significant relationship between Hypothesis highest degree earned and measures of \#3e

$$
\mathrm{H}_{1}: \mathrm{P}_{1} \neq \mathrm{P}_{2}
$$


Nul1 There is not a significant relationship between Hypothesis highest degree earned and measures of $\# 3 e$ satisfaction.

$$
\mathrm{H}_{0}: \mathrm{P}_{\mathrm{D}}=\mathrm{P}_{2}
$$

Analyses Bivariate correlational analyses (Kendall's tau) \#3e of each measure of degree earned and measures of satisfaction. These tests will be used for significance and for direction of relationship. Level of confidence - .05 two-tailed.

Summary

Thus, with an instrument that has been designed to include previously validated research and methodology that has been subjected to critical review and approval by research and evaluation specialists, data have been collected in 1984 from a random sample of one-third $(N=2,133)$ of the public school teacher population actively involved in K-12 classroom instruction in seven participating public school districts from the Portland Metropolitan Area. The data have been subjected to statistical analyses in order to bring information to the three major research questions and the identified hypotheses related to the job attitudes of teachers. Findings will be discussed in the following chapter. 


\section{CHAPTER V}

\section{ANALYSES OF RESULTS}

The results of this study are presented in four sections. The first section addresses response and respondent information for the sample. The second section addresses the first research question and findings. The third section addresses the four parts of the second research question and findings. The fourth section addresses the five sections of the third research question.

\section{Response and Respondent Information}

of the population of public schoolteachers actually involved in classroom instruction, grades Pre-K-K-12, with full- or part-time assignments in the seven participating school districts identified as the Portland Metropolitan Area (PMA), a random sample of one-third received questionnaires $(\mathrm{N}=2,133)$. The response ratio is .67698 , or nearly 68 percent $(n=1,444)$, of valid cases subjected to statistical analyses.

\section{The First Research Question and Findings}

Question \#1 HOW SATISFIED ARE TEACHERS IN THE PMA WITH THEIR JOBS?

To test the research hypothesis that teachers in the PMA are generally satisfied with their jobs, ohi-Square $\left(X^{2}\right)$ tests were conducted on frequencies of responses on each of the seven items directly assessing satisfaction (II.24, II.25, IV.1, IV.2, IV.3, IV.8, 
IV.46). ${ }^{15}$ The level of significance set was .05 - two-tailed, nondirectional. The results that follow show that for each of the seven items, the null hypothesis was rejected. There is direct, significant evidence that teachers in the PMA are very satisfied with their jobs.

II.24 All in all, how satisfied are you with your present job or assignment in teaching?

\begin{tabular}{|c|c|c|c|c|}
\hline Category & $\begin{array}{c}\text { Cases } \\
\text { Observed }\end{array}$ & $\begin{array}{l}\text { Expected } \\
\text { Frequency }\end{array}$ & Residual & $\%$ \\
\hline $\begin{array}{l}\text { Very satisfied } \\
\text { Somewhat satisfied } \\
\text { Neither . / nor ... } \\
\text { Somewhat dissatisfied } \\
\text { Very dissatisfied }\end{array}$ & $\begin{array}{r}542 \\
638 \\
97 \\
134 \\
26\end{array}$ & $\begin{array}{l}287.4 \\
287.4 \\
287.4 \\
287.4 \\
287.4\end{array}$ & $\begin{array}{r}254.6 \\
350.6 \\
-190.4 \\
-153.4 \\
-261.4\end{array}$ & $\begin{array}{r}38 \\
44 \\
7 \\
9 \\
2\end{array}$ \\
\hline Very dissatisfied & 1,437 & & & \\
\hline Chi-Square & \multicolumn{2}{|c|}{ Degrees of Freedom } & \multicolumn{2}{|c|}{ Significant beyond } \\
\hline 1099.009 & 4 & & .001 leve & \\
\hline
\end{tabular}

Table II. indicates that $82 \%$ of the teacher respondents express degrees of satisfaction (ranging from somewhat to very); $7 \%$ indicate being neither satisfied nor dissatisfied; and $11 \%$ indicate degrees of dissatisfaction (ranging from somewhat to very). Thus, the Chi-square test of this item is significant beyond the .001 level, and the null hypothesis is rejected. (See Table II.)

15 Among the seven items, IV.46 is the single-most direct measure of satisfaction, with II.25 following as a secondary indicator. 


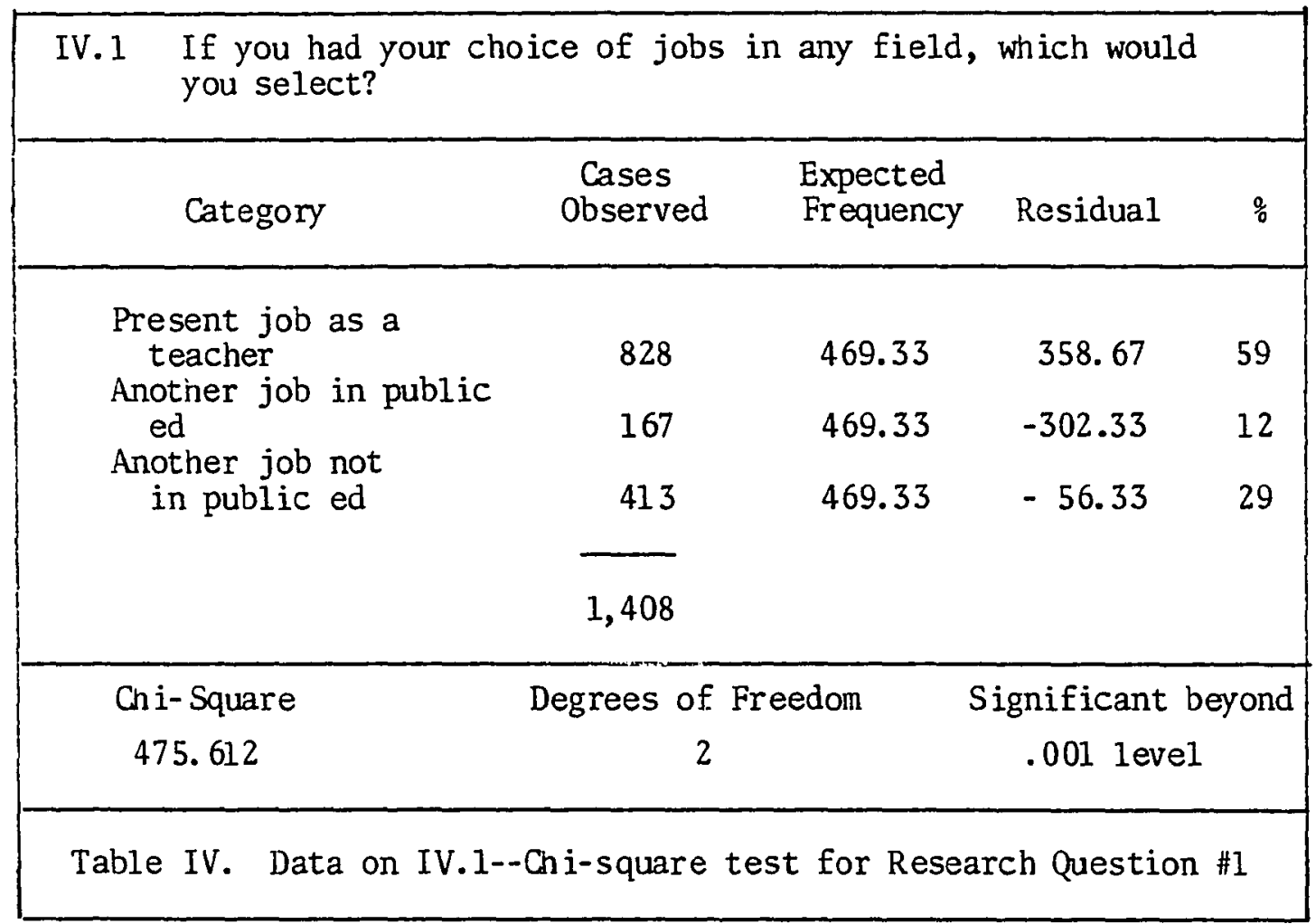

Table V. indicates that $72 \%$ of the teacher respondents would choose to remain in their present jobs as teachers; $7 \%$ would prefer a job as a building administrator; $6 \%$ would prefer a job as a district administrator; and $15 \%$ would prefer some other job in public education outside of teaching or administration. Thus, the Chi-square test of this item is significant beyond the .001 level, and the null hypothesis is rejected. (See Table V.)

Table VI. indicates that $64 \%$ of the teacher respondents would definitely or probably elect to become a teacher again; $19 \%$ are uncertain; and $16 \%$ would probably or definitely not become a teacher again. Thus, the chi-square test of this item is significant beyond the .001 level, and the null hypothesis is rejected. (See Table VI.) 
IV.2 If you had your choice of jobs in the field of public education, which would you select?

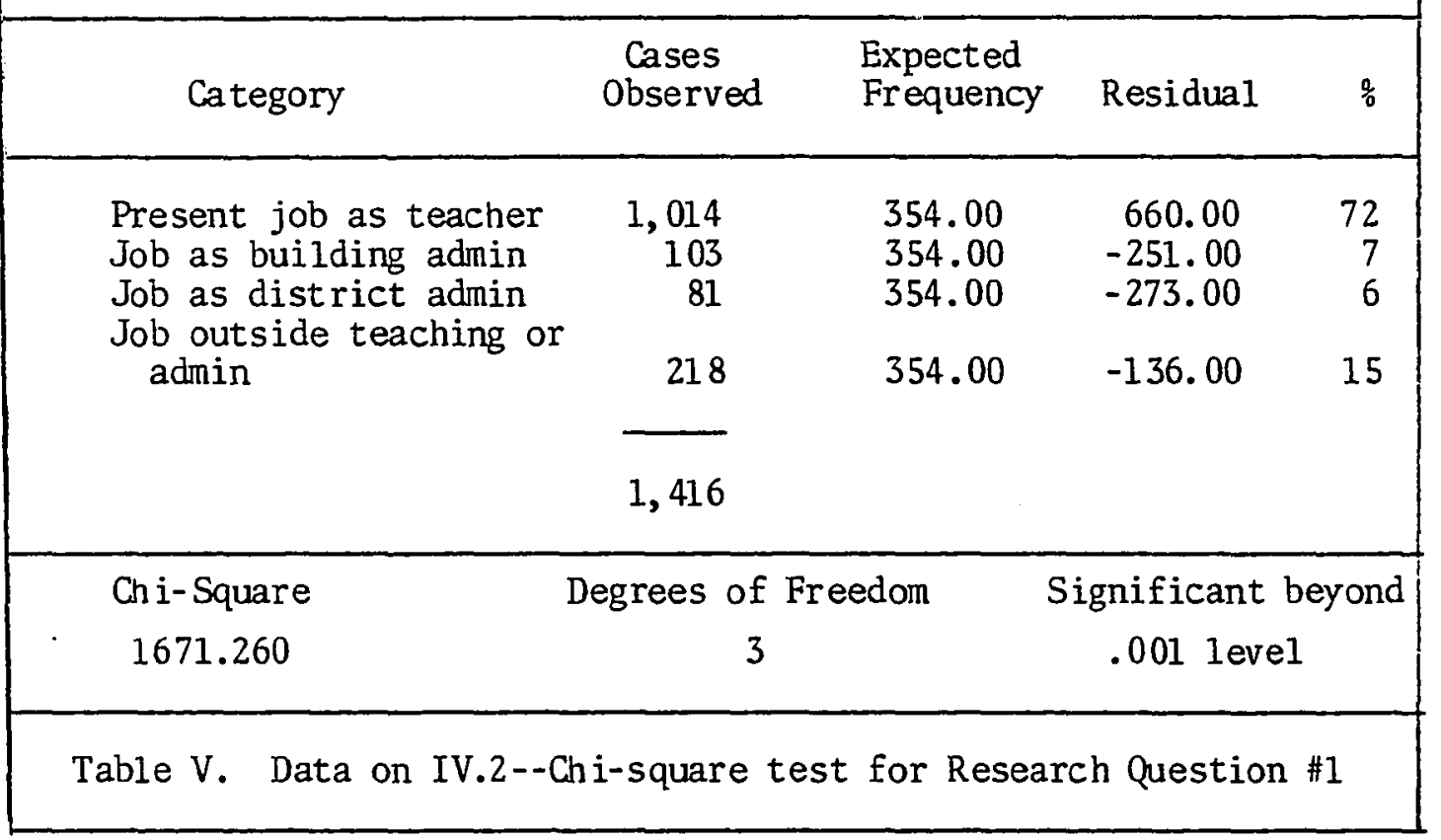

Table VII. indicates that $96 \%$ of the teacher respondents indicate receiving degrees of pleasure from teaching (ranging from some to great); $2 \%$ indicate receiving neither pleasure nor displeasure; and $1 \%$ indizate receiving some degrees of displeasure. Thus, the Chi-square test of this item is significant beyond the .001 level, and the null hypothesis is rejected. (See Table VII.)

Table VIII. indicates that $87 \%$ of the teacher respondents express degrees of satisfaction about teaching (ranging from more satisfied than not to extremely satisfied); 6\% indicate being neither satisfied nor dissatisfied; $7 \%$ indicate degrees of dissatisfaction (ranging from more dissatisfied than satisfied to extremely dissatisfied). Thus, the Chi-square test of this item is significant beyond the .001 level, and the null hypothesis is rejected. (See Table VIII.) 


\begin{tabular}{|c|c|c|c|c|}
\hline \multicolumn{5}{|c|}{$\begin{array}{l}\text { IV.46 Which of these statements comes closest to describing your } \\
\text { feelings about teaching? }\end{array}$} \\
\hline Category & $\begin{array}{l}\text { Cases } \\
\text { Observed }\end{array}$ & $\begin{array}{l}\text { Expected } \\
\text { Frequency }\end{array}$ & Residual & $\%$ \\
\hline $\begin{array}{l}\text { Extremely satisfied } \\
\text { Very satisfied } \\
\text { More satisfied than not } \\
\text { Neither ... / nor ... } \\
\text { More dissatisfied than } \\
\text { satisfied } \\
\text { Very dissatisfied } \\
\text { Extremely dissatisfied }\end{array}$ & $\begin{array}{r}67 \\
9 \\
10 \\
1,422\end{array}$ & $\begin{array}{l}203.14 \\
203.14 \\
203.14 \\
203.14\end{array}$ & $\begin{array}{r}40.86 \\
399.86 \\
199.86 \\
-117.14 \\
-136.14 \\
-194.14 \\
-193.14\end{array}$ & $\begin{array}{r}17 \\
42 \\
28 \\
6\end{array}$ \\
\hline $\begin{array}{c}\text { Chi-Square } \\
1519.871\end{array}$ & \multicolumn{2}{|c|}{$\begin{array}{c}\text { Degrees of Freedom } \\
6\end{array}$} & \multicolumn{2}{|c|}{$\begin{array}{l}\text { Significant beyond } \\
.001 \text { level }\end{array}$} \\
\hline e VIII. Data o & 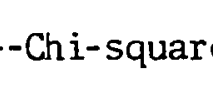 & - & & \\
\hline
\end{tabular}

Summary - Research Question \#1. All seven of the null hypotheses used to test Research Question \#1 are rejected beyond the .001 level of significance. Thus, the data provide direct, significant evidence that teachers in the Portland Metropolitan Area are very satisfied with their jobs.

The Second Research Question and Findings

Question \#2 WHAT ARE THE PRIMARY DIFFERING FACTORS AFFECTING TEACHER SATISFACTION AND DISSATISFACTION, AND DO THESE FACTORS AND THEIR RELATIONSHIP TO SATISFACTION AND DISSATISFACTION CONFORM WITH HERZBERG AND LORTIE THEORIES? 
To test two aspects of the second research question and predictions ( $2 \mathrm{a}$. and $2 \mathrm{~b}$. ), two separate sets of statistical tests (Kendall's tau) were conducted and subjected to analyses of findings. To gain additional information on two other aspects of this research question and predictions ( $2 c$. and $2 \mathrm{~d}$. ), visual inspections of frequencies were conducted and are reported in rank order of percentages as findings. The data from the two statistical tests (2a. and $2 \mathrm{~b}$. ) and the visual inspections (2c. and $2 \mathrm{~d}$. ) are reported as follows:

The Test of Motivators/Intrinsic Factors as Related to Satisfaction

The test of motivators or intrinsic factors and their relationship to satisfaction is based on the list previously identified by Herzberg and others (1959, p. 81) as the five primary factors operating as motivators or satisfiers and generally acknowledged by Lortie (1975) and others as related to "psychic" or intrinsic elements associated with work content and subjective responses to that content. They are included in the present study $\left(Q_{2}\right)$ as follows: (See Table IX.)

\begin{tabular}{|c|c|c|}
\hline $\begin{array}{c}\text { Item } \\
\mathrm{Q}_{2}\end{array}$ & Factor - Herzberg & Factor $-Q_{2}$ \\
\hline II.I & Achievement & Sense of achievement \\
\hline II . 2 & Recognition & $\begin{array}{l}\text { Amount of recognition you } \\
\text { receive }\end{array}$ \\
\hline II .3 & Work itself & $\begin{array}{l}\text { Teaching itself as a kind } \\
\text { of work }\end{array}$ \\
\hline II. 4 & Responsibility & $\begin{array}{l}\text { Amount of responsibility } \\
\text { you have }\end{array}$ \\
\hline II. 5 & Advancement & Opportunity for advancement \\
\hline Table IX. & \multicolumn{2}{|c|}{$\begin{array}{l}\text { Tested Motivators/Intrinsic Factors as Related to } \\
\text { Satisfaction - Herzberg List }\end{array}$} \\
\hline
\end{tabular}


The Test of Hygienes/Extrinsic Factors as Related to Dissatisfaction

The test of hygienes or extrinsic factors and their relationship to dissatisfaction is based on the list previously identified by Herzberg and others (1959, p. 81) as the primary factors operating as hygienes or potential dissatisfiers and generally acknowledged by Lortie (1975) and others are related to extrinsic elements associated with work context or the conditions of work and subjective responses to that context. They are included in the present study $\left(Q_{2}\right)$ as follows: (See Table X.)

\begin{tabular}{|c|c|c|}
\hline $\begin{array}{l}\text { Item } \\
\mathrm{Q}_{2}\end{array}$ & Factor - Her zberg & Factor $-Q_{2}$ \\
\hline II. 7 & Salary & Salary \\
\hline II. 8 & $\begin{array}{l}\text { Interpersonal relations - } \\
\text { supervisor }\end{array}$ & $\begin{array}{l}\text { Interpersonal relations with } \\
\text { your supervising administra- } \\
\text { tor }\end{array}$ \\
\hline II. 13 & Supervision & $\begin{array}{l}\text { Supervision/professional } \\
\text { competence of the adminis- } \\
\text { trator to whom you report }\end{array}$ \\
\hline II. 14 & $\begin{array}{l}\text { Policies and practices - } \\
\text { company or organization } \\
\text { (district) }\end{array}$ & $\begin{array}{l}\text { Policies and practices of } \\
\text { your school district }\end{array}$ \\
\hline II. 15 & $\begin{array}{l}\text { Policies and practices - } \\
\text { company or organization } \\
\text { (school) }\end{array}$ & $\begin{array}{l}\text { Policies and practices of } \\
\text { your school }\end{array}$ \\
\hline II. 16 & Working conditions & $\begin{array}{l}\text { Working conditions in your } \\
\text { school }\end{array}$ \\
\hline Table X. & \multicolumn{2}{|c|}{$\begin{array}{l}\text { Tested Hygienes/Extrinsic Factors as Related to Dissatis- } \\
\text { faction - Herzberg List }\end{array}$} \\
\hline
\end{tabular}


Analyses for Motivators -- Relationship to Satisfaction

(2a.) To test the research hypothesis that motivators, as defined by Herzberg, or intrinsic factors, as defined by Lortie, will contribute to job satisfaction more than they will contribute to dissatisfaction--that there is a direct, significant relationship between measures of motivators (Herzberg), or intrinsic factors (Lortie), and measures of satisfaction--bivariate correlational analyses (Kendall's tau) ${ }^{16}$ were conducted on each measure of motivators (II.1, 2, 3, 4, 5), also defined as intrinsic factors, and each measure of satisfaction (II.25 and IV.46). There is evidence of a moderate, significant relationship between measures of motivators (Herzberg), or intrinsic factors (Lortie), and measures of satisfaction. The test of this item is significant beyond the .001 level. The null hypothesis is rejected, one-tailed test: (See Table XI.)

(2a.) Table XI indicates a moderate, significant relationship between satisfaction and motivators (Herzberg), also defined as intrinsic factors (Lortie). Bivariate correlational analyses (Kendall's tau) provide evidence of a uniformly moderate and significant relationship between satisfaction and motivators. The findings are statistically significant on all ten of the items tested. The null hypothesis is rejected at a signficance level beyond .001 , one-tailed test. The following information may help to clarify and support the analyses: (See Table XI.)

16 Statistical assistance for the analyses of data tested with Kendall's tau has been provided by Gary Williams, Research and Evaluation, Portland Public Schools. 


\begin{tabular}{|c|c|c|c|c|c|c|}
\hline & \multirow{3}{*}{ SATISFACTION INDICATORS } & \multicolumn{5}{|c|}{ MOTIVATORS/INTRINSIC FACTORS } \\
\hline & & $\begin{array}{l}\text { Achieve- } \\
\text { ment }\end{array}$ & $\begin{array}{l}\text { Recogni- } \\
\text { tion }\end{array}$ & $\begin{array}{l}\text { Work } \\
\text { Itself }\end{array}$ & $\begin{array}{l}\text { Responsi- } \\
\text { bility }\end{array}$ & $\begin{array}{l}\text { Advance- } \\
\text { ment }\end{array}$ \\
\hline & & II. 1 & II. 2 & 11.3 & II. 4 & II. 5 \\
\hline II. 25 & $\begin{array}{l}\text { All in all, how satisfied are you } \\
\text { with your role as a teacher? }\end{array}$ & $\begin{array}{l}. .4940^{*} \\
\text { N }(1429) \\
\text { Sig. } .000 * *\end{array}$ & $\begin{array}{l}\text { N } .3558 \\
\text { Sig. } .000\end{array}$ & $\begin{array}{l}.5523 \\
N(1426) \\
\text { Sig. } .000\end{array}$ & $\begin{array}{l}. .3831 \\
N(1425) \\
\text { Sig. } .000\end{array}$ & $\begin{array}{l}. .3498 \\
N(1418) \\
\text { Sig. } .000\end{array}$ \\
\hline IV.46 & $\begin{array}{l}\text { Which of these statements comes } \\
\text { closest to describing your } \\
\text { feel ings about teaching? }\end{array}$ & $\begin{array}{l}.4620 \\
N(1412) \\
\text { Sig. } .000\end{array}$ & $\begin{array}{l}.3346 \\
N(1413) \\
\text { Sig. } .000\end{array}$ & $\begin{array}{l}.5376 \\
N(1410) \\
\text { Sig. } .000\end{array}$ & $\begin{array}{l}. .3441 \\
N(1409) \\
\text { Sig. } .000\end{array}$ & $\begin{array}{l}. .3376 \\
N(1402) \\
\text { Sig. } .000\end{array}$ \\
\hline
\end{tabular}

* The correlational values

** Significant beyond the .001 level 
As previously noted, item IV.46 has been used consistently as the primary indicator of satisfaction; item II.25 has been used consistently as the secondary indicator of satisfaction.

In Kendall's tau--with a direct, positive relationship as is indicated in this test--high will tend to cluster with high, and low will tend to cluster with low. The coding range was set with \#1 (low) as "very satisfied" and with \#5 (high) as "very dissatisfied." Thus, low (very satisfied) has tended to cluster with low (very satisfied) to reject the null hypothesis at a significance level beyond .001, one-tailed test.

As additional information for the analyses, the following strengths of relationships are acknowledged:

.33 or below is termed a weak relationship

.34 to .66 is termed a moderate relationship

.67 and above is termed a strong relationship

In this test, the strengths of relationships are seen to range from .3346 to .5523 ; thus, the strengths of relationship are uniformly moderate and significant between satisfaction and motivators. (See Table XI.)

Summary (2a.) On all ten of the items tested, there is evidence of a uniformly moderate and significant relationship between satisfaction and motivators (or intrinsic factors), and the null hypothesis is rejected. (See Table XI.).

Analyses for Hygienes -- Relationship to Dissatisfaction

(2b.) To test the research hypothesis that hygienes, as defined 
by Herzberg, or extrinsic factors, as defined by Lortie, will contribute to dissatisfaction more than they will contribute to satisfaction--that there is an inverse, significant relationship between measures of hygienes (Herzberg), or extrinsic factors (Lortie), and measures of satisfaction--bivariate correlational analyses (Kendall's tau) were conducted on each measure of hygienes (II. 7, 8, 13, 14, 15, 16), also defined as extrinsic factors, and each measure of satisfaction (II.25 and IV.46). There is not statistical evidence of an inverse, significant relationship between measures of hygienes (Herzberg), or extrinsic factors (Lortie), and measures of satisfaction. There is statistical evidence of a significant relationship between measures of hygienes and measures of satisfaction, but the relationship is positive and operates opposite to the direction predicted. Thus, the null hypothesis is accepted beyond the .001 level of significance, one-tailed test: (See Table XII.)

(2b.) Table XII indicates a weak, significant relationship between satisfaction and hygienes (Herzberg), also defined as extrinsic factors (Lortie). Bivariate correlational analyses (Kendall's tau) provide evidence of a uniformly weak and significant relationship between satisfaction and hygienes (or extrinsic factors) that is opposite to the direction predicted. The findings are statistically significant on all twelve of the items tested. Thus, the null hypothesis is accepted at a significance level beyond .001, one-tailed test. The following information may help to clarify and support the analyses: (See Table XII.) 


\begin{tabular}{|c|c|c|c|c|c|c|c|}
\hline & \multirow{3}{*}{ SATISFACTION INDICATORS } & \multicolumn{6}{|c|}{ HYGIENES/EXTRINSIC FACTORS } \\
\hline & & Salary & $\begin{array}{l}\text { Interpers. } \\
\text { Supervisor }\end{array}$ & $\begin{array}{l}\text { Supervis. } \\
\text { Competence }\end{array}$ & $\begin{array}{l}\text { Pol./Prac. } \\
\text { District }\end{array}$ & $\begin{array}{l}\text { Pol./Prac. } \\
\text { School }\end{array}$ & $\begin{array}{l}\text { Working } \\
\text { Conditions }\end{array}$ \\
\hline & & II. 7 & II. 8 & II.13 & II.14 & II.15 & II.16 \\
\hline II. 25 & $\begin{array}{l}\text { All in all, how satisfied are you } \\
\text { with your role as a teacher? }\end{array}$ & $\begin{array}{l}. .2238 * \\
\mathrm{~N}(1431) \\
\text { Sig. } .000 * *\end{array}$ & $\begin{array}{l}.2189 \\
\mathrm{~N}(1435) \\
\text { Sig. } .000\end{array}$ & $\begin{array}{l}\mathrm{N}(1428) \\
\text { Sig. } .000\end{array}$ & $\begin{array}{l}. .2434 \\
N(1432) \\
\text { Sig. } .000\end{array}$ & $\begin{array}{l}.2790 \\
N(1427) \\
\text { Sig. } .000\end{array}$ & $\begin{array}{l}.2895 \\
\text { N }(1430) \\
\text { Sig. } .000\end{array}$ \\
\hline IV. 46 & $\begin{array}{l}\text { Which of these statements comes } \\
\text { closest to describing your } \\
\text { feelings about teaching? }\end{array}$ & $\begin{array}{l}.2284 \\
\mathrm{~N}(1414) \\
\text { Sig. } .000\end{array}$ & $\begin{array}{l}.2041 \\
N(1418) \\
\text { Sig. } .000\end{array}$ & $\begin{array}{l}. .1780 \\
N(1411) \\
\text { Sig. } .000\end{array}$ & $\begin{array}{l}. .2273 \\
N(1416) \\
\text { Sig. } .000\end{array}$ & $\begin{array}{l}. .2655 \\
N(1412) \\
\text { Sig. } .000\end{array}$ & $\begin{array}{l}.2855 \\
\text { N }(1414) \\
\text { Sig. .000 }\end{array}$ \\
\hline
\end{tabular}

* The correlational values

** Significant beyond the .001 level 
As previously noted, item IV.46 has been used consistently as the primary indicator of satisfaction; item II.25 has been used consistently as the secondary indicator of satisfaction.

In Kendall's tau-with a direct positive relationship as is indicated in this test--high will tend to cluster with high, and low will tend to cluster with low. In an inverse or negative relationship, as was predicted, high will tend to cluster with low, and low will tend to cluster with high. The coding range was set with $\# 1$ (low) as "very satisfied" and with \#5 (high) as "very dissatisfied." In this test, low (very satisfied) has tended to cluster with low (very satisfied). Inasmuch as the inverse relationship is not reflected in the tendencies, these data provide evidence to accept the null hypothesis beyond the .001 level of significance, one-tailed test.

As additional information for the analyses, and as defined for discussion of $2 a ., .33$ or below is termed to be a weak relationsnip. In this test, the strengths of relationships are seen to range from .1780 to .2895 ; thus, the strengths of relationship are uniformly weak and significant between satisfaction and hygienes. (See Table XII.)

Sumnary (2b.) On all twelve of the items tested, there is evidence of a uniformly weak and significant relationship between satisfaction and hygienes (or extrinsic factors), and the null hypothesis is accepted. (See Table XII.) 
Factors Contributing Most Frequently to Satisfaction and Dissatisfaction of Teachers in the PMA--Conformity with Herzberg's Factors

(2c.) In an effort to identify the factors in the present study $\left(Q_{2}\right)$ that contribute most frequently to teacher satisfaction as well as the factors that contribute most frequently to teacher dissatisfaction, to see how these factors conform with Herzberg's identified list of primary factors operating as motivators or satisfiers and the identified list of primary factors operating as hygienes or potential dissatisfiers (1959, p. 81), a visual inspection of the frequencies of teacher responses, converted to percentages, provides the following data: (See Tables XIII, XIV, XV, XVI, XVII, XVIII, XIX.)

Factors Contributing Most Frequently to Satisfaction. The factors identified by teacher respondents in the present study $\left(Q_{2}\right)$ as those contributing most frequently to degrees of satisfaction, in percentanges, are as follows: (See Table XIII.)

\begin{tabular}{|c|c|c|c|c|}
\hline $\begin{array}{l}\text { Item } \\
Q_{2}\end{array}$ & Factor & $\begin{array}{l}\% \\
Q_{2}\end{array}$ & $\begin{array}{l}\mathrm{N} \\
\mathrm{Q}_{2}\end{array}$ & Response \\
\hline II. 10 & $\begin{array}{l}\text { Interpersonal relations } \\
\text { with students } \\
\text { (subordinates) }\end{array}$ & 92 & (1434) & \multirow[t]{5}{*}{$\begin{array}{l}\text { express degrees of } \\
\text { satisfaction from } \\
\text { somewhat to very }\end{array}$} \\
\hline II.1 & Sense of achievement & 89 & (1432) & \\
\hline II. 3 & $\begin{array}{l}\text { Teaching as a kind } \\
\text { of work (work itself) }\end{array}$ & 86 & $(1430)$ & \\
\hline II.9 & $\begin{array}{l}\text { Interpersonal relations } \\
\text { with fellow teachers } \\
\text { (peers or colleagues) }\end{array}$ & 86 & (1438) & \\
\hline II. 19 & $\begin{array}{l}\text { Opportunities to help } \\
\text { others }\end{array}$ & 82 & (1430) & \\
\hline Table & $\begin{array}{l}\text { II. Factors Contributin } \\
\text { of Teachers in th } \\
\text { Herzberg's Theory }\end{array}$ & $\begin{array}{l}\text { Most } \\
\text { PMA } \\
\text { 959) }\end{array}$ & $\begin{array}{l}\text { Frequen } \\
\text { (1984, }\end{array}$ & $\begin{array}{l}\text { - Job Satisfaction } \\
\text { - Confornity with }\end{array}$ \\
\hline
\end{tabular}


This list of factors identified by teacher respondents in the PMA (1984, $Q_{2}$ ) as those contributing most frequently to degrees of satisfaction does not appear to conform with the list previously identified by Herzberg and others (1959, p. 81) as primary factors operating as motivators or satisfiers. This list includes: (See Tables IX and XIII.)

- two factors identified by Herzberg et al. (1959) as motivators (II.1 and II.3)--achievement and work itself;

- two factors identified by Herzberg et al. (1959) as hygienes (II.9 and II.10)--interpersonal relations with peers and interpersonal relations with subordinates;

- one factor not identified by Herzberg et al. (1959) that is defined in this study as a motivator and related to job content or work itself (which is identified in the Herzberg research)--the opportunities to help others. (See Appendix C.)

Factors Contributing Most Frequently to Dissatisfaction. The factors identified by teacher respondents in the present study $\left(Q_{2}\right)$ as those contributing most frequently to degrees of dissatisfaction, in percentages, are as follows: (See Table XIV.)

This list of factors identified by teacher respondents in the PMA (1984, $Q_{2}$ ) as those contributing most frequently to degrees of dissatisfaction does not conform with the 1 ist previously identified by Herzberg and others (1959, p. 81) as primary factors operating as hygienes or dissatisfiers; however, each of the identified factors is included in the list of hygienes or extrinsic factors. (See Appendix C.) This list includes: (See Tables X and XIV.)

- three factors identified by Herzberg's researchers (1959) as hygienes (II.7, II.12, II.14); II.7--salary, and II.14--policies and practices of the company or organization (school district) are identified as primary factors; 
- two factors identified as hygienes in the present study (also identified by Moxley, 1977) as significant in a study of teachers (II.20, II.22)--time spent preparing for teaching and time spent on school-related activities outside of teaching or preparation for teaching. (See Table XIV.)

\begin{tabular}{|c|c|c|c|c|}
\hline $\begin{array}{l}\text { Item } \\
\mathrm{Q}_{2}\end{array}$ & Factor & $\begin{array}{l}\% \\
Q_{2}\end{array}$ & \multicolumn{2}{|r|}{ Response } \\
\hline II. 7 & Salary & 44 & (1435) & $\begin{array}{l}\text { express degrees of } \\
\text { dissatisfaction } \\
\text { from somewhat to } \\
\text { very }\end{array}$ \\
\hline II. 20 & $\begin{array}{l}\text { Time spent preparing } \\
\text { for teaching }\end{array}$ & 35 & $(1430)$ & \\
\hline II. 12 & Status & 33 & $(1439)$ & \\
\hline II. 22 & $\begin{array}{l}\text { Time spent on school- } \\
\text { related activities } \\
\text { outside of teaching } \\
\text { and preparation for } \\
\text { teaching }\end{array}$ & 30 & $(1429)$ & \\
\hline II. 14 & $\begin{array}{l}\text { Policies and practices } \\
\text { of the school district }\end{array}$ & 29 & $(1435)$ & \\
\hline Table & $\begin{array}{l}\text { Factors Contributin } \\
\text { Dissatisfaction of } \\
\text { Conformity with Her }\end{array}$ & $\begin{array}{l}\text { lost } \\
\text { cher } \\
\text { rg's }\end{array}$ & $\begin{array}{l}\text { equently } \\
\text { in the } \mathrm{F} \\
\text { heory }\end{array}$ & $\begin{array}{l}\text { Job } \\
\left(1984, Q_{2}\right)-\end{array}$ \\
\hline
\end{tabular}

The Factor Contributing Most Frequently to Satisfaction of Teachers in the PMA - Conformity with Lortie's Theory

(2d.) In an effort to identify the factor in the present study $\left(Q_{2}\right)$ that contributes most frequently to teacher satisfaction, to see if the identified factor conforms with Lortie's identification of goals and achievements related to interrelations with students, or "reaching students," as the primary source of "psychic" or intrinsic reward (satisfaction) for teachers (1975, pp. 101, 104, 106, 109), a 
visual inspection of the highest frequency of teacher responses on factors and expressions of satisfaction, converted to percentages, provides the following data: (See Table XV.)

\begin{tabular}{|cllll|}
\hline $\begin{array}{c}\text { Item } \\
\mathrm{Q}_{2}\end{array}$ & Factor & $\begin{array}{l}\% \\
\mathrm{Q}_{2}\end{array}$ & $\begin{array}{l}\mathrm{N} \\
\mathrm{Q}_{2}\end{array}$ & Response \\
\hline II.10 & $\begin{array}{l}\text { Interpersonal relations } \\
\text { with your students }\end{array}$ & 92 & $(1434)$ & $\begin{array}{l}\text { Express degrees of } \\
\text { satisfaction from } \\
\text { somewhat to very }\end{array}$ \\
\hline Table XV. & $\begin{array}{l}\text { The Factor Contributing Most Frequently to Job Satisfaction } \\
\text { of Teachers in the PMA (1984, } \\
\text { Lortie's Theory (1975) }\end{array}$ & \\
\hline
\end{tabular}

This finding conforns with Lortie's theory on the primary sources of satisfaction or reward for schoolteachers. This finding is further supported by the following data on frequencies of responses, converted to percentages, on other items in the 1984 survey instrument $\left(Q_{2}\right)$. (See Tables XVI, XVII.)

In the section of the 1984 survey instrument $\left(Q_{2}\right.$, III.1-25) which asks the respondents to rank factors on the basis of their importance, the highest single frequency and resulting percentage conform with Lortie's view that work with students is very important and provides very important enjoyment (satisfaction) for teachers: (See Table XVII.)

In comparing frequencies of responses from the 1981 study $\left(Q_{1}\right.$, Falkenstein, 1982; Hathaway, 1982) with frequencies of responses from the present study $\left(Q_{2}\right)$, on compatible items, and conversion to 


\begin{tabular}{|c|c|c|c|c|}
\hline $\begin{array}{l}\text { Item } \\
\mathrm{Q}_{2}\end{array}$ & Factor & $\begin{array}{l}q_{0} \\
Q_{2}\end{array}$ & $\begin{array}{l}\mathrm{N} \\
\mathrm{Q}_{2}\end{array}$ & Response \\
\hline IV.8 & Pleasure from teaching & 96 & $(1423)$ & $\begin{array}{l}\text { express degrees of } \\
\text { pleasure }\end{array}$ \\
\hline IV. 10 & $\begin{array}{l}\text { Like working with } \\
\text { students }\end{array}$ & 95 & (1437) & $\begin{array}{l}\text { express degrees of } \\
\text { liking from a great } \\
\text { deal to } \mathrm{KK}\end{array}$ \\
\hline IV.16 & $\begin{array}{l}\text { Successful in meeting the } \\
\text { intellectual needs of } \\
\text { students as individuals }\end{array}$ & 98 & $(1420)$ & $\begin{array}{l}\text { express degrees of } \\
\text { success with from } \\
\text { more than half to } \\
\text { about half }\end{array}$ \\
\hline IV. 26 & $\begin{array}{l}\text { Students describe you } \\
\text { as a teacher }\end{array}$ & 91 & (1411) & $\begin{array}{l}\text { express degrees of } \\
\text { from above average } \\
\text { to outstanding }\end{array}$ \\
\hline IV. 27 & $\begin{array}{l}\text { Feelings of success as } \\
\text { a teacher }\end{array}$ & 86 & (1422) & $\begin{array}{l}\text { express degrees of } \\
\text { feeling successful } \\
\text { the additional } 14 \% \\
\text { express mixed fee1 } \\
\text { ings }\end{array}$ \\
\hline IV. 31 & $\begin{array}{l}\text { Personal growth from } \\
\text { being a teacher }\end{array}$ & 96 & (1426) & $\begin{array}{l}\text { express degrees of } \\
\text { growth from more } \\
\text { than average to } \\
\text { average }\end{array}$ \\
\hline IV. 32 & Achievenent as a teacher & 83 & (1411) & $\begin{array}{l}\text { express achievement } \\
\text { above expectations; } \\
\text { with an added } 15 \% \\
\text { expressing moderate } \\
\text { or expected } \\
\text { achievements }\end{array}$ \\
\hline IV. 45 & $\begin{array}{l}\text { The factor that would } \\
\text { influence you to change } \\
\text { as a teacher }\end{array}$ & 83 & $(1413)$ & $\begin{array}{l}\text { express that the } \\
\text { "knowledge that it } \\
\text { would be 'good for } \\
\text { kids'" would serve } \\
\text { as the primary } \\
\text { change factor }\end{array}$ \\
\hline IV.47 & $\begin{array}{l}\text { The most important } \\
\text { source of satisfaction } \\
\text { for you in teaching }\end{array}$ & 78 & $(1421)$ & $\begin{array}{l}\text { express "the times } \\
\text { I know I have } \\
\text { 'reached' a student } \\
\text { or group of stu- } \\
\text { dents as each } \\
\text { learns" with an } \\
\text { added 15: selecting } \\
\text { "the chance to } \\
\text { associate with } \\
\text { children or young } \\
\text { people and relate } \\
\text { with them" }\end{array}$ \\
\hline & $\begin{array}{l}\text { Sources of Satisf } \\
\left.Q_{2}\right) \text {--Conformity } w\end{array}$ & $n f$ & The & , \\
\hline
\end{tabular}




\begin{tabular}{|clcll|}
\hline $\begin{array}{l}\text { Item } \\
\text { Q2 }\end{array}$ & Factor & $\begin{array}{l}\mathrm{Q}_{2} \\
\mathrm{Q}_{2}\end{array}$ & $\begin{array}{l}\mathrm{N} \\
\text { Response }\end{array}$ \\
\hline III.1 & $\begin{array}{l}\text { Enjoyment in working } \\
\text { with students }\end{array}$ & 88 & $(1433)$ & $\begin{array}{l}\text { Very important } \\
\text { (Highest rank) }\end{array}$ \\
\hline Table XVII. & $\begin{array}{l}\text { A Very Important Source of Satisfaction for Teachers in } \\
\text { the PMA (1984, Q2) } \\
\text { (1975) }\end{array}$ & \\
\hline
\end{tabular}

Compared Data -- Compatible Items from 1981 Study $\mathrm{Q}_{1}$ and 1984 Study (Q2)

percentages, the following data serve to conform with Lortie's theory and to identify primary sources of satisfaction and their importance to teachers in the PMA: (See Tables XVIII, XIX.)

In the sections of the 1981 survey instrument ( $Q_{1}$, Items 68-88) and in the 1984 survey instrument $\left(Q_{2}\right.$, III.1-25) which ask the respondents to rank factors on the basis of their importance, the highest single frequency and resulting percentage from both studies conform with Lortie's view that work with students is very important and provides very important enjoyment (satisfaction) for teachers: (See Tables XVIII, XIX.)

\begin{tabular}{|llllllll|}
\hline $\begin{array}{c}\text { Item Item } \\
\mathrm{Q}_{1}\end{array} \mathrm{Q}_{2}$ & Factor & $\mathrm{Q}_{1}$ & $\begin{array}{c}\mathrm{N} \\
\mathrm{Q}_{1}\end{array}$ & $\begin{array}{l}\mathrm{Q}_{2} \\
\mathrm{Q}_{2}\end{array}$ & $\begin{array}{l}\mathrm{N} \\
\mathrm{Q}_{2}\end{array}$ & Response \\
\hline 68 & III.I & $\begin{array}{l}\text { Enjoyment in working } \\
\text { with students }\end{array}$ & 85.6 & $(1534)$ & 88 & (1433) & $\begin{array}{l}\text { Very important } \\
\text { (Highest rank) }\end{array}$ \\
\hline Table XVIII. & $\begin{array}{l}\text { A Very Important Source of Satisfaction for Teachers in } \\
\text { the PMA--Compared Data (1981 and 1984)---Conformity with } \\
\text { Lortie's Theory }\end{array}$ \\
\hline
\end{tabular}




\begin{tabular}{|c|c|c|c|c|c|c|c|}
\hline $\begin{array}{c}\text { Item } \\
Q_{1} \\
(1981)\end{array}$ & $\begin{array}{c}\text { Item } \\
Q_{2} \\
(1984)\end{array}$ & Factor & $\xi Q_{1}$ & $\left(\mathrm{NQ}_{1}\right)$ & $8_{2}$ & $\left(\mathrm{NQ}_{2}\right)$ & Response \\
\hline $\begin{array}{l}36 \\
58\end{array}$ & IV. 10 & $\begin{array}{l}\text { Like working with students } \\
\text { (matching item) }\end{array}$ & $\begin{array}{l}94.5 \\
98.5\end{array}$ & $\begin{array}{l}(1522) \\
(1519)\end{array}$ & 95 & (1437) & $\begin{array}{l}\text { Express degress of } \\
\text { liking from a great } \\
\text { deal to } 0 . \mathrm{K} \text {. }\end{array}$ \\
\hline & IV. 16 & $\begin{array}{l}\text { How successful as a teacher - } \\
\text { individual needs of students }\end{array}$ & & & 98 & $(1420)$ & $\begin{array}{l}\text { Feel successful in } \\
\text { degrees from all to } \\
\text { about half }\end{array}$ \\
\hline 57 & IV. 27 & $\begin{array}{l}\text { Al1 in all, how successful } \\
\text { as a teacher }\end{array}$ & 97 & $(1520)$ & 86 & $(1422)$ & $\begin{array}{l}\text { Feel success ful from } \\
\text { very to quite to } \\
\text { average }(+148 \text { mixed) }\end{array}$ \\
\hline 53 & IV. 31 & $\begin{array}{l}\text { Personal growth from being } \\
\text { a teacher }\end{array}$ & 96.1 & $(1522)$ & 96 & $(1426)$ & $\begin{array}{l}\text { More than average } \\
\text { growth to average }\end{array}$ \\
\hline 97 & IV. 45 & $\begin{array}{l}\text { The factor that would } \\
\text { influence you to change as } \\
\text { a teacher }\end{array}$ & 75.4 & (1454) & 83 & $(1413)$ & $\begin{array}{l}\text { The knowledge that it } \\
\text { would be good for } \\
\text { "kids" }\end{array}$ \\
\hline 89 & IV. 47 & $\begin{array}{l}\text { The most important source } \\
\text { of satisfaction for you } \\
\text { in teaching }\end{array}$ & 70.4 & (1538) & 78 & $(1421)$ & $\begin{array}{l}\text { The times I know I } \\
\text { have "reached" a } \\
\text { student or group of } \\
\text { students; with an } \\
\text { added } 15.9 \%\left(Q_{1}\right) \text { and } \\
15 \%\left(Q_{2}\right) \text { selecting } \\
\text { the chance to associate } \\
\text { with children or young } \\
\text { people and relate with } \\
\text { them }\end{array}$ \\
\hline
\end{tabular}

Table XIX. Sources of Satisfaction for Teachers in the PMA--Compared bata (1981 and 1984)--Conformity with Lortie's Theory ( $\eta_{1}$ and $Q_{2}-$-Compatible Items) 


\section{Summary - Research Question \#2}

As a summary of findings for Research Question \#2 and the related predictions, hypotheses, and tests conducted and subjected to statistical analyses, as well as the visual inspections and reported findings, the present study includes the following:

2a. There is evidence of a uniformly moderate and significant relationship between motivators or intrinsic factors and satisfaction. The null hypothesis is rejected beyond the .001 level of significance, one-tailed test. (See Table XI.)

2b. There is evidence of a uniformly weak and significant relationship between hygienes or extrinsic factors and satisfaction. The null hypothesis is accepted beyond the .001 level of significance, one-tailed test. (See Table XII.)

2c. Visual inspection of the frequencies of responses of teachers in the PIMA indicates a ranking of factors contributing most frequently to satisfaction and dissatisfaction; the list of identified factors does not conform with the list of ranked factors previously identified by Herzberg and others (1959, p. 81) as those which serve as primary factors operating as motivators or satisfiers and the primary factors operating as hygienes or dissatisfiers. (See Tables XIII, XIV.)

2d. Visual inspection of the frequencies of responses of teachers in the PMA indicates the factor which contributes most frequently to satisfaction, and this finding does 
conform with Lortie's theory on the sources of "psychic" or intrinsic reward (satisfaction) for schoolteachers (1975, pp. 101, 104, 106, 109, 119-124, 187-200). (See Tables XV, $X V I, X V I I, X V I I I, X I X$.

The Third Research Question and Findings

Question \#3 HOW DOES JOB SATISFACTION AND DISSATISFACTION VARY AS A FUNCTION OF THE FOLLOWING TEACHER "DEMDGRAPHIC" FACTORS :

(3a.) Age

(3b.) Sex

(3c.) Grade level

(3d.) Years in service

(3e.) Education (highest degree earned)

To test the general research prediction that job satisfaction and dissatisfaction will vary significantly as a function of each of the factors of age, sex, grade level, years in service, and education (highest degree earned), five separate sets of tests (Kendall's tau) were conducted on the bases of separate research predictions for each item (3a., 3b., 3c., 3d., 3e.), and subjected to separate analyses of findings, as follows:

Age

(3a.) To test the research hypothesis that there is a significant relationship between age and measures of satisfaction, bivariate correlational analyses (Kendall's tau) were conducted on the 
measure of age (I.2) and on each measure of satisfaction (II.24, II. 25, IV.1, IV.3, IV.8, IV.46). Item IV. 46 has been used as the primary indicator of satisfaction; item II. 25 has been used as the secondary indicator, level of confidence - .05, two-tailed. The findings that follow indicate that there is a significant relationship between age and satisfaction, and the relationship is weak and inverse. 0lder teachers indicate more satisfaction than younger teachers. The null hypothesis is rejected at the .05 level of significance, two-tailed test, as follows: (See Table XX.)

\begin{tabular}{|c|c|c|}
\hline \multicolumn{2}{|c|}{ Variable pair - Satisfaction/Age } & $t$ \\
\hline II. 24 & $\begin{array}{l}\text { All in all, how satisfied are } \\
\text { you with your present job or } \\
\text { assignment in teaching? }\end{array}$ & $\begin{array}{l}-.0381 \\
N(1428) \\
\text { Sig. } .040\end{array}$ \\
\hline *II. 25 & $\begin{array}{l}\text { All in all, how satisfied are } \\
\text { you with your role as a } \\
\text { teacher? }\end{array}$ & $\begin{array}{l}-.0495 \\
N(1429) \\
\text { Sig. } .012\end{array}$ \\
\hline IV.I & $\begin{array}{l}\text { If you had your choice of jobs } \\
\text { in any field, which would you } \\
\text { select? }\end{array}$ & $\begin{array}{l}-.0121 \\
\mathrm{~N}(1401) \\
\text { Sig. } .295\end{array}$ \\
\hline IV. 2 & $\begin{array}{l}\text { If you had your choice of jobs } \\
\text { in the field of public ed., } \\
\text { which would you select? }\end{array}$ & $\begin{array}{l}-.0331 \\
\mathrm{~N}(1408) \\
\text { Sig. } .069\end{array}$ \\
\hline IV. 3 & $\begin{array}{l}\text { If you had it to do all over } \\
\text { again, would you still become } \\
\text { a teacher? }\end{array}$ & $\begin{array}{l}.0131 \\
N(1419) \\
\text { Sig. } .269\end{array}$ \\
\hline IV. 8 & $\begin{array}{l}\text { How much pleasure do you get } \\
\text { from teaching? }\end{array}$ & $\begin{array}{l}-.0232 \\
\mathrm{~N}(1414) \\
\text { Sig. } .155\end{array}$ \\
\hline *IV. 46 & $\begin{array}{l}\text { Which of these statements comes } \\
\text { closest to describing your } \\
\text { feelings about teaching? }\end{array}$ & $\begin{array}{l}-.0486 \\
N(1414) \\
\text { Sig. .012 }\end{array}$ \\
\hline
\end{tabular}


Table $\mathrm{XX}$ shows that in tests using IV.46 as the primary indicator of job satisfaction and II.25 as the secondary indicator of satisfaction, bivariate correlational analyses (Kendall's tau) provide evidence that there is a weak, inverse and significant relationship between age and satisfaction. The older teacher tends to be more satisfied than the younger teacher.

In support of these analyses, the test indicates an inverse relationship between age and satisfction. High (the older teacher) has tended to cluster with low (satisfied, very satisfied); low (the younger teacher) has tended to cluster with high (less satisfied, dissatisfied). The strengths of relationship range from -.0121 to -.0486; therefore, the strength of relationship betwen age and satisfaction is weak. The findings are statistically significant on the primary and secondary indicators tested (IV.46 and II.25); therefore, the null hypothesis is rejected at the .05 level of significance, two-tailed test. (See Table XX.)

$\underline{\text { Sex }}$

(3b.) To test the research hypothesis that there is a significant relationship between sex and measures of satisfaction and that women will express greater satisfaction with teaching than men will, bivariate correlational analyses (Kendall's tau) were conducted on the measure of sex (I.I) and on each measure of satisfaction (II.24, II.25, IV.1, IV.2, IV.3, IV. 8, IV.45). Item IV.46 has been used as the primary indicator of satisfaction; item II.25 has been used as the secondary indicator, level of confidence - .05, 
one-tailed. The findings that follow indicate a significant relationship between sex and satisfaction, and the relationship is weak. Women indicate more satisfaction with teaching than men do. The null hypothesis is rejected at the .05 level of significance, one-tailed test, as follows: (See Table XXI.)

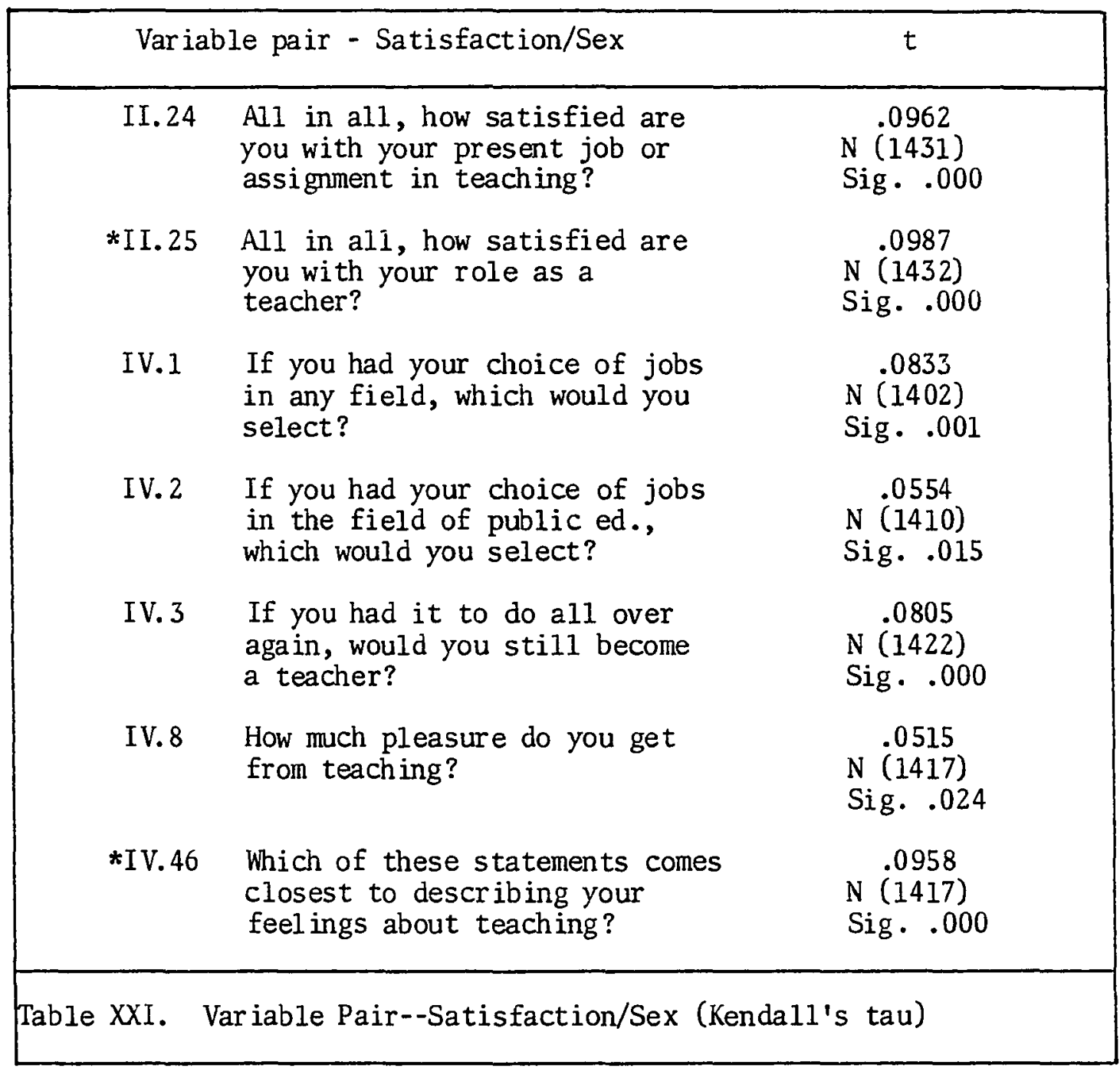

Table XXI shows that in tests using IV.46 as the primary indicator of job satisfaction and II. 25 as the secondary indicator of satisfaction, bivariate correlational analyses (Kendall's tau) provide evidence that there is a weak and significant relationship between sex 
and satisfaction. Women tend to be more satisfied with teaching than men are. (See Table XX.)

In support of these analyses, the test indicates a direct or positive relationship between sex and satisfaction. Low (women) has tended to cluster with low (satisfied, very satisfied); and high (men) has tended to cluster with high (less satisfied, dissatisfied). The strengths of relationship range fom .0515 to .0987 ; therefore, the strength of relationship between sex and satisfaction is weak. The findings are unifomnly significant on all items tested; therefore, the null hypothesis is rejected at the .05 level of significance, one-tailed test. (See Table XXI.)

Grade Leve1

(3c.) To test the research hypothesis that there is a significant relationship between grade level of assignment and measures of satisfaction and that teachers of primary and lower grades will express greater satisfaction than teachers of higher and upper grade, bivariate correlational analyses (Kendall's tau) were conducted on the measure of grade level (I.13) and on each measure of satisfaction (II.24, II.25, IV.2, IV.3, IV.8, IV.46). Item IV.46 has been used as the primary indicator of satisfaction; item II.25 has been used as the secondary indicator, level of confidence - .05, one-tailed. The findings that follow indicate that there is a significant relationship between grade levels and satisfaction. Teachers of lower grades indicate more satisfaction than teacher of nigher grades. The null hypothesis is rejected at the .05 level of significance, one-tailed test, as follows: (See Table XXII.) 


\begin{tabular}{|c|c|c|}
\hline \multicolumn{2}{|c|}{ Variable pair - Satisfaction/Grade Level } & $t$ \\
\hline II .24 & $\begin{array}{l}\text { All in all, how satisfied are } \\
\text { you with your present job or } \\
\text { assignment in teaching? }\end{array}$ & $\begin{array}{l}.1237 \\
\mathrm{~N}(1344) \\
\text { Sig. .000 }\end{array}$ \\
\hline *II .25 & $\begin{array}{l}\text { All in all, how satisfied are } \\
\text { you with your role as a } \\
\text { teacher? }\end{array}$ & $\begin{array}{l}: 1393 \\
N(1344) \\
\text { Sig. .000 }\end{array}$ \\
\hline IV.1 & $\begin{array}{l}\text { If you had your choice of jobs } \\
\text { in any field, which would you } \\
\text { select? }\end{array}$ & $\begin{array}{l}\mathrm{i}(0841 \\
\mathrm{N}(1315) \\
\text { Sig. . .000 }\end{array}$ \\
\hline IV.2 & $\begin{array}{l}\text { If you had your choice of jobs } \\
\text { in the field of public ed., } \\
\text { which would you select? }\end{array}$ & $\begin{array}{l}.0422 \\
N(1322) \\
\text { Sig. .038 }\end{array}$ \\
\hline IV.3 & $\begin{array}{l}\text { If you had it to do all over } \\
\text { again, would you still become } \\
\text { a teacher? }\end{array}$ & $\begin{array}{l}.0834 \\
\mathrm{~N}(1334) \\
\text { Sig. } .000\end{array}$ \\
\hline IV. 8 & $\begin{array}{l}\text { How much pleasure do you get } \\
\text { from teaching? }\end{array}$ & $\begin{array}{l}\text { Ni(1148 } \\
\text { Sig. .000 }\end{array}$ \\
\hline *IV.46 & $\begin{array}{l}\text { Which of these statements comes } \\
\text { closest to describing your } \\
\text { feelings about teaching? }\end{array}$ & $\begin{array}{l}\mathrm{i}(1338 \\
\mathrm{N}(1331) \\
\text { Sig. .000 }\end{array}$ \\
\hline
\end{tabular}

Table XXII shows that in tests using IV.46 as the primary indicator of job satisfaction and II.25 as the secondary indicator of satifaction, bivariate correlational analyses (Kendall's tau) provide evidence that there is a weak and significant relationship between grade level and satisfaction. Teachers of primary or lower grades tend to be more satisfied than teachers of higher or upper grades. (See Table XXII.) 
In support of these analyses, the test indicates a direct or positive relationship between grade level of assignment and satisfaction. Low (primary or lower grades) has tended to cluster with low (satisfied, very satisfied); high (upper grades) has tended to cluster with high (less satisfied, dissatisfied). The strengths of relationship range from .0422 to .1393; therefore, the strength of relationship between grade level of assignment and satisfaction is weak. The findings are uniformly significant on all items tested; therefore, the null hypothesis is rejected at the .05 level of significance, one-tailed test. (See Table XXII.)

Years in Service

(3d.) To test the research hypothesis that there is a significant relationship between years in service (total years in teaching) and measures of satisfaction, bivariate correlational analyses (Kendall's tau) were conducted on the measure of years in service (I.6) and each measure of satisfaction (II.24, II.25, IV.1, IV.2, IV.3, IV. 8, IV.46). Item IV.46 has been used as the primary indicator of satisfaction; item II.25 has been used as the secondary indicator, level of confidence - .05, two-tailed. The findings that follow indicate that there is a nonsignificant, inverse relationship between years in service and satisfaction. Teachers with greater numbers of years in service do not indicate a significant level of greater satisfaction than teachers with lesser numbers of years in service. The null hypothesis is accepted at the .05 level of significance, two-tailed test, as follows: (See Table XXIII.) 


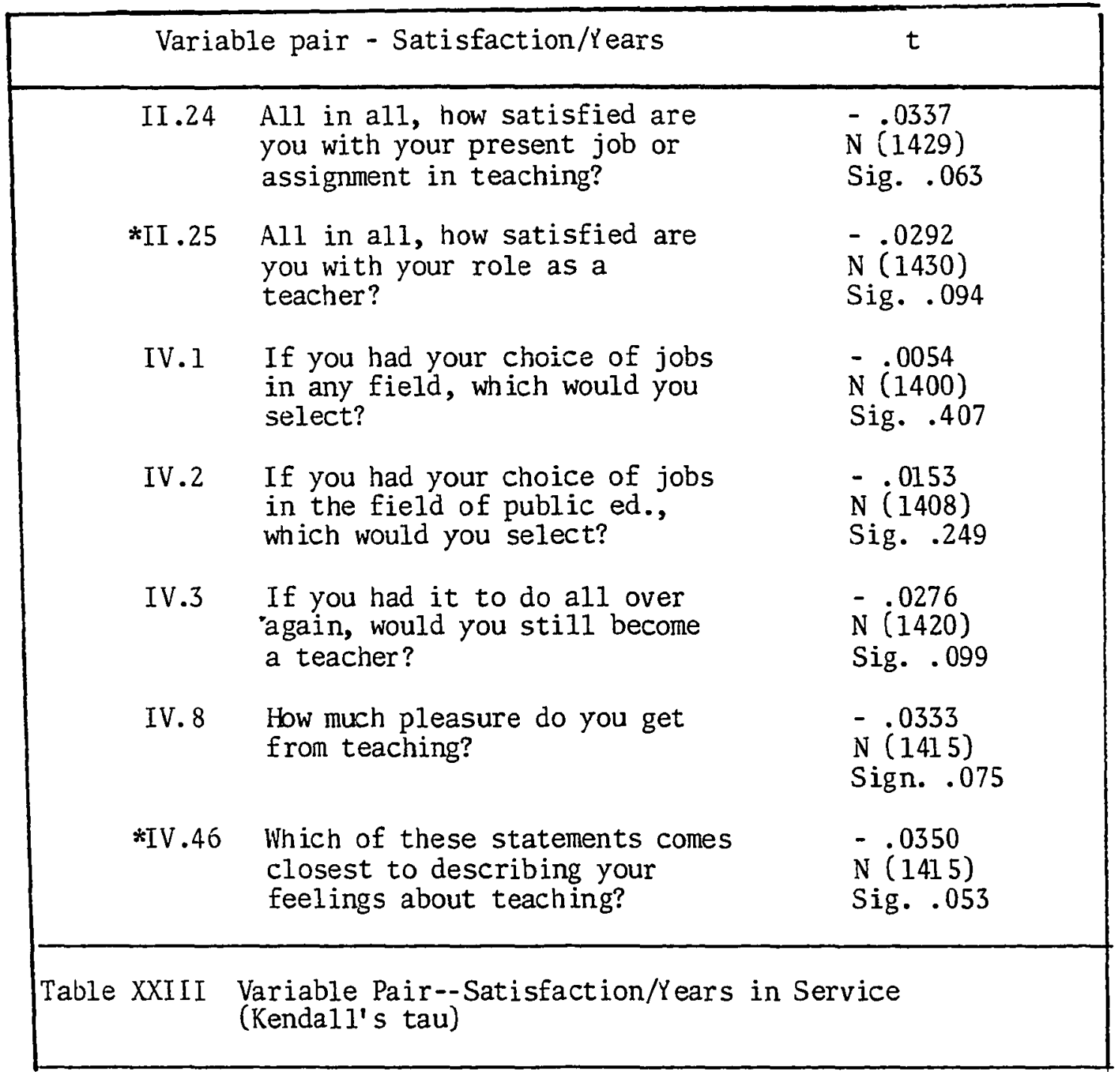

Table XXIII shows that in tests using IV.46 as the primary indicator of job satisfaction and II.25 as the secondary indicator of satifaction, bivariate correlational analyses (Kendall's tau) provide evidence that there is a weak and nonsignificant relationship between years of service and satisfaction. Although there appears to be a tendency for teachers with greater numbers of years in service to indicate more job satisfaction than teachers with fewer years in 
service, the apparent tendency is nonsignificant. (See Table XXIII.)

In support of these analyses, the test indicates an inverse relationship between years in service and satisfaction. High (greater numbers of years in service) has tended to cluster with low (satisfied, very satisfied); 1ow (lesser numbers of years in service) has tended to cluster with high (less satisfied, dissatisfied). The strengths of relationship range from .0054 to .0350 ; therefore, the strength of relationship between years of service and satisfaction is weak. The findings are uniformly nonsignificant on all items tested; therefore, the null hypothesis is accepted at the .05 level of significance. (See Table XXIII.)

Education (Highest Degree Earned)

(3e.) To test the research hypothesis that there is a significant relationship between highest degree earned and measures of satisfaction, bivariate correlational analyses (Kendall's tau) were conducted on the measure of highest earned academic degree (I.4) and each measure of satisfaction (II.24, II.25, IV.1, IV.2, IV.3, IV.8, IV.46). Item IV.46 has been used as the primary indicator of satisfaction; item II.25 has been used as the secondary indicator, level of confidence - .05, two-tailed. The findings that follow indicate a nonsignificant relationship between the highest degree earned and satisfaction. The null hypothesis is accepted at the .05 level of significance, two-tailed test, as follows: (See Table XXIV.) 


\begin{tabular}{|c|c|c|}
\hline \multicolumn{2}{|c|}{$\begin{array}{c}\text { Variable pair - Satisfaction/Educational } \\
\text { Degree }\end{array}$} & $t$ \\
\hline II . 24 & $\begin{array}{l}\text { All in all, how satisfied are } \\
\text { you with your present job or } \\
\text { assignment in teaching? }\end{array}$ & $\begin{array}{l}\quad .0226 \\
\mathrm{~N}(1428) \\
\text { Sig. } .182\end{array}$ \\
\hline *I I .25 & $\begin{array}{l}\text { All in all, how satisfied are } \\
\text { you with your role as a } \\
\text { teacher? }\end{array}$ & $\begin{array}{l}-.0149 \\
\mathrm{~N}(1429) \\
\text { Sig. } .277\end{array}$ \\
\hline IV. $I$ & $\begin{array}{l}\text { If you had your choice of jobs } \\
\text { in any field, which would you } \\
\text { select? }\end{array}$ & $\begin{array}{l}.0329 \\
N(1399) \\
\text { Sig. } .100\end{array}$ \\
\hline IV.2 & $\begin{array}{l}\text { If you had your choice of jobs } \\
\text { in the field of public ed., } \\
\text { which would you select? }\end{array}$ & $\begin{array}{l}.0819 \\
N(1407) \\
\text { Sig. } .001\end{array}$ \\
\hline IV. 3 & $\begin{array}{l}\text { If you had it to do all over } \\
\text { again, would you still become } \\
\text { a teacher? }\end{array}$ & $\begin{array}{l}\quad .0113 \\
\mathrm{~N}(1419) \\
\text { Sig. } .320\end{array}$ \\
\hline IV. 8 & $\begin{array}{l}\text { How much pleasure do you get } \\
\text { from teaching? }\end{array}$ & $\begin{array}{l}-.0187 \\
\mathrm{~N}(1414) \\
\text { Sign. } .237\end{array}$ \\
\hline *IV.46 & $\begin{array}{l}\text { Which of these statements comes } \\
\text { closest to describing your } \\
\text { feelings about teaching? }\end{array}$ & $\begin{array}{l}-.0140 \\
\mathrm{~N}(1414) \\
\text { Sig. } .284\end{array}$ \\
\hline Table XXIV & $\begin{array}{l}\text { iable Pair--Satisfaction/Highest } \\
\text { ndall's tau) }\end{array}$ & Earned \\
\hline
\end{tabular}

Table XXIV shows that in tests using IV.46 as the primary indicator of job satisfaction and II.25 as the secondary indicator of satifaction, bivariate correlational analyses (Kendall's tau) provide evidence that there is a weak and nonsignificant inverse relationship between highest degree earned and satisfaction. Although there appears to be a tendency reflected in these items for teachers with 
higher degrees to indicate more job satisfaction than teachers with lower degrees, the apparent tendency is nonsignificant and the inverse relationship is not maintained in four of the seven items tested. (See Table XXIV.)

In support of these analyses, the test does not indicate a significant relationship between highest academic degree earned and satisfaction. The items tested as the primary and secondary indicators of satisfaction provide evidence that there is a weak and nonsignificant inverse relationship between highest degree earned and satisfaction. On these two test items (IV.46 and II.25), high (master's degree or above) has tended to cluster with low (satisfied, very satisfied); low (bachelor's degree) has tended to cluster with high (less satisfied, dissatisfied); however, four of the seven items tested indicate a direct or positive relationship in which high has tended to cluster with high and low has tended with low. The strengths of relationship are unifomly weak and range from .0113 to .0819 on the direct or positive findings, and from -.0140 to -.0149 on the inverse or negative findings. The findings are nonsignificant on the primary and secondary indicators tested (IV.46 and II.25); therefore, the null hypothesis is accepted at the .05 level of significance. (See Table XXIV.)

Sumnary - Research question \#3

As a summary of findings for Research Question \#3 and the related predictions, hypothesis, and tests conducted and subjected to statistical analyses, the present study includes the following: 
3a. There is evidence of a weak and significant relationship between age and job satisfaction. Older teachers indicate more satisfaction than younger teachers. The null hypothesis is rejected at the .05 level of significance, two-tailed test. (See Table XX.)

3b. There is evidence of a weak and significant relationship between sex and job satisfaction. Women indicate more satisfaction with teaching than men do. The null hypothesis is rejected at the .05 level of significance, one-tailed test. (See Table XXI.)

3c. There is evidence of a weak and significant relationship between grade level of assignment and job satisfaction. Teachers of lower grades indicate more satisfaction than teachers of higher grades. The null hypothesis is rejected at the .05 level of significance, one-tailed test. (See Table XXII.)

3d. There is evidence of a weak and nonsignificant, inverse relationship between years in service (total years in teaching) and job satisfaction. Teachers with greater numbers of years in teaching do not indicate a significant level of greater satisfaction than teachers with lesser numbers of years in service. The null hypothesis is accepted at the .05 level of significance, two-tailed test. (See Table XXIII.)

3e. There is evidence of a weak and inverse, nonsignificant relationship between highest earned academic degree and job 
satisfaction. Teachers with higher academic degrees (beyond bachelor's) do not indicate a significant level of greater satisfaction than teachers with lower academic degrees (bachelor's). The null hypothesis is accepted at the .05 level of significance, two-tailed test. See Table XXIV.)

A discussion of findings, conclusions, and recommendations for further study will follow in the final chapter. 
CHAPTER VI

SUMMARY, DISCUSSION, CONCLUSIONS, AND RECOMENDATIONS

This final chapter will include the following:

- summary of the purpose, design, population and procedures for the study;

- discussion of the findings related to the research hypotheses and other findings;

- conclusions that may be drawn from the findings;

- recommendations that may be made based on the findings.

It is appropriate to acknowledge the seven school districts that supported the value of the data collection and cooperated in the distribution of materials related to the study, and it is also appropriate to acknowledge the 1,444 public school teachers that took time during the spring term of 1984 to respond to the survey instrument and thus made the study possible. It is in the fullest recognition of this acknowledgement that the data have been subjected to analyses in the hope that the information may be of some benefit to the public, public educators, and personnel services in public school districts.

\section{Summary}

This study addresses job satisfaction of Pre-K/K-12 public school teachers actively involved during the spring of 1984 in classroom instruction in seven school districts identified as the Portland Metropolitan Area. The study is designed, in part, as a follow-up to 
a similar study conducted in 1981. It is also designed, in part, to see how the data from current research will conform with theories associated with research from Herzberg et al. (1959) and Lortie (1975).

The purpose of the present study is to collect and analyze information on job satisfaction of teachers in the Portland Metropolitan Area as data applied to three basic research questions:

1. How satisfied are teachers in the PMA with their jobs?

2. What are the primary differing factors affecting teacher satisfaction and dissatisfaction, and do these factors and their relationship to satisfaction and dissatisfaction conform with Herzberg and Lortie theories?

3. How does satisfaction and dissatisfaction vary as a function of the following teacher "demographic" factors:

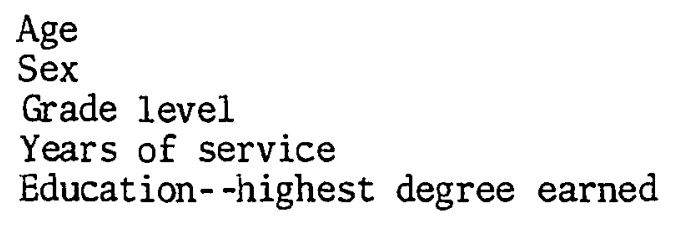

Population Studied

The population studied is identified as the Portland Metropolitan Area. The PMA was identified in the 1981 study completed by Falkenstein (1982) and Hathaway (1982). The present study includes seven cooperating districts from Oregon and Washington.

Selection of respondents for sample was based on the criteria that they were regularly elected teachers in the identified public school districts and were actively involved in classroom instruction of students during the spring of 1984. Full-and part-time teachers participated in the study; probationary and permanently elected teachers participated in the study; substitute and temporary teachers did not participate in the study. The sample was formed by random 
selection of one-third of the teacher population of the participating districts, with grade levels ranging from Pre-K/K through grade twelve, and included teachers of self-contained classrooms, teachers of particular subject areas, teachers of special student populations-including handicapped, ESL-bilingual, Talented and Gifted, Chapter I, or Alternative programs--as well as teachers of students with diverse and broad-ranging ability or achievment levels.

The survey instrument was distributed to 2,133 teachers; the data analyses are based on 1,444 valid cases or a response ratio of .67698 or nearly $68 \%$.

\section{Procedures}

The data were collected by survey instrument. The survey instrument for this study has been designed and developed as a modification of a questionnaire used in 1981 by Falkenstein and Hathaway $\left(Q_{1}\right)$. The modifications include addition of items to address research by Herzberg et al. (1959) and Lortie (1975).

Packets of questionnaires and distribution instructions for random samplings were delivered to central administration offices of the seven participating school districts (April 18, 1984), for distribution to schools for one-third of the teaching staff. All questionnaires were returned to the Personnel Office of Portland Public Schools within one month (by May 18, 1984), as subject to data analyses. The resulting data were keypunched (August, 1984) for analyses by computer (Honeywell 66/60, Portland Public Schools) .

The data were statistically evaluated by three tests: 
(1) frequency counts of items, (2) Chi-square $\left(x^{2}\right)$, and (3) bivariate correlational analyses (Kendall's tau). Visual inspections of frequency counts of compatible items on $Q_{1}$ and $Q_{2}$ were also made to compare selected frequency counts from 1981 and 1984, as follow-up study of job satisfaction of public school teachers in the Portland Metropolitan Area.

\section{Discussion}

\section{Research Question \#1 and Findings}

Question \#1 HOW SATISFIED ARE TEACHERS IN THE PMA WITH THEIR JOBS?

To test the research hypothesis that teachers in the PMA are generally satisfied with their jobs, Chi-Square $\left(x^{2}\right)$ tests were conducted on frequencies of responses on each of the seven items directly assessing satisfaction. Among the seven items, two items (IV.46 and II.25) were used throughout the analyses as the single-most direct measure of satisfaction and the secondary indicator. All seven items used to test Research Question \#1 are significant beyond the .001 level of significance. Thus, the data provide direct, significant evidence that teachers in the Portland Metropolitan Area are very satisfied with their jobs. However, analyses of responses to the items and factors tested provide evidence for discussion.

Satisfaction with Present Job or Assignment. The data indicate that $82 \%$ of the teacher respondents express degrees of satisfaction (ranging from somewhat to very) with their present job or assignment; $7 \%$ report being neither satisfied nor dissatisfied; and $11 \%$ express 
degrees of dissatisfaction (ranging from somewhat to very). Thus, the evidence suggests that the public school teachers in the population studied are very satisfied with the jobs they now hold and their particular assignments. The specific factors which contribute to expressions of satisfaction and dissatisfaction will receive further consideration in ensuing discussion of findings. (See Table II.)

Satisfaction with Role as a Teacher. The data indicate that $85 \%$ of the teacher respondents express degrees of satisfaction (ranging from somewhat to very) with their role as a teacher; $7 \frac{a}{0}$ report being neither satisfied nor dissatisfied; and $7 \%$ express degrees of dissatisfaction (ranging from somewhat to very). Thus, the evidence suggests that the public school teachers in the population studied are very satisfied with their roles as teachers. The specific factors which contribute to these expressions are subject to further examination. (See Table III.)

Job Preference. Three items tested offer data on job preferences of teachers as choices to remain in the field of public education or to work in some other field outside of public education $\left(Q_{2}\right.$, Items IV.1, 2, 3). These items are identified as indicators of job satisfaction. Although $59 \%$ of the teacher respondents affirm that they would choose teaching over any job in any field, $12 \%$ note that they would prefer some other job in public education, and $29 \%$ acknowledge that they would prefer some other job outside public education. On the item addressing job preference in the field of public education, $72 \%$ report that they would choose to remain in their present jobs as classroom teachers; $13 \%$ express preference for 
jobs as adninistrators at building or district levels; and $15 \%$ express preference for unspecified jobs outside of teaching or administration. On the item addressing whether the respondents would still become teachers if they could start all over again, $64 \%$ report that they would definitely or probably elect to enter teaching again; $19 \%$ note that they are uncertain; and $16 \%$ affirm that they would probably or definitely not enter teaching again. (See Tables IV, V, VI.)

Two items in the 1981 study by Falkenstein (1982) and Hathaway (1982) permit comparisons of responses from a similar population in the PMA. In 1981, 53.7\% reported that they would definitely or probably still choose to become teachers if they had it to do all over again; $21.3 \%$ noted that they would definitely or probably not choose to become teachers again $\left(Q_{1}\right.$, Item 29). On an item that narrowed the response selection to "yes" or "no" $\left(Q_{1}\right.$, Item 54), the response to "yes" in the 1981 study rose to $74.4 \%$; the response to "no" was 25. $5 \%$. (See Appendix G.)

The Nationwide Teacher Opinion Polls, conducted by NEA from 1979 through 1983, offer some additional opportunity for comparison of response percentages on the job preferences of teachers if they could start all over again. In the 1979 NEA Teacher Opinion Poll, 59\% responded that they would certainly or probably become teachers again; $10 \%$ noted that they were not sure what choice they would make; and $32 \%$ determined that they would certainly or probably not become teachers again (1979, p. 12). In the 1980 NEA Poll, 59\% responded that they would certainly or probably enter teaching again, but the percentage 
suggesting that they would certainly or probably not enter teaching again had risen to $41 \%$ (1980, p. 14, Phi Delta Kappan, September, 1980, p. 49). In the 1981 NEA Poll, 56\% reported that they would certainly or probably become teachers again, and the percentage determining that they would certainly or probably not enter teaching again had risen to $46 \%$ (1981, p. 15, NEA Research, Today's Educator, September-October, 1981). By 1983, the NEA Poll suggests an increase in job preference related to job satisfaction. In 1983, 58\% reported that they would certainly or probably become teachers again, but $43 \%$ still indicated that they would certainly or probably not enter teaching again (1983, p. 9).

Thus, the percentage of responses of teachers in the PMA in 1984 suggests a somewhat higher degree of preference for their jobs in the classrooms of their public schools than do the teachers surveyed similarly in nationwide polls conducted by the NEA from 1979 through 1983. However, the following indicators must be included within the context of a significant level of job satisfaction in the population examined:

- When given the options of preference for some other job in any field, $12 \%$ report that they would prefer some other job in public education, and $29 \%$ report that they would prefer some other job outside public education;

- When given the options of preference for some other job in public education, $28 \%$ note that they would prefer some job other than classroom teaching;

- When asked if they would still enter teaching if they could start all over again, $19 \%$ express uncertainty and $16 \%$ determine that they would probably or definitely not enter teaching again. 
Along with a generally satisfied population of teachers, there are also those who identify that they would elect to something else inside or outside of public education. This finding merits additional consideration.

Pleasure Received from Teaching. The data indicate that $96 \%$ of the teacher respondents receive pleasure from teaching in degrees ranging from some to great; $2 \%$ receive neither pleasure nor displeasure; and $1 \%$ receives some degree of displeasure.

The specific factors which may contribute to attitudes or feelings of pleasure or displeasure with teaching may be suggested in following discussion of findings. (See Table VII.)

Job Satisfaction. As the single-most direct indicator of job satisfaction in the present study of job satisfaction of public school teachers in the PMA, item IV.46 offers evidence that teachers in the population studied are very satisfied with their jobs. The data indicate that $87 \%$ of the teacher respondents express degrees of satisfaction about teaching (ranging from more satisfied than not to extremely satisfied); $6 \%$ note being neither satisfied nor dissatisfied; $7 \%$ identify degrees of dissatisfaction (ranging from more dissatisfied than satisfied to extremely dissatisfied). (See Table XIII.)

The Nationwide Teacher Opinion Polls from 1980 and 1981 offer some opportunity for comparison of the general concept of job satisfaction of teachers across the nation and teachers in the PMA in 1984. The NEA Poll of 1980 reports that more than one-third (35\%) of the surveyed teachers expressed dissatisfaction with their current 
jobs as teachers, with almost $9 \%$ identifying that they were very dissatisfied. The report notes that "teachers in city school systems, systems with 25,000 or more students, and in high schools are a little more dissatisfied than other teachers" (1980, p. 13). These findings are echoed in the Phi Delta Kappan report of the 1980 NEA investigation of teacher attitudes (1980, p. 49). The NEA Poll of 1981 reports similar findings that more than one-third (37\%) are dissatisfied with their current jobs as teachers, with $12 \%$ identifying that they were very dissatisfied. This reports notes that "those who teach in cities or suburban areas are more dissatisfied than are other teachers" (1981, p. 15).

Although the current study does not attempt to measure relative job satisfaction of teachers in the larger or smaller districts or of teachers in the urban or suburban communities of the PMA, the overall measures indicate a higher degree of job satisfaction for the teachers in the PMA than that cited in the 1980 and 1981 polls conducted by the NEA. However, even as it is statistically significant to identify the $82 \%$ of the teachers who express satisfaction with their jobs, it is also important to note the $7 \%$ who express dissatisfaction with their jobs. Thus, it is important to consider the primary differing factors affecting teacher satisfaction and dissatisfaction. In this study, and in the following discussion, this consideration includes findings on various factors and their relationship to satisfaction and dissatisfaction as well as inspections of data to consider how the various factors and assessments of the factors conform with Herzberg's and Lortie's theories. 
Summary - Research Question \#1. Thus, data indicate that a significant number of teachers in the PMA are very satisfied with their jobs and roles as teachers in public school classrooms; however, a segment of this sample does not express satisfaction. It is important to address what factors contribute to satisfaction and dissatisfaction in order to consider how factors contributing to satisfaction might be maintained or increased and how factors contributing to dissatisfaction might be eased or reduced. (See Tables II, III, IV, V, VI, VII, VIII.)

Research Question \#2 and Findings

Question \#2 WHAT ARE THE PRIMARY DIFFERING FACTORS AFFECTING TEACHER SATISFACTION AND DISSATISFACTION, AND DO THESE FACTORS AND THEIR RELATIONSHIP TO SATISFACTION AND DISSATISFACTION CONFORM WITH HERZBERG AND LORTIE THEORIES?

To test two aspects of the second research question and predictions, bivariate correlational analyses (Kendall's tau) tests were conducted on measures of satisfaction (IV.46 and II.25) and measures of motivators or intrinsic factors and measures of hygienes or extrinsic factors. The prediction for motivators was that they would contribute to satisfaction more than they would contribute to dissatisfaction. The prediction for hygienes was that they would contribute to dissatisfaction more than they would contribute to satisfaction. The test of motivators or intrinsic factors as related to satisfaction was drawn from Herzberg et al. (1959, p. 81) and included the following factors: 


$$
\begin{aligned}
& \text { Achievement } \\
& \text { Recognition } \\
& \text { Work itself } \\
& \text { Responsibility } \\
& \text { Advancement }
\end{aligned}
$$

The test of hygienes or extrinsic factors as related to dissatisfaction was drawn from Herzberg et al. (1959, p. 81) and included the following factors:

$$
\begin{aligned}
& \text { Salary } \\
& \text { Interpersonal relations--Supervisor } \\
& \text { Supervision } \\
& \text { Policies and practices of the company or organization } \\
& \text { (school and district) } \\
& \text { Working conditions } \\
& \text { To gain additional information on two other aspects of this } \\
& \text { research question and predictions, visual inspections of frequencies } \\
& \text { were conducted on responses from the present study and converted to } \\
& \text { percentages in an effort to identify factors contributing most } \\
& \text { frequently to satisfaction and dissatisfaction and to see how these } \\
& \text { identified factors might conform with Herzberg's identified list of } \\
& \text { motivators or intrinsic factors and hygienes or extrinsic factors } \\
& \text { (1959, p. } 81 \text { ). The visual inspection included consideration of } \\
& \text { frequencies of responses of the factors contributing most frequently } \\
& \text { to satisfaction of teachers to see how this data might conform with } \\
& \text { Lortie's theory that goals and achievements related to interrelations } \\
& \text { with students, or "reaching students," tend to serve as the primary } \\
& \text { ing }
\end{aligned}
$$


source of "psychic" or intrinsic reward (satisfaction) for teachers (1975, pp. 101, 104, 106, 109, 119-125). The visual inspection included consideration of frequencies of responses in a section of the instrument which asked for a ranking of factors on the bases of their importance (III.1-25). And, finally, the visual inspection included comparing data from 1981 study $\left(Q_{1}\right.$, Falkenstein, 1982; Hathaway, 1982) with frequencies of responses from the present study $\left(Q_{2}\right)$ on compatible items in an effort to see if responses would be the same or similar or if they would suggest noted change in very important sources of satisfaction for teachers of a similar population of the PMA over a period of time.

The Relationship of Motivators to Satisfaction. Findings from the statistical evaluations of measures of satisfaction (IV.46 and II.25) and measures of motivators or intrinsic factors (II.1, 2, 3, 4, 5) indicate that there is a uniformly direct and significant relationship between measures of motivators and measures of satisfaction, and the strength of relationship is seen to be moderate. Thus, in this study, motivators are seen to contribute to satisfaction more than they are seen to contribute to dissatisfaction, and the relationship is seen to be significant:

The tested factors that are seen to contribute significantly to satisfaction of teachers in the PMA are: (See Table IX.)

Achievement

Recognition

Work itself

Responsibility

Advancement 
These findings would tend to conform with Herzberg's theory on motivators inasmuch as these factors are seen to operate as motivators or satisfiers (e.g., contributors to satisfaction at a level of significance beyond .001). And, inasmuch as these factors are seen to contribute significantly to expressions of satisfaction of teachers in the PMA, it will be appropriate to consider them in efforts to improve or change levels of satisfaction or to ease or reduce levels of dissatisfaction for teachers in the PMA.

The Relationship of Hygienes to Dissatisfaction. Findings from the statistical evaluations of measures of satisfaction (IV.46 and II.25) and measures of hygienes or extrinsic factors (II.7, 8, 13, 14, $15,16)$ indicate that there is a uniformly weak and significant relationship between satisfaction and hygienes. Thus, in this study, hygienes are not seen to contribute to dissatisfaction more than they contribute to satisfaction at a level of significance of .05. They are seen to contribute to satisfaction at a level of significance beyond .001 (and contrary to prediction).

The tested factors that are seen to contribute significantly to satisfaction of teachers in the PMA are: (See Table X.)

\author{
Salary \\ Interpersonal relations - Supervisor \\ Supervision - Competence of supervisor \\ Policies and practices of district \\ Policies and practices of school \\ Working conditions
}


These findings would not tend to conform with Herzberg's theory on hygienes and their operation as dissatisfiers inasmuch as these factors are seen to operate as motivators or satisfiers (e.g., contributors to satisfaction at a level of significance beyond $.001)^{15}$ However, if these factors are seen to contribute significantly to expressions of satisfaction of teachers in the PMA, they are also worthy of consideration in efforts to improve or change levels of satisfaction or to ease or reduce levels of dissatisfaction for teachers in the PMA.

Factors Contributing Most Frequently to Satisfaction of Teachers in the PMA - Conformity with Herzberg's Factors. In an effort to identify the factors that contribute most frequently to teacher satisfaction in the PMA and to see how these factors conform with Herzberg's list of primary factors operating as motivators or satisfiers, a visual inspection of the frequencies of teacher responses, converted to percentages, indicates that the following factors contribute most frequently to satisfaction of teachers in the PMA: (See Table XIII.)

Interpersonal relations with students

Sense of achievement

Teaching as a kind of work (work itself)

Interpersonal relations with fellow teachers

(peers or colleagues)

Opportunities to help others

15 For additional discussion of hygienes and their operation as satisfiers or dissatisfiers, see Moxley (1977) and Wernimont (1966). 
This list of factors contributing most frequently to degrees of satisfaction of teachers in the PMA does not appear to conform with Herzberg's list of primary factors operating as motivators. It does include two factors from the Herzberg findings--achievement and work itself. It also includes two factors identified in research as hygienes--interpersonal relations with peers and interpersonal relations with subordinates. One factor not included in Herzberg's study that is defined in this study as a motivator and related to the job content or work of teachers is identified--the opportunities to help others (Moxley, 1977).

The adjustment of Herzberg's factor of interpersonal relations with subordinates to address interpersonal relations with students ${ }^{16}$ appears to be a major factor in study of a public school teacher population. The adjustment is appropriate inasmuch as teachers are charged with supervision of students; however, the relationship is identified as a major contributor to job satisfaction of teachers in the PMA. In addition, when interpersonal relations with peers is defined to mean interpersonal relations with fellow teachers or colleagues, this factor appears to be a contributor to the job satisfaction of teachers in the PMA. The added factor, defined as a motivator and related to work itself, the opportumities to help others, appears to be a contributor to the job satisfaction of teachers in the PMA.

16The adjustment of Interpersonal Relations - Subordinates to Interpersonal Relations - Students is based on similar adjustment in the research of Moxley (1977, pp. 15, 21, 22) and Sergiovanni (1966, p. 42). 
Thus, the Factors contributing most frequently to satisfaction of teachers in the PMA become particularly worthy of consideration in efforts to improve or change levels of satisfaction for the teachers studied.

Factors Contributing Most Frequently to Dissatisfaction of Teachers in the PMA - Conformity with Herzberg's Factors. In an effort to identify the factors that contribute most frequently to teacher dissatisfaction in the PMA to see how these factors conform with Herzberg's list of primary factors operating as hygienes or dissatisfiers, a visual inspection of the frequencies of teacher responses, converted to percentages, indicates that the following factors contribute most frequently to expressions of dissatisfaction of teachers in the PMA: (See Table XIV.)

\author{
Salary \\ Time spent preparing for teaching \\ Status
}

Time spent on school-related activities outside of teaching and preparation for teaching

Policies and practices of the school district

This list of factors identified by teacher respondents in the PMA as those which contribute to expressions of dissatisfaction does not conform with the list identified by Herzberg and others (1959, p. 81) as primary factors operating as hygienes for accountants and engineers; however, each of these factors is identified in Herzberg's research as a hygiene or extrinsic factor, or has been previously defined as a hygiene or extrinsic factor, that will serve as a potential 
dissatisfier (See Appendix C). The current data indicate that three of the primary factors in this list from the current study do match the list provided by Herzberg's team of researchers. Two matching factors from the earlier studies and the present study are noted among the top five (or primary factors) as: salary and policies and practices of the company or organization (district); one additional factor, noted in Herzberg research as a hygiene, but not in the top five, and also noted in this study is: status. The added factors dealing with time spent preparing for teaching as well as with time spent on school-related activities outside of teaching and preparation for teaching are seen to be major contributors to expressions of dissatisfaction. ${ }^{17}$ (See Table XIV.)

Thus, the factors contributing most frequently to dissatisfaction of teachers in the PMA are appropriate to consider in efforts to improve or change levels of satisfaction and to ease or reduce levels of dissatisfaction for the teachers studied.

The Factor Contributing Most Frequently to Satisfaction of Teachers in the PMA - Conformity with Lortie's Theory. In an effort to identify the factor in the present study that contributes most frequently to teacher satisfaction, to see if the factor conforms with Lortie's identification of goals and achievements related to

17 Time as a factor significant to the study of teachers and attitudes toward teaching has been included in the present study based on a similar consideration in research by Lortie (1975) and Moxley (1977). The factors of time spent in teaching, time spent preparing for teaching, and time spent on school-related activities outside of preparation for teaching have been previously defined as hygienes and related to working conditions. Time spent in teaching was not noted by teachers in the PMA as a major contributor to dissatisfaction. 
interactions with students as the primary source of "psychic" or intrinsic reward (satisfaction) for teachers (1975, pp. 101, 104, 106, 109, 119-125), a visual inspection of the frequencies of responses, converted to percentages, indicates that the following factor contributes most frequently to satisfaction of teachers in the PMA: (See Table XV.)

\section{Interpersonal relations with students}

These data are supported by other items in the present study $\left(Q_{2}\right)$ that seek assessments from teachers on feelings and attitudes related to working with students and their interrelationships with students. Teacher responses to items related to feelings and attitudes identified in working with students indicate very positive expressions of pleasure in working with students (96\%), liking students $(95 \%)$, feelings of success as a teacher $(98 \%, 91 \%$ and $86 \%$ on similar items), personal growth from being a teacher (96\%), achievement as a teacher $(98 \%)$. The data are also supported by the responses of teachers that a primary factor that would influence change in a long-time practice or behavior as a teachor would be the "knowledge that it would be 'good for kids'" ( $83 \%)$. In addition, $78 \%$ of the teacher respondents report that the most important source of satisfaction in teaching stems from "the times I know I have reached a student or group of students as each learns," and another $15 \%$ select "the chance to associate with children or young people and relate with them" as the most important source of satisfaction in being a teacher. (See Table XVI.)

In the section of the 1984 survey instrument $\left(Q_{2}\right.$, III.1-25) 
which asks the respondents to rank factors on the basis of their importance, the highest single frequency and resulting percentage conforms with Lortie's view that work with students is very important and provides very important enjoyment (satisfaction) for teachers. In the present study, $88 \%$ selected enjoyment in working with students as very important (the highest rank). (See Table XVII.)

The 1981 study $\left(Q_{1}\right.$, Falkenstein, 1982 \& Hathaway, 1982) offers an opportunity to compare frequencies of responses with data from the present study $\left(1984, Q_{2}\right)$ on compatible items addressing important sources of satisfaction to teachers in the PMA. In 1981, 94.5\% indicate degrees of liking work with students from a great deal to O.K.; in 1984, 95\% offer the same indication. In both studies, nearly all of the teachers (1981, 97\%, 86\% and 14\%; 1984, 98\%) express feeling successful in meeting the needs of from all to about half of the students as individuals. In the two studies, the percentage is similar at $96.1 \%$ (1981) and $96 \%$ (1984) that express a sense of personal growth from teaching. The factor that would influence change as a teacher is acknowledged by $75.4 \%$ of the respondents in 1981 and by $83 \%$ of the respondents in 1984 as "the knowledge that it would be 'good for kids."' The most important source of satisfaction in teaching is acknowledged by $86.3 \%$ of the respondents in 1981 and 93\% of the respondents in 1984 as either "the times I know I have 'reached' a student or group of students" or "the chance to associate with children or young people and relate with them." (See Tables XVIII, XIX.)

Thus, the data from the present study, supported by compatible 
data from the study done in 1981 on a similar population of teachers, suggest an apparent tendency of teachers in the PMA to identify interrelationships with students as the factor contributing most frequently to job satisfaction. This indicator is supported by data from other corresponding items from the 1981 and 1984 studies, as discussed. (See Table XIX.)

The indicator that teachers in the PMA receive major satisfaction from their interrelationships with students and attach major importance to this factor does conform with Lortie's theory that teachers receive primary "psychic" or intrinsic rewards (satisfactions) from goals and objectives related to interrelationships with students (1975, pp. 101, $104,106,-109,119-125)$.

Thus, the role of the teacher working in close relationship with students is worthy of careful attention in efforts to change or reform education. The data from 1981 and 1984 would suggest that any effort to separate the teacher from the students in the PMA would impact markedly on teacher job satisfaction.

The Factor Contributing Most Frequently to Dissatisfaction of Teachers in the PMA. Although teachers in the PMA provide data to suggest that they are very satisfied with their jobs as teachers, they have also provided some indicators of dissatisfaction and some identification of factors that contribute to dissatisfaction. Among the identified factors contributing most frequently to dissatisfaction of teachers in the PMA is salary. (See Table XIV.) In the section of the survey instrument asking respondents to rank factors from satisfaction to dissatisfaction (II.7), 37\% report degrees of 
satisfaction with their salary as teachers; $17 \%$ note neither satisfaction nor dissatisfaction; and $44 \%$ express degrees of dissatisfaction. In the section of the survey instrument asking repondents to rank factors from important to unimportant (III.4), 92\% report that salary is important (from somewhat to very); 5\% determine that the factor is neither important nor unimportant; and $2 \%$ say that it is somewhat unimportant.

Thus, for teachers in the PMA, the factor of salary is identified as the factor contributing most frequently to dissatisfaction, and it is further identified as very important to teachers. The data from this study indicate that salary as a factor does operate in direct and significant relationship with satisfaction, but the factor can also contribute to dissatisfaction.

Summary - Research Question \#2. The data from statistical measures and visual inspections indicate that differing factors affect teacher satisfaction and dissatisfaction.

The identified factors, tested as motivators or intrinsic factors, seen to contribute significantly to satisfaction of teachers in the PMA are: (See Table IX.)

\section{Achievement \\ Recognition \\ Work itself \\ Responsibility \\ Advancement}

The identified factors, tested as hygienes or extrinsic factors, also seen to contribute significantly to satisfaction of teachers in the PMA (and contrary to the prediction) are: (See Table X.) 


\author{
Salary \\ Interpersonal relations - Supervisor \\ Supervisor - Competence of supervisor \\ Policies and practices of district \\ Policies and practices of school \\ Working conditions
}

The visual inspections of frequencies of responses, converted to percentages, offer indications that the following factors contribute most frequently to satisfaction of teachers in the PMA: (See Table XIII.)

Interpersonal relations with students

Sense of achievement

Teaching as a kind of work (work itself)

Interpersonal relations with fellow teachers

Opportunities to help others

The visual inspections of frequencies of responses, converted to percentages, offer indications that the following factors contribute most frequently to dissatisfaction of teachers in the PMA: (See Table XIV.)

Salary

Time spent preparing for teaching

Status

Time spent on school-related activities outside of teaching and preparation for teaching

Policies and practices of the school district 
The visual inspections of frequencies of responses, converted to percentages, offer indications that the factor contributing most frequently to satisfaction of teachers in the PMA is: (See Table XV.)

Interpersonal relations with students

This finding is supported by data from other items in the study that address attitudes and feelings of teachers in their relationships with their students. This finding is further supported by compared data from the 1981 study $\left(Q_{1}\right)$ and the 1984 study $\left(Q_{2}\right)$, addressing compatible items on teacher attitudes and feelings about their relationships with students and the importance of such relationships.

The visual inspections of frequencies of responses, converted to percentages, offer indications that the factor contributing most frequently to dissatisfaction of teachers in the PMA is: (See Table XIV.)

\section{Salary}

In addition, $92 \%$ report that this factor is from somewhat to very impor tant.

The findings in the present study of motivators or intrinsic factors, as tested, do appear to conform with Herzberg's identified list of primary factors serving as motivators or satisfiers to the degree that the identified factors are seen to contribute significantly to satisfaction of teachers in the PMA. (See Table XI.)

The findings in the present study of hygienes or extrinsic factors, as tested, do not appear to conform with Herzberg's identified list of primary factors serving as hygienes or dissatisfiers inasmuch as the identified factors are seen to 
contribute significantly to satisfaction of teachers in the PMA. (See Table XII.)

The visual inspections conducted in the present study to attempt to identify the factors that contribute most frequently to satisfaction of teachers in the PMA set up a list that does not appear to conform with Herzberg's identified list of primary motivators or the "dual-factor" theory. Teachers in the PMA provide evidence to suggest that motivators and hygienes may operate as satisfiers or contributors to satisfaction. (See Table XIII.)

The visual inspections conducted in the present study to attempt to identify the factors that contribute most frequently to dissatisfaction of teachers in the PMA set up a list that does not appear to conform with Herzberg's identified list of primary hygienes; however, the factors that apparently contribute most frequently to dissatisfaction of teachers are defined as hygienes. (See Table XIV.)

The visual inspections conducted in the present study to attempt to identify the factor that contributes most frequently to satisfaction of teachers in the PMA indicates a finding that does appear to conform with Lortie's theory that teachers receive primary or very important "psychic" or intrinsic rewards (satisfactions) from interrelationships with students. (See Table XV.)

This study has provided data to indicate tendencies and apparent tendencies for differing factors to affect job satisfaction and dissatisfaction of teachers in the PMA; and it has also provided data that have been inspected to see how factors and their relationship to satisfaction and dissatisfaction conform with Herzberg's and Lortie's 
theories. Before any attempt to draw conclusions from these findings, it is also appropriate to consider how job satisfaction and dissatisfaction vary as a function of "demographic" factors of the teacher population studied.

Research Question \#3 and Findings

Question \#3 HOW DOES JOB SATISFACTION AND DISSATISFACTION VARY AS A FUNCTION OF THE FOLLOWING "DEMOGRAPHIC" FACTORS:

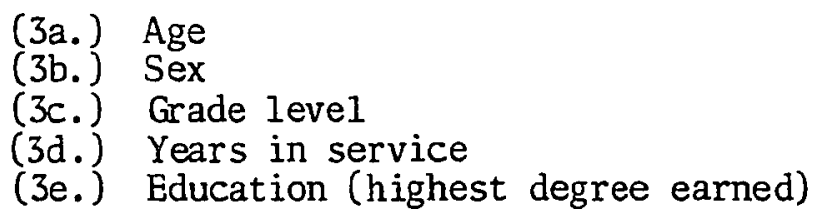

To test the general research prediction that job satisfaction and dissatisfaction will vary significantly as a function of each of the factors of age, sex, grade level, years in service, and education (highest degree earned), five separate sets of tests were conducted, as bivariate correlational analyses (Kenda11' tau) on each measure of satisfaction (II.24, II.25, IV.1, IV.3, IV.8, IV.46) and each measure of the identified demographic factor (3a-e.). Item IV.46 has been used consistently as the primary indicator of satisfaction; item II.25 has been used as the secondary indicator. Separate predictions were made for each of the identified demographic factors and their relationship to job satisfaction and subjected to separate analyses of findings, as follows:

Age (3a.). The population studied in 1984 includes teachers ranging in age from 20-25 to over 65 . The mean falls in the age category 41-45. The median and mode are represented by teachers aged 
36-40. Thirty-two percent of the teachers studied are younger than the median; $23 \%$ reflect the median; and $42 \%$ are older. (See Table XXV.)

\begin{tabular}{|lcr|}
\hline Category & Frequency & \% \\
\hline $20-25$ & 31 & 2 \\
$26-30$ & 183 & 13 \\
$31-35$ & 245 & 17 \\
$36-40$ & 327 & 23 \\
$41-45$ & 223 & 16 \\
$46-50$ & 154 & 11 \\
$51-55$ & 154 & 11 \\
$56-60$ & 86 & 6 \\
$61-65$ & 29 & 2 \\
Over 65 & 3 & 0 \\
& 1,435 & \\
& & \\
\hline Mean (category) & 4.534 & \\
Median & 4.00 & \\
Mode & 4.00 & \\
\hline Table XXV. - Ages of the Teachers in the PMA in 1984 (Item I. 2) \\
\hline
\end{tabular}

Comparative data from the study completed in 1981 indicate an increase in the ages of the teachers in the PMA in 1984. In 1981, $4.7 \%$ of the teachers fell in the age category 20-25; in 1984, the percentage in this category has dropped to $2 \%$. In $1981,15.8 \%$ are in the age category $26-30$; in 1984 , this percentage is $13 \%$. In 1981, $21.8 \%$ are in the age category $31-35 ;$ in $1984,17 \%$ fall in that age range. In $1981,16.6 \%$ are in the $36-40$ range; in 1984 , this category 
has increased to $23 \%$. In $1981,13.2 \%$ are in the $41-45$ category; in 1984, $16 \%$ are in this range. In $1981,8.4 \%$ are in the $46-50$ range; in 1984, $11 \%$ are in this range. Ages $51-55$ remain the same in the two studies at $11 \%$. Another slight variation is apparent in the older teachers. In $1981,6.3 \%$ of the teachers fell in the range 56-60; in 1984, 6\% are in this range. In 1981, $2.2 \%$ are in the range over 60 ; in 1984, $2 \%$ are in the over 60 category. In 1981, the median age Category is slightly under the age category of $36-40$; in $1984,36-40$ is the indicated median. Similarly, in 1981, the mode is the age category 31-35; and in 1984, the mode is the age category 36-40. (See Table XXVI; See Figure 8.)

These data indicate an apparent tendency for teachers in the PMA in 1984 to represent a slightly older age group. In 1981, 42.3\% are younger than 36-40, in 1984, 32\% are younger than 36-40. In 1981, 4.1. $1 \%$ are in the ranges older than $36-40$, in $1984,42 \%$ are in this saine range. The age category of $36-40$, as already noted, has increased from $16.6 \%$ in 1981 to $23 \%$ in 1984.

The slight decrease in the figures noted in 1981 and 1984 for those in the age categories over 55 indicates an apparent and very slight drop in 1984. In 1981, 8.5\% fell in this range; in 1984, 8\% fall in this range. (See Figure 8.)

The data indicating an apparent increase in the age of teachers are also reflected in the demograhic data from the Nationwide Teacher Opinion Poll of 1983, including mean years of age as figures from 1973, 1978, and 1983, as follows: (See Table XXVII.) 


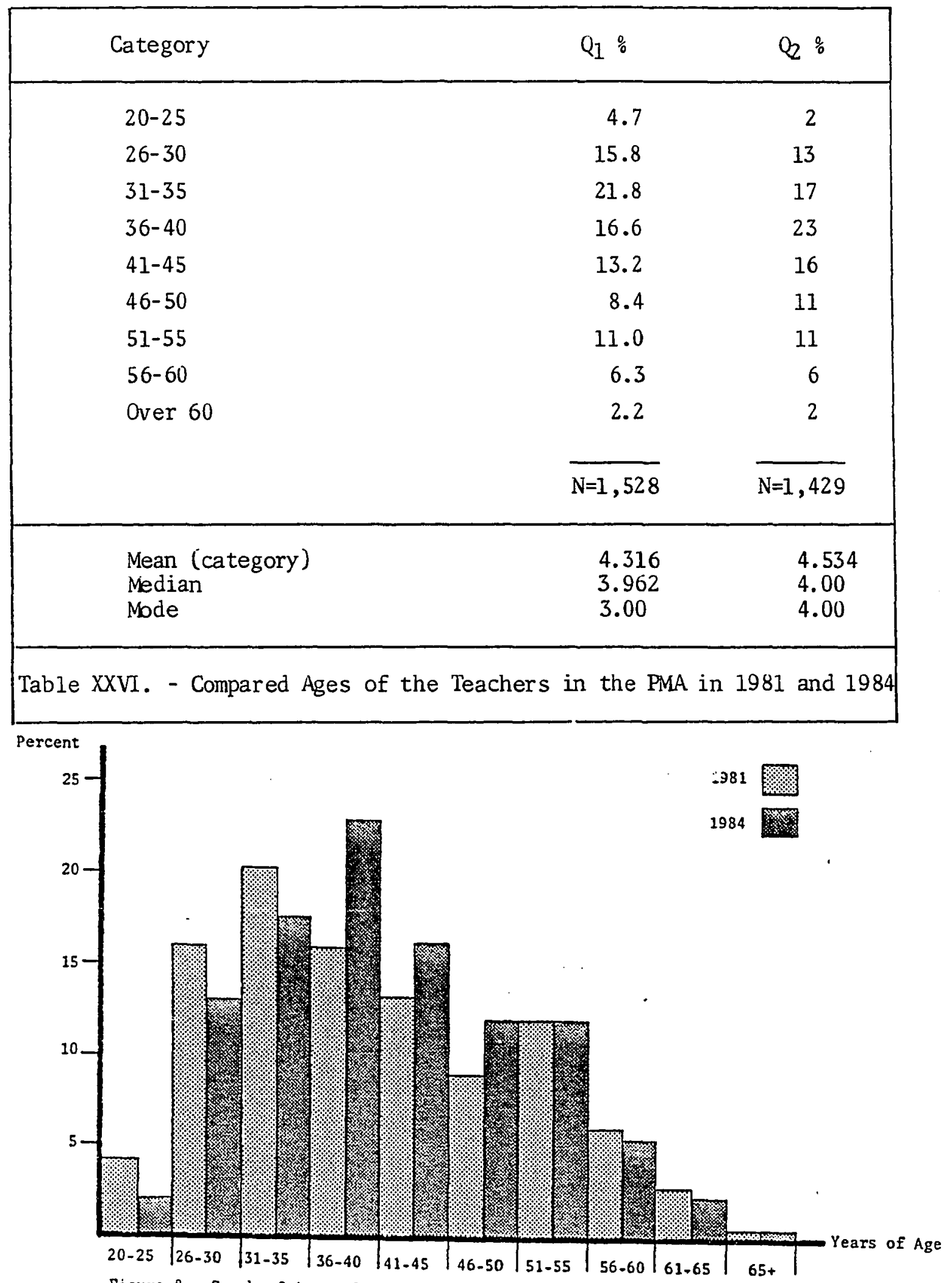

Pigure B - Graph of Ages of Teachers in the PAlA, 1981 and 1984 


\begin{tabular}{|cccc|}
\hline Age of teachers - mean years & 1973 & 1978 & 1983 \\
\hline All teachers & 37 & 38 & 41 \\
Elementary & 38 & 39 & 41 \\
Secondary & 35 & 38 & 41 \\
Men & 35 & 37 & 41 \\
Women & 38 & 39 & 40 \\
\hline Table XXVII. - National Demographic Data (Age) & & \\
\hline
\end{tabular}

(NEA, 1983, Demographic Highlights, p. 7)

These data may be summarized to suggest that there are fewer younger teachers in the PMA, there are more teachers in the middle age ranges, and there are slightly fewer teachers in the ranges beyond age fifty-five. These data could be simply the results of responses in the sample, or they could serve as some indicator of a changing population. The adjustments noted with both the younger and older teachers are subject to inquiry. Are fewer younger candidates looking toward education as a chosen field of career? Are fewer younger teachers being hired? Are fewer younger teachers remaining in the profession? Are the teachers of retirement age leaving voluntarily to reap retirement benefits afforded to public employees who reach age fifty-five and who have at least thirty years of public service in the State of Oregon (or age fifty-eight with at least fifteen years of public service)? Or do the older teachers represent a population of increasing dissatisfaction with the realities of public education in the PMA? 
The current study does not presume to address all the questions related to ages of teachers in the PMA, but it does provide some data on the relationship between age and measures of satisfaction.

(3a.) To test the research hypothesis that there is a significant relationship between age and measures of satisfaction, bivariate correlational analyses (Kendall's tau) were conducted on the measure of age (I.2) and each measure of satisfaction (IV.46 and II.25 as the primary and secondary indicators). Findings from the statistical evaluations of satisfaction and age indicate that there is a weak, inverse, and significant relationship between age and satisfaction. Older teachers tend to be more satisfied than younger teachers. (See Table XX.)

The data were subjected to cross tabulations for additional findings, as follows: (See Tables XXVIII, XXIX.) (See Figures 9, 10.)

Table XXVIII shows that over all age categories $87.8 \%$ express degrees of satisfaction; $6.1 \%$ express neither satisfaction nor dissatisfaction; and $6.0^{\circ}$ express degrees of dissatisfaction. In a group that is generally very satisfied with teaching, $93.6 \%$ express degrees of satisfaction in the age category $20-25 ; 86.2 \%$ express degrees of satisfaction in the age category $26-30 ; 84.5 \%$ express degrees of satisfaction in the age category $31-35 ; 88 \%$ express degrees of satisfaction in the age category $36-40 ; 84.6 \%$ express degrees of satisfaction in the age category $41-45 ; 88.6^{\circ}$ express degrees of satisfaction in the age category 46-50; $91.4 \%$ express degrees of satisfaction in the age category $51-55 ; 85.8 \%$ express degrees of satisfaction in the age category $56-60 ; 93.1 \%$ express degrees of 


\begin{tabular}{|c|c|c|c|c|c|c|c|c|c|c|c|}
\hline INDICATOR & & & & & & & BY AGE & & & & \\
\hline IV.46 FEELINGS ABOUT TEACHING & $20-25$ & $26-30$ & $31-35$ & $36-40$ & $41-45$ & $46-50$ & $51-55$ & $56-60$ & $61-65$ & Over 65 & Raw Total \\
\hline Extremely satisfied & $\begin{array}{r}6 \\
19.4\end{array}$ & $\begin{array}{r}30 \\
16.6\end{array}$ & $\begin{array}{r}39 \\
16.3\end{array}$ & $\begin{array}{r}49 \\
15.1\end{array}$ & $\begin{array}{r}38 \\
17.2\end{array}$ & $\begin{array}{r}19 \\
12.8\end{array}$ & $\begin{array}{r}30 \\
19.9\end{array}$ & $\begin{array}{r}18 \\
21.2\end{array}$ & $\begin{array}{r}12 \\
41.4\end{array}$ & $\begin{array}{r}1 \\
33.3\end{array}$ & $\begin{array}{r}242 \\
17.1\end{array}$ \\
\hline Very satisfied & $\begin{array}{r}12 \\
38.7\end{array}$ & $\begin{array}{r}80 \\
44.2\end{array}$ & $\begin{array}{r}83 \\
34.7\end{array}$ & $\begin{array}{r}143 \\
44.0\end{array}$ & $\begin{array}{r}100 \\
45.2\end{array}$ & $\begin{array}{r}68 \\
45.6\end{array}$ & $\begin{array}{r}66 \\
43.7\end{array}$ & $\begin{array}{r}39 \\
45.9\end{array}$ & $\begin{array}{r}6 \\
20.7\end{array}$ & $\begin{array}{r}1 \\
33.3\end{array}$ & $\begin{array}{r}598 \\
42.3\end{array}$ \\
\hline More satisfied than not & $\begin{array}{r}11 \\
35.5\end{array}$ & $\begin{array}{r}46 \\
25.4\end{array}$ & $\begin{array}{r}80 \\
33.5\end{array}$ & $\begin{array}{r}94 \\
28.9\end{array}$ & $\begin{array}{r}58 \\
26.2\end{array}$ & $\begin{array}{r}45 \\
30.2\end{array}$ & $\begin{array}{r}42 \\
27.8\end{array}$ & $\begin{array}{r}16 \\
18.8\end{array}$ & $\begin{array}{r}9 \\
31.0\end{array}$ & $\begin{array}{r}1 \\
33.3\end{array}$ & $\begin{array}{r}402 \\
28.4\end{array}$ \\
\hline $\begin{array}{l}\text { Neither satisfied } \\
\text { nor dissatisfied }\end{array}$ & $\begin{array}{r}2 \\
6.5\end{array}$ & 6.6 & $\begin{array}{r}18 \\
7.5\end{array}$ & $\begin{array}{r}19 \\
5.8\end{array}$ & $\begin{array}{r}13 \\
5.9\end{array}$ & $\begin{array}{r}10 \\
6.7\end{array}$ & $\begin{array}{r}7 \\
4.6\end{array}$ & $\begin{array}{r}4 \\
4.7\end{array}$ & $\begin{array}{r}1 \\
3.4\end{array}$ & & $\begin{array}{r}86 \\
6.1\end{array}$ \\
\hline $\begin{array}{l}\text { More dissatisfied } \\
\text { than satisfied }\end{array}$ & & $\begin{array}{r}12 \\
6.6\end{array}$ & $\begin{array}{r}15 \\
6.3\end{array}$ & $\begin{array}{r}13 \\
4.0\end{array}$ & $\begin{array}{r}8 \\
3.6\end{array}$ & $\begin{array}{r}7 \\
4.7\end{array}$ & $\begin{array}{r}2 \\
2.6\end{array}$ & $\begin{array}{r}6 \\
7.1\end{array}$ & $\begin{array}{r}1 \\
3.4\end{array}$ & & $\begin{array}{r}66 \\
4.7\end{array}$ \\
\hline Very dissatisfied & & $\begin{array}{l}1 \\
.6\end{array}$ & $\begin{array}{r}2 \\
.8\end{array}$ & $\begin{array}{l}1 \\
.3\end{array}$ & $\begin{array}{r}2 \\
.9\end{array}$ & & $\begin{array}{l}1 \\
.7\end{array}$ & $\begin{array}{r}2 \\
2.4\end{array}$ & & & $\begin{array}{r}9 \\
.6\end{array}$ \\
\hline Extremely dissatisfied & & & $\begin{array}{r}2 \\
.8\end{array}$ & $\begin{array}{r}5 \\
1.5\end{array}$ & $\begin{array}{l}2 \\
.9\end{array}$ & & $\begin{array}{l}1 \\
.7\end{array}$ & & & & $\begin{array}{l}10 \\
.7\end{array}$ \\
\hline Column Total & $\begin{array}{r}31 \\
2.2\end{array}$ & $\begin{array}{r}181 \\
12.8\end{array}$ & $\begin{array}{r}239 \\
16.9\end{array}$ & $\begin{array}{r}325 \\
23.0\end{array}$ & $\begin{array}{r}221 \\
15.6\end{array}$ & $\begin{array}{r}149 \\
10.5\end{array}$ & $\begin{array}{r}151 \\
10.7\end{array}$ & $\begin{array}{r}85 \\
6.0\end{array}$ & $\begin{array}{r}29 \\
2.1\end{array}$ & $\begin{array}{r}3 \\
.2\end{array}$ & 1414 \\
\hline
\end{tabular}


satisfaction in the age category of 61-65. The cells representing teachers over age 65 include only three respondents. Of these, all three express degrees of satisfaction. (See Table XXVIII; See Figure 9.)

The highest percentage of expressions of satisfaction is indicated by the age category of 20-25; the lowest percentage of expressions of satisfaction is indicated by the age category of 31-35.

Over all age categories, $6.0 \%$ express degrees of dissatisfaction. In the category 20-25, no respondents indicate degrees of dissatisfaction. In the category $26-30,7.2 \%$ indicate degrees of dissatisfaction. In the category $31-35,7.9 \%$ indicate degrees of dissatisfaction. In the category 36-40, 5.8\% express degrees of dissatisfaction. In the category $41-45,5.4 \%$ express degrees of dissatisfaction. In the category 46-50, 4.7\% express degrees of dissatisfaction. In the category 51-55, 4\% express degrees of dissatisfaction. In the category 56-60, 9.5\% express degrees of dissatisfaction. In the category $61-65$, only one respondent $(3.4 \%)$ identifies degrees of dissatisfaction. The cells representing teachers over age 65 include only three respondents. As previously noted, no teacher in. this category reports degrees of dissatisfaction. (See Table XXVIII.)

The highest percentage of expressions of dissatisfaction is indicated by the age category 56-60; the lowest percentage of expressions of dissatisfaction is indicated by the absence of response in the cells for 20-25 and over 65. (See Figure 10.)

The highest percentage of expressions of being neither satisfied 
Satisfaction

Neither/nor

$\square$ Dissat isfaction

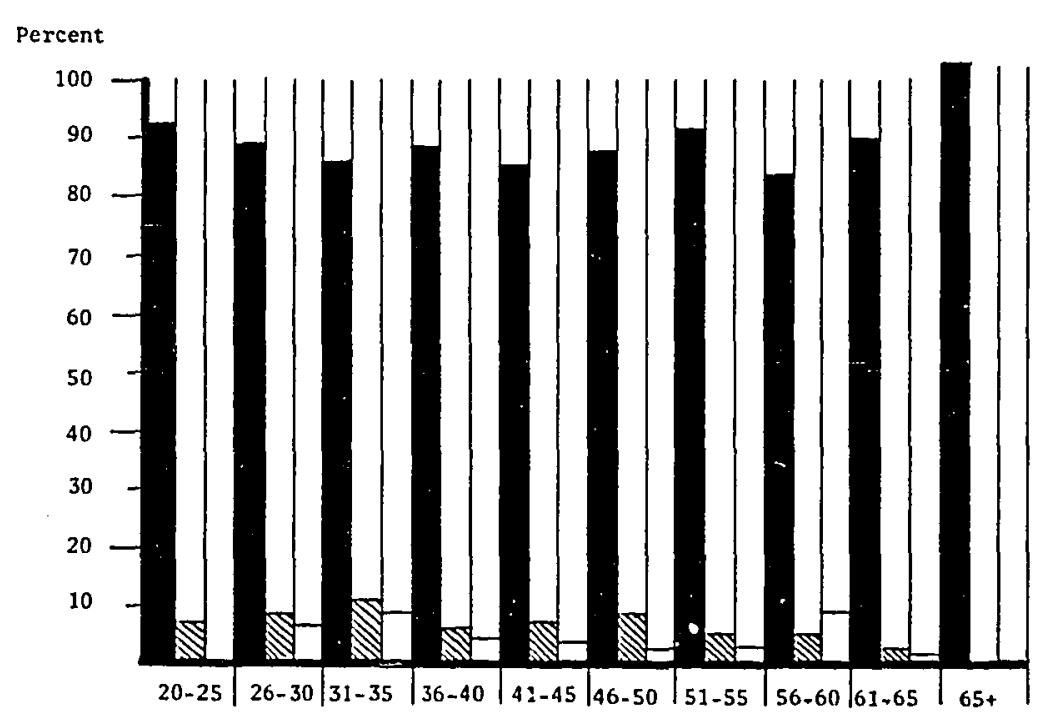

Pigure 9 . Satisfaction Indicator (IV.46) by Age, 1984

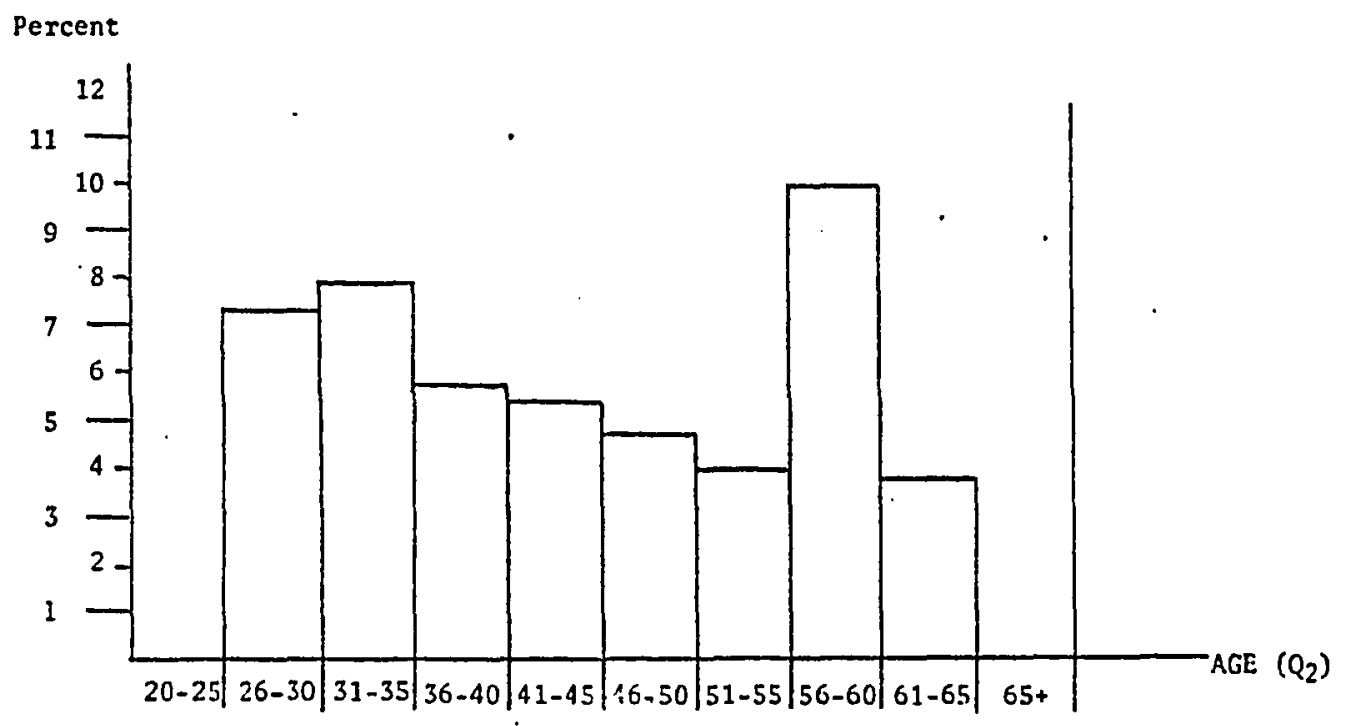

Figure 10 - Dissatisfaction Indicator $(I V, 46)$ by Age, PlA, 1984 


\begin{tabular}{|c|c|c|c|c|c|c|c|c|c|c|c|}
\hline INDICATOR & & & & & & & Y AGE & & & & \\
\hline II.25 HOW SATISFIED WITH ROLE & $20-25$ & $26-30$ & $31-35$ & $36-40$ & $41-45$ & $46-50$ & $51-55$ & $56-60$ & $61-65$ & Over 65 & Raw Total \\
\hline Very satisfied & $\begin{array}{r}9 \\
29.0\end{array}$ & $\begin{array}{r}76 \\
41.8\end{array}$ & $\begin{array}{r}93 \\
38.1\end{array}$ & $\begin{array}{r}113 \\
34.7\end{array}$ & $\begin{array}{r}91 \\
41.0\end{array}$ & $\begin{array}{r}65 \\
42.8\end{array}$ & $\begin{array}{r}70 \\
45.5\end{array}$ & $\begin{array}{r}39 \\
45.3\end{array}$ & $\begin{array}{r}17 \\
58.6\end{array}$ & $\begin{array}{r}2 \\
66.7\end{array}$ & $\begin{array}{r}575 \\
40.2\end{array}$ \\
\hline Somewhat satisfied & $\begin{array}{r}18 \\
58.1\end{array}$ & $\begin{array}{r}78 \\
42.9\end{array}$ & $\begin{array}{r}111 \\
45.5\end{array}$ & $\begin{array}{r}164 \\
50.3\end{array}$ & $\begin{array}{r}106 \\
47.7\end{array}$ & $\begin{array}{r}66 \\
43.4\end{array}$ & $\begin{array}{r}64 \\
41.6\end{array}$ & $\begin{array}{r}34 \\
39.5\end{array}$ & $\begin{array}{r}10 \\
34.5\end{array}$ & & $\begin{array}{r}651 \\
45.6\end{array}$ \\
\hline $\begin{array}{l}\text { Neither satisfied } \\
\text { nor dissatisfied }\end{array}$ & $\begin{array}{r}3 \\
9.7\end{array}$ & $\begin{array}{r}12 \\
6.6\end{array}$ & $\begin{array}{r}23 \\
9.4\end{array}$ & $\begin{array}{r}21 \\
6.4\end{array}$ & $\begin{array}{r}11 \\
5.0\end{array}$ & $\begin{array}{r}13 \\
8.6\end{array}$ & $\begin{array}{r}9 \\
5.8\end{array}$ & $\begin{array}{r}4 \\
4.7\end{array}$ & $\begin{array}{r}1 \\
3.4\end{array}$ & $\begin{array}{r}1 \\
33.3\end{array}$ & $\begin{array}{r}98 \\
6.1\end{array}$ \\
\hline Somewhat dissatisfied & $\begin{array}{r}1 \\
3.2\end{array}$ & $\begin{array}{r}15 \\
8.2\end{array}$ & $\begin{array}{r}16 \\
6.6\end{array}$ & $\begin{array}{r}24 \\
7.4\end{array}$ & $\begin{array}{r}11 \\
5.0\end{array}$ & $\begin{array}{r}7 \\
4.6\end{array}$ & $\begin{array}{r}8 \\
5.2\end{array}$ & $\begin{array}{r}7 \\
8.1\end{array}$ & $\begin{array}{r}1 \\
3.4\end{array}$ & & $\begin{array}{r}90 \\
6.3\end{array}$ \\
\hline Very dissatisfied & & $\begin{array}{r}1 \\
.5\end{array}$ & $\begin{array}{l}1 \\
.4\end{array}$ & $\begin{array}{r}4 \\
1.2\end{array}$ & $\begin{array}{r}3 \\
1.4\end{array}$ & $\begin{array}{l}1 \\
.7\end{array}$ & $\begin{array}{r}3 \\
1.9\end{array}$ & $\begin{array}{r}2 \\
2.3\end{array}$ & & & $\begin{array}{r}15 \\
1.0\end{array}$ \\
\hline Column Total & $\begin{array}{r}31 \\
2.2\end{array}$ & $\begin{array}{r}182 \\
12.7\end{array}$ & $\begin{array}{r}244 \\
17.1\end{array}$ & $\begin{array}{r}326 \\
22.8\end{array}$ & $\begin{array}{r}222 \\
15.5\end{array}$ & $\begin{array}{r}152 \\
10.6\end{array}$ & $\begin{array}{r}154 \\
10.8\end{array}$ & $\begin{array}{r}86 \\
6.0\end{array}$ & $\begin{array}{r}29 \\
2.0\end{array}$ & $\begin{array}{r}3 \\
.2\end{array}$ & 1429 \\
\hline
\end{tabular}


nor dissatisfied is indicated by the age category 31-35; the lowest percentage of expressions of being neither satisfied nor dissatisfied is reported by the age category $61-65$, with no response in the cell for over 65. (See Figures 9 and 10.)

Table XXIX shows that over all age categories, $85.8 \%$ express degrees of satisfaction; $6.1 \%$ express neither satisfaction nor dissatisfaction; and $7.3 \%$ express degrees of dissatisfaction. In a group that is generally very satisfied with teaching, $85.1^{\circ}$ express degrees of satisfaction in the age $20-25 ; 84.7 \%$ express degrees of satisfaction in the age $26-30 ; 85 \%$ express degrees of satisfaction in the age $36-40 ; 86.7 \%$ express degrees of satisfaction in the age 46-50; 87. $1 \%$ express degrees of satisfaction in the age $51-55 ; 84.8 \%$ express degrees of satisfaction in the age $56-60 ; 93.1 \%$ express degrees of satisfaction in the age 61-65. The cells representing teachers over 65 include only three respondents; of these, two report that they are very satisfied, and one reports being neither satisfied nor dissatisfied. (See Table XXIX.)

The highest percentage of expressions of satisfaction is indicated by the age category of $61-65(93.1 \%)$; the lowest percentage of expression of satisfaction is indicated by the age category of 20-25.

Over all age categories, $7.3 \%$ express degrees of dissatisfaction. In the category $20-25,3.2 \%$ express degrees of some dissatisfaction. In the category $26-30,8.7 \%$ express degrees of dissatisfaction. In the category $31-35,7 \%$ express degrees of dissatisfaction. In the category $36-40,8.6 \%$ express degrees of dissatisfaction. In the category $41-45,6.4 \%$ express degrees of dissatisfaction. In the 
category 46-50, 5.3\% express degrees of dissatisfaction. In the category 51-55, 7.1\% express degrees of dissatisfaction. In the category $56-60,10.4 \%$ express degrees of dissatisfaction. In the category $61-65,3.4 \%$ express degrees of dissatisfaction.

The highest percentage of expressions of dissatisfaction is indicated by the age category of 56-60; the lowest percentage of expressions of dissatisfaction is indicated by the age category of 61-65.

The highest percentage of expressions of being neither satisfied nor dissatisfied is indicated by the age category 20-25 (exempting the percentage for the three respondents over age 65); the lowest percentage of expressions of being neither satisfied nor dissatisfied is indicated by the age category 61-65. (See Table XXIX.)

Tables XXVIII and XXIX both show:

- high percentages of expressions of satisfaction with teaching in the PMA.

- teachers in the category 20-25 reporting either degrees of satisfaction or degrees of being neither satisfied nor dissatisfied (with only one respondent in that age category reporting being somewhat dissatisfied).

- an increase in job dissatisfaction between the categories of 20-25 and 26-30.

- an increase in job dissatisfaction between the categories of 51-55 and 56-60.

- the highest degree of job dissatisfaction in the category of 56-60.

- the three respondents in the cells over 65 selecting degrees of satisfaction or the single indicator of being neither satisfied nor dissatisfied. (The small samplo in this category does not permit extended analyses, except to note the absence of representation and to note the absence of expressions of dissatisfaction.) (See Tables XXVIII, XXIX.) 
Summary (Age) (3a.). The comparative data from 1981 and 1984 provide some apparent indication that teachers in the PMA are slightly older as a population than they were in 1981. The median in 1981 is slightly younger than the median age of 36-40 indicated in 1984. The mode in 1981 is 31-35; the mode in 1984 is 36-40. The percentage representing the age categories younger than $36-40$ has declined since 1981. The percentage in the age categories older than 36-40 has remained nearly constant. The indications that teachers are becoming slightly older as a population are reflected in national demographic data. (See Table XXVII; See Figure 8.)

The findings from bivariate correlational studies (Kendall's tau) indicate that there is a weak, inverse, and significant relationship between age and satisfaction. 0lder teachers tend to be more satisfied than younger teachers. (See Table XX.)

The findings from cross tabulations of categories of age and satisfaction indicate that teachers in all the age categories express high percentages of job satisfaction with teaching. The data provide some apparent indication of an increase in job dissatisfaction between the age categories of 20-25 and 26-30. In addition, the data provide some apparent indication of the highest degree of dissatisfaction in the age category of 56-60. These findings are worthy of further consideration on the bases of potential for impact on the overall population or on the bases for personnel services. (See Tables XXVIII, XXIX; See Figures 9 and 10.)

It is now appropriate to address data on relationships between sex and indicators of job satisfaction for teachers in the PMA. 


\begin{tabular}{|lcl|}
\hline Category & Frequency & $\%$ \\
\hline Female & 980 & 68 \\
Male & 458 & 32 \\
\cline { 2 - 3 } & 1,438 & \\
\hline Mean (category) & 1.318 & \\
Median & 1.00 \\
Mode & 1.00 & \\
\hline Table XXX. - Sex of Teachers in the PMA in 1984 (I tem I.1) \\
\hline
\end{tabular}

Sex (3b.). The population studied in 1984 includes 980 women and 458 men for a total of 1,438 respondents identified by sex (six missing cases). (See Table XXX.)

Comparative data from the study completed in 1981 suggest a slight increase in the percentage of female teachers and a slight decrease in the percentage of male teachers in the population of teachers in the PMA. In 1981, 63.7\% are female; in 1984, 68\% are female. In $1981,36.3 \%$ are male; in $1984,32 \%$ are male. In 1981 , the women represent slightly less than two-thirds of the sample, and the men represent slightly more than one-third $(\mathrm{N}=1538)$. In 1984 , the women represent slightly more than two-thirds of the sample, and the men represent slightly less than one-third $(N=1444)$. (See Table XXX; See Figure 11.)

The reflected pattern is similar to that identified in the Nationwide Teacher Opinion Poll of 1983, citing figures from 1973, 


\begin{tabular}{|c|c|c|}
\hline Category & $Q_{1} \%$ & $Q_{2} \%$ \\
\hline Female & 63.7 & 68 \\
\hline \multirow[t]{2}{*}{ Male } & 36.3 & 32 \\
\hline & $(\mathrm{N}=1538)$ & $(\mathrm{N}=1444)$ \\
\hline $\begin{array}{l}\text { Mean (category) } \\
\text { Median } \\
\text { Mode }\end{array}$ & $\begin{array}{l}1.363 \\
1.285 \\
1.00\end{array}$ & $\begin{array}{l}1.318 \\
1.00 \\
1.00\end{array}$ \\
\hline $\begin{array}{r}\text { Table XXXI. - Comparati } \\
1981\left(\mathrm{Q}_{1}\right)\end{array}$ & ers in & \\
\hline
\end{tabular}

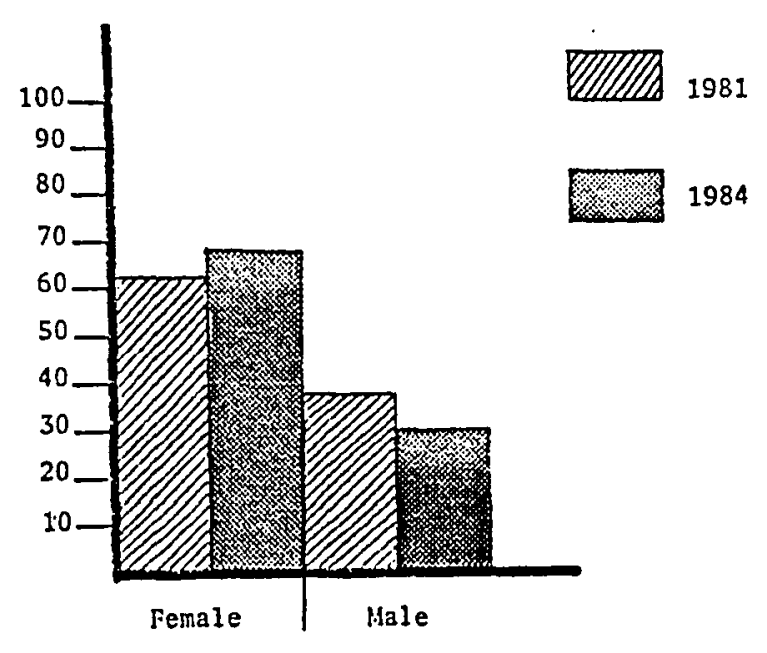

Figure 11 - Scx of Teachers in PMA, $1981 \& 1984$ 
1978, and 1983, as follows: (See Table XXII.)

\begin{tabular}{|cccc|}
\hline Sex & 1973 & 1978 & 1983 \\
\hline Women & $64 \%$ & $66 \%$ & $67 \%$ \\
Men & 36 & 34 & 33 \\
\hline Table XXXII. - National & Demographic Data (Sex) \\
\hline
\end{tabular}

(NEA, 1983, Demographic Highlights, p. 7)

Sampling may provide small differences that may not necessarily signal a pattern; however, the data tend to suggest that the PMA may be reflecting a national trend to increase the numbers of women teachers and decrease the numbers of men teachers in the classrooms.

(3b.) To test the research hypothesis that there is a significant relationship between sex and measures of satisfaction and that women will express greater satisfaction with teaching than men will, bivariate correlational analyses (Kendall's tau) were conducted on the measure of sex (I.1) and each measure of satisfaction (using IV. 46 and II. 25 as the primary and secondary indicators). Findings from the statistical evaluations of job satisfaction and sex indicate that there is a weak and significant relationship between sex and satisfaction with teaching. Women tend to be more satisfied with teaching than men are. (See Table XXI.)

The data were subjected to cross tabulation for additional findings, as follows: (See Tables XXXIII, XXXIV.) 


\begin{tabular}{|lrrr|}
\hline INDICATOR & \multicolumn{3}{c}{ BY SEX } \\
\hline IV.46 FEELINGS ABOUT TEACHING & Female & Male & Raw Total \\
\hline Extremely satisfied & 187 & 55 & 242 \\
& 19.4 & 12.2 & 17.1 \\
Very satisfied & 412 & 189 & 601 \\
& 42.7 & 41.9 & 42.4 \\
More satisfied than not & 267 & 135 & 402 \\
& 27.6 & 29.9 & 28.4 \\
Neither satisfied & 51 & 34 & 85 \\
nor dissatisfied & 5.3 & 7.5 & 6.0 \\
More dissatisfied & 38 & 29 & 67 \\
than satisfied & 3.9 & 6.4 & 4.7 \\
Very dissatisfied & 6 & 3 & 9 \\
& .6 & .7 & .6 \\
Extremely dissatisfied & 5 & 5 & 10 \\
& .5 & 1.1 & .7 \\
\hline Column Total & 966 & 451 & 1417 \\
& & 31.8 & \\
\hline Table XXXII. - Cross Tabulations - Satisfaction & Indicator (IV.46) \\
& & & \\
\hline
\end{tabular}

Table XXXIII shows that $87.9 \%$ of the women and men respondents report degrees of satisfaction with teaching; 6: express neither satisfaction nor dissatisfaction; and $6 \%$ express degrees of dissatisfaction. In a group that is generally satisfied, $89.7 \%$ of the women express degrees of satisfaction with teaching; 5.3\% express neither satisfaction nor dissatisfaction; and $5 \%$ express degrees of dissatisfaction. In a group that notes slightly less satisfaction, $84 \%$ of the men express degrees of satisfaction with teaching; $7.5 \%$ 


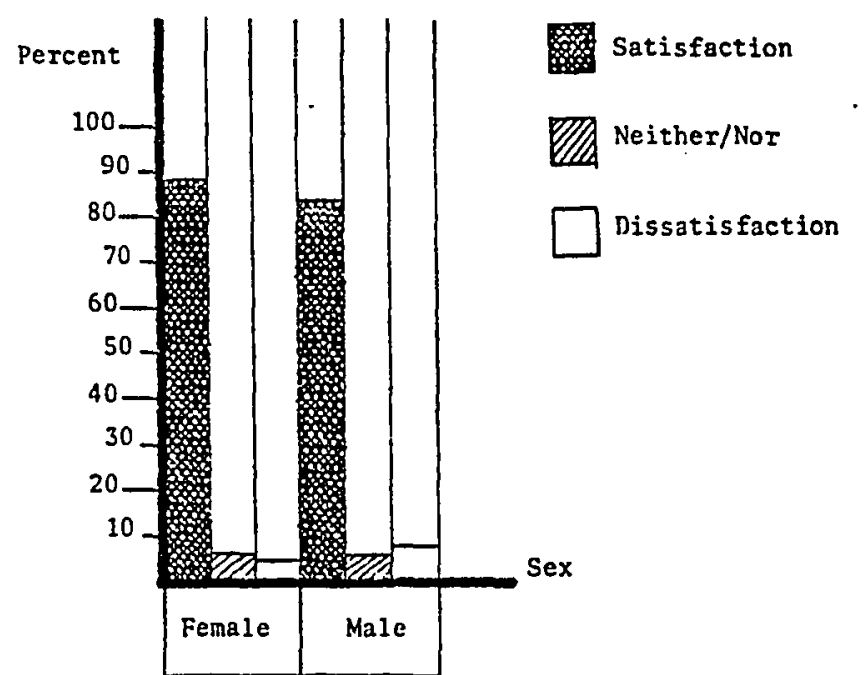

Figure 12 - Satisfaction Indicator (IV.46) by Sex
Percent

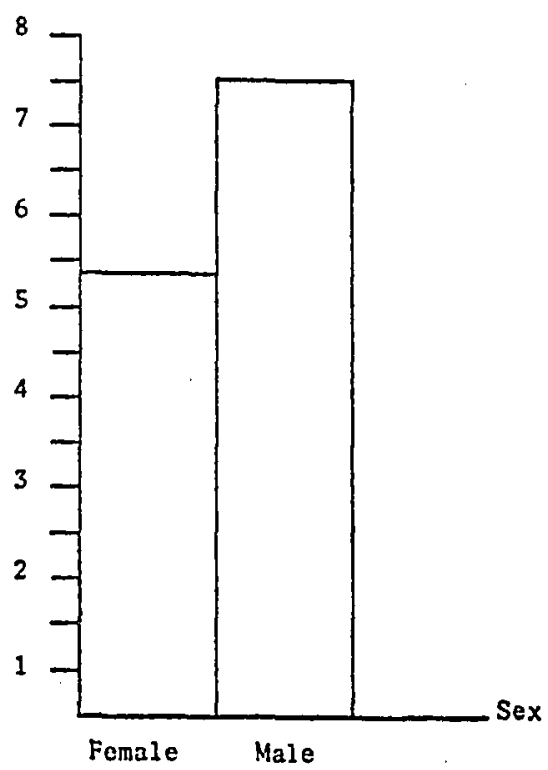

Figure 13 - Dissatisfaction Indicator (IV.46) by Sex, 1984

express neither satisfaction nor dissatisfaction; and $8.2 \%$ express degrees of dissatisfaction. (See Table XXXIII; See Figure 12.)

Table XXXIV shows that $85.9 \%$ of the women and men respondents note degrees of satisfaction with teaching; $6.8 \%$ express neither satisfaction nor dissatisfaction; and $7.3 \%$ express degrees of dissatisfaction. In a sample group that is generally satisfied, $88.8 \%$ of the women express degrees of satisfaction with teaching; $5.4 \%$ express neither satisfaction nor dissatisfaction; and 5.8 report degrees of dissatisfaction. From the sample, $79.8 \%$ of the men express degrees of satisfaction; $9.7 \%$ express neither satisfaction nor dissatisfaction; and $10.5 \%$ express degrees of dissatisfaction. (See Table XXIX.) 


\begin{tabular}{|c|c|c|c|}
\hline INDICATOR & \multicolumn{3}{|c|}{ BY SEX } \\
\hline II .25 HOW SATISFIED WITH ROLE & Female & Male & Raw Total \\
\hline Very satisfied & $\begin{array}{r}417 \\
42.7\end{array}$ & $\begin{array}{r}160 \\
35.2\end{array}$ & $\begin{array}{r}577 \\
40.3\end{array}$ \\
\hline Somewhat satisfied & $\begin{array}{r}450 \\
46.1\end{array}$ & $\begin{array}{r}203 \\
44.6\end{array}$ & $\begin{array}{r}653 \\
45.6\end{array}$ \\
\hline $\begin{array}{l}\text { Neither satisfied } \\
\text { nor dissatisfied }\end{array}$ & $\begin{array}{r}53 \\
5.4\end{array}$ & $\begin{array}{r}44 \\
9.7\end{array}$ & $\begin{array}{r}97 \\
6.8\end{array}$ \\
\hline Somewhat dissatisfied & $\begin{array}{r}49 \\
5.0\end{array}$ & $\begin{array}{r}41 \\
9.0\end{array}$ & $\begin{array}{r}90 \\
6.3\end{array}$ \\
\hline Very dissatisfied & $\begin{array}{r}8 \\
.8\end{array}$ & $\begin{array}{r}7 \\
1.5\end{array}$ & $\begin{array}{r}15 \\
1.0\end{array}$ \\
\hline Column Total & $\begin{array}{r}977 \\
68.2\end{array}$ & $\begin{array}{r}455 \\
31.8\end{array}$ & 1432 \\
\hline $\begin{array}{c}\text { Table XXXIV. - Cross Tabulations } \\
\text { by Sex, } 1984\end{array}$ & action & ant & (II .25) \\
\hline
\end{tabular}

Tables XXXIII and XXXIV both show:

- that both women and men express high percentages of job satisfaction.

- that women express greater satisfaction with teaching than men do. (See Tables XXXIII, XXXIV.)

Summary (Sex) (3b.). The comparative data from 1981 and 1984 provide some apparent indication that the population of women teachers in the PMA is increasing and the population of men teachers is decreasing. (See Table XXXI; See Figure 11.). At present, women represent slightly more than two-thirds of the teaching population; men represent slightly less than one-third. (See Table $X X X$.) The 
indications that more women and fewer men are in teaching are reflected in national demographic data. (See Table XXXII.)

The findings from bivariate correlational analyses (Kendall's tau) indicate that there is a weak and significant relationship between sex and satisfaction with teaching. Women tend to be more satisfied with teaching than men are. (See Table XXI.)

The findings in the present study that women report greater satisfaction with teaching than men do are consistent with the findings of Chapman and Lowther (1982) in their study of graduates of teacher training programs in Michigan, from 1946-1976 (pp. 241-247).

The findings from cross tabulations of categories of sex and satisfaction show that both women and men teachers express high percentages of satisfaction with teaching. The data support the tendency of women to express greater satisfaction with teaching than men do. (See Tables XXXIII, XXXIV; See Figures 12, 13.)

The higher percentages of men expressing neither satisfaction nor dissatisfaction or degrees of dissatisfaction coupled with the reduction of representation of men in the teaching population are worthy of careful consideration in terms of the potential for impact on the overall population or on the bases for personnel services.

Grade Level (3c.). The population studied in 1984 includes teachers assigned to teach grade levels of students ranging from preprimary (PreK) through kindergarten (K) through grade 12 . In the current study, the primary or lower grades are generally defined to range from PreK - $\mathrm{K}$ through grades 4-6. The higher or upper grades are generally defined to range from 6-8 (upper elementary or middle 
school) or 7-9 (junior high) through $9-12$ (secondary). Of 1,352 valid cases representing the respondents on grade level, the mean is slightly above grade 6; the median is grades 6-8; and the mode is grades 1-3. (See Table XXXV; see Figure 14.)

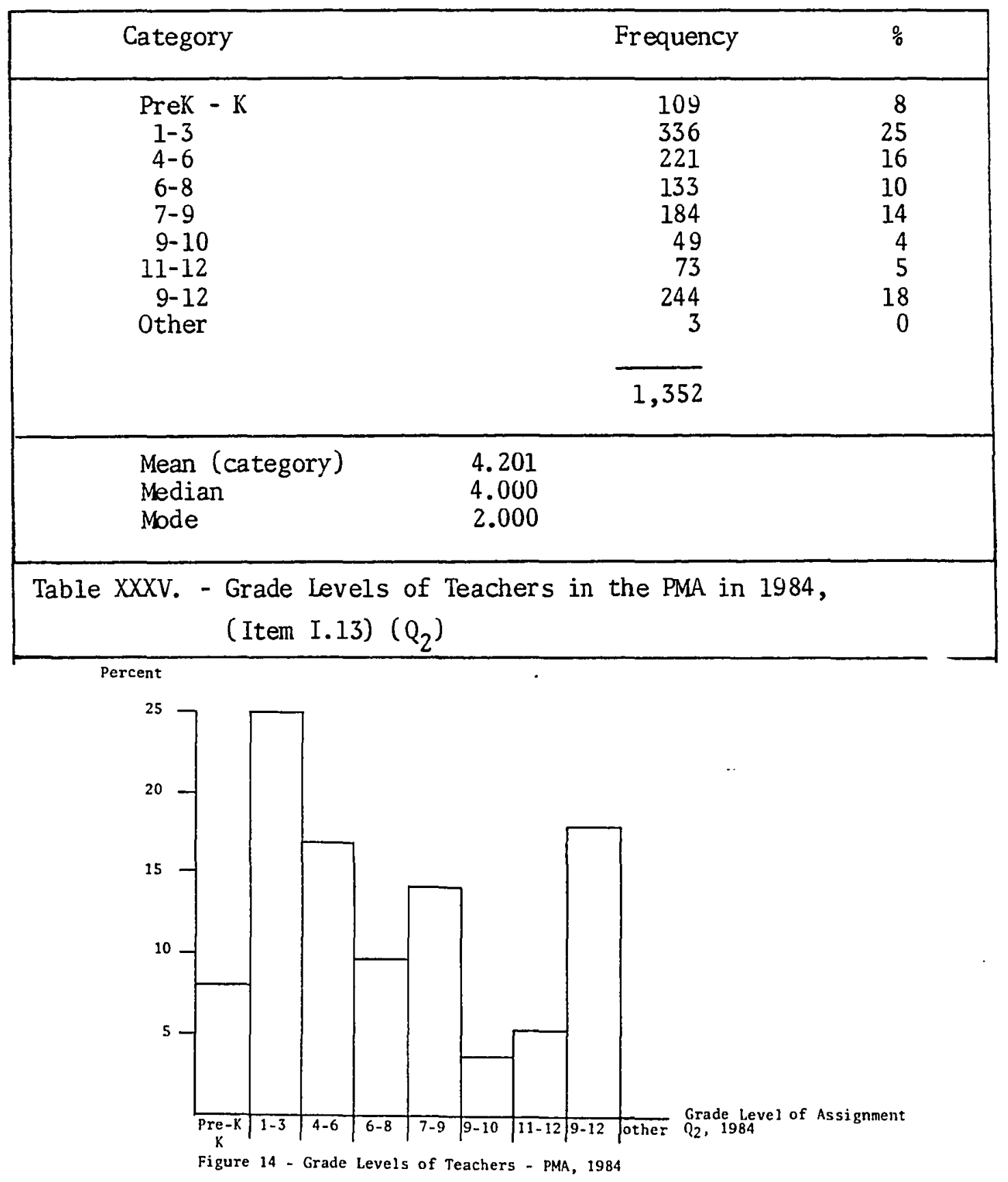


The participating school districts in 1981 and 1984 include early childhood education programs (Pre-K-K), primary schools with grade levels ranging from $\mathrm{K}-4$ through $\mathrm{K}-6$, elementary schools with grade levels ranging from $\mathrm{K}-8$; middle schools (6-8), junior high schools (7-9), and secondary schools with grade levels ranging from 9-12 and 10-12. Because the grade levels are not matched on the 1981 study (Q, Item 10) and the 1984 study (Q 2 , Item I.13), only limited data can be compared on the grade levels of assignment of the teachers responding in the two studies of the PMA. The 1981 study included no specific catery for Pre-K-K; in 1984, 8\% of the teachers report teaching at this primary level. In 1981, 39.1\% of the teachers indicated teaching at primary or elementary grade levels 1-3 and 4-6; in $1984,41 \%$ report teaching in similar assignments. In $1981,22.2 \%$ identified teaching at upper grade levels of 7-9; in 1984, 14\% report this assignment with an additional $10 \%$ at grades $6-8$ to total $24 \%$ at upper elementary or middle school or junior high grade levels. In 1981, 19.9\% noted teaching at upper or secondary grades 10-12. In 1984, $27 \%$ report teaching at upper or secondary grades 9-12. (See Table XXXVI.)

In 1981, the mean, median, and mode all fell at or near grades 7-9. In 1984, the mean is slightly above grade 6; the median is grades $6-8$; and the mode is grades $1-3$. (See Table XXXVI.)

The data on grade levels of assignments of teachers from the 1981 study and the 1984 study can be viewed alongside the data from the Nationwide Teacher Opinion Poll of 1983, reflecting national distributions of teachers by assignment from 1973, 1978, 1983 (See 


\begin{tabular}{|c|c|c|}
\hline Category & $Q_{1} \%$ & $U_{2} \frac{\circ}{6}$ \\
\hline PreK - K & & 8 \\
\hline $1-3$ & 19.3 & 25 \\
\hline $4-6$ & 19.8 & 16 \\
\hline $6-8$ & & 10 \\
\hline $7-9$ & 22.2 & 14 \\
\hline $9-1.0$ & & 4 \\
\hline $9-12$ & & 18 \\
\hline $10-12$ & 19.9 & \\
\hline $11-12$ & & 5 \\
\hline \multirow[t]{2}{*}{ Other } & 4.9 & \\
\hline & $\mathrm{N}=1,462$ & $\mathrm{~N}=1,352$ \\
\hline Mean (category) & 2.992 & 4.201 \\
\hline Median & 2.992 & 4.000 \\
\hline Mode & 3.000 & 2.000 \\
\hline \multicolumn{3}{|c|}{$\begin{array}{l}\text { Table XXXVI. - Grade Levels of Teachers in the PMA in } 1981\left(Q_{1}\right) \\
\text { and in } 1984\left(Q_{2}\right)\end{array}$} \\
\hline
\end{tabular}

Table XXXVII); however, this information is not provided to suggest a particular relationship or pattern, due to the many possibilities for grouping students by grade levels in the school districts with in the PMA: (See Table XXXVII.)

(3c.) To test the research hypothesis that there is a significant relationship between grade level of assignment and measures of satisfaction and that teachers of primary and lower grades will express greater satisfaction than teachers of higher and upper grades, bivariate correlational analyses (Kenda1l's tau) were 


\begin{tabular}{|llll|}
\hline $\begin{array}{l}\text { Distribution of Teachers } \\
\text { by Assignment }\end{array}$ & 1973 & 1978 & 1983 \\
\hline Elementary & $51 \%$ & $50 \%$ & $48 \%$ \\
Middle or Junior High & 22 & 18 & 21 \\
Senior High & 28 & 32 & 31 \\
\hline Table XXXVII. - National Demographic Data (Grade Levels/Assignment) \\
\hline
\end{tabular}

(NEA, 1983, Demographic Highlights, p. 6)

conducted on the measure of grade level (I.13) and each measure of satisfaction (using IV.46 and II.25 as the primary and secondary indicators). Findings from the statistical evaluations of satisfaction and grade level of assignment indicate that there is a weak and significant relationship between grade level and satisfaction. Teachers of primary or lower grades tend to be more satisfied than teachers of higher or upper grades.

The data were subjected to cross tabulations for additional findings, as follows: (See Tables XXXVIII, XXXIX.)

Table XXXVIII shows that $87.5 \%$ of the respondents at all grade levels express degrees of satisfaction; $6.1^{\circ}$ express neither satisfaction nor dissatisfaction; and $6.3 \%$ express degrees of dissatisfaction. At Pre-K-K levels, 88.9\% express degrees of satisfaction; $7.4 \%$ express neither satisfaction nor dissatisfaction; and $3.7 \%$ express degrees of dissatisfaction. At grades 1-3, 90.4\% express degrees of satisfaction; $4.2 \%$ express neither satisfaction nor dissatisfaction; and $5.4 \%$ express degrees of dissatisfaction. At 


\begin{tabular}{|c|c|c|c|c|c|c|}
\hline \multicolumn{2}{|l|}{ INDICATOR } & \multicolumn{5}{|c|}{ BY GRADE LEVEL } \\
\hline IV.46 FEELINGS ABOUT TEACHING & $\operatorname{PreK} / \mathrm{K}$ & $1-3$ & 4-6 & $\begin{array}{l}6-8 / \\
7-9 *\end{array}$ & $9-12$ & Raw Total \\
\hline Extremely satisfied & $\begin{array}{r}29 \\
26.9\end{array}$ & $\begin{array}{r}80 \\
24.1\end{array}$ & $\begin{array}{r}38 \\
17.3\end{array}$ & $\begin{array}{r}40 \\
12.9\end{array}$ & $\begin{array}{r}42 \\
11.7\end{array}$ & $\begin{array}{r}229 \\
17.2\end{array}$ \\
\hline Very satisfied & $\begin{array}{r}47 \\
43.5\end{array}$ & $\begin{array}{r}154 \\
46.4\end{array}$ & $\begin{array}{r}85 \\
38.6\end{array}$ & $\begin{array}{r}126 \\
40.5\end{array}$ & $\begin{array}{r}149 \\
41.4\end{array}$ & $\begin{array}{r}561 \\
42.1\end{array}$ \\
\hline More satisfied than not & $\begin{array}{r}20 \\
18.5\end{array}$ & $\begin{array}{r}66 \\
19.9\end{array}$ & $\begin{array}{r}75 \\
34.1\end{array}$ & $\begin{array}{r}93 \\
29.9\end{array}$ & $\begin{array}{r}122 \\
33.9\end{array}$ & $\begin{array}{r}376 \\
28.2\end{array}$ \\
\hline $\begin{array}{l}\text { Neither satisfied } \\
\text { nor dissatisfied }\end{array}$ & $\begin{array}{r}8 \\
7.4\end{array}$ & $\begin{array}{r}14 \\
4.2\end{array}$ & $\begin{array}{r}12 \\
5.5\end{array}$ & $\begin{array}{r}24 \\
7.7\end{array}$ & $\begin{array}{r}23 \\
6.4\end{array}$ & $\begin{array}{r}81 \\
6.1\end{array}$ \\
\hline $\begin{array}{l}\text { More dissatisfied } \\
\text { than satisfied }\end{array}$ & $\begin{array}{r}3 \\
2.8\end{array}$ & $\begin{array}{r}15 \\
4.5\end{array}$ & $\begin{array}{r}6 \\
2.7\end{array}$ & $\begin{array}{r}22 \\
7.1\end{array}$ & $\begin{array}{r}19 \\
5.3\end{array}$ & $\begin{array}{r}65 \\
4.9\end{array}$ \\
\hline Very dissatisfied & & $\begin{array}{l}1 \\
.3\end{array}$ & $\begin{array}{r}3 \\
1.4\end{array}$ & $\begin{array}{r}3 \\
1.0\end{array}$ & $\begin{array}{l}1 \\
.3\end{array}$ & $\begin{array}{r}8 \\
.6\end{array}$ \\
\hline Extremely dissatisfied & $\begin{array}{l}1 \\
.9\end{array}$ & $\begin{array}{r}2 \\
.6\end{array}$ & $\begin{array}{l}1 \\
.5\end{array}$ & $\begin{array}{r}3 \\
1.0\end{array}$ & $\begin{array}{r}3 \\
.8\end{array}$ & $\begin{array}{l}10 \\
.8\end{array}$ \\
\hline Column Total & $\begin{array}{l}108 \\
8.1\end{array}$ & $\begin{array}{r}332 \\
24.9\end{array}$ & $\begin{array}{r}220 \\
16.5\end{array}$ & $\begin{array}{r}311 \\
27.0\end{array}$ & $\begin{array}{r}360 \\
27.0\end{array}$ & 1331 \\
\hline
\end{tabular}

*Grades 6-8 and 7-9 were coded together to reflect teachers assigned to upper elementary grades, iniddle schools, and junior high schools. 


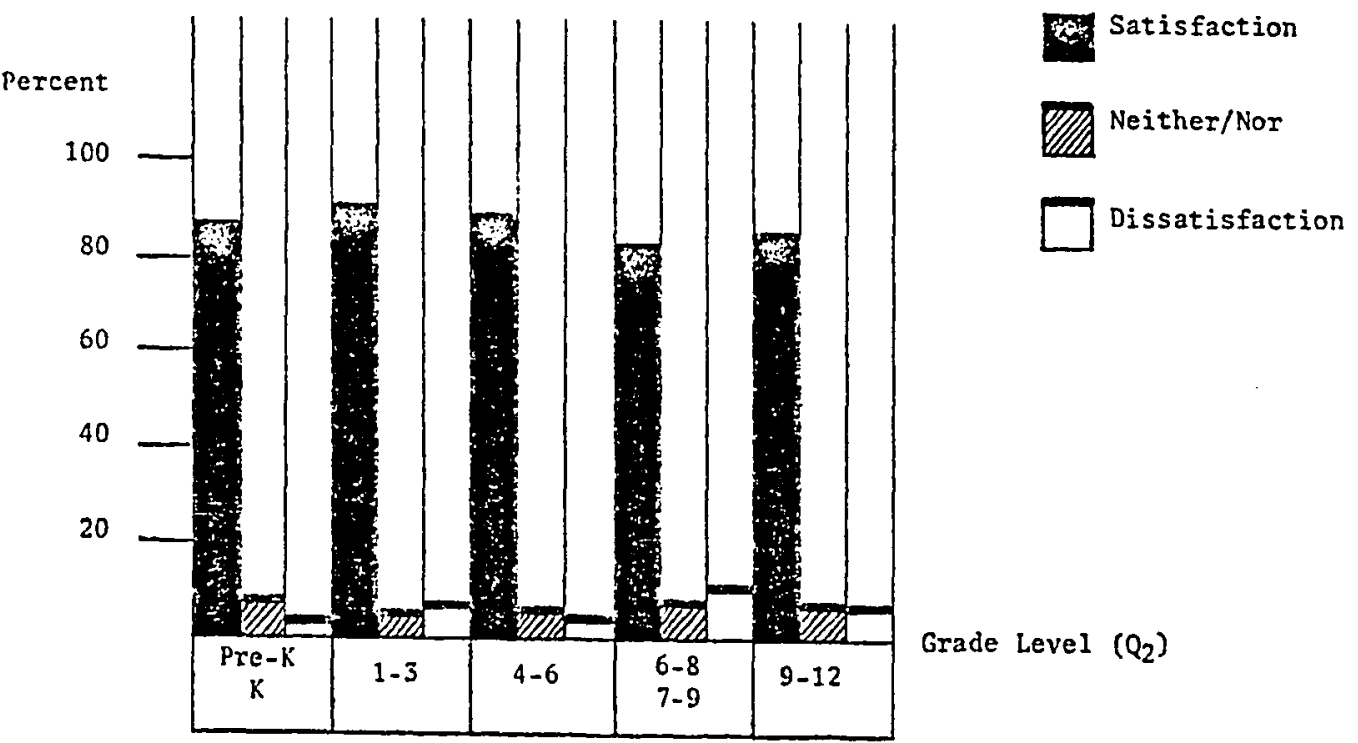

Figure 15 - Satisfaction Indicator (IV.46) By Grade Level, 1984

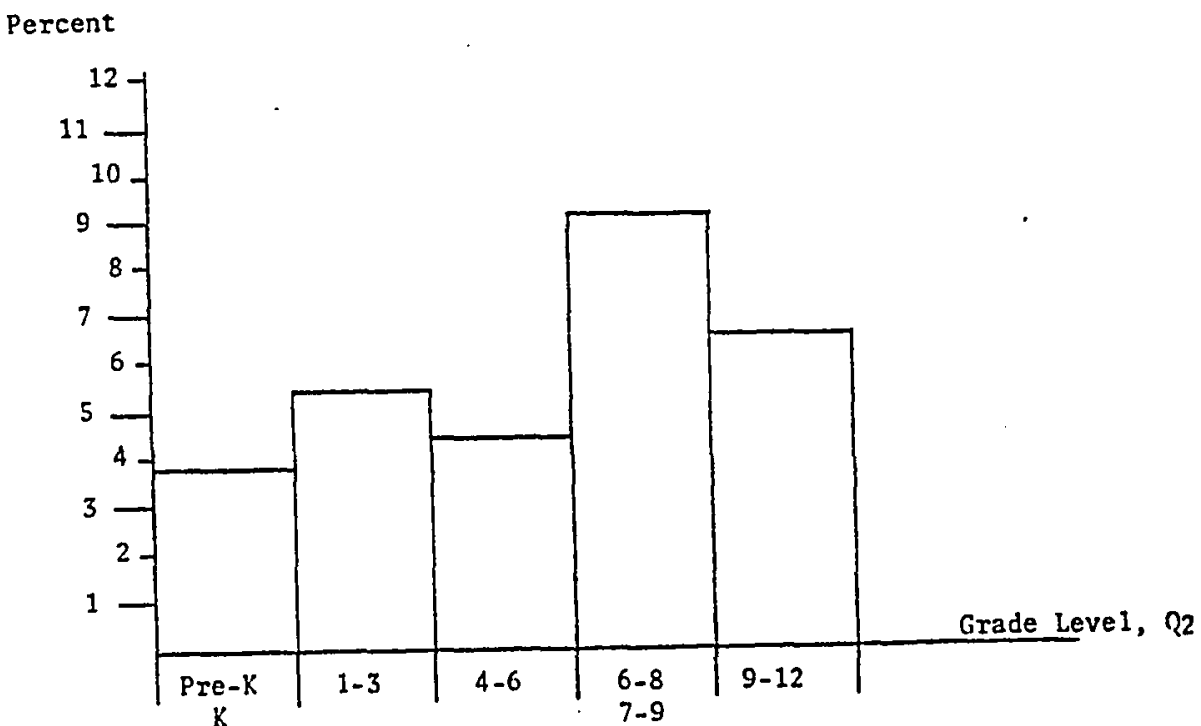

Figure 16 - Dissatisfaction Indicator (IV.46) by Grade Level, 1984 
grades $4-6,90 \%$ express degrees of satisfaction; $5.5 \%$ express neither satisfaction nor dissatisfaction; and $4.6 \%$ express degrees of dissatisfaction. At grades $6-8$ or $7-9,83.3 \%$ express degrees of satisfaction; 7.7\% express neither satisfaction nor dissatisfaction; and $9.1 \%$ express degrees of dissatisfaction. At grades 9-12, $87 \%$ express degrees of satisfaction; $6.4 \%$ express neither satisfaction nor dissatisfaction; and $6.4 \%$ express degrees of dissatisfaction. (See Table XXXVIII; See Figures 15 and 16.)

In support of the research prediction and findings from bivariate correlational analyses, Table XXXVIII shows that the highest percentage of satisfaction is expressed by teachers assigned at grade levels 1-3 (closely followed by teachers assigned through grade levels 4-6); the lowest percentage of satisfaction is expressed by teachers assigned at grades $6-8$ or 7-9. The lowest percentage of those expressing neither satisfaction nor dissatisfaction is shown by teachers at grade levels 1-3; the highest percentage for this category is found at grades $6-8$ or 7-9. The highest percentage of dissatisfaction is expressed by teachers at grades $6-8$ or $7-9$; the lowest percentage of dissatisfaction is expressed by teachers at Pre-K-K levels. From Pre-K-K through grades 4-6, teachers express higher percentages of satisfaction than do teachers assigned to upper grades $6-8,7-9,9-12$; however, teachers assigned to teach at grade levels 9-12 report an increase in expressed satisfaction over the teachers assigned at grades 6-8 or 7-9--junior high and middle school grades or upper grades in elementary schools or junior high and middle school grades. (See Table XXXVIII; See Figures 15 and 16.) 


\begin{tabular}{|c|c|c|c|c|c|c|}
\hline INDICATOR & & & BY G & E LEVEL & & \\
\hline II.25 HOW SATISFIED WITH ROLE & PreK/K & $1-3$ & $4-6$ & $\begin{array}{l}6-8 / \\
7-9 *\end{array}$ & $9-12$ & Raw Total \\
\hline Very satisfied & $\begin{array}{r}57 \\
52.3\end{array}$ & $\begin{array}{r}166 \\
49.6\end{array}$ & $\begin{array}{r}96 \\
43.4\end{array}$ & $\begin{array}{r}104 \\
32.9\end{array}$ & $\begin{array}{r}117 \\
32.2\end{array}$ & $\begin{array}{r}540 \\
40.2\end{array}$ \\
\hline Somewhat satisfied & $\begin{array}{r}41 \\
37.6\end{array}$ & $\begin{array}{r}140 \\
41.8\end{array}$ & $\begin{array}{r}99 \\
44.8\end{array}$ & $\begin{array}{r}143 \\
45.3\end{array}$ & $\begin{array}{r}189 \\
52.1\end{array}$ & $\begin{array}{r}612 \\
45.5\end{array}$ \\
\hline $\begin{array}{l}\text { Neither satisfied } \\
\text { nor dissatisfied }\end{array}$ & $\begin{array}{r}6 \\
5.5\end{array}$ & $\begin{array}{r}15 \\
4.5\end{array}$ & $\begin{array}{r}12 \\
5.4\end{array}$ & $\begin{array}{r}35 \\
11.1\end{array}$ & $\begin{array}{r}27 \\
7.4\end{array}$ & $\begin{array}{r}95 \\
7.1\end{array}$ \\
\hline Somewhat dissatisfied & $\begin{array}{r}4 \\
3.7\end{array}$ & $\begin{array}{r}14 \\
4.2\end{array}$ & $\begin{array}{r}13 \\
5.9\end{array}$ & $\begin{array}{r}28 \\
8.9\end{array}$ & $\begin{array}{r}25 \\
6.9\end{array}$ & $\begin{array}{r}84 \\
6.3\end{array}$ \\
\hline Very dissatisfied & $\begin{array}{r}1 \\
.9\end{array}$ & & $\begin{array}{r}1 \\
.5\end{array}$ & $\begin{array}{r}6 \\
1.9\end{array}$ & $\begin{array}{r}5 \\
1.4\end{array}$ & $\begin{array}{r}13 \\
1.0\end{array}$ \\
\hline Column Tota1 & $\begin{array}{l}109 \\
8.1\end{array}$ & $\begin{array}{r}335 \\
24.9\end{array}$ & $\begin{array}{r}221 \\
16.4\end{array}$ & $\begin{array}{r}316 \\
23.5\end{array}$ & $\begin{array}{r}363 \\
27.0\end{array}$ & 1344 \\
\hline
\end{tabular}

*Grades six-eight and seven-nine were coded together to reflect teachers assigned to upper elementary grades, middle schools, and junior high schools. 
Table XXXIX shows that $85.7 \%$ of the respondents at all grade levels express degrees of satisfaction; $7.1 \%$ express neither satisfaction nor dissatisfaction; and $7.3 \%$ express degrees of dissatisfaction. At Pre-K-K levels, 89\% express degrees of satisfaction; $5.5 \%$ express neither satisfaction nor dissatisfaction; and $4.5 \%$ express degrees of dissatisfaction. At grade levels 1-3, 91.4\% express degrees of satisfaction; $4.5 \%$ express neither satisfaction nor dissatisfaction; and $4.2 \%$ express degrees of dissatisfaction. At grades 4-6, 88.2\% express degrees of satisfaction; $5.4 \%$ express neither satisfaction nor dissatisfaction; and $6.5 \%$ express degrees of dissatisfaction. At grades 6-8 or 7-9, $78.2 \%$ express degrees of satisfaction; those expressing neither satisfaction nor dissatisfaction increases to $11.1 \%$; and those expressing degrees of dissatisfaction increases to $10.8 \%$. At grades $9-12, \quad 84.3 \%$ express degrees of satisfaction; $7.4 \%$ express neither satisfaction nor dissatisfaction; and $8.3 \%$ express degrees of dissatisfaction. (See Table XXXIX.)

In support of the research prediction and findings from bivariate correlational analyses, Table XXXIX shows that the highest percentage of satisfaction is expressed by teachers assigned at grade levels from 1-3; the lowest percentage of satisfaction is expressed by teachers assigned at grade levels from 6-8 or 7-9. The lowest percentage of those expressing neither satisfaction nor dissatisfaction is reported at grades 1-3; the highest percentage for this category is marked by the abrupt increase at grades $6-8$ or 7-9. The highest percentage of dissatisfaction is expressed by teachers assigned at grade levels from 
6-8 or 7-9; the lowest percentage of dissatisfaction is expressed by teachers assigned at grade levels from 1-3. From Pre-K through 4-6, teachers express higher percentages of satisfaction than do the teachers assigned to upper grades $(6-8,7-9,9-12)$; however, teachers assigned to teach at grade levels 9-12 indicate an increase in expressed satisfaction over the teachers assigned at grades 6-8 or 7-9--junior high and middle school grades or upper grades in elementary schools. (See Table XXXIX.)

Tables XXXVIII and XXXIX both show:

- high percentages of expressions of satisfaction with teaching at all grade levels of the PMA.

- the highest percentages of satisfaction are expressed by teachers assigned at grade levels from 1-3.

- the nighest percentages of dissatisfaction are expressed by teachers assigned at grade levels from 6-8 or 7-9.

- that teachers assigned from Pre-K through 4-6 express greater satisfaction with teaching than do the teachers assigned at grades from $6-8,7-9$, or $9-12$.

- an increase in satisfaction between teachers at upper grades 6-8 or 7-9 and teachers at the traditional secondary levels of grades 9-12.

(See Tables XXXVIII and XXXIX.)

These tables not only draw attention to the reported satisfaction levels of the teachers assigned at primary or lower grades, but they also draw attention to the recorded decrease in satisfaction levels of the teachers assigned to the upper elementary or middle or junior high grade levels. (See Figures 15 and 16.)

Summary (Grade Levels) (3c.). The findings from bivariate correlational studies (Kendall's tau) indicate that there is a weak 
and significant relationship between grade levels and satisfaction. Among a generally satisfied group of teachers at all grade levels, the teachers of primary or lower grades tend to be more satisfied than the teachers at higher or upper grades. (See Table XVII.)

The findings from cross tabulations of categories of grade levels and satisfaction suggest that teachers in the primary or lower grades express nigher percentages of satisfaction than do the teachers in the higher or upper grades. The highest percentages of those expressing neither satisfaction nor dissatisfaction and of those expressing degrees of dissatisfaction are noted for teachers of grades 6-8 or 7-9 --the middle school, junior high, or upper elementary grades. Teachers at the traditional secondary levels (grades 9-12) record an increase in satisfaction over teachers at the upper elementary or middle or junior high school levels. (See Tables XXXVIII, XXXIX.)

These data conform with findings from Bentzen, Williams, and Heckman (1980), associated with the Goodlad research on "Effective Schools," that elementary teachers are more satisfied with their jobs than are secondary teachers (pp. 394-397). However, the data from teachers in the PMA would suggest that teachers through grades 4-6 are more satisfied than teachers at grades $6-8$ or $7-9$, and that secondary teachers (9-12) are more satisfied than teachers at grades 6-8 or 7-9.

Years in Service (3d.). The population studied in 1984 includes teachers ranging from one through more than thirty-five years in service. The mean falls in the category of slightly more than fifteen years in service $(16-20)$. The median and mode are represented by 
teachers with 11-15 years in service. Thirty-six percent of the teachers studied have fewer than 11-15 years in service; $24 \%$ have 11-15 years of service; and $40 \%$ have more than fifteen years of service. (See Table XL; See Figure 17.)

\begin{tabular}{|c|c|c|c|}
\hline Category & & Frequency & $\%$ \\
\hline $1-5$ & & 200 & 14 \\
\hline $6-10$ & & 309 & 22 \\
\hline $11-15$ & & 342 & 24 \\
\hline $16-20$ & & 277 & 19 \\
\hline $21-25$ & & 150 & 10 \\
\hline $26-30$ & & 90 & 6 \\
\hline $31-35$ & & 54 & 4 \\
\hline \multirow[t]{2}{*}{ More than 35} & & 14 & 1 \\
\hline & & 1,436 & \\
\hline $\begin{array}{l}\text { Mean (category) } \\
\text { Median } \\
\text { Mode }\end{array}$ & $\begin{array}{l}3.295 \\
3.000 \\
3.000\end{array}$ & & \\
\hline Table XL. - Total Years & i & AA, 198 & \\
\hline
\end{tabular}

Comparative data from the study completed in 1981 mark an increase in the years of service of teachers in the PMA in 1984. In $1981,17.7 \%$ of the teachers record from 1-5 years of service; in 1984, the percentage in this category is down to $14 \%$. In $1981,25.2 \%$ report 6-10 years of service; in 1984, the percentage in this category is down to $22 \%$. In $1981,34.9 \%$ record $11-20$ years of service; in 1984, 

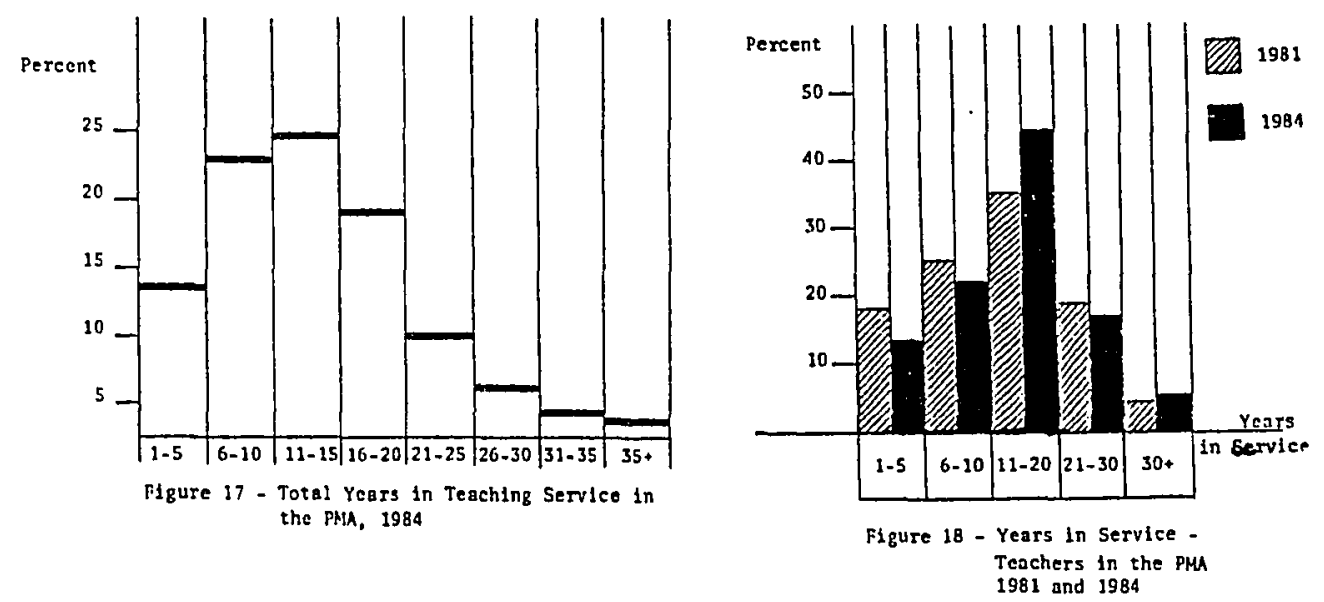

the percentage in this category is up to $43 \%$. In $1981,18.1 \%$ report 21-30 years of service; in 1984, the percentage in this category is at $16 \%$. In 1981, $4.2 \%$ chart more than 30 years of service; in 1984, $5 \%$ note more than thirty years of service. In 1981, the mean is represented by 11-20 years of service (or slightly more than ten years of service); in 1984, the mean is represented by $21-30$ years of service (or slightly more than twenty years of service). In both studies, the mode is represented by $11-20$ years of service. (See Table XLI; see Figure 18.)

These data suggest an apparent tendency for teachers in the PMA in 1984 to represent a population with more years in service than was found in 1981. Some of the variations might be due to sampling; however, the appearance of a trend is worthy of consideration in terms 
of potential for impact and implication for personnel services. (See Table XLI; See Figure 18.)

\begin{tabular}{|lcc|}
\hline Category & $Q_{1} \%$ & $Q_{2} \%$ \\
\hline $1-5$ & 17.7 & 14 \\
$6-10$ & 25.2 & 22 \\
$11-20$ & 34.9 & 43 \\
$21-30$ & 18.1 & 16 \\
More than 30 & 4.2 & 5 \\
& & \\
\hline Mean (category) & 2.659 & 3.295 \\
Median & 3.702 & 3.000 \\
Mode & 3.000 \\
\hline Table XLI. - Compared Years in Service of Teachers in the PMA \\
in 1981 (Item 3) and 1984 (Item I.6) \\
\hline
\end{tabular}

The data indicating an apparent increase in the total years of teaching service are also reflected in the demographic data from the Nationwide Teacher Opinion Poll of 1983, charting mean years of service from 1973, 1978, and 1983, as follows: (See Table XLII.)

\begin{tabular}{|lccc|}
\hline Teaching Experience--Mean Years & 1973 & 1978 & 1983 \\
\hline $\begin{array}{l}\text { Total years in teaching - mean } \\
\text { Total years in present } \\
\text { system--mean }\end{array}$ & $11 \%$ & $12 \%$ & $15 \%$ \\
\hline Table XLII. - National Demographic Data (Years in Service) & \\
\hline
\end{tabular}

(NEA, 1983, Demographic Highlights, p. 6) 
These data could be summarized to suggest that there are fewer new teachers in the ranks, with from 1-10 years in service; there are more teachers with from 11-20 years of service; and the numbers of teachers with more than 20 years of service are remaining fairly constant. This seems to suggest that the mean for years of service is not only increasing in the PMA and across the nation but also that this increase is a signal of a trend or change in the profile of teachers in the classrooms in public school systems. (See Tables XL, XLI, XLII; See Figures 17-18.)

The current study does not presume to address all the issues that may be related to the present indicators, but it does provide some data on the relationship between years of service and measures of satisfaction.

(3d.) To test the research hypothesis that there is a significant relationship between years in service and satisfaction, bivariate correlational analyses (Kendall's tau) were conducted on the measure of years in service (I.6) and on each measure of satisfaction (using IV.46 and II.25 as the primary and secondary indicators). Findings from the statistical evaluations indicate that there is a nonsignificant, inverse relationship between years in service and satisfaction. Although there appears to be a tendency for teachers with greater numbers of years in service to reflect more job satisfaction than teachers with fewer years in service, the apparent tendency is nonsignificant. (See Table XXIII.)

The data were subjected to cross tabulations for additional findings, as follows: (See Tables XLIII, XLIV.) 
Table XLIII shows that over all categories of years in service, $87.8 \%$ of the teachers express degrees of satisfaction; $6.0 \%$ express neither satisfaction nor dissatisfaction; and $6.0 \%$ express degrees of dissatisfaction. In a group that is generally very satisfied with service in teaching, $86.2 \%$ express satisfaction in the category of 1-5 years in teaching; $87.9 \%$ express satisfaction in the category of 6-10 total years; $86.6 \%$ express satisfaction in the category of 11-15 total years; $90.5 \%$ express satisfaction in the categories of 16-20 and 21-25 total years; $83.3 \%$ express satisfaction in the category of $26-30$ total ars; $86.8 \%$ express satisfaction in the category of $31-35$ total years; and $92.8 \%$ express satisfaction in the category of over 35 total years of service. (See Table XIIII; See Figure 19.)

The highest percentage of expressions of satisfaction is noted by those with more than 35 years of service, closely followed by those with from 16-25 total years of service; the lowest percentage of expressions of satisfaction is indicated by those with from 26-30 total years of service. (See Table XLIII; See Figure 19.)

Over all categories of years of service, $6.0 \%$ express degrees of dissatisfaction. In the category $1-5$ years, $7.7 \%$ express degrees of dissatisfaction. In the category 6-10 yaers, $7.2 \%$ express degrees of dissatisfaction. In the category 11-15 years, $6 \%$ express degrees of dissatisfaction. In the category $16-20$ years, $3.6 \%$ express degrees of dissatisfaction. In the category 21-25 years, $4.8 \%$ express degrees of dissatisfaction. In the category 26-30 years, the expressed degrees of dissatisfaction increase sharply to $11.1 \%$. Only one respondent ( $1.9 \%$ ) notes degrees of dissatisfaction in the category 31-35 years. And, 


\begin{tabular}{|c|c|c|c|c|c|c|c|c|c|}
\hline INDICATOR & & & & TOTAL Y & ARS IN & EACHING & & & \\
\hline IV.46 FEELINGS ABOUT TEACHING & $1-5$ & $6-10$ & $11-15$ & $16-20$ & $21-25$ & $26-30$ & $31-35$ & $\begin{array}{l}\text { Over } \\
35\end{array}$ & $\begin{array}{l}\text { Raw } \\
\text { Total }\end{array}$ \\
\hline Extremely satisfied & $\begin{array}{r}30 \\
15.4\end{array}$ & $\begin{array}{r}51 \\
16.6\end{array}$ & $\begin{array}{r}56 \\
16.7\end{array}$ & $\begin{array}{r}48 \\
17.6\end{array}$ & $\begin{array}{r}20 \\
13.5\end{array}$ & $\begin{array}{r}21 \\
23.3\end{array}$ & $\begin{array}{r}8 \\
15.1\end{array}$ & $\begin{array}{r}8 \\
57.1\end{array}$ & $\begin{array}{r}242 \\
17.1\end{array}$ \\
\hline Very satisfied & $\begin{array}{r}84 \\
43.1\end{array}$ & $\begin{array}{r}122 \\
39.7\end{array}$ & $\begin{array}{r}138 \\
41.2\end{array}$ & $\begin{array}{r}132 \\
48.4\end{array}$ & $\begin{array}{r}69 \\
46.6\end{array}$ & $\begin{array}{r}31 \\
34.4\end{array}$ & $\begin{array}{r}24 \\
45.3\end{array}$ & $\begin{array}{r}2 \\
14.3\end{array}$ & $\begin{array}{r}602 \\
42.5\end{array}$ \\
\hline More satisfied than not & $\begin{array}{r}54 \\
27.7\end{array}$ & $\begin{array}{r}97 \\
31.6\end{array}$ & $\begin{array}{r}96 \\
28.7\end{array}$ & $\begin{array}{r}67 \\
24.5\end{array}$ & $\begin{array}{r}45 \\
30.4\end{array}$ & $\begin{array}{r}23 \\
25.6\end{array}$ & $\begin{array}{r}14 \\
26.4\end{array}$ & $\begin{array}{r}3 \\
21.4\end{array}$ & $\begin{array}{r}399 \\
28.2\end{array}$ \\
\hline $\begin{array}{l}\text { Neither satisfied } \\
\text { nor dissatisfied }\end{array}$ & $\begin{array}{r}12 \\
6.2\end{array}$ & $\begin{array}{r}15 \\
4.9\end{array}$ & $\begin{array}{r}25 \\
7.5\end{array}$ & $\begin{array}{r}15 \\
5.5\end{array}$ & $\begin{array}{r}7 \\
4.7\end{array}$ & $\begin{array}{r}5 \\
5.6\end{array}$ & $\begin{array}{r}6 \\
11.3\end{array}$ & & $\begin{array}{r}85 \\
6.0\end{array}$ \\
\hline $\begin{array}{l}\text { More dissatisfied } \\
\text { than satisfied }\end{array}$ & $\begin{array}{r}13 \\
6.7\end{array}$ & $\begin{array}{r}17 \\
5.5\end{array}$ & $\begin{array}{r}16 \\
4.8\end{array}$ & $\begin{array}{r}6 \\
2.2\end{array}$ & $\begin{array}{r}5 \\
3.4\end{array}$ & $\begin{array}{r}8 \\
8.9\end{array}$ & $\begin{array}{r}1 \\
1.9\end{array}$ & $\begin{array}{r}1 \\
7.1\end{array}$ & $\begin{array}{r}67 \\
4.7\end{array}$ \\
\hline Very dissatisfied & $\begin{array}{r}1 \\
.5\end{array}$ & $\begin{array}{r}2 \\
.7\end{array}$ & $\begin{array}{l}1 \\
.3\end{array}$ & $\begin{array}{r}2 \\
.7\end{array}$ & $\begin{array}{r}2 \\
1.4\end{array}$ & $\begin{array}{r}1 \\
1.1\end{array}$ & & & $\begin{array}{r}9 \\
.6\end{array}$ \\
\hline Extremely dissatisfied & $\begin{array}{l}1 \\
.5\end{array}$ & $\begin{array}{r}3 \\
1.0\end{array}$ & $\begin{array}{r}3 \\
.9\end{array}$ & $\begin{array}{r}2 \\
.7\end{array}$ & & $\begin{array}{r}1 \\
1.1\end{array}$ & & & $\begin{array}{l}10 \\
.7\end{array}$ \\
\hline Column Total & $\begin{array}{r}195 \\
13.8\end{array}$ & $\begin{array}{r}307 \\
21.7\end{array}$ & $\begin{array}{r}335 \\
23.7\end{array}$ & $\begin{array}{r}273 \\
19.3\end{array}$ & $\begin{array}{r}148 \\
10.5\end{array}$ & $\begin{array}{r}90 \\
6.4\end{array}$ & $\begin{array}{r}53 \\
3.7\end{array}$ & $\begin{array}{r}14 \\
1.0\end{array}$ & 1415 \\
\hline
\end{tabular}




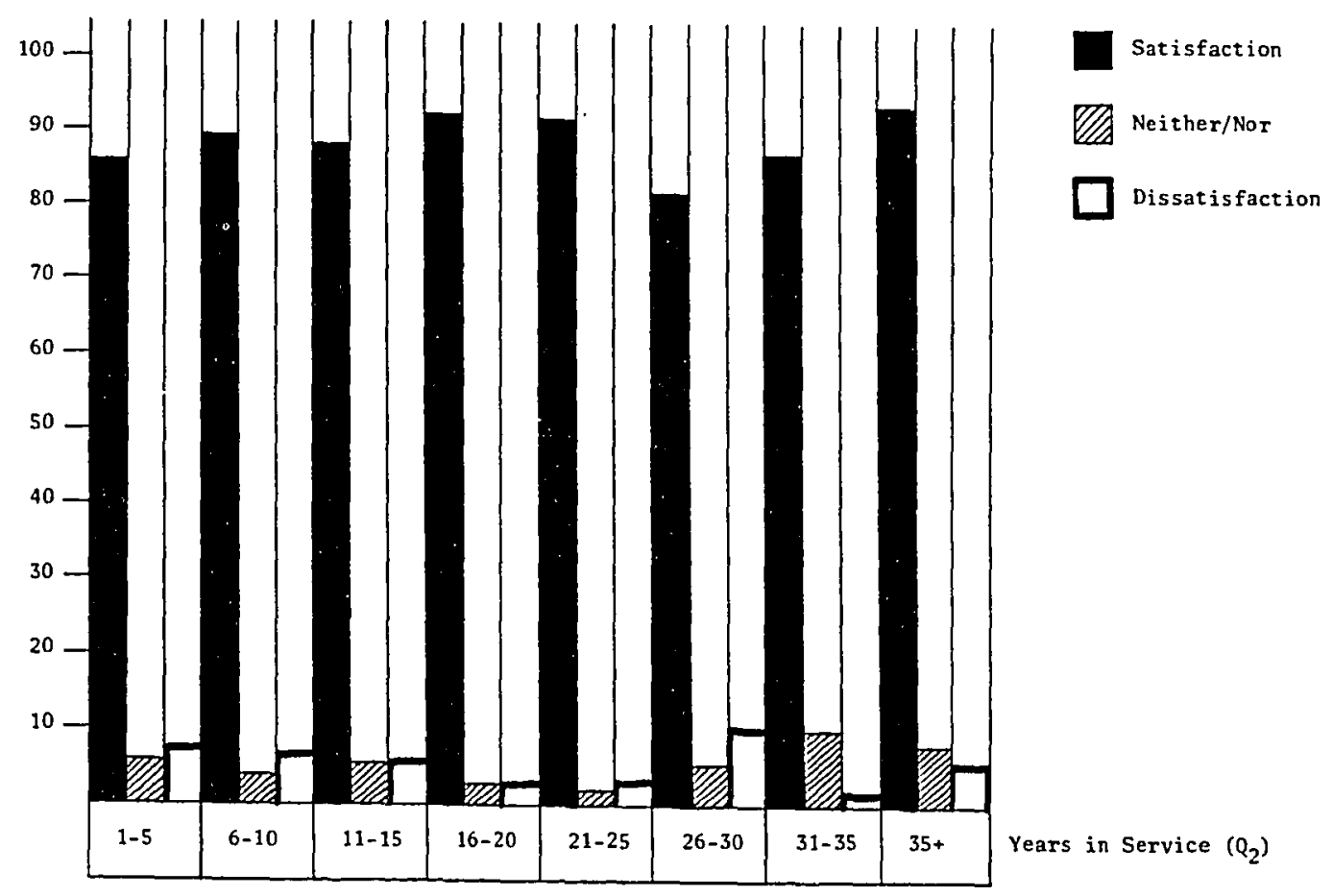

Figure 19 - Satisfaction Indicator (IV.46) By Years in Service, 1984

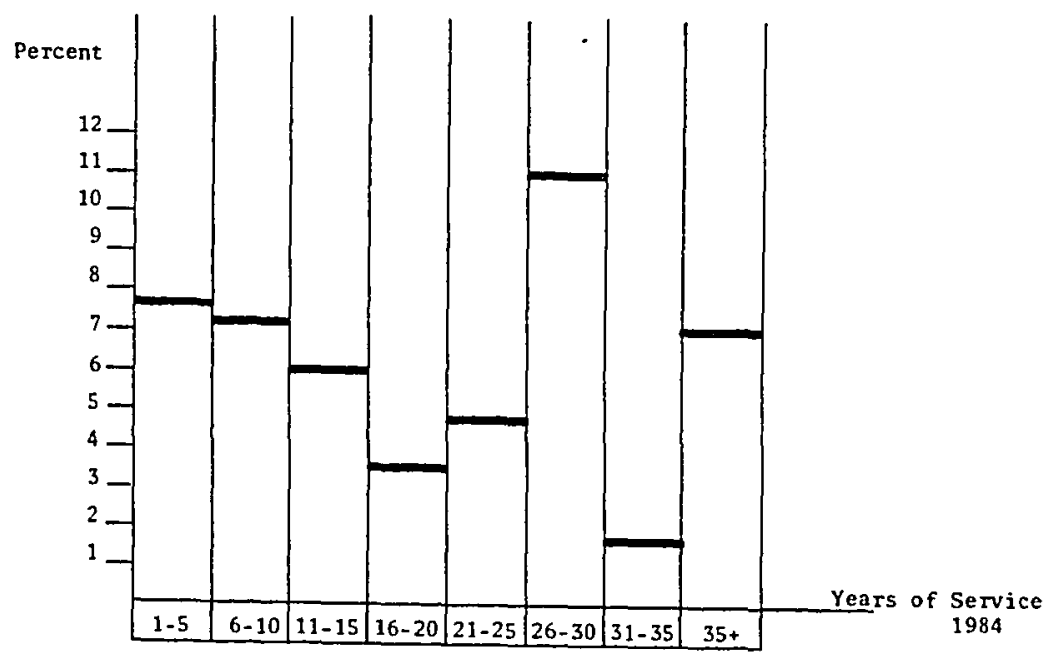

Figure 20 - Dissatisfaction Indicator (IV.46) By Years of Service, 1984 
again, only one respondent $(7.1 \%)$ reports degrees of dissatisfaction in the category of more than 35 years of service. (See Table XLIII; See Figure 20.)

The highest percentage of expressions of dissatisfaction is recorded by teachers with 26-30 years of service; the lowest percentage of expressions of dissatisfaction is reflected by the one respondent with from 31-35 years of service. If this percentage is exempted due to the small size of the cell, the next lowest percentage of dissatisfaction occurs in the category for 16-20 years. (See Table XXXVIII; See Figure 20.)

The highest percentage of expressions of being neither satisfied nor dissatisfied is charted by respondents with from 31-35 total years in teaching; the lowest percentage of expressions of being neither satisfied nor dissatisfied is shown by teachers with 21-25 years of service, and this figure is closely followed by teachers with from 6-10 years of service. (See Table XLIII; See Figure 19.)

Thus, although the teachers with the greater numbers of years of service reflect an apparent tendency to express greater satisfaction than the teachers with lesser numbers of years of service, the apparent tendency is nonsignificant. Consideration of these data should include address to the indicator of a sharp increase in dissatisfaction for some teachers with many years of teaching service. Additional consideration might be directed to the sharp increase in the expression of being neither satisfied nor dissatisfied that is suggested by teachers with $31-35$ years of service. (See 


\begin{tabular}{|c|c|c|c|c|c|c|c|c|c|}
\hline INDICATOR & & & & TOTAL Y & ARS IN & EACHING & & & \\
\hline II.25 HOW SATISFIED WITH ROLE & $1-5$ & $6-10$ & $11-15$ & $16-20$ & $21-25$ & $26-30$ & $31-35$ & $\begin{array}{l}\text { Over } \\
35\end{array}$ & $\begin{array}{l}\text { Raw } \\
\text { Tota1 }\end{array}$ \\
\hline Very satisfied & $\begin{array}{r}75 \\
37.9\end{array}$ & $\begin{array}{r}123 \\
39.9\end{array}$ & $\begin{array}{r}130 \\
38.2\end{array}$ & $\begin{array}{r}115 \\
41.7\end{array}$ & $\begin{array}{r}62 \\
41.3\end{array}$ & $\begin{array}{r}39 \\
43.3\end{array}$ & $\begin{array}{r}23 \\
42.6\end{array}$ & $\begin{array}{r}11 \\
78.6\end{array}$ & $\begin{array}{r}578 \\
40.4\end{array}$ \\
\hline Somewhat satisfied & $\begin{array}{r}92 \\
46.5\end{array}$ & $\begin{array}{r}144 \\
46.8\end{array}$ & $\begin{array}{r}159 \\
46.8\end{array}$ & $\begin{array}{r}131 \\
47.5\end{array}$ & $\begin{array}{r}66 \\
44.0\end{array}$ & $\begin{array}{r}34 \\
37.8\end{array}$ & $\begin{array}{r}23 \\
42.6\end{array}$ & 14.3 & $\begin{array}{r}651 \\
45.5\end{array}$ \\
\hline $\begin{array}{l}\text { Neither satisfied } \\
\text { nor dissatisfied }\end{array}$ & $\begin{array}{r}14 \\
7.1\end{array}$ & $\begin{array}{r}19 \\
6.2\end{array}$ & $\begin{array}{r}27 \\
7.9\end{array}$ & $\begin{array}{r}16 \\
5.8\end{array}$ & $\begin{array}{r}11 \\
7.3\end{array}$ & $\begin{array}{r}7 \\
7.8\end{array}$ & $\begin{array}{r}5 \\
9.3\end{array}$ & & $\begin{array}{r}99 \\
6.9\end{array}$ \\
\hline Somewhat dissatisfied & $\begin{array}{r}15 \\
7.6\end{array}$ & $\begin{array}{r}20 \\
6.5\end{array}$ & $\begin{array}{r}22 \\
6.5\end{array}$ & $\begin{array}{r}9 \\
3.3\end{array}$ & $\begin{array}{r}9 \\
6.0\end{array}$ & $\begin{array}{r}8 \\
8.9\end{array}$ & $\begin{array}{r}3 \\
5.6\end{array}$ & $\begin{array}{r}1 \\
7.1\end{array}$ & $\begin{array}{r}87 \\
6.1\end{array}$ \\
\hline Very dissatisfied & $\begin{array}{r}2 \\
1.0\end{array}$ & $\begin{array}{r}2 \\
.6\end{array}$ & $\begin{array}{r}2 \\
.6\end{array}$ & $\begin{array}{r}5 \\
1.8\end{array}$ & $\begin{array}{r}2 \\
1.3\end{array}$ & $\begin{array}{r}2 \\
2.2\end{array}$ & & & $\begin{array}{r}15 \\
1.0\end{array}$ \\
\hline Column Total & $\begin{array}{r}198 \\
13.8\end{array}$ & $\begin{array}{r}308 \\
21.5\end{array}$ & $\begin{array}{r}340 \\
23.8\end{array}$ & $\begin{array}{r}276 \\
19.3\end{array}$ & $\begin{array}{r}150 \\
10.5\end{array}$ & $\begin{array}{r}90 \\
6.3\end{array}$ & $\begin{array}{r}54 \\
3.8\end{array}$ & $\begin{array}{r}14 \\
1.0\end{array}$ & 1430 \\
\hline
\end{tabular}


Table XIIII; See Figures 19 and 20.)

Table XLIV shows that over all categories of years in service, $85.9 \%$ of the teachers express degrees of satisfaction; $6.9 \%$ express neither satisfaction nor dissatisfaction; and $7.1 \%$ express degrees of dissatisfaction. In a group that is generally very satisfied with service in teaching, $84.4 \%$ express satisfaction in the category of 1-5 total years in teaching; $86.7 \%$ express satisfaction in the category of 6-10 total years; $85.0 \%$ express satisfaction in the category of 11-15 total years; $89.2 \%$ express satisfaction in the category of 16-20 total years; $85.3 \%$ express satisfaction in the category of $21-25$ total years; $87.3 \%$ express satisfaction in the category of 26-30 total years; $85.2 \%$ express satisfaction in the category of 31-35 total years; and $92.9 \%$ express satisfaction in the category over 35 total years. (See Table XLIV.)

The highest percentage of expressions of satisfaction is recorded by those with more than 35 years of service; the next highest percentage is reflected by those with from 16-20 years of service. The lowest percentage of expressed satisfaction is charted by those with from 1-5 years of service. (See Table XLIV.)

Over all categories of years of service, $7.1 \%$ express degrees of dissatisfaction. In the category of $1-5$ total years, $8.6 \%$ express degrees of dissatisfaction. In both categories of 6-10 and 11-15 years, $7.1 \%$ express degrees of dissatisfaction. In the category of 16-20 years, $5.1 \%$ express degrees of dissatisfaction. In the category of 21-25 years, $7.3 \%$ express degrees of dissatisfaction. In the category of $26-30$ years, the percentage increases to $11.1 \%$. In the 
category of $31-35$ years, $5.6 \%$ report being somewhat dissatisfied; no respondent notes being very dissatisfied. In the category over 35 years, only one respondent reports being somewhat dissatisfied, to reflect $7.1 \%$. (See Table XLIV.)

The highest percentage of expressions of dissatisfaction is charted by teachers in the category of 26-30 years of service; the lowest percentage of expressions of dissatisfaction is marked by teachers in the category of 16-20 total years of service. (See Table XLIV.)

The highest percentage of expressions of being neither satisfied nor dissatisfied is reported by respondents with $31-35$ years of service; the lowest percentage of expressions of being neither satisfied nor dissatisfied is reflected by respondents with from 16-20 years of service. (See Table XLIV.)

Tables XLIII and XLIV both show:

- that the teacher population indicates a high degree of job satisfaction.

- that teachers with many years of service reflect a high degree of satisfaction, but the expressed satisfaction is not indicated to be significantly greater than that expressed by teachers with fewer years of service.

- that among very satisfied teachers with many years of service there are also those reporting to be neither satisfied nor dissatisfied or to be dissatisfied.

(See Tables XIIII, XLIV.)

Summary (Years of Service) (3d.). The data from 1981 and 1984 suggest an apparent trend for an increase in the total years of teaching service for the teachers in the PMA. (See Tables XL and XLI; See Figure 17.) This apparent trend is also reflected in data from 
NEA studies from 1973 through 1983 (1983). (See Table XLII.)

In a generally satisfied group, teachers with many years of service do not reflect greater satisfaction than those with fewer years in teaching. (See Tables XXIII, XIIII, XLIV.)

Cross tabulations suggest a high degree of satisfaction in teachers with many years of service, but the data also suggest apparent indications of an increase in being neither satisfied nor dissatisfied and an increase in dissatisfaction in teachers with many years of service. These indicators are worthy of additional consideration in terms of potential impact on the teaching population and the classrooms in public school systems. Thus, these indicators may be of significance to personnel services for public school systems. (See Tables XXIII, XLIII, XLIV; See Figures 17-20.)

Education (Highest Degree Earned) (3e.). The population studied in 1984 includes teachers with degrees from bachelor through doctoral. The mean falls between bachelor's and master's degree. The median and mode are represented by teachers holding a master's degree. The six teachers $(.4 \%)$ holding doctoral degrees do not represent a reflected percentage in the study. (See Table XLV.)

Comparative data from the study completed in 1981 suggest a very similar level of education (highest earned degree) for the teachers in the PMA in 1984. In 1981, 44\% held bachelor degrees; $55.1 \%$ held master degrees; and .9\% held doctoral degrees. In 1984, 45\% hold bachelor degrees; $55 \%$ hold master degrees, and six respondents (.4\%) hold doctoral degrees. (See Table XLVI, see Figure 22.)

The data from the teachers in the PMA in 1981 and 1984 show very 


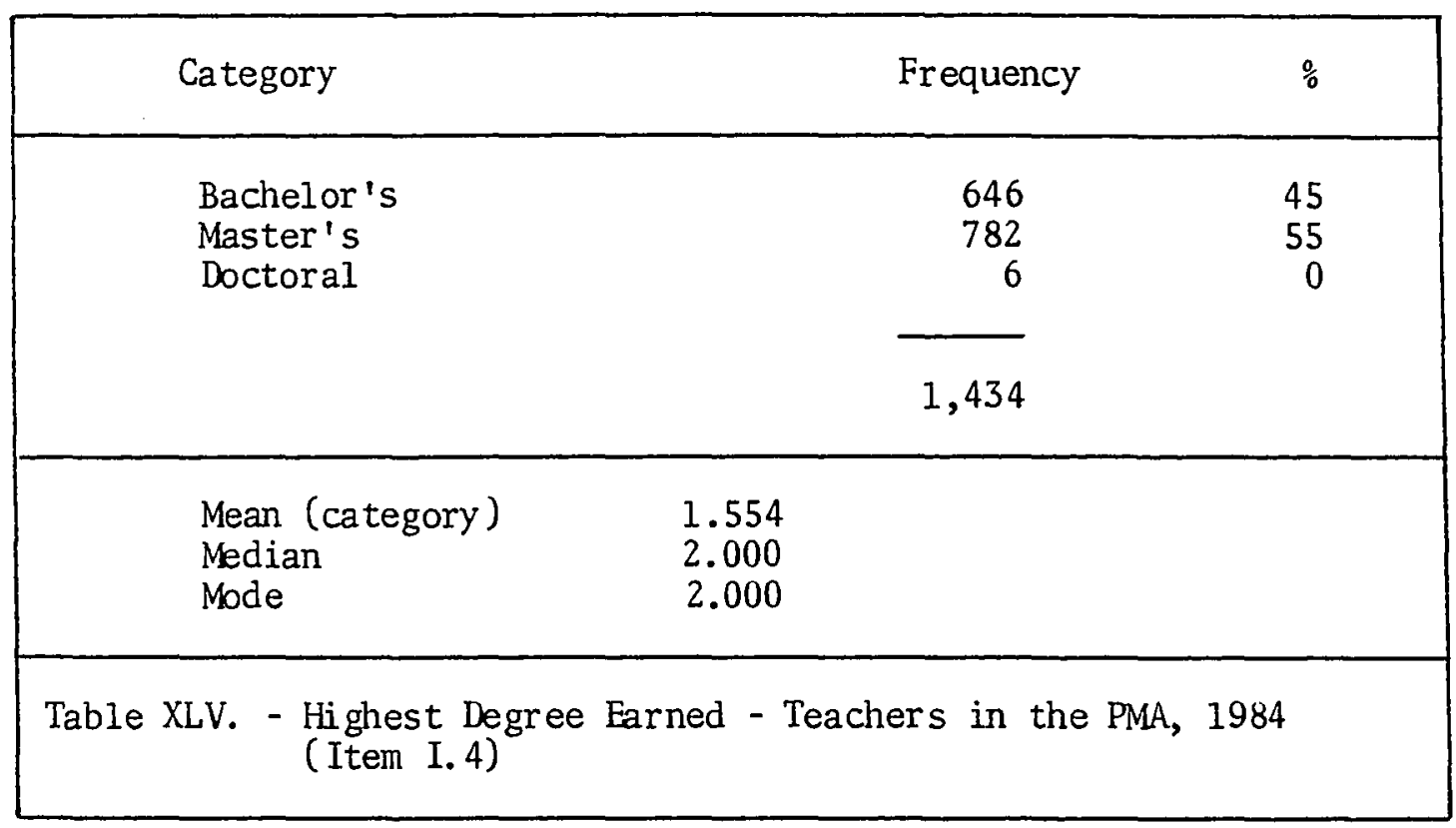

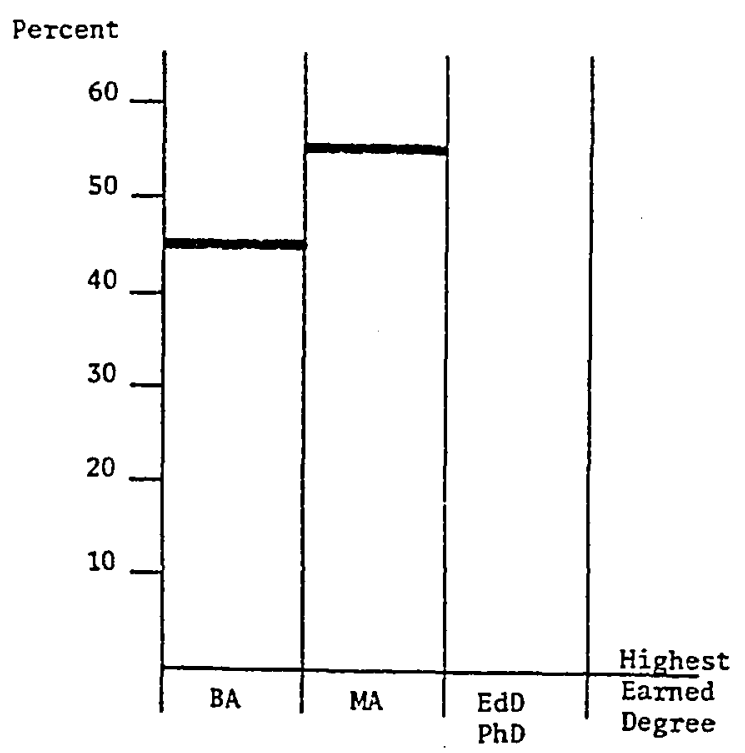

Figure 21 - Highest Earned Degree Teachers in the PMA, 1984 


\begin{tabular}{|c|c|c|}
\hline Category & $\mathrm{Q}_{1} \%$ & $Q_{2} \%$ \\
\hline Bachelor's & 44.0 & 45.0 \\
\hline Master's & 55.1 & 55.0 \\
\hline \multirow[t]{2}{*}{ Doctoral } & .9 & 0 \\
\hline & $(\mathrm{N}=1,526)$ & $(\mathrm{N}=1,434)$ \\
\hline $\begin{array}{l}\text { Mean (category) } \\
\text { Median } \\
\text { Mode }\end{array}$ & $\begin{array}{l}1.568 \\
1.608 \\
2.000\end{array}$ & $\begin{array}{l}1.554 \\
2.000 \\
2.000\end{array}$ \\
\hline $\begin{array}{r}\text { Table XLVI. - Compared } \\
\text { in the PV }\end{array}$ & gree Ear & E Teachers \\
\hline
\end{tabular}

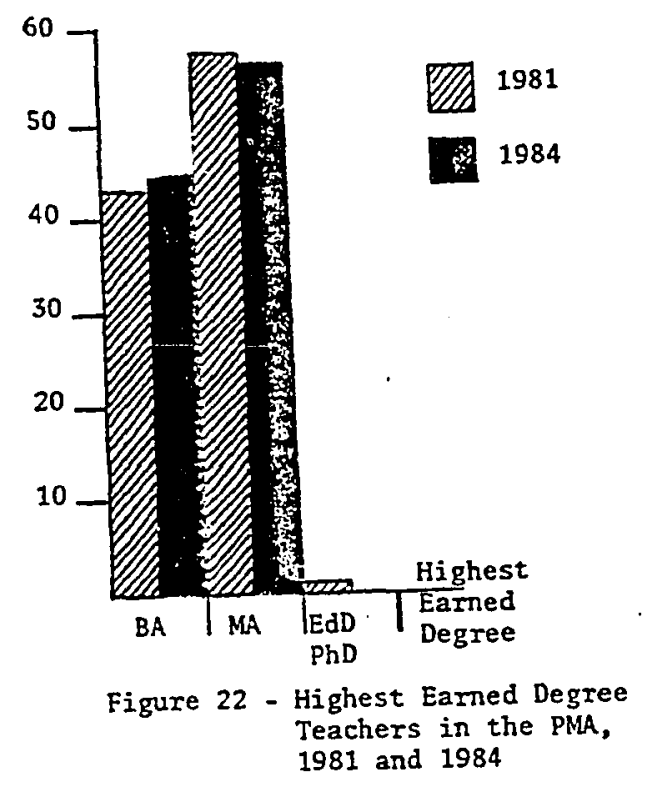


similar percentages for those holding academic degrees. (See Tables XLV, XLVI; See Figures 21, 22.) However, data from the Nationwide Teacher Opinion Poll, 1983, considering national indicators of highest degree held in 1973, 1978, and 1983, do suggest a trend toward increasing numbers of teachers earning their master's degree as follows: (See Table XLVII.)

\begin{tabular}{|lcccc|}
\hline Highest degree earned & 1973 & 1978 & 1983 & $\begin{array}{c}\text { (PMA } \\
\text { 1984) }\end{array}$ \\
\hline Bachelor's & $66 \%$ & $54 \%$ & $48 \%$ & $(45 \%)$ \\
Master's (or six years) & 33 & 46 & 52 & $(55)$ \\
Doctoral & 0 & 0 & 0 & $(0)$ \\
\hline Table XLVII. - National Demographic Data (High Academic Degree Earned) \\
\hline
\end{tabular}

(NEA, 1983, Demographic Highlights, p. 5)

It is appropriate to note that the percentages reflected by the teachers in the PMA appear to be slightly above the national indicators for teachers holding a master's degree. (See Table XLVII.)

These data could be summarized to suggest that the level of education for teachers in the PMA is relatively stable and that the PMA has a percentage of teachers holding master's degrees that is slightly higher than the percentages reflected nationally. (See Tables XLV, XLVI, XLVII.)

The current study does provide some data on the relationship between highest earned degree and measures of satisfaction, as reported by teachers in the PMA. 
(3e.) To test the research hypothesis that there is a significant relationship between highest degree earned and measures of satisfaction, bivariate correlational analyses (Kendall's tau) were conducted on the measure of highest degree earned (I.4) and on each measure of satisfaction (using IV.46 and II.25 as the primary and secondary indicators). Findings from the statistical evaluations provide evidence that there is a weak and nonsignificant inverse relationship between highest degree earned and satisfaction with teaching. Although there appears to be a tendency for teachers with higher degrees to reflect more job satisfaction than teachers with lower degrees, the apparent tendency is nonsignificant. Thus, this study does not provide evidence that teachers with higher degrees are more satisfied with teaching than teachers with lower degrees. (See Table XXIV.)

The data were subjected to cross tabulations for additional findings, as follows: (See Tables XLVIII, XLIX.)

Table XLVIII shows that over all categories of academic degrees held, $87.7 \%$ of the teachers express degrees of satisfaction; $6.1 \%$ express neither satisfaction nor dissatisfaction; and $6 \%$ express degrees of dissatisfaction. In a group that is generally very satisfied, $87.6 \%$ of the teachers with bachelor's degrees express degrees of satisfaction; and $89 \%$ of the teachers with master's degrees hold similar views. Of the six respondents holding doctoral degrees, 8.3.3\% (or five subjects) express degrees of satisfaction; however, the sample is very small $(.4 \%)$ and not subject to extensive analyses. (See Table XLVIII.) 


\begin{tabular}{|c|c|c|c|c|}
\hline INDICATOR & & BY HIC & REE EARNED & \\
\hline IV.46 FEELINGS ABOUT TEACHING & BA & MA & Doctora1 & Raw Tota1 \\
\hline Extremely satisfied & $\begin{array}{r}112 \\
17.6\end{array}$ & $\begin{array}{r}129 \\
16.7\end{array}$ & $\begin{array}{r}2 \\
33.3\end{array}$ & $\begin{array}{r}243 \\
17.2\end{array}$ \\
\hline Very satisfied & $\begin{array}{r}255 \\
40.1\end{array}$ & $\begin{array}{r}340 \\
44.0\end{array}$ & $\begin{array}{r}1 \\
16.7\end{array}$ & $\begin{array}{r}596 \\
42.1\end{array}$ \\
\hline More satisfied than not & $\begin{array}{r}190 \\
29.9\end{array}$ & $\begin{array}{r}210 \\
27.2\end{array}$ & $\begin{array}{r}2 \\
33.3\end{array}$ & $\begin{array}{r}402 \\
28.4\end{array}$ \\
\hline $\begin{array}{l}\text { Neither satisfied } \\
\text { nor dissatisfied }\end{array}$ & $\begin{array}{r}40 \\
6.3\end{array}$ & $\begin{array}{r}45 \\
5.8\end{array}$ & $\begin{array}{r}1 \\
16.7\end{array}$ & $\begin{array}{r}86 \\
6.1\end{array}$ \\
\hline $\begin{array}{l}\text { More dissatisfied } \\
\text { than satisfied }\end{array}$ & $\begin{array}{r}35 \\
5.5\end{array}$ & $\begin{array}{r}32 \\
4.1\end{array}$ & & $\begin{array}{r}67 \\
4.7\end{array}$ \\
\hline Very dissatisfied & $\begin{array}{r}1 \\
.2\end{array}$ & $\begin{array}{r}8 \\
1.0\end{array}$ & & $\begin{array}{r}9 \\
.6\end{array}$ \\
\hline Extremely dissatisfied & $\begin{array}{r}3 \\
.5\end{array}$ & $\begin{array}{r}7 \\
.9\end{array}$ & & $\begin{array}{l}10 \\
.7\end{array}$ \\
\hline Column Total & $\begin{array}{r}636 \\
45.0\end{array}$ & $\begin{array}{r}772 \\
54.6\end{array}$ & $\begin{array}{r}6 \\
.4\end{array}$ & 1414 \\
\hline
\end{tabular}




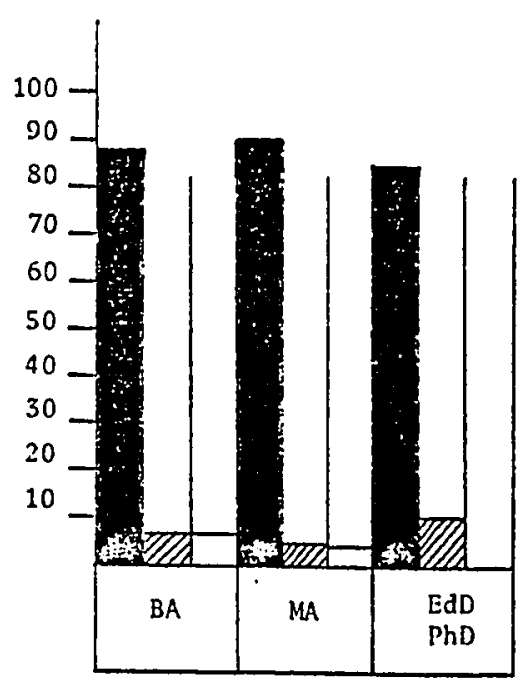

Figure 23 - Satisfaction Indicator (IV.46) by

Highest Degree Earned, 1984

-.- Highest Degree Earned -.-
Satisfaction

UNeither/Nor

$\square$ Dissatisfaction

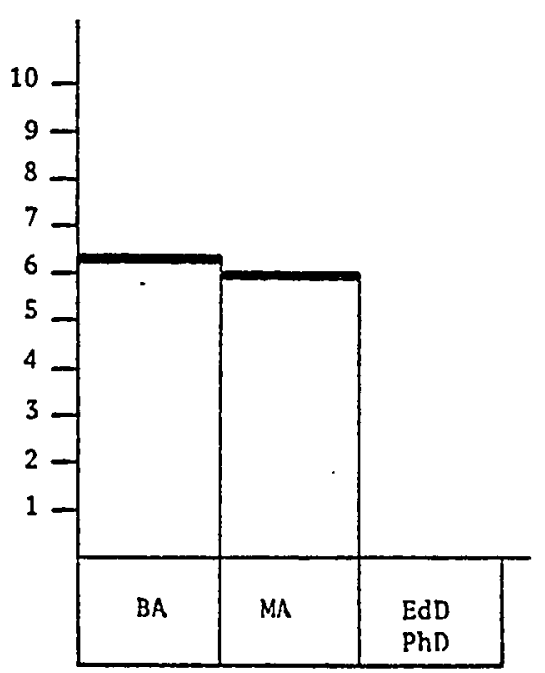

Figure 24 - Dissatisfaction Indicator (IV.46) by

Highest Degree Earned, 1984 
The percentages expressing satisfaction are very similar; however, those with master's degrees express slightly higher percentages of satisfaction than those with bachelor's degrees; and those with doctoral degrees express the lowest percentages of satisfaction. (See Figure 23.)

Over all categories of academic degrees, $6.0 \%$ express degrees of dissatisfaction. Of the holders of bachelor's degrees, $6.2 \%$ express degrees of dissatisfaction, and of the holders of master's degrees, $6.0 \%$ express degrees of dissatisfaction. Again, the percentages are very similar. The respondents holding doctoral degrees do not express dissatisfaction with teaching. (See Figure 24.)

Some small variation is noted in the percentages of those expressing neither satisfaction nor dissatisfaction. of those with bachelor's degrees, $6.3 \%$ express neither satisfaction nor dissatisfaction; of those with master's degrees, $5.8 \%$ express similarly; and of those with doctoral degrees, one respondent, representing $16.7 \%$, expresses this view.

Thus, these data show very similar percentages of responses within the categories of degree holders. The findings are nonsignificant, and the population, as a whole, indicates a high degree of satisfaction with teaching.

The data from this table might be summarized to suggest that the level of academic degree held is not a major factor contributing to job satisfaction of teachers in the PMA. (See Tables XXIV, XLVIII.)

Table XLIX shows that over all categories of academic degrees held, $85.8 \%$ of the teachers express degrees of satisfaction; $6.9 \%$ 


\begin{tabular}{|lrrrr|}
\hline \multicolumn{1}{|c}{ INDICATOR } & \multicolumn{3}{c|}{ BY HIGHEST DEGREE EARNED } \\
\hline II.25 HOW SATISFIED WITH ROLE & BA & MA & Doctoral & Raw Total \\
\hline & 251 & 322 & 2 & 575 \\
Very satisfied & 39.0 & 41.3 & 33.3 & 40.2 \\
& 301 & 347 & 3 & 651 \\
Somewhat satisfied & 46.8 & 44.5 & 50.0 & 45.6 \\
Nei ther satisfied & 45 & 53 & 1 & 99 \\
nor dissatisfied & 7.0 & 6.0 & 16.7 & 6.9 \\
Somewhat dissatisfied & 42 & 47 & & 89 \\
& 6.5 & 6.0 & & 15 \\
Very dissatisfied & 4 & 11 & & 1.0 \\
& .6 & 1.4 & 6 & 1429 \\
\hline Column Total & 643 & 780 & .4 & 1984 \\
\hline
\end{tabular}


express neither satisfaction nor dissatisfaction; and $7.2 \%$ express degrees of dissatisfaction. In a group that is generally very satisfied, $85.8 \%$ of those with bachelor's degrees and of those with master's degrees express satisfaction. Of the six respondents holding doctoral degrees, five (or $83.3 \%$ ) express satisfaction.

The percentages expressing satisfaction are identical for those with bachelor's and master's degrees, and very close for the small group of respondents with doctoral degrees.

Over all categories of academic degrees, $7.2 \%$ express degrees of dissatisfaction. Of those with bachelor's degrees, $7.2 \%$ express dissatisfaction, and of those with master's degrees, $7.4 \%$ express dissatisfaction. The respondents holding doctoral degrees do not express dissatisfaction. The reported percentages are almost identical and do not permit statistical evaluations of small differences that could be the result of the sampling. What may be considered is that more than $7 \%$ of the respondents express degrees of dissatisfaction.

In the group expressing neither satisfaction nor dissatisfaction, $7.0 \%$ of those with bachelor's degrees express this view, and $6.0 \%$ of those with master's degrees express similarly. One respondent with a doctoral degree, representing $16.7 \%$ of the category, selects this ranking.

Thus, these data indicate very similar responses across the categories of degree holders. The findings are nonsignificant, and the population, as a whole, expresses a high degree of satisfaction with teaching. 
Tables XLVIII and XLIX both show:

- a high degree of job satisfaction across all levels of degree holders.

- the level of academic degree held is not a major contributor to the job satisfaction of teachers in the PMA. (See Table XXIV.)

(See Tables XLVIII and XLIX.)

However, the group expressing neither satisfaction nor dissatisfaction or dissatisfaction should not be overlooked.

Summary (Highest Degree Earned) (3e.). The data from 1981 and 1984 suggest that teachers in the PMA may be slightly above national percentages for those holding master's degrees. At present, $45 \%$ hold bachelor's degrees, 55\% hold master's degrees, and of the group sampled, $.4 \%$ hold doctoral degrees. The percentages are very similar between 1981 and 1984 and do not reflect a trend in the PMA. (See Tables XL, XLI, XLII; See Figures 21, 22.)

In a generally satisfied group, teachers with higher earned degrees do not reflect greater satisfaction with teaching than those with lower degrees. (See Table XXIV.)

Cross tabulations suggest a high degree of satisfaction across all categories of academic degree levels. Percentages of those with bachelor's degrees and master's degrees are very similar on expressions of satisfaction and dissatisfaction, with a small difference in the percentage expressing neither satisfaction nor dissatisfaction. The single respondent holding a doctoral degree and expressing this view does not permit an extension of analyses. (See Tables XLVIII, XLIX; See Figures 23, 24.) 
However, along with a group of teachers that reports a high degree of job satisfaction, there are also those that express neither satisfaction nor dissatisfaction or dissatisfaction. The factors contributing to dissatisfaction are worthy of consideration; however, the data from this study do not support a prediction or conclusion that the level of academic degree held is a major contributor to job satisfaction or dissatisfaction of teachers in the PMA. (See Tables XLV, XLVI, XLVII, XLVIII, XLIX; See Figures 21, 22, 23, 24.)

Sumnary (Demographic Factors) (3a-e.) (Research Question \#3 and Findings). As a sumnary to the findings of Research Question \#3 and predictions that satisfaction and dissatisfaction will vary significantly as a function of each of the following factors of age, sex, grade level, years of service, and education (highest degree earned), statistical evaluations indicate that three of the demographic factors are significantly related to satisfaction and dissatisfaction and two are not.

The three demographic factors that indicate significant relationships to satisfaction and dissatisfaction are age (3a.), sex (3b.), and grade level of assignment (3c.):

Age (3a.) - There is a significant relationship between age and job satisfaction of teachers. The older teacher tends to be more satisfied than the younger teacher. Satisfaction levels appear to be highest for teachers 20-25 and the few remaining in teachers at ages over 65. Satisfaction levels appear to drop slightly for teachers 41-45 and 56-60. There is an increase in dissatisfaction between age categories 20-25 and 26-30 and again 
between 51-55 and 56-60 that may deserve additional study. There is an increase in expressions of being neither satisfied nor dissatisfied for teachers in the age categories 31-35 and 46-50. In addition, there is an apparent tendency toward an increase in the age of the teacher population in the PMA that is consistent with national indicators. (See Tables XX, XXV, XXVI, XXVII, XXVIII, XXIX; See Figures 8, 9, 10.)

Sex (3b.) - There is a significant relationship between sex and job satisfaction of teachers. Women tend to be more satisfied than men are. In addition, there is an apparent tendency for more women and fewer men to be in teaching in the PMA. These data are consistent with national indicators. (See Tables XXI, XXX, XXXI, XXXII, XXXIII, XXXIV.; See Figures 11, 12, 13.)

Grade Level (3c.) - There is a significant relationship between grade level of assignment and job satisfaction for teachers. The teachers of primary grades (Pre- $K$ - 4-6) tend to be more satisfied than the teachers of upper grades (6-8, 7-9, 9-12). Satisfaction levels appear to be highest for teachers assigned at grade levels 1-3. Satisfaction levels appear to drop between grade levels $4-6$ and $6-8$ or 7-9 and increase again for teachers 9-12. There is an increase in dissatisfaction between grade levels 4-6 and 6-8 or 7-9. The highest level of dissatisfaction is expressed by teachers assigned to grades 6-8 or 7-9. There is an increase in expressions of being neither satisfied nor dissatisfied for teachers assigned to grades 6-8 or 
7-9. The fiñdings on increases of dissatisfaction and expressions of being neither satisfied nor dissatisfied for teachers in grades 6-8 or 7-9 may deserve additional study. (See Tables XXII, XXXV, XXXVI, XXXVII, XXXVIII, XXXIX; See Figures 14, $15,16$.

The two demographic factors that do not indicate significant relationships to satisfaction and dissatisfaction are years of service (3d.) and education (highest degree earned) (3e.):

Years of Service (3d.) - This study does not find a significant relationship between years of service and job satisfaction of teachers in the PMA; however, comparative data from 1981 and 1984 do suggest an apparent decrease in teachers with from 1-10 years of service and an increase in teachers with 11-20 years of service. These findings are similar to national indicators that the mean for years of service for teachers as a population is increasing. In the PMA, satisfaction levels appear to be highest for teachers with 16-20, 21-25, and more than 35 years of experience. Satisfaction levels appear to drop between 21-25 and 26-30 years of experience. There is an apparent increase in dissatisfaction noted between 21-25 and 26-30 years of service. There is an increase in expressions of being neither satisfied nor dissatisfied for teachers with 31-35 years of experience.

Although these data would suggest an apparent tendency for teachers with many years of experience to be more satisfied than teachers with fewer years of experience, the satisfaction level 
is high for teachers in all categories of years of experience; the levels of satisfaction for teachers with many years of experience seems to be countered by an increase of being neither satisfied nor dissatisfied and of being dissatisfied by teachers with many years of experience; and the findings on relationship between years of service and job satisfaction for teachers in the PMA are nonsignificant. These data might be summarized to suggest that years of service are not a major factor contributing to job satisfaction or dissatisfaction of teachers in the PMA. (See Tables XXIII, XL, XLI, XLII, XLIII, XLIV; See Figures 17, $18,19,20$.

Highest Degree Earned (3e.) - This study does not find a significant relationship between highest degree earned and job satisfaction of teachers in the PMA. Findings suggest that the educational level of teachers in the PMA is relatively stable, with a reflected percentage holding master's degrees that is slightly above the national indicators. Satisfaction levels appear to be almost identical between teachers holding bachelor's degrees and those holding master's degrees. Dissatisfaction levels appear to be almost identical between teachers holding bachelor's degrees and master's degrees. Findings are very similar for those expressing neither satisfaction nor dissatisfaction in the two degree categories. of the six respondents reporting a doctoral degree, five express degrees of satisfaction, and one expresses being neither satisfied nor dissatisfied. These data might be summarized to suggest that the 
level of academic degree held is not a major contributor to job satisfaction or dissatisfaction of teachers in the PMA. (See Tables XXIV, XLV, XLVI, XLVII, XLVIII, XLIX; See Figures 21, 22, $23,24$.

Other Findings

Additional findings that may relate to the research questions and the overall job satisfaction or dissatisfaction of teachers in the PMA will be summarized for brief discussion, as follows: (See Appendix F.)

Teaching as a Kind of Work (II.3). Teaching as a kind of work, or work itself, identified as a motivator, appears to be related to satisfaction. Eighty-six percent express degrees of satisfaction with this factor; $6 \%$ report neither satisfaction nor dissatisfaction; and $7 \%$ record degrees of dissatisfaction $(\mathrm{N}=1430)$. These figures are similar to the overall expressions of satisfaction and dissatisfaction from the group studied.

The findings from Item III.23, The Intellectual Activity and Challenge of Teaching, as an importance ranking of the associated motivator related to work itself, provide an additional dimension to the indicators that teaching as a kind of work brings large percentages of expressed satisfaction. Ninety-five percent of the teacher respondents report that the intellectual activity and challenge of teaching is important to them; only $5 \%$ select the neutral ranking; and only six respondents $(0 \%)$ note the unimportance of this factor $(\mathrm{N}=1431)$.

Additional data are related in Item III.24, Influencing Young People's Education, and the importance ranking of this factor. 
Ninety-seven note that this is important; only $2 \%$ select the neutral ranking; and only six respondents $(0 \%)$ suggest that the factor is unimportant $(\mathrm{N}=1433)$.

These data would suggest that a large number of teachers in the PMA receive satisfaction from teaching as a kind of work, and part of that satisfaction is apparently related to intrinsic elements associated with teaching; the intellectual activity, the challenge, and the opportunity to influence young people's education.

Sense of Achievement (II.1). Sense of achievement, identified as a motivator, is related to satisfaction of the teachers in the PMA. Eighty-nine percent express degrees of satisfaction with their achievement as teachers; $5 \%$ report neither satisfaction nor dissatisfaction; and $6 \%$ acknowledge degrees of dissatisfaction $(\mathrm{N}=1432)$.

This finding is supported by Item III.11 and the importance ranking for the factor. Ninety-eight percent identify the personal feelings of success or achievement as important; only $1 \%$ selects the neutral ranking; and four respondents $(0 \%)$ record that it is unimportant $(\mathrm{N}=1434)$.

This finding is further supported by Item III.16, Maintaining a Positive Learning Atmosphere for Students, identified as a related motivator or intrinsic factor. Ninety-six percent of the sample affirm that this factor is important; only $1 \%$ elects the neutral ranking; and only one respondent $(0 \%)$ notes that this factor 1 inked to success or achievenent for the teacher is unimportant $(\mathrm{N}=1432)$. 
Another indicator of the importance of achievement or success as a teacher is provided by Item III.22, Knowing That You Are Effective as a Teacher, and the importance ranking. Ninety-nine percent of the teachers identify this factor as important; only $1 \%$ elects the neutral ranking; and only one respondent $(0 \%)$ reports that it is somewhat umimportant $(\mathrm{N}=1432)$.

In a related item (IV.13), $99 \%$ of the teachers note that they are able to maintain a positive learning climate for their students from about half of the time to almost all of the time; only $1 \%$ reports being able for less than half of the time; and only one respondent $(0 \%)$ acknowledges being seldom or never able ( $N=1432)$.

When asked about their success in meeting the intellectual needs of students as individuals (IV.16), $98 \%$ state that they are successful with from about half to almost all of their students; and only $1 \%$ records meeting this goal with less than half of their students $(\mathrm{N}=1420)$.

When asked how they think they would be described as teachers by their students (IV.26), by the parents of their students (IV.23), and by other teachers (IV.9), the teachers in the PMA provide the following data. Ninety-one percent say they would be described by their students as from above average to outstanding; $9 \%$ say they would be described as average; and only respondent ( $0 \%$ ) says the ranking from students would be below average $(\mathrm{N}=1411)$. Eighty-seven percent think they would be described by parents as from above average to outstanding; $11 \%$ think the ranking would be average; and only one respondent $(0 \%)$ thinks the description would be below average 
$(\mathrm{N}=1414)$. Ninety-three percent think they would be described by other teachers as from above average to outstanding; $7 \%$ think the ranking would be average, and only one respondent $(0 \%)$ thinks the description would be below average $(\mathrm{N}=1426)$.

When asked for an overall ranking of how successful they feel as teachers (IV.27), 86\% report feeling successful from quite to very; $14 \%$ chart mixed feelings about being successful; and only two respondents $(0 \%)$ record feeling quite unsuccessful $(\mathrm{N}=1422)$.

When asked for an overall ranking of how much they think they have achieved as teachers (IV.32), 93\% note that their achievements are from quite a bit to a great deal and above expectations; $15 \%$ rank their achievements as moderate and about as expected; only $2 \%$ find their achievements to be below average or less than expected $(\mathrm{N}=1411)$.

All the data would suggest that teachers want to be successful and receive satisfaction from self-determinations that they are successful in their acnievements as teachers, a factor with high percentages of importance attached. In general, teachers believe they are successful in teaching; and they believe that their students, the parents of their students, and other teachers will describe them as successful.

Amount of Recognition (II.2). Amount of recognition received, identified as a motivator, indicates reduced expressions of satisfaction from teachers in the PMA. Fifty-two percent express satisfaction with the amount of recognition received from teaching; 23\% express neither satisfaction nor dissatisfaction; and $24 \%$ indicate degrees of dissatisfaction $(\mathrm{N}=1432)$. This finding suggests that 
teachers do not believe they receive a great amount of recognition, and the lack of recognition contributes to dissatisfaction for nearly one-fourth of the respondents in this study.

The finding that recognition or praise for work and efforts can contribute to job satisfaction and dissatisfaction for teachers is supported by Item III.10 and the importance ranking for this factor. Eighty-nine percent of the sample group identifies this factor as important; $9 \%$ elect the neutral position; and only $3 \%$ rank the factor as unimportant $(\mathrm{N}=1434)$. Teachers may or may not expect to receive recognition for their efforts, but they value this factor, and it has potential for contributing to their job satisfaction.

And although this study does not address performance of teachers, research addressing "Effective Schools" and what makes them effective for students may suggest another element of support for the importance of praise or recognition as a powerful influence in education and achievement (Brookover \& Lezntte; 1979; Edmonds and Edmonds et al, 1977, 1978, 1979; Goodlad et al, 1979-80; Madden et al, 1976). The research of Rutter and his associates (1979), in study of secondary schools and their effects on children, finds consistent relationships between rewards and praise and outcomes:

Al1 forms of reward, praise or appreciation tended to be associated with better outcomes (Rutter, M., Maughan, B., Mortimore, P., Ouston, J., with Smith, A., 1979, p. 123).

If high expectations and praise influence the performance of children, as learners, it is also quite possible that recognition or praise for work and efforts could operate to influence the performance of teachers. The factor is seen to be a motivator and related to 
intrinsic or psychic rewards, and it is furthermore seen to be closely related to needs previously identified by Maslow (1954) and the primary or first-level factors established by Herzberg et al (1959).

Amount of Autonomy (II.23). Seventy percent of the respondents express satisfaction with the amount of autonomy they have as teachers; nearly a quarter $(23 \%)$ express neither satisfaction nor dissatisfaction; and $7 \%$ express dissatisfaction with this factor, identified as a motivator and related to work itself $(\mathrm{N}=1412)$. These data would suggest that teachers are generally satisfied--or at least not generally dissatisfied--with the amount of autonomy they have as classroom teachers in the PMA. The finding could alsc suggest that teachers expect to have a certain amount of autonomy in their teaching roles.

The view that teachers expect to have a certain amount of freedom in their teaching is supported by Item III.2, Freedom to Teach as You Wish, and Item III.3, Feeling of Power or Authority in Work, and the importance rankings of these factors identified as motivators and related to the intrinsic factor of work itself. Ninety-six percent of the respondents report that freedom to teach is important; only $3 \%$ allot this factor the neutral ranking; and only four respondents $(0 \%)$ identify the factor as somewhat unimportant $(\mathrm{N}=1433)$. Seventy-one percent affinn that the feeling of power or authority in work is important; $16 \%$ find it neither important nor unimportant; $3 \%$ identify it as an unimportant factor $(\mathrm{N}=1431)$.

This finding is further supported by Item III.15, Being Creative in Teaching, and the importance rankings. Ninety-six percent of the 
respondents rank the factor as important; $4 \%$ select the neutral ranking; and only $1 \%$ suggests that it is unimportant $(\mathrm{N}=1430)$. The factor is identified as a motivator or an intrinsic factor related to the content of work and subjective response. These data would suggest that teachers strongly believe in being creative.

When asked how often they have the opportunity to design their instructional programs and teach more or less as they choose (IV.15), $91 \%$ acknowledge this opportumity from half to almost all of the time; $0 \%$ indicates this opportunity less than half of the time; and $2 \%$ determine that they seldom or never have the opportunity $(\mathrm{N}=1427)$.

When asked how much they like to try something "new" in the classroom (IV.44), 62\% report that they tend to be one of the first; $37 \%$ indicate they tend to wait a while, but only $1 \%$ notes a tendency to be one of the last $(\mathrm{N}=1421)$.

Thus, some amount of autonomy or freedom to teach, accompanied by some feeling of power or authority in work and some opportunity to be creative in program design or teaching, is seen to be important to most teachers and is also seen to contribute to job satisfaction of teachers in the PMA.

Amount of Responsibility (II.4). Amount of responsibility, identified as a motivator, offers mixed feelings. Seventy-two percent of the teachers express degrees of satisfaction with the amount of responsibility they have as teachers; $16 \%$ report neither satisfaction nor dissatisfaction; and $12 \%$ express degrees of dissatisfaction $(\mathrm{N}=1429)$. Additional data on this factor are indicated in Item III.25, Accepting Your Responsibilities as a Teacher, and the 
importance ranking. Ninety-six percent acknowledge that this is important; only $3 \%$ select the neutral ranking; and only six respondents $(0 \%)$ suggest that it is unimportant $(N=1433)$.

Thus, about three-fourths of the group are satisfied with responsibility and acknowledge its importance. Others evidently accept responsibility without apparent satisfaction or dissatisfaction--perhaps because this factor is closely related to the role of the teacher. But others are dissatisfied. Additional study might bring more information to bear on the rankings on this factor.

Opportumity for Advancement (II.5). Opportunity for advancement, identified as a motivator, indicates a sharply reduced level of satisfaction from a population that is nevertheless greatly satisfied. Forty percent express degrees of satisfaction with this factor; $32 \%$ express neither satisfaction nor dissatisfaction; and $28 \%$ express degrees of dissatisfaction $(\mathrm{N}=1421)$. This finding would tend to support Lortie's view that teaching is "front-loaded" and that teachers enter the classrooms knowing that they will not have a great opportunity for advancement (1975, pp. 82, 205, 211, 212). Nearly a third of the sample indicates neither satisfaction nor dissatisfaction with this factor, but the percentage expressing dissatisfaction is worthy of additional consideration.

The finding that opportumity for promotion or advancement can contribute to job satisfaction and dissatisfaction of teachers is supported by Item III.7 and the importance ranking of the factor. Seventy-four percent rank that the opportunity for advancement as important; $21 \%$ report that it is neither important nor unimportant; 
and $4 \%$ find it unimportant. Thus, nearly three-fourths of the group studied acknowledge importance for this factor, and one-fourth ranks it as unimportant $(\mathrm{N}=1432)$.

Opportunity to Grow and Develop (II.6). Opportunity to grow and develop, identified as a motivator, is related to professional expectations for teachers and is regarded with mixed attitudes by teachers in the PMA. Sixty-two percent express satisfaction with their opportunities to grow and develop as teachers; $20 \%$ express neither satisfaction nor dissatisfaction; and $19 \%$ report dissatisfaction $(\mathrm{N}=1432)$. The population area studied includes urban and suburban communities with colleges and universities available to teachers seeking continuing education or higher degrees. In addition, the districts offer staff development and inservice activities. Some of the districts provide other incentives such as tuition reimbursements or increases in salary for teachers completing additional college or university credited coursework. Still, one-fifth of the teachers studied express neither satisfaction nor dissatisfaction, and nearly one-fifth express dissatisfaction with opportunities to grow and develop. This factor merits additional consideration.

The finding that opportunity for growth contributes to job satisfaction and dissatisfaction for teachers is supported by Item III.6 and the importance ranking on this factor, identified as a motivator/intrinsic factor and related to Maslow's hierarchy of needs (1954). Ninety-three percent of the sample acknowledge the importance of the opportunity for personal growth; 7\% select the neutral ranking; 
and only $1 \%$ identifies it as unimportant ( $\mathrm{N}=1431)$.

When asked how much being a teacher has contributed to personal growth (IV.31), 96\% acknowledge personal growth from moderate to a great deal; only $2 \%$ note slight growth; and another $2 \%$ rate very little if any personal growth as a result of being a teacher $(\mathrm{N}=1426)$.

When asked how much opportunity they have for continuing education or professional growth as teachers (IV.40), 95\% acknowledge from moderate to great opportunity; and only $5 \%$ report lack of opportunity $(\mathrm{N}=1428)$.

When asked how much incentive they have to continue education or professional growth (IV.41), 88\% acknowledge from moderate to great incentive; however, the percentage expressing lack of incentive increases to $13 \%(\mathrm{~N}=1425)$.

In sumnary, these data suggest that the opportunity to grow and develop can contribute to job satisfaction and dissatisfaction; about one-fifth of the teachers note neither satisfaction nor dissatisfaction with their opportunities to grow and develop as professionals; and about one-fifth express dissatisfaction with their opportunities for growth. But $93 \%$ express the importance of having opportunity to grow, and only $1 \%$ identifies it as unimportant. Ninety-six percent believe they have benefited in growth from teaching; 95\% indicate that they have opportunity for growth, but those reporting incentive drops to $88 \%$, with $13 \%$ acknowledging a lack of incentive. These indicators suggest a need for additional study and might serve as a commentary on an area of concern that might be better supported by personnel services. 
Opportunity to Help Others (II.19). Eighty-two percent of the sample group express satisfaction with their opportunities as teachers to help others; $13 \%$ record neither satisfaction nor dissatisfaction; and only $5 \%$ express degrees of dissatisfaction $(\mathrm{N}=1430)$. This factor, identified as a motivator, is also identified as a primary contributor to the job satisfaction of teachers in the PMA. Teachers attach value to the opportunity to help others and evidently receive satsfaction froin being able to help others.

Receiving Feedback. When asked to rank the importance of receiving feedback to improve teaching (Item III.20), 91\% rank this factor--identified as a motivator--as important; $8 \%$ elect the neutral ranking of neither important nor unimportant; and only $1 \%$ marks it as unimportant $(\mathrm{N}=1431)$.

When asked how much positive or negative feedback they receive as teachers from immediate supervisors (IV.30), from other teachers (IV.28), and from parents of students or others outside of the field of education (IV.29), the teachers in the PMA offer the following data. Eighty-six percent suggest that they receive more positive than negative feedback from their supervisors; $10 \%$ state that the amounts of feedback are about equal; $4 \%$ note that they receive more negative than positive feedback; and $1 \%$ reports that the great amount of feedback is negative $(\mathrm{N}=1385)$. Ninety percent affirm that they receive more positive than negative feedback from other teachers; $9 \%$ find the positive and negative feedback to be about equal; and $1 \%$ states that the feedback from colleagues is largely negative $(\mathrm{N}=1391)$. Eighty-five percent report that the feedback from parents 
of students is more positive than negative; $12 \%$ think the amounts are about equal; and $4 \%$ note that they receive more negative than positive feedback from parents and the community $(\mathrm{N}=1389)$.

These data may be sumnarized to suggest that teachers in the PMA value feedback; and, in general, nearly $90 \%$ view the type of feedback they receive as more positive than negative; about $10 \%$ think the feedback is more or less equal; and from $1 \%$ to $4 \%$ think the feedback is mostly negative. The strongest suggestion of positive feedback seems to be linked to fellow teachers $(90 \%)$, with nearly equal expressions of positive feedback from school administrators and parents or community members $(86 \%$ or $85 \%$ ).

However, when asked to select an indicator used most to gauge the effectiveness of their own teaching (IV.38), teachers in the PMA provide the following information. Only $7 \%$ elect the reactions of other teachers. Twenty-one percent select the opinions of their students. Only $6 \%$ prefer the assessments of the principal. Only $1 \%$ prefers the assessments of a chairperson or team leader. Eighteen percent look to results from student exams and tests. Five percent look to the reactions from parents. And the highest indicator of all is $42 \%$ that suggest that they rely most on their own opinions and assessments $(\mathrm{N}=1402)$.

These findings may be summarized to suggest that teachers evidently prefer to rely on their own judgments (42\%); the next highest percentage elects the opinions of their students $(21 \%)$. Other data would suggest that teachers are willing to receive feedback from other teachers, but they are less willing to accept these opinons as 
gauges of their own teaching; and they do not express strong willingness to accept the assessments of their supervising administrators as a major gauge of their own teaching effectiveness. These findings suggest a need for more study.

Sources for Insights and Ideas. When asked to select the most useful source for getting insights and ideas as teachers (IV.39), the group from the PMA offer the following data. Sixteen percent elect inservice courses given by the district. The largest group (43\%) recommend informal conversations with colleagues and friends. Eight percent elect educational magazines and books, and only $1 \%$ elect educational media (such as films, TV, or video). Only $3 \%$ elect meetings held in district, and $9 \%$ recommend meetings held outside the district. A slightly higher percentage (17\%) chooses coursework given by a college or university. And only $2 \%$ find the best source to be the immediate supervisor $(\mathrm{N}=1402)$.

This data would again suggest the importance of the relationships between fellow teachers as a source for insights and ideas or feedback other than as an evaluator of effectiveness. With the exception of the very low percentage that credit educational media, the next lowest percentage $(2 \%)$ acknowledges the immediate supervisor as a source for insights and ideas that are credited by the teacher as most useful to teaching. This finding suggests a need for more consideration.

Working Conditions (II.16). Sixty-nine percent of the teachers note satisfaction with their working conditions; $14 \%$ select the neutral ranking; and $17 \%$ express dissatisfaction with this factor that has been identified as a hygiene and related to work context $(\mathrm{N}=1432)$. 
The finding that working conditions can contribute to satisfaction and dissatisfaction for teachers is further amplified by data from the importance ranking on this factor (III.17). Ninety-eight percent of the teachers affirm the importance of working conditions; only $2 \%$ select the neutral ranking; and only six respondents $(0 \%)$ find the factor to be unimportant $(\mathrm{N}=1432)$.

When asked to rank how pleasant their schools are as places in which to teach and work (IV.12), 83\% find their schools to be pleasant places in which to teach and work; $8 \%$ find them to be neither pleasant nor unpleasant; and $8 \%$ find them to be unpleasant from somewhat to very $(\mathrm{N}=1437)$.

This study does not address some of the elements in the school and work of the teacher that might be related to working conditions (e.g., condition of building, availability of resources, etc.). However, some of the "Effective Schools" research indicates that the structure in which teaching occurs is not as important as how the human beings in the educational structure interrelate with one another in support of instructional goals. More attention to this factor in terms of the overall job satisfaction of teachers in the PMA might bring additional suggestion on where improvements might be made to improve the rankings on the factor.

Time Spent Preparing for Teaching (II.20). Slightly less than half $(45 \%)$ of the teachers acknowledge satisfaction with the amount of time they spend preparing for teaching; nearly one-fifth (19\%) express neither satisfaction nor dissatisfaction; and more than one-third (35\%) record degrees of dissatisfaction with this factor that is so 
closely related to the role of the teacher $(N=1430)$. In the section seeking importance rankings (III.13), 91\% acknowledge the importance of this factor; $8 \%$ find it somewhat unimportant; and $1 \%$ finds it somewhat unimportant $(\mathrm{N}=1423)$. These data could suggest the need for additional study of expectations of those planning to enter teaching; the findings could also suggest that districts and schools should consider this factor in planning the work schedule for teachers. If successful instruction is based on successful preparation, then it seems to be important for teachers to commit time to preparation for teaching, and it seems to be equally important for districts and schools to provide some time and support for teacher preparation for classroom teaching.

Time Spent Teaching (II.21). Seventy percent of the teachers express satisfaction with the amount of time they spend teaching; $14 \%$ express neither satisfaction nor dissatisfaction; and $18 \%$ express degrees of dissatisfaction with this factor identified as a hygiene or extrinsic factor related to the context of work and so closely related to the role of the teacher $(\mathrm{N}=1422)$. In addition to those that are satisfied with this factor, there are also those that are dissatisfied.

In the section seeking importance rankings (III.12), 96\% note that time spent in the classroom teaching is important; $4 \%$ select the neutral ranking; and $1 \%$ finds it to be somewhat unimportant $(\mathrm{N}=1424)$.

These data would suggest that teachers value the time they spend teaching and receive satisfaction from the act of teaching; however, the group expressing dissatisfaction would also suggest additional study to try to determine the nature of the dissatisfaction and to try 
to consider what might influence the ranking. The finding might also suggest that teacher preparation programs in colleges and universities should focus student attention even more directly on this vital element of the role of the teacher.

Time Spent on School-Related Activities Outside of Teaching and Preparation for Teaching (II.22). Slightly more than one-third (38\%) of the teacher respondents express satisfaction with the time they spend on school-related activities outside of teaching and preparation for teaching; nearly one-third (32\%) express neither satisfaction nor dissatisfaction; and nearly one-third $(30 \%)$ express dissatisfaction with this factor, identified as a hygiene $(\mathrm{N}=1429)$. The data provide indicators that nearly identical percentages are satisfied, neutral, and dissatisfied. This finding could suggest that those expressing satisfaction or no indication of dissatisfaction accept this factor as related to the role of teaching; but the group expressing dissatisfaction is worthy of consideration. Districts and schools may wish to give additional attention to this factor, to see how teacher time is dedicated and to see what might be done to improve expressions of satisfaction or to reduce expressions of dissatisfaction with this factor.

Preference for Extra Time. When asked how they would elect to spend two more hours a week in the field of education, if the time were made available (IV.21), the teachers indicate preferences in several areas that may serve as indicators for building schedules. Eight percent elect work on a curriculum committee; $44 \%$ elect lesson planning; $4 \%$ elect community relations; $8 \%$ want more time in class 
teaching; $21 \%$ seek time for individual student tutoring; only $2 \%$ would prefer work on a school policy comnittee; $4 \%$ would hold parent conferences; and $10 \%$ select more time for extracurricular student activities $(\mathrm{N}=1415)$.

These data might be summarized to suggest that nearly half (44\%) of the group would like to have more time for lesson planning; about one-fifth would like to have more time for individual student tutoring; and one-tenth would like to spend more extracurricular time with students. Thus, most of the teachers would elect to direct more time to planning for teaching or working with students in other than the formal or full class settings.

Effect on Personal Life (II.17). Slightly more than half of the teachers $(55 \%)$ express satisfaction with the impact of being a teacher as an effect on personal 1ife; one-fifth (20\%) select the neutral ranking; and nearly one-quarter (24\%) express dissatisfaction $(\mathrm{N}=1437)$. The factor is identified as a hygiene.

In the importance ranking of Item III.18, Personal Life Outside of School, $88 \%$ percent note the importance of the factor; $10 \%$ elect the neutral ranking; and only $3 \%$ find it to be unimportant ( $N=1429)$.

These data would suggest that many teachers value their personal lives outside of teaching or acknowledge importance to their personal lives; teaching impacts on personal life; and this impact is not satisfying for all teachers. The percentages in the neutral rankings also suggest that some teachers expect teaching to influence their personal lives and do not indicate reaction to the impact. The percentages expressing dissatisfaction are worthy of additional 
consideration.

Job Security (II.18). Slightly more than three-fourths (77\%) of the sample group express satisfaction with their job security as teachers; 13\% select the neutral ranking; and one-tenth of those studied are reporting some dissatisfaction with this factor, an identified hygiene $(\mathrm{N}=1439)$. However, it should not be overlooked that an aggregate of $90 \%$ expresses either satisfaction or no particular indication of dissatisfaction with job security of teachers in the PMA. This finding could suggest a sense of stability in the PMA that leads to a sense of security for a large percentage of the present staff of teachers in the participating school districts.

The finding that job security can contribute to job satisfaction and dissatisfaction of teachers is supported by Item III. 8 and the importance rankings on this factor, identified as a hygiene and extrinsic factor. Ninety-three percent of the sample group affirm the importance of job security; $6 \%$ select the neutral ranking; and only $1 \%$ identifies the factor as unimportant $(N=1431)$. Teachers value their job security, and many teachers in the PMA relate this factor to their job satisfaction.

When asked how secure they feel in their jobs as teachers in the PMA, 98\% note feeling secure from $0 . K$. to very; only $2 \%$ report feeling insecure in their jobs $(\mathrm{N}=1434)$.

Status (II.12). Less than half of the teachers studied (43\%) express satisfaction with their status as teachers; $25 \%$ select the neutral ranking; and about one-third ( $33 \%$ ) express dissatisfaction $(N=1439)$. This factor, identified as a hygiene, appears to be a 
contributor to dissatisfaction for many teachers. These findings tend to relate to the finding that teachers do not reflect high percentages of satisfaction in the amount of recognition they receive.

The finding that status contributes to satisfaction for less than half of the group studied and to dissatisfaction for about one-third of the group studied is amplified by the importance ranking on this factor (III.14). Seventy-six percent note that status in the community as a teacher is important; $21 \%$ elect the neutral ranking; and $4 \%$ rate it as unimportant $(\mathrm{N}=1432)$.

This factor might be further studied in relationship to teacher expectations and concepts of rewards within systems of human enterprise. At the same time, parents and community members might be further involved in consideration of this factor to disclose information that might improve the rankings of this factor.

Salary (II.7). Salary, identified as a hygiene, is related to satisfaction and dissatisfaction of teachers. Thirty-eight percent express satisfaction with this factor; $17 \%$ report neither satisfaction nor dissatisfaction; and $44 \%$ record dissatisfaction $(\mathrm{N}=1435)$. These data may be summarized to suggest that nearly half of the population studied is dissatisfied with the income of a teacher in the PMA.

This finding is supported by Item III.4, Receiving a Good Salary, and the importance ranking of this factor. Ninety-two percent of the respondents acknowledge the importance of this factor; $5 \%$ select the neutral ranking; and only $2 \%$ report that the factor is somewhat unimportant $(\mathrm{N}=1 / 32)$. These findings serve to support the importance of the factor and its potential in relationship to the job 
satisfaction of teachers.

Interpersonal Relations with Supervising Adninistrator (II.8). More than two-thirds $(69 \%)$ of the teachers sampled express satisfaction in their interpersonal relations with their supervising administrators; $13 \%$ note neither satisfaction nor dissatisfaction; and $18 \%$ express dissatisfaction $(\mathrm{N}=1439)$. This factor is identified as a hygiene, but it also operates as a contributor to satisfaction for a large percentage of the population studied. These data may be summarized to suggest that some teachers do not indicate satisfaction or dissatisfaction about their relationships with their administrators, and nearly one-fifth is dissatisfied with these relationships.

The finding that interpersonal relations with administrators can contribute to job satisfaction and dissatisfaction of teachers is supported by Item III.9, Support from Your Administrators, and the importance ranking of this factor, identified as a hygiene. Ninety-eight percent of the sample group affirm the importance of support from school administrators; only $2 \%$ select the neutral ranking; and only seven respondents $(0 \%)$ report that this factor is unimportant $(\mathrm{N}=1431)$.

When asked to rank the amount of professional support given by building administrators (IV.19), $60 \%$ percent of the sample group rank the administrative support in the building as above expectations; 23\% rank this factor as about what is expected; $14 \%$ note some lack of support; and $4 \%$ find the support level to be far below expectations $(\mathrm{N}=1432)$. 
These data could be summarized to suggest that $83 \%$ of the teachers are receiving administrative support at the expectancy level or above; $18 \%$ are not receiving administrative support at the expectancy level. Thus, a group of almost one-fifth of the sample is indicating a need that is not being met. Teachers value support from their building administrators; and some of the teachers are evidently not receiving an adequate level of such support.

The factor may well deserve additional study, particularly in terms of personnel services.

Supervision/Competence of Administrator (II.13). About two-thirds $\left(66_{0}^{\circ}\right)$ of the teachers studied express satisfaction with the supervision and competence of their administrators; $13 \%$ elect the neutral ranking and about one-fifth (21\%) report dissatisfaction $(\mathrm{N}=1430)$. This factor appears to be related to interpersonal relationships between teachers and their administrators.

When asked to rank the professional competence of their supervising administrators (IV.18), $90 \%$ rank their administrators from average to very competent; $8 \%$ rank their administrators as below average in competence, and $3 \%$ find their administrators to be very incompetent $(\mathrm{N}=1425)$.

A growing field of literature on "Effective Schools," by Goodlad et al (1979-80) and others, targeting the principal as instructional leader for effective schooling, is directing attention to rapport between teachers and administrators and the importance of the perceptions by teachers of the leadership styles of their administrators. Chapman (1983, pp. 40-50) finds that the school 
administrator operates as a factor in teacher job satisfaction. These data could be summarized to suggest that principals who are viewed as competent supervisors and who understand effective techniques of interrelationship with teachers could contribute to job satisfaction of teachers. The benefit potential seems to recomnend continuing staff development for professional growth of administrators as well as for teachers, and it further recommends attention to personnel services for public educators in the PMA.

Interpersonal Relations with Fellow Teachers (II.9). Eighty-six percent of the teachers sampled report satisfaction with their interpersonal relations with their fellow teachers (a percentage notably higher than the $69 \%$ expressing satisfaction with their interpersonal relations with their adninistrators, II.8); 10\% express neither satisfaction nor dissatisfaction; and only $4 \%$ identify degrees of dissatisfaction ( $N=1438)$. This factor, catalogued as a hygiene, operates as a contributor to satisfaction for a large segment of the population studied.

The finding that interpersonal relations with fellow teachers is a major factor contributing to job satisfacton for teachers in the PMA is supported by the importance ranking (III.19) for the factor. Ninety-two percent acknowledge the importance of their relationships with other teachers; $7 \%$ elect the neutral ranking; and only $1 \%$ finds these relationships to be somewhat unimportant $(\mathrm{N}=1433)$.

When asked to describe their relationships with other teachers (IV.25), the teachers in the PMA offer the following rankings. Twenty percent say their closest friends are other teachers in and out of 
school. Nearly half $(48 \%)$ say they spend some social time outside of school with other teachers. Slightly more than one-quarter $(28 \%)$ note that they associate freely with other teachers, but only during school hours. Four percent report that they have very few personal contacts with other teachers; and only one respondent $(0 \%)$ identifies having no personal contacts with other teachers $(\mathrm{N}=1427)$.

When asked how often they tend to agree with other teachers on standards for teaching (IV.20), the sample group reports strong patterns of agreement with fellow colleagues. Eighty-six percent state that they agree from more than half the time to almost all the time; $12 \%$ note agreement about half the time; and only $2 \%$ determine that they disagree more than they tend to agree with other teachers $(\mathrm{N}=1421)$.

These data may be summarized to suggest that the interpersonal relationships of teachers with other teachers are related to overall job satisfaction of teachers. Teachers value their contacts with other teachers. Districts may well consider what measures could be taken to promote the intercommunication and relationships of colleagues in the teaching profession. These data would suggest that most teachers welcome the opportunity to get together with other teachers. Teaching is a social profession, and the social contacts or interrelationships with other teachers serve for many as a source of job satisfaction, a source of feedback, and a source of reinforcement or dialogue leading to agreements on standards for teaching. Interpersonal Relations with Students (II.10). The factor of interpersonal relations with students is identified as one of the 
major factors contributing to satisfaction of teachers in the PMA. The factor has been adjusted from the Herzberg factor of interrelations with subordinates, based on earlier research by Moxley (1977), Sergiovanni (1966) and others. In Herzberg's research, the factor, as initially classified, serves as a hygiene. However, Lortie (1975) identifies the relationship of teachers with students as a primary or intrinsic and "psychic" element of reward (or satisfaction) for teachers (pp. 104, 106, 122-133, ff.) This finding is supported in the current study. Ninety-two percent of the teachers express satisfaction with their interpersonal relations with their students; $6 \%$ express the neutral ranking; and only $2 \%$ mark dissatisfaction $(\mathrm{N}=1434)$. These data would suggest that the contact of teachers with students is a vital contributor to job satisfaction. The opportunity for such contact should be promoted or protected. This factor is worthy of careful consideration, particularly in terms of classload for teachers or the mechanization of instructional programs. These data suggest that any move to separate the teacher from the students is likely to have negative impact on the overall job satisfaction of the teacher.

Enjoyment in Working with Students (III.1). Eighty-eight percent of those sampled affirm that enjoyment in working with students is very important to them; $11 \%$ rank that it as somewhat important. Thus, $99 \%$ of the sample group acknowledge the importance of the enjoyment received in working with students. Only $1 \%$ elects the neutral rank; and only three respondents $(0 \%)$ do not acknowledge the importance of this factor $(\mathrm{N}=1433)$. This finding serves to support the data on the 
satisfaction teachers receive from interpersonal relations with students. The combined elements of satisfaction in interpersonal relationships and enjoyment in working with students serve to identify the factor contributing most frequently to expressed satisfaction of teachers and the indicator of how important this relationship is to teachers.

Student Ability/Achievement Levels Preferred to Teach. When asked what ability or achievement levels of students they would prefer to teach (IV.7), $8 \%$ note that they would prefer students with below average ability/achievement levels; $17 \%$ electe to teach students with average ability/achievement levels; $36 \%$ report a preference for the somewhat above average students; only $7 \%$ mark a preference for the far above average or gifted children; and $32 \%$ indicate that they would choose to teach children of mixed abilities or achievements.

Thus, about a third $(36 \%)$ of the sample group expresses a preference for teaching the somewhat above average students; and another third $(32 \%)$ would prefer to teach in heterogeneous classrooms. Less than $10 \%$ of the teachers elect to teach in each category of the below average or the gifted children. This finding could lead to additional research.

Opinions About Students. When asked to express opinions about liking or disliking students (IV.10), $87 \%$ report liking students from a great deal to quite a bit; $8 \%$ find them $0 . K$. to work with; and $4 \%$ acknowledge some dislike $(\mathrm{N}=1437)$. In ranking opinions about working with their students, $78 \%$ describe their students as a pleasure or generally good to work with; $\tau^{\circ}$ find them $0 . K$. to work with; and 
$16 \%$ acknowledge that they are sometimes difficult or very difficult to work with $(\mathrm{N}=1436)$.

The percentage expressing a liking for their students is slightly higher than the percentage indicating that it is a pleasure or $0 . K$. to work with their students; this leads to a suggestion that teachers may like children that are difficult to work with. Few teachers report a disliking for their students (4\%); with a larger group (16\%) acknowledging difficulty in varying degrees in their work with children.

Interpersonal Relations with Parents/Community (II.I1). Teachers in the PMA are generally satisfied in their relations with parents and other community members. This factor, identified as a hygiene, also operates as a satisfier. Nearly three-fourths $(71 \%)$ of the teachers express satisfaction in their relationships with parents and community members; $22 \%$ express the neutral ranking; and $8 \%$ express degrees of dissatisfaction $(\mathrm{N}=1435)$. The finding that many teachers receive satisfaction in their contacts with parents is complemented by the Grolier Survey of 1981: What Parents Believe About Education $(\mathrm{N}=1130)$. The Grolier Survey concludes that parents believe they should be involved in the education of their children, including communicating with teachers. However, the study also notes that frequency of contact is not the sole indicator of parental concern for the education of children. Some parents believe that the quality of schooling available to their children is good, and they therefore deternine that frequent contact with teachers is not necessary (pp. 2-6) 
The finding that many teachers receive satisfaction in their contacts with parents is supported by I tem III.5, Support from Parents of Students and the importance ranking for this factor, identified as a nygiene or extrinsic factor. Ninety-six percent of the sampled group acknowledge the importance of parental support; only $3 \%$ select the neutral ranking; and only $1 \%$ notes the unimportance of this factor $(\mathrm{N}=1431)$.

When asked how much support they receive from the parents in their school community (IV.17), $50 \%$ of the teachers express from above average to great support; $32 \%$ record about average support; and $18 \%$ note some or great lack of support $(\mathrm{N}=1432)$. Thus, about half express positive views on the amount of parental support received; about one-third select a neutral ranking; and about one-fifth report lack of support from the parents in their school community.

When asked how often they would have parents participate in the classroom and school-related decision making and activities (IV.22), 13\% of the teachers chart that they would seek parental participation as often as possible; $32 \%$ suggest they would like more parent participation; 45\% mark a preference for the status quo; $5 \%$ would prefer less parental involvement, and 5\% would prefer it seldom or never $(\mathrm{N}=1432)$.

These data may be summarized to suggest that nearly all teachers believe parental participation is important; about three-fourths of the teachers express satisfaction in their interpersonal relations with parents and other community members; some teachers would like to have more parental involvement in school affairs; and some teachers would 
like to have more support from parents in their school communities. Only a small percentage (less than $10 \%$ ) expresses dissatisfaction with interpersonal relations with parents; and only $5 \%$ of the sample group express opposition to parental involvement in school affairs.

Policies and Practices of the School District (II.14). About half of the teachers sampled $(49 \%)$ express satisfaction with the policies of the school district; nearly a quarter (23\%) elect the neutral ranking of neither satisfaction nor dissatisfaction; and the remaining $29 \%$ express dissatisfaction with this factor $(\mathrm{N}=1435)$. These data could suggest that many teachers are more closely involved in the policies and practices of their schools than they are with their school districts, but it could also serve to support the importance of public information and public relations or close communications between the policy makers of school districts and the staff in the schools. The percentage recording dissatisfaction merits attention.

Policies and Practices of the School (II.15). Slightly less than two-thirds $(62 \%)$ of the teachers studied express satisfaction with the policies and practices of their scilvols; 17\% elect the neutral ranking; and $21 \%$ find dissatisfaction with this factor $(\mathrm{N}=1429)$. The level of indicated satisfaction is somewhat higher than that indicated for the policies and practices of the school district; however, the percentage reporting dissatisfaction is worthy of attention.

In the importance rankings on the related factor, Item III.21, Observing School Policies and Regulations, $81 \%$ find this factor to be 
important; $16 \%$ find it to be neither important nor unimportant; and $3 \%$ find it to be unimportant $(\mathrm{N}-1430)$. Thus, policies and practices of the school can contribute to satisfaction and dissatisfaction, or some neutral ranking in between, and a segment of the teacher population does not regard the matter of observing school policies and regulations as of any particular importance.

The finding suggests a need for improved communicaton between school administrators and school staff. The finding further suggests that staff involvement or shared decision making in recommending policies and practices for the school might improve the rankings of this factor (Brooks, 1982; Ouchi, 1981).

Management and Employee Relations - District and School. Two items in the study address management and employee relations in the teacher's district and school. When asked how they would describe management and employee relations in their districts (IV.42), teachers in the PMA offer the following data. Fifty-one percent find these conditions to be from generally good to very good in their districts; $40 \%$ find conditions to be sometimes good--sonetimes not; $9 \%$ find conditions to be from generally not good to seldom or never good $(\mathrm{N}=1424)$. When asked to describe management and employee relations in their schools (IV.43), the teachers respond as follows. Sixty-six percent find these conditions to be from generally good to very good in their schools; $24 \%$ find them to be mixed as sometime good-sometimes not; and $10 \%$ find conditions to be from generally not good to seldom or never good $(N=1424)$. The median and mode on both items suggest that teachers see management and employee relations as 
generally good in their districts and in their schools. The somewhat higher indicator of mixed feelings for the district $(40 \%)$ than for the school (24\%) may suggest that teachers are more familiar with the workings of the school or that they associate issues linked with management or collective bargaining with the district. However, the negative findings are very similar for district and school $(9 \%$ and $10 \%)$, and the large segment of the group (90-91\%) expresses from positive to mixed conditions.

Qualifications for Another Job Outside of Teaching. The teachers in the sample offer mixed views about their qualifications for another job outside of teaching. Sixty-nine percent report that they felt qualified to get another job when they entered teaching; $20 \%$ note uncertainty; and $11 \%$ suggest that they felt unqualified for another position (IV.4) $(\mathrm{N}=1429)$. In response to Item IV.5, seeking data on how qualified teachers feel to get some job outside teaching at this time, $69 \%$ affirm feeling qualified; $21 \%$ show uncertainty; and $10 \%$ suggest that they feel unqualified $(\mathrm{N}=1430)$.

These data may be summarized to suggest that many teachers who feel qualified to hold a position outside of education elect to enter and remain in teaching; however, about one-fifth of the sample group reports uncertainty, and about one-tenth believes they are only qualified as teachers--or at least are not qualified for other than teaching.

Job Expectations. Two items seek information on how the role of teacher has fulfilled expectations for the role and the profession (IV.6 and IV.14). Twenty-nine percent affirm that the role has 
surpassed expectations at job entry; $52 \%$ note that the role is about as expected; $18 \%$ suggest that being a teacher has not fulfilled expectations held at the outset $(\mathrm{N}=1425)$. Twenty-nine percent think that the profession has surpassed expectations at job entry; $50 \%$ determine that it has met expectations; and $22 \%$ suggest that it has not met expectations $(\mathrm{N}=1422)$.

These data might be summarized to suggest that about four-fifths of the teachers believe that being a teacher and the profession of teaching has met or surpassed expectations at job entry; about one-fifth of the group sampled reports that their expectations have not been met. This finding supports a continuing need for sound preparation for job entry and continuing personnel services throughout the teaching career. Additional study may help determine how teacher expectations relate to similar indicators from workers in other fields of enterprise in the PMA.

Job Projections. Five items in the study address teacher projections for promotions or jobs other than teaching and provide the following data. When asked what they thought they would do if they were offered a promotion that would take them out of the classrooms (IV.33), 36\% think that they will definitely or probably accept; $29 \%$ note that they will hesitate and wonder what to do; and $36 \%$ think that they will definitely or probably refuse $(\mathrm{N}=1410)$. When asked how they thought they would feel if they were offered a position that would take them out of the classrooms (IV.34), 57\% think that they would feel loss; $37 \%$ note that they would have mixed feelings; and only $7 \%$ determine that they will feel gain $(\mathrm{N}=1402)$. When asked how likely it 
is that they will initiate an effort to leave teaching for some other job in public education within the next year (IV.35), 84\% report that it is not likely; and $16 \%$ note that it is likely $(\mathrm{N}=1425)$. When asked how likely it is that they will initiate an effort to seek another job outside of public education within the next year (IV.36), 85\% suggest that it is not likely; and $14 \%$ identify that it is likely ( $N=1423)$. When asked where they hope to be professionally in five years (IV.37), $56 \%$ hope to remain in teaching; $16 \%$ hope to be promoted in the field of public education; $13 \%$ hope to be working outside of public education; and $15 \%$ hope to be not working by choice $(\mathrm{N}=1389)$.

These data may be summarized to suggest that many teachers have strong commitments to teaching; more than a third (36\%) report that they would refuse a promotion that would take them out of the classroom; more than half $(57 \%)$ think that they would feel loss if they left the classroom. Many of the teachers ( $84 \%$ and $85 \%$ ) affirm their commitments to the classrooms for at least a year; and more than half $(56 \%)$ affirm their commitments to teaching for five years. The $15 \%$ noting that they hope to be not working by choice may be reflecting hopes for retirement available to teachers who reach voluntary retirement ages and who have the established years of service in Oregon. About a third (36\%) of the teachers suggest that they would accept a promotion that would take them out of the classroom; $7 \%$ report that they would feel gain in leaving the classroom; $16 \%$ acknowledge that they will try to make sone job move in or outside education in the next year; a similar percentage (16\%) suggests that they hope to be promoted within five years; and another 
similar percentage (13\%) hopes to work outside education within five years. These indicators may be useful as predictors for adjustments in staffing patterns in the PMA in the next year or so; they should at least serve to suggest what the teachers would prefer to be doing. Sources of Satisfaction (Forced Choice). Three items in the study ask teachers to make forced choices on the most important source of teaching satisfaction in each list. The teachers offer the following data: (See Tables L, LI, LII.)

Item IV.47

\section{$\because Q_{2}$}

The opportunity to study, read, and plan for classes

The chance to develop mastery of discipline and classroom management

The times I know I have "reached" a student or group of students as each learns

The chance to associate with children or young people and relate with them

Table L. - Percentages - Sources of Satisfaction, 1984, Forced Choices

These data may be sumnarized to suggest apparent indications of support for statistical findings. The highest reported frequency on I tem IV.47 suggests that teachers find an important source of satisfaction in "reaching" students as each learns. The highest reported frequency on Item IV.48 suggests that teachers find an 


\begin{tabular}{|lr|}
\hline \multicolumn{1}{|c|}{ Item IV.48 } & $\%$ \\
\hline The chance to grow personally & 17 \\
The salary I earn & 5 \\
The status I have & 1 \\
The recognition I receive & 1 \\
The opportunity to teach children or influence \\
student Iearning & 77 \\
& \\
\hline & \\
\hline & Table LI. - Percentages - Sources of Satisfaction, 1984, \\
\hline
\end{tabular}

\section{I tem IV.49}

The relative security of income, position

The vacation times (travel, study, etc.)

The opportunity to earn a living without much competition or interference

The special "rightness" of my position 16

$\begin{array}{ll}\text { The serse of achievement I have as a teacher } & 47\end{array}$

Table LII. - Percentages - Sources of Satisfaction, 1984, Forced Choices

important source of satisfaction in the opportunity to teach children or influence learning. The highest reported frequency on Item IV.49 


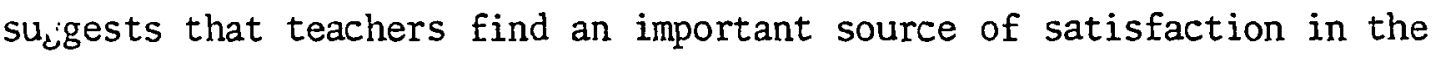
sense of achievement they have as teachers.

The Factor to Influence Change in Teaching (Forced Choice). When asked what factor more than any other would influence change in a long time teaching practice or behavior pattern associated with teacher, the teachers in the PMA offer the following data: (See Table LIII.)

\begin{tabular}{|c|c|}
\hline Item IV.45 & $\%$ \\
\hline More money & 7 \\
\hline The knowledge that it would be "good for kids" & 83 \\
\hline A "mandate" from the school board or administration & 3 \\
\hline The fact that it's "new" and you want to try it & 7 \\
\hline & $(N=1413)$ \\
\hline $\begin{aligned} \text { Table LIII. - Percentages - The Factor To Influence } \\
\text { in Teaching, } 1984 \text { (Forced Choice) }\end{aligned}$ & \\
\hline
\end{tabular}

These data may be summarized to suggest apparent indications of support for statistical findings. The highest reported frequency on Item IV.45 suggests that the knowledge that something would be "good for kids" would serve as a factor to influence change in teaching practices or behavior patterns. Thus, if districts or schools are concerned with change or reform, it will be vital to consider whether the teaching staff is convinced (or can be assured) that the change is "good for kids." 
Summary - Discussion of Findings Related to the Research Hypothesis and Other Findings. Thus, following preliminary discussion of findings for each of the three research questions and following discussion of other findings from the study, it is now appropriate to draw some conclusions from the collected data.

\section{Conclusions}

Research Question \#1 - Job Satisfaction and Dissatisfaction

Public school teachers in the seven school districts identified as the Portland Metropolitan Area are very satisfied with their jobs and with their roles as teachers in public school classrooms. Over half of them (59\%) would choose teaching over any job in any field. Almost three-fourths of them $(72 \%)$ would choose to remain as teachers over any job in public education. Almost two-thirds (64\%) would choose to become teachers again if they had the chance to start all over again. The percentage of teachers that would choose to become teachers again suggests a sonewhat higher degree of job preference than the figures from teachers surveyed in nationwide polls conducted by the NEA from 1979 through 1983. Almost all of the teachers in the current study (96\%) report that they receive pleasure from their teaching. More than eighty percent $(82 \%)$ note that they are reasonably satisfied with their present job or assignment. The present study offers strong indicators that the teachers surveyed express highly significant degrees of satisfaction or pleasure and preference for their jobs as teachers and their roles or assignnents in their districts and their schools. 
However, alongside such positive data, it is still appropriate to acknowledge the much smaller group of teachers that do not express these views. The study also finds that about $7 \%$ of the teachers are not satisfied with their jobs; about $11 \%$ are not satisfied with their role. When given the options of preference for some other job in any field, $12 \%$ suggest that they would prefer some other job in public education, and $29 \%$ suggest that they would prefer some other job outside public education. When given the options of preference for some other job in public education, $28 \%$ opt for some job other than classroom teaching. When asked if they would still enter teaching if they could start all over again, $19 \%$ report uncertainty, and $16 \%$ affirm that they would probably or definitely not become teachers again. These figures are far below the national indicators from NEA teacher polls (1983, p. 9). But, the figures serve as reminders that along with a generally satisfied group of public school teachers in the classrooms, there are those who would prefer to be doing something else inside or outside of public education (Bloland \& Selby, 1980).

It is important to consider what serves to satisfy teachers as well as what serves to dissatisfy them. Such an identification may serve to reinforce present expressions of satisfaction and to moderate the expressions of dissatisfaction. This study does not address how satisfaction or dissatisfaction may impact on performance, but it is not difficult to surmise that dissatisfied teachers reflect their attitudes and feelings in some way in their jobs and in their relationships with others in the community, in the schools, and in the 
classrooms.

It is also important to remember that attitudes and feelings are subject to change for a variety of reasons. The current levels of satisfaction of the teachers in the PMA may seem to be highly reassuring to the public and to those who administer to public education; however, such indicators should not serve as signals tht all is well and that the topic of job satisfaction of teachers deserves no further attention.

JOB SATISFACTION

FOR TEACHERS IN

THE PMA, 1984
- Expressions of satisfaction with:

- role as a teacher

- present assignment

- choice of job

- Expressions of preference for job

- Expressions of receiving pleasure from job

- Expressions of attitudes and feelings of being satisfied with teaching as an occupation

Figure 25. Job Satisfaction for Teachers in the PMA - Factors

Research Question \#2 - Factors Contributing to Job Satisfaction or Dissatisfaction - Conformity with Herzberg and Lortie Theory

What does serve to satisfy or dissatisfy the teachers in the PMA? The data from the present study suggest that all of the factors tested can serve, to some degree, as contributors to job satisfaction or dissatisfaction. However, more specifically, in the attempt to identify significant contributors to job satisfaction and dissatisfaction of the teachers, the present study includes an address to the 16 first-level factors, previously identified by Herzberg et al. (1959, p. 81). The factors were further catalogued as a dichotomy of 
motivators or hygienes. The motivators were identifed as satisfiers or intrinsic factors and related to job content, or the work itself, and the hygienes were identified as dissatisfiers or extrinsic factors and related to job context or the conditions of the work. The a priori identification of the factors to be examined as intrinsic or extrinsic was established to be compatible with Lortie's research (1975), inasmuch as his study also addresses factors in the work world of schoolteachers as intrinsic or extrinsic. Lortie acknowledges that the intrinsic elements of the job and role of schoolteachers become synonymous with "psychic" rewards, that which makes the job of schoolteachers worthwhile, that which brings pleasure or satisfaction. Thus, the present study attempts to recognize similarities and differences in the Herzberg research $(1959,1966)$ and the Lortie research (1975) and is designed to examine the previously identified factors, to see how the factors serve as contributors to satisfaction or dissatisfaction of the teachers studied. And on this basis, the factors were subjected to statistical analyses.

A set of five primary factors that were previously identified by Herzberg et al. (1959, p. 81) were accepted as motivators or intrinsic factors for examination. These factors are:

$$
\begin{aligned}
& \text { Achievement } \\
& \text { Recognition } \\
& \text { Work itself } \\
& \text { Responsibility } \\
& \text { Advancement }
\end{aligned}
$$


A set of five primary factors that were previously identified by Herzberg et a1. (1959, p. 81) were accepted as hygienes or extrinsic factors for examination. These factors are:

\author{
Salary \\ Interpersonal relations - Supervisor \\ Supervision \\ Policies and practices of the company \\ or organization \\ Working conditions
}

To gain additional information, to see what factors contribute most significantly to satisfaction and dissatisfaction of teachers in the PMA and to see how the identified factors might conform with findings from Herzberg et al (1959) on the "dual-factor" operation of motivators or hygienes and with findings from Lortie (1975) that teachers gain their primary intrinsic or "psychic" rewards from their goals and achievements related to interrelations with students, or to "reaching" students, the present study includes visual inspections of frequencies of responses, converted to percentages. And, finally, the visual inspections also include some address to data from an earlier study (1981) of teachers in the PMA (Falkenstein, 1982; Hathaway, 1982), to see if responses would be the same or similar or if they would suggest apparent trends or changes in the sources of satisfaction for teachers of a similar population over a three-year period.

The aggregate of data permits some conclusions of how various factors operate as contributors to satisfaction or dissatisfaction, and it also permits some conclusions on how the factors that 
contribute most frequently to satisfaction and dissatisfaction of the teachers in the PMA conform with the findings from research by Herzberg et al. $(1959,1966)$ and by Lortie (1975).

The Relationship of Motivators (Intrinsic Factors) to
Satisfaction. The findings from the statistical evaluations of the previously identified motivators indicate that there is a significant relationship between the identified motivators and satisfaction. Thus, a conclusion may be drawn that motivators contribute to satisfaction more than they contribute to dissatisfaction, and the relationship is seen to be significant. As previously identified by Herzberg et a1. (1959) and for the purposes of this study, the factors studied as motivators or intrinsic factors that contribute significantly to the job satisfaction of teachers in the PMA are:

$$
\begin{gathered}
\text { Achievement } \\
\text { Recognition } \\
\text { Work itself } \\
\text { Responsibility } \\
\text { Advancement }
\end{gathered}
$$

These findings would tend to conform with Herberg's view of motivators inasmuch as these factors are seen to operate as satisfiers or contributors to satisfaction at a level of significance beyond .001. Most simply, from these data, motivators are seen to contribute to teacher job satisfaction. These data permit conclusions that teachers care about achievement, receiving recognition, the work of teaching, the responsibility they have as teachers, and opportunities for advancement. Furthermore, inasmuch as these factors are seen to 
contribute to expressions of satisfaction of teachers in the PMA, it will be important to recognize them in efforts to improve or change levels of satisfaction or to ease or reduce levels of dissatisfaction for teachers in the PMA.

The Relationship of Hygienes (Extrinsic Factors) to
Dissatisfaction. The findings from the statistical evaluations of the previously identified hygienes do not support the prediction that there is a significant relationship between the identified hygienes and dissatisfaction. The data indicate that there is a significant relationship between the hygienes, as tested, and satisfaction. Thus, a conclusion may be drawn that the tested hygienes contribute to satisfaction more than they contribute to dissatisfaction for the teachers in the PMA. The factors studied as hygienes or extrinsic factors that contribute significantly to the job satisfaction of teachers in the PMA are:

$$
\begin{gathered}
\text { Salary } \\
\text { Interpersonal relations - Supervisor } \\
\text { Supervision - Competence of supervisor } \\
\text { Policies and practices of district } \\
\text { Policies and practices of school } \\
\text { Working conditions }
\end{gathered}
$$

Thus, as tested, the hygienes operate contrary to the research predictions. And, these findings do not tend to conform with Herzberg's view on hygienes and their operation as dissatisfiers. The listed factors are seen to contribute to job satisfaction of the teachers studied at a significant level beyond .001 . 
Most simply, from these data, hygienes are seen to contribute to teacher job satisfaction. These data permit conclusions that teachers care about salary, interpersonal relationships with their supervisors, the supervision provided by their supervisors, the perceived competence of their supervisors, the policies and practices of their school districts and their schools, and their working conditions. Furthermore, if these factors operate significantly as contributors to job satisfaction of teachers in the PMA, they should be recognized in efforts to improve or change levels of satisfaction to ease or reduce levels of dissatisfaction for teachers in the PMA.

Factors Contributing Most Frequently to Satisfaction of Teachers in the PMA - Conformity with Herzberg's Identified Factors. The data previously identified and testesd as an a priori list of motivators and hygienes (Herzberg et al., 1959) provide information that both sets of factors serve to contribute to teacher satisfaction more than they serve to contribute to teacher dissatisfaction. This information, however, does not serve to answer the questions: What factors contribute most frequently to the high levels of satisfaction expressed by the teachers in the PMA? Do teachers in the PMA accept the same factors as those previously identified by Herzberg as their own primary or major factors contributing to job satisfaction? The data would permit some conclusion that the teachers studied in the PMA in 1984 acknowledge the Herzberg list of five primary motivators as contributors to satisfaction, but they establish a somewhat different list of factors contributing most frequently to their own satisfaction, as data drawn from the frequencies of their responses 
and rankings on items converted to percentages. (See $Q_{2}$, II.1-25, Appendices $\mathrm{D}$ and $\mathrm{F}$. ) The teachers in the PMA indicate that the following factors contribute most frequently to job satisfaction:

Interpersonal relations with students

Sense of achievement

Teaching as a kind of work (work itself)

Interpersonal relations with fellow teachers

(peers or colleagues)

Opportunities to help others

The findings do not fully conform with Herzberg's views on how factors operate or which factors are primary contributors to satisfaction. Achievement and teaching as a kind of work conform with two primary factors drawn from Herzberg's list of motivators (intrinsic factors). But Herzberg's research addresses interpersonal relations with subordinates and with peers as hygienes or potential dissatisfiers that will not operate as satisfiers. When these factors are adjusted and construed to mean interpersonal relations with students and with fellow teachers, they are found to contribute most frequently to the job satisfaction of the teachers studied. It would appear to follow, then, that hygienes can contribute to satisfaction, as has been previously suggested in this study; and, it could also follow that for teachers the significant factors of interpersonal relations with students and the interpersonal relationships with other teachers are operating as motivators or satisfiers. The present research permits conjecture that both conclusions are possible and apparently indicated by data that may serve as evidence. Most simply, the present research 
indicates that hygienes (or extrinsic factors) can operate as satisfiers or contributors to satisfaction; and the present research indicates that interpersonal relationships with students and other teachers serve as major factors contributing to satisfaction for the teachers in the PMA. Very possibly, these two factors are operating as motivators for these teachers. An accompanying rationale might be that the adjustment of the two discussed factors as used in an organizational setting to the closest parallel in an educational setting may well serve to change the identification of each of these factors on a dichotomy such as has been set up by Herzberg for the "dual-factor" theory. If data from Lortie's research will tend to support the assumption that interrelationships with students and goals and achievements related to "reaching" students serve as powerful and primary intrinsic factors of "psychic" reward (satisfaction), then as intrinsic factors, they may be appropriately identified as motivators. Within this context, and in accord with the data from the present study of teachers (1984), the findings for these factors do not conform with Herzberg's organizational theory, and they do conform with Lortie's sociological theory about schoolteachers. (See Appendix C.)

If Herzberg would accept the adjustment of the previously identified hygiene on interpersonal relations - peers to mean other teachers, if he would accept the adjustment of the previously identified hygiene on interpersonal relations - subordinates to mean students, and if he would accordingly accept the placement of these two factors on the motivator column operating as intrinsic factors for these educators, then he would acknowledge these factors to be 
operating in relationship to growth-fulfillment needs. (See Figure 3; See Figure 26.)

One added factor, the opportunity to help others, previously defined as a motivator and related to intrinsic elements of the work itself, is also identified as a factor that contributes most frequently to job satisfaction of teachers in the PMA. Public school teachers are people oriented and presumably committed to public service. It could well be that an interest in helping others leads potential teachers into teaching, based on an accompanying expectation that teaching offers the opportunity to help others. In any event, having the opportunity to help others serves as a contributor to job satisfaction for the teacher in the PMA.

Thus, the data permit conclusions that interrelations with students and other teachers, having a sense of achievement as a teacher involved in the act of teaching and "teaching" students, teaching itself as a kind of work, accompanied by opportunities to help others, are factors that contribute most frequently to the job satisfaction of teachers in the PMA. Accordingly, these factors should be recognized in efforts to change or improve public education. The data would suggest that teachers must have the opportunity to interrelate with their students and their fellow teachers; they must have an opportunity to gain or hold a sense of achievement; they must have an opportunity to help others; these elements of teaching are closely related to teaching itself as a kind of work. The data from the current study suggest that these factors should be carefully considered in efforts to improve levels of 
satisfaction for teachers, and that the reduction or loss of opportunity to receive these major sources of satisfaction would have a resulting negative impact on the overall attitudes and feelings of teachers in the PMA about the job and role of teaching. (See Figure 26.)

FACTORS CONTRIBUTING MOST FREQUENTLY TO JOB SATISFACTION OF TEACHERS IN THE PMA, 1984
- Interpersonal relations with students

- Sense of achievement

- Teaching as a kind of work (work itself)

- Interpersonal relations with fellow teachers or colleagues - Opportunities to help others

Figure 26. Factors Contributing Most Frequently to Job Satisfaction of Teachers in the PMA, 1984

The Factor Contributing Most Frequently to Satisfaction of Teachers in the PMA - Conformity with Lortie's Theory. What factor contributes most frequently to satisfaction of teachers in the PMA? The data from visual inspections of frequencies of responses, converted to percentages, indicate that the factor contributing most frequently to expressions of teachers' job satisfaction is interpersonal relations with students. (See Figure 27.) These data are supported by other items in the study that address teachers' assessments of their feelings and attitudes related to working with students and their interrelationships with students. Ninety-two percent express satisfaction in their interpersonal relationships with their students (II.10). Measures of receiving pleasure in working with students, liking students, having feelings of success as a 


\section{THE FACTOR CONTRIBUTING \\ MOST' FREQUENTLY TO JOB \\ SAT ISFACT ION IN THE PMA \\ Interpersonal relations \\ with students}

Figure 27. The Factor Contributing Most Frequently to Job Satisfaction of Teachers in the PMA, 1984

teacher and achievement as a teacher all range beyond $90 \%$. When given the opportunity to identify a factor that would influence change in a long-time teaching practice or behavior, more than $80 \%$ select the "knowledge that it would be good for 'kids." Additionally, more than three-quarters (78\%) of the teachers report that the most important source of satisfaction in teaching stems from "the times I know I have reached a student or group of students as each learns," and another 15\% select "the chance to associate with children or young people and relate with them" as the important source of satisfaction in being a teacher. (See Tables XV, XVI, XVII.) The 1981 study by Falkenstein (1982) and Hathaway (1982) offered an opportunity for comparison of data on compatible items addressing important sources of satisfaction for teachers in similar populations. The findings from the earlier study are very similar to those in the 1984 study and support the conclusion that the most important source of satisfaction for teachers in the PMA is from interrelationships with students and goals and achievements related to students. (See Tables XVIII, XIX.) The finding that teachers receive major satisfaction from interrelationships with students and attach major importance to this factor does conform with Lortie's theory that teachers receive primary "psychic" or intrinsic rewards (satisfactions) from goals and 
objectives related to interrelationships with students (1975, pp. 101, $104,106,109)$.

The finding that the primary source of satisfaction for teachers is directly linked to their work and interpersonal relationships with students is consistent in the 1981 study and in the 1984 study. These strong indicators would suggest that any effort to separate the teacher from the students in the PMA would have negative impact on the job satisfaction of the teachers.

Teachers are social beings (Bidwell, 1973; Lieberman \& Miller, 1978); teaching is directly involved with interrelationships of people; the school is a social environment; teachers want to be involved, most of all, with students. In addition, they mark the importance of their relationships with their colleagues. Collectively, these indicators serve as strong reminders of factors that are valued by teachers, evidently rooted in their expectations and experiences as teachers, and probably engrained in needs as human beings that directed many of them toward the roles of teaching in the first place. Every indicator of factors that contribute most frequently to job satisfaction of teachers, summiting with the selection of interpersonal relations with students, addresses the importance of the teachers' interpersonal relationships with other human beings in the enterprise of the school. The research is imbedded in statistical analyses, but the findings clearly serve as reminders that the study is sociological; the organization of human beings involved in the processes of education should include fullest attention to this vital element of the enterprise. 
Factors Contributing Most Frequently to Dissatisfaction of Teachers in the PMA - Conformity with Herzberg's Identified Factors. The data previously identified and tested as an a priori list of hygienes (Herzberg et al., 1959) provide information to indicate that the identified hygienes serve to contribute to satisfaction more than they contribute to dissatisfaction among the highly satisfied teacher in the PMA. This information, however, does not serve to answer the questions: What factors contribute most frequently to the levels of dissatisfaction that teachers in the PMA do express? Do teachers in the PMA accept the same factors as those previously identified by Herzberg as their own primary or major factors contributing to job dissatisfaction? The data would permit some conclusions that the teachers studied in the PMA in 1984 acknowledge the Herzberg list of five primary hygienes, but they relate them significantly to satisfaction not to dissatisfaction; and they establish a somewhat different list of factors contributing most frequently to their own dissatisfaction, as data drawn from the frequencies of their responses and rankings on items $\left(Q_{2}, I I .1-25\right)$ converted to percentages. (See Appendices $D$ and F.)

The teachers in the PMA indicate that the following factors contribute most frequently to job dissatisfaction:

$$
\text { Salary }
$$

Time spent preparing for teaching

Status

Time spent on school-related activities outside of teaching and preparation for teaching

Policies and practices of the school district 
The findings do not fully conform with Herzberg's list of primary hygienes that contributed to dissatisfaction of accountants and engineers in the organizational research (1959); however, each of the above-listed factors has been previously defined as a hygiene or extrinsic factor, and each as been identified as contributing most frequently to dissatisfaction of the teachers in the study. The Herzberg list does include salary and policies and practices of the company or organization (adjusted to mean school and district). The teachers in the PMA rank the policies and practices of the school district in the top five factors contributing to dissatisfaction; they do not rank the policies and practices of the school quite as high on the list of contributors to dissatisfaction. Teachers are generally closer to the policy making and related practices in their schools than they are with the same factors in the school district (Hearn, 1971). This might account for the somewhat higher expression of dissatisfaction with the policies and practices of the school district and the somewhat lower ranking for the expression of dissatisfaction for this factor when it is associated with the school. This may, to some degree, reflect a "we-they" perception of the daily workings and intentions of the schools as being somewhat separate from the working and intentions of the school district, its administrators and the Board of Education--those who establish the policies and regulations that pattern the practices for the entire system of schools and staff in the district as an entity. This expression of ranked dissatisfaction might be improved by bringing teachers into closer comnunication with their school districts or into the policy-making 
processes of their school districts. Certainly, teachers need to feel that they are fully considered in the setting of policies and the implemented practices in their schools and in their school districts. Brooks (1982, p. 44) reinforces the need of teachers to be involved in decision-making processes within the educational system addressing goal-based reform.

Status matters to teachers, and teachers in the study group note some degree of dissatisfaction with the amount of status they receive. Lortie has noted that teaching is "front-1oaded" (1975, pp. 84, 204, 211, 212). Teachers entering teaching do not expect great status from their positions, and the teachers in the current study do not express great degrees of dissatisfaction with their perceived lack of status. But they do indicate this factor as a factor that contributes most frequently to their dissatisfaction in their jobs. Time is another matter of concern and potential dissatisfaction for teachers. Teachers in the PMA indicate that time spent preparing to teach and time spent on school-related activities outside of teaching and preparation for teaching are factors that contribute most frequently to their dissatisfaction. It is appropriate to note that they do not rank time spent in teaching within the list of major dissatisfiers. Teachers entering teaching would presumably expect to spend time preparing for their lessons and on school-related activities outside of the time spent in teaching, but it may well be that some do not realize how much time they will need to spend planning lessons or in school-related activities that are ancillary to their roles but not directly related to teaching. 
Efforts to change or improve public education in the PMA should include consideration of the indications provided by the schoolteachers in the study group. These teachers suggest that they are greatly satisfied, but it is reasonable to conclude that efforts to improve the identified areas of their dissatisfaction might serve to increase their levels of satisfaction or at least to reduce the levels of dissatisfaction. This conclusion is couched, however, in recognition of Herzberg's "dual-factor" theory that posits that hygienes will contribute to dissatisfaction but not operate significantly to contribute to satisfaction. Within Herzberg's "dual-factor" theory the absence of the factor contributing to dissatisfaction would result in the state of being neither satisfied nor dissatisfied. Although the "dual-factor" theory is not upheld in the present research, the theory on the action of hygienes may serve as a caution or reminder. More money, more time to do what is regarded as important by teachers or what they think teachers are supported to do, and more status may not automatically serve to impact positively on expressed dissatisfactions over a prolonged period. These factors are accompanied by the acknowledgement from Herzberg et al. (1959) that they are probably subject to continuing attention, as pain-avoidance needs; gratification may simply result in the absence of pain until the need is again identified. (See Figures 3 and 28.)

The Factor Contributing Most Frequently to Dissatisfaction of Teachers in the PMA. What factor contributes most frequently to dissatisfaction of teachers in the PMA? The data from visual inspections of frequencies of responses, converted to percentages, 
FACTORS CONTRIBUTING MOST FREQUENTLY TO JOB DISSATISFACTION OF TEACHERS IN THE PMA, 1984
- Salary

- Time spent preparing for teaching

- Status

- Time spent on school-related activities outside of teaching and preparation for teaching

o Policies and practices of the school district

Figure 28. Factors Contributing Most Frequently to Job Dissatisfaction of Teachers in the PMA, 1984

indicate that the factor contributing most frequently to expressions of teachers' job dissatisfaction is salary. (See Table XIV; See Figure 29.)

THE FACTOR CONTRI BUTING

MOST FREQUENTLY TO JOB

DI SSATISFACTION IN THE

PMA

Figure 29. The Factor Contributing Most Frequently to Job

Dissatisfaction of Teachers in the PMA, 1984

In the section asking respondents to rank factors from satisfaction to dissatisfaction, more than one third (37\%) express dissatisfaction with salary. In the section asking respondents to rank factors from important to unimportant, more than ninety percent $(92 \%)$ mark the importance of salary; only $2 \%$ find it to be unimportant. The additional finding that salary is significantly related to job satisfaction draws attention to the factor and its importance whether it is identified as a hygiene, as it has been in Herzberg et al. (1959) and for the present study, or whether some future research will find it to be a motivator or strongly related to motivation. If it is operating as a hygiene--as a pain-avoidance 
factor--it is subject to close monitoring. Gratification of the need-increase in salary--does not serve to remove the likelinood that the need will again be identified. (See Figures 3 and 29.)

Very simply, almost all of the teachers in the PMA think salary is important, and more than a third express dissatisfaction with the salaries received. Teachers may not expect to receive large salaries (Lortie, 1975, pp. 84, 204, 211, 212), but it is reasonable to conclude that they want to be certain the public and their districts are aware that what they do receive is important to them; furthermore, it is a factor that contributes most frequently to their expressed dissatisfaction, and it is a factor that also operates as a contributor to their expressed satisfaction with their jobs as public school teachers. However, it is also interesting to note that when teachers were asked to indicate what factor would influence them to change a long-time practice or behavior pattern associated with teaching (IV.45), only 7\% suggest that "more money" would be a major influence; the belief that it would be "good for kids" is the identified factor that would influence change $(83 \%)$.

Surmary (Research Question \#2). The following list of conclusions drawn from the second research question may serve as a sumnary to this section:

1. Of the factors tested, the data indicate that each of the factors can operate as contributors to job satisfaction or dissatisfaction of the teachers in the PMA.

2. The factors previously identified by Herzberg et al (1959) as primary motivators or intrinsic factors were tested in the current study and are seen to be significantly related to job satisfaction of the teachers in the PMA. 


\begin{tabular}{|c|c|c|}
\hline & WOTIVATORS & \\
\hline Self-actualization & $\begin{array}{l}\text { Responsibility } \\
\text { Advancenent }\end{array}$ & $\begin{array}{l}\text { Interpersonal relations/student } \\
\text { Achievement vork itsslf }\end{array}$ \\
\hline Ego & $\begin{array}{l}\text { Recognition } \\
\text { Achievement }\end{array}$ & $\begin{array}{c}\text { Recognition } \\
\text { Status }\end{array}$ \\
\hline Belonginess, Social, Love & Conditions and Relations & $\begin{array}{l}\text { Interpersonal relations/teacher } \\
\text { Opportunities to help others } \\
\text { Responsibilitis }\end{array}$ \\
\hline Safety and Security & Fringes & $\begin{array}{l}\text { Time Job security Conditions } \\
\text { Policies \& practices } \\
\text { Suneryisien/Suneryisor }\end{array}$ \\
\hline Physiological & Salary & Salary \\
\hline & HYGIENES & \\
\hline Maslow (1954) & Herzberg (1959) & Perko (1984) - PMA \\
\hline
\end{tabular}

Figure 30 - Needs and Gratification as Related to Motivators and Hygienes

This figure is an adaptation of Naslow's theory of hierarchical needs (1954) and Herzberg's dual-factor or bidimensional theory of growth needs as motivators and pain avoidance needs as hygienes (1959 \&1974). (Drawn from Kaiser, 1981, F. 36; adajted for this study) 
3. The factors previously identified by Herzberg et a1. (1959) as primary hygienes or dissatisfiers were tested in the current study and are seen to be significantly related to job satisfaction of the teachers in the PMA. This finding is contrary to the research prediction and brings question to Herzberg's "dual-factor" theory and its applicability for study of teachers in the PMA.

4. The factors contributing most frequently to job satisfaction of teachers in the PMA are:

Interpersonal relations with students

Sense of achievement

Teaching as a kind of work (work itself)

Interpersonal relations with other teachers.

Opportunities to help others

This list does not fully conform with Herzberg's research on how factors operate, but it does include two of the previously identified motivators, and a variation may be based on the adjustment of two of his factors identified as interpersonal relations - peers and subordinates to mean fellow teachers and students. The other factor identified in the current study is an addition, previously identified as a motivator and related to work itself, opportunities to help others.

5. The factor contributing most frequently to job satisfaction of teachers in the PMA is:

Interpersonal relations with students

This finding is supported by findings from earlier study of a sinilar population (Falkenstein, 1982; Ha thaway, 1982), and it does conform with Lortie's sociological study of school teachers (1975).

6. The factors contributing most frequently to job dissatisfaction of teachers in the PMA are:

Salary

Time spent preparing for teaching

Status

Time spent on school-related activities outside of teaching or preparation for teaching

Policies and practices of the school district

7. The factor contributing most frequently to job dissatisfacton of teachers in the PMA is:

Salary 
This factor is highly important to teachers, and an increase in salary may not contribute to prolonged satisfaction. The factor can operate to contribute to dissatisfaction, but it can (and does) also operate to contribute to satisfaction. This study accepts the identification of the factor as a hygiene. This study does not permit the conclusion that the factor is related to motivation (or levels of performance).

8. Each of the identified factors is important to be considered in efforts to improve levels of satisfaction or reduce expressed levels of dissatisfaction as they may be seen to be related to needs and gratifications operating as motivators or hygienes. (See Figure 30.)

Research Question \#3 - Demographic Factors and Their Relationship to Job Satisfaction or Dissatisfaction

This study addresses five demographic factors--age, sex, grade level, years in service, and highest degree earned--and includes data that permit some conclusion on each factor and its relationship to measures of job satisfaction. In addition, the data on each of the factors have been compared with findings on the same or similar factors in earlier study of the similar population (Falkenstein, 1982; Hathaway, 1982) and with national indicators (NEA, 1979-1983). These comparisons were made to sec how the present population in the PMA conforms with the population studied in 1981; and to see how the population conforms with summary data from nationwide study.

Age. The data from the present study indicate that teachers in the PMA are growing slightly older as a population than they were in 1981. (See Tables XXV, XXVI; See Figures 8, 9, 10.) At present, the mean falls in the age category 41-45. The median and mode are represented by teachers aged 36-40. From the compared data of 1981 and 1984, fewer teachers in the population are in the 20-25, 26-30, 
31-35, 56-60 and over 60 age categories in 1984; more teachers in the population are in the 36-40 and 41-45 age categories. The population is holding as a constant in the 51-55 age category. The national indicators find that teachers are increasing in age as a population. The mean years for teachers have risen from 37 in 1973 to 41 in 1983 (NEA, 1983, p. 7). (See Table XXVII.) Teachers as a population and in the PMA are growing older. Why? The data from the present study does not address this question; however, some suppositions are as follows: fewer younger teachers are entering the school systems; they may well have fewer opportunities for jobs, and they may well be looking elsewhere to establish career paths. The teachers in the systems may well be holding onto seniority and jobs with high degrees of security. The data from the present study would also suggest that they have other important reasons for staying in teaching--they are satisfied with many aspects of their jobs and their roles as teachers. Some of the older teachers are leaving the system; this may be due, in part, to retirement programs for public employees in the State of Oregon.

Is there a significant relationship between age and measures of satisfaction, and if so, what is it? The findings from statistical evaluations of satisfaction and age indicate that there is a significant and inverse relationship between age and measures of satisfaction. Older teachers tend to be more satisfied than younger teachers. (See Table XX.) The data further suggest that among a group of highly satisfied teachers, those in the age category over 65 (a very small sample) and those in the age category 20-25 express 
highest percentages of satisfaction, and the lowest expression of satisfaction is indicated by the age category 31-35. The highest percentage of expressions of dissatisfaction is indicated by the age category 56-50, and the lowest percentage of expression of dissatisfaction is indicated for age categories 20-25 and over 65 . (See Tables XX, XXV, XXVI, XXVII, XXVIII, XXIX; See Figures 8, 9, 10.)

These data may be seen to suggest that there is a slight increase in dissatisfaction between the age categories 20-25 and 26-30. Perhaps the newness of the job is wearing off, or the maturity of the 26-30 year old teachers may be an influence. The somewhat lower level of satisfaction in the 31-35 age category may suggest something akin to "the seven-year itch." Perhaps, some of these teachers are looking toward other career paths inside or outside of education. Those who stay in public education appear to reflect increasing satisfaction or decreasing dissatisfaction until the age category of 56-60. These teachers may be "itching to retire," waiting it out, or subject to other vicissitudes of increasing age juxtaposed with the rigors of teaching. The current study does not permit such conclusions, only conjecture. Additional research might help respond to some of the suppositions.

If the patterns of satisfaction as related to age are foumd to be reasonably constant, these data may be helpful to building administrators and personnel services for District employees. It would appear to be important to find out just how and why age appears to have a significant relationship to the satisfaction of the teacher, and just how and why the older teacher tends to be significantly more 
satisfied. The answer may simply be that those who stay tend to stay because they are satisfied or settled or that teaching suits them. Again, these suggestions may be linked to the propensities and expectations of those who enter teaching, those who choose to leave teaching, and those who choose to stay in teaching for a variety of reasons that this study addresses and offers as possible conclusions.

In any event, the finding that teachers are growing older as a population is worthy of careful consideration in terms of how this may impact on public education and public school systems.

Sex. The data from the present study indicate that there are fewer men and more women in the school systems of the PMA than there were in 1981. At present, the teacher population reflected in the study group is $68 \%$ women and $32 \%$ men. In 1981, the population studied reflected $63.7 \%$ women and $36.3 \%$ men. This apparent trend is supported by national indicators that the teacher population is shifting slightly to include more women teachers and to include fewer men (NEA, 1983, p. 7).

Is there a significant relationship between the sex of the teacher and job satisfaction? The findings from statistical evaluations of satisfaction and sex suggest that there is a significant relationship between sex and job satisfaction for teachers. (See Table XXI.) It is appropriate to note that the group of teachers studied is highly satisfied, $89.7 \%$ of the women express degrees of satisfaction with teaching, and $84 \%$ of the men express degrees of satisfaction. Five percent of the women express dissatisfaction, and $8.2 \%$ of the men express dissatisfaction. 
If women are somewhat more satisfied with teaching than men are, what contributes to the expressed levels of satisfaction for the women and the slightly lower levels of satisfaction (or slightly higher levels of dissatisfaction) for the men? This study does not draw conclusions to this particular question, but the data may permit some conjecture. Teaching is a profession that has long been identified as stereotypically "suitable" for women who work. Men entering teaching may be more likely to be interested in moving into administration, and they may be more favored than women applicants for election into such positions. Men may be seen to have more job opportunities in the "open market" than women have had. If these patterns are changing, the data would still permit some conjecture on the increase of women in public education. More women are entering the job market, including public education, as members of households with both partners working; more women are also entering the job market, including public education, as single parents working to support families, or as the only worker in the household.

If, indeed, these trends continue, it will be important to consider how the adjustment will impact on public education and public school systems. What might be some ways to attract more men into teaching and keep them in teaching? Are there particular grade levels that might be particularly benefited by having more men as the classroom teachers? Further study may draw more information into this field of inquiry. The present study simply permits acknowledgement to the finding as ancillary to the indicated data that there is a significant relationship between teaching and the sex of the teacher, 
and that women are somewhat more satisfied with teaching than men are. (See Tables XXI, XXX, XXXI, XXXII, XXXIII, XXXIV; See Figures $11,12,13$.

Grade Level. The data from the present study indicate some adjustment in the percentages of teachers assigned at grade levels in 1981 and 1984; however, because the school districts in the sample include many types of grouping for primary schools, elementary schools, middle schools or jumior high schools, and secondary schools, these data may not reflect a particular trend. However, it is noted from the two studies ( 1981 and 1984) that the mean, median, and mode all fell at or near grades 7-9 in 1981. In 1984, the mean is slightly above grade 6; the median is grades 6-8; and the mode is grades 1-3. (See Tables XXXV, XXXVI.) Again, this could simply be an outcome from the sampling. National indicators from NEA polls suggest some drop in the percentages of teachers at the elementary grades, a slight drop in percentages of teachers at the middle or junior high schools, and slight increase in the percentages of teachers in the high or secondary schools (1983, p. 6). Public schools have done some reduction of staff over the past several years, due, in part, to shifting populations of students and reduced or adjusted budgets to cover the operations of the schools. Some additional emphasis has been given to staffing patterns for the primary grades and for the middle school or junior high grades. Within the population of the PMA, some of the districts have closed schools or changed grade levels in the buildings. All or any of these factors may be operating as influences on apparent patterns. It could be useful to continue to 
monitor the percentages of teachers assigned at various grade levels, to chart or predict changes that could be of particular interest to personnel services of public school systems as administrators are involved in staffing and projecting areas of need or surplus in candidates or employees, subject areas, grade levels, and ancillary programs in the districts and their schools.

Is there a significant relationship between grade level of assignment and measures of teacher job satisfaction, and if so, what is it? The findings from statistical evaluations of satisfaction and grade level of assignnent indicate that there is a significant relationship between grade level and satisfaction. Teacher of primary grades through grades 4-6 report a somewhat higher expression of satisfaction than do teachers of higher grades--from $6-8$ or 7-9 through 9-12. Additionaliy, the data indicate an apparent increase in the satisfaction of teachers assigned to grades 1-3 over the teachers assigned to Pre-K-K levels. Teachers at grade levels 1-3 report the highest percentage of expressed satisfaction; the pattern holds almost constant through 4-6, and then the degree of expressed satisfaction drops for teachers assigned to grades $6-8$ or 7-9, the grade levels usually identified as upper elementary or middle or junior high schools. Again the degree of satisfaction appears to increase for the teachers assigned to grades $9-12$ in the standard secondary school configuration or in other secondary school patterns inside that range of grade levels. Why do the teachers of the primary grades express greater degrees of satisfaction than the teachers of the upper grades? This present study does not presume to answer that question. 
However, some conjecture is possible. Children in grades 1-3 are presumably ready for school and generally very willing to attend school; children in grades 4-6 still reflect those tendencies. Children in grades 6-8 or 7-9 are moving into puberty or adolescence; they are sometimes more restless about their schooling or their willingness to "pay attention to the teacher" and to acknowledge the immediate pleasures and benefits of going to school. In addition, the teachers assigned to teach at these grade levels may reflect staffing and program adjustments in school and districts dealing wth shifting student populations and presently contracted personnel. It is sometimes necessary to assign teachers at grade levels where they may not be most prepared or interested in order to cover classrooms or instructional programs or to meet contractual conditions or agreements resulting from collective bargaining. Teachers at secondary levels are more often subject-oriented and tend to be assigned within the areas of their particular subject orientation and certification. Additionally, the students in high schools are maturing. These factors may account for the slight increases in satisfaction noted in the current data for secondary teachers.

However, it is once again important to suggest that the teachers in the PMA indicate very high degrees of satisfaction. There is a significant relationship between grade level of assignment and expressed satisfaction with teaching. The highest percentage of expressed satisfaction is recorded in the primary grades, from 1-3 through 4-6; the lowest percentage of expressed satisfaction and the highest percentage of expressed dissatisfaction is found for the 
teacher of grades 6-8 or 7-9; the satisfaction levels increase slightly and the dissatisfaction levels decrease slightly for the teachers assigned at grades 9-12. Additional study and analyses may account for some of these findings or see if these findings are truly reflective of any particular and significant pattern for teachers in the PMA. But the present findings tend to conform with findings from research related to "Effective Schools" suggesting that elementary teachers are more satisfied with their jobs than secondary teachers are (Bentzen et al, 1980, pp. 394-397). (See Tables XXII, XXXV, XXXVI, XXXVII, XXXVIII, XXXIX; See Figures 14, 15, 16.)

Years in Service. The data from the present study indicate that there is an apparent tendency for teachers to represent a population with more years in service than was indicated in 1981. Some of the variations might be due to sampling; however, the trend is suggested in the PMA. (See Table XLI.) At present, there is a decrease noted in the percentages of teachers with from 1-5, 6-10, and from 21-30 years of service. This might be related to a slow up in hiring, with fewer teachers entering public school systems in the PMA, accompanied by the numbers in the 21-30 years of service range that may be electing to leave the system and accept early or voluntary retirement. There is an increase indicated in the percentages of teachers with from 11-20 years of service and a very slight increase in the group of teachers with more than 30 years of service. The increase shown for those in the 11-20 year range might be related to job security of teachers with quite a few years invested in teaching, as well as the indicators in this study that the teachers are highly 
satisfied with teaching as a total population. Another conjecture for the small group of teachers remaining in the system after more than 30 years of service is that if they stay that long, they evidently like teaching or cannot envision a change in their career paths. Teachers in Oregon who are 55 years of age and who have 30 or more years of service are eligible for early or voluntary retirement benefits. The indicators that teachers are becoming a population with more years in service is supported by national indicators that the mean for total years in teaching has risen from $11 \%$ in 1973 to $15 \%$ in 1983, and similarly, that the mean for total years in the present system has risen from 8 in 1973 to 12 in 1983 (NEA, 1983, p. 6). The job market is tightening in public education, and teachers are tending to hold onto their jobs. The present study does not provide all the answers to why. Some of the explanation is identified in economic trends in the PMA and across the United States. Some of the explanation might be better addressed in future research.

However, the present study does include some address to the general question of whether there is a significant relationship between years of service and satisfaction (as is found in the test of age and measures of satisfaction). Data in the current research do not support a finding of a significant relationship between years in service and the job satisfaction of the teachers in the PMA. Any apparent tendency for the teacher to be more satisfied than the teacher with fewer years is nonsignificant in the present research. The population studied is highly satisfied as a group. The data provide some suggestion that although satisfaction may increase for 
some teachers with many years of service, dissatisfaction may also increase for some other teachers, and the group of teachers noting neither satisfaction nor dissatisfaction may be reflecting some element of "marking time."

The findings that teachers are reflecting a population with increasing years of service suggest continuing address to this pattern in terms of potential for impact on public education. Additionally, this factor merits consideration for staffing patterns and personnel services for the school districts in the PMA. (See Tables XXIII, XL, XLI, XLII, XLIII, XLIV; See Figures 17, 18, 19, 20.) Education (Highest Degree Earned). The present study indicates that the mean for highest degree earned for teachers in the PMA now falls between bachelor's and master's degree. The median and mode are represented by teachers holding master degrees. Very few teachers in the PMA hold doctoral degrees and do not reflect a sample percentage. (See Tables XLV, XLVI.) When these data are compared with the data from 1981, the figures are very similar and permit no suggestion of trend or change. (See Table XLVII.) When the data from the PMA in 1981 and in 1984 are compared with data from nationwide study, it would appear that teachers holding master degrees in the PMA reflect slightly higher percentages than the national indicators (NEA, 1983, p. 5). (See Tables XLV, XLVI, XLVII.)

These indicators permit some suggestion that the teacher population in the PMA is relatively stable in terms of the percentages holding bachelor and master degrees, and the PMA reflects a somewhat higher percentage of teachers holding master degrees than the 
percentages reflected nationally. These findings are not surprising when they are considered in relationship to the ages of the teachers in the PMA and the years of service of the teachers in the PMA. The PMA encompasses many colleges and universities and provides considerable opportunity for continuing education of the public school teachers working in this area. In addition, some of the school districts provide a variety of incentive programs (such as salary increments or tuition reimbursements) for teachers continuing their professional education as credited or non-credited inservice in teacher-related workshops or coursework.

Is there a significant relationship between the highest degree held and measures of satisfaction? The findings from the present study do not identify a significant relationship between satisfaction and highest degree earned. The findings do suggest some apparent tendency for teachers with higher degrees than bachelor to be somewhat more satisfied, but these data are nonsignificant. Again, these findings could be mirrored against the conclusions on age and satisfaction and years of service and satisfaction. But, in a population that is highly satisfied with teaching, there are not significant data to permit a conclusion that teachers with higher degrees are more satisfied with teaching than teachers with lower degrees, or the reverse. (See Tables XLVIII, XLIX.)

Additional study might address this general topic in relationship to teacher performance. Such data may well provide additional rationale for "plus hour" salary schedules or tuition reimbursements as teacher incentives that are not only intended to improve 
performance and may reflect or result in increased levels of satisfaction for the teacher, but that could also reinforce the assumption that continuing education does result in improved teacher perfornance.

If improved teacher performance results in improved sense of achievement for the teacher as Lawler and Porter suggest (1967, pp. 20-28), then the data from the present study would suggest that the improved sense of achievement wili impact positively on the satisfaction of the teachers in the PMA. (See Tables XXIV, XLV, XLVI, XLVII, XLVIII, XLIX; See Figures 21, 22, 23, 24.)

Summary (Research Question \#3). The following list of conclusions drawn from the third reseach question may serve as a summary to this section:

1. Three of the demographic factors tested (age, sex, grade level) are seen to be significantly related to job satisfaction for teachers in the PMA; two of the factors (years in service, highest degree earned) are not seen to be significantly related to job satisfaction for teachers in the PMA.

2. Age - Teachers in the PMA in 1984 reflect a slightly older population than was indicated in 1981. In 1984, the mean age is represented by. the age category 41-45; the median and mode are represented by teachers in the 36-40 age category. This is consistent with national indicators that the teaching population is aging.

There is a significant relationship between age and job satisfaction for the teachers in the PMA. The older teachers tend to be slightly more satisfied than the younger teachers.

3. Sex - Teachers in the PMA reflect a population with more women and fewer men than was indicated in 1981. In 1984, the women represent more than two-thirds of the teaching group $(68 \%)$; the men represent less than one-third of the group $(32 \%)$. This finding is consistent with national indicators that there are more women and fewer men in teaching (as data collected from 1973 through 1983). 
There is a significant relationship between sex and job satisfaction for the teachers in the PMA. Women tend to be more satisfied than men.

4. Grade Levels of Assignment - There is not a clear pattern to reflect a change in grade levels of assignment over the last three years that might not be due to sampling, change in programs or demographics of student populations. Any reflected change in the PMA does not necessarily reflect national indicators. At present, the mean grade level is slightly above grade 6; the median is grades 6-8, and the mode is grades 1-3.

There is a significant relationship between grade level of assignment and job satisfaction for the teachers in the PMA. Teachers of the primary grades (through 4-6) indicate greater satisfaction than teachers of higher or upper grades (6-8, 7-9, or 9-12). Among a population of very satisfied teachers, the teachers of grades 1-3 express highest degrees of satisfaction, and the teachers of grades 6-8 or 7-9 express the lowest degrees of satisfaction and the highest degrees of dissatisfaction.

5. Years in Service - Teachers in the PMA indicate a tendency for the population to have more years in service in 1984 than they reflected in 1981. There is an indicated decrease in teachers with from 1-5, 6-10, and 21-30 years of service; there is an indicated increase in teachers with from 11-20 and more than 30 years of service. National indicators find similarly that the mean for total years in service and total years in the present system has risen over the period from 1973 to 1983 .

The present study does not find data to support the prediction that there is a relationship between years in service and job satisfaction. The findings are nonsignificant. There is an apparent tendency for teachers with more years in service to reflect some greater degree of satisfaction than teachers with fewer years of service; however, the data also indicate a concomitant increase in dissatisfaction for the teacher with many years of service. All teachers in the population reflect high levels of job satisfaction that are not seen to be directly related to the numbers of years in service.

6. Highest Degree Earned - Teachers in the PMA reflect earned degrees held in 1984 to be very similar to those held in 1981. Forty-five percent hold bachelor degrees and fifty percent hold master degrees in 1984. Too few teachers holding doctoral degrees were included in the sample to be 
identified as a percentage. The teacher population in the PMA appears to be stable in the representation of teachers with bachelor and master degrees. The percentage of teachers in the PMA holding master degrees is somewhat higher than national indicators.

The present study does not find data to support the prediction that there is a relationship between highest degree earned and job satisfaction for the teachers in the PMA. The findings are nonsignificant. All teachers in the population reflect high levels of job satisfaction that are not seen to be directly related to degree held.

\section{Other Conclusions}

The findings from the study permit some additional conclusions to the applicability of Herzberg's theory and Lortie's theory for a study of public school teachers, as well as some conclusions from other findings.

Conclusions in General on Applicability of Herzberg Theory for Study of Public School Teachers. The findings from the present study offer mixed data on the general applicability of Herzberg Theory for study of public school teachers. The "dual-factor" theory provides a basic dichotomy for an identification of factors as motivators or intrinsic factors that may serve as satisfiers but will not serve as dissatisfiers along with an identification of factors as hygienes or extrinsic factors that may serve as dissatisfiers but will not serve as satisfiers. The present study does not presume to validate Herzberg's theory; the present study does address how findings from the teachers in the PMA will (or will not) conform with the factors identified by Herzberg et al. (1959) research. The Herzberg list of primary motivators is accepted by teachers in the PMA as contributing 
significantly to job satisfaction; however, the Herzberg list of primary hygienes is also accepted by teachers in the PMA as contributing significantly to job satisfaction. The list compiled from visual inspections of frequency counts of the factors identified to contribute to satisfaction of teachers in the PMA does not conform with the previously identified list from Herzberg research. It is possible to suggest that the adjustment of the two hygienic factors interpersonal relationships with peers and subordinates to mean fellow teachers and students is highly appropriate to a study of schoolteachers, but the factors no longer operate in the educational setting as they did in another organizational setting. Furthermore, it is possible to suggest that for teachers these two factors are operating as motivators. In any event, the data permit conclusion that these two factors are directly and significantly related to the job satisfaction of the teachers in the PMA. The Herzberg theory has been very useful in the design and analyses of the study even though the findings from the present study of schoolteachers do not fully conform with Herzberg's "dual-factor" theory.

It is appropriate to note that the factors identified by teachers in the PMA as contributing most frequently to their dissatisfaction are all previouly identified as hygienes by Herzberg research. They are simply not all the same hygienes that the Herzberg research establishes. Again, it is appropriate to note that two of the factors are a match (salary and policies and practices/district). And these factors identified by the teachers in the PMA are adjustments based on research by Moxley (1977), Lortie (1975) and Falkenstein (1982) and 
Hathaway (1982). The added factors appear to be highly appropriate to a study of schoolteachers. The added factors are two items on time spent on other than teaching. The other factor that contributes frequently to dissatisfaction of teachers is that of status. Herzberg acknowledges it as a hygiene; his research does not find it to operate as one on the primary list. The teachers in the PMA do offer indication that this factor is on the primary list of factors that contribute most frequently to the small degree of dissatisfaction that the group studied identifies.

In short, Herzberg's theory has been useful to the study. It is appropriate to note that some of the factors have been adjusted for the population of this study. The adjustments are appropriate to the purposes and potential benefits of a study of schoolteachers. Within that acknowledgement of adjustment and intention, the findings in the present study do not fully conform with those associated with Herzberg's organizational theory, identified as the "dual-factor" or "two-factor" or "bidimensional." The present study finds that all factors tested can operate to contribute to satisfaction or dissatisfaction. In the present study, very few teachers accept the neutral ranking (the assessment of being neither satisfied nor dissatisfied), and that finding does not permit a conclusion to support the "dual-factor" theory. In this study, the neutral ranking appears to operate within a continuum that is greatly skewed toward satisfaction. In accord with Herzberg's research, the motivators do serve to contribute to satisfaction more than they contribute to 
dissatisfaction, and the factors which contribute most frequently to dissatisfaction for the teachers in the PMA are classified as hygienes.

Conclusions of General Applicability of Lortie Theory for Study of Public School Teachers. The findings from the present study offer strong support for the research developed by Lortie in his sociological study of scoolteachers (1975). His findings that teachers receive primary "psychic" or intrinsic rewards from their interpersonal relations with their students and from their goals and achievements related to their students are supported throughout the present study of schoolteachers. His suggestions that teachers are dissatisfied by whatever comes between them and their primary commitments to students are also supported by indicators in the present study of some expressed dissstisfaction with use of time for other than for teaching or for work with students. His overall assessinents that teachers enter teaching with expectations related to "front-loading" are not tested in the present study, but his views may well augnent the findings in the present study. He suggests that teachers entering the system do not expect to receive high salaries, or great recognition, or high status. And he may well be correct. In general, the population studied in 1984 indicates that teaching has fallen in line with entry-level expectations. To the degree that the teachers are dissatisfied, they find dissatisfaction in their salary, recognition, status, and some other previously discussed factors. But, they are not highly dissatisfied; and, in general, they reflect a population that has chosen to teach, has chosen to remain in teaching, and would once again choose to teach if other opportunities were 
presented inside or outside the field of public education. Teachers in the PMA indicate that they like to teach; they like students and relationships with fellow teachers; they receive pleasure from teaching; and they like their jobs and assignments as teachers. They indeed reflect social attitudes and the importance of relationships witn people and the opportumity to help others. The sociological study of Lortie (1975), followed by the research of Falkenstein (1982) and Hathaway (1982), has been very useful to the design of the present study and the analyses of findings in the present study of schoolteachers in the PMA in 1984.

Conclusions of the General Applicability of Combining Herzberg's Theory and Lortie's Theory for Study of Public School Teachers. The coupling of Herzberg's theory and Lortie's theory has proved useful to the study of public school teachers in the PMA. If no theory has emerged to address the job satisfaction of schoolteachers, the organizational theory of Herzberg and the sociological theory of Lortie have served in the design of the present instrument as well as in the processes of analyses of data collected from the teachers in the PMA. In general, then, the combined theories of Herzberg and Lortie have been a benefit to the purposes and processes of the present study on job satisfaction from the public school teachers in the PMA in 1984. Conclusions from Other Findings. It is appropriate to include some additional conclusions that may be drawn from the other findings from the present study: 
Teaching as a Kind of Work:

Teaching Itself as a Kind of Work (II.13), identified as a motivator, appears to be related to job satisfaction. Eighty-six percent of the teachers express satisfaction with this factor. As a similar item, the importance ranking on The Intellectual Activity and Challenge of Teaching (III.23) identifies that 95\% of the teachers rank this factor as important to them. Ninety-seven percent rank Influencing Young People's Education (III.24) as important to them. The data would suggest that many teacher in the PMA receive satisfaction from their work as teachers, and part of the satisfaction is apparently related to intrinsic elements of teaching that include the intellectual activity, the challenge, and the opportunity to influence young people's education. This finding may well suggest that these factors serve as attractors or expectations for those who enter teaching and receive satisfaction from teaching. In any event, the data would suggest that teachers expect teaching to include intellectual activity and challenge and they expect to have influence of the education of their students. And these factors may be seen to contribute to the expressed satisfaction of teachers assessing their work.

Sense of Achievement:

Eighty-nine percent of the teachers express satisfaction with their Sense of Achievement as teachers (II.1). Ninety-eight percent rank Personal Feelings of Success or Achievement (III.11) as important. Ninety-six percent identify Maintaining a Positive 
Learning Atmosphere (III.16) as important. Ninety-nine percent rank Knowing That You Are Successful as a Teacher (III.22) to be important. Ninety-nine percent of the teachers indicate that they are able to maintain a positive atmosphere for their students from about half of the time to almost all of the time. Ninety-eight percent indicate that they are successful in meeting the intellectual needs of their students as individuals in rankings from about half to almost all of their students (IV.13). Ninety-one percent think they would be described by their students (IV.26) as from above average to outstanding; $87 \%$ think they would be described by parents (IV.23) similarly; 93\% think they would be described by other teachers (IV.9) with the same positive ranking. On the overall ranking of how successful they feel as teachers (IV.27), 86\% indicate feeling quite to very successful. When asked how much they think they have achieved as teachers, (IV.32) 93\% rank their achievements from quite a bit to a great deal above their expectations. Teachers want to be successful, and they receive satisfaction from believing that they are successful in the ratings of their students, the parents, and other teachers. Finally, they receive satisfaction from their self-determinations that they have met or exceeded their own expectations and that they have succeeded or achieved as schoolteachers in the PMA. Simply, they feel good when they believe they have reasons to give themselves a "pat on the back." Amount of Recognition:

About half of the teachers studied $(52 \%)$ indicate 
satisfaction with the amount of recognition they receive; $47 \%$ indicate either the neutral or passive ranking or degrees of dissatisfaction with this factor (II.2). Eighty-nine percent of the teachers studied affirm that this factor is important to them. These findings suggest that recognition contributes to satisfaction and dissatisfaction of teachers, but that many teachers do not believe they receive a great amount of recognition. It may well be that they do not necessarily enter teaching with an expectation of receiving great amounts of recognition, but their own assessments of their achievements suggest that they would like to be recognized for what they do and try to do (Lortie, 1975, pp. 130, 133, 161). Research on "Effective Schools" (Goodlad et al., 1979-80) emphasizes the need to express high expectations for students and to find reasons to offer them praise. Rutter et al (1979, p. 123) finds consistent linkages between rewards and praise. It is not difficult to extend this rationale toward the teacher. Expectation and praise or recognition may well be related to performance (Rist, 1970). Maslow (1954), Herzberg et al. (1959), and Lortie (1975) all emphasize the need of the worker to receive some kind of notice, and Lortie finds that teachers receive very little positive recognition (1975, pp. 130, 133, 161). Where can the recognition come from? Parents and other community members are a vital source of recognition potential; so are school and district administrators; so are other teachers; and so are students. The extension of the educational philosophy that teachers should be 
expected to do a good job as teachers should include also the positive element of recognition when they do what they are expected to do and what they themselves expect to do and what they evidently believe, in the PMA at least, that they are able to do.

Amount of Autonomy:

Seventy percent of the teachers in the PMA express satisfaction with the amount of autonomy they have as teachers (II.23). Ninety-six percent of the teachers affirm the importance of having freedom to teach (III.2), and $71 \%$ support the importance of having a feeling of power or authority in their work (III.3). Ninety-six percent support the importance of being creative in teaching (III.15). These findings suggest that almost all of the teachers want to have freedom to teach, and they want to be creative. They are not quite as supportive of the term power; it may have a negative context for teachers--still, almost three-quarters of them think it is important. These data would suggest that they believe they have an acceptable amount of autonomy in their roles as teachers. Ninety-one percent affirm that they have the opportunity to design their own instructional programs from about half to almost all of the time. Sixty-two percent acknowledge that they like to be annong the first to try something "new" in the classroom, and another $37 \%$ concede that they are also willing to try something "new" after they wait a while. However, it is interesting to note that when teachers were asked to indicate what factor would 
influence them to change a long-time practice or behavior pattern associated with their teaching (IV.45), only $7 \%$ report that the fact that something was "new" would be a major influence; the knowledge that it would be "good for kids" is the identified factor that will influence change $(83 \%)$.

Teachers want some degree of autonomy or freedom to teach as they choose; they evidently like to have some feeling of power or authority--they express the importance of being able to influence the learning of young people--and they want some opportunity to be creative in designing instructional programs or in teaching. These feelings and attitudes contribute to the job satisfaction and dissatisfaction of teachers in the PMA (Kulpa, 1981; Moeller, 1973).

\section{Amount of Responsibility:}

About three-fourths of the teachers express satisfaction with the amount of responsibility they have (II.4); $16 \%$ are in the middle ranking; and $12 \%$ express dissatisfaction. The findings are mixed. But almost all of the teachers (96\%) acknowledge the importance of accepting responsibilities as a teacher (III.25). In general, teachers enter teaching with an expectation to have responsibilities, and most of them are not dissatisfied with this factor of their work as teachers. Additional study might be able to bring more data to the expressed dissatisfaction in a factor that is so closely related to the role of the teacher and that almost all of the teachers accept as important. 
Opportunity for Advancement:

Only forty percent of the teachers express satisfaction with their opportunity for advancement; $32 \%$ select the neutral ranking, and $28 \%$ note dissatisfaction (II.5). This finding appears to support Lortie's view that teaching is "front-loaded." Teachers entering the field do not expect to have great. opportunity for advancement (1975, pp. 82, 104, 211, 212). If the satisfied group is coupled with the neutral group, the percentage is increased to $72 \%$ that are not expressing dissatisfaction. The $28 \%$ that are dissatisfied with this factor merit consideration. This percentage is nearly identical with the $29 \%$ that have suggested they would choose some line of work outside of public education if they could (IV.1). But it is considerably higher than the $6 \%$ who said they would prefer to be school administrators or the additional $15 \%$ who said they would like to be in public education but outside the classroom (IV.2). In any event, this finding might well be related to possibilities for guidance and counseling at job entry and for continuing personnel services to be available for the teachers who indicate that they want to be at some higher or other position inside or outside education. The needs and expectations of individuals are subject to change for many reasons, and more than a quarter of this studied group is suggesting some kind of need or aspiration that is not being met and is related in some way to expressions of dissatisfaction. Or, it could simply be that they have accepted the premise that they will not be able to advance, and 
this, in itself, may create some degree of dissatisfaction. Additional study might shed more light on the findings for this factor.

Opportunity to Grow and Develop:

Teachers in the PMA offer mixed findings on their opportunities to grow and develop (II.6). About two-thirds (62\%) express satisfaction with this factor, $20 \%$ select the neutral ranking; and $19 \%$ express dissatisfaction. Ninety-three percent affirm the importance of having this opportunity (III.6). When asked if they have the opportunity (IV.40), 95\% say they do have opportunity. When asked if they have incentive to continue their educations or professional growth, $88 \%$ say they do have incentive (IV.41). When asked how much being a teacher has contributed to their personal growth, 96\% acknowledge growth from teaching. The PMA includes colleges and universities; districts offer inservice courses and workshops; some of the districts offer tuition reimbursements and incremental pay scheduled as incentives for teachers who continue professional growth. The opportumity for growth is seen to be a contributor to job satisfaction and dissatisfaction in this study. Maslow (1954) and Herzberg (1959) relate this factor to need and fulfillment. Herzberg identified the factor as a motivator and intrinsic.

The opportunity for growth is seen to be a contributor to job satisfaction and dissatisfaction in this study. Most of the teachers studied believe having opportunity to grow is important, and most agree that they have the opportunity. Most agree they 
have that experienced personal growth from being teachers. Not quite as many affirm that they have incentive to continue professional growth. And a fifth express dissatisfaction with their opportunities to grow and develop. This finding suggests the need for more study to bring more information to what some teachers need and why they do not believe they have the opportunity to grow and develop in their roles as teachers (Weathersby, 1977). Additionally, more study might bring additional information to the findings that the other four-fifths of the group studied are either satisfied or at least not dissatisfied with the opportunity they have to grow and develop in their roles as teachers in the PMA.

Receiving Feedback:

Ninety-one percent of the teachers note that receiving feedback is important (III.20). Most of the teachers indicate that most of the feedback they receive from their supervisors (IV.30), from other teachers (IV.28) and from parents or community members (IV.29) is more positive than negative. The highest ranking for positive feedback is related to that received from other teachers ( $89 \%$ ); the rankings for positive feedback from school administrators and parents is only slightly lower and the percentages are almost identical ( 86 and $85 \%$ ). When asked to select an indicator used most often to gauge the effectiveness of their teaching (IV.38), the largest percentage of teachers (42\%) indicate a preference for relying on their on judgments, and only $6 \%$ elect the assessments of the principal. The rankings of the 
research itens permit summary suggestions that a major source of feedback for many of the teachers is the reactions from other teachers. Teachers are willing to receive feedback from other teachers, but they are less willing to accept these opinions as gauges of their own teaching. Teachers do not express strong preference for receiving assessments of their teaching from their supervisors. Teachers apparently value feedback; they indicate that most of what they receive is positive; they indicate that much positive feedback comes from other teachers. But when they seek gauges of their effectiveness as teachers, they seem to prefer their own assessments over the sources of feedback in the schools where they teach (students, teachers, chairpersons or team leaders, administrators, exams and tests of their own students), or from the parents of their students. These findings suggest a need for more study.

Sources for Insights and Ideas:

Where do teachers get their most useful insights and ideas as teachers? (IV.39). Teachers in the PMA credit their informal conversations with fellow teachers as the highest ranked source $(43 \%)$. Seventeen percent choose college and university courses; $16 \%$ choose inservice courses. Less than $10 \%$ choose educational magazines and books $(8 \%)$, or attending meetings held outside the district $(9 \%)$. Only $3 \%$ elect meetings held in district. Only $2 \%$ elect the immediate supervisor. And only $1 \%$ elects educational media. 
These data may be summarized to suggest that teachers look to their colleagues and friends for useful insights and ideas. Other data in the study support the view that teachers value their interpersonal relations with their fellow teachers. They give modest credit to college and university and district inservice courses. They do not give very high rankings to attending meetings or reading educational resource materials. They give almost no credit to educational meaia, perhaps because the American public--including teachers--is already steeped in media.

The finding that they give so little credit $(2 \%)$ to their supervisors is worthy of careful consideration. They see colleagues as resources for useful insights and ideas; they do not see their building administrators as similar resources. Why? These indicators suggest the need for additional study. Working Conditions:

Sixty-nine percent of the teachers in the PMA express satisfaction with their working conditions; $14 \%$ elect the neutral ranking; and $17 \%$ express dissatisfaction with this factor, identified as a hygiene (II.16). Thus, the factor is seen to contribute to satisfaction and dissatisfaction. Almost all of the teachers in the study acknowledge that working conditions are important (III.17, 98\%). When asked to rank how pleasant their schools are as places in which to teach and work (IV.12), 83\% indicate pleasant surroundings. This study does not address some of the elements in the school and work of the teacher that 
are probably seen to be related to working conditions: condition of building, access to resources, etc. However, some of the research on "Effectve Schools" (Austin, 1979; Goodlad et al, 1979-80) finds that the structure in which the teaching (or learning) occurs is not as important as how the human beings interrelate with one another in the educational enterprise. This findings suggests a need to reinforce what has been indicated to contribute to job satisfaction for so many of the teachers in the PMA; however, the finding that about $17 \%$ indicate dissatisfaction with their working conditions should not be overlooked.

Additional study might bring more specific information to the findings that for some of the teachers in the PMA their working conditions are evidently contributing to expressions of dissatisfaction.

Use of Time:

Less than half of the teachers in the PMA express satisfaction with the amount of time they spend preparing for teaching (II.20). The factor has already been indicated as one contributing most frequently to expressed dissatisfaction. The factor is closely related to the role of teaching. Teachers evidently agree. Ninety-one percent acknowledge that it is important (III.13). It is also presumably related to the expectations of teachers entering the profession. But something about the amount of time they must spend in preparation for teaching is serving to contribute to dissatisfaction. These findings suggest attention to this factor for those entering 
teaching. Districts and schools may acknowledge this factor in planning work schedules for teachers. If successful instruction is based on careful planning, then it is important for teachers to comnit adequate time to preparation for teaching (or lesson plannirg), and it is important for districts and schools to plan for both time and administrative support as resources for teachers to prepare for teaching.

Seventy percent of the teachers express satisfaction with the amount of time they spend in teaching, a much higher percentage than that recorded for satisfaction with time spent in preparation for teaching $(45 \%$, II. 20); $14 \%$ select the neutral ranking, and $18 \%$, or almost one-fifth, express dissatisfaction with this hygiene factor that is so directly related to the role of the public school teacher assigned to classrooms (II.21). Almost all of the teachers agree that this factor is important (III.12, $96 \%$ ). Yet along with those that are satisfied or at least not dissatisfied, there are also those that are dissatisfied with a vital component of their jobs. In general, these data appear to suggest that teachers value the time they spend in teaching and they receive satisfaction from the act of teaching. The group expressing dissatisfaction would also support a need for additional study to bring more information to the nature of the expressed dissatisfaction with time spent in teaching. Are these expressions of a wish for a shorter work day, a shorter work year, fewer classes, fewer students? These questions have not been addressed in the present study; and thus, the findings from 
the current study do not permit extended conclusions or much supposition beyond bringing some notice to identified rankings for satisfaction and dissatisfaction with time spent in teaching as provided by the teachers in the classrooms in the PMA.

Time Spent on School-Related Activities Outside of Teaching and Preparation for Teaching (II.22):

Slightly more than one-third $(38 \%)$ of the teacher respondents express satisfaction with the time they spend on school-related activities outside of teaching and preparation for teaching; nearly one-third $(32 \%)$ express neither satisfaction nor dissatisfaction; and nearly one-third (30\%) express dissatisfaction with this factor, identified as a hygiene $(\mathrm{N}=1429)$. The data provide indicators that nearly identical pecentages are satisfied, neutral, and dissatisfied. This finding coula suggest that those expressing satisfaction or no indication of dissatisfaction accept this factor as related to the role of teaching; but the group expressing dissatisfaction is worthy of consideration. Districts and schools may wish to give additional attention to this factor, to see how teacher time is dedicated and to see what might be done to improve expressions of satisfaction or to reduce expressions of dissatisfaction with this factor.

Time Spent Teaching (II.21):

Seventy percent of the teachers express satisfaction with the amount of time they spend teaching; $14 \%$ express neither satisfaction nor dissatisfaction; and $18 \%$ express degrees of 
dissatisfaction with this factor identified as a hygiene or extrinsic factor related to the contex of work and so closely related to the role of the teacher $(N=1422)$. Along with those that are satisfied with this factor, there are also those that are dissatisfied.

In the section seeking importance rankings (III.12), 96\% indicate that time spent in the classroom teaching is important; $4 \%$ elect the neutral ranking; and $1 \%$ finds it somewhat unimportant $(\mathrm{N}=1424)$.

These data would suggest that teachers value the time they spend teaching and receive satisfaction from the act of teaching; however, the group expressing dissatisfaction would also suggest additional study to try to determine the nature of the dissatisfaction and to try to consider what might improve the ranking. The finding might also suggest that teacher preparation programs in colleges and universities should focus student attention even more directly on this vital element of the role of the teacher.

When asked how they would choose to spend two more hours a week in the field of education--if the time were available to them--the highest percentage $(44 \%)$ select lesson planning. This reinforces the earlier suggestion that the factor of time spent preparing for lessons might be improved in rankings for teachers if they had more in-school time to dedicate to planning. Another $21 \%$ would choose to work in tutoring individual students; $10 \%$ would choose to work with students in extracurricular activities; 
8\% would choose to spend the time teaching and a matching group would choose to work with curriculum committees. Four percent would elect community relations and a matching group would choose to hold parent conferences. Only $2 \%$ would choose to work on a school policy comittee.

Nearly half of the group would like to have more time for lesson planning. Another $39 \%$ would like to do something involving students. The small finding of $2 \%$ who would choose to work on school policy committees would seem to counter the recomnendation that teachers might be more directly involved in decision-making processes leading to the development and implementation of policies and related practices. This low finding may only suggest that within selections for spending two hours, teachers have other priorities; and these are related to lesson planning time and working with students. Other findings suggest that school policies and procedures do contribute to expressed dissatisfaction for $21 \%$ of the teachers studied (II.14). Additional study might bring more information to this area of expressed dissatisfaction inasmuch as it is not found to be where teachers would prefer to put a small, additional gift of time.

Effect on Personal Life:

Teaching has an effect on personal life. Slightly more than half of the sample group (55\%) reports satisfaction with the effect on personal life that they relate to their work as teachers; $20 \%$ elect the neutral rank; and almost one-fourth (24\%) 
express dissatisfaction (II.17). Eighty-eight percent rank personal life outside of school as important (III.18). These findings would suggest that most teachers value their personal lives outside of school, and they know that teaching does impact on personal activities. The $55 \%$ who are satisfied and the $20 \%$ who do not indicate that they are dissatisfied might suggest that most teachers enter teaching with the expectation that their teaching will influence their personal lives. Still, $24 \%$ are suggesting that their expectations for their personal lives and the expectations related to their roles as teachers do not fit together in a way that is satisfying. This finding may be considered for guidance and counseling of those entering teaching; it may also be useful to districts and schools planning teacher work schedules; finally, it may serve as a reinforcement for continuing personnel services for public school teachers, including available resources associated with guidance and counseling for professional employees.

Job Security:

Ninety percent of the teachers in the PMA report either satisfaction or a neutral ranking for job security (II.18). Ten percent express dissatisfaction. Teachers in Oregon may earn permanent election after three years. Teachers with fewer than three years may not feel particularly secure. Some districts and schools in the PMA are in processes of closing some schools or adjusting or eliminating some programs for a variety of reasons. These ongoing actions affect staff, and some teachers may believe 
that their jobs or assignments are in jeopardy or will be in jeopardy. Reduction-in-force--"riffing"--possibilities can quickly undermine the sense of job security. But when asked how secure they feel in their jobs as teachers, only $2 \%$ in the PMA note that they feel less than secure (IV.24). In the PMA, the number of teachers who feel secure (98\%) appears to reinforce the general stability of the area. The one-tenth expressing dissatisfaction would appear to be a fairly normal indicator of those who do not yet have tenure or believe that they might not be permanently elected or that they might not be reassigned to an area they prefer or some other ancillary concern. The high level of teachers reporting satisfaction with the assignments and jobs they now hold in the PMA tends to override any grave concern for the percentage indicating dissatisfaction with their job security. However, for the one-tenth who are expressing dissatisfaction, some problem is real enough to merit consideration. Once again, assistance to these teachers may be provided through their school or district administrators or through their available personnel services.

Interpersonal Relations with Supervising Administrator:

More than two-thirds $(69 \%)$ of the teachers sampled express satisfaction with their interpersonal relations with their supervising administrators; $13 \%$ elect the neutral ranking; and 18\% express dissatisfaction (II.8). Almost all of the teachers (98\%) affirm the importance of receiving support from their administrators. When asked how much support they receive in 
relationship to their expectations, $83^{\circ}$ indicate that they receive administrative support in degrees from above to about what they would expect; the remaining $18 \%$ indicate lack of support from some to far below expectations. The factor coniributes to satisfaction and dissatisfaction. Most of the teachers are satisfied or at least not dissatisfied with their interpersonal relations with their administrators $(82 \%)$. Almost all of the teachers note that they want support, and most of the teachers report that they receive support. This finding might be related to the low ranking administrators receive as sources for useful insights and ideas related to teaching ( $2 \%$, IV.39).

In addition, teachers do not affirm that their administrators are a preferred source as a gauge for their teaching effectiveness (6\%, IV.38); however, they generally acknowledge that the feedback they receive from their administrators is more positive than negative (IV.30). This could lead to the suggestion that teachers are satisfied when they have the opportunity to interrelate with their administrators on something other than a formal basis. These findings suggest a need for added study in the area of teacher-administrator relationships as they may be related to supervision, evaluation, and the principal as an instructional leader (Goodlad et al., 1979-80). It will be difficult for the principal to serve as an instructional leader if teachers do not value the input from the principal. The findings in the present study suggest that more than forty 
percent of the teachers in the PMA $(43 \%)$ put highest stock in the useful information they get from other teachers (IV.39). More than forty percent $(42 \%)$ look to themselves for assessments of their own effectiveness as teachers (IV.38). And only a few look to their supervising administrators for assessments of their teaching effectiveness (IV.38, $6 \%$ ) or as sources for getting useful insights and ideas (IV.39, $2 \%$ ).

Supervision/Competence of Administrator:

About two-thirds $(66 \%)$ express satisfaction with the supervision and competence of their administrators; $13 \%$ elect the neutral ranking; and $21 \%$ report dissatisfaction (II.13). This finding appears to be related to the interpersonal relationships between teachers and their administrators, along with their views on receiving feedback and sources of information that are useful to them as teachers. In ranking their administrators for professional competence, $90 \%$ rank their administrators from average in competence to very competent; $11 \%$ rank their adninistrators below average in competence (IV.18). This leads to a question of what being a competent administrator means to schoolteachers. They seem to like the interrelationships with their school administrators more than they like supervision by their administrators. They seem to express respect for the competence of their administrators, but they do not see them as very useful sources for insights and ideas to be used in teaching, and they do not identify them as favored gauges for teaching effectiveness. These findings may be mirrored against 
the growing research that promotes the role of the building administrator as the instructional leader (Goodlad et al, 1979-80). At this point, it does not appear to be indicated in the present study that the teachers view their administrators as instructional leaders. They seem to value support from their administrators, and they seem to believe they are competent in some aspect of administration or management, but the relationship does not seem to extend to what they think they need or want in order to be effective teachers. These findings suggest a need for further study in the area of teacher-principal relationships and role perceptions.

Enjoyment in Working with Students:

Interpersonal relations with students (II.10) has already been addressed as one of the primary factors contributing most frequently to expressed job satisfaction of teachers in the PMA. This finding is reinforced by an ancillary finding that $88 \%$ of the teachers in the PMA determine that enjoyment in working with students is very important to them. The combined elements of satisfaction in their interpersonal relations with students and their enjoyment in working with students serve to reinforce Lortie's findings that teachers receive their primary "psychic" or intrinsic rewards in their relationships with students and in the goals and activities related to achievements in "reaching" their students as individuals (1975). Student Ability Levels Preferred to Teach:

It is interesting to note that teachers in the PMA express 
the highest percentage of preference $(36 \%)$ to teach students with somewhat above average achievenent or ability levels, with a very similar percentage $(32 \%)$ noting preference to teach children of mixed abilities or achievements. Seventeen percent report that they prefer to teach students with average achievement/ability levels. The percentages are nearly matching for teachers electing to teach the below average children (8\%) and for teachers electing to teach the far above or average or gifted children (7\%) (IV.7). These findings may be further summarized to suggest that about a third (36\%) would prefer to teach children with from average to slightly above average achievement/ ability levels; another third would prefer to teach in heterogeneous classrooms. Less than ten percent elect the special student populations of below or very far above average. It would appear that most teachers see themselves as best placed where most of the chidren are. Teachers electing to teach those who are far below or above what is deemed to be average achievement/ability levels may well perceive that the needs of these children are best met by teachers with special training, abilities, or interests, and concomitant commitments.

Opinions About Students:

Eighty-seven percent of the teachers in the PMA note that they like students from quite a bit to a great deal; $8 \%$ find them 0.K. to work with, and $4 \%$ express some dislike (IV.10). Seventy-eight perceni describe their students as a pleasure or generally good to work with; $7 \%$ find them to be $0 . K$. to work 
with; and $16 \%$ acknowledge that they are sometimes difficult to work with (IV.11). The percentage expressing a liking for students is somewhat higher than the percentage reporting that it is a pleasure or O.K. to work with their students. Teachers may like children that are difficult to work with. Very few teachers identify a disliking for their students (4\%), but $16 \%$ acknowledge some difficulty in their work with children. Teaching and learning are not always easy to couple. The teachers in the PMA are very satisfied as teachers; they feel that they are successful as teachers and achieve as teachers. They do not necessarily suggest that all teaching is done without some difficulty or that all achievements are made without some degree of difficulty. It may be that in knowing that or expecting that, teachers elect to teach, believe in their abilities as teachers, and continue their commitments to teaching. Interpersonal Relations with Parents/Community:

Nearly three-fourths (71\%) of the teachers in the PMA are generally satisfied in their relations with parents and other community members; $22 \%$ express the neutral ranking; and $8 \%$ express dissatisfaction (II.11). Almost all of them (96\%) affirm that support from parents is important (III.5). Eighty-two percent acknowledge that they receive parental support in from average to great amounts (IV.17). Eighteen percent report a lack of parental support. About a third (32\%) express a preference to have more parent participation in school-related activities; almost half (45\%) like the amount of parent participation they 
now have (unspecified); and about $5 \%$ would prefer less parental involvement than they now have (unspecified amount) (IV.22). These data may be summarized to suggest that nearly all teachers believe parental participation is important; about three-fourths of the teachers express satisfaction in their interpersonal relationships with parents and other comnunity members; some teachers would like to have more parental involvement; some teachers would like things as they are; some teachers would prefer little or no parental involvement in the workings of the schools. The finding that teachers express satisfaction in their contacts with parents is complemented by the Grolier Survey (Karatzas, 1983), with findings that parents believe they should be involved in the education of their children, and they believe they should communicate with the teachers of their children. Parents do not believe that frequency of contact is the sole indicator of their concern for the education of their children. If the quality of schooling is seen to be good by the parents, they may well detemine that frequent contact is not necessary (1983, pp. 2-6). However, the data on teacher need for recognition as a motivator and intrinsic factor draw attention back to the parents. If teachers generally feel comfortable with relationships with parents, then it could serve as powerful reinforcement for teachers if the parents would extend more recognition to the teachers they believe are doing a good job as well as the attention being given to the teachers they do not believe are doing a good job. More positive recognition might be 
of great value to public school teachers.

Management and Employee Relations - District and School:

Ninety-one percent of the teachers in the PMA describe management and employee relations in their districts to be from good to sometimes good and sometimes not; $9 \%$ describe to the contrary (IV.42). Ninety percent find the same factor in their schools to range from good to sometimes good and sometimes not; and $10 \%$ describe to the contrary. The median and mode on both factors suggest that teachers see management and employee relations as generally good in their districts and in their schools. These findings tend to reinforce the general stability for the school districts in the PMA and the relations between management and teacher employees, and they tend to reinforce the expressions of teacher satisfaction with their jobs in the PMA. The percentage describing counter views should not be overlooked. Something is contributing to their indications that relationships are less than good (Kulpa, 1981; Martin, 1978). Communications between employees and their school and district administrators, and vice versa, might alleviate these expressions of concerns for some. More efforts toward open communication might adjust any perceptions of "we-they" that may be associated with relationships between management (adninistrators/supervisors) and employees (teachers) in order to promote common goals and positive management and employee relations. District offices are sometimes seen to be working toward objectives other than those prioritized by staff in the schools. In reality, the goals are 
the same or intermeshed, and should not be separated. The common objectives address the education of children in public schools. Job Qualifications for Another Job Outside of Teaching:

Sixty-nine percent of the teachers in the PMA report that they felt qualified to get another job when they entered teaching; $20 \%$ are uncertain, and $11 \%$ note that they felt unqualified for another line of work (IV.4). The figures are almost identical in response to how qualified they now feel to get another job outside of teaching (IV.5). These data may suggest that many teachers who feel qualified for other employment choose to become teachers. The group indicating uncertainty about qualifications or lack of qualifications for other employment outside of teaching may be making accurate assessments of their interests or their abilities. Those who do not feel that they are qualified for any other job but teaching may be excellent teachers, or, at any rate, they may be strongly attached to the role of the teacher and the job of teaching; but they may also be experiencing some sense of "career lock-in" (Lowther, Stark, Austin, Chapman, \& Hutcheson, 1981). This study does not address performance of teachers and, therefore, does not pemnit more than presentation of data and some speculation. More study may bring more information to the whole area of job qualifications as they may be related to performance on the job. Job Expectations:

Teachers come to the job of teaching with certain expectations which may or may not be met. Furthermore, expectations are 
subject to change, and they may vary in importance or priority of the individual shaping the expectations. Eighty-one percent of the teachers studied suggest that the role has met or surpassed expectations held at the outset (IV.6); $18 \%$ find that it has not. Seventy-nine percent report that the profession has met or surpassed expectations; $22 \%$ note that it has not. Thus, about four-fifths of the teachers affirm that being a teacher and the profession of teaching has met or surpassed their entry-level expectations; and about one-fifth conclude that their expectations have not been met. These data suggest some support for career guidance and counseling of teacher candidates, and continuing personnel services as available resources for teaching personnel. Additional study may help determine how teacher expectations that are set and met or not met may measure against similar indicators from workers in other fields of enterprise. This study has provided data on what factors serve to satisfy or dissatisfy teachers. Furthermore, the data indicate that the teachers studied are very satisfied. The data on job expectations tend to support the view that most teachers in the PMA have come to teaching with expectations that can be met and that have been met in greater or lesser degrees of reward and priority. Job Projections:

Findings from related items on job projections for teachers in the present study group (IV.33), IV.34, IV.35, IV.36, and IV.37) may be summarized to suggest that many teachers now 
teaching in public schools in the PMA have strong commitments to teaching. More than a third (36\%) think that they would refuse a promotion that would take them out of the classroom; more than half $(57 \%)$ think that they would feel loss is they left the classroom. Many of the teachers (84 and $85 \%$ ) affirm their. commitments to the classrooms for at least a year; and more than half $(56 \%)$ project to remain in teaching for the next five years. The $15 \%$ identifying that they hope to be not working by choice may reflect projections for volumtary retirement. As a counterbalance of data, about a third (36\%) suggest that they would accept a promotion that would take them out of the classroom; 7\% think that they would feel gain in leaving the classroom; about $15 \%$ project that they will try to make job changes in or outside education in the next year; a similar percentage expresses hope or aspiration to be promoted within five years; and another similar percentage hopes to work outside public education within five years. Within a population that reflects stability and likes job security, still, there are indicators of attrition, upward mobility, and opportunities for young educators to enter teaching in the PMA. These indicators may be useful predictors for the staffing patterns in the PMA in the next year or for the next few years. They may at least suggest what currently employed teachers would prefer to be doing. And in most cases, that appears to be teaching in public school classrooms in the PMA. 
Surmary - Conclusions

Teachers in the PMA are social beings. The schools districts in the PMA and their schools are organizations. Teachers work within the theoretical and physical construct of organizations. The present study has consistently viewed them in that context. This study finds that teachers are social beings oriented toward interpersonal relations, sharing or giving to others as teachers, helping others as teachers; however, they have needs and expectations, of varying degrees of importance, that may or may not be met within their work roles in the organizational systems of the schools and districts represented in the study. This study has defined an organization as a body or structure of individuals brought together as a systematized unit or entity for a common purpose or enterprise in which the workers have identified roles and responsibilities addressing the common goals of the organization. The system of organization (including division of labor and a pyramid of control), theoretically and in practice, represents a dynamic process of action, evaluation, and change. The process includes the goals, the roles and responsibilities, the persons in the roles, and the allocation of available or identified resources. In short, the entire structure and intention of the organization are subject to reform and change as the organization perpetuates. The dynamics are similar in public education and public educational systems. And within that system, teachers address the goals of the organization and their own goals for the purposes of teaching children, the enterpzise of public educators and public education. In the present study, teachers in the PMA have identified 
what serves to satisfy and dissatisfy them. They have provided additional data on how they prioritize the various factors that serve to satisfy them. The study finds that each of the factors studied can operate to contribute to satisfaction or dissatisfaction. Some of the factors are intrinsic, and some of the factors are extrinsic. Satisfaction of the intrinsic factors seems to be a joint process, a blending of the needs and expectations of the worker in combination with what is available in the work itself that will contribute to the worker's evaluations of gratification (Lawler \& Porter, 1967, p. 24). Satisfaction or gratification of the extrinsic factors is more often seen to rest more directly within the control of the organization (Lawler \& Porter, 1967, pp. 23-24); but again, the attitudes and feelings of the workers toward the hygienic factors rest with the worker, in terms of needs, and expectations, and assessments of what is due or "fair" or possible within the context of the work and the conditions of the work. The intrinsic elements are more often intangible; the extrinsic factors are more tangible.

Thus, a central concern for school districts, as organizations, is to consider how the goals of the individual may be integrated with those of the organization for common benefit. Concepts for integrating individual teachers and their individual expectations with the expectations and goals of the organization of the school district and its schools may include address to "organizational fit." How does the teacher as an employee fit within the organizational structure? Districts may seek congruence in staff recruitment and assignment; they may recognize that incongruence can be a positive factor or 
benefit to change and growth; they may work to achieve some kind of blending between congruence and incongruence, to effect the most rational human groupings and at the same time to produce a minimum of undesirable side effects and a maximun of collective satisfactions (Etzioni, 1964, p. 2). In Modern Organizations (1964), EŁzioni emphasizes the social environment of organizational systems and suggests that it is important to recruit persons who have the "requisite psychological characteristics" (p. 110). The present study finds that the teachers in the PMA indicate high degrees of satisfaction that probably indicate that most have entered the teaching profession with what is necessary as a teacher in order to be a satisfied teacher. In Integrating the Individual and the Organization (1964), Argyris develops a theme that both the individual and the worker must be able to give a little bit in order to profit from each other (p. 3). "The incongruence between the individual and the organization can provide the basis for continued challenge," leading toward growth and development for both the worker and the organization ( $p .7$ ). The present study finds a measure of incongruence in the expressed attitudes and feelings of the teachers in the PMA. They are not all satisfied, and they are not all satisfied to the same degree with the same content and context of their roles and their work as teachers. The understandings of the "incongruences" could form a basis for increased effectiveness of the teachers and their school districts and schools. In Theory Z (1981), Ouchi has emphasized the importance of the "social factors" within the organizational work setting. The present study reinforces the 
importance of the "social factors" in the educational setting for the public school teachers in the PM. The study finds that their prinary satisfactions come from factors including interpersonal relations and intrinsic elements associated with other people and goals related to achievement with or service to other people. Brooks (1982) has directed recommendations for change in educational organizations to include fullest consideration of the significance of psychological or social factors and the significance of needs and rewards as essential to organizational renewal (p. 44). He recommends that school organizations seek data from staff members and include these data in the analytical processes that will lead to the development of policies to guide the school system toward positive change or reform. The design of this study has attempted to honor that recommendation in its address to problem, purpose and potential for benefit. The present study and its findings and conclusions permit some attention to recommendations in support of the job satisfaction of the teachers in the PMA.

\section{Recommendations}

Recommendations for Further Research

As a continuation of the present study, the following additional research is recommended:

1. A regular process of monitoring the job satisfaction of the teachers in the PMA to assess attitudes and feelings seen to contribute to job satisfaction and dissatisfaction of the teaching staff, and to see if the expressions of job 
satisfaction and dissatisfaction suggest patterns or significant changes that should be considered by those administering to public education and those effecting and implementing policies and practices in public education.

2. An extension of the present study to see if the assessed attitudes and feelings of satisfaction and dissatisfaction of the teachers in the PMA could be reflected in a larger population and, thus, permit some generalization. The present study does not permit generalization beyond the population studied in the PMA and the assessments that are permitted by the comparisons of data from 1981 and 1984 and the notations of some similarity in national demographic indicators.

3. A continuing study of the demographic factors of teachers in the PMA to monitor change in the age, sex, grade level of assignment, years in service, and highest degree earned that may mark patterns that could impact on public education.

4. A comparative study of job satisfaction of other workers in private enterprise along with schoolteachers in the same area, to see how the factors contributing to the job satisfaction and dissatisfaction of workers in private enterprise may be compared with the factors identified by the public school teachers in the PMA.

5. Continuing study on how teachers receive feedback, what kind of feedback is most useful to them, and where they look for insights and ideas related to teaching. The present study 
indicates that teachers do not look to their administrators as particularly useful resources for gauging teacher effectiveness or as sources for useful insights and ideas about teaching. The research from "Effective Schools" pronotes the role of the principal as instructional leader. If the principals are to be legitimate instructional leaders, they will need to have credibility with teachers as valid resources for feedback and as sources for useful ideas and insights related to what matters to the teachers, and this study finds that what matters to teachers is teaching students and associated interrelationships and goals.

6. More study of how the teacher views working conditions as contributing to job satisfaction and dissatisfaction. The present study does not address many factors that may be related to the issue of working conditions; the present study finds a somewhat lower assessment of working conditions in the PMA than for many other factors that are explored in the present study.

7. Additional study to consider what could be done to ease teacher concerns over time spent in activities other than teaching. Tine spent in teaching is something of a concern to teachers in the present study, but they express somewhat higher degrees of concern over time spent in preparation for teaching and time spent on other activities outside of lesson planning and teaching. 
8. Continuing study to see what kinds of interpersonal contacts between teachers and other teachers, or teachers and administrators, or teachers and parents and other community members could serve to reinforce such relationships and what benefits could be identified that might serve to increase job satisfaction.

9. Additional study to see what would serve to improve teacher rankings of the policies and procedures of their schools and their districts as contributors to job satisfaction. The present study finds that teachers accept the importance of policies and procedures in schools and districts, but they do not report high degrees of satisfaction with these factors, and they do not identify great willingness to give priority time to planning and input processes for the development of district and school policies.

10. A long-term study to see what impact counseling and guidance services for candidates in teacher training programs might have on job satisfaction of teachers at entry level and over extended periods of time. Areas of focus might include: expectations of candidates, considerations of how teaching will require much time that may in turn affect personal life, identification of what candidates consider to be primary rewards in order to feel job satisfaction, identification of what candidates consider to be primary goals in relationship to teaching or other occupations. 
11. A long-term or more extensive study to see what impact counseling and guidance services for presently employed teachers might have on job satisfaction of teachers in various age categories, in various grade levels of assignment, during the probationary period and after permanent election or after various numbers of years of service (Glass \& Grant, 1983, pp. 210-213). The present study finds some patterns in various demographic factors that suggest some need for continuing personnel service that may or may not now be available or identified as a resource for teachers who wish to have more opportunity for growth and development or advancement or for career opportunities inside or outside of public education. Services might include recommendations for continuing education or training and identification of such resources.

12. Additional study of teachers within the construct of sociological theory and organizational theory, in continuing efforts to identify effective ways to integrate the individual teacher within the organization of school districts and schools--as efforts to promote positive and goal-based change and reform in public education as a continuing dynamic.

13. Additional study to address the relationships between motivation of the teacher and the job satisfaction of the teacher. Deci (1975), Herzberg, (1959, 1968), Maslow (1943, 1954), and Vroom (1964) offer some approach to this field of inquiry. But, the present study does not attempt to explore 
whether the factors that are identified as motivators, or intrinsic factors, are indeed also operating to motivate teachers in their classrooms. And, the present study provides some indication that hygienes are capable of contributing to satisfaction and dissatisfaction. Logically, then, they might be capable of contributing to the motivation of employees who seek gratification from them. Sergiovanni and Carver (1980) suggest that all workers can be motivated to work by something; they are simply not all equally motivated by the same factors. More study might be directed to identify means by which organizations could better determine which of their employees are motivation seekers and which are hygiene seekers (p. 119). (See Figure 6.) The present study suggests that most of the teachers in the PMA are primarily satisfied by the intrinsic factors, also identified as motivators; but the teachers also report that hygienes can and do operate as satisfiers, even if they are extrinsic factors. A study of how the factors contributing to expression of job satisfaction also may contribute to the motivation of the employee in the work role (in this case, the teacher in the job of teaching) could be very helpful to school districts and their schools. This research could serve to identify recommended areas for staff development for school administrators charged with supervision and evaluation of their teachers, with an ancillary expectation that the school administrators could be better able to motivate or 
assist their teachers to be as effective as possible in teaching. Reasonabiy, the motivated teacher is more likely to be an effective teacher than the unmotivated teacher (Herzberg et al., 1959; Herzberg, 1968; Meyers, 1977; Vernon, 1969; Vroom, 1964).

14. Additional study to address the relationships between the performance of the teacher and the job satisfaction of the teacher. The present study has looked at the factors that contribute to job satisfaction and dissatisfaction; it has not attempted to link the factors to teacher performance. In addition, the present study makes no attempt to determine whether satisfaction leads to more effective performance or whether it stems from effective performance and concomitant feelings of achievement or success (Lawler \& Porter, 1967, p. 23). In some probability, the dynamics of satisfaction lead to and stem from effective performance. As Chase has suggested, the relationships may well be cyclical (1976-77, p. 1). The present study finds that the teachers in the sample are very satisfied. It is reasonable to assume that their expressed satisfaction is reflected in some way in their social relationship with others in their schools and comnunities and that it relates in some way to their performance; therefore, the particular arena of study that might clarify how job satisfaction of teachers may be seen to be related to the performance of teachers is recommended for further research (Brophy, 1979). 
Other Recommendations

The current study has provided data to indicate that the teachers in the PMA are highly satisfied with their jobs and their roles as public school teachers; however, the current study has also provided data to indicate some factors that apparently tend to contribute to expressions of job dissatisfaction. It seems highly important for the school districts in the PMA to continue to monitor the attitudes and feelings of the teaching staff as various factors and influences may be seen to contribute to degrees of satisfaction and dissatisfaction. Assumptions that teachers are highly satisfied should not serve to promote views that all is well and will always be well. The current data suggest that the school districts sampled and their teaching staff have effective interrelationships in terms of districts being able to provide--in large degree-what teachers need or expect in order to express job satisfaction. But, the expressions of factors that contribute to job dissatisfaction should not be overlooked. And the entire complex of factors that contributes to job satisfaction and dissatisfaction may be subject to change for a variety of reasons. This assumption reinforces the need for continuing study and attention to indicators of patterns or changes in attitudes and feelings of teachers about particular factors or about overall assessments of the roles of teachers and the jobs of teaching in public school systems in the PMA.

The current study provides data to suggest that about one-third of the teachers presently employed in the districts and schools of the PMA would prefer to be doing something other than working as classroom 
teachers or as public educators. This finding serves to recommend additional attention to areas for focus in the preparation and training of candidates for teaching as well as for the continuing education and services essential to district employees. Candidates roadying to enter teaching should always be assured of guidance and counseling services, broad and varied opportunities for observation and training in the field of education, and mentor support from practicing teachers as they elect and prepare to become public school educators. Candidates should be encouraged to assess their personal and professional expectations alongside what may be realized as gratifications or rewards from a profession that is dedicated to giving and sharing. Teachers in the profession should have access to similar services and experiences of continuing education and opportunity for growth, and they should be encouraged to make similar assessments about what they do, why they do it, and how they feel about their jobs and roles as teachers. The teachers in the PMA clearly suggest that although they receive many rewards from teaching the rewards are not all tangible. The primary rewards are more likely to be intangible. Such realizations, stemming from assessments of what teaching is along with some projection of what it can be and what it can provide, may serve to protect and promote job satisfaction of those entering teaching and of those remaining in the professional work of teaching. However, expectations and goals are subject to change, and employees within the system of public education need continuing guidance and counseling opportunities in order to promote the satisfaction of the individual within the system or to consider 
options for the individual outside the system. This might include the identification of opportunities for continuing education of the employee as a professional educator. It might include the identification of opportunities for job transfer or "latticing" within the system, which may address either some other lateral move or some advancing move. It might also include fullest consideration by districts of what services or training may prepare employees who can no longer be effective as teachers or who do not wish to remain in the system as teachers to make positive moves for alternative employment outside the system. Although many of the teachers in the present study report that they felt qualified for some other job when they entered teaching and still feel qualified for some other job if they chose to leave teaching, some others report that they did not feel qualified for any job other than teaching when they entered teaching and they do not now feel qualified for any other job in lieu of teaching. Somewhere in that group may be highly qualified and dedicated teachers, operating as high achievers; somewhere in that group may also be less successful or less satisfied teachers who would like to get out, but they may lack the resources or the assistance to get out (Glass \& Grant, 1982, pp. 210-213).

The current study provides data to suggest that teachers need to believe that they are achieving as teachers. Their self-assessments suggest that they do believe they are achieving in their efforts as teachers. But they also note that they do not receive great recognition for their efforts, and they do not believe they have any great degree of status in their comnunities that is directly related 
to their roles as teachers or the profession of teaching. They do not necessarily expect to have great amounts of recognition or high levels of status as teachers, but they clearly would like more recognition and status than they now have. Recognition can come from within school districts and schools. And sometimes it does. Sources for teacher recognition in the schools can be as positive notice of the small things, the day-to-day things, as well as positive notice of the grander identification of some outstanding achievement or some award won that will almost automatically bring some notice. Administrators, other teachers, the students can be the proactive initiators of small or bigger notices of recognition for "job well done" by teachers. Districts can also contribute to the positive recognition of their teachers. And sometimes they do. Perhaps more could be done to draw some additional recognition to the numbers of teachers doing their jobs well. Letters of commendation in the personnel file may be all it would take to make some teachers believe that they are truly valued professionals in their schools and their school districts. Additional efforts from personnel services could contribute to the beliefs of teachers that they are valued and recognized employees, appreciated for their successes and supported in their areas of need in order to be successful teachers and individuals feeling and expressing satisfaction in their personal and professional lives. Additionally, the public can contribute to the positive recognitions of teachers working in and contributing to their school communities. Recognition can come from parents of the students in the schools; it can also come from the community members who are willing to applaud areas of effort 
from teachers making contributions to community projects or goals. A note to the teacher, a telephone call to the teacher--in recognition or commendation--may be all it would take to make it a good day for the teacher who has just been recognized for something positive as feedback from outside of the school itself. And sometimes the recognition comes, and sometimes it does not. And teachers suggest that a little more recognition would contribute to job satisfaction; it might also contribute to their perceptions of their own valued status in their schools and in their school comnunities.

The current study provides data to suggest that teachers receive primary satisfactions in their interrelationships and their achievements associated with their students. This finding should serve as a caution and a reminder to school districts not to lose sight of what is of primary importance to schoolteachers, not only in the PMA, but evidently in some kind of generalized context (Lortie, 1975). Teachers need to be able to relate with their students, not only in the classrooms as teacher and groups of students, but also as teacher in or out of the classroom interrelating with individual students. Teachers need to be able to believe that they are able to maintain a positive learning atmosphere for their students, that they are able to meet the individual needs of most of their students, that they are "reaching" their students and having some influences on the education of their students. They need to be able to believe that they are helping others, with primary focus on their students. They need to be able to believe that they are supported in their teaching enterprises and that the barriers between them and their students are 
removed to the degree possible. School districts and schools considering mechanization of teaching or adjustments of teacher-student ratios should not lose sight of how important that interrelationship opportunity is for the teachers in the PMA.

The current study provides data to suggest that teachers are not particularly dissatisfied with their interrelationships with their immediate supervisors or building administrators, and they rank then favorably in competence and supervision, but they do not rank them highly as resources for gaining useful insights or ideas about teaching, and they do not rank them highly as gauges of their own effectiveness as teachers. If the building administrators are to be highly effective as instructional leaders, they must be seen by the teachers as competent in areas of instructional leadership, delivering effective feedback within the supervision and evaluation cycle, and providing useful insights and ideas that relate to the primary objectives of the teachers. More study may give some additional direction to how building administrators could become better identified or legitimated as primary sources of instructional resources and leadership within school buildings (Ignatovich, Cusick, \& Ray, 1979).

The current study finds that teachers receive primary satisfaction from their interrelationships with other teachers. In addition, they recognize other teachers as sources for useful insights and ideas. This leads to recommendations that districts and schools recognize the potential benefits in setting aside planning time for teachers to meet in department or grade level groups. It also leads 
to suggestions that teachers be permitted or encouraged to team in some part of the school instructional programs (Arikado, 1975). Teachers may be effective in mentor roles, not only for student teachers, but also for teachers currently in the system. A "buddy system" might be of sorne particular benefit if the senior or "master" teacher has particular skills that could assist the program of some other teacher. The "master" teacher could also be a less senior teacher in the system, who has entered teaching with special skills or has acquired unique or special skills that could be useful to other teachers. This option might give some added recognition to less senior teachers within a population that now includes many senior teachers. In short, the dynamic of the "master" role could work from senior to less senior, and from less senior to senior, to promote peer recognition and effective teaching. Districts may also be recommended to look even more often toward their own teachers to serve as the instructors of their inservice. Workshops have proven to be popular and valuable approaches to inservice. A two-hour workshop on a tightly focused topic could be instructed by one or more teachers with special skills or with some creative approach to teaching. Teachers who attend such workshops need not make large time commitments, may gain imnediate and practical approaches to teaching in their classroom, and will have the opportunity to interrelate with other teachers. Teachers who instruct such workshops, singularly or in teams, have the opportunity to receive some additional peer recognition for something they know how to do well and something they are willing to share as additional opportumities to help others--in 
this case, other teachers.

The current study finds that teachers are generally willing to have parents involved in school-related activities. This might serve as a recommendation to more parents to be involved in support of school programs and the enterprises of the school. The potential of parents to serve as supporters of the schools in terms of positive change and reform is one that can be suggested as a vital resource. Parents can serve as supporters of schools in their relationships with their children; transmitted belief from the parent to the child in support of what the school and the teachers are trying to do could go a long way in making the joint efforts of the educators and the learners more positive. Parents could be further involved in planning groups making recommendations to school systems. The efforts of the parents and the schools should be clearly identified as collaborative. The issues of public education should not be construed as in opposition or as "we-they." Many teachers in this study (85\%) report that they receive much positive feedback from the parents of their students or other community members (IV.29). This would suggest that positive linkages could be promoted and strengthened if teachers were more often able to involve parents in additional dimensions of the instructional programs and the goals for students, intercommunicating in such a way that the teacher could receive feedback, in a positive exchange of information that would not be regarded as threatening or damaging to the teacher or to the parents and might be of some additional benefit to instructional programs and the teaching of children. The issues of public education should be 
construed as efforts that are most likely to be effective in meeting the educational needs of children if parents and school systems work together and communicate with one another in support of common interests. And sometimes they do, and sometimes they do not do all that might be done to promote the most positive learning environment possible for the children who come to the schools and the classrooms where classroom teachers are responsible for initiating vital learning processes for their students.

The current study finds that teachers are not highly satisfied with the amount of time they spend on lesson planning or on the amount of time they spend on school-related activities outside time committed to preparation for teaching or the act of teaching. They also identify some expressed concern for the impact of teaching on their personal lives. Some of the time comnitments are probably a "given," and some impact on personal life is probably another "given" for teachers, but it may be that some adjustments in the work schedules of teachers could ease the sense of concern that is presently indicated. Some additional time might be scheduled for planning. Perhaps, some adjustments to time systems could permit some alternative schedule or trade-off for the time teachers spend on extracurricular activities outside the school day, or in the evenings. Extra-responsibility pay is not always possible, and the present study suggests that although salary is a factor that contributes either to job satisfaction or job dissatisfaction--and is currently identified as a factor that is contributing most frequently to expressions of job dissatisfaction-additional pay may not be the answer to the expenditure of time and 
the resulting impact on personal life that is seen by teachers to be expected or required of them inside work roles.

Among the highly satisfied teachers in the PMA are some who are not quite so satisfied. Some of the demographic indicators suggest that something is going on to decrease degrees of job satisfaction and to increase degrees of job dissatisfaction for the teachers of the upper or higher grades of the elementary, middle, or junior high schools (6-8 or 7-9). Some of this may simply be attributable to the maturation or approaching puberty of the children and some changes in their approaches to learning during the middle years of their public schooling; some of the decrease in satisfaction and increase in dissatisfaction of the teachers assigned to teach at these grade levels may suggest a need for special or additional training for teachers of these grades. Additional study might target some additional areas for resources for teachers or for added support services for some of the children in these grades.

The current study finds that teachers in the PMA are growing older as a population and are increasing in their total mean years of service as teachers. Furthermore, the percentages of men in the total teaching force are decreasing while the percentages of women are increasing. Each of these factors merits close monitoring in terms of potential impact on public education. In addition, the findings serve to suggest that some additional services may be helpful to older employees, and employees with many years of service (Glass \& Grant, 1983, pp. 210-213). Additional research might address the women entering and remaining in the system and of the men not entering 
and/or not remaining in the system. The growing number of older employees coupled with the numbers of employees reflecting increasing numbers of years of service suggest that fewer younger candidates have an opportumity to enter teaching in a fixed or structured job market. Public education is generally seen to benefit from its broad representation of teachers of various ages, reflecting broadly differing backgrounds and cultures as well as equity of representation of men and women. Teaching has long attracted more women into public education than it has attracted men. Men who enter public education are more often inclined to seek advancement within the system or to seek other career paths outside the system than are the women. Women have often tended to view teaching as preliminary to marriage or having a family, and they have tended less often than men to see themselves as potential candidates for advancement within the system or as qualified candidates for jobs outside the system. The stereotypical attitudes are changing, but the data from the present study still serve as reminders that such indicators bear careful monitoring. Public education will seek to continue to attract highly qualified young candidates, men and women, from a broad spectrum of socioeconomic and cultural backgrounds. Public education will seek to maintain such representation in its teaching personnel. Teachers value job security, and job security is closely associated with the job of being a public educator. The public and public educators may be able to find ways to perinit senior educators to adjust work patterns within the system and to consider other viable career options that may be seen to benefit the teachers and the system. The 
public and public educators, working cooperatively with colleges and universities, may be able to find added ways to encourage young candidates with teaching potential to seek teaching credentials with some better hope of securing teaching positions than some of them may now have. Certainly, public education does not wish to turn away from the "bright-and-shiny-eyed" young candidates who stand on the threshhold of public education as teachers and who may elect another career because of lack of promise in the job market of public education. Furthermore, public education does not wish to neglect or discourage the staff that has entered the teaching profession and has chosen to remain in teaching. In summary, the goals of public education include active recruitment of qualified teachers, and the active and continuing employment of qualified educators. Ideally, the entering teacher brings optimism and enthusiasm into teaching, and the practicing teacher carries forward with optimism and enthusiasm. Just as ideally, the teacher leaving teaching to work elsewhere or to conclude working leaves with the associated rewards of achievement and some recognition of a job well done. Each of these dynamics recomnends careful consideration of what it may mean to public education if the scales of representation in the public teaching forces are tipping increasingly toward fewer younger teachers and more older teachers, fewer entering teachers and more teachers with many years of service, and fewer men teachers and more women teachers. At present, the teaching staff in the PMA is representative of that which is regarded as essential to good public education. Those that are entering the system indicate job satisfaction; those in the system 
indicate job satisfaction. There is job opportunity for qualified young teachers, and there is opportunity for more experienced teachers to feel good about what they do. In addition, there is opportunity for senior educators to elect options for retirement or to elect to remain in teaching. These elements of the fabric of public education are valuable to promote and protect.

Thus, with consideration of purposes and the hope that the study of job satisfaction of the teachers in the PMA will (or could) be of practical use and benefit to the public, to public educators, and to personnel services, the data have been collected and analyzed, leading to discussions of the findings of the three research questions and other related findings. The discussion has led to some conclusions (and some conjectures). The conclusions have led to some recommendations for further study and some general recommendations to promote and protect the job satisfaction of the teachers now employed in the PMA and those that may be entering employment in the PMA as teachers in the classrooms of the public schools and districts organized and dedicated to provide effective education for children. 
BI BLIOGRAPHY

ACSA School management digest $(1979,18)$. Burlingame, California: Association of California School Administrators.

Adams, D.W. (1975). Tired and frustrated teachers, Today's Education, 64 (1), 36, 40-41.

Adams, J.S. (1963). Toward an understanding of equity, Journal of Abnormal Psychology, 67 (1963), 422-436, in Ashbaugh, 1982, 197.

AFT report describes teachers under stress (1984, May 9). Report on Education Research, 5.

Alderferer, C.P. (1969). An emperical test of a new theory of human needs, Organizational Behavior and Human Performance, 4 New York: Journal Department, Academic Press, Inc.

Argyris, C. (1964). Integrating the individual and the organization. New York: John Wiley \& Sons.

Argyris, C. (1957). Personality and Organization. New York: Harper ६ Row.

Argyris, C. (1973). Personality and organization theory revisited, Administrative Science Quarterly, 18 (2), $141-67$.

Arikado, M. (1975). Team teaching: What makes it work, Education Canada, 27-29.

Ashbaugh, C.R. (1982). What is job satisfaction? Planning and Changing 13 (4). Normal, Illinois: Department of Educational Administration \& Foundations, Illinois State University, 195-203.

Ashton, P. \& Webb, R.B. (1984). Teacher efficacy linked to school climate. EU-LINE 5-16-84.

Austin, G.R. (1979). Exemplary schools and the search for effectiveness, Educational Leadership, 37 (1).

Bentzen, M.M.; Williams, R.C.; \& Heckman, P. (1980). A study of schooling: Adult experiences in schools. Phi Delta Kappan, 394-397.

Berliner, D.C. (1980). Using research on teaching for the improvement of classroom practice, Theory into Practice, 19, (4). Ohio State University, College of Education.

Bidwell, C.E. (1973). The social psychology of teaching, The second handbook of research on teaching (1973). R.M. Travers (ed.). Chicago: Rand MoNally \& Co., 413-414, 458-470. 
Bloland, P.A. \& Selby, T.J. (1980). Factors associated with career change among secondary scinool teachers: A review of the literature, Educational Research Quarterly, 5 (3), 13-24.

Boyer, E.L. (1983). High School: A report on secondary education in America. The Carnegie Foundation for the Advancement of Teaching. New York: Harper \& Row.

Boynan, N.J. (1982). Administration of educational institutions, Encyclopedia of educational research, (5th ed.), 22-49.

Bredeson, P.V.; Fruth, M.J.; \& Kasten, K.L. (1983). Organizational incentives and secondary school teaching. Journal of Research and Development in Education, 16 (4), 52-58.

Bridges, E.M. (1983). The management of teacher incompetence. Institute for Research on Educational Finance and Governance. Project Report 83-A20. School of Education, Stanford University. Paper presented at Conference 'Research and Thought in Educational Administration." Rutgers University, 1-30.

Brookover, W.B. \& Lezotte, L.W. (1979). Changes in school characteristics coincident with changes in student achievement. Occasional Paper \#17 (Executive Summary). The Institute for Research on Teaching. East Lansing, Michigan: Michigan State University.

Brooks, M. (1982). School organization renewal, Educational Forum XLVII (1), 37-45.

Brophy, J.E. (1979). Teacher behavior and its effects. Journal of Educational Psychology.

Brown, S. \& McIntyre, D. (1982). Influences upon teachers' attitudes to different types of innovation: A study of Scottish integrated science. Curriculum Inquiry, 12:1. The Ontario Institute for Studies in Education. New York: John Wiley \& Sons, Inc., 35-51.

Burke, R.J. (1966). Are Herzberg's motivators and hygienes unidimensional? Journal of Applied Psychology, 50 (4), 317-321.

Centers, R. \& Bugental, D.E. (1966). Intrinsic and extrinsic motivations. Journal of Applied Psychology, 50 193-197.

Chapman, D.W. (1983). Career satisfaction of teachers. Educational Research Quarterly, 2, 40-50.

Chapman, D.W. \& Lowther, M.A. (1982). Teachers' satisfaction with teaching. Journal of Educational Research, 241-247.

Chase, F.S. (1976, 1977). The administrator as implementor of the goals of education for our time, Administrator's Notebook, 25 (1), $1-4$. 
Chaucer, G. (1964). Prologue, The Canterbury tales. Baltimore, Maryland: Penguin Books, Inc., 25.

Childers, J.H. (jr.) \& Podemski, R.S. (1982-83). Confronting idealistic teacher expectations: Strategies for training . . Teacher Educator, 18 (Winter), 2-10.

Cooke, R.A., Kornbluh H.; \& Abramis D.A. (1982). Research: Michigan teachers vs. a national sample of workers on quality of worklife, Pni Delta Kappan, 636-637.

Coverdale, G.M. (1974). Some determinants of teacher morale in Australia. Educational Research, 34-39.

Coverdale, G.M. (1975). Teacher morale: A pilot study. Centre for Advancement of Teaching Education, Monograph 4. North Ryde, Australia: MacQuarie University. $63 \mathrm{pp}$.

Daniel, T.A. \& Esser, J.K. Intrinsic motivation as influenced by rewards, task interest, and task structure, Journal of Applied Psychology, 65 (5), 566-573.

Darling-Hammond, L. (1984). Beyond the Commission Reports: The coming crisis in teaching. Santa Monica, California: Rand $(\mathrm{R}-3177-\mathrm{RC}), 1-19$.

Davis, F.W. (1981). Job satisfaction and stress. Journal of Physical Education -- Recreation and Dance, 37-38.

Deci, E.L. (1975). Intrinsic motivation. New York: Plenum Press.

Deever, R.M. \& Shockley, H.A. (1975). Job satisfaction of teachers in selected extended school year program. Research Reports on Educational Administration, 5 (5), Bureau of Educational Research and Services.

Deschamp, P.R. \& Beck, T.M. (1979). Teacher transfers: A survey of teachers' opinions on factors influencing their period of stay in schools with a low staff-retention rate, Studies in Rural Education, 2. Perth, Australia: Western Australia Education Department, $47 \mathrm{pp}$. (microfiche).

Dreeben, R. (1973). The school as a workplace. The second handbook of research on teaching. R.M. Travers (ed.) Chicago: Rand Movally छ Co., pp. 458-470.

Duke, D. (1984). Teaching: An imperiled profession. Albany, New York: State University of New York Press.

Durbin, K. (1983). Teaching: A troubled profession, The Oregonian.

Earls, N.F. (1981). How teachers avoid burnout. Journal of Physical Education - Recreation and Dance, $41-43$. 
Edmonds, R. (1978). A discussion of the literacure and issues related to effective schooling. Prepared for the National Conference in Urban Education. St. Louis, Missouri.

Edmonds, R. (1979). Effective schools for the urban poor, Educational Leadership, 37 (1).

Edmonds, R.R. \& Fredericksen, J.R. (1977). Search for effective schools: The identification and analysis of city schools that are instructionally effective for poor children. A proposal for the National Institute of Education. Cambridge, Massachusetts: Harvard Graduate School for Education.

Eliot, T.S. (1963). A fragment of an agon, T.S. Eliot collected poems 1909-1962. New York: Harcourt, Brace, \& WorId, 123.

Etzioni, A. (1964). Modern organizations. Englewood Cliffs, New Jersey: Prentice-Hall, Inc.

Evenson, J.S. (1979). A survey of work-related attitudes of professionals in special education. Independent research and development project reports, 1. San Francisco, California: Far West Laboratory for Educational Research \& Development.

Ewen, R.B. (1964). Some determinants of job satisfaction: A study of the generality of Herzberg's theory. Journal of Applied Psychology, 48. (3), $161-163$.

Ewen, R.B., Hulin, C.L., Smith, P.C. \& Locke, E.A. (1966). An emperical test of the Herzberg Two-Factor theory. Journal of Applied Psychology, 50, 544-550.

Falkenstein, L. (1982). Why do they stay? A study of teacher motivation and reward. American Educational Research Association, Annual Meeting, New York.

Farrell, P. (1984). Special on schools - a tale of mediocrity, The Oregonian, CA.

Fitzgerald, S.M. (1978). Career needs and satisfactions of teachers: A replication study. Michigan State University, 52 pp.

Frase, L.E.; Hetzel, R.W.; \& Grant, R.T. (1982). Merit Pay: A research-based alternative in Tucson. Phi Delta Kappan, 266-269.

Fraser, K.P. (1980). Supervisory behavior and teacher satisfaction. The Journal of Educational Administration, 18 (2), 224-231.

Freeman, W.J. (1979). Managing for motivation: Herzberg's Motivation-Hygiene Theory and its application to 4-H leadership. National Intern Report. Washington, D.C.: National Four-H Club Foundation, $58 \mathrm{pp}$. 
Friedlander, F. (1960). Motivations to work and organizational performance. Journal of Applied Psychology, 50 (2), 143-152.

Friedlander, F. (1963). Underlying sources of job satisfaction. Journal of Applied Psychology, 47 (4), 246-250.

Glass, J.C. \& Grant, K.A. (December, 1983). Counseling in the later years: A growing need. The Personnel and Guidance Journal, 210-213.

Goodlad, J.I. et al. (1979-1980). A study of schooling, Phi Delta Kappan.

Gorton, R.A. (1982). Teacher satisfaction, Encyclopedia of educational research (5th ed.), 1903-1909.

Grant, G., Acharya, U., Franz, S., Hawkins, R., Kohli, W., \& Prakash, M.S. (1983). The teacher's predicament. Teachers College Board, Spring, 593-609.

Greenfield, W. \& Blase, J.J. (1981). Opportunities for principals motivating teachers: Understanding the factors that shape performance. NASSP Bulletin, 1-10.

Hathaway, W.E. (1982). Research and evaluation: Challenges to the myths of education. Address presented at the Washington Educational Research Association's Annual Meeting, Seattle, Washington.

Haughey, M.L. \& Murphy, P.J. (1983). Are rural teachers satisfied witn the quality of their work life? Education, 56-66.

Hearne, J.J. (1971). Teachers' sense of alienation with respect to school system structure, Phi Delta Kappan, 42, 312.

Helawell, D. \& Smithers, A. (1963). Commitment to teaching of postgraduate and college-trained students, Educational Research, 16 (1), 46-51.

Help! Teacher can't teach'. Time, (1980). 54-60.

Henderson, D.L.; Darby, C.E.; \& Maddux, C.D. (1982). Moonlighting, salary, morale, and the approaching teacher shortage: A follow-up study. $17 \mathrm{pp}$.

Hersey, P. \& Blanchard, K.H. (1977). Management of organizational behavior: Utilizing human resources (3rd ed.). Englewood Cliffs, New Jersey: Prentice-Hall, Inc.

Herzberg, F. (1968). One more time, how do you motivate employees? Harvard Business Review, 53-62.

Herzberg, F. (1966). Work and the nature of man. Cleveland, Ohio: The World Publishing Co. 
Herzberg, F., Mausner, B., Peterson, R.0., Capwell, D.F. (1957). Job attitudes: Review of research and opinion. Pittsburg, Pennsylvania: Psychological Service of Pittsburg.

Herzberg, F.; Mausner, B.; \& Snydernan, B.B. (1959). The motivation to work (2nd ed.). New York: John Wiley \& Sons, Inc.

Herzberg, F.; Wiener, Y.; Mathapo, J.; \& Wiesen, L.E. (1974). Motivation-hygiene correlates of mental health: An examination of motivation inversion in a clinical population, Journal of Consulting and Clinical Psychology, 411-419.

Hinkle, D.E. \& Oliver, J.D. (1983). How large should the sample be? A question with no simple answer? Or . . Educational and psychological measurement, 1051-1059.

Holdaway, E.A. (1978). Satisfaction of teachers in Alberta with their work and working conditions. Report of a study. Edmonton, Alberta: Alberta University, Lepartment of Educational Administration, $186 \mathrm{pp}$.

Hoppock, R. (1935). Job satisfaction. New York \& London: Harper \& Brothers Publishers.

House, R.J. \& Wigdor, L.A. (1967). Herzberg's dual factor theory of job satisfaction and motivation: A review of the evidence and a criticism, Personnel Psychology, 20, 369-389.

Ignatovich, F.R.; Cusick, P.A.; \& Ray, J.E. (1979). Value/belief patterns of teachers and those administrators engaged in attempts to influence teaching. Research series \#43. East Lansing, Michigan: The Institution for Research on Teaching.

Ingle, E.B., Jr. \& Munsterman, R.E. (1977). Relationship of values to group satisfaction. (microfiche, $15 \mathrm{pp}$. ).

Jago, A.G. \& Vroom, V.H. (1975). Perceptions of leadership style: Superior and subordinate behavior, descriptions of decision-making behavior. Organizational and Administrative Sciences, 103-120.

Kaiser, J.S. (1981). Motivation deprivation: No reason to stay. The Clearing House, 55, 35-38.

Kaiser, J.S. (1982). Teacher longevity: Motivation or burnout. The Clearing House, 56, 17-19.

Karatzas, V. (1983). The Grolier Survey: What parents believe about education, News. Grolier, Inc. Danbury, Connecticut: Grolier, Inc.

Kaufman, A.H. \& Buffer, J.J. (jr.) (1978). An assessment of job satisfaction of industrial arts teacher educators. Journal of Industrial Teacher Education, 16 (1), 45-56. 
Kenda11, M.G. Rank correlation methods. London: Griffin, 1948, in Fundamental statistics in psychology and education, (1956) 4th ed., H.F. Harlow, ed., New York: MCGraw-Hill, 308.

Key characteristics of teachers in public elementary and secondary schools - 1972-73 to 1979-80. (1981). Education, Science and Culture of Statistics, Canada. Ottawa, Ontario: Canadian Teachers' Federation, $168 \mathrm{pp}$.

Knoop, R. (1981). Leadership styles of principals and teachers' job satisfaction, satisfaction and supervision, and participation in decision making, in papers presented during the CASEA sessions at the 1981 Annual Conference of the Canadian Society for Study of Education, 1-22.

Krecje, R.V. \& Margan, D.W. (1970). Determining sample size for research activities, Educational and Psychological Measurement, 30, 607-610.

Kulpa, C.M. \& Steitz, J.A. (1981). Powerlessness, job satisfaction and teachers' perceptions of adminstrative management. Presented at the American Educational Research Association, Los Angeles, California.

Lawler, E.E. (III) \& Porter, L.W. (1967). The effect of performance on job satisfaction. Industrial Relations: A Journal of Economy and Society, 7 (1), 20-28.

Leggett, S. (1981). Managing schools in hard times. Chicago, Illinois: Teach 'em, Incorporated.

Levitov, J. \& Wangberg, E. (1983). Identifying factors of teacher stress and job dissatisfaction. Thrust, 12, 20, 21.

Liebernan, A. \& Miller, L. (1978). The social realities of teaching, Teachers College Record, 80 (1), 54-68.

Locke, E.A., Smith, P.C., Kendall, L.M., Hulin, C.L. \& Miller, A.M. (1964). Convergent and discriminant validity for areas and methods of rating job satisfaction. Journal of Applied Psychology, 48 (5), 313-319.

Locke, EA. (1969). What is job satisfaction? Organizational Behavior and Human Performance, $4: 4,309-366$.

Lortie, D.C. (1973) in Second handbook of research on teaching. Robert M.W. Travers (ed.) Chicago, Illinois: Rand McNally Publishing Co., The American Educational Research Association, 413, $414,458,469-70,472,476,478,487,491,496-497$.

Lortie, D.C. (1975). Schoolteacher: A sociological study. Chicago, Illinois: University of Ciicago Press. 
Lowther, M.A.; Stark, J.S.; Austin, A.E.; Chapman, D.W.; \& Hutcheson, S.M. (1981). Career lock-in as a factor in teachers' perceptions of occupational and life satisfaction. A paper prepared for the Annual Meeting of AERA, Los Angeles, California.

Madden, J.V., Lawson, D.R., \& Sweet, D. (1976). School effectiveness study: State of California. Paper presented at the Annual Meeting of the American Educational Research Association, San Francisco.

Maddux, C.D.; Henderson, D.; \& Darby, C. (1980). A survey of Texas public school teachers. Huntsville, Texas: College of Education, Sam Houston State University.

Martin, W.B.W. (1978). Issues and perceived participation for school change: Theory and practice, Teachers College Record, 80 (1), 140-156.

Maslow, A.H. (1954). Motivation and personality. New York: Harper \& Row.

Maslow, A.H. (1943). A theory of human motivation, Psychology Review 50 (July, 1943), 370-396.

Medved, JA. (1982). The applicability of Herzberg's Motivation-Hygiene Theory, Educational Leadership, 39 (7), 555.

Metzger, D.J. \& Wangberg, E.G. (1981). Many female teachers would choose other jobs. Phi Delta Kappan, 213.

Meyers, S.M. (1977). Who are your motivated workers? in David R. Hampton, Behavior concepts in management, Belmont, California: Dickenson Publishing Company, 1968, p. 64; originally published in Harvard Business Review, January-Febr:ary, 1964, 73-88; in Hersey \& Blanchard, Management of organizational behavior: Utilizing human resources (3rd ed.), p. 66.

Michaels, C.E. \& Spector, P.E. (1982). Causes of employee turnover: A test of the Mobley, Griffeth, Hand, and Meglino Model. Applied Psychology, 67 (1), 53-59.

Miskel, C. \& Heller, L. (1973). The educational work components study: An adapted set of measures for work motivation, Journal of Experimental Education, 42 (1), 45-50.

Miskel C.G., Glasnapp, D.R., \& Hatley, R.V. (1972). Public school teachers' work motivation, organizational incentives, job satisfaction, and primary life interests. National Center for Educational Research and Development. Lawrence, Kansas: Kansas University, $94 \mathrm{pp}$.

Moeller, G.H. (1973). Bureaucracy and teachers' sense of power, in S.D. Seiber and D.E. Wilder (eds.). The school in society. New York: Free Press. 
Moracco, J.C.; D'Arienzo, R.V.; \& Danford, D. (1983). Comparison of perceived occupational stress between teachers who are contented and discontented in their career choices. The Vocational Guidañce Quarterly, 32, 44-51.

Moxley, L.S. (1977). Job satisfaction of faculty teaching higher education. An examination of Herzberg's dual-factor theory and Porter's need satisfaction research. (microfiche, 64 pp.)

Murnane, R.J. \& Phillips, B.R. (1977). The school as a workplace: What matters to teachers. Mathematica Policy Research. Seattle, Washington; Philadelphia, Pennsylvania, $58 \mathrm{pp}$.

National Commission on Excellence in Education (1983). A nation at risk: The imperative for educational reform. Washington, D.C.: United States Department of Education.

Nationwide Teacher Opinion Poll, 1979. (1979). NEA Research, Memo. Washington, D.C.: National Education Association, 1-27.

Nationwide Teacher Opinion Poli, 1980. (1980). NEA Research. Washington, D.C.: National Education Association, 35 pp.

Nationwide Teacher Opinion Poll, 1981. (1981). NEA Research. Washington, D.C.: National Education Association, 35 pp.

Nationwide Teacher Opinion Poll, 1983. (1983). NEA Research. Washington, D.C.: National Education Association, 15 pp.

NEA research (September-October, 1981). Teacher opinion poll - Job satisfaction, Today's Educator.

NEA survey investigates teacher attitudes, practices. (1980). Phi Delta Kappan, 49-50.

Nederveen, P. (1982). Teacher job satisfaction and modern language curricular variables in Alberta. International Center for Research on Bilingualism, (1-137).

O'Reilly, C.A., III \& Caldwell, D.F. (1980). Job choice: The impact of intrinsic and extrinsic factors on subsequent satisfaction and commitment, Journal of Applied Psychology, 65 (5), 559-565.

Ouchi, W. (1981). Theory Z. New York: Avon Books.

Pajak, E. \& Blumberg, A. (1979). Teachers' attachment to work. April, 1979. Syracuse University, prepared for presentation at the American Educational Research Association's Annual Meeting, San Francisco.

Pascale, R.T. \& Athos, A.G. (1981). The art of Japanese management. New York: Warner Books, Simon \& Schuster. 
Pellicer, L.0. (November, 1984). Job satisfaction - Its impact upon teacher attendance. NASSP Bulletin, 44-46.

Peterson, R.B. (1976). A cross cultural study of secondary school teachers' attitudes regarding job satisfaction, professionalism, and collective negotiations (Sweden and State of Washington), Journal of Collective Negotiations, $\underline{5}$ (2), 113-124.

Peterson, R.M. (1978). Work concepts in the schools: A survey of educators' opinions about work. San Francisco, California: Far West Laboratory for Educational Research \& Development, (microfiche, 54 pp.).

Purrington, G.S. \& Jones, A.S. (1970). Work environment, risk taking, and the walkout behavior of teachers. Final Report. Tallahassee, Florida, December, 63 pp.

Retsinas, J. (1982). Teachers and professional autonomy, Educational Forum, XLVII (1), 25-36.

Rist, R. (1970). Student social class and teacher expectations: The self-fulfilling prophecy in ghetto education, Harvard Education Review, 40, 411-51.

Roethlisberger, F.J. \& Dickson, W.J. (1939). Management and the worker. Cambridge, Massachusetts: Harvard University Press.

Rutter, M. et al. (1979). Fifteen thousand hours: Secondary schools and their effects on children. Cambridge, Massachusetts: Harvard Dniversity Press.

Saleh, S.D. (1964). A study of attitude change in the preretirement period. Journal of Applied Psychology, 48 (5), 310-312.

Schmidt, G.L. (1980). Meeting one's needs: An organizational model for employee job satisfaction. NASSP Bulletin, 80-88.

Seashore, S.E. \& Taber, T.D. (1975). Job satisfaction indicators and their correlates. American Behavioral Scientist, 18 (3), 333-368.

Sergiovanni, T.J. (1967). Factors which affect satisfaction and dissatisfaction of teachers, Journal of Education Administration, 5 (1), 68-82.

Sergiovanni, T. (1966). Satisfaction and dissatisfaction of teachers. Final Report (\#BR-5-8394). New York: Rochester University, $158 \mathrm{pp}$.

Sergiovanni, T.J. \& Carver, F.D. (1980). The new school executive: A theory of administration. New York: Harper \& Row. (Herzberg and job satisfaction, 79-158). 
Sheppard, B.G. (1979). The communication education coordinator: Sources of job satisfaction and dissatisfaction. Charlottesville, North Carolina: Mid-Atlantic Center for Community Education, 86 pp.

Siegel, S. (1956). Nonparametric statistics for the behavioral sciences. New York: McGraw-Hill.

Silberman, C. (1970). Crisis in the classroom: The remaking of American education. New York: Random House.

Silver, P.F. (1982). Research Information Service: Synthesis of research on teacher motivation. Educational Leadership, 551-555.

Soliman, H. (1970). Motivation-Hygiene Theory of Job Attitudes: An empirical investigation and an attempt to reconcile both the oneand the two-factor theory of job attitudes. Journal of Applied Psychology, 54 (5), 452-461.

Sparks, D.C. (1979). A biased look at teacher job satisfaction, The Clearing House, 52, 447-449.

Spiegel, M.R. (1961). Theory and problems of statistics. New York: Schaum Publishing Co.

Statistical package for the social sciences, 2nd ed. (1975). New York: McGraw-Hill.

Steinberg, M. (1984). 7,300 teachers on strike in eight states, The Oregonian, Al8 3M.

Sweeney, J. (1981). Professional discretion and teacher job satisfaction. The Educational Digest (condensed from The High School Journal) (October, 1981; February, 1982, 28-29.a).

Sweeney, J. (1981). Responsibility and fulfillment of needs - Burnout remedies? Phi Delta Kappan, 676.

Sweeney, J. (1981). Teacher dissatisfaction on the rise: Higher level needs unfulfilled. Education, 102, 203-208.

Teacher opinion poll: Job satisfaction. (1981). NEA Research. Today's Educator.

Teachers; personalities, beliefs studied for clues to job problems. (1984). Education U.S.A. 281, 288.

Thurman, J.E. (1977). Job satisfaction: An international overview, International Labour Review, 117 (3), 249-67, Geneva, Switzerland: ILO Publications, in ASCA Digest, 1979.

Vernon, M.D. (1969). Human motivation. New York: Cambridge University Press. 
Villeme, M.G. \& Hall, B. (1980). The relation of teacher attitude to major, employment status, teaching level, and satisfaction with teaching for first-year teachers, Humanist Educator, 85-90.

Vroom, V.H. (1966). Some observations regarding Herzberg's Two-Factor Theory. Paper delivered at the American Psychological Association, Chicago, Illinois.

Vroom, V.H. (1964). Work and motivation. New York: John Wiley \& Sons, Inc.

Waller, W. (1965). A sociology of teaching (1932). New York: John Wiley, Science Edition.

Wangberg, E.G.: Metzger, D.J.; \& Levitov, J.E. (1982). Working conditions and career options lead to female elenentary teacher job dissatisfaction. Journal of Teacher Education, 33 (5) 37-40.

Weathersby, R. (1977). A synthesis of research and theory on adult development: Its implications for adult learning and postsecondary education. Special qualifying paper, Harvard University Graduate School.

Wernimont, P.F. (1966). Intrinsic and extrinsic factors in job satisfaction, Journal of Applied Psychology, 50 (1), 44-50.

Williamson, T.R. \& Karras, E.J. (1970). Job satisfaction variables among female clerical workers. Journal of Applied Psychology, 54 (4), 343-346.

Young, I.P. \& Davis, B. (1983). The applicability of Herzberg's Dual Factor Theory(ies) for public school superintendents. Journal of Research and Development in Education, 16 (4), 59-66. 
Administration of educational institutions (1982). Encyclopedia of Educational Institutions (5th ed.), 22-49.

Boros, 0.K. (ed.) (1953). The fourth mental measurements yearbook. Highland Park, New Jersey, Gryphon Press, 797-99.

Callahan, R.E. (1962). Education and the cult of efficiency. Cnicago: University of Chicago Press.

Campbe1l, R.F.; Cunningham, L.L.; \& McPhee, R. (1965). The organization and control of American schools. Columbus, Ohio: Charles E. Merrill.

Clark, D.L.; Lotto, L.S.; \& McCarthy, M.M. (March, 1980). Factors associated with success in urban elementary schools, Phi Delta Kappan.

Cleborne, D. et al. (1980). A survey of Texas Public School teachers. Maddux, Texas. $11 \mathrm{pp.}$

Conen, M. (April-May, 1981). Effective schools: What the research says, Today's Education.

Coleman, J.S, et al. (1966). Equality of educational opportunity. Washington, D.C.: Office of Education.

Cremin, LA. (1961). The transformation of the school. New York: Alfred A. Knopf.

Crocteau, J.M. The myth of teacher burnout. Tallahassee, Florida: Leon County Teacher Education Center, 1-7.

Dearman, N.B. \& Plisko, V.W. (1981). The condition of education. Statistical Report - National Center for Education Statistics. Office of Educational Research and Improvement. Washington, D.C.: U.S. Department of Education, U.S. Government Printing Office.

Edwards, A.L. (1957). Techniques of attitude scale construction. New York: Appleton-Century-Crofts, Inc.

Effective management and the behavioral sciences: Conversations from organizational dynamics. (1978). W. Dowling (ed.). American Management Association. New York: Amacom.

Elmore, P.B. \& Beggs, D.L. Salience of concepts and comnitments to extreme judgments in the response patterns of teachers, Education, 95 (4), 325-330. 
Fansher, T.A. \& Buxton, T.H. (1984). A job satisfaction profile of the female secondary school principal in the United States. NASSP Bulletin, 32-39.

Fundamental statistics in psychology and education, 4th ed. (1956). H.F. Harlow, ed., New York: McGraw-Hill.

Gallup, G. (1969). How the nation views the public schools. Princeton, New Jersey: Gallup International.

General thesis instructions (1975). Office of Graduate Studies and Research. Portland, Oregon: Portland State University.

Good schools: What makes them work (1981). Education USA: Special Report. Arlington, Virginia: National School Public Relations Association.

Gracy, H.L. (1972). Curriculum or craftsmanship: Elementary school teachers in a bureaucratic system.

Grant, G. (1981). The character of education and the education of character, Daedalus, 110 (3), 135-50.

Guilford, J.P. (1965). Fundamental statistics in psychology and education (4th ed.). New York: McGraw-Hill Book Company.

Hosford, P.L. (ed.) (1984). Using what we know about teaching. Alexandria, Virginia: Association for Supervision \& Curriculum Development.

Job satisfaction rates high with teachers. (1983) NEA Research Department, Nationwide Teacher Opinion Poll, Research Memo. Washington, D.C.: NEA, 1-15.

Joyce, B.R. ¿ Weil, M. (1972). Models of teaching. Englewood Cliffs, New Jersey: Prentice-Hall, Inc.

Miller, M. (1981). Where to go for what: How to research, organize, and present your ideas. Englewood Cliffs, New Jersey: Prentice-Hall, Inc.

Papers presented during CASEA sessions at the 1981 Annual Conference of the Canadian Society for the Study of Education. Atlantic Institute of Education, Halifax, Nova Scotia (Canada) (1981). Saskatoon, Saskatchewan: Canadian Association for the Study of Educational Administration.

Postman, N. (1979). Teaching as a conserving activity. New York: Delacorte Press.

Postman, N. (1967). Teaching as a subversive activity. New York: Charles Weingartner. 
Publication manual of the American Psychological Association (2nd ed.). (1981). Baltimore, Maryland: Garamond/Pricemark Press, Inc.

Publication manual of the American Psychological Association (3rd ed.). (1983). Washington, D.C: APA.

Roth, A.J. (1982). The research paper: Process, form, and content (4th ed.) Belmont, California: Wadsworth Publishing Company.

Sarason, S. (1971). The culture of the school and the problem of change. Boston: AlIyn \& Bacon. (Ch. 10-The teacher, the role, and its dilemmas).

Simon, A. \& Boyer, E.G. (1967). Mirrors for behaviors: An anthology of observation instruments. Philadelphia: Research for Better Schools.

Standards for evaluations of educational programs, projects, and materials. (1981). The Joint Committee on Standards for Educational Evaluations. New York: McGraw-Hill Book Company.

Sternberg, D. (1981). How to complete and survive a doctoral dissertation. New York: St. Martin's Press.

Style Manual for Theses and Dissertations. Office of Graduate Studies and Research. Portland, Oregon: Portland State University.

Swidler, A. (1979). Organization without authority: Dilemmas of social control in free schools. Cambridge, Massachusetts: Harvard University Press.

Turabian, K.L. (1973). A manual for writers of term papers, theses, and dissertations (4th ed.). Chicago, Illinois: University of Chicago Press.

Vroom, V.H. \& Pahl, B. (1971). Relationship between age and risk taking among managers, Journal of Applied Psychology, 55 (5), $339-405$.

Wakefield, J.A., jr.; Cunningham, C.H.; \& Edwards, D.D. Teacher attitudes and personality, 345-47.

Weiss, E.H. (1982). The writing system for engineers and scientists. Englewood Cliffs, New Jersey: Prentice-HaII, Inc.

Worth, D. A review of research: Effective schools. 


\section{APPENDICES}

Appendix

Page

A Sumnary of Investigations Attempting to Replicate or Investigate Herzberg Theory (A.1 Burke, 1966;

A.2 House \& Wigdor, 1967) ............ 393

B Studies of Teachers and Factors Associated with Job Satisfaction (Perko, 1984) . . . . . . . . 4 400

C List of Factors Defined as Motivators or Hygienes (Herzberg, Lortie) ............. 414

D Questionnaire $\left(Q_{2}\right), 1984$........... 415

E Questionnaire $\left(Q_{1}\right), 1981$........... 426

F Tables of Items - Questionnaire $\left(Q_{2}\right), 1984$. . . . . 437

G Comparative Items $\left(Q_{1}, 1981\right.$ and $\left.Q_{2}, 1984\right) \ldots . . . . .470$ 
PLEASE NOTE:

Copyrighted materials in this document have not been filmed at the request of the author. They are available for consultation, however, in the author's university library.

These consist of pages:

393-399

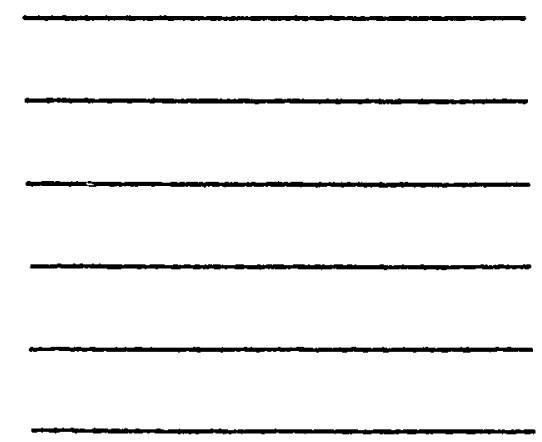

\section{University \\ Microfilms International}

300 N. ZEEB RD.. ANN ARBOR, MI 48106 (313) 761.4700 
APPENDIX B

STUDIES OF TEACHERS AND FACTORS ASSOCLATED WITH JOB SATISFACIION

\begin{tabular}{ll}
\hline $\begin{array}{l}\text { AUTHOR(S) } \\
\text { DATE(S) } \\
\text { LOCALE }\end{array}$ & $\begin{array}{l}\text { FOCUS OF STUDY } \\
\text { METHOD OF DATA COLLECTION }\end{array}$ \\
\hline $\begin{array}{l}\text { American Federation of } \\
\text { Teachers } \\
\text { 1984 }\end{array}$ & Teachers under stress -- \\
New Orleans, Louisiana & AFT study of six urban schools
\end{tabular}

Ashbaugh, C.R. 1980

Bentzen, M.M., Williams, R.C. and Heckman, P. 1980

California

(Goodlad Associates)

Bidwel1, C.E.
1973

Chicago

Bidwell, C.E.

1973

Chicago

Bloland, P.A. and Selby, T.J. 1980

Caifornia

Bredeson, P.V.,

Organizational incentives and Fruth, M.J., Kasten, K.L. 1983

Ohio, Wisconsin, Nebraska
Considers theories and definitions for job satisfaction

Are teachers satisfied with their jobs? Would they choose teaching again? Are elementary teachers more satisfied than secondary ones?

Samped 1344 teachers; used questionnaire.

The social psychology of teaching, considers teaching as a social process to promote the understanding of teaching from a social-psychological perspective, review of literature -- includes Lortie (1969).

Considers teaching as a social process.

Factors associated with career change among secondary school teachers as a review of literature.
Poor working conditions, increased job responsibilities, and a lack of professional rewards are converging to place teachers under stress.

Finds that educators, particularly elementary and secondary teachers are motivated by intrinsic and extrinsic factors

Seventy-five percent agreed wit statements of job satisfaction; only 128 agreed strongly with these statements.

Teaching is a series of interactions, defined work, but not routine and standardized.

Teaching as a social process cannot occur except through interpersonal exchange. Variation in social organizations of schools may be related to variation in the social and normative structure or social and moral order.

Notes teacher surplus, considers qualitative and humanistic aspects of occupational turnover along with an examination of contributing factors for better understanding of issues involved.

Extrinsic rewards are within the control of the organization.
Sampled teachers (present and former) and administrators from 8 midwestern school districts $(\mathrm{N}=60)$; used personal interviews. 
Bridges, E.M.

1983

California

Brooks, M.

1982

New York

Brown, S. \& McIntyre, D.

1982

Scotland

Burke, R.J

1966

Michigan

Canadian Teachers Fed. 1972-73 to $1979-80$

Ottawa, Ontario, Canada

Centers, R. and Bugental, D.E. 1966

Los Angeles, CA

Chapman, D.W.

1983

New York
The management of teacher competence

Provides definitions of competency and failure

School organizational renewal

Influences upon teachers' attitudes to different types of innovation -- a study of teacher attitudes toward integrated science

Sampled 86 science teachers from science departments of 8 comprehensive schools: used 46-item questionnaire

Questions Herzberg 's motivators and hygienes as unidimensional to test Herzberg assumptions

Sampled 187 college students, used unfolding techniques by Coombs (1964)

Key characteristics of teachers in public elementary and secondary schools -. trends in teacher characteristics

Sampled public elementary and secondary teachers in Canada

Intrinsic and extrinsic job motivations among different segments of the working population

Sampled 692 workers, crosssection; used personal interviews

Career satisfaction of teachers

Sampled 437 teachers; used College Alumni Questionnaire

Cites Lortie and Sergiovanni
A current problem is the qualit: of the teaching force. The fittest are not surviving.

Addresses changes in public
education. education.

Notes that teacher contribution should be offset by rewards which are not given; teachers are being required to do more for less. Individuality is diminishing.

In certain circunstances, it ma be possible to create organizational conditions through which teachers may be influenced to adopt more favorable attitudes to change, particularly if such changes do not depend on changing teacher attitudes.

Does not support Herzberg, does not find unidimensional attributes underlying both motivator: and hygienes.

Findings include: reduction in median class size, more part-

time teachers, decrease in positions of added responsibility and promotional opportunities, decrease in principalships held by females, decrease in proportion of females in full-time teaching force, decrease in the proportion of teachers under ages 25 and 30 , increase in the proportion of teachers with at least one degree.

Extrinsic or intrinsic job components are valued in relationship to higher and lower occupational levels.

Personal characteristics do not significantly predict career satisfaction for teachers. 
Chapman, D.W. and Lowther, M.A. 1982

Chase, F.S.
1976-77 Chicago

ChiIders, J.H., Jr. and Podemski, R.

1982-83

Arkansas

Cooke, R.A.,

Kornbluh, H., and Abramis, D.J. 1982

Michigan

Coverdale, G.M. 1974-1975 (1971) Australia

Davis, F. 1981

Connecticut

Deever, R.M. and Shockley, H.A. 1975

Arizona
Teachers' satisfaction with teaching

Sampled 400 graduates from $U$ of Michigan teaching certification programs per year for period between 1946 and $1976=5764$; response of 518 (2933), final sample of 542 who had taught continuously, used questionnaire.

The administrator as inmplementor of the goals of education for our time -. focus on the cycle of morale, motivation, work, achievement, and satisfaction.

Teacher expectations

Michigan teachers vs, a national sample of workers on quality of worklife.

Compared worklives of teachers in 1979 with a national sample of workers in 1977. Sampled 200 Michigan teachers; used personal interviews and questionnaires.

Same determinants of teacher morale in Australia.

Sampled 750 elementary and secondary teachers in New South Wales (1971); response of $22 \%$; used questionnaire.

Job satisfaction and stress -$\mathrm{K}-12$ physical educators, public education -- burnout

Sampled 246 public school physical educators in Connecticut; used questionnaire and personal interview

Sumnary of a doctoral dissertation by Joseph E. Clauson: Job Satisfaction of Teachers in Selected Extended School Year Program.

Sampled 181 teachers with extended school year programs; response $80 \%$ used questionnaire (morale tendency score MS)
Women indicate greater satisfaction with their teaching careers than men. Satisfaction in teaching is negatively related to supervision and leadership (or administrative skills). Writing ability is negatively related to satisfaction.

Career satisfaction is related to assigning little importance to activities difficult to achieve.

Satisfaction grows out of a sense of achievement and of being valued in the organization.

Unrealistic expectations may be major contributors to job dissatisfaction, loss of confidence, burnout.

Teachers are significantly less satisfied with the quality of their worklives, more fearful of losing their jobs and more likely to experience problems with their jobs than are workers in a nationwide sample.

Findings confirm high levels of dissatisfaction based on conditions of service rather than salary or other material benefits.

Dimensions among variables foumc to predict job satisfaction include morale of the group, professioral commitment of the individual, leader behavior, disengagement behavior of the group.

There is a significant relationship between many factors and characteristics of teachers involved in extended year programs. Teaching staff should be involved in the planning and program development and should have adequate orientation. 
Deschaap, P A. and Beck, T.M. 1979

Perth, Australia

Earls, N.F.

1981

Wisconsin

Education USA

1984

Washington, D.C. Ed-Line (5-I 6-84)

(Ashton, P. and

Webb, R.B.

Florida)

Evenson, J.S.

1979

California, Utah, and Nevada

Ewen, R.B.

1964

Illinois

Ewen, R.B., Hulin, C.L. Smith, P.C., \& Locke, E.A. 1966

Falkenstein, L.C.

(\& Hathaway, W.)

1981

Oregon
An empirical test of the

A survey of teachers' opinions on factors influencing their period of stay in schools with a low staff retention rate in rurai schools in Australia.

Sampled 335 teachers in 26 elementary and secondary schools in W. Australia and 79 teachers who had resigned or moved; used questionnaire

How teachers avoid burnout

In-depth interviews from two studies 1979-1981 of Physical Education teachers with an average of more than 12 years teaching experience.

Teachers' personalities, beliefs studied for clues to job problems. Teacher efficacy linked to school climate.

Interviews of teachers in six Southeastern schools.

Work-related attitudes of professionals in special education

Sampled 1066 special educators nationally; response $50 \%$; used questionnaire .. A Survey of Opinions About Work

Same determinants of job satisfaction: A study of the generality of Herzberg's theory

Herzberg Two-Factor theory

Sampled employees over 35 in 21 "units"; used the Job Descriptive Index (JDI)

Teacher study questionnaire

Sampled 2,377 public school teachers in seven districts in the Portland Metropolitan Area; response 64.77 ; used 108-item questionnaire -based on Lortie research in School teacher (1975).
Data reveal that the teachers feel disadvantaged in rural service based on high cost of living, cost of travel, poor housing, little financial incentives, little professional contact and support, limited opportunity to study for promotion, restricted social life, disruption to family life, poor reception from residents.

Causes of burnout include: repetition of teaching as a deterrent to enthusiasm, sumner employment, responsibilities such as coaching that consume time and energy; moonlighting related to low salary; and continuing study.

Conditions of teaching need changing. School improvements that do not address the causes of teacher dissatisfaction or the unwillingness of students to enter teaching are "unlikely to improve the academic performance of students or the quality of school life" (Patricia Ashton, Univ. of Florida).

The work concept scale score for special educators is found to be significantly higher for special educators than for social studies teachers and significantly lower than that for career/vocational teachers.

This paper criticizes Herzberg ' theory and discusses deficiencies in the methodology. It concludes that the Herzberg results cannot be generalized beyond the situation in which they were maintained.

Findings do not support Herzbers two-factor theory nor the traditional theory of bi-polar continuuis.

Teachers are satisfied with their jobs; primary satisfaction and sense of reward comes from work with students; burnout may be overrated. 
Fansher, TA. and Buxton, T.H.

1984

South Carolina

Fitzgerald, S.M. 1978 (1972-1977) Michigan
A job-satisfaction profile of the female second school principal in the U.S.

Sampled 408 female principals; response 658 ; used questionnaire (Job Discription Index JDI )

Replication study of career needs and satisfaction of teachers (1972-1977)

Sampled 208 teachers, response of $85 \%$ in 1972 and $57 \%$ in 1977; used questionnaire (including MIQ)

Frase, L.E., Hetzel, R.W., Merit pay -- alternative: and Grant, R.T.

1982

Arizona

Fraser, K.P.

1980

Montana

Freenan, W.J.

1978

Michigan

Friedlander, $\mathrm{F}$.

1966

California

Friedlander, $F$.

1963

California based on Herzberg's Theory

Supervisory behavior and teacher satisfaction

Sampled 370 Montana public school teachers; response $828(1978-79)$ used questionnaire

Managing for motivation: Herzberg's MotivationHygiene Theory and its Application to $4-\mathrm{H}$ Organizational factors contributing to motivation interviewed on 13 job factors.

Motivations to work and organizational performance

Sanmled 1047 technical personnel classified as white collar workers and 421 blue collar workers; used questionnaires.

Underlying sources of job satisfaction

Sarmpled 10,000 employees in a large midwestern manufacturing company; response $92 \%$, used questionnaire
Sarmpled 149 4-H leaders,
Overall level of job satisfaction is quite high for sample group. The five sub-areas of satisfaction include supervision from others, people, work, pay, and promotion.

Service is most satisfying aspect of teaching; work accomplishment is least satisfying. Cooperation of staff and liking the job were most important factors.

Outlines a Program for Excellence to reward teachers in excellence with classroom instruction.

Satisfaction with supervision serves as one element (but distinct from) of job satisfaction.

Largely supports Herzberg Theory on motivators and hygienes; some factors act as both satisfiers and dissatisfiers.

Findings that white collar workers are primarily motiveted by social environment of the job, and to a lesser extent by oppor tunity for recognition through advancement.

Findings include an indication 3 underlying groms of job elements important to job satis fartion: social and technical environment, intrinsic work aspects, and recognition through advancement. No significant differences in overall job satisfaction among the three groups were found. 
Grant, G. et al 1983

Syracuse, N.Y.

Greenfield, H. and

Blase, J.J.

1981

Ohio and New Mexico

Haughey, M.L. and Murphy, P.J.

1983

Canada

Hellawell, D. and Smithers, A.

1973

Henderson, D.L. and

Darby, C.E.; and Maddux, C.D.

1982

Texas

Hersey, $P$, and

Blanchard, $K$.

1972

New Jersey

Herzberg, F., Mathapo, J. Wiener, Y., \& Wiesen, L.E. 1974

Ohio
Teacher's Predicament. The withd rawal of teachers from teaching as a crisis in education, citing a variety of factors

Motivating Teachers: Understanding the factors that shape performance -- what teachers say about their role and responsibilities -as data for principals in working with staff to improve schools.

To some degree this paper extends Lortie findings.

Are rural teachers satisfied with the quality of their workclife -- job satisfaction

Sampled 1148 teachers, $46 \%$ response, used questionnaire

Commitment to teaching of post-graduate and collegetrained students

Sempled 274 from University Department of Education, graduates in two colleges of education, students in Busines Education, and students in 3-year courses in two colleges of education; used questionnaires (1970-71).

Moonlighting, salary, morale, and the approaching teacher shortage: a follow-up study

Sampled 491 Texas teachers; response of $65 \%$; used questionnaire

Management of organizational behavior -- utilizing human resources

Focus on Herzberg Theory

Motivation-hygiene correlates of mental health; An examination of motivational inversion in a clinical population
A third to a half of all teachers say they would not enter teaching again. Numbers of teachers with 20 years or more of experience has been reduced by half in last 15 years.

Two to three years are required to achieve teaching mastery, and during this time young teachers experience frustration. Expectations and student behavior are significant factors. Achieving valued outcomes is important to teachers.

Twenty-two percent are highly satisfied with their jobs. Itens associated with working conditions contributed to satisfaction and dissatisfaction.

Findings confirm that many students in programs of education would have preferred other career choices.

Follow-up to 1980 study confirms that crisis exists in Texas. Many teachers plan to leave teaching and blame low salary or need to work outside teaching as major factors.

Finds Herzberg Theory as one of the most interesting series of studies in areas of needs and the importance of esteem and self-actualization.

Indices of inversion as a direct relationship between the severity of mental disorder and the degree of motivational inversion were obtained from Herzberg's critical-incident method. 
Holdaway, E.A.

1978

Edmonton, Alberta,

Canada

Hoppock, R.

1935

Northeastern region, US

House, R.J. and

Wigdor, L A.

1967

Ingle, E.B., Jr. and Munsterman, R.E. 1977

Illinois and Indiana

Jago, A.G. and

Vroom, V.H.

1975

Yale University
Satisfaction of teachers in Alberta with their work and working conditions. Included study of Herzberg Dual-Factor Theory.

Sampled 1379, 586 response; used questicrnaire, survey of 21 Alberta school systems

Job satisfaction -- including comparative study of ext reme expressions of satisfaction and disatisfaction by teachers

Sampled 500 teachers, identified extreme attitudes for 100 satisfied and 100 dissatisfied teachers; used questionnaires of 200 items for the extremes sampled.

Criticism of Herzberg's DualFactor Theory of Job Satisfaction and Motivation

Relationship of values to group satisfaction -- principal-teacher value congruence in relationship to group satisfaction in elementary schools, rural and small town schools in Illinois and Indiana.

Sarpled 192 teachers from 12 schools; response 798; used VAL-ED and Heslin Group Satisfaction Inventory.

Perceptions of leadership style: Superior and subordinate descriptions of decisionmaking behavior.

Sampled 39 managers, how they would act in response to 30 cases (Vroom and Yetton problem-set). Each manager gave same set of cases to subordinates under direct supervision, purpose to explore combunity.

Kaiser, J.S. 1981

Motivation deprivation of teachers leaving many no
The factors contributing most to overall teacher satisfaction are related to "working with students." The factors contributing most to overall dissatisfaction are related to "attitudes of society and parents," "administration and policies," and "physical conditions."

Findings confinn direct or indirect relationships between job satisfaction and emotional adjustment and other variables.

Discusses Herzberg Dual-Factor Theory, lists various studies using the basic theory, finds the theory to be an oversimplification and method bound. Brings Herzberg Theory into question.

High morale schools had greater principal-teacher value incongruence. Schools with a high degree of group morale had a greater degree of value dispersion. Principals as a group hold similar values; teachers tend to differ in values from principals. The principal seem: to be key in fostering morale.

Evidence does not support a hig! level of perceived commonality, but typical subordinate does perceive difference in response for self and for supervisor. Findings suggest that subordinates see the supervisor as more autocratic than the supervisor describes self. reason to stay in teaching. Cites Herzberg Theory and Maslow Theory.
Cites factors specific to motivation needs of teachers and motivation factors specific to teaching. 
Kaiser, J.S. 1982

Illinois

Kaufman, A.H. and Buffer, J.J., Jr. 1978

Virginia and Ohio

Knoop, R.

1981

Saskatoon, Saskatchewan Canada

Lawler, E.E. III and

Porter, L.W.

1967

Massachusetts and

Cali fornia

Levitov, J. and

Wangberg, $\mathrm{E}$.

1983

New Orleans, Louisiana

Locke, E.A., Smith, P.C., Kendall, L.M., Hulin, C.L. and Miller, A.M.

1964

New York (Cornell Univ.)
Teacher longevity: motivation or burnout

Links teacher needs to Maslow and Herzberg Theory; focus on longevity and performance.

An assessment of job satisfaction of industrial arts teachers ( 1 imited to college professors). Sampled 350 industrial arts teachers; response $62.5 \%$.

Tested Herzberg Theory; used questionnaire

Effects of leadership styles of principals on teacher job satisfaction, satisfaction with supervision, and participation in decision-making.

Sampled 1812 elementary and secondary teachers; response rate of $91 \%$; used questionnaire (Hoppock scale and other scales).

The effect of performance on job satisfation -. investigation of the relationship of rewards to job satisfaction

Collected data from 148 middle and lower level managers in five organizations, manufacturing and social service and welfare agencies.

Identifying factors of teacher stress and job dissatisfaction

Sampled 397 teachers in large urban system; used Teacher Stress Scale (TSS)

Convergent and discriminant validity for areas and methods of rating job satisfaction

Sampled 133 employees from 2 companies, using rating method from scowl to smile, and a direct graphic rating
Factors specific to teacher motivation needs and job inducements are those identified by Maslow and Herzberg (hygiene and motivators).

Deprivation of such factors leads to burnout and leaving the profession.

Findings do not support the twofactor theory. Both extrinsic and intrinsic job dimensions serve as sources of job satisfaction and dissatisfaction.

Findings confirm that considerate leadership behavior is desirable in education. Consideration is related to teacher satisfaction. Teaching is a work situation which demands considerate leadership. Positiv: work outcomes for teachers rest more and more on the school principal.

Satisfaction is dependent upon performance. Performance may lead to rewards that may lead to increased job satisfaction. Intrinsic rewards are more likely to be related to gond performance since they are given by the self to the self.

Extrinsic rewards are given by others and mainly satisfy lower level needs.

Nine factors are identified as contributing to job stress and job dissatisfaction for teachers.

A rating method employing faces from scowl to smile and a direct graphic method were best. Pay, promotions, and supervision showed greater discriminant validity than work and people areas.

Does not accept Herzberg theory 
Locke, E A.

1969

Maryland

Lortie, D.C.

1973

Lortie, D.C.

1975

Boston, Mass. and

Dade County, Florida

Maddux, C.D.,

Henderson, $\ddot{D}$. and

Darby, C.

1980

Texas

Medved, J A.

1982

Ohio

Metzger, D.J. and Wangberg, E.G.

1981

New Orleans, Louisiana

Michaels, C.E. and Spector, P.E.

1982

Florida
Seeks better understanding of the definition of job satisfaction, what it is.

Discusses value hierarchies, overall job satisfaction, Herzberg Dual-Factor Theory; measurement of satisfaction and values.

Observations on teaching as work

A sociological study of schoolteachers, attempting to define the nature and content of the ethos of schoolteaching.

Sampled 94 teachers in Five Towns in the Boston Metropolitan Area; followed with study of more than 5,000 educators in Dade County, Florida; used personal interview in first study and questionnaires in follow-up study.

A survey of Texas public school teachers.

Sampled 424 teachers in Houston area school district; response $70 \%$; used questionnaire

Teacher job satisfaction using Herzberg Motivation-Hygiene Theory and Maslow Theory.

Sampled 70 teachers from a small midwestern suburban school system; used a questionnaire

Survey of elementary teachers -- job choice of female elementary teachers

Sampled 208 of the female elementary teachers in four school systems; response of 658 ; used questionnaire.

Causes of employee turnover -job satisfaction and perceived alternative employment opportunities.

Sampled 180 permanent employees of a community health center in urban S.E. Uniter States, $69 \%$ response; used questionnaire.
Argues that lack of understanding of job satisfaction and dissatisfaction is based on lack of understanding of what joo satisfaction is, based on implicit conception of causality and policy of correlation without sxplanation.

Notes that schools, in comparison with other institutions have received little social scientific description useful to investigators.

Found that teachers are present oriented. Teachers receive primary rewards from their work with students and are caught in tentions from any activities that tend to intervene between what they deem their primary commi tments as teachers of students. Issues of intervention are termed "the roots of ambivalence."

One in three teachers are considering leaving teaching.

Motivating factors contribute most often to satisfaction and if absent contribute most often to dissatisfaction.

Forty percent of female elementary teachers would not choose to enter teaching again.

Factors influencing job satisfaction and turnover include pre-employment expectations, perceived job characteristics, organizational conmitment. 
Miskel, C.G. Glasnapp, D.R., and Hal tey, D.V. 1972

Kansas

Miskel, C. and

Heller, L.

1973

$\mathrm{U}$. of Kansas and Baylor

College of Medicine

Moracco, J.C. D'Arienzo, R. V. and Danford, D.

1983

Middle Atlantic States

Moxley, L..S.

1977

Michigan

Murnane, R.J. and

Phillips, B.R.

1977

Pennsylvaria

NEA Teacher Opinion Poll

1979

1980

1981

1983
Public school teachers' work motivation, organizational incentives, job satisfaction, and primary life interests.

Sampled 3400 public school teachers in Kansas; used questionnaire to collect data on 14 variables.

Educational work components study, measures for work motivation (WCS) -- uses He rzberg theory to develop EWCS questionnaire.

Sampled 745 (graduate students, administrators, and teachers); used instrument based on Herzberg Theory.

Comparison of perceived occupational stress between teachers who are contented and discontented in their career choices.

Sampled 691 teachers -- teacher stress survey -- Middle Atlantic states, urban systen; response $52 \%$; used questionnaire.

Job satisfaction of faculty teaching higher education. An examination of Herzberg's Dual-Factor Theory and Porter's Need Satisfaction Research.

Sarmled 200 faculty members, 48. 78 response; used questionnaire.

The school as a workplace: what matters to teachers

Sanpled 650 public school teachers in seven schools in Midwest urban school district; used questionnaire

Teacher attitudes on various aspects of teaching

1979 - sampled 2,148; response 82. 7f; used questionnaire

1980 - sampled 2,165; response 80.38 ; used questionnaire

1981 - sampled 1,709; response 74.06 ; used questionnaire

1983 - sanpled 1,978; response 79. $6 \%$, used questionnaire
Findings indicate that female elementary and secondary teachers who score high on satisfaction are also job oriented, hold a job with potential for persona? challenge and development, with less work pressure in the job, where more incentives exist, tolerance for work pressure is higher.

Findings indicate high potential for probing relationships based on work motivation, using EWCS. Major focus is development of instrument for educators or as related to schools and school districts instead as related to Herzberg's study of companies and industrial workers.

Fifty-two percent said they would not become teachers again. Thirty-five percent are dissatisfied.

Satisfaction frequencies and global satisfaction scores showed higher education faculty to be "overwhelmingly satisfied" with their teaching positions.

For all seven schools, teachers in different schools have different levels of job satisfaction.

1979 - Thirty-two percent would not become tearhers again.

1980 - Forty-one percent would not or would probably not become teachers aga in (52\% male, $35 \%$ female would prefer not becoming teachers again.

1981 - Thirty-seven percent dissatisfied with their jobs; $45 \%$ would probabiy not become teachers again.

1983 - Fifty-eight percent would definitely or probably choose teaching again; $25 \%$ would definitely not choose teaching again; 50\% plan to remain until retirement. 
Nederveen, $\mathrm{P}$.

1982

Quebec, Canada

Pajak, E. and

Blumberg, A.

1979

California

Peterson, R.B. 1976

Washington

Peterson, R.M. 1978

Colorado

Purrington, G.S. and Jones, A.S. 1970

Florida

Retsinas, $\mathrm{J}$. 1982

Rhode Is land
Teacher job satisfaction and modern language variables in Alberta.

Sampled 763 teachers; response of 488 , used questionnaire

Teachers' attachment to work. Addresses central life interests of public school teachers.

Sampled 132 teachers in N.Y., response of $80 \%$, used questionnaire. Cites Lortie Theory on career rewards and present rather than future orientation of teachers.

A cross-cultural study of secondary school teachers attitudes regarding job satisfaction, professionalism, and collective negotiations (Sweden and State of Washington)

Sampled 318 Washington and 308 Swedish secondary school teachers, overall response rate of $50+\xi$; used Purdue Teachers Opinionnaire.

Work concepts in the schools: A survey of educators' opinions about work.

Sampled 1300 administrators, teachers, coumselors and other unclassified; response 32.58 ; used questionnaire.

Focus included job satisfaction

Work enviroment, risk taking, and the walk-out behavior of teachers.

Sampled 512 Florida teachers (1967-68); response rate of $53 \%$ of 400 questionnaires received.

Uses Herzberg Theory.

Teachers and professional autonomy -- quest for power, continuing lack of power
Findings confirm correlations between job satisfaction and personal factors.

Teachers found to differ from other occupational groups, the majority found to be not job oriented in their overall central life interests.

Results show interrelationships of teacher attitudes regarding job satisfaction, professionalism, and collective negotiations.
Satisfaction relates to developing values and attitudes as educators, preparing students with realistic expectations, developing student competencies. Dissatisfaction relates to pay inequities, poor job design, lack of worker control in addition to beliefs that hard work builds character and it is important to job success to know the right people.

Teacher decisions to welk-out are influenced by degree of satisfaction with intrinsic and extrinsic work factors.

Satisfaction, dissatisfaction, and risk taking propensity each significantly predict walk-out and nonwalk-out behavior.

Teachers call themselves professionals, demanding a voice in educational policy, yet they remain line workers hired to perform specific tasks. 
Saleh, S.D.

1964

Ontario, Canada

(Cleveland, Ohio)

Schmidt, G.L.

1980

Illinois

Seashore, S.E. and

Taber, T.D.

1975

Michigan

Sergiovanni, T.

1966

New York

Sergiovanni, T.J. and Carver, F.D.

1980

Illinois

Sheppard, B.G.

1979

Mid-Atlantic States

Silver, P.F.

1982

Illinois

Soliman, H.M.

1970

Illinois
A study of attitude change in the preretirement period

Sampled 85 male managerial eniloyees from Cleveland companies; used personal interviews

Followed Herzberg theory

Ar organizational model for employee job satisfaction -addresses Herzberg Theory and meeting employee needs.

Job satisfaction indicators and their correlates

Satisfaction and dissatisfac tion of tcachers. Included study of Herzberg Dual-Factor Theory.

Sampled 127 teachers, $56 \%$

response; used personal interviews

Establishing a theory of administration for the new school executive, with focus on teachers.

Addresses and supports

Herzberg Theory (Chapter 6).

Sources of job satisfaction and dissatisfaction for community education coordinators, using Herzberg Theory and research.

Sarmpled 45 conmunity coordinators in six states; used personal interviews and critical incident techniques.

Synthesis of research on teacher motivation

Focus on Herzberg and Vroom Theories - combines the two theories: The Job Factors Approach. and the Expectancy Approach

An empirical investigation and an attempt to reconcile both the one- and two-factor theories of job attitudes.

Compared Herzberg method of question with Job Description Index.

Sampled 550, $18 \%$ response rate (some teachers); used a fourpart questionnaire.
Job-related factors provide satisfaction; context-related factors determine dissat isfaction. Choosing attainable sources of satisfaction is more satisfying than choosing more difficult ones to attain -context related is more attainable than job related. Supports Herzberg.

Establishes franework for an organizational directed toward employee job satisfaction.

Confirms study of job satisfaction as a social indicator for three reasons.

Some factors are polar in a positive direction; some are polar in a negative direction.

Suggests that we have misjudged what really makes a difference in stimulating teachers to improve their performance.

Finds that Herzberg motivation hygiene theory can be applied to community education coordinators. Achievement, recognition, and interpersonal relations with subordinates were factors serving to motivate to high level job performance.

Addresses two theoretical frameworks: Herzberg job factor theory and Vroom's expectancy theory as important to research and practice. Silver combines the two franeworks.

Replication of the motivationhygiene theory instrument reveals the same need categories of motivators and ingienes. The theory is found to be a function of its own methodology. 
Sparks, D.C.

1979

Michigan

Sweeney, J.

1981-82

I owa

Sweeney, J Winter, 1981 Iowa

Villeme, M.G. and 1980

Florida

Vroom, V.H.

1966

Illinois

Wang berg, E.G.

Metzger, D.J. and

Levitov, J.E.

1982

New Orleans

Wernimont, P.E.

1966

Minnesota
A biased look at teacher job satisfaction

Sampled 50 teachers, response of $88 \%$; used questionnaires

Burnout remedies -- professional discretion and teacher job satisfaction

Sarmpled 23 Iowa high schols $(N=1295)$; used questionnaire

Teacher dissatisfaction on the rise: higher level needs unfulfilled

Sampled 1295 secondary teachers in three Iowa secondary schools; used questionnaire

The relation of teacher attitude to major, employment status, teaching level, and satisfaction with first-year teachers.

Sampled 468 ed. grads.; response 5.7६; used MAAI and Likert-type education scale

Observations regarding Herzberg's Two-Factor Theory

Working conditions and career options lead to female elementary teacher job dissatisfaction.

Sampled 208 of fenale teachers from four school districts $(\mathrm{N}=255) 65 \%$ respone rate;

used questionnaire

Intrinsic and extrinsic factors in job satisfaction of accountants and engineers, attermts to shed light on how different factors of job attitudes operate.

Sampled 132 accountants and engineers, used forced-choice and free-choice item responses, based on Herzberg Theory.
Forty-six percent of respondents are dissatisfied with their jobs, and an equal amount confin that they would not choose to enter teaching if they could do it all over again.

Teacher needs for esteem and self-actualization are in "worst condition." Teachers feel a lack of prestige and accomplishment.

Greatest need category is esteem and self-actualization. As age of teacher increases need deficiency decreases. Schools are not meeting higher level needs of secondary teachers and needs deficiencies appear to be increasing.

The attitude a new teacher holds is more affected by the level ai which the teacher is teaching more than it is by the type of training the teacher has received.

Says Herzberg's Theory is ambiguous, open to varying interpretations.

Forty percent indicate they would not rechoose elementary teaching. Major factors of dissatisfaction are working conditions and perceptions of women's role in professions.

Results of study differ from those of Herzberg. Finds that either extrinsic or intrinsic factors can result if feelings of satisfaction or dissatisfaction. In this study, the five strongest dissatisfiers are the identified intrinsic factors. 
Williamson, T.R.

1970

Ohio

Young, I.P. and Davis, B.

1983

National study
Job satisfaction variables among female clerical workers

Sampled 34 female workers; asked to rank 10 job characteristics (Burke, 1966, replication)

Considers Herzberg theory for the 10 characteristics (Burke, 1966, replication)

Ranking for self and opposite sex and same sex

The applicability of Herzberg's Dual-Factor Theory for Public School Superintendents.

Sampled 100 , response of $72 \%$; used semantic differential, based on concepts and rating scales.
Disagrees with Burke.

Finds a basic difference between two female groups. College female rank motivators higher for "self" than female clerical workers do. College female have greater need for self-actualization and have greater anticipation of opportunities for advancement and higher responsibilities and other motivators than do the clerical females.

Recormends use of other than Herzberg Theory for research of educators, as group specific theory. Says what is needed is an overall theory appropriate for all educational employees. 
APPENDIX C

\begin{tabular}{|c|c|c|c|c|c|}
\hline \multicolumn{3}{|c|}{ MOTIVATORS - INTRI NSIC FACTORS } & \multicolumn{3}{|c|}{ HYGIENES - EXTRINSIC FACTORS } \\
\hline II. 1 & III. 1 & IV. 1 & II. 7 & III .4 & IV.12 \\
\hline 2 & 2 & 2 & 8 & 5 & 17 \\
\hline 3 & 3 & 3 & 9 & 8 & 18 \\
\hline 4 & 6 & 8 & $10^{* *}$ & 9 & 19 \\
\hline 5 & 7 & 9 & 11 & 12 & 20 \\
\hline 6 & 10 & $10 *$ & 12 & 13 & 22 \\
\hline 19 & 11 & $11 *$ & 13 & 14 & 24 \\
\hline 23 & 15 & 13 & 14 & 17 & 25 \\
\hline 24 & 16 & 14 & 15 & 18 & 42 \\
\hline \multirow[t]{14}{*}{25} & 20 & 15 & 16 & 19 & 43 \\
\hline & 22 & 16 & 17 & 21 & \\
\hline & 23 & 23 & 18 & & . \\
\hline & 24 & 26 & 20 & & \\
\hline & 25 & 27 & 21 & & \\
\hline & & 28 & 22 & & \\
\hline & & 29 & & & \\
\hline & & 30 & & & \\
\hline & & 31 & & & \\
\hline & & 32 & & & \\
\hline & & 40 & & & \\
\hline & & 41 & & & \\
\hline & & 44 & & & \\
\hline & & 46 & & & \\
\hline \multicolumn{3}{|c|}{$\begin{array}{l}\text { *I tems IV. } 10 \text { and } 11 \text { are consid- } \\
\text { ered as motivators - intrinsic } \\
\text { factors related to work itselff } \\
\text { and work or interpersonal rela- } \\
\text { tions with students accord } \\
\text { with Lortie theory that students } \\
\text { and work with students offer } \\
\text { primary intrinsic or psychic } \\
\text { rewards for teachers. }\end{array}$} & \multicolumn{3}{|c|}{$\begin{array}{l}\text { **I tem II.10 is considered } \\
\text { as a hygiene - extrinsic } \\
\text { factor in accord with Herzberg } \\
\text { theory as an adjustment of in } \\
\text { interpersonal relations - } \\
\text { subordinates, now construed to } \\
\text { mean interpersonal relations - } \\
\text { siudents (Moxley, 1977; } \\
\text { Sergiovanni, 1966). }\end{array}$} \\
\hline
\end{tabular}




\section{TEACHER STUDY QUESTIONNAIRE}

Dear Colleague: The purpose of this questionnaire is to gain more insight into the personal attitudes and feelings of teachers about teaching. We hope to be able to learn more about your primary areas of satisfaction and dissatisfaction and what is most important to you as a teacher. This information should be very helpful as wo work together to consider ways to change or improve our educational system.

Your help is very important if this study is to give an accurate description of the attitudes and feelings of teachers in our school classrooms.

All individual responses will be confidential, to be used for statistical data analyses. The compiled results will be made available, upon request and completion of the stucty, to all who participate.

Thank you so much for your time and cooperation in helping with this study. When you finish your responses, seal the questionnaire in the envelope and return it to your school office - WITHIN FIVE DAYS. The sealed envelopes will be collected and returned to:

Laura L Porko

c/o School oi Education

Portland State University

Portland, Oregon 


\section{PART I}

Bsckground Intormation: Circle the letter or write in the appropriate response to the following items of background information about you:

1. Sex
A. Fernale
B. Male

2. Age (at last birthday):
A. $20-25$
F. $46-50$
B. $26-30$
G. $\quad 51-55$
C. 31-35
H. $\quad 56-60$
D. $36-40$
l. 61-65
E. $\quad 41-45$
J. Over 65

3. Marital status:
A. Never married
C. Divorced
B. Married
D. Widowed

4. Highest earned academic degree:
A. Bachelor's
B. Mester's
C. Doctoral

5. How old were you when you first entered teaching?
A. $20-25$
B. $26-30$
C. $31-35$
D. $36-40$
E. $\quad 41-45$
F. Over 45

6. Total years in teaching:
A. $1-5$
E 21-25
B. $6-10$
F. $26-30$
C. $11-15$
G. $31-35$
D. $16-20$
H. More than 35

7. In how many separate districts have you taught?
A. One
D. 6-7
B. $2-3$
E. More than 7
C. $4-5$

8. In how many separate schools have you taught?
A. One
D. 6-7
B. $2-3$
E. Morethan 7
C. 4-5

9. Do you have tenure in your present position in your present district?
A. Yes
B. No

10. How many years have you taught in the district where you now teach?
A. $1-5$
E. $21-25$
B. $6-10$
F. $26-30$
C. $11-15$
G. $\quad 31-35$
D. $16-20$
H. More than 35

11. How many years have you taught in the school where you now teach?
A. $i-5$
E. 21-25
B. $6-10$
F. $26-30$
C. $11-15$
G. 31-35
D. $16-20$
H. More than 35

12. What is the approximate number of students in your school?
A. Fewer than
100 students
B. 100 to
200 students
C. 201 to 500 students
D. 501 to 800 students
E $\quad 801$ to 1,000 students
F. 1,001 to 1,500 students
G. Morettran 1,500 students

13. What is your present grede level of teaching assignment?
A. Pre-K-K
B. 1-3
E $\quad 7-9$
C. $4-6$
F. $9-10$
D. 6-8
G. $11-12$
H. $9-12$

14. If you teach a specific subject area, what is your major aree of assignment?
A. Social studies/history/civics
B. Language arts/speech/literature
C. Science/mathematics
D. Health/physical education
E. Art/music
F. Business/vocational or career ed.
G. Other:

15. In general, what ability/achievement level students are you now teaching?
A. Very slow learners
B. Slow learners or underachievers
C. Average ability/achievement
D. Above average abllity/achievement
E Extremely high/gifted ability or achievement
F. Mixed ability or achievement

16. If your mejor teaching assignment involves work with a special student population, please indicate:
A. Handicapped
D. Chapter I
B. ESL-Bilingua
E. Alternative Progrer
C. Talented and Gifted F. Other

17. Do you hold any other position outside of your job as a teacher for which you recoive salary or wages?
A. Yes
B. No 
PART II

Teaching Factors: After each of the following items, circle the letter in the appropriate column to indicate if you are: (A) VERY SATISFIED, (B) SOMEWHAT SATISFIED, (C) NEITHER SATISFIED NOR DISSATISFIED, (D) SOMEWHAT DISSATISFIED, (E) VERY DISSATISFIED with that aspect of your position and role as a teacher:

\begin{tabular}{|c|c|c|c|c|c|c|}
\hline & TEACHING FACTOR & 点恶 & 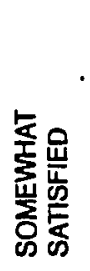 & 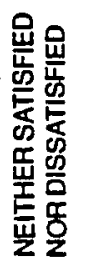 & 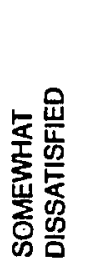 & 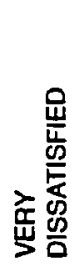 \\
\hline 1. & Sense of achieverrent & A & B & C & D & E \\
\hline 2. & Amcunt of recognition you recoive & A & $\mathbf{B}$ & C & D & $\mathbf{E}$ \\
\hline 3. & Teaching itself as a kind of work & A & $\mathbf{B}$ & C & $D$ & $E$ \\
\hline 4. & Amount of respocisibillity you have & A & B & C & D & $E$ \\
\hline 5. & Opporturitty for advancement & A & 8 & C & D & $\mathbf{E}$ \\
\hline 6. & Opportunity to grow and develop in your job & A & B & C & $D$ & $\mathbf{E}$ \\
\hline 7. & Salary & A & B & C & D & $\mathbf{E}$ \\
\hline 8. & Interpersonal relations with your supervising administrator & A & B & C & D & $\mathbf{E}$ \\
\hline 9. & Interpersonal relations with your fellow teachers & A & B & c & $D$ & $E$ \\
\hline 10. & Interpersonel relations with your students & A & B & C & D & $\mathbf{E}$ \\
\hline 11. & $\begin{array}{l}\text { Interpersonal reiations with the parents of your students and members of the } \\
\text { community }\end{array}$ & A & B & C & D & $\mathbf{E}$ \\
\hline 12. & Amount of status you have as a teacher & A & B & $\mathrm{C}$ & D & $\mathbf{E}$ \\
\hline 13. & Supervision/professional compatence of the administrator to whom you report & A & B & C & D & $\mathbf{E}$ \\
\hline 14. & Policies and practices of your school district & A & B & C & D & E \\
\hline 15. & Policies and practices of your school & A & B & C & D & $\mathbf{E}$ \\
\hline 16. & Working conditions in your school & A & B & C & D & $\mathbf{E}$ \\
\hline 17. & Personal life as affected by your work as a teacher & A & B & C & $D$ & E \\
\hline 18. & Job security & A & B & C & $D$ & $E$ \\
\hline 19. & Opportunities to help others in your job as a teacher & A & B & C & $D$ & $E$ \\
\hline 20. & Amount of time you spend preparing for teaching & A & $\mathbf{B}$ & C & $D$ & $E$ \\
\hline 21. & Amount of time you spend teaching your students & A & $\mathbf{B}$ & C & D & $E$ \\
\hline 22. & $\begin{array}{l}\text { Amount of time you spend on school related activities outside of classroom } \\
\text { preparation and teaching students }\end{array}$ & A & B & C & D & $E$ \\
\hline 23. & Amount of autonomy you have in your position & A & B & C & D & E \\
\hline 24. & All in all. how satisfied are you with your present job or assignment in teaching? & A & $\mathbf{B}$ & c & $\mathbf{D}$ & $\mathbf{E}$ \\
\hline 25. & All in all, how satisfled are you with your role as a teacher? & A & 은 & C & D & E \\
\hline
\end{tabular}




\section{PART III}

Importance Rating: After each of the following items, circle the letter in the appropriate column, to indicate if the item is: (A) VERY IMPORTANT, (B) SOMEWHAT IMPORTANT, (C) NEITHER IMPORTANT MOR UNIMPORTANT, (D) SOMEWHAT UNIMPORTANT, (E) VERY UNIMPORTANT to you in your role and position as a teacher:

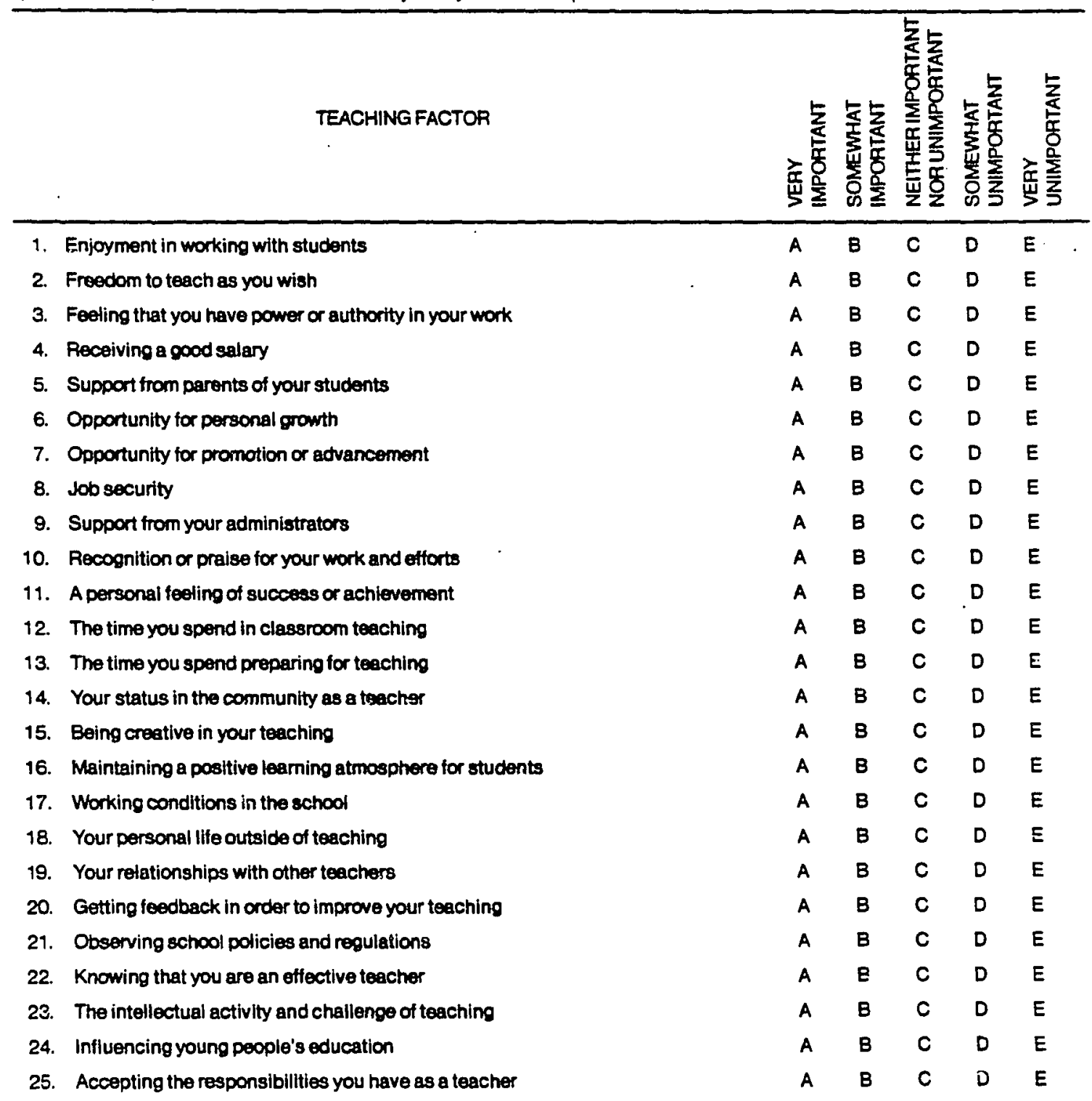




\section{PART IV}

Personal Attitudes and Feelings About Tesching: This section of the questionnaire deals more personally with the attitudes and feelings you hold about yourself as a teacher and the teaching profession. For each item, circle the letter of the response most closely matching your own feelings and attitudes.

1. If you had your choice of jobs in any fietd, which would you select?

A. Your present job as a teacher

B. Another job in the field of public education

C. Another job in another field outside of public education

2. If you had your choice of jobs in the field of public education, which would you select?

A. Your present job as a classroom teacher

B. A job as a school building administrator

C. A job as a school district administrator

D. Another job outside of the classroom or administration

3. If you had it to do all over again, would you still become a teecher?
A. Definitely become a teacher again
B. Probably become a teacher again
C. Uncertain about becoming a taacher again
D. Probably not become a teacher again
E Definitely not become a teacher again

4. When you became a teecher, how qualified did you feel you were at that time to get some other job outside of teaching?

A. Very well qualified

B. Somewhat qualified

C. Uncertain about my qualifications

D. Somewhat unqualified

E. Very unqualified

5. If you wanted to do so now, how qualified do you feel to get a job outside of teaching?
A. Very wetl qualififed
B. Somewhat quallfied
C. Uncertain about my qualifications
D. Somewhat unqualified
E. Very unqualified

6. In general, how has your role as a teecher fulfilled the expectations you had when you first decided to become a teacher?
A. Far above my expectations
B. Above what l expected
C. About what l expected
D. Below what l expected
E Far below what l expected

7. If you had your choice, what ability/achievement level of students would you prefer to teach?
A. Far below ayerage
D. Somewhat above average
B. Somewhat bolow average
E. Far above average/gifted
C. Average
F. Mixed ability or achievement

8. How much pleasure do you get from teaching?
A. Great pleasure
B. Some picasure
C. Noither pleasure not displeasure
D. Some displeasure
E Great displessure 
PART IV (continued)

9. How do you think other teachers would describe you as a teacher?
A. Very good or Outstanding
B. Above average
C. Average - neither good nor poor
D. Below average
E. Very poor

10. How much do you like working with the students you have in your classes this year?
A. A great deal
B. Quite a bit
C. O.K. I guess
D. Some dislike
E. Great dislike

11. In general, how would you describe the studerits you work with today?
A. A pleasure to work with
B. Generally good to work with
C. O.K. to work with
D. Sometimes difficult to work with
E. Very difficult to work with

12. How pleasant is your school as a place in which to teach and work?
A. Very pleasant
B. Somewhat pleasant
C. Nolther pleasant nor unpleasent
D. Somowhat unpleasant
E. Very unpleasant

13. How often are you able to maintain a positive learning climate for your students?
A. Able almost all of the time
B. Able more than half of the time
C. Able about half of the time
D. Able less than half of the time
E Seldornor never able

14. In general, how has the teaching profession - as you now view it - fulfilled the expectations you had when you first decided to enter teaching as a profession?
A. Far above my expectations
B. Above what l expected
C. Abcut what l expected
D. Below what I expected
E. Far below what l expected

15. How often do you have the opportunity to design your own instructional programs and teach your students more or less as you choose?
A. All or almost all of the time
B. More than hall of the tima
C. Maybe half of the time
D. Less than half of the time
E. Seldom or never

16. How successful are you in meeting the intellectual needs of your students as individuals?
A. Successful with all or almost all of the students
B. Successful with more then half of the students
C. Successful with about helf of the students
D. Successful with less than half of the students
E. Successful with very few or almost none of the students 
PART IV (continued)

17. As a teacher, how much support do you have from the parents in your school community?

A. Great support

B. Above average support

C. About average support, I guess

D. Less than average support, some lack of support

E. Great lack of support

18. How do you rate the professional competence of your supervising administrator?
A. Very compotent
B. Above average competence
C. Average competence
D. Below average competence
E. Very incompetent

19. How much professional suppori do your building administrators give you?
A. Support far beyond my expectations
B. Above average support
C. About what l expoct
D. Less than average support, some lack of support
E. Support far below my expectations, great lack of support

20. How often do you and your fellow teachers tend to agree on standerds for teeching?
A. Agree almost all the time
B. Agree more than we disagree
C. Agree maybe half of tha time
D. Disagree more than we agree
E Disagree aimost all the time

21. As a teacher, if you could have twe more hours a weok to devote to the field of education, which of the following would be your first choice for the extra time?
A. Curriculum committee
E. Individual student tutoring
B. Lesson planning
C. Community relations
F. School policy committee
D. In-class teaching
G. Parent conferences
H. Extra-curricular student activities

22. If you had your choice, how often would you have parents participate in classroom and school related decision-making and activities?

A. Very often - as often as possible

B. More often than they do now

C. About as often as they do now

D. Less often than they do now

E. Seldom or never

23. How do you think the parents of your students would describe you as a teecinar?
A. Very good or outstanding
B. Above everass
C. Average - neither pood nor poor
D. Below average
E Very poor

24. How secure do you feel in your job as a teacher?
A. Very secure
B. Quite secure
C. Not cortain - O.K., I guess
D. Quite insecure
E. Very insecure 
PART IV (continued)

25. How would you describe your relationships with other teachers?

A. My closest triends are other teachers, in and out of school

B. I spend some social time outside of school with other teachers

C. I associate freely with other teschers, but only during school time

D. I have very few personal contacts with other teachers

E. I do not have personal contects with other teachers

26. How do you think your students would describe you as a teacher?
A. Very good or outstanding
B. Above average
C. Average - nelther good nor poor
D. Below average
E. Very poor

27. All in all, how successful do you feel as a teacher
A. Very successful
B. Quite successiul
C. Mixed feelings about being successful
D. Cluite unsuccessful
E. Very unsuccessful

28. How much positive or negative feedback as a teecher do you receive from fellow teachers?
A. A great amount of positive feedback
B. More positive than negative feedback
C. About equal amounts of positive and negative feedback
D. More negative than positive feedback
E. A great amount of negative feedback

29. How much positive or negative feedback as a teacher do you recelve from the parents of your students or others outside of the field of education?
A. A great amount of positive feedback
B. More positive than negetive feedbeck
C. About equal amounts of positive and negative teedback
D. More negative than positive feedback
E. A great amount of negative feedback

30. How much positive or negative feedback as a teachs, do you receive from your immediate supervisor or administrator?
A. A great amount of positive feodback
B. More positive than negative feedbeck
C. About equal amounts of positive and negative feedback
D. More negative than positive feedback
E. A great amount of negative feedback

31. How much do you think being a teacher has contributed to your growth as a person?
A. A great deal
B. Quite a bit
C. Moderately
D. Slightly
E. Very little, if at all

32. How much do you think you have echieved as a teacher?
A. A great deal - more than l expected
B. Qulte a bit - above average
C. Moderately - about what l expected
D. Not very much - below average
E. Little or nothing - much less than I expected 
PART IV (continued)

33. If you were offered a promotion to another position in your school or district that would take you out of the classroom, what do you think you would do?

A. I would definitely accept

B. I would probably accept

C. I would hesitate and wonder what to do

D. I would probably refuse

E. I would dofinitely rafuse

34. If you were offered a promotion to another position in your school or district that would take you out of the classroom, how do you think you would feel?

A. I would fee! real loss if I left the clessroom

B. I would feel some loss if I left the classroom

C. I would have mixed feelings if I left the classroom

D. I would feel some gain if I left the classroom

E. I would feet real gain if I lett the classroom

35. How likely is it that you will initiate an effort to leave teaching for scrire other position in public education within the next year?
A. Not likely
B. Somewhat likely
C. Very likely

36. How likeiy is it that you will initlate an effort to seek another job outside of public education within the next year?
A. Not likely
B. Somowhat likely
C. Very likely

37. Where do you hope to be protessionaily in five years?
A. Teaching
B. Promoted in the field of public education
C. In arother position outside of public education
D. Not working (by choice)

38. Which of the following indicators do you rely on most to gauge the effectiveness of your teaching? (Choose only one)
A. Reactions of other teachers familiar with your work
B. Opinions expressed by your students generally
C. Assessments made by the principal
D. Assessments made by a chairperson or team leader
E. Results of student examinations and various other tests
F. Reactions from parents of students
G. Your own opinions and assessments

39. As far as getting insights and ideas as a teacher, which of the following is most useful to you? (Choose only one)
A. Inservice courses given by the school system
8. Informal conversations with colleagues and friends
C. Educational magazines and boots
D. Educationel media (films, television, video-tapes, etc.)
E. Meetings you attend in your school district
F. Moetings you attend outside of your school district
G. Coursework given by a college or university
H. Your immediate supervisor 
PART IV (continued)

40. How much opportunity do you feel you have for your continuing education or professional growth as a teacher?

A. Great opportunity

B. Good opportunity

C. Moderate opportunity

D. Lack of opportunity

E. Great lack of opportunity

41. How much incentive do you have to continue your education or professional growth?

A. Great incentive

B. Good incentive

C. Moderate incentive

D. Lock of incentive

E. Great lack of incentive

42. How would you describe management and employee relations in your district?

A. Excollent or very good

B. Generally good

C. Sometimes good - sometimes not

D. Generally not good

E. Seldom or never good

43. How would you describe management and emplovee relations in your school?

A. Excellent or very good

B. Generally good

C. Sometimes good-sometimes not

D. Generally not oood

E. Seldom or never good

44. How much do you like to try something "new" in the cisssroom?

A. I tend to be one of the first to try something "new" in the classroom

B. I tend to wait a while before I try something "new" in the classroom

C. I tend to be one of the last to try something "new" in the classroom

45. Of the following, what factor - more than any other - would influence you to change a long-time practice or behavior pattern essociated with your teaching?

A. More money

B. The knowledge that it would be "good for kids"

C. A "mandate" or similar requirement from either the school board or the administration

D. The fact that it's "new," and you want to try it

46. Which of these statements comes closest to describing your feelings about teaching?

A. I am extremely satisfied with teaching as my occupation

B. I am very satisfied with teaching as my occupation

C. I am more satisfied than not with teaching as my occupation

D. I Im neither satisfied nor dissatisfled -1 guess l'm in the middle

E. I am more dissatisfied than satisfied with tesching as my occupation

F. I am very dissatistied with teaching as my occupation

G. I am extromely dissatisfied with teaching as my occupation

47. Of the following, which is the most important source of satisfaction for you in teaching?
A. The opportunity to sturdy, read, and plan for classes
B. The chance to devetop masten; of discipline and classroom management
C. The times I know I have "reached" a student or group of students as each laams
D. The chance to associate with children or young people and relate with them 
PART IV (continued)

48. Of the following, which is the most important source of satisfaction to you?

A. The chance to grow personally

B. The salary l earn in my profession as a teacher

C. The status I have in the community as a teacher

D. The recognition I receive as a teacher

E. The opportunity to teach children or influence student learning

49. Of the following, which is the most important source of satisfaction to you?

A. The relative security of income and position

B. The vacation times which can permit travel, study, family activities, etc.

C. The opportunity to eam a living without much competitton or interterence

D. The special "rigtitriess" of my position for me

E The sense of achievement I have as a teacher

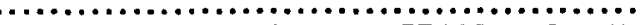
PLEASE WRITEIN YOUROWN BRIEF RESPONSES TO THE FOLLOWING QUESTIONS:

50. What gives you the most satisfaction as a teacher?

51. What gives you the mast dissatisfaction as a teacher?

52. What was your primary reason for becoming a teacher?

53. What is your primary reason for staying in teaching?

54. Of the various things you do as a teacher, what is most important to you?

55. Of the various things you do as a teacher, what is loast important to you?

56. What one change might increase your satlsfaction as a teacher?

57. What do you think you have lost by being a teecher?

58. What do you think you have gained by being a teacher?

Thank you for completing this questionnaire! Please seal it in the envelope for return to Laura L. Porko, c/o Portland State University, School of Education. The information will be confidential, to be used for statistical data analyses. 
APPENDIX E

TEACHER STUDY QUESTIOHIIAIRE

Dear Colleague: In the last several years great changes have taken place in society and our educational system as well. Hany of these changes have required that all of us in ceaching $=$ :-pond to unexpected challenges and at times, stresses, as weli. ihe purpose of this study is to gain more insight into way these changes have affected the teaching process and mist particularly how they have shaped the feelings and goals of teachers. Your assistance is needed vezy much if this study is to in any way provide an accurate description of the teachina profession today. Of cousse, all answers wili be confidential. The final compiled results will, havever, be shared with all persons participating in this study.

Thank you for your cooperation and help with this study.

D.. Lynda C. Fa!kenstein, Portland state Universizy 
PaIt I:

Background Information. Please fill in and/or circle the appropriate response to the following items.

1. Your gender:

A. Ferale

B. Male

2. Your aze:
A. $20-25$
B. $26-30$
C. $31-35$
D. $36-40$
E. 41-45
F. $46-50$
G. $51-55$
H. $56-60$
I. Over 60

3. Years in teaching:
A. $1-5$
D. $2 I-30$
B. $6-10$
E. $31-40$
C. $11-20$
E. More than 40

4. Marieal status:
A. Married C.
C. Widowed

B. Singl.

Divorced

5. How many years have you taughe in the districe in which you are presently employed?

A. $1-5$ E. 21-25

B. $6-10$ F. $26-30$

C. $11-15$ G. 31-35

D. $16-20$ H. More than 55

6. How many years have you taught in the school in which you are presently assigned?

i. $1-5$ E. $31-40$

B. 6-10 F. More than 40

C. $\quad 11-20$

D. $21-30$

7. In how many different schools have you taught?
A. $1-2$
D. $7-8$
B. $3-4$
C. $5-6$
E. More than 8

8. In how many separate districts have you taught?
A. $1-2$
B. $3-4$
C. $5-6$
D. $7-8$

9. Is your salary the major means of support for you and/or your family?

A. Yes

B. No
10. What is your present yadzlevel teaching assignment?

A. $1-3$ D. $10-12$

B. $4-6$ E. Othe:

C. 7-9

11. What is the approximate size of your school district?

A. 1,000 seudenes or under

B. $1,001-5,000$ students

C. $5,001-10,000$ students

D. $10,001-20,000$ seudents

E. $20,001-35,000$ students

F. Over 32,000 students

12. If you are a junior inigh or secondary teacher, what is your major area of respons. bility?

A. Social studies/history civics

B. English/language ares/ speech

C. Science/math

D. Health/ghjoical eduati....

E. Art/mugic

F. Business/vocationai

G. Other

13. Is your school:

A. Public

B. Private

14. Are you presenty taking

any college/university

courses related to sudr job?

A. Yes

B. No

15. Are you pregeitly taking an: in-gervices courses. to your job?

A. Yes

B. No

16. What is the higheit acaderi: degree which you hold?

A. Bachelor's

B. Master's

C. Doctorate 
pag:2 2

17. In genaral, what achievement andor ability level student

are you presently taaching?

A. Very slow learrats

B. Slow learners and/or underachievers

C. Avezage ability/achievement level

D. Above average learners/ high achievement level

E. Extremely high/gifted levels of ability/achievement.
PART II. The second part of this questionnaire concerns attitudes and feelisgs you personally hold about the profession. Please mart: the responses most closely matchic: your own.

25. How much has your reaching styl: changed since you started teaching?

A. Not at ail D. A great

B. Somewhat

C. A fait anount

18. Apgrorimately how old were you when you first entered teaching?
A. 20-25
C. $36-45$
B. 26-35
D. Over 45

19. How many jobs outside the teaching professior have you held as an adule?
A. None
C. 3-4
B. 1-2
D. 5
E. More than 5

20. When was the last time you enrolled in college/university or in-service course-work related to your job?

A. Within the last 2 gears

B. Between 3 and 5 yearg ago

C. Between 6 and 10 yea=s $a g 0$

D. Between 11 and 15 years ago

E. Nore than 15 years ago

21. Do you have tenure in your present position?
A. íes
B. No

22. Do you hold any official responsibility in addition to teaching, e.8. (coach, department head)?

A. Yes B. No please indicate for how many years you have been tenured.
A. $1-5$
D. $21-30$
B. $6-10$
E. More than 30
C. $11-20$
F. Dossn't apply

24. If the answer to \#22 is yes, indicate what that responsibility is.

A. Department head E. Other

3. Tean leader

C. Director of a grojram

D. Cosc!i

29. If you had it to do over again, would you still ence; teaching?

A. Never choose teaching

B. Would still congicer it as an option but probably not take it up

6. Hon much jo you like to try "zew" things in the classroom?
A. Vot at a!l
B. Somewhat
D. A great
C. A fair amount dea 1

27. When a new way of teaching or aew textbook is suggested do you :

A. Ask immediately to $t=y$ it

B. Expect it will be a good idea

C. Prefer to wait to see is it works out

D. Feel most such ideas are fads and not want to $0 \geq$ : involved

28. How interesting to you find

teaching?

A. Nor at at?

B. A little

C. Quite a bit

A great deal

c. Would consider teaching as a good option

D. Most probabiy choose teaching

E. Definitely choose teaching 
page 3

30. Compared to whes you first started yout carets how interesting do you find your ceaching today? A. Much more interesting

B. More interesting

C. About the sane

D. Less interesting

E. Much less interesting

31. How good do you think most other teachers are?

A. Extremely good

B. Good

C. Average

D. Not very good

E. POOI

32. What ability/achievement-level of student would you prefer to ceach.if the choice were entirely up to you?

A. Extremely low

B. Lower than average

C. Average

D. Above average

E. Highest/gifted levels

33. Compared to when you started your career do you enjoy your job:

A. Yuch more

B. Jomewhat more

C. About the same

D. Somewhat less

E. A great deal less

34. How much do you think most other teachers enjoy their work?

A. A grear deal

B. Quite a bit

C. An average amount

D. Not very much

E. Not at all

35. How would other teachers describe you as teacher?

d. The best

B. Very good

C. Good

D. Average

E. Below averaze

F. POOI
36. How much do you like working with the kind of stuuents yut have today?

A. A great deal

B. Quite a bit

C. An average amoune

D. Not very much

E. Not at all

37. On the whole. how wavld ynu describe studentg today?

A. "A pleasure" to wo:k with

B. Gererally good

C. Ok to work with

D. Sometimes difficul:

E. Very hard to work with

38. Have you ever rinidered

leaving teaching?

A. Yes

B. No

39. If your answer to $\$ 38$ is yes please indicate how often.

A. Does not apply

B. A few times a year

C. About once a month

D. At least once a week

E. Other

40. How many career options did you seriously consider before choosing teaching?

A. A great number

B. Several

C. Some

D. Not very many

E. No others

41. Did you have another job and then switch to teaching?

A. Yes

B. No

42. If yes, was the job

A. Clerical

B. Professional

C. Skilled

D. Other 
page 4

43. To what extent are you free to

do (mote or lesg) what you wane

in che class room?

A. A zaeat deal

B. Quitc a bit

C. An average amount

D. Not very

E. Not at a1d

44. How much power as a teacher do you feel you have over students?

A. A great deal

B. Quite a bit

C. An average amount

D. Not very much

E. None at all

45. How much power do you feel you have as a faculty menber - in relacion to the policy and direction of your school?

A. A great deal E. None at all

B. Quite a bit

C. An average amount

D. Not very much

46. Do you have to augment your salary with an outside job?

A. Yes

B. No

47. Do you have a spouse who also works?

A. Yes

B. No

C. Does not apply

48. Generally speaking, how good a job do you think parents are doing today in preparing their children to work in school?

A. An extremely good job

B. A good job

C. in average job

D. A below average job

E. A poot job

49. How do you think pirents of your students would describe you as

a teacher?

A. The best

B. An above average teacher

C. An average teacher

D. A below average teache:

E. A poor teacher
20. If you decided to change pro-

fessions, how easy do you

think it would be for you to

find another job?

A. Extzemely easy

B. Fairly easy

C. Average difficulty

D. Extremely difficult

E. Impossible

51. How would you describe your relationship with fellow teachers?

A. My closest friends are other teachers?

B. I get along well with teachers in school and see a few socially

c. I only see other teachers in school

D. I have no personal contacts with other teachers

52. How secure do you feel about your job?

A. A great deal

B. Quite a bit

C. An average amount

D. Not very

E. Not at all

53. How much do you think being a teacher has contributed to your personai growth?

A. A great deal

B. Quite a bit

C. An average amount

D. Not very much

E. Not at all

54. If rou had your choich, would you go into t-aching again?

A. Y Yes

B. No

55. How supportive of your efforts do your local building admin-

iserators seen to ha?

A. A great amount

B. More than averase

C. An average amourt

D. Below average

E. Not supportive at all 
56. How much praise aboit your teaching do you receive from iellow teachers, students, parents oz administzators?

A. A $g=e a c$ amount

B. Mor than averaze

C. Averaga amount

D. Below average

E. None at a 11

57. Hou successful do you Eeel as a teacher?

d. Extremely successful

B. Above average suceesstul

C. Successful

D. Not very successful

E. Very unsuccessful

58. Gerezally, how much do you like scuden $s$ coday?

A. A great deal

B. Above average

C. An averaze amount

D. Not very much

E. Don't like them senerally

59. Compared to when you first started teaching do you like students:

A. A great deal more

B. A lierle more

C. The same as you used to

D. Less

E. A great deal less

60. Compared to when you started teaching do you like your job:

A. A great deal wore

B. A litcle more

C. The same as you did

D. Less

E. A great deal less

61. Hor easy do you think it would be

for your school to replace you?

A. Extremely easy

B. Easy

C. Average difficuley

D. Difficule

E. Infossible

62. If you aze married or living with sopeone, how does that person

Eeel about your teaching job?

A. Extremeiy pleased with it

B. Generally likes it

C. Eeels it's ok

D. Doesn't care for it too much

E. Doesa't like it at all

E. Does not apply
63. How successeul as a teacher do you thint others think you are?

A. Extrenely suce :sful

B. Generally successful

C. Average euccessEul

D. Unsuccessful

E. Very unsuccessfu1

64. How much would you like to be promoted?

d. Very much "ish promotion

B. Would like promotion

C. Pümotion would be or

D. Probably wouldn't want it

E. Definitely don't want it

65. How much would you like to go into adminsitration?

A. A great denl

B. An avezage amount

C. Hould ba ok

D. Probably wot? In't want it

E. Definicely don't want work in administration

66. Generelly speaking, how do you feel about takisg more university course work?

A. Am very enthusiastic

B. Like tiie idea

C. It's ok

D. Don't particularly like the thought

E. Don't like the idea $a=$ all

67. How "brighe" do you thint. the najority of teachers are?

A. Excremely intellizent

B. Above averge in their intelizigence

C. Of average incelligence

D. Below average in their incelligence

E. Not very bright

Please go on to next page 


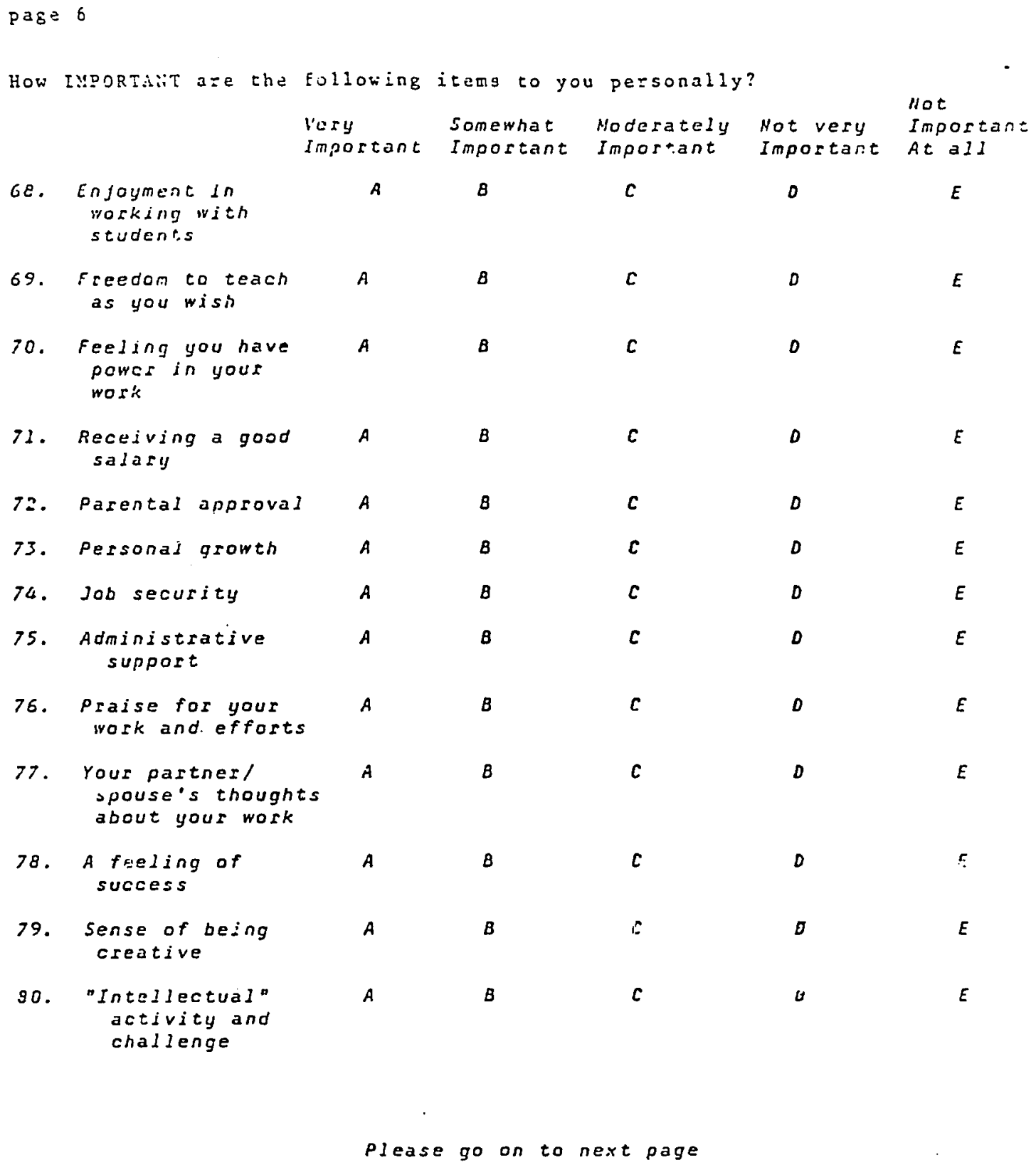


How much SATISFACTIOH do the rollowing items provide lievas a teacher and as a person?

$\begin{array}{llll}\text { A great Above average Average alow } & \text { Average } & \text { at } \\ \text { Deal amount } & \text { anount }\end{array}$

81. Your salary

A $B$

\section{B}

c

D

a 11
82. The summer
"vacation"
months

A B

c

o

$E$

83. Your students

84. Your colleagues

A

8

A

$B$

85. Feeling of influence $A$ over young people's

B

lives

85. Jab security

A

B

B

\section{D}

E

87. Feeling of being

A creative

88. Intellectual grouth $A$ and activity

$B$

$c$

$c$

c

0

$E$

$E$

o

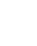

$E$

E

C D

C $D$

$\boldsymbol{E}$

88. Of the following items, which provides you the most satisfaction?

A. . The salary I earn in my profession

B. The respect I raceive from others

C. The opportunity to wield some influence

0 . I receive no satisfaction at ali from these things

89. Teachers can enjoy a variety of things in their work. Which of the

following is the most importint source of satisfaction for you?

A. The opportunity teaching gives me to study, read, and plan for classes

B. The chance it offers to develop mastery of discipline and classroom management

c. The times I know I have "reached" a student or group of stidents as they have learned

o. The chance to szsociate with children or young people and to develop relationships with them

E. The sense of being creative and learning haw to do things bette:

$F$. Hone of the above

G. Other 
page 8

90. Which of the following tnings do you like best about te. =hinn?

$A$. The relative security of income and position

B. The time (especially summer) which can permit travel, family activities, etc.

c. The opportunity it offers to earn a living rithout much ivalry and competition with other people

D. None of the above

E. Other

91. How free to change jobs do yau feel today?

A. I feel very free and would have many choices

0 . I feel relatively free and feel there are options for me other than teaching

c. I do not feel free very much and sense few options are out there for me at this point in my life

D. I do not feel at all free about changing jobs and don't feel any options for other jobs exist for me

92. How wrold you describe management and employee relations in your Oistrict?

A. Excedlent

B. Very good

C. $\operatorname{cood}$

D. Hot very good

E. Very negative

93. How would you describe management and employee relations in yout specific school?

A. Excellent

B. Very goad

C. Good

D. Hot very good

E. Very negative

94. Has your district ever been involved in a teacher's strike?

A. Yes

B. Ho

95. How would (or has) being involved in - strike affect your attitude about teaching?

A. It wouldn't bother me one way or the other

B. It would bocher me a bit in a negative may

C. It would bother me greatly in a negative way

D. It would probably make me feel better about teaching

E. It would make me feel much better ajout teaching

96. How much satisfaction do you get from "the act o: teaching" itielf?

A. A great deal

8. An above average amount

C. An average amount

D. A belor average amount

E. None at all 
pase 9

97. iriat facter moro ibur amy other would iniluence you to change a long-tinc prastice or behavior pattern assocjated with teaching?

A. Nore money

2. Knowledge that it would be "good far kids"

c. A "maniate" of similar requirement from either school board or administration

D. None of the above

E. Cther

98. Which of the statements comes closest to describing your feelings about taaching?

A. I am extremely satisfied with teaching as my occupation

B. I am very satisfied with teaching as my occupation

C. I am more satisfied than not with teaching as my occupation

D. I am equally satisfied and dissatisfied-I'm in the aiddle

E. I am more dissatisfied than satisfied with teaching as my occupation

F. I am extremely dissatisfied with teaching as my occupation

PART III Please resoond to the following questions:

99. What is the most important satisfaction you receive in your wo:k as a teacher?

100. Hhat are the "fun" things in your work?

101. What do you think you lose by being a teacher rather than in another line of work?

102. If you had it to do all over, what occupation would you choose?

103. Whesejdo you hope to be, professionally, in lo years?

104. Why do you think most of youz colleagues remain in teaching? 
page 10

105 Can you think of a.7j changes which might increase your satisfaction with teaching as an occupation?

106. Hhat makes you feel best about teaching?

107. What do you gain by being in teaching rather than in any other line of ivork?

THAIIK YOU VERY MUCH FOR COMPLETING THIS QUESTIOHAIIRE. FINAL

TALLIES AHD INTERPRETATIOHS OF COHSOLIDATEO DATA HILL BE PROVIDEN YUUR DISTRICT ADHIIIISTRATORS HITHIH A FEW HOHIHI. III THE EVEHT YOU IVISH TO RECEIVE A COPY OF THE WRITTEN REPORT FEFI FREE TO HRITE TO HE DIRECTLY.

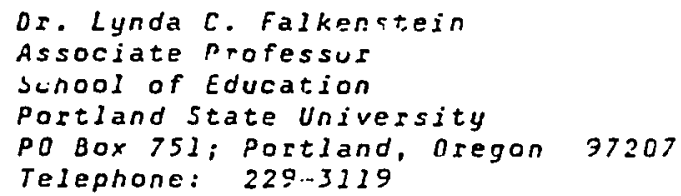


II.I Sense of Achievement (Motivator)

\begin{tabular}{|c|c|c|c|}
\hline \multicolumn{2}{|c|}{ Category } & Frequency & $\$$ \\
\hline \multirow{2}{*}{\multicolumn{2}{|c|}{$\begin{array}{l}\text { Very satisfied } \\
\text { Somewhat satisfied } \\
\text { Neither satisfied nor dissatisfied } \\
\text { Somewhat dissatisfied } \\
\text { Very dissatisfied }\end{array}$}} & $\begin{array}{r}531 \\
744 \\
76 \\
72 \\
9\end{array}$ & $\begin{array}{r}37 \\
52 \\
5 \\
5 \\
1\end{array}$ \\
\hline & & 1,432 & \\
\hline $\begin{array}{l}\text { Mean } \\
\text { Standard Deviation } \\
\text { Median } \\
\text { Range } \\
\text { Mode }\end{array}$ & $\begin{array}{l}1.802 \\
.802 \\
2.00 \\
4.00 \\
2.00\end{array}$ & & \\
\hline
\end{tabular}

II.2 Amount of Recognition Received (Motivator)

\begin{tabular}{|c|c|c|c|}
\hline \multicolumn{2}{|c|}{ Category } & Frequency & $\%$ \\
\hline \multicolumn{2}{|c|}{$\begin{array}{l}\text { Very satisfied } \\
\text { Samewhat satisfied } \\
\text { Neither satisfied nor dissatisfied } \\
\text { Samewhat dissatisfied } \\
\text { Very dissatisfied }\end{array}$} & $\begin{array}{r}226 \\
522 \\
335 \\
256 \\
93\end{array}$ & $\begin{array}{r}16 \\
36 \\
23 \\
18 \\
6\end{array}$ \\
\hline $\begin{array}{l}\text { Mean } \\
\text { Standard Deviation } \\
\text { Median } \\
\text { Range } \\
\text { Mode }\end{array}$ & $\begin{array}{l}2.628 \\
1.139 \\
2.00 \\
4.00 \\
2.00\end{array}$ & & \\
\hline
\end{tabular}

II.3 Teaching as a Kind of Work (Morivator)

\begin{tabular}{|c|c|c|c|}
\hline \multicolumn{2}{|c|}{ Category } & Frequency & 8 \\
\hline \multirow{2}{*}{\multicolumn{2}{|c|}{$\begin{array}{l}\text { Very satisfied } \\
\text { Somewhat satisfied } \\
\text { Neither satisfied nor dissatisfied } \\
\text { Samewhat dissatisfied } \\
\text { Very dissatisfied }\end{array}$}} & $\begin{array}{r}649 \\
588 \\
87 \\
90 \\
16\end{array}$ & $\begin{array}{r}45 \\
41 \\
6 \\
6 \\
1\end{array}$ \\
\hline & & 1,430 & \\
\hline $\begin{array}{l}\text { Mean } \\
\text { Standard Deviation } \\
\text { Median } \\
\text { Range } \\
\text { Mode }\end{array}$ & $\begin{array}{l}1.766 \\
.902 \\
2.00 \\
4.00 \\
1.00\end{array}$ & & \\
\hline
\end{tabular}


II.4 Amount of Responsibility (Motivator)

\begin{tabular}{|c|c|c|c|}
\hline \multicolumn{2}{|c|}{ Category } & Frequency & के \\
\hline \multirow{2}{*}{\multicolumn{2}{|c|}{$\begin{array}{l}\text { Very satisfied } \\
\text { Sonewhat satisfied } \\
\text { Neither satisfied nor dissatisfied } \\
\text { Somewhat dissatisfied } \\
\text { Very dissatisfied }\end{array}$}} & $\begin{array}{r}519 \\
521 \\
227 \\
136 \\
26\end{array}$ & $\begin{array}{r}36 \\
36 \\
16 \\
10 \\
2\end{array}$ \\
\hline & & 1,429 & \\
\hline $\begin{array}{l}\text { Mean } \\
\text { Standard Deviation } \\
\text { Median } \\
\text { Range } \\
\text { Mode }\end{array}$ & $\begin{array}{l}2.041 \\
1.032 \\
2.00 \\
4.00 \\
2.00\end{array}$ & & \\
\hline
\end{tabular}

II.5 Opportunity for Advancement (Motivator)

\begin{tabular}{|c|c|c|c|}
\hline \multicolumn{2}{|c|}{ Category } & Frequency & $q$ \\
\hline \multirow{2}{*}{\multicolumn{2}{|c|}{$\begin{array}{l}\text { Very satisfied } \\
\text { Somewhat satisfied } \\
\text { Neither satisfied nor dissatisfied } \\
\text { Somewhat dissatisfied } \\
\text { Very dissatisfied }\end{array}$}} & $\begin{array}{l}225 \\
336 \\
452 \\
261 \\
147\end{array}$ & $\begin{array}{l}16 \\
24 \\
32 \\
18 \\
10\end{array}$ \\
\hline & & 1,421 & \\
\hline $\begin{array}{l}\text { Mean } \\
\text { Standard Deviation } \\
\text { Median } \\
\text { Range } \\
\text { Mode }\end{array}$ & $\begin{array}{l}2.837 \\
1.201 \\
3.00 \\
4.00 \\
3.00\end{array}$ & & \\
\hline
\end{tabular}

\section{II.6 Opportunity to Grow and Develop (Motivator)}

\begin{tabular}{|c|c|c|c|}
\hline \multicolumn{2}{|c|}{ Category } & Frequency & $\xi$ \\
\hline \multirow{2}{*}{\multicolumn{2}{|c|}{$\begin{array}{l}\text { Very satisfied } \\
\text { Samewhat satisfied } \\
\text { Neither satisfied nor dissatisfied } \\
\text { Somewhat dissatisfied } \\
\text { Very dissatisfied }\end{array}$}} & $\begin{array}{r}374 \\
510 \\
283 \\
194 \\
71\end{array}$ & $\begin{array}{r}26 \\
36 \\
20 \\
14 \\
5\end{array}$ \\
\hline & & 1,432 & \\
\hline $\begin{array}{l}\text { Mean } \\
\text { Standard Deviation } \\
\text { Median } \\
\text { Range } \\
\text { Mode }\end{array}$ & $\begin{array}{l}2.356 \\
1.149 \\
2.00 \\
4.00 \\
2.00\end{array}$ & & \\
\hline
\end{tabular}


II.7 Salary (Hygiene)

\begin{tabular}{|c|c|c|c|}
\hline \multicolumn{2}{|c|}{ Category } & Frequency & $\%$ \\
\hline \multirow{2}{*}{\multicolumn{2}{|c|}{$\begin{array}{l}\text { Very satisfied } \\
\text { Somewhat satisfied } \\
\text { Neither satisfied nor dissatisfied } \\
\text { Somewhat dissatisfied } \\
\text { Very dissatisfied }\end{array}$}} & $\begin{array}{l}104 \\
452 \\
249 \\
426 \\
204\end{array}$ & $\begin{array}{r}7 \\
31 \\
17 \\
30 \\
14\end{array}$ \\
\hline & & 1,435 & \\
\hline $\begin{array}{l}\text { Mean } \\
\text { Standard Deviation } \\
\text { Median } \\
\text { Range } \\
\text { Mode }\end{array}$ & $\begin{array}{l}3.121 \\
1.207 \\
3.00 \\
4.00 \\
2.00\end{array}$ & & \\
\hline
\end{tabular}

\section{II.8 Interpersonal Relations with Supervising Administrator (Hygiene)}

\begin{tabular}{|c|c|c|c|}
\hline \multicolumn{2}{|c|}{ Category } & Frequency & $\stackrel{a}{b}$ \\
\hline \multirow{2}{*}{\multicolumn{2}{|c|}{$\begin{array}{l}\text { Very satisfied } \\
\text { Somewhat satisfied } \\
\text { Neither satisfied nor dissatisfied } \\
\text { Somewhat dissatisfied } \\
\text { Very dissatisfied }\end{array}$}} & $\begin{array}{r}611 \\
390 \\
187 \\
167 \\
84\end{array}$ & $\begin{array}{r}42 \\
27 \\
13 \\
12 \\
6\end{array}$ \\
\hline & & 1,439 & \\
\hline $\begin{array}{l}\text { Mean } \\
\text { Standard Deviation } \\
\text { Median } \\
\text { Range } \\
\text { Mode }\end{array}$ & $\begin{array}{l}2.113 \\
1.238 \\
2.00 \\
4.00 \\
1.00\end{array}$ & & \\
\hline
\end{tabular}

I...9 Interpersonal Relations with Fellow Teachers (Hygiene)

\begin{tabular}{|c|c|c|c|}
\hline \multicolumn{2}{|c|}{ Category } & Frequency & $q$ \\
\hline \multirow{2}{*}{\multicolumn{2}{|c|}{$\begin{array}{l}\text { Very satisfied } \\
\text { Somewhat satisfied } \\
\text { Neither satisfied nor dissatisfied } \\
\text { Somewhat dissatisfied } \\
\text { Very dissatisfied }\end{array}$}} & $\begin{array}{r}676 \\
558 \\
137 \\
62 \\
5\end{array}$ & $\begin{array}{r}47 \\
39 \\
10 \\
4 \\
0\end{array}$ \\
\hline & & 1,438 & \\
\hline $\begin{array}{l}\text { Mean } \\
\text { Standard Deviation } \\
\text { Median } \\
\text { Range } \\
\text { Mode }\end{array}$ & $\begin{array}{l}1.722 \\
.832 \\
2.00 \\
4.00 \\
1.00\end{array}$ & & \\
\hline
\end{tabular}


II.10 Interpersonal Relations with Students (Hygiene/Herzberg; Motivator/ Lortie)

\begin{tabular}{|c|c|c|c|}
\hline \multicolumn{2}{|c|}{ Category } & Frequency & 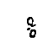 \\
\hline \multirow{2}{*}{\multicolumn{2}{|c|}{$\begin{array}{l}\text { Very satisfied } \\
\text { Somewhat satisfied } \\
\text { Nej.ther satisfied nor dissatisfied } \\
\text { Somewhat dissatisfied } \\
\text { Very dissarisfied }\end{array}$}} & $\begin{array}{r}773 \\
543 \\
84 \\
27 \\
7\end{array}$ & $\begin{array}{r}54 \\
38 \\
6 \\
2 \\
0\end{array}$ \\
\hline & & 1,434 & \\
\hline $\begin{array}{l}\text { Mean } \\
\text { Standard Deviation } \\
\text { Median } \\
\text { Kange } \\
\text { Mode }\end{array}$ & $\begin{array}{l}1.572 \\
.731 \\
1.00 \\
4.00 \\
1.00\end{array}$ & & \\
\hline
\end{tabular}

\section{II.11 Interpersonal Relations with Parents/Community (Hygiene)}

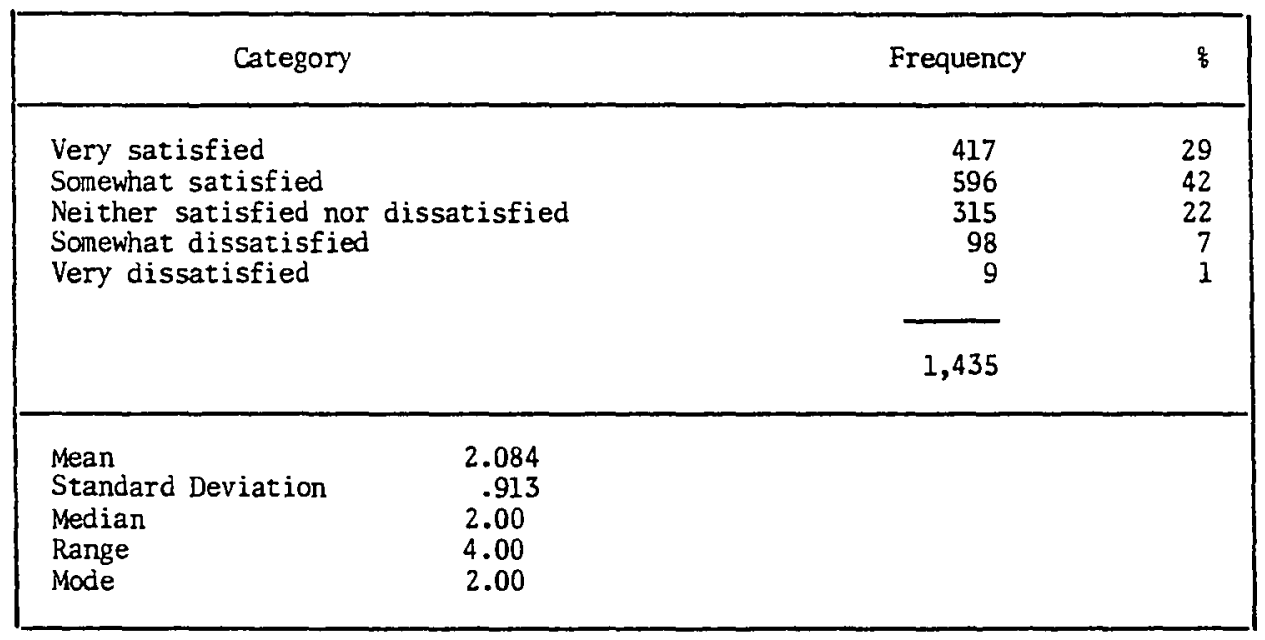

\section{II.12 Status (Hygiene)}

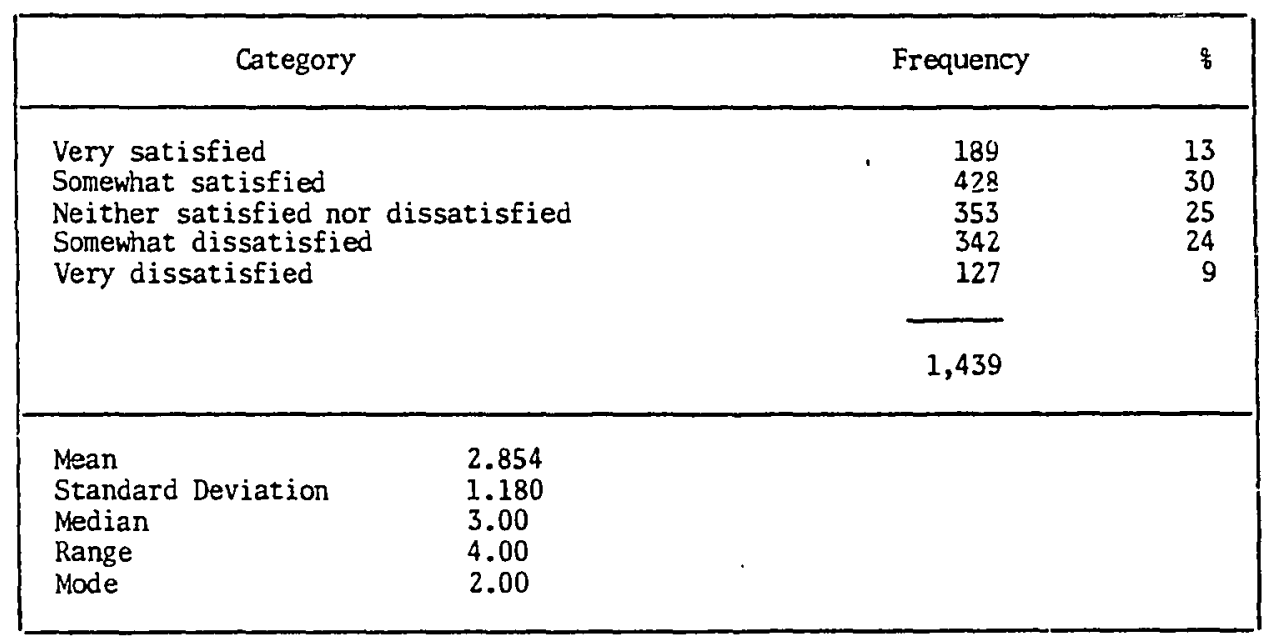


II.13 Supervision/Competence of Administrator (Hygiene)

\begin{tabular}{|c|c|c|c|}
\hline \multicolumn{2}{|c|}{ Category } & Frequency & : \\
\hline \multirow{2}{*}{\multicolumn{2}{|c|}{$\begin{array}{l}\text { Very satisfied } \\
\text { Somewhat satisfied } \\
\text { Neither satisfied nor dissatisfied } \\
\text { Somewhat dissatisfied } \\
\text { Very dissatisfied }\end{array}$}} & $\begin{array}{r}542 \\
407 \\
184 \\
210 \\
87\end{array}$ & $\begin{array}{r}38 \\
28 \\
13 \\
15 \\
6\end{array}$ \\
\hline & & 1,430 & \\
\hline $\begin{array}{l}\text { Mean } \\
\text { Standard Deviation } \\
\text { Median } \\
\text { Range } \\
\text { Mode }\end{array}$ & $\begin{array}{l}2.226 \\
1.262 \\
2.00 \\
4.00 \\
1.00\end{array}$ & & \\
\hline
\end{tabular}

II.14 Policies and Practices of the School District (Hygiene)

\begin{tabular}{|c|c|c|c|}
\hline \multicolumn{2}{|c|}{ Category } & Frequency & $\%$ \\
\hline \multirow{2}{*}{\multicolumn{2}{|c|}{$\begin{array}{l}\text { Very satisfied } \\
\text { Somewhat satisfied } \\
\text { Neither satisfied nor dissatisfied } \\
\text { Somewhat dissatisfied } \\
\text { Very dissatisfied }\end{array}$}} & $\begin{array}{r}138 \\
563 \\
328 \\
352 \\
54\end{array}$ & $\begin{array}{r}10 \\
39 \\
23 \\
25 \\
4\end{array}$ \\
\hline & & 1,435 & \\
\hline $\begin{array}{l}\text { Mean } \\
\text { Standard Deviation } \\
\text { Median } \\
\text { Range } \\
\text { Mode }\end{array}$ & $\begin{array}{l}2.736 \\
1.051 \\
3.00 \\
4.00 \\
2.00\end{array}$ & & \\
\hline
\end{tabular}

II.15 Policies and Practices of School (Hygiene)

\begin{tabular}{|c|c|c|c|}
\hline \multicolumn{2}{|c|}{ Category } & Frequency & 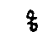 \\
\hline \multirow{2}{*}{\multicolumn{2}{|c|}{$\begin{array}{l}\text { Very satisfied } \\
\text { Somewhat satisfied } \\
\text { Neither satisfied nor dissatisfied } \\
\text { Somewhat dissatisfied } \\
\text { Very dissatisfied }\end{array}$}} & $\begin{array}{r}283 \\
601 \\
249 \\
257 \\
39\end{array}$ & $\begin{array}{r}20 \\
42 \\
17 \\
18 \\
3\end{array}$ \\
\hline & & 1,429 & \\
\hline $\begin{array}{l}\text { Mean } \\
\text { Standard Deviation } \\
\text { Median } \\
\text { Range } \\
\text { Mode }\end{array}$ & $\begin{array}{l}2.418 \\
1.079 \\
2.00 \\
4.00 \\
2.00\end{array}$ & & \\
\hline
\end{tabular}


II.16 Working Conditions (Hygiene)

\begin{tabular}{|c|c|c|c|}
\hline \multicolumn{2}{|c|}{ Category } & Frequency & $\%$ \\
\hline \multirow{2}{*}{\multicolumn{2}{|c|}{$\begin{array}{l}\text { Very satisfied } \\
\text { Somewhat satisfied } \\
\text { Neither satisfied nor dissatisfied } \\
\text { Somewhat dissatisfied } \\
\text { Very dissatisfied }\end{array}$}} & $\begin{array}{r}414 \\
574 \\
195 \\
199 \\
50\end{array}$ & $\begin{array}{r}29 \\
40 \\
14 \\
14 \\
3\end{array}$ \\
\hline & & 1,432 & \\
\hline $\begin{array}{l}\text { Mean } \\
\text { Standard Deviation } \\
\text { Median } \\
\text { Range } \\
\text { Mode }\end{array}$ & $\begin{array}{l}2.23 \\
1.115 \\
2.00 \\
4.00 \\
2.00\end{array}$ & & \\
\hline
\end{tabular}

II.17 Effect on Personal Life (Hygiene)

\begin{tabular}{|c|c|c|c|}
\hline \multicolumn{2}{|c|}{ Category } & Frequency & $q$ \\
\hline \multirow{2}{*}{\multicolumn{2}{|c|}{$\begin{array}{l}\text { Very satisfied } \\
\text { Somewhat satisfied } \\
\text { Neither satisfied nor dissatisfied } \\
\text { Somewhat dissatisfied } \\
\text { Very dissatisfied }\end{array}$}} & $\begin{array}{r}305 \\
492 \\
293 \\
298 \\
49\end{array}$ & $\begin{array}{r}21 \\
34 \\
20 \\
21 \\
3\end{array}$ \\
\hline & & 1,437 & \\
\hline $\begin{array}{l}\text { Mean } \\
\text { Standard Deviation } \\
\text { Median } \\
\text { Range } \\
\text { Mode }\end{array}$ & $\begin{array}{l}2.509 \\
1.138 \\
2.00 \\
4.00 \\
2.00\end{array}$ & & \\
\hline
\end{tabular}

II.18 Job Security (Hygiene)

\begin{tabular}{|c|c|c|c|}
\hline \multicolumn{2}{|c|}{ Category } & Frequency & $\xi$ \\
\hline \multirow{2}{*}{\multicolumn{2}{|c|}{$\begin{array}{l}\text { Very satisfied } \\
\text { Somewhat satisfied } \\
\text { Neither satisfied nor dissatisfied } \\
\text { Somewhat dissatisfied } \\
\text { Very dissatisfied }\end{array}$}} & $\begin{array}{r}501 \\
609 \\
183 \\
111 \\
35\end{array}$ & $\begin{array}{r}35 \\
42 \\
13 \\
8 \\
2\end{array}$ \\
\hline & & 1,439 & \\
\hline $\begin{array}{l}\text { Mean } \\
\text { Standard Deviation } \\
\text { Median } \\
\text { Range } \\
\text { Mode }\end{array}$ & $\begin{array}{l}2.006 \\
1.002 \\
2.00 \\
4.00 \\
2.00\end{array}$ & & \\
\hline
\end{tabular}


II.19 Upportunities to Help Others (Motivator)

\begin{tabular}{|c|c|c|c|}
\hline \multicolumn{2}{|c|}{ Category } & Frequency & q \\
\hline \multirow{2}{*}{\multicolumn{2}{|c|}{$\begin{array}{l}\text { Very satisfied } \\
\text { Somewhat satisfied } \\
\text { Neither satisfied nor dissatisfied } \\
\text { Somewhat dissatisfied } \\
\text { Very dissatisfied }\end{array}$}} & $\begin{array}{r}575 \\
598 \\
188 \\
57 \\
12\end{array}$ & $\begin{array}{r}40 \\
42 \\
13 \\
4 \\
1\end{array}$ \\
\hline & & 1,430 & \\
\hline $\begin{array}{l}\text { Mean } \\
\text { Standard Deviation } \\
\text { Median } \\
\text { Range } \\
\text { Mode }\end{array}$ & $\begin{array}{l}1.834 \\
.861 \\
2.00 \\
4.00 \\
2.00\end{array}$ & & \\
\hline
\end{tabular}

II.20 Time Spent Preparing for Teaching (Hygiene)

\begin{tabular}{|c|c|c|c|}
\hline \multicolumn{2}{|c|}{ Category } & Frequency & $q$ \\
\hline \multirow{2}{*}{\multicolumn{2}{|c|}{$\begin{array}{l}\text { Very satisfied } \\
\text { Somewhat satisfied } \\
\text { Neither satisfied nor dissatisfied } \\
\text { Somewhat dissatisfied } \\
\text { Very dissatisfied }\end{array}$}} & $\begin{array}{l}171 \\
478 \\
276 \\
387 \\
118\end{array}$ & $\begin{array}{r}12 \\
33 \\
19 \\
27 \\
8\end{array}$ \\
\hline & & 1,430 & \\
\hline $\begin{array}{l}\text { Mean } \\
\text { Standard Deviation } \\
\text { Median } \\
\text { Range } \\
\text { Mode }\end{array}$ & $\begin{array}{l}2.862 \\
1.181 \\
3.00 \\
4.00 \\
2.00\end{array}$ & & $\therefore$ \\
\hline
\end{tabular}

I1.21 Time Spent Teaching (Hyg iene)

\begin{tabular}{|c|c|c|c|}
\hline \multicolumn{2}{|c|}{ Category } & Frequency & $\xi$ \\
\hline \multirow{2}{*}{\multicolumn{2}{|c|}{$\begin{array}{l}\text { Very satisfied } \\
\text { Somewhat satisfied } \\
\text { Neither satisfied nor dissatisfied } \\
\text { Somewhat dissatisfied } \\
\text { Very dissatisfied }\end{array}$}} & $\begin{array}{r}322 \\
674 \\
196 \\
206 \\
24\end{array}$ & $\begin{array}{r}23 \\
47 \\
14 \\
14 \\
2\end{array}$ \\
\hline & & 1,422 & \\
\hline $\begin{array}{l}\text { Mean } \\
\text { Standard Deviation } \\
\text { Median } \\
\text { Range } \\
\text { Mode }\end{array}$ & $\begin{array}{l}2.252 \\
1.016 \\
2.00 \\
4.00 \\
2.00\end{array}$ & & \\
\hline
\end{tabular}


II.22 Time Spent on School Related Activities Outside of Teaching and Preparation for Teaching (Hygiene)

\begin{tabular}{|c|c|c|c|}
\hline \multicolumn{2}{|c|}{ Category } & Frequency & $q$ \\
\hline \multirow{2}{*}{\multicolumn{2}{|c|}{$\begin{array}{l}\text { Very satisfied } \\
\text { Somewhat satisfied } \\
\text { Neither satisfied nor dissatisfied } \\
\text { Somewhat dissatisfied } \\
\text { Very dissatisfied }\end{array}$}} & $\begin{array}{r}137 \\
403 \\
455 \\
342 \\
92\end{array}$ & $\begin{array}{r}10 \\
28 \\
32 \\
24 \\
6\end{array}$ \\
\hline & & 1,429 & \\
\hline $\begin{array}{l}\text { Mean } \\
\text { Standard Deviation } \\
\text { Median } \\
\text { Range } \\
\text { Mode }\end{array}$ & $\begin{array}{l}2.894 \\
1.073 \\
3.00 \\
4.00 \\
3.00\end{array}$ & & \\
\hline
\end{tabular}

II.23 Amount of Autonomy (Motivator/Work Itself)

\begin{tabular}{|c|c|c|c|}
\hline \multicolumn{2}{|c|}{ Category } & Frequency & $\%$ \\
\hline \multirow{2}{*}{\multicolumn{2}{|c|}{$\begin{array}{l}\text { Very satisfied } \\
\text { Somewhat satisfied } \\
\text { Neither satisfied nor dissatisfied } \\
\text { Somewhat dissatisfied } \\
\text { Very dissatisfied }\end{array}$}} & $\begin{array}{r}399 \\
589 \\
322 \\
81 \\
21\end{array}$ & $\begin{array}{r}28 \\
42 \\
23 \\
6 \\
1\end{array}$ \\
\hline & & 1,412 & \\
\hline $\begin{array}{l}\text { Mean } \\
\text { Standard Deviation } \\
\text { Median } \\
\text { Range } \\
\text { Mode }\end{array}$ & $\begin{array}{l}2.105 \\
.929 \\
2.00 \\
4.00 \\
2.00\end{array}$ & & \\
\hline
\end{tabular}

II.24 How Satisfied with Present Job or Assignment in Teaching (Motivator)

\begin{tabular}{|c|c|c|c|}
\hline \multicolumn{2}{|c|}{ Category } & Frequency & $q$ \\
\hline \multirow{2}{*}{\multicolumn{2}{|c|}{$\begin{array}{l}\text { Very satisfied } \\
\text { Somewhat satisfied } \\
\text { Neither satisfied nor dissatisfied } \\
\text { Somewhat dissatisfied } \\
\text { Very dissatisfied }\end{array}$}} & $\begin{array}{r}542 \\
638 \\
97 \\
134 \\
26\end{array}$ & $\begin{array}{r}38 \\
44 \\
7 \\
9 \\
2\end{array}$ \\
\hline & & 1,437 & \\
\hline $\begin{array}{l}\text { Mean } \\
\text { Standard Deviation } \\
\text { Median } \\
\text { Range } \\
\text { Mode }\end{array}$ & $\begin{array}{l}1.931 \\
.988 \\
2.00 \\
4.00 \\
2.00\end{array}$ & & \\
\hline
\end{tabular}


II.25 How Satisfied with Role as Teacher (Motivator)

\begin{tabular}{|c|c|c|c|}
\hline \multicolumn{2}{|c|}{ Category } & Frequency & $:$ \\
\hline \multirow{2}{*}{\multicolumn{2}{|c|}{$\begin{array}{l}\text { Very satisfied } \\
\text { Somewhat satisfied } \\
\text { Neither satisfied nor dissatisfied } \\
\text { Somewhat dissatisfied } \\
\text { Very dissatisfied }\end{array}$}} & $\begin{array}{r}581 \\
653 \\
99 \\
90 \\
15\end{array}$ & $\begin{array}{r}40 \\
45 \\
7 \\
6 \\
1\end{array}$ \\
\hline & & 1,438 & \\
\hline $\begin{array}{l}\text { Mean } \\
\text { Standard Deviation } \\
\text { Median } \\
\text { Range } \\
\text { Mode }\end{array}$ & $\begin{array}{l}1.821 \\
.886 \\
2.00 \\
4.00 \\
2.00\end{array}$ & & \\
\hline
\end{tabular}

III.1 Enjoyment in Working with Students (Motivator/Lortie)

\begin{tabular}{|c|c|c|c|}
\hline \multicolumn{2}{|c|}{ Category } & Frequency & $q$ \\
\hline \multirow{2}{*}{\multicolumn{2}{|c|}{$\begin{array}{l}\text { Very important } \\
\text { Somewhat important } \\
\text { Neither important nor unimportant } \\
\text { Somewhat unimportant } \\
\text { Very unimportant }\end{array}$}} & $\begin{array}{r}1,262 \\
157 \\
11 \\
2 \\
1\end{array}$ & $\begin{array}{r}88 \\
11 \\
1 \\
0 \\
0\end{array}$ \\
\hline & & 1,433 & \\
\hline $\begin{array}{l}\text { Mean } \\
\text { Standard Deviation } \\
\text { Median } \\
\text { Range } \\
\text { Mode }\end{array}$ & $\begin{array}{l}1.132 \\
.383 \\
1.00 \\
4.00 \\
1.00\end{array}$ & & \\
\hline
\end{tabular}

III.2 Freedom to Teach As You Wish (Motivator/Work Itself)

\begin{tabular}{|c|c|c|c|}
\hline \multicolumn{2}{|c|}{ Category } & Frequency & $q$ \\
\hline \multirow{2}{*}{\multicolumn{2}{|c|}{$\begin{array}{l}\text { Very important } \\
\text { Somewhat important } \\
\text { Neither important nor unimportant } \\
\text { Somewhat unimportant } \\
\text { Very unimportant }\end{array}$}} & $\begin{array}{r}878 \\
508 \\
43 \\
4 \\
0\end{array}$ & $\begin{array}{r}61 \\
35 \\
3 \\
0 \\
0\end{array}$ \\
\hline & & 1,433 & \\
\hline $\begin{array}{l}\text { Mean } \\
\text { Standard Deviation } \\
\text { Median } \\
\text { Range } \\
\text { Mode }\end{array}$ & $\begin{array}{l}1.423 \\
.567 \\
1.00 \\
3.00 \\
1.00\end{array}$ & & \\
\hline
\end{tabular}


III.j Feeling of Power or Authority in Work (Motivator/Work Itself)

\begin{tabular}{|c|c|c|c|}
\hline \multicolumn{2}{|c|}{ Category } & Frequency & $\frac{\mathrm{o}}{\mathrm{b}}$ \\
\hline \multirow{2}{*}{\multicolumn{2}{|c|}{$\begin{array}{l}\text { Very important } \\
\text { Somewhat important } \\
\text { Neither important nor unimportant } \\
\text { Somewhat unimportant } \\
\text { Very unimportant }\end{array}$}} & $\begin{array}{r}626 \\
523 \\
232 \\
34 \\
16\end{array}$ & $\begin{array}{r}44 \\
27 \\
16 \\
2 \\
1\end{array}$ \\
\hline & & 1,431 & \\
\hline $\begin{array}{l}\text { Mean } \\
\text { Standard Deviation } \\
\text { Median } \\
\text { Range } \\
\text { Mode }\end{array}$ & $\begin{array}{l}1.806 \\
.871 \\
2.00 \\
4.00 \\
1.00\end{array}$ & & \\
\hline
\end{tabular}

\section{III.4 Receiving a Good Salary (Hygiene)}

\begin{tabular}{|c|c|c|c|}
\hline \multicolumn{2}{|c|}{ Category } & Frequency & $q$ \\
\hline \multirow{2}{*}{\multicolumn{2}{|c|}{$\begin{array}{l}\text { Very important } \\
\text { Somewhat important } \\
\text { Neither important nor unimportant } \\
\text { Somewhat unimportant } \\
\text { Very unimportant }\end{array}$}} & $\begin{array}{r}736 \\
589 \\
77 \\
25 \\
5\end{array}$ & $\begin{array}{r}51 \\
41 \\
5 \\
2 \\
0\end{array}$ \\
\hline & & 1,432 & \\
\hline $\begin{array}{l}\text { Mean } \\
\text { Standard Deviation } \\
\text { Median } \\
\text { Range } \\
\text { Mode }\end{array}$ & $\begin{array}{l}1.585 \\
.705 \\
1.00 \\
4.00 \\
1.00\end{array}$ & & \\
\hline
\end{tabular}

\section{III.5 Support from Parents of Students (Hygiene)}

\begin{tabular}{|c|c|c|c|}
\hline \multicolumn{2}{|c|}{ Category } & Frequency & $q$ \\
\hline \multirow{2}{*}{\multicolumn{2}{|c|}{$\begin{array}{l}\text { Very important } \\
\text { Somewhat important } \\
\text { Neither important nor unimportant } \\
\text { Somewhat unimportant } \\
\text { Very unimportant }\end{array}$}} & $\begin{array}{r}984 \\
390 \\
42 \\
14 \\
1\end{array}$ & $\begin{array}{r}69 \\
27 \\
3 \\
1 \\
0\end{array}$ \\
\hline & & 1,431 & \\
\hline $\begin{array}{l}\text { Mean } \\
\text { Standard Deviation } \\
\text { Median } \\
\text { Range } \\
\text { Mode }\end{array}$ & $\begin{array}{r}1.363 \\
.598 \\
1.00 \\
4.00 \\
1.00\end{array}$ & & \\
\hline
\end{tabular}


III.6 Opportunity for Personal Growth (Motivator)

\begin{tabular}{|c|c|c|c|}
\hline \multicolumn{2}{|c|}{ Category } & Frequency & $\frac{9}{8}$ \\
\hline \multirow{2}{*}{\multicolumn{2}{|c|}{$\begin{array}{l}\text { Very important } \\
\text { Somewhat important } \\
\text { Neither important nor unimportant } \\
\text { Somewhat unimportant } \\
\text { Very unimportant }\end{array}$}} & $\begin{array}{r}842 \\
486 \\
95 \\
8 \\
2\end{array}$ & $\begin{array}{r}59 \\
34 \\
7 \\
1 \\
0\end{array}$ \\
\hline & & 1,433 & \\
\hline $\begin{array}{l}\text { Mean } \\
\text { Standard Deviation } \\
\text { Median } \\
\text { Range } \\
\text { Mode }\end{array}$ & $\begin{array}{l}1.494 \\
.658 \\
1.00 \\
4.00 \\
1.00\end{array}$ & & \\
\hline
\end{tabular}

III.7 Opportunity for Promotion or Advancenent (Motivator)

\begin{tabular}{|lrr|}
\hline \multicolumn{1}{|c|}{ Category } & Frequency \\
\hline Very important & 464 & 32 \\
Somewhat important & 603 & 42 \\
Neither important nor unimportant & 299 & 21 \\
Sonewhat unimportant & 48 & 18 \\
Very unimportant & & 1,432 \\
& & \\
& & \\
\hline Mean & 1.990 & \\
Standard Deviation & .883 & \\
Median & 2.00 & \\
Range & 4.00 & \\
Mode & 2.00 & \\
\hline
\end{tabular}

III.8 Job Security (Hygiene)

\begin{tabular}{|c|c|c|c|}
\hline \multicolumn{2}{|c|}{ Category } & Frequency & $q$ \\
\hline \multirow{2}{*}{\multicolumn{2}{|c|}{$\begin{array}{l}\text { Very important } \\
\text { Somewhat important } \\
\text { Neither important nor unimportant } \\
\text { Somewhat unimportant } \\
\text { Very unimportant }\end{array}$}} & $\begin{array}{r}875 \\
456 \\
87 \\
12 \\
1\end{array}$ & $\begin{array}{r}61 \\
32 \\
6 \\
1 \\
0\end{array}$ \\
\hline & & 1,431 & \\
\hline $\begin{array}{l}\text { Mean } \\
\text { Standard Deviation } \\
\text { Median } \\
\text { Range } \\
\text { Mode }\end{array}$ & $\begin{array}{l}1.468 \\
.655 \\
1.00 \\
4.00 \\
1.00\end{array}$ & & \\
\hline
\end{tabular}


III.9 Support from Your Administrators (Hygiene)

\begin{tabular}{|c|c|c|c|}
\hline \multicolumn{2}{|c|}{ Category } & Frequency & \% \\
\hline \multirow{2}{*}{\multicolumn{2}{|c|}{$\begin{array}{l}\text { Very important } \\
\text { Somewhat important } \\
\text { Neither important nor unimportant } \\
\text { Somewhat unimportant } \\
\text { Very unimportant }\end{array}$}} & $\begin{array}{r}1,167 \\
222 \\
35 \\
4 \\
3\end{array}$ & $\begin{array}{r}82 \\
16 \\
2 \\
0 \\
0\end{array}$ \\
\hline & & 1,431 & \\
\hline $\begin{array}{l}\text { Mean } \\
\text { Standard Deviation } \\
\text { Median } \\
\text { Range } \\
\text { Mode }\end{array}$ & $\begin{array}{l}1.221 \\
.513 \\
1.00 \\
4.00 \\
1.00\end{array}$ & & \\
\hline
\end{tabular}

III.10 Recognition or Praise for Work and Efforts (Motivator)

\begin{tabular}{|c|c|c|c|}
\hline \multicolumn{2}{|c|}{ Category } & Frequency & $q$ \\
\hline \multirow{2}{*}{\multicolumn{2}{|c|}{$\begin{array}{l}\text { Very important } \\
\text { Somewhat important } \\
\text { Neither important nor unimportant } \\
\text { Somewhat unimportant } \\
\text { Very umimportant }\end{array}$}} & $\begin{array}{r}629 \\
642 \\
128 \\
26 \\
9\end{array}$ & $\begin{array}{r}44 \\
45 \\
9 \\
2 \\
1\end{array}$ \\
\hline & & 1,434 & \\
\hline $\begin{array}{l}\text { Mean } \\
\text { Standard Deviation } \\
\text { Median } \\
\text { Range } \\
\text { Mode }\end{array}$ & $\begin{array}{l}1.706 \\
.755 \\
2.00 \\
4.00 \\
2.00\end{array}$ & & \\
\hline
\end{tabular}

III.11 Personal Feeling of Success or Achievement (Motivator)

\begin{tabular}{|c|c|c|c|}
\hline \multicolumn{2}{|c|}{ Category } & Frequency & $q$ \\
\hline \multirow{2}{*}{\multicolumn{2}{|c|}{$\begin{array}{l}\text { Very important } \\
\text { Somewtat important } \\
\text { Neither important nor unimportant } \\
\text { Somewhat unimportant } \\
\text { Very unimportant }\end{array}$}} & $\begin{array}{r}1,176 \\
234 \\
20 \\
3 \\
1\end{array}$ & $\begin{array}{r}82 \\
16 \\
1 \\
0 \\
0\end{array}$ \\
\hline & & 1,434 & \\
\hline $\begin{array}{l}\text { Mean } \\
\text { Standard Deviation } \\
\text { Median } \\
\text { Range } \\
\text { Mode }\end{array}$ & $\begin{array}{r}1.200 \\
.457 \\
1.00 \\
4.00 \\
1.00\end{array}$ & & \\
\hline
\end{tabular}


III.12 Time Spent in Classroom Teaching (Hygiene)

\begin{tabular}{|c|c|c|c|}
\hline \multicolumn{2}{|c|}{ Category } & Frequency & $:$ \\
\hline \multirow{2}{*}{\multicolumn{2}{|c|}{$\begin{array}{l}\text { Very important } \\
\text { Somewhat important } \\
\text { Neither important nor unimportant } \\
\text { Somewhat unimportant } \\
\text { Very unimportant }\end{array}$}} & $\begin{array}{r}947 \\
412 \\
56 \\
8 \\
1\end{array}$ & $\begin{array}{r}67 \\
29 \\
4 \\
1 \\
0\end{array}$ \\
\hline & & 1,424 & \\
\hline $\begin{array}{l}\text { Mean } \\
\text { Standard Deviation } \\
\text { Median } \\
\text { Range } \\
\text { Mode }\end{array}$ & $\begin{array}{l}1.388 \\
.599 \\
1.00 \\
4.00 \\
1.00\end{array}$ & & \\
\hline
\end{tabular}

III.13 Time Spent Preparing for Teaching (Hygiene)

\begin{tabular}{|c|c|c|c|}
\hline \multicolumn{2}{|c|}{ Category } & Frequency & q \\
\hline \multirow{2}{*}{\multicolumn{2}{|c|}{$\begin{array}{l}\text { Very important } \\
\text { Somewhat important } \\
\text { Neither important nor unimportant } \\
\text { Somewhat unimportant } \\
\text { Very unimportant }\end{array}$}} & $\begin{array}{r}783 \\
511 \\
115 \\
12 \\
2\end{array}$ & $\begin{array}{r}55 \\
36 \\
8 \\
1 \\
0\end{array}$ \\
\hline & & 1,423 & \\
\hline $\begin{array}{l}\text { Mean } \\
\text { Standard Deviation } \\
\text { Median } \\
\text { Range } \\
\text { Mode }\end{array}$ & $\begin{array}{l}1.552 \\
.690 \\
1.00 \\
4.00 \\
1.00\end{array}$ & & \\
\hline
\end{tabular}

III.14 Status in Community as a Teacher (Hygiene)

\begin{tabular}{|c|c|c|c|}
\hline \multicolumn{2}{|c|}{ Category } & I:requency & $q$ \\
\hline \multirow{2}{*}{\multicolumn{2}{|c|}{$\begin{array}{l}\text { Very inportant } \\
\text { Somewhat important } \\
\text { Neither important nor unimportant } \\
\text { Somewhat unimportant } \\
\text { Very unimportant }\end{array}$}} & $\begin{array}{r}434 \\
652 \\
299 \\
39 \\
8\end{array}$ & $\begin{array}{r}30 \\
46 \\
21 \\
3 \\
1\end{array}$ \\
\hline & & 1,432 & \\
\hline $\begin{array}{l}\text { Mean } \\
\text { Standard Deviation } \\
\text { Median } \\
\text { Range } \\
\text { Mode }\end{array}$ & $\begin{array}{r}1.977 \\
.819 \\
2.00 \\
4.00 \\
2.00\end{array}$ & & \\
\hline
\end{tabular}


III.15 Being Creative in Teaching (Motivator)

\begin{tabular}{|c|c|c|c|}
\hline \multicolumn{2}{|c|}{ Category } & Frequency & $\because$ \\
\hline \multirow{2}{*}{\multicolumn{2}{|c|}{$\begin{array}{l}\text { Very important } \\
\text { Somewhat important } \\
\text { Neither important nor unimportant } \\
\text { Somewhat unimportant } \\
\text { Very unimportant }\end{array}$}} & $\begin{array}{r}939 \\
422 \\
58 \\
11 \\
1\end{array}$ & $\begin{array}{r}66 \\
30 \\
4 \\
1 \\
0\end{array}$ \\
\hline & & 1,430 & \\
\hline $\begin{array}{l}\text { Mean } \\
\text { Standard Deviation } \\
\text { Median } \\
\text { Range } \\
\text { Mode }\end{array}$ & $\begin{array}{l}1.402 \\
.613 \\
1.00 \\
4.00 \\
1.00\end{array}$ & & \\
\hline
\end{tabular}

II.16 Maintaining a Positive Learning Atmosphere for Students (Motivator)

\begin{tabular}{|lrr|}
\hline \multicolumn{1}{|c|}{ Category } & Frequency & \\
\hline Very important & 1,223 & 85 \\
Somewhit important & 196 & 14 \\
Neither important nor unimportant & 12 & 1 \\
Somewhat unimportant & 1 & 0 \\
Very unimportant & & 1,432 \\
& & \\
& & \\
\hline Mean & 1.156 & \\
Standard Deviation & .396 & \\
Median & 1.00 & \\
Range & 4.00 & \\
Mode & 1.00 & \\
\hline
\end{tabular}

III.17 Working Conditions in School (Ligiene)

\begin{tabular}{|lrr|}
\hline \multicolumn{1}{|c|}{ Category } & Frequency & \\
\hline Very important & 939 & 66 \\
Somewhat important & 458 & 32 \\
Neither important nor unimportant & 29 & 2 \\
Somewhat unimportant & & 2 \\
Very unimportant & & 1,432 \\
& & \\
& & \\
\hline Mean & 1.374 & \\
Standard Deviation & .555 & \\
Median & 1.00 & \\
Range & 4.00 & \\
Mode & 1.00 & \\
\hline
\end{tabular}


III.18 Personal Life Uutside of Teaching (Hygiene)

\begin{tabular}{|c|c|c|c|}
\hline \multicolumn{2}{|c|}{ Category } & Frequency & $q$ \\
\hline \multirow{2}{*}{\multicolumn{2}{|c|}{$\begin{array}{l}\text { Very important } \\
\text { Somewhat important } \\
\text { Neither important nor unimportant } \\
\text { Somewhat unimportant } \\
\text { Very unimportant }\end{array}$}} & $\begin{array}{r}926 \\
329 \\
142 \\
22 \\
10\end{array}$ & $\begin{array}{r}65 \\
23 \\
10 \\
2 \\
1\end{array}$ \\
\hline & & 1,429 & \\
\hline $\begin{array}{l}\text { Mean } \\
\text { Standard Deviation } \\
\text { Median } \\
\text { Range } \\
\text { Mode }\end{array}$ & $\begin{array}{l}1.503 \\
.791 \\
1.00 \\
4.00 \\
1.00\end{array}$ & & \\
\hline
\end{tabular}

III.19 Relationships with Other Teachers (Hygiene)

\begin{tabular}{|c|c|c|c|}
\hline \multicolumn{2}{|c|}{ Category } & Frequency & $q$ \\
\hline \multirow{2}{*}{\multicolumn{2}{|c|}{$\begin{array}{l}\text { Very important } \\
\text { Somewhat important } \\
\text { Neither important nor unimportant } \\
\text { Somewhat unimportant } \\
\text { Very unimportant }\end{array}$}} & $\begin{array}{r}659 \\
657 \\
105 \\
9 \\
3\end{array}$ & $\begin{array}{r}46 \\
46 \\
7 \\
1 \\
0\end{array}$ \\
\hline & & 1,433 & \\
\hline $\begin{array}{l}\text { Mean } \\
\text { Standard Deviation } \\
\text { Median } \\
\text { Range } \\
\text { Mode }\end{array}$ & $\begin{array}{l}1.632 \\
.665 \\
2.00 \\
4.00 \\
1.00\end{array}$ & & \\
\hline
\end{tabular}

III.20 Getting Feedback to Improve Teaching (Motivator)

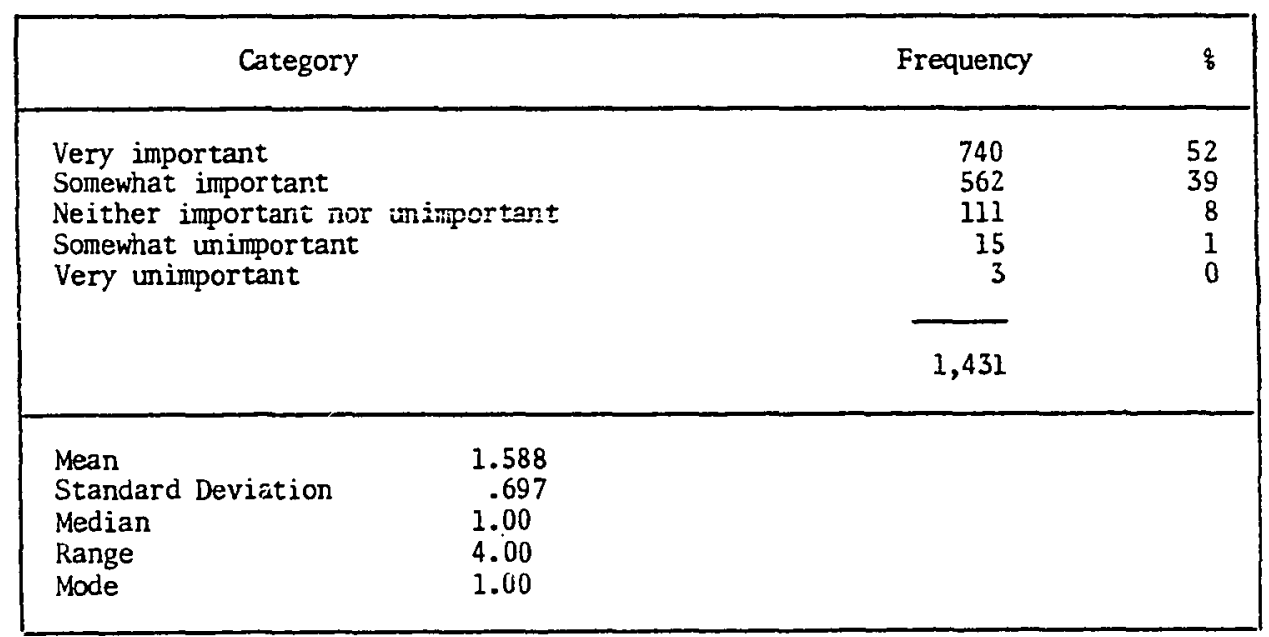


III.21 Observing School Policies and Regulations (Hygiene)

\begin{tabular}{|lrr|}
\hline \multicolumn{1}{|c|}{ Category } & Frequency & $q$ \\
\hline Very important & 525 & $3 \%$ \\
Samewhat important & 631 & 44 \\
Neither important nor unimportant & 226 & 16 \\
Sanewhat unimportant & 42 & 3 \\
Very unimportant & 6 & \\
& & 1,430 \\
& & \\
\hline Mean & & \\
Standard Deviation & 1.862 & \\
Median & 2.814 & \\
Mange & 4.00 & \\
\hline
\end{tabular}

III.22 Knowing That You Are Effective as a Teacher (Motivator)

\begin{tabular}{|lrr|}
\hline \multicolumn{1}{|c|}{ Category } & Frequency & \\
\hline Very important & 1,168 & 82 \\
Sanewhat important & 244 & 17 \\
Neither important nor unimportant & 19 & 1 \\
Sanewhat uningportant & 1 & 0 \\
Very unimportant & & 1,432 \\
& & \\
& & \\
\hline Mean & & \\
Standard Deviation & 1.200 & \\
Median & .441 & \\
Range & 1.00 & \\
Mode & 4.00 & \\
\hline
\end{tabular}

III.23 The Intellectual Activity and Gallenge of Teaching (Motivator)

\begin{tabular}{|c|c|c|c|}
\hline \multicolumn{2}{|c|}{ Category } & Frequency & $q$ \\
\hline \multirow{2}{*}{\multicolumn{2}{|c|}{$\begin{array}{l}\text { Very important } \\
\text { Samewhat important } \\
\text { Neither important nor unimportant } \\
\text { Samewhat unimportant } \\
\text { Very unimportant }\end{array}$}} & $\begin{array}{r}896 \\
454 \\
75 \\
5 \\
1\end{array}$ & $\begin{array}{r}63 \\
32 \\
5 \\
0 \\
0\end{array}$ \\
\hline & & . 1,431 & \\
\hline $\begin{array}{l}\text { Mean } \\
\text { Standard Deviation } \\
\text { Median } \\
\text { Range } \\
\text { Mode }\end{array}$ & $\begin{array}{l}1.435 \\
.617 \\
1.00 \\
4.00 \\
1.00\end{array}$ & & \\
\hline
\end{tabular}


III.24 Influencing Young People's Education (Motivator)

\begin{tabular}{|c|c|c|c|}
\hline \multicolumn{2}{|c|}{ Category } & Frequency & $:$ \\
\hline \multirow{2}{*}{\multicolumn{2}{|c|}{$\begin{array}{l}\text { Very important } \\
\text { Somewhat important } \\
\text { Neither important nor unimportant } \\
\text { Somewhat unimportant } \\
\text { Very unimportant }\end{array}$}} & $\begin{array}{r}1,062 \\
333 \\
32 \\
5 \\
1\end{array}$ & $\begin{array}{r}74 \\
23 \\
2 \\
0 \\
0\end{array}$ \\
\hline & & 1,433 & \\
\hline $\begin{array}{l}\text { Mean } \\
\text { Standard Deviation } \\
\text { Median } \\
\text { Range } \\
\text { Mode }\end{array}$ & $\begin{array}{l}1.290 \\
.529 \\
1.00 \\
4.00 \\
1.00\end{array}$ & & \\
\hline
\end{tabular}

III.25 Accepting Your Responsibilities as a Teacher (Motivator)

\begin{tabular}{|c|c|c|c|}
\hline \multicolumn{2}{|c|}{ Category } & Frequency & 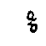 \\
\hline \multirow{2}{*}{\multicolumn{2}{|c|}{$\begin{array}{l}\text { Very important } \\
\text { Somewhat important } \\
\text { Neither important nor unimportant } \\
\text { Somewhat unimportant } \\
\text { Very unimportant }\end{array}$}} & $\begin{array}{r}1,065 \\
317 \\
45 \\
5 \\
1\end{array}$ & $\begin{array}{r}74 \\
22 \\
3 \\
0 \\
0\end{array}$ \\
\hline & & 1,433 & \\
\hline $\begin{array}{l}\text { Mean } \\
\text { Standard Deviation } \\
\text { Median } \\
\text { Range } \\
\text { Mode }\end{array}$ & $\begin{array}{l}1.297 \\
.549 \\
1.00 \\
4.00 \\
1.00\end{array}$ & & \\
\hline
\end{tabular}

IV.I If you had your choice of jobs in any field, which would you select?

\begin{tabular}{|c|c|c|c|}
\hline \multicolumn{2}{|c|}{ Category } & Frequency & $\frac{8}{6}$ \\
\hline \multirow{3}{*}{\multicolumn{2}{|c|}{$\begin{array}{l}\text { Your present job as a teacher } \\
\text { Another job in the field of public education } \\
\text { Another job in another field outside of } \\
\text { public education }\end{array}$}} & $\begin{array}{l}828 \\
167\end{array}$ & $\begin{array}{l}59 \\
12\end{array}$ \\
\hline & & 413 & 29 \\
\hline & & 1,408 & \\
\hline $\begin{array}{l}\text { Median } \\
\text { Mode }\end{array}$ & $\begin{array}{l}1.00 \\
1.00\end{array}$ & & \\
\hline
\end{tabular}


IV.2 If you had your choice of jobs in tle field of public education, which would you select?

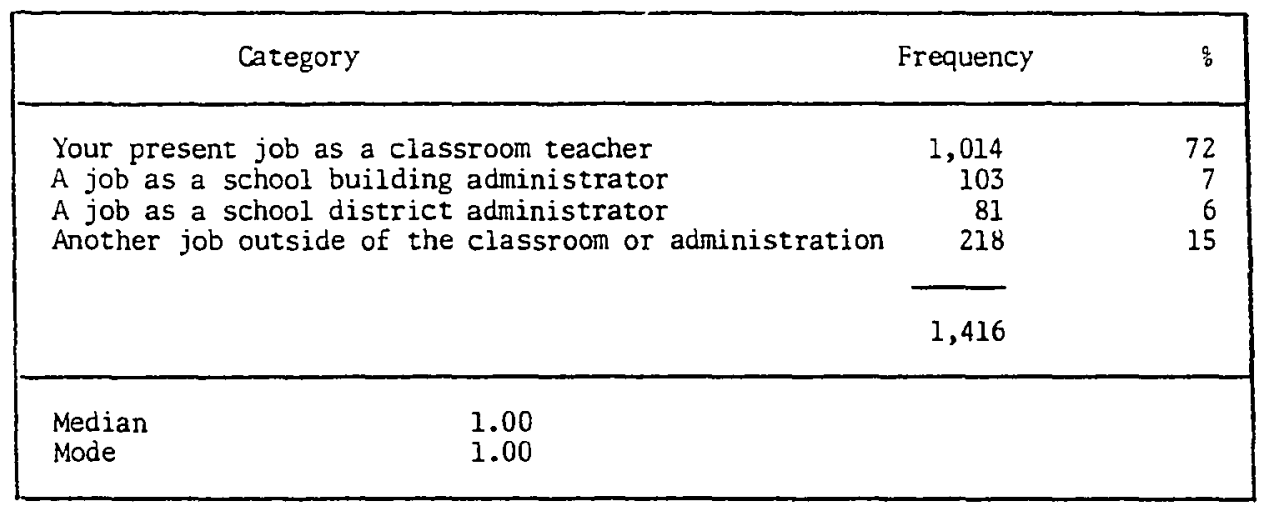

IV.3 If you had it to do all over again, would you still become a teacher?

\begin{tabular}{|c|c|c|}
\hline Category & Frequency & $\frac{q}{8}$ \\
\hline $\begin{array}{l}\text { Definitely become a teacher again } \\
\text { Probably become a teacher again } \\
\text { Uncertain about becoming a teacher again } \\
\text { Probably not become a teacher again } \\
\text { Definitely not become a teacher again }\end{array}$ & $\begin{array}{r}463 \\
487 \\
275 \\
169 \\
64\end{array}$ & $\begin{array}{r}30 \\
34 \\
19 \\
12 \\
4\end{array}$ \\
\hline & 1,428 & \\
\hline $\begin{array}{l}\text { Median } \\
\text { Mode }\end{array}$ & & \\
\hline
\end{tabular}

IV.4 When you became a teacher, how qualified did you feel you were at that time to get some other job outside of teaching?

\begin{tabular}{|c|c|c|c|}
\hline \multicolumn{2}{|c|}{ Category } & Frequency & $q$ \\
\hline \multirow{2}{*}{\multicolumn{2}{|c|}{$\begin{array}{l}\text { Very well qualified } \\
\text { Somewhat qualified } \\
\text { Uncertain about qualifications } \\
\text { Somewhat unqualified } \\
\text { Very urqualified }\end{array}$}} & $\begin{array}{r}422 \\
560 \\
283 \\
86 \\
78\end{array}$ & $\begin{array}{r}30 \\
39 \\
20 \\
6 \\
5\end{array}$ \\
\hline & & 1,429 & \\
\hline $\begin{array}{l}\text { Median } \\
\text { Mode }\end{array}$ & $\begin{array}{l}2.00 \\
2.00\end{array}$ & & \\
\hline
\end{tabular}


IV.5 If you wanted to do so now, how qualified do you feel to get a job outside teaching?

\begin{tabular}{|lrr|}
\hline \multicolumn{1}{|c|}{ Category } & Frequency & \\
\hline Very well qualified & 382 & 27 \\
Somewhat qualified & 595 & 42 \\
Uncertain about qualifications & 306 & 21 \\
Somewhat unqualified & 91 & 6 \\
Very unqualified & 56 & 4 \\
& & 1,430 \\
\hline Median & & \\
\hline
\end{tabular}

IV. 6 How has your role as a teacher fulfilled the expectations you had when you first decided to become a teacher?

\begin{tabular}{|c|c|c|c|}
\hline Category & & Frequency & $\%$ \\
\hline \multirow{2}{*}{\multicolumn{2}{|c|}{$\begin{array}{l}\text { Far above my expectations } \\
\text { Above what I expected } \\
\text { About what I expected } \\
\text { Below what I expected } \\
\text { Far below what I expected }\end{array}$}} & $\begin{array}{r}63 \\
356 \\
743 \\
234 \\
28 \\
1\end{array}$ & $\begin{array}{r}4 \\
25 \\
52 \\
16 \\
2 \\
0\end{array}$ \\
\hline & & 1,425 & \\
\hline $\begin{array}{l}\text { Median } \\
\text { Mode }\end{array}$ & $\begin{array}{l}3.00 \\
3.00\end{array}$ & & \\
\hline
\end{tabular}

IV.7 If you had your choice, what ability/achievement level of students would you prefer to teach?

\begin{tabular}{|lcr|}
\hline \multicolumn{1}{|c|}{ Category } & Frequency & \\
\hline Far below average & 31 & 2 \\
Somewhat below average & 82 & 6 \\
Average & 241 & 17 \\
Somewhat above average & 506 & 36 \\
Far above average/gifted & 105 & 32 \\
Mixed ability or achievement & 451 & \\
& & 1,418 \\
& & \\
\hline Median & 4.00 & \\
Made & 4.00 & \\
\hline
\end{tabular}


IV.8 How much pleasure do you get from teaching?

\begin{tabular}{|c|c|c|c|}
\hline \multicolumn{2}{|c|}{ Category } & Frequency & $\%$ \\
\hline \multirow{2}{*}{\multicolumn{2}{|c|}{$\begin{array}{l}\text { Great pleasure } \\
\text { Some pleasure } \\
\text { Neither pleasure nor displeasure } \\
\text { Some displeasure } \\
\text { Great displeasure }\end{array}$}} & $\begin{array}{r}746 \\
623 \\
31 \\
20 \\
3\end{array}$ & $\begin{array}{r}52 \\
44 \\
2 \\
1 \\
0\end{array}$ \\
\hline & & 1,423 & \\
\hline $\begin{array}{l}\text { Median } \\
\text { Mode }\end{array}$ & $\begin{array}{l}1.00 \\
1.00\end{array}$ & & \\
\hline
\end{tabular}

IV.9 How do you think other teachers would describe you as a teacher?

\begin{tabular}{|lrr|}
\hline \multicolumn{1}{|c|}{ Category } & Frequency & \\
\hline Very good or outstanding & 540 & 38 \\
Above average & 781 & 55 \\
Average--neither good nor poor & 104 & 7 \\
Below average & 1 & 0 \\
Very poor & 1,426 \\
& & \\
\hline Median & & \\
\hline Mode & 2.00 & \\
\hline
\end{tabular}

IV.10 How much do you like working with the students you have in your classes this year?

\begin{tabular}{|c|c|c|c|}
\hline Category & & Frequency & $q$ \\
\hline \multirow[t]{2}{*}{$\begin{array}{l}\text { A great deal } \\
\text { Quite a bit } \\
\text { 0.K. I guess } \\
\text { Some dislike } \\
\text { Great dislike }\end{array}$} & & $\begin{array}{r}564 \\
587 \\
122 \\
61 \\
3\end{array}$ & $\begin{array}{r}46 \\
41 \\
8 \\
4 \\
0\end{array}$ \\
\hline & & 1,437 & \\
\hline $\begin{array}{l}\text { Median } \\
\text { Mode }\end{array}$ & $\begin{array}{l}2.00 \\
1.00\end{array}$ & & \\
\hline
\end{tabular}


IV.II In general, how would you describe the students you work with today?

\begin{tabular}{|lrr|}
\hline \multicolumn{1}{|c|}{ Category } & Frequency \\
\hline A pleasure to work with & 358 & 25 \\
Generally good to work with & 759 & 53 \\
O.K. to work with & 95 & 7 \\
Sometimes difficult to work with & 184 & 30 \\
Very difficult to work with & & \\
& & \\
& 2.00 & \\
\hline Median & 2.00 & \\
\hline
\end{tabular}

IV.12 How pleasant is your school as a place in which to teach and work?

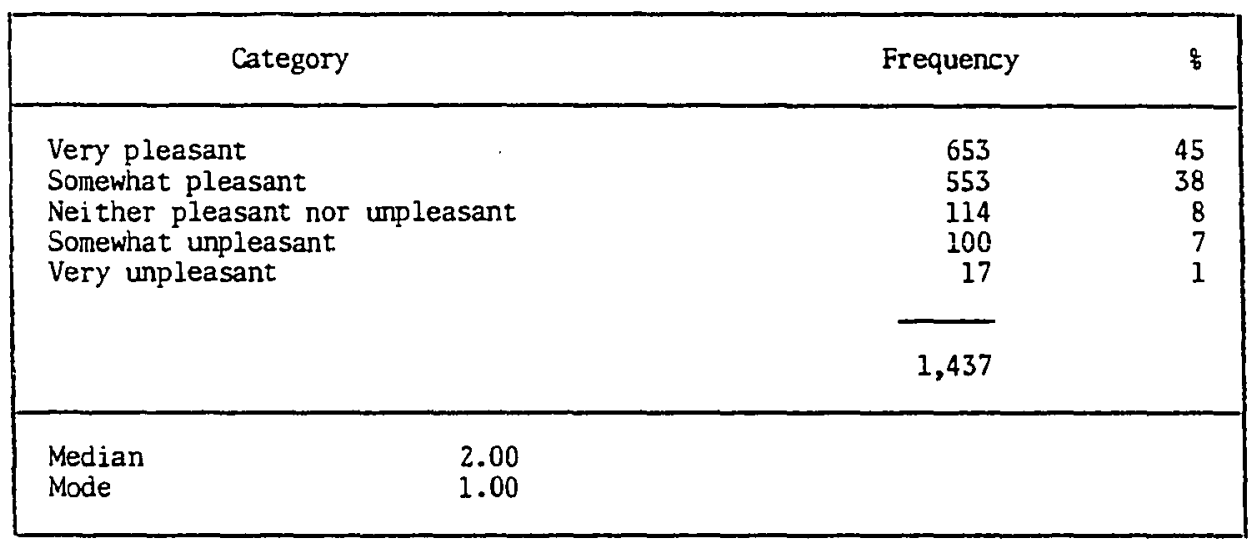

IV.13 How often are you able to maintain a positive learning climate for your students?

\begin{tabular}{|c|c|c|}
\hline Category & Frequency & $q$ \\
\hline $\begin{array}{l}\text { Able almost all of the time } \\
\text { Able more than half of the time } \\
\text { Able about half of the time } \\
\text { Able less than half of the time } \\
\text { Seldom or never able }\end{array}$ & $\begin{array}{r}775 \\
529 \\
110 \\
17 \\
1\end{array}$ & $\begin{array}{r}54 \\
37 \\
8 \\
1 \\
0\end{array}$ \\
\hline & 1,432 & \\
\hline $\begin{array}{l}\text { Median } \\
\text { Mode }\end{array}$ & & \\
\hline
\end{tabular}


IV.14 In general, how has the teaching profession--as you now view it-fulfilled the expectations you had when you first decided to enter teaching as a profession?

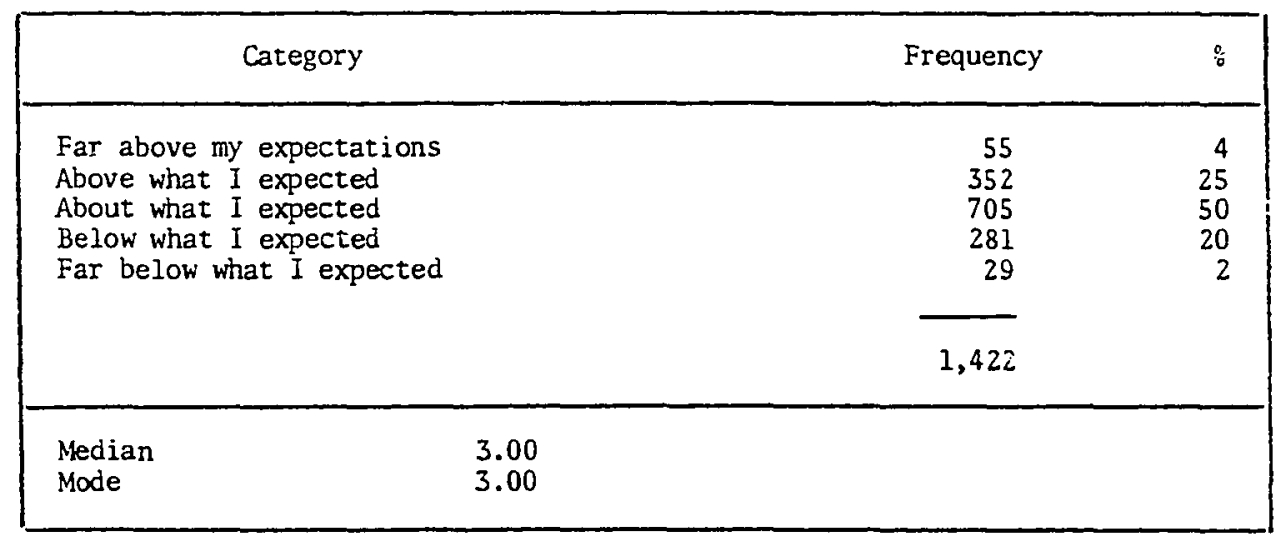

IV.15 How of ten do you have the opportunity to design your instructional programs and teach your students more or less as you choose?

\begin{tabular}{|c|c|c|}
\hline Category & Frequency & 8 \\
\hline \multirow[t]{2}{*}{$\begin{array}{l}\text { All or almost all of the time } \\
\text { More than half of the time } \\
\text { Maybe half of the time } \\
\text { Less than half of the time } \\
\text { Seldom or never }\end{array}$} & $\begin{array}{r}718 \\
410 \\
175 \\
92 \\
32\end{array}$ & $\begin{array}{r}50 \\
29 \\
12 \\
6 \\
2\end{array}$ \\
\hline & 1,427 & \\
\hline $\begin{array}{l}\text { Median } \\
\text { Mode }\end{array}$ & & \\
\hline
\end{tabular}

IV.16 How successful are you in neeting the intellectual needs of your students as individuals?

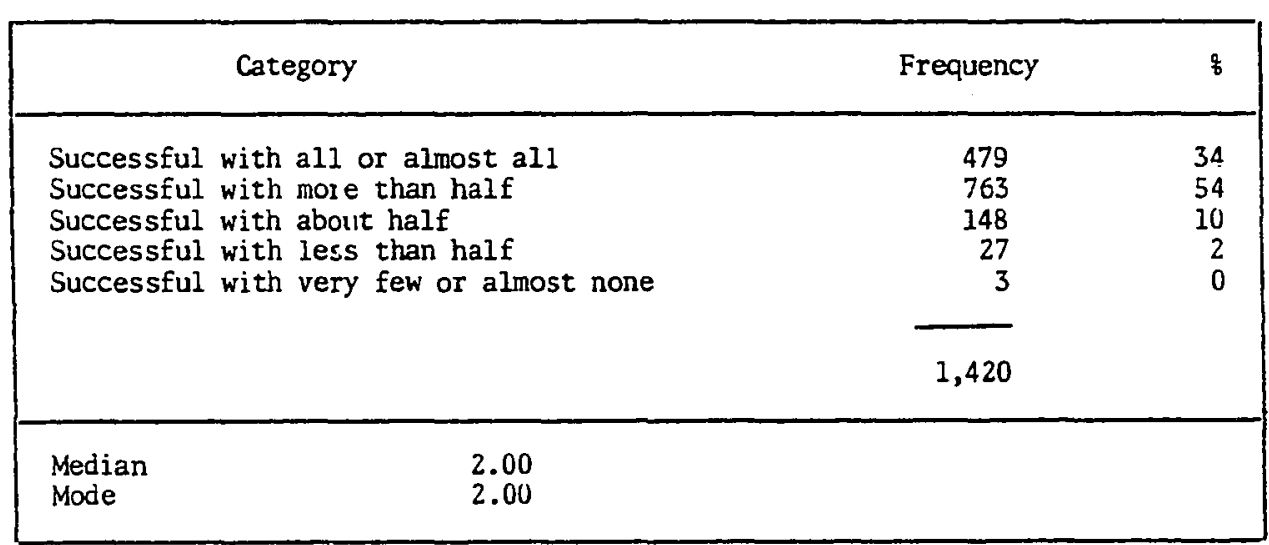


IV.17 As a teacher, how much support do you have from the parents in your school comnunity?

\begin{tabular}{|lcr|}
\hline \multicolumn{1}{|c|}{ Category } & Frequency & \\
\hline Great support & 197 & 14 \\
Above average support & 515 & 36 \\
About average support, I guess & 463 & 32 \\
Less than average support, some lack & 68 & 13 \\
Great lack of support & & 1,432 \\
& & \\
\hline Median & 3.00 & \\
Mode & 2.00 & \\
\hline
\end{tabular}

IV.18 How do you race the professional competence of your supervising adninistrator?

\begin{tabular}{|c|c|c|c|}
\hline Category & & Frequency & $q$ \\
\hline \multirow[t]{2}{*}{$\begin{array}{l}\text { Very competent } \\
\text { Above average competence } \\
\text { Average competence } \\
\text { Below average competence } \\
\text { Very incompetent }\end{array}$} & & $\begin{array}{r}537 \\
408 \\
322 \\
121 \\
37\end{array}$ & $\begin{array}{r}38 \\
29 \\
23 \\
8 \\
3\end{array}$ \\
\hline & & 1,425 & \\
\hline $\begin{array}{l}\text { Median } \\
\text { Mode }\end{array}$ & $\begin{array}{l}2.00 \\
1.00\end{array}$ & & \\
\hline
\end{tabular}

IV.19 How much professional support do your building administrators give you?

\begin{tabular}{|c|c|c|}
\hline Category & Frequency & $q$ \\
\hline $\begin{array}{l}\text { Support far above my expectations } \\
\text { Above average support } \\
\text { About what I expect } \\
\text { Less than average, some lack of support } \\
\text { Support below my expectations, great lack }\end{array}$ & $\begin{array}{r}209 \\
651 \\
325 \\
195 \\
52\end{array}$ & $\begin{array}{r}15 \\
45 \\
23 \\
14 \\
4\end{array}$ \\
\hline & 1,432 & \\
\hline $\begin{array}{l}\text { Median } \\
\text { Mode }\end{array}$ & & \\
\hline
\end{tabular}


IV.20 How of ten do you and your fellow teachers tend to agree on standards for teaching?

\begin{tabular}{|lrr|}
\hline \multicolumn{1}{|c|}{ Category } & Frequency & \\
\hline Agree almost all of the time & 385 & 27 \\
Agree more than we disagree & 836 & 59 \\
Agree maybe half of the time & 171 & 12 \\
Disagree more than we agree & 27 & 2 \\
Disagree almost all of the time & 2 & \\
& & 1,421 \\
& & \\
\hline Mean & 1.892 & \\
Median & 2.00 & \\
Mode & 2.00 & \\
\hline
\end{tabular}

IV.21 As a teacher, if you could have two more hours a week to devote to tr.e field of education, which of the following would be your first choice for the extra time?

\begin{tabular}{|c|c|c|}
\hline Category & Frequency & $\%$ \\
\hline \multirow[t]{2}{*}{$\begin{array}{l}\text { Curriculum conmittee } \\
\text { Lesson planning } \\
\text { Community relations } \\
\text { In-class teaching } \\
\text { Individual student tutoring } \\
\text { School policy committee } \\
\text { Parent conferences } \\
\text { Extra-curricular student activities }\end{array}$} & $\begin{array}{r}115 \\
620 \\
52 \\
119 \\
293 \\
23 \\
55 \\
138\end{array}$ & $\begin{array}{r}8 \\
44 \\
4 \\
8 \\
21 \\
2 \\
4 \\
10\end{array}$ \\
\hline & 1,415 & \\
\hline $\begin{array}{l}\text { Median } \\
\text { Mode }\end{array}$ & & \\
\hline
\end{tabular}

IV.22 If you had your choice, how of ten would you have parents participate in classroom and school related decision-making and activities?

\begin{tabular}{|c|c|c|}
\hline Category & Frequency & $q$ \\
\hline \multirow[t]{2}{*}{$\begin{array}{l}\text { Very often, as often as possible } \\
\text { More often than they do now } \\
\text { About as often as they do now } \\
\text { Less often than they do now } \\
\text { Seldom or never }\end{array}$} & $\begin{array}{r}182 \\
462 \\
637 \\
67 \\
75\end{array}$ & $\begin{array}{r}13 \\
32 \\
45 \\
5 \\
5\end{array}$ \\
\hline & 1,423 & \\
\hline $\begin{array}{l}\text { Median } \\
\text { Mode }\end{array}$ & & \\
\hline
\end{tabular}


IV.23 How do you think the parents of your students would describe you as a teacher?

\begin{tabular}{|lrr|}
\hline \multicolumn{1}{|c|}{ Category } & Frequency & \\
\hline Very good or outstanding & 445 & 31 \\
Above average & 807 & 57 \\
Average--neither good nor poor & 161 & 12 \\
Below average & 1 & 0 \\
Very poor & 1,414 \\
& & \\
& & \\
\hline Median & 2.00 & \\
Mode & 2.00 & \\
\hline
\end{tabular}

IV.24 How secure do you feel in your job as a teacher?

\begin{tabular}{|c|c|c|c|}
\hline Category & & Frequency & $q$ \\
\hline \multirow[t]{2}{*}{$\begin{array}{l}\text { Very secure } \\
\text { Quite secure } \\
\text { Not certain--0.K. I guess } \\
\text { Quite insecure } \\
\text { Very insecure }\end{array}$} & & $\begin{array}{r}685 \\
603 \\
115 \\
21 \\
10\end{array}$ & $\begin{array}{r}48 \\
42 \\
8 \\
1 \\
1\end{array}$ \\
\hline & & 1,434 & \\
\hline $\begin{array}{l}\text { Median } \\
\text { Mode }\end{array}$ & $\begin{array}{l}2.00 \\
2.00\end{array}$ & & \\
\hline
\end{tabular}

IV.25 How would you describe your relationships with other teachers?

\begin{tabular}{|c|c|c|}
\hline Category & Frequency & $q$ \\
\hline $\begin{array}{l}\text { My closest friends are other teachers, in and out } \\
\text { of school } \\
\text { I spend some social time outside of school with } \\
\text { other teachers } \\
\text { I associate freely with other teachers, but only } \\
\text { during school hours } \\
\text { I have very few personal contacts with other } \\
\text { teachers } \\
\text { I do not have personal contacts with other teachers }\end{array}$ & $\begin{array}{r}294 \\
679 \\
394 \\
59 \\
1 \\
1,427\end{array}$ & $\begin{array}{r}21 \\
48 \\
28\end{array}$ \\
\hline $\begin{array}{r}2.00 \\
2.00\end{array}$ & & \\
\hline
\end{tabular}


IV.26 How do you think your students would describe you as a teacher?

\begin{tabular}{|c|c|c|}
\hline Category & Frequency & $\%$ \\
\hline \multirow[t]{2}{*}{$\begin{array}{l}\text { Very good or outstanding } \\
\text { Above alirage } \\
\text { Average--neither good nor poor } \\
\text { Below average } \\
\text { Very poor }\end{array}$} & $\begin{array}{r}532 \\
749 \\
129 \\
1 \\
0\end{array}$ & $\begin{array}{r}38 \\
53 \\
9 \\
0 \\
0\end{array}$ \\
\hline & 1,411 & \\
\hline $\begin{array}{l}\text { Median } \\
\text { Mode }\end{array}$ & & \\
\hline
\end{tabular}

IV.27 All in all, how successful do you feel as a teacher?

\begin{tabular}{|c|c|c|}
\hline Category & Frequency & $q$ \\
\hline \multirow[t]{2}{*}{$\begin{array}{l}\text { Very successful } \\
\text { Quite successful } \\
\text { Mixed feelings about being successful } \\
\text { Quite unsuccessful } \\
\text { Very unsuccessful }\end{array}$} & $\begin{array}{r}480 \\
744 \\
196 \\
2 \\
0\end{array}$ & $\begin{array}{r}34 \\
52 \\
14 \\
0 \\
0\end{array}$ \\
\hline & 1,422 & \\
\hline $\begin{array}{l}\text { Median } \\
\text { Mode }\end{array}$ & & \\
\hline
\end{tabular}

IV.28 How much positive or negative feedback as a teacher do you receive from other teachers?

\begin{tabular}{|lrr|}
\hline \multicolumn{1}{|c|}{ Category } & Frequency & \\
\hline A great amount of positive & 401 & 29 \\
More positive than negative & 853 & 61 \\
About equal amounts of positive/negative & 120 & 9 \\
More negative than positive & 14 & 1 \\
A great amount of negative & 2 & 0 \\
& 1,391 & \\
& & \\
\hline Median & & \\
Mode & 2.00 & \\
\hline
\end{tabular}


IV.29 How much positive or negative feedback as a teacher do you receive from the parents of your students or olners outside of the field of public education?

\begin{tabular}{|lrr|}
\hline Category & Frequency & \\
\hline A great amount of positive & 342 & 25 \\
More positive than negative & 829 & 60 \\
About equal amounts of positive/negative & 170 & 12 \\
More negative than positive & 53 & 1 \\
A great amount of negative & 1,389 & \\
& & \\
\hline Median & 2.00 & \\
Mode & 2.00 & \\
\hline
\end{tabular}

IV.30 How much positive or negative feedback as a teacher do you receive from your immediate supervisor or administrator?

\begin{tabular}{|c|c|c|}
\hline Category & Frequency & $q$ \\
\hline \multirow[t]{2}{*}{$\begin{array}{l}\text { A great amount of positive } \\
\text { More positive than negative } \\
\text { About equal anounts of positive/negative } \\
\text { More negative than positive } \\
\text { A great amount of negative }\end{array}$} & $\begin{array}{r}496 \\
692 \\
135 \\
50 \\
10 \\
2\end{array}$ & $\begin{array}{r}36 \\
50 \\
10 \\
4 \\
1 \\
0\end{array}$ \\
\hline & 1,385 & \\
\hline $\begin{array}{ll}\text { Median } & 2.00 \\
\text { Mode } & 2.00\end{array}$ & & \\
\hline
\end{tabular}

IV.31 How much do you think being a teacher has contributed to your growth as a person?

\begin{tabular}{|c|c|c|c|}
\hline Category & & Frequency & $q$ \\
\hline \multirow[t]{2}{*}{$\begin{array}{l}\text { A great deal } \\
\text { Quite a bit } \\
\text { Moderately } \\
\text { Slighily } \\
\text { Very little, if at all }\end{array}$} & & $\begin{array}{r}604 \\
571 \\
203 \\
26 \\
22\end{array}$ & $\begin{array}{r}42 \\
40 \\
14 \\
2 \\
2\end{array}$ \\
\hline & & 1,426 & \\
\hline $\begin{array}{l}\text { Median } \\
\text { Mode }\end{array}$ & $\begin{array}{l}2.00 \\
1.00\end{array}$ & & \\
\hline
\end{tabular}


IV.32 How much do you think you have achieved as a teacher?

\begin{tabular}{|c|c|c|}
\hline Category & Frequency & $q$ \\
\hline \multirow[t]{2}{*}{$\begin{array}{l}\text { A great deal--more than I expected } \\
\text { Quite a bit--above average } \\
\text { Moderately--about what I expected } \\
\text { Not very much--below average } \\
\text { Little or nothing--much less than expected }\end{array}$} & $\begin{array}{r}392 \\
781 \\
208 \\
26 \\
4\end{array}$ & $\begin{array}{r}28 \\
55 \\
15 \\
\because \\
0\end{array}$ \\
\hline & 1,411 & \\
\hline $\begin{array}{l}\text { Median } \\
\text { Mode }\end{array}$ & & \\
\hline
\end{tabular}

IV.33 If you were offered a promotion to another position in your school district that would take you out of the classroom, what do you think you would do?

\begin{tabular}{|c|c|c|}
\hline Category & Frequency & : \\
\hline $\begin{array}{l}\text { Definitely accept } \\
\text { Probably accept } \\
\text { Hesitate and wonder what to do } \\
\text { Probably refuse } \\
\text { Definitely refuse }\end{array}$ & $\begin{array}{l}134 \\
362 \\
413 \\
333 \\
168\end{array}$ & $\begin{array}{l}10 \\
26 \\
29 \\
24 \\
12\end{array}$ \\
\hline & 1,410 & \\
\hline $\begin{array}{l}\text { Median } \\
\text { Mode }\end{array}$ & & \\
\hline
\end{tabular}

IV.34 If you were offered a promotion to another position in your school or district that would take you out of the classroom, how co you think you would feel?

\begin{tabular}{|c|c|c|c|}
\hline Category & & Frequency & $\xi$ \\
\hline \multirow[t]{2}{*}{$\begin{array}{l}\text { Feel real loss } \\
\text { Feel some loss } \\
\text { Would have mixed feelings } \\
\text { Would feel some gain } \\
\text { Would feel real gain }\end{array}$} & & $\begin{array}{r}435 \\
359 \\
512 \\
65 \\
31\end{array}$ & $\begin{array}{r}31 \\
26 \\
37 \\
5 \\
2\end{array}$ \\
\hline & & 1,402 & \\
\hline $\begin{array}{l}\text { Median } \\
\text { Mode }\end{array}$ & $\begin{array}{l}2.00 \\
3.00\end{array}$ & & \\
\hline
\end{tabular}


IV.35 How likely is it that you will initiate an effort to leave teaching for some other position in public education within the next year?

\begin{tabular}{|c|c|c|c|}
\hline Category & & Frequency & \& \\
\hline \multirow[t]{2}{*}{$\begin{array}{l}\text { Not likely } \\
\text { Somewhat likely } \\
\text { Very likely }\end{array}$} & & $\begin{array}{r}1,201 \\
151 \\
73\end{array}$ & $\begin{array}{r}84 \\
.11 \\
5\end{array}$ \\
\hline & & 1,425 & \\
\hline $\begin{array}{l}\text { Median } \\
\text { Mode }\end{array}$ & $\begin{array}{l}1.00 \\
1.00\end{array}$ & & \\
\hline
\end{tabular}

IV.36 How likely is it that you will initiate an effort to seek another job outside of public education within the next year?

\begin{tabular}{|c|c|c|c|}
\hline Category & & Frequency & $\xi$ \\
\hline $\begin{array}{l}\text { Not likely } \\
\text { Somewhat likely } \\
\text { Very likely }\end{array}$ & & $\begin{array}{r}1,215 \\
147 \\
61\end{array}$ & $\begin{array}{r}85 \\
10 \\
4\end{array}$ \\
\hline & & 1,423 & \\
\hline $\begin{array}{l}\text { Median } \\
\text { Mode }\end{array}$ & $\begin{array}{l}1.00 \\
1.00\end{array}$ & & \\
\hline
\end{tabular}

IV.37 Where do you hope to be professionally in five years?

\begin{tabular}{|c|c|c|}
\hline Category & Frequency & $q$ \\
\hline \multirow[t]{2}{*}{$\begin{array}{l}\text { Teaching } \\
\text { Promoted in the field of public education } \\
\text { In another position outside of public education } \\
\text { Not working (by choice) }\end{array}$} & $\begin{array}{r}773 \\
218 \\
186 \\
211 \\
1\end{array}$ & $\begin{array}{r}56 \\
16 \\
13 \\
15 \\
0\end{array}$ \\
\hline & 1,389 & \\
\hline $\begin{array}{l}\text { Median } \\
\text { Mode }\end{array}$ & & \\
\hline
\end{tabular}


IV.38 Which of the following indicators do you rely on most to gauge the effectiveness of your teaching? (Choose only one.)

\begin{tabular}{|c|c|c|c|}
\hline \multicolumn{2}{|c|}{ Category } & Frequency & 8 \\
\hline \multirow{2}{*}{\multicolumn{2}{|c|}{$\begin{array}{l}\text { Reactions of other teachers } \\
\text { Opinions expressed by your students } \\
\text { Assessments made by the principal } \\
\text { Assessments made by a chairperson/team leader } \\
\text { Results of student exams and tests } \\
\text { Reactions from parents } \\
\text { Your own opinions and assessments }\end{array}$}} & $\begin{array}{r}101 \\
291 \\
82 \\
17 \\
246 \\
70 \\
593 \\
2\end{array}$ & $\begin{array}{r}7 \\
21 \\
6 \\
1 \\
18 \\
5 \\
42 \\
0\end{array}$ \\
\hline & & 1,402 & \\
\hline $\begin{array}{l}\text { Mean } \\
\text { Median } \\
\text { Mode }\end{array}$ & $\begin{array}{l}4.86 \\
5.00 \\
7.00\end{array}$ & & \\
\hline
\end{tabular}

IV.39 As far as getting insights and ideas as a teacher, which of the following is most useful to you? (Choose only one.)

\begin{tabular}{|c|c|c|}
\hline Category & Frequency & $q$ \\
\hline $\begin{array}{l}\text { Inservice courses given by the school system } \\
\text { Informal conversations with colleagues and friends } \\
\text { Educational magazines and books } \\
\text { Educational media (films, TV, video, etc.) } \\
\text { Meetings you attend in your district } \\
\text { Meetings you attend outside your district } \\
\text { Coursework given by a college/university } \\
\text { Your imediate supervisor }\end{array}$ & $\begin{array}{r}225 \\
607 \\
109 \\
11 \\
49 \\
130 \\
240 \\
31\end{array}$ & $\begin{array}{r}16 \\
43 \\
8 \\
1 \\
3 \\
9 \\
17 \\
2\end{array}$ \\
\hline & 1,402 & \\
\hline $\begin{array}{l}\text { Median } \\
\text { Mode }\end{array}$ & & \\
\hline
\end{tabular}

IV.40 How much opportunity do you feel you have for your continuing education or professional growth as a teacher?

\begin{tabular}{|c|c|c|c|}
\hline Category & & Frequency & $\%$ \\
\hline \multirow[t]{2}{*}{$\begin{array}{l}\text { Great opportunity } \\
\text { Good opportumity } \\
\text { Moderate opportunity } \\
\text { Lack of opportunity } \\
\text { Great lack of opportunity }\end{array}$} & & $\begin{array}{r}371 \\
666 \\
309 \\
64 \\
16 \\
1\end{array}$ & $\begin{array}{r}26 \\
47 \\
22 \\
4 \\
1 \\
0\end{array}$ \\
\hline & & 1,428 & \\
\hline $\begin{array}{l}\text { Median } \\
\text { Mode }\end{array}$ & $\begin{array}{l}2.00 \\
2.00\end{array}$ & & \\
\hline
\end{tabular}


IV.4I How much incentive do you have to continue your education or professional growth?

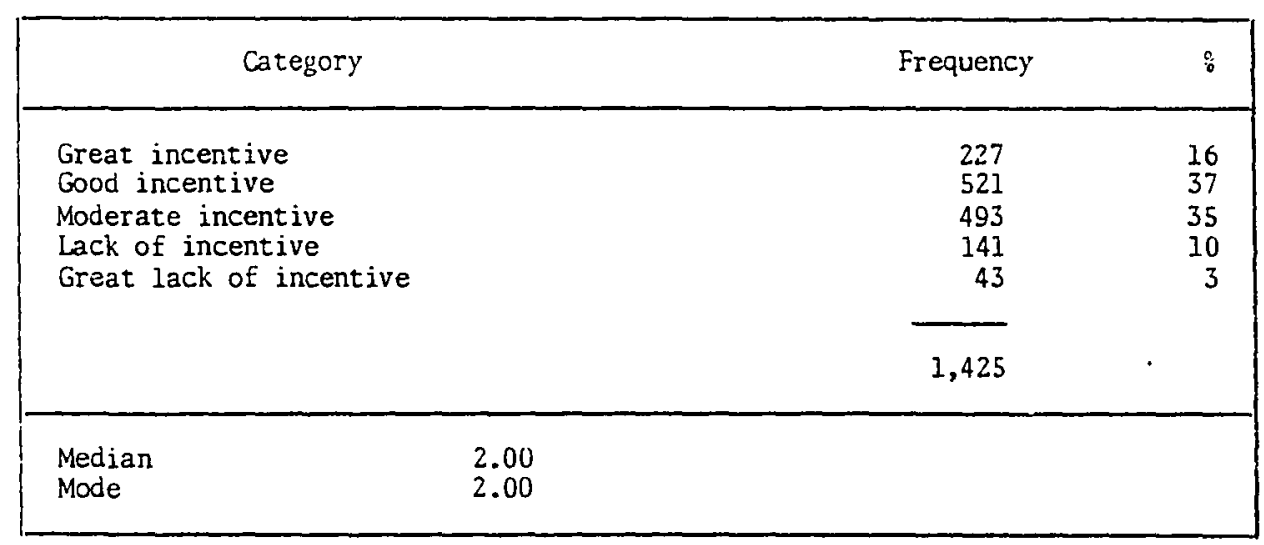

IV.42 How would you describe management and employee relations in your district?

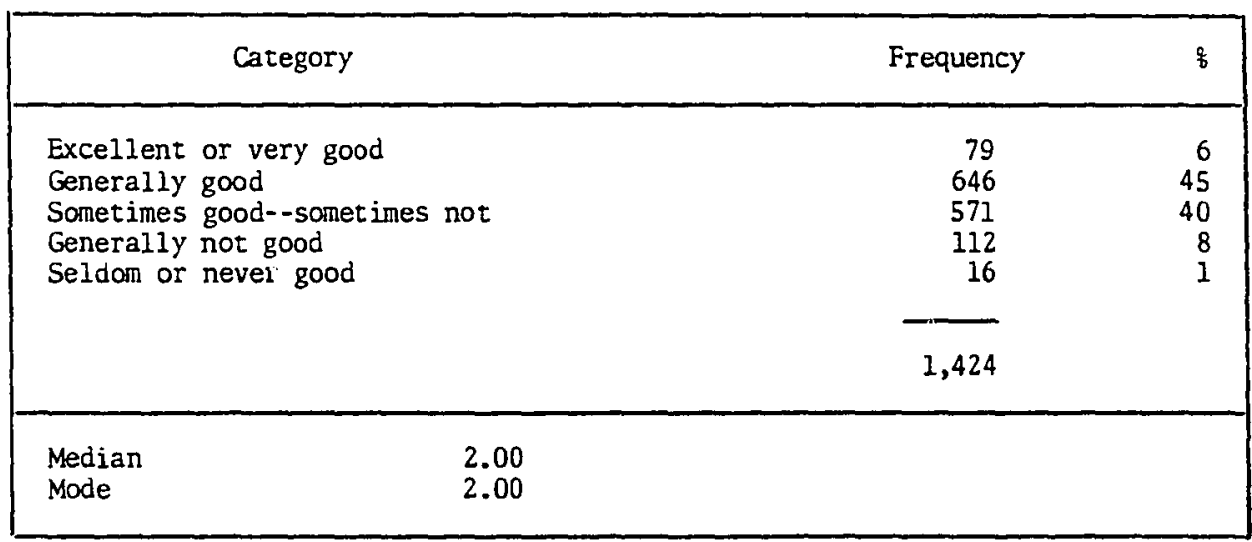

IV.43 How would you describe managenent and employee relations in your school?

\begin{tabular}{|c|c|c|}
\hline Category & Frequency & 告 \\
\hline \multirow[t]{2}{*}{$\begin{array}{l}\text { Excellent or very good } \\
\text { Generally good } \\
\text { Sometimes good--sometimes not } \\
\text { Generally not good } \\
\text { Seldon or never good }\end{array}$} & $\begin{array}{r}308 \\
621 \\
343 \\
121 \\
31\end{array}$ & $\begin{array}{r}22 \\
44 \\
24 \\
8 \\
2\end{array}$ \\
\hline & 1,424 & \\
\hline $\begin{array}{l}\text { Median } \\
\text { Mode }\end{array}$ & & \\
\hline
\end{tabular}


IV.44 How much do you like to try something "new" in the classroon?

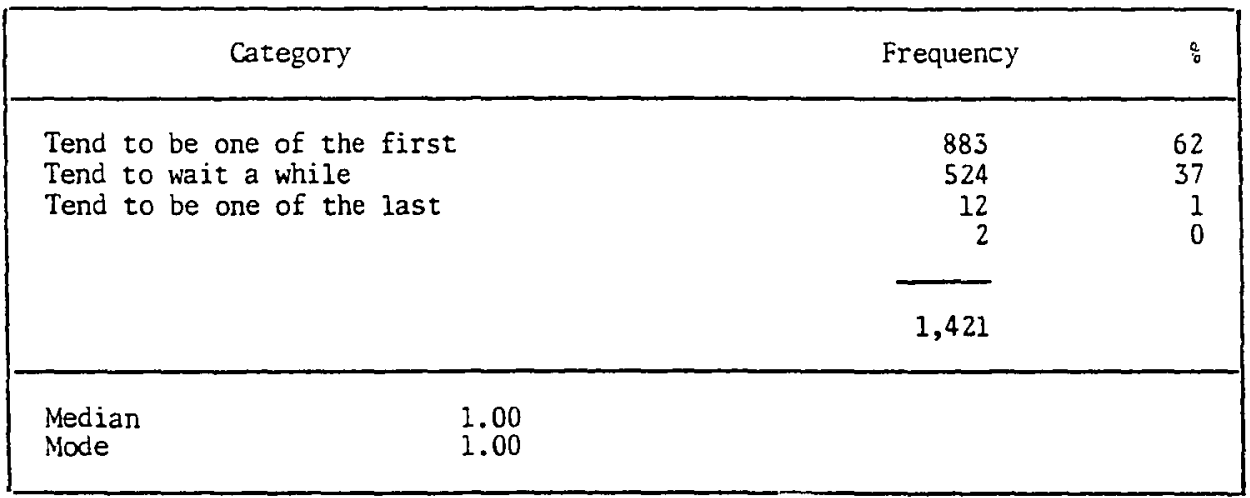

IV.45 of the following, what factor--more than any other--would influence you to change a long time practice or behavior pattern associated with your teaching?

\begin{tabular}{|lrr|}
\hline \multicolumn{1}{|c|}{ Category } & Frequency \\
\hline & & 101 \\
More money & 1,171 & 79 \\
The knowledge that it would be "good for kids" & 92 & 7 \\
A "mandate" from school board or administration & \\
The fact that it's "new" and you want to try it & 1,413 \\
& & \\
\hline
\end{tabular}

IV.46 Which of these statements comes closest to describing your feelings about teaching?

\begin{tabular}{|lrr|}
\hline Category & Frequency & \\
\hline I am extremely satisfied & 244 & 17 \\
I an very satisfied & 603 & 42 \\
I an more satisfied than not & 403 & 28 \\
I am neither satisfied nor dissatisfied & 86 & 6 \\
I am more dissatisfied than satisfied & 10 & 1 \\
I am very dissatisfied & 1 & \\
I am extremely dissatisfied & 1,423 & \\
& & \\
& & \\
\hline
\end{tabular}


IV.47 of the following, which is the most important source of satisfaction for you in teaching?

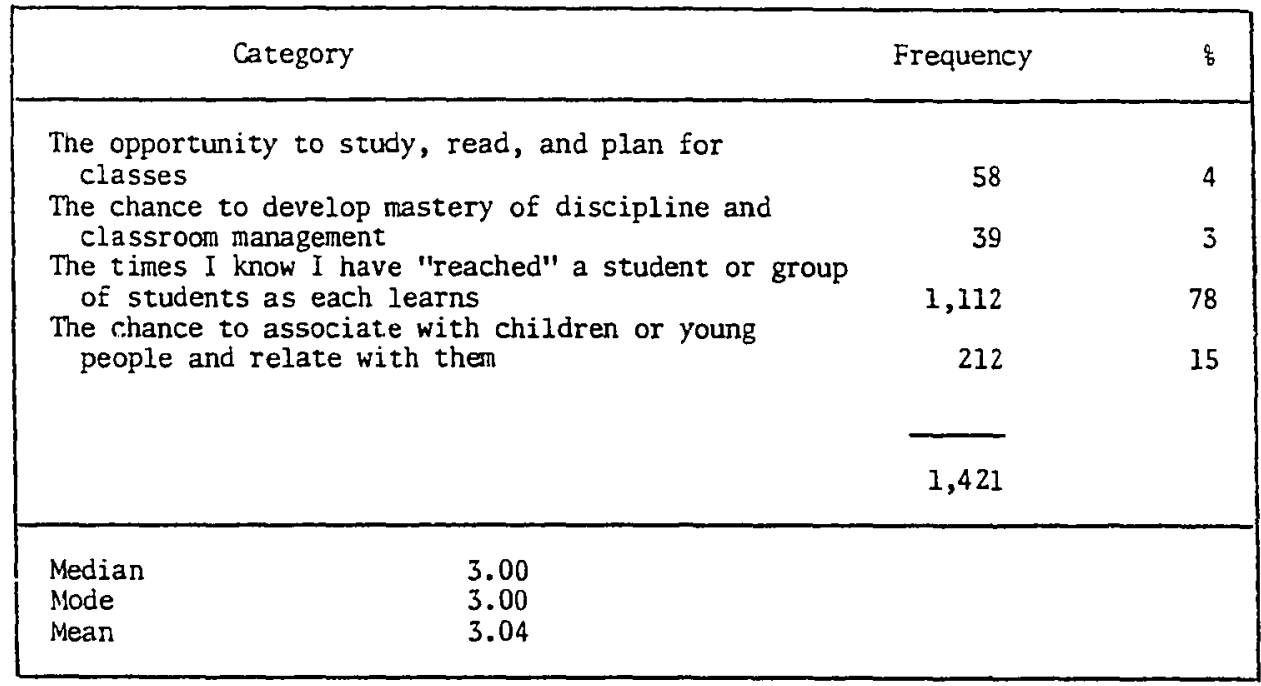

IV.48 of the following, which is the most important source of satisfaction to you?

\begin{tabular}{|c|c|c|}
\hline Category & Frequency & $q$ \\
\hline \multirow[t]{2}{*}{$\begin{array}{l}\text { The chance to grow personally } \\
\text { The salary I earn } \\
\text { The status I have } \\
\text { The recognition I receive } \\
\text { The opportunity to teach children or influence } \\
\text { student learning }\end{array}$} & $\begin{array}{r}234 \\
68 \\
11 \\
16 \\
1,073\end{array}$ & $\begin{array}{r}17 \\
5 \\
1 \\
1 \\
77\end{array}$ \\
\hline & 1,402 & \\
\hline $\begin{array}{l}\text { Median } \\
\text { Mode }\end{array}$ & & \\
\hline
\end{tabular}

IV.49 of the following, which is the most important source of satisfaction to you?

\begin{tabular}{|lrr|}
\hline \multicolumn{1}{|c|}{ Category } & Frequency & \\
\hline The relative security of income, position & 149 & 11 \\
The vacation times (travel, study, etc.) & 324 & 24 \\
The opportunity to earn a Iiving without much & 38 & 3 \\
competition or interference & 221 & 47 \\
The special "rightness" of my position & 641 & \\
The sense of achievement I have as a teacher & 1,373 \\
& & \\
\hline \\
Median & & \\
Mode & 4.00 & \\
\hline
\end{tabular}


If you had it to do all over again, would you still become a teacher?

54

Q1 \&

74.4

Definitely yes

Probably yes

Uncertain

Probably not

Definitely not

Mean
Median
Mode

29

IV.3

Note: Response categories do not match exactly; Q1 does not include the category for "uncertain." The response indicators are reversed from negative to positive in Q1 and from positive to negative in Q2.

Q1 includes an item ( $\# 54$ ) that reduces choice to yes or no. The response rate to yes is $74.4 \%$; the response rate to no is $25.5 \%$. For Q2, the combined response for yes is $64 \%$; the cambined response for uncertain or no is $34 \%$.

What ability/achievement level would you prefer to teach if the choice were up to you?

$32 \quad$ IV.7

\begin{tabular}{|c|c|c|}
\hline Category & Q1 \& & Q2 \\
\hline \multirow[t]{2}{*}{$\begin{array}{l}\text { Far below average/extremely low } \\
\text { Somewhat below average/lower than average } \\
\text { Average } \\
\text { Somewhat above average/above average } \\
\text { Far above average/highest or gifted } \\
\text { Mixed ability or achievenent }\end{array}$} & $\begin{array}{r}2.5 \\
11.2 \\
31.9 \\
46.1 \\
8.2\end{array}$ & $\begin{array}{r}2 \\
6 \\
17 \\
36 \\
7 \\
32\end{array}$ \\
\hline & 1,332 & 1,418 \\
\hline $\begin{array}{l}\text { Mean } \\
\text { Median } \\
\text { Mode }\end{array}$ & $\begin{array}{l}3.468 \\
3.596 \\
4.00\end{array}$ & $\begin{array}{l}4.363 \\
4.00 \\
4.00\end{array}$ \\
\hline
\end{tabular}

Note: Q1 did not include the category for mixed ability or achievement; however, Q1 or Q2 both report that the frequency mode for teachers is to teach above average students. 
How would other teachers describe you as a teacher?

$35 \quad$ IV. 9

\begin{tabular}{|lcc|}
\hline \multicolumn{1}{|c|}{ Category } & Q1 & Q2 \% \\
\hline The best/very good or outstanding & 5.1 & 38 \\
Good/above average & 54.1 & 56 \\
Average & 4.6 & 7 \\
Below average & .1 & 1 \\
Poor/very poor & .1 & 0 \\
& $-1,465$ & 1,426 \\
& & \\
\hline Mean & 2.411 & 1.696 \\
Median & 2.331 & 2.00 \\
Mode & 2.00 & 2.00 \\
\hline
\end{tabular}

Note: In 1981, 95.2\% of the responding teachers rated themselves in the opinions of other teachers describing them as from the best or very good or outstanding to above average. In 1984, $93 \%$ rate themselves in the same categories in the opinions of other teachers.

Bow much do you like the students you work with today?

\begin{tabular}{|c|c|c|c|}
\hline & 58 & 36 & IV.10 \\
\hline Category & Q1 & Q1 \& & Q2 \& \\
\hline \multirow[t]{2}{*}{$\begin{array}{l}\text { A great deal } \\
\text { Quite a bit/above average } \\
\text { O.K., I guess/an average amount } \\
\text { Not very much/some dislike } \\
\text { Not at all/great dislike }\end{array}$} & $\begin{array}{r}37.8 \\
38.8 \\
21.9 \\
1.3 \\
.2\end{array}$ & $\begin{array}{r}34.7 \\
40.8 \\
19 \\
5.1 \\
.4\end{array}$ & $\begin{array}{r}46 \\
41 \\
8 \\
4 \\
0\end{array}$ \\
\hline & 1,519 & 1,522 & 1,437 \\
\hline $\begin{array}{l}\text { Mear } \\
\text { Median } \\
\text { Mode }\end{array}$ & $\begin{array}{l}1.873 \\
1.814 \\
2.00\end{array}$ & $\begin{array}{l}1.957 \\
1.875 \\
2.00\end{array}$ & $\begin{array}{l}1.714 \\
2.00 \\
1.00\end{array}$ \\
\hline
\end{tabular}

Note: Q1 finds $94.5 \%$ of teacher responses ranging from liking students a great deal to 0.K.; Q2 finds 95\% of teachers responses for the same range.

Q1 finds 5.6\% indicating some degree of dislike; Q2 finds $4 \%$ indicating the same.

In a follow-up question from $1981,98.5 \%$ of the respondents rate liking students to at least an average or $0 . \mathrm{K}$. amount; $2.5 \%$ indicated degrees from some to great dislike. 
How would you describe the students you work with today?

37

IV.11

\begin{tabular}{|c|c|c|}
\hline Category & Q1 & $02 \%$ \\
\hline \multirow[t]{2}{*}{$\begin{array}{l}\text { A pleasure to work with } \\
\text { Generally good to work with } \\
0 . K \text {. to work with } \\
\text { Sometimes difficult to work with } \\
\text { Very difficult to work with }\end{array}$} & $\begin{array}{r}11.1 \\
46.1 \\
9.6 \\
28.6 \\
4.6\end{array}$ & $\begin{array}{r}25 \\
53 \\
7 \\
13 \\
3\end{array}$ \\
\hline & 1,474 & 1,436 \\
\hline $\begin{array}{l}\text { Mean } \\
\text { Median } \\
\text { Mode }\end{array}$ & $\begin{array}{l}2.696 \\
2.344 \\
2.00\end{array}$ & $\begin{array}{l}2.157 \\
2.00 \\
2.00\end{array}$ \\
\hline
\end{tabular}

Note: Both Q1 and Q2 find the mode of teacher responses on this item to be that the students are generally good to work with. Q1 finds $68 \%$ of the teacher responses finds students within the range from a pleasure to 0.K.; Q2 finds $85 \%$ of the teacher responses within the same range.

To what extent are you free to do (more or less) what you want in the classroom--design your own instructional programs and teach your students more or less as you choose?

43

IV.15

\begin{tabular}{|c|c|c|}
\hline Category & Q1 & Q2 \% \\
\hline \multirow[t]{2}{*}{$\begin{array}{l}\text { All or almost all the time/a great deal } \\
\text { More than half of the time/quite a bit } \\
\text { Maybe half the time/an average amount } \\
\text { Less than half the timc/not very } \\
\text { Seldom or never/not at all }\end{array}$} & $\begin{array}{r}47.7 \\
36.2 \\
12.4 \\
3.6 \\
.1\end{array}$ & $\begin{array}{r}50 \\
29 \\
12 \\
6 \\
2\end{array}$ \\
\hline & 1,521 & 1,427 \\
\hline $\begin{array}{l}\text { Mean } \\
\text { Median } \\
\text { Mode }\end{array}$ & $\begin{array}{l}1.723 \\
1.564 \\
1.00\end{array}$ & $\begin{array}{l}1.816 \\
1.00 \\
1.00\end{array}$ \\
\hline
\end{tabular}

Note: In 1981, 83.98 reported an above average amount of freedom to teach more or less as they wish, with $12.4 \%$ reporting an average amount of freedom; in 1984, 798 indicate more than average amount of freedom.

In $1981,3.48$ reported less than an average or very little amount of freedom to teach more or less is they wish; in 1984, the percentage increases to $8 \%$. 
How successful do you feel as a teacher (meeting the intellectual needs of your students as individuals)?
57
IV.16
IV.27

\begin{tabular}{|lccc|}
\hline \multicolumn{1}{|c}{ Category } & Q1 & Q2 & Q2 \\
\hline $\begin{array}{l}\text { Extremely successful/successful } \\
\text { with almost all }\end{array}$ & 19 & 34 & 34 \\
$\begin{array}{l}\text { Above average--successful with } \\
\text { more than half }\end{array}$ & 51.2 & 54 & 52 \\
$\begin{array}{l}\text { Successful--successful with about } \\
\text { half } \\
\text { Not very successful--successful } \\
\text { with less than half } \\
\text { Very unsuccessful--successful } \\
\text { with very few or almost none }\end{array}$ & 26.8 & 10 & 14 \\
& 3.0 & 2 & 0 \\
\hline $\begin{array}{l}\text { Mean } \\
\text { Median }\end{array}$ & 1,520 & 1,420 & 0 \\
\hline Mode & 2.139 & 1.811 & 1,422 \\
\hline
\end{tabular}

Note: In 1981, 97\% of the respondents indicated that they feel successful to an average degree; in 1984, 98 indicate similar feelings of success as teachers (meeting the intellectual needs of students as individuals).

In 1981, 3.16 indicated lack of success, success with less than half or with almost none of the students; in 1984,28 indicate similar lack of success.

How much professional support do your building administrators give you?

55

IV.19

\begin{tabular}{|c|c|c|}
\hline Category & Q1 \& & Q2 \& \\
\hline \multirow[t]{2}{*}{$\begin{array}{l}\text { Great support beyond expectations } \\
\text { Above average } \\
\text { Average/about what I expect } \\
\text { Below average/sone lack of support } \\
\text { Great lack of support/not supportive }\end{array}$} & $\begin{array}{r}32.3 \\
35.6 \\
22.8 \\
7.8 \\
1.5\end{array}$ & $\begin{array}{r}15 \\
45 \\
23 \\
14 \\
4\end{array}$ \\
\hline & 1,506 & 1,432 \\
\hline $\begin{array}{l}\text { Mean } \\
\text { Median } \\
\text { Mode }\end{array}$ & $\begin{array}{l}2.106 \\
1.598 \\
2.00\end{array}$ & $\begin{array}{l}2.462 \\
2.00 \\
2.00\end{array}$ \\
\hline
\end{tabular}

Note: In the 1981 study, $90.7 \%$ of the responding teachers rated their administrators as giving them support in ranges from great to average; in the 1984 study, $83 \%$ indicate similar ratings.

In the 1981 study, $9.3 q$ of the responding teachers rated their administrators as giving them support in ranges from below average to great lack of support; in the 1984 study, $18 \%$ indicate similar ratings. 
How do you think the parents of your students would describe you as a teacher?

49

IV.23

\begin{tabular}{|lcc|}
\hline \multicolumn{1}{|c|}{ Category } & Q1 \& & Q2 ₹ \\
\hline The best/very good or outstanding & 8.7 & 31 \\
Above average & 70.4 & 57 \\
Average--neither good nor poor & 20.5 & 11 \\
Below average & .2 & 0 \\
Poor & .1 & 0 \\
& 1,466 & 1,414 \\
& & \\
\hline Mean & 2.127 & 1.801 \\
Median & 2.086 & 2.00 \\
Mode & 2.00 & 2.00 \\
\hline
\end{tabular}

Note: In the 1981 study, $79.1 \%$ of the responding teachers rated themselves in the opinions of the parents of students describing them as from the best or very good or outstanding to above average; in the 1984 study, 888 rate themselves in the same categories in the opinions of the parents of their students.

How secure do you feel in your job as a teacher?

\begin{tabular}{|c|c|c|}
\hline & 52 & IV. 24 \\
\hline Category & Q1 \& & Q2 \& \\
\hline \multirow[t]{2}{*}{$\begin{array}{l}\text { Very secure/a great deal } \\
\text { Quite secure/quite a bit } \\
\text { Not certain--0.K., I guess/average amount } \\
\text { Quite insecure/not very } \\
\text { Very insecure/not at all }\end{array}$} & $\begin{array}{r}42.8 \\
36.6 \\
15.0 \\
3.9 \\
1.6\end{array}$ & $\begin{array}{r}48 \\
42 \\
8 \\
1 \\
1\end{array}$ \\
\hline & 1,521 & 1,434 \\
\hline $\begin{array}{l}\text { Mean } \\
\text { Median } \\
\text { Mode }\end{array}$ & $\begin{array}{l}1.85 \\
1.697 \\
1.00\end{array}$ & $\begin{array}{l}1.653 \\
2.00 \\
2.00\end{array}$ \\
\hline
\end{tabular}

Note: In 1981, 79.4\% reported feeling an above average amount of job security; in 1984, 908 report feeling an above average anount of job security. 
How would you describe your relationships with fellow teachers?

51

\begin{tabular}{|c|c|c|}
\hline Category & Q1 & Q2 \& \\
\hline \multirow{5}{*}{$\begin{array}{l}\text { My closest friends are other teachers } \\
\text { I spend some social time outside of school with } \\
\text { other teachers } \\
\text { I only associate with other teachers in school } \\
\text { I have few personal contacts with other teachers } \\
\text { I do not have personal contacts with other teachers }\end{array}$} & 15.8 & 21 \\
\hline & 71.2 & 48 \\
\hline & 12.3 & $\begin{array}{r}28 \\
4\end{array}$ \\
\hline & 2.6 & 0 \\
\hline & 1,498 & 1,427 \\
\hline Mean & & \\
\hline Median & 1.98 & 2.00 \\
\hline Mode & 2.00 & 2.00 \\
\hline
\end{tabular}

Note: In 1981, $87 \%$ of the teacher respondents indicated social contact with teachers outside of school time; in 1984, 698 of the teacher respondents indicate social contact outside of school time.

In $1981,12.38$ indicated association with other teachers other than during school hours; in 1984. $28 \%$ indicate this association as limited to school hours.

How much do you think being a teacher has contributed to your jersonal growth?

53

Q1 : Category

\begin{tabular}{|c|c|c|}
\hline Category & Q1 & Q2 \& \\
\hline $\begin{array}{l}\text { A great deal } \\
\text { Quite a bit } \\
\text { An average amount--moderately } \\
\text { Not very much--slightly } \\
\text { Very little if at all--not at all }\end{array}$ & $\begin{array}{r}41.7 \\
40.3 \\
14.1 \\
3.8 \\
.1\end{array}$ & $\begin{array}{r}42 \\
40 \\
14 \\
2 \\
2\end{array}$ \\
\hline & 1,522 & 1,426 \\
\hline $\begin{array}{l}\text { Mean } \\
\text { Median } \\
\text { Mode }\end{array}$ & $\begin{array}{l}1.805 \\
1.707 \\
1.00\end{array}$ & $\begin{array}{l}1.802 \\
2.00 \\
1.00\end{array}$ \\
\hline
\end{tabular}

Note: In 1981, 828 of the respondents indicated more than an average or moderate contribution to their personal growth as stemming from their role in teaching, and $14.1 \%$ confimed an average or moderate contribution; in 1984, the percentages are almost identical.

In both studies, $4 \%$ acknowledge little or no contribution to personal growth as stemning from the teaching role.

The response frequencies in percentages are very similar over the three year period. 
How would you describe management and employee relations in your district?

\begin{tabular}{|lcc|}
\hline \multicolumn{1}{|c|}{92} & IV.42 \\
\hline Category & Q1 & Q2 \\
\hline Excellent/very good & 3.9 & 6 \\
Very good/generally good & 20.6 & 45 \\
Good--sometimes good/sometimes not & 46.4 & 40 \\
Not very good/generally not good & 25.7 & 8 \\
Very negative/seldom or never good & 3.4 & 1 \\
& & \\
& 1,507 & 1,424 \\
\hline Mean & & 2.537 \\
Median & 3.041 & 2.00 \\
Mode & 3.05 & 2.00 \\
\hline
\end{tabular}

Note: In 1981, 70.9!; of the respondent: confimed district management and employee relations from excellent or very good to at least an average degree of govi; in 1984, $91 \%$ report similar ratings.

In 1981, 29.18 confirmed not very good to very negative ratings for district management and employee relations; in 1984, 98 report similar negative ratings.

How would you describe management and employee relations in your school?

\begin{tabular}{|c|c|c|}
\hline & 93 & IV. 43 \\
\hline Category & Q1 \& & Q2: \\
\hline \multirow[t]{2}{*}{$\begin{array}{l}\text { Excellent/very good } \\
\text { Very good/generally good } \\
\text { Good--sometimes good/sometimes not } \\
\text { Not very good'generally not good } \\
\text { Very negative/seldom or never good }\end{array}$} & $\begin{array}{r}20.4 \\
32.8 \\
32.0 \\
12.6 \\
2.2\end{array}$ & $\begin{array}{r}22 \\
44 \\
24 \\
8 \\
2\end{array}$ \\
\hline & 1,510 & 1,424 \\
\hline $\begin{array}{l}\text { Mean } \\
\text { Median } \\
\text { Mode }\end{array}$ & $\begin{array}{l}2.433 \\
2.401 \\
2.00\end{array}$ & $\begin{array}{l}2.26 \\
2.00 \\
2.00\end{array}$ \\
\hline
\end{tabular}

Note: In $1981,85.28$ of the respondents confimed management and employee relations in their schools to at least an average degree; in 1984, $90 \%$ report similar ratings.

In $1981,14.8 \%$ of the respondents rated management and employee relations as from not very good to seldom or never good; in 1984, this response is at $10 \%$. 
What factor, more than any other, would influence you to change a long time practice or behavior associated with your teaching?
97
IV. 45

\begin{tabular}{|lcc|}
\hline \multicolumn{1}{|c|}{ Category } & Q1 & Q2 \\
\hline $\begin{array}{l}\text { More money } \\
\text { The knowledge that it would be good for "kids" }\end{array}$ & 75.4 & 73 \\
A mandate or similar requirement from either \\
$\begin{array}{l}\text { the school board or administration } \\
\text { The fact that it's new and you want to try it }\end{array}$ & 5.8 & 3 \\
None of the above & 4.9 & 7 \\
& 1,454 & 1,413 \\
\hline $\begin{array}{l}\text { Mean } \\
\text { Median }\end{array}$ & 2.239 & 2.093 \\
Mode & 2.055 & 2.00 \\
\hline
\end{tabular}

Note: In 1981, 75.48 of the respondents indicated that they would be influenced to change a long time practice or behavior associated with teaching if they knew that it would be good for "kids"; in 1984, 83\% make a similar response.

Which of the statements comes closest to describing your feelings about teaching?
98
IV.46

\begin{tabular}{|lcc|}
\hline \multicolumn{1}{|c|}{ Category } & Q1 $\%$ & Q2 \% \\
\hline Ext remely satisfied & 19.3 & 17 \\
$\begin{array}{l}\text { Very satisfied } \\
\text { More satisfied than not } \\
\text { Equally satisfied and dissatisfied/ } \\
\text { neither satisfied nor dissatisfied/ } \\
\text { in the middle }\end{array}$ More dissatisfied than satisfied & 24.3 & 42 \\
$\begin{array}{l}\text { Very dissatisfied } \\
\text { Extremely dissatisfied }\end{array}$ & 12.3 & 6 \\
& 5.1 & 5 \\
& 1.6 & 0 \\
\hline Mean & 1,517 & $1,4.3$ \\
Median & 2.512 & 2.439 \\
Mode & 2.321 & 2.00 \\
\hline
\end{tabular}

Note: In 1981, $81 \%$ of the teachers responced to categories indicating satisfaction to a greater degree than dissatisfaction or from extreme to above average satisfaction; in $1984,87 \%$ report similar degrees of satisfaction.

In $1981,6.76$ reported degrees of dissatisfaction from moderate to extreme; in 1984, 6 percent report to more dissatisfaction than satisfaction. 
Which of the following is the most important source of satisfaction for you?

89

Category

The opportunity to study, read, plan for classes The chance to develop mastery of discipline and classroom management

The time I know I have "reached a student or group of students as each learns

The chance to associate with children or young people and relate with young people
Q1 \%

2.1

1.3

70.4

15.9

$$
1,350
$$

3.376

Mean

Median

Mode

3.163
IV. 47

Q2 \&

4

3

78

15

1,421

3.00

3.00 